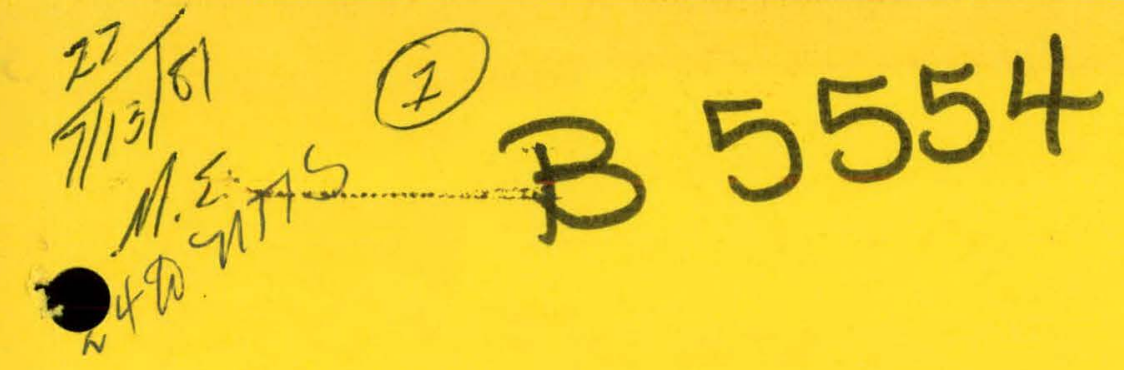

\title{
Assessing the Local Windfield with Instrumentation
}

\section{MASTER}

\section{T. G. Zambrano}

Aerovironment, Inc.

145 Vista Avenue

Pasadena, California 91107

October 1980

Prepared for

Pacific Northwest Laboratory

Under Agreement B-92864-A-H

Pacific Northwest Laboratory

Operated for the U.S. Department of Energy

by Battelle Memorial Institute

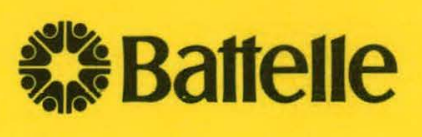




\section{DISCLAIMER}

This report was prepared as an account of work sponsored by an agency of the United States Government. Neither the United States Government nor any agency Thereof, nor any of their employees, makes any warranty, express or implied, or assumes any legal liability or responsibility for the accuracy, completeness, or usefulness of any information, apparatus, product, or process disclosed, or represents that its use would not infringe privately owned rights. Reference herein to any specific commercial product, process, or service by trade name, trademark, manufacturer, or otherwise does not necessarily constitute or imply its endorsement, recommendation, or favoring by the United States Government or any agency thereof. The views and opinions of authors expressed herein do not necessarily state or reflect those of the United States Government or any agency thereof. 


\section{DISCLAIMER}

Portions of this document may be illegible in electronic image products. Images are produced from the best available original document. 


\title{
NOTICE
}

This report was prepared as an account of work sponsored by the United States Government. Neither the United States nor the Department of Energy, nor any of their employees, nor any of their contractors, subcontractors, or their employees, makes any warranty, express or implied, or assumes any legal liability or responsibility for the accuracy, completeness or usefulness of any information, apparatus, product or process disclosed, or represents that its use would not infringe privately owned rights.

The views, opinions and conclusions contained in this report are those of the contractor and do not necessarily represent those of the United States Govermment or the United States Department of Energy.

\author{
PACIFIC NORTHWEST LABORATORY \\ operated by \\ BATTELLE \\ for the \\ UNITED STATES DEPARTMENT OF ENERGY \\ Under Contract DE-AC06-76RLO 1830
}

\author{
Printed in the United States of America \\ Available from \\ National Technical Information Service \\ United States Department of Commerce \\ 5285 Port Royal Road \\ Springfield, Virginia 22151
}

Price: Printed Copy $\$$

*; Microfiche $\$ 3.00$

NTIS

*Pages Selling Price

$\begin{array}{lr}001-025 & \$ 4.00 \\ 026-050 & \$ 4.50 \\ 051-075 & \$ 5.25 \\ 076-100 & \$ 6.00 \\ 101-125 & \$ 6.50 \\ 126-150 & \$ 7.25 \\ 151-175 & \$ 8.00 \\ 176-200 & \$ 9.00 \\ 201-225 & \$ 9.25 \\ 226-250 & \$ 9.50 \\ 251-275 & \$ 10.75 \\ 276-300 & \$ 11.00\end{array}$


ASSESSING THE LOCAL WINDFIELD WITH INSTRUMENTATION

T. G. Zambrano

Aeroviroment, Inc.

145 Vista Avenue

Pasadena, California 91107

October 1980

Prepared for

Pacific Northwest Laboratory Under Agreement B-92864-A-H

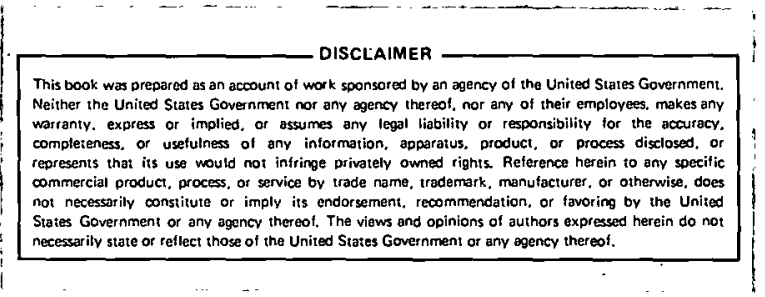

Pacific Northwest Laboratory Richland, Washington 99352 
THIS PAGE

\section{WAS INTENTIONALLY \\ LEFT BLANK}




\section{ACKNOWLEDGEMENTS}

The author acknowledges the consultation and technical contributions of Dr. Stel Walker, Messrs. John Wade and Robert Baker for their participation in the initial field survey. Also, the author would like to acknowledge the contributions of Messrs. Gary Arcemont and Melvin Smith for their assistance and analysis of the six-month field survey. Special thanks is also given to Mr. Thomas Hiester of Pacific Northwest Laboratory. 
THIS PAGE

\section{WAS INTENTIONALLY \\ LEFT BLANK}




\section{EXECUTIVE SUMMARY}

This report concerns the development and testing of a technique for the initial screening and evaluation of potential sites for wind-energy conversion systems (WECS). The methodology was developed through a realistic siting exercise. The siting exercise involved measurements of winds along the surface and winds aloft using a relatively new instrument system, the Tethered Aerodynamic Lifting Anemometer (TALA) kite; notation of ecological factors such as vegetation flagging, soil erosion and site exposure, and verification of an area best suited for wind-energy development by establishing and maintaining a wind monitoring network. The siting exercise was carried out in an approximately 100-square-mile region of the Tehachapi Mountains of Southern California. The results showed that a comprehensive site survey involving field measurements, ecological survey, and wind-monitoring can be an effective tool for preliminary evaluation of WECS sites.

The first step involved preliminary screening of the site using available data and a tour of the area. Of the 100 square miles comprising the study region, only a 20-square-mile area containing major ridgelines was considered suitable for WECS investigation. The preliminary site investigation showed that in this remaining 20 square miles there would most probably be one orographic feature per square mile which would make a local area suitable for WECS siting.

The second step involved investigating 16 candidate sites in a detailed field assessment survey. The survey was conducted during a one-week period when winds were from the dominant northwest direction. The goal of the survey was to use various windenergy assessment techniques to judge the merits and disadvantages of wind-monitoring at each respective site. For each wind-energy assessment technique -- namely, ecological features, short-term anemometry, and serviceability -- each site was ranked with respect to the other 15 in order of merit. This ranking was a preliminary wind-energy assessment criterion. The final result was a combination of the three sets of rankings into a matrix to obtain, from best to worst, the most suitable sites for installing wind-monitoring stations. 
Many of the techniques used in this second step were novel to wind-energy assessment. The TALA. kites proved to be a versatile field instrument (but not without design flaws) and continually indicated a more uniform vertical profile of wind speed than would be obtained from a $1 / 7$ power law. The vegetation survey involved the development of a deformation index for California oak, which will be refined when annual wind speed statistics for the data are obtained. Portable, modular 10-m wind-monitoring stations specifically designed for study application were shown to be satisfactory low-cost field instruments.

In the third step, nine sites of the original 16 candidate sites were equipped with 10-m wind-monitoring stations. Wind speed and wind-direction were continuously recorded during a six-month period. Two stations out of nine had wind-direction monitoring capabilities. However, for future surveys it is recommended that wind direction data be taken at all wind-monitoring locations. Presently, an additional six months of wind-monitoring is being performed with support from the California Energy Commission.

Using the recorded six-month data, results from the field assessment survey, and continued TALA measurements, wind-field analysis, power-availability estimate, and comparison of wind energy assessment techniques were made.

The wind-field analysis identified four basic wind-flow patterns in the study region -- summer nor thwest, winter northwest, summer southeast, and Santa Ana flow -and their respective diurnal patterns, frequency, and wind speed distribution. In general, it was seen that during the summer and early fall northwest flow can be enhanced by a channeled northwest flow up the axis of the San Joaquin Valley. The study region is located at the terminus of the valley and is recipient of the up-valley flow. At other times during summer and early fall, an inversion layer caps the San Joaquin Valley and inhibits the flow of air over the study region. During late evening, the high ridges of the study area were exposed to upper-level flows. Periods of high winds on these ridges corresponded to strong upper-level winds associated with weather fronts and active upperlevel atmospheric circulation. These winds tend to be the strongest during the winter and spring seasons when the atmospheric circulation is most active. 
The wind-speed distributions for each of the 9 wind-monitoring sites were determined and the wind-energy flux obtained on a seasonal (summer and fall) and annual (estimated) basis. There is a ridgeline running approximately 7 miles in an area referred to as La Liebre, where the annual estimated wind-energy flux exceeds $400 \mathrm{watts} / \mathrm{m}^{2}$, corresponding to a constant steady energy wind of about $9 \mathrm{~m} / \mathrm{sec}(20 \mathrm{mph})$ at the $50-\mathrm{m}$ level, with some areas showing a seasonal wind-energy flux in excess of 500 watts $/ \mathrm{m}^{2}$ (a steady energy wind of $22 \mathrm{mph}$ ). The energy wind is defined as the continuous wind which would have the same energy as the actual wind distribution. Most other regions that were investigated showed an estimated seasonal wind energy flux rarely exceeding 200 watts $/ \mathrm{m}^{2}$ (a steady energy wind of $15 \mathrm{mph}$ ) at the $50-\mathrm{m}$ level.

Wind-energy distributions were applied to a hypothetical, large WECS, of which the Boeing design for the MOD-2, $2500 \mathrm{~kW}$ rated, $100-\mathrm{m}$ rotor diameter propeller-type unit is a typical example. In the most promising regions of the study area such a single unit would produce $5.7 \times 10^{6} \mathrm{~kW}-\mathrm{hr}$ per year, corresponding to an annual average power of $0.65 \mathrm{MW}$. Based upon simplified single-line design with a two-rotor-diameter spacing between hubs and an assumed $90 \%$ land availability, an array of 56 units located in the most promising ridgelines could produce $320 \times 10^{6} \mathrm{~kW}-\mathrm{hr}$ per year, corresponding to an average power of $36.4 \mathrm{MW}$. Array modifications and optimum turbine sizing and selection were not considered in the initial survey.

Comparisons of recorded six-month data to the results of the field assessment survey showed that the wind-energy assessment techniques used were able to identify sites which were most immediate and reliable for WECS development, and also those with marginal development potential. Data analysis showed a need to refine initial relationships concerning the mechanics of tree deformation.

The insights gained during the course of this program are the basis of our conclusion that, with improvement of the vegetation indices and further field experience with the TALA systems, this program for assessing local wind fields constitutes a reliable costeffective technique for WECS siting in complex terrain. 
THIS PAGE

\section{WAS INTENTIONALLY \\ LEFT BLANK}


ACKNOWLEDGEMENTS

EXECUTIVE SUMMARY

iii

TABLE OF CONTENTS

LIST OF FIGURES

LIST OF TABLES

ix

IST OF TABLES

INTRODUCTION

xii

FIELD ASSESSMENT SURVEY AND OPERATIONS

DATA ASSESSMENT - INITIAL SITE SCREENING

FIELD ASSESSMENT SURVEY PROCEDURES

INSTRUMENTATION

FIELD ASSESSMENT SURVEY RESULTS

SIX-MONTH DATA RESULTS

DATA ANALYSIS

MEAN WIND SPEEDS

FREQUENCY DISTRIBUTIONS

WIND FIELD ANALYSIS OF THE TEHACHAPI MOUNTAIN STUDY REGION

GENERAL METEOROLOGICAL CONDITIONS

LARGE SCALE SYNOPTIC PATTERNS

BASIC FLOW PATTERNS 61

FREQUENCY OF STORMS 71

OTHER ENVIRONMENTAL ASPECTS OF THE TEHACHAPI MOUNTAIN STUDY 75

REGION

FAULTS

ECONOMIC GEOLOGY

TRANSMISSION LINE PROXIMITY

POWER AVAILABILITY ESTIMATES

AVAILABLE WIND ENERGY

WIND TURBINE ARRAY ESTIMATES

USE OF RAYLEIGH DISTRIBUTION

COMPARISON OF FIELD ASSESSMENT SURVEY RESULTS WITH RECORDED DATA 93

CONCLUSIONS AND RECOMMENDATIONS 101

$\begin{array}{ll}\text { REFERENCES } & 103\end{array}$

APPENDIX A - SITE PHOTOGRAPHS 


\section{LIST OF FIGURES}

$\underline{\text { Page }}$

$\begin{array}{llc}\text { FIGURE } 1 & \text { Tehachapi Mountain Study Region } & 2\end{array}$

FIGURE 2 Detail of Tehachapi study area $\quad 10$

FIGURE 3 Prominent ridgelines of Tehachapi study region 12

FIGURE 4 Candidate sites at the Tehachapi study region 14

FIGURE 5 Deformation ratio defination 19

FIGURE 6 Ten meter (33-ft) wind monitoring station and hardware list 22

$\begin{array}{lll}\text { FIGURE } 7 & \text { Flow diagram of } 10-\mathrm{m} \text { tower measuring station } & 23\end{array}$

$\begin{array}{lll}\text { FIGURE } 8 & \text { Cup anemometer } & 23\end{array}$

$\begin{array}{lll}\text { FIGURE } 9 \text { Wind vane } & 23\end{array}$

FIGURE $10 \quad$ Velocity, direction, and turbulence profiles for selected sites using 30 TALA measurements (1100-1700 PST 30 April 1979)

FIGURE $11 \quad$ Diurnal cycle of wind speed for selected sites (data from Table 2) 33

FIGURE 12 AV station locations . . 43

$\begin{array}{lll}\text { FIGURE } 13 & \text { Wind turbine configurations } & 48\end{array}$

FIGURE 14 Comparison of mean hourly averages taken in Tehachapi Mountains 50 with long-term mean hourly averages from Sandberg and Bakersfield stations

FIGURE 15 Frequency distribution for November 1979 - AV Site 1 (Tunis Ridge) 52

FIGURE 16 Frequency distribution for November 1979 - AV Site 2 (La Liebre 52 Ridge)

FIGURE 17 Frequency distribution for November 1979 - AV Site 3 (Winters 53 Ridge)

FIGURE 18 Frequency distribution for November 1979 - AV Site 4 (Grapevine 53 Ridge)

FIGURE 19 Frequency distribution for November 1979 - AV Site 5 (Antelope 54 Valley)

FIGURE 20 Frequency distribution for November 1979 - AV Site 6 (Geghus) 
FIGURE 21 Frequency distribution for November 1979 - AV Site 7 (TunisGeghus)

FIGURE 22 Frequency distribution for November 1979 - AV Site 8 (Tunis Ridge) 55

FIGURE 23 Frequency distribution for November 1979 - AV Site 9 (La Liebre 56 Ridge)

FIGURE 24 Frequency distribution for the period December 1977 - November 1978 for Sandberg Weather Station - based on three-hour averaged mean wind speed (knots) at 33-feet AGL

FIGURE $25 \quad$ Normal January sea level pressure and temperature

FIGURE $26 \quad$ Normal July sea level pressure and temperature 60

FIGURE 27 Trends of high and low pressure cell movement obtained from $20 \quad 60$

FIGURE 28 La Liebre Ridge viewed from the Antelope Valley looking northwest into the direction of prevailing summer flow

FIGURE 29 San Joaquin Valley viewed from AV Station 9 (La Liebre Ridge) looking northwest through the Pastoria Creek Valley into the direction of prevailing summer flow

FIGURE $30 \quad$ Rime icing on flagged California Oak tree located near AV Station 768 (Tunis-Geghus) in the Tehachapi Study Region

FIGURE 31 Rime icing on flagged (northwest) California Oaks located near AV 68 Station 6 (Geghus) in the Tehachapi Study Region

FIGURE 32 Areas suitable for wind turbine development

FIGURE 33 Typical power output curve for a large WECS

FIGURE 34 Wind energy-direction distribution for AV Station 9 - La Liehre Ridge, November 1979

FIGURE 35 Wind energy-direction distribution for AV Station 5 - Antelope Valley, November 1979

FIGURE 36 Wind energy-direction distribution for a 12-month period at Sandberg Weather Station

FIGURE 37 Comparison of Calculated Deformation Ratio (D) for California Oak with Estimated Annual Wind Speeds 


\section{LIST OF TABLES}

Page

TABLE 1 Summary of TALA wind speed measurements taken at candidate sites during 30 April 1979.

TABLE 2 Summary of hourly averaged wind speeds obtained from portable recording stations at selected candidate sites in the Tehachapi study are.

TABLE 3

Short-term wind measurement.

TABLE 4

Vegetation analysis of Tehachapi study region.

TABLE 5

Ecological survey ranking results.

TABLE 6

Site topography and serviceability.

TABLE 7

Ranking matrix for Tehachapi study region.

TABLE 8

Summary of monthly average wind speed (in mph) at monitoring stations in the Tehachapi study area (May-November 1979).

TABLE 9

Summary of wind speed, wind direction, and temperature data obtained in the study region on July 28,1979 during summer northwest flow conditions.

TABLE 10

Summary of wind speed, wind direction, and temperature data obtained in the study region on November ?6, 1979 during winter northwest flow conditions.

TABLE 11

Summary of wind speed, wind direction, and temperature data obtained in the study region on September 24, 1979.

TABLE 12 Number of Santa Ana cases by months, Southern California region, 1951-1960.

TABLE 13 Mean number of days with measurable precipitation and thunderstorm occurrences.

TABLE 14

Average wind energy flux (watts $/ \mathrm{m}^{2}$ ) for the Tehachapi Mountain study region.

TABLE 15 Estimate of large WECS average seasonal power and total energy output $(\mathrm{kW})$ for specific sites in the Tehachapi Mountains.

TABLE 16

Estimated seasonal energy output $\left(\mathrm{kW}-\mathrm{hr} \times 10^{9}\right)$ for single-line wind turbine arrays on the Tehachapi Mountains. 
TABLE 17 Comparison of capacity factors for large WECS obtained from actual $N$ ind speedfrequency distribution and Rayleigh distribution for November 1979.

TABLE 18 Comparison of Preliminary Field Survey Results with data obtained from the six month monitoring program in the Tehachapi study region.

TABLE 19 Comparison of Vegetation Survey Results with data obtained from the six month monitoring program in the Tehachapi study region. 


\section{INTRODUCTION}

To use wind energy, locations of adequate resource must first be identified. Since many regions considered to have good potential for wind-energy conversion systems (WECS) are located in remote mountainous terrain, there is a need to develop a methodology which, when examining a remote region, would determine which specific area would be the most suitable for WECS.

This report is concerned with the development and testing of an observational methodology for the initial screening and for the evaluation of potential WECS sites through a realistic siting exercise. Involved in the siting exercise were measurements of surface and winds aloft to $100 \mathrm{~m}$ above the surface using a relatively new instrument system, the Tethered Aerodynamic Lifting Anemometer (TALA) kite; notation of ecological factors such as vegetation flagging, soil erosion and site exposure; and verification of an area best suited for wind-energy development by establishing and maintaining a wind-monitoring network. The siting exercise was carried out in an approximately 100-square-mile region of the Tehachapi Mountains in Southern California (Figure 1).

A description of the program methodology is given below. Subsequent chapters report the application and evaluation of this technique when used in the Tehachapi Mountains.

The program consisted of three steps: (1) data assessment, (2) field survey, and (3). regional investigation/verification.

The initial step is a thorough examination of all meteorological information available for the study region. This examination includes a review of all available temperature, precipitation, surface- and upper-level wind data. State and local climatological data summaries published by the National Weather Service of the National Oceanic and Atmospheric Administration (NOAA) are available in most areas. Other climatic data may be available from the United States or state forest agencies, utility companies, or other agencies. 


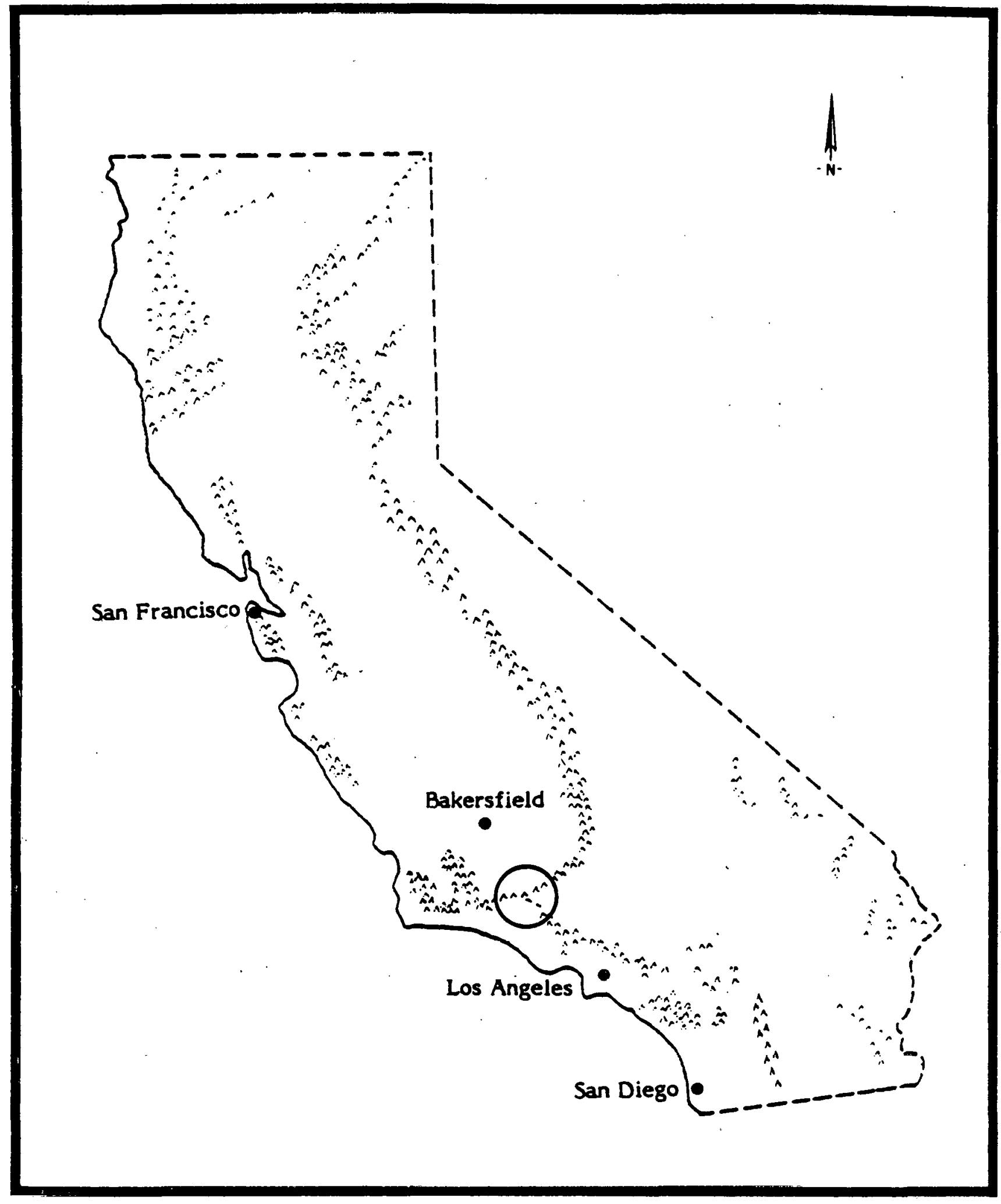

FIGURE 1. Tehachapi Mountain study region. 
The wind data may come in many forms. Obtaining the hourly observations is preferred although much can be gathered from most data summaries. The NOAA climatic data give daily, monthly and annual mean wind-velocity data for many stations, usually airports or key points for air traffic control. In these cases, a wind rose study can be useful in understanding the general flow pattern in the region. The persistence and strength of the wind flow should be analyzed on a monthly, seasonal, and annual basis. The mean maximum and minimum temperatures are also very useful in delineating areas of high temperature gradients which usually indicate strong winds. However, caution should be used when interpreting temperature gradients over mountainous areas, since many gradients may be due entirely to elevation differences.

Areas of maximum precipitation are also noted from the state climatological summaries. These high precipitations are generally confined to the well-exposed mountains where upslope winds play a major role in precipitation. If hills or a mountain range force air masses to ascend, there is usually a speed-up of the airflow as it passes over the exposed ridges.

Once meteorological data is summarized on a daily, seasonal, or annual basis, it should be viewed in relation to the local topography to delineate areas that are readily subjected to a meteorological influence. For example, it is generally observed in mountainous regions that strong winds occur when the stream flow from the surface to at least $400 \mathrm{mb}$ is moderate to strong and is nearly perpendicular to a mountain barrier. If the most significant orographic lifting occurs in the layer below $500 \mathrm{mb}$, then there is a tendency to produce an inversion above the mountaintop level (Grant et al., 1969). Then, if an area of strong subsidence travels normal to that mountain range, the force lifting from below, coupled with the sinking air from above, will result in strong downslope winds along that particular ridgeline.

U.S. Geologica! Survey maps scaled at 1:250,000, 1:62,500, or 1:31,250 series are useful. Other topographic maps may be available, such as sectional aeronautical charts (1:500,000 scale) available from the Federal Aviation Administration, U.S. Department of Commerce, or the U.S. Department of Defense. Raised relief maps of the area are also useful to familiarize one with the major topographic features of the region. 
For a large mountainous region, this initial task of meteorological data assessment can (1) save time, (2) provide valuable information on the characteristics of the region, (3) facilitate making arrangements to obtain daily weather observations during the siting experience, and (4) facilitate early coordination with local residents, forest service personnel, etc., as to their knowledge of where locally strong winds prevail and what regions are navigable.

The second step in a program for assessing the local wind field with instrumentation involves a field investigation. A wind-energy siting team investigates meteorologically identified regions to provide information on areas where data are not available. To determine the most suitable sites for wind-energy systems, several procedures are used. The first, conducted prior to and during the field program, involves analyses of topographic maps and aeronautical charts. The second procedure is an intensive short-térm field measurement program (referred to as check anemometry) of surface and winds aloft using portable anemometers, TALA systems, and collection of all available historical data conducted ideally on days when the wind flow is from the prevailing direction. The third procedure is an ecological field survey in which such factors as vegetation flagging, site exposure, and terrain features are studied. The results of each wind prospecting method are then combined into a matrix from which each candidate site is weighed as to its merits and disadvantages for wind monitoring.

The check anemometry survey is made on days when the wind flow is from the prevailing direction. Wind measurements are made utilizing hand-held anemometers and the TALA kite. The approach is to select a base station within a region and measure wind velocity profiles coordinated (by walkie-talkie) with two other TALA systems in the nearby areas. Readings (10-minute averages) at the $10-\mathrm{m}$ to $100-\mathrm{m}$ level are taken. The TALA traverses are then compared to the base unit to determine temporal changes. The result of this check anemometry comparison is one procedure in defining the specific areas for installation of wind-measuring stations.

Another procedure is an inspection of the vegetation in the vicinity of prospective sites. Vegetation throughout an area can be surveyed and used as one subjective index of wind strength. Bushes and trees exposed to persistently strong winds will exhibit a wind-swept form with most of the vegetation found on the lee side of the main stem. 
Grasses will appear in clumps, clipped short, and aligned with the prevailing wind. Locations with extremely strong mean wind speeds (greater than $27 \mathrm{mph}$ ) will probably have bushes and grasses (Putnam, 1948) only. Trees, where present, will display various degrees of wind shaping depending upon the wind's strength (Hewson et al., 1979). Trees in moderate wind locations (mean speeds greater than $12 \mathrm{mph}$ ) will have asymmetric crowns with small branches and twigs swept downwind from the prevailing wind direction. Tree trunks will be elliptically shaped with major axes parallel to the prevailing wind. direction. Tree rings will be wider on the lee side of the tree for conifers and narrower on the lee side for deciduous trees. In the windiest locations, trees will be completely flagged with all branches swept by prevailing winds to the lee side of the tree. In extreme winds, the trunk will be swept parallel to the ground, and tree rings will exhibit extremely eccentric growth.

Vegetation can also be used to determine the extent of strong winds. Often, in complex terrain, there may be large variations in wind strength over small spatial distances due to terrain irregularities and the inhomogeneous nature of the wind-field.

In the third step for assessing the local wind field with instrumentation, each of the promising sites identified from the field assessment is instrumented with temporary but durable instruments. The general requirement of a wind-energy prospecting device is that the data obtained be sufficient to generate (1) a diurnal distribution of wind speed, and (2) a joint frequency distribution of wind-speed and wind-direction with respect to time. The former is required to understand local meteorology and in matching the power availability with demand. The latter is the most concise summary of the local wind-energy availability and predominant flow patterns.

The actual instrumentation will be a factor of the cost and scope of the wind-energy prospecting. Strip-chart recorders were used in this siting exercise because of their availability; however, solid-state digital recorders are now becoming cost competitive and should be seriously considered when deciding on instrumentation.

This report consists of nine chapters with contributions from all scientists, meteorologists, and technicians involved in this WECS siting exercise. The principal author is Mr. Thomas G. Zambrano, program manager. 
The second chapter discusses the field assessment activities and operations during the program, with particular emphasis on wind monitoring station site selection and field equipment reliability, problems, and solutions. In the third chapter, results from wind measurements conducted during the program year are reported. Selected station results are presented; complete data from all stations are included in the appendix. Data from historical sites are also reported.

The fourth chapter is a detailed wind-flow analysis of the study region using results obtained from the array of temporary wind-monitoring stations and observations and historical data gathered during the study period. The fifth chapter is a brief description of other environmental aspects of the study region. In the sixth chapter, important power availability estimates are made and reported, with particular attention to system requirements for large megawatt-size WECS.

The seventh chapter summarizes the siting exercise and compares initial findings from the field assessment survey, in view of recorded data and results. Conclusions and recommendations are made in the eighth chapter, and the ninth chapter is a compilation of all references cited herein. 


\section{FIELD ASSESSMENT SURVEY AND OPERATIONS}

This chapter discusses the results obtained from the first and second steps of the siting exercise - that is, the data assessment and field survey. Also in this chapter is a detailed account of the methodology used of TALA kites, equipment operation, and performance.

\section{DATA ASSESSMENT - INITIAL SITE SCREENING}

The Tehachapi Mountains region of Southern California was chosen for this siting exercise for several reasons. Several studies (Traci and Phillips, 1977; Baker and Wade, 1978; Lindley, 1977) indicated the region possesses a combination of characteristics which would seem promising for WECS.

In conducting a mesoscale regional investigation from surface data and upper-air data available from Bakersfield, Sandberg Mountain, and Edwards Air Force Base, Traci (1977) reported that for much of the time $(\sim 60 \%)$ low-level prevailing winds from the San Joaquin Valley area are at near-normal incidence to the high (1500 to $2500-\mathrm{m}$ ) ridge-like structure comprising the Tehachapis. Concerning the results of a mathematical windfield model, Traci et al. reported that:

... there is a large extent of high wind area encompassing the Tehachapi ridge, the Frazier and Pinos mountain area (SW corner of the region), and the Sandberg mountain area (south-central region). The mean wind throughout much of this region at $546 \mathrm{~m} \mathrm{AGL} \mathrm{(above} \mathrm{ground} \mathrm{level)} \mathrm{is} \mathrm{greater} \mathrm{than} 10 \mathrm{~m} / \mathrm{sec}$.

Furthermore,

... for the near-neutral stability case, at the $42 \mathrm{~m}$ to $63 \mathrm{~m} \mathrm{AGL}$, air flows over and is augmented by the terrain rather than flowing primarily around the terrain as in the $4800 \mathrm{~m} \mathrm{AGL}$ case .... a relatively low speed $2 \mathrm{~m} / \mathrm{sec}$ flow (exists) in the San Joaquin Valley area which is enhanced to $6 \mathrm{~m} / \mathrm{sec}$ at the highest points of the 
Tehachapi ridge and in the mountainous area at the SW corner of the region and decreases to $2.5 \mathrm{~m} / \mathrm{sec}$ in the desert region. The velocity vector(s) also shows the relatively two-dimensional nature of the flow over the Tehachapi ridge area.

Another study conducted in 1978 by Baker and Wade (1978) affirmed this strong local augmentation effect at several areas of the Tehachapi Mountains, most notably, the region north of Tejon Pass. In a field inspection of the region, Baker and Wade commented that:

... the vegetation on the north side of Tejon Pass consisted of a grove of ancient black oaks. These oaks were remarkable in that the trunks were extremely eccentric with the major axis northwest through southeast. When wind causes eccentric growth the major axis is parallel to the prevailing wind direction.... Tejon Ranch Supervisor of Ranch Wildlife and Security, John Ortega, said that several other regions of the ranch had similar tree flagging; however, most of the other exposed ridges on the ranch present severe access problems.

Thirdly, in a study conducted by Lindley (1977) investigating the feasibility of using wind machines to provide part of the energy required to pump. water in the California Aqueduct, the south-central area of the Tehachapi Mountains was selected as the baseline site because:

(1) almost half the total energy used by the Aqueduct is projected for the Edmonston Pumping Plant and over three-quarters of the energy will be used by the combination of the Edmonston Pumping Plant (located near the northeast slope of the Tehachapis on the San Joaquin Valley floor) and the next three upstream and two downstream stations; (2) this series of pumps runs throughout the calendar year and is at least partly schedulable; (3) of the three most attractive wind energy sites located, Sandberg, Altamont, and Devers, the largest and most reliable set of wind data is available for Sandberg; (4) while Bald Mountain, where Sandberg Station is located, is too small for a major WECS installation, there are large suitable aras at nearby Tejon Mountain, Liebre Mountain, and the Antelope Valley floor. 
In summary, consistent in all three investigations is the attractiveness of the wind resource in the Tehachapi Mountains as proven by limited measurements. Likewise, all three investigations specified the south-central area of the Tehachapi Range, the most prominent wind region, although the likelihood that each available region contains areas where the wind energy would be greater than those measured was noted.

Figures 2 through 4 are relief maps of the south-central area of the Tehachapi Mountains chosen for this siting exercise. Figure 2 is a relief map detailing the study area. This 100-square-mile region of the Tehachapis is part of El Tejon Ranchos. El Tejon Ranchos includes four land grants: El Tejon, La Liebre, Castaic, and Los Alamos y Agua Caliente. El Tejon covers the northwest slopes leading into the San Joaquin Valley; La Liebre covers the southwest region, including the Antelope Valley; Castac covers the southeast region locally referred to as the Grapevine; and Los Alamos y Agua Caliente covers the south-central region. This last area is the major area to be investigated in this study. The region is comprised of fairly high ( 3000 to $5000 \mathrm{ft}$ ) rolling mountains with a $10 \%$ to $20 \%$ slope on the northwest (windward) side, and a continuous, finger-like downslope to the high desert (southeast) side into the Antelope Valley. Vegetation is largely grass and sage and grows during the brief wet season (December through February, generally in the form of snow), then lies dormant during the dry summer season. Temperatures are fairly moderate, although subfreezing temperatures will occur, as will those exceeding $90^{\circ} \mathrm{F}$. In the lower elevations there are trees, primarily California oak, growing on the north-facing slopes and where run-off water is available. The higher elevations are wind-scoured with tight groves of oaks interlaced and trimmed to a uniform height by strong winds and icing. In some areas, these trees are so dense they are barely penetrable. The Tejon Ranch uses the land for cattle grazing as it is too dry and steep for crop growing. The California oak is also farmed for tirewood and hardwood veneer.

The California Aqueduct, which traverses southwest through the San Joaquin Valley, transects this region of the Tehachapis through a series of tunnels and siphons. Because of the Aqueduct water, the flat lowland of the San Joaquin Valley to the northeast is capable of growing crops, most notably cotton and fruit trees. The higher flatlands in the Antelope Valley to the southwest are far less productive for crops due to inaccessibility of Aqueduct water and salinity of the soil. A cement plant is located on the southwest slope 


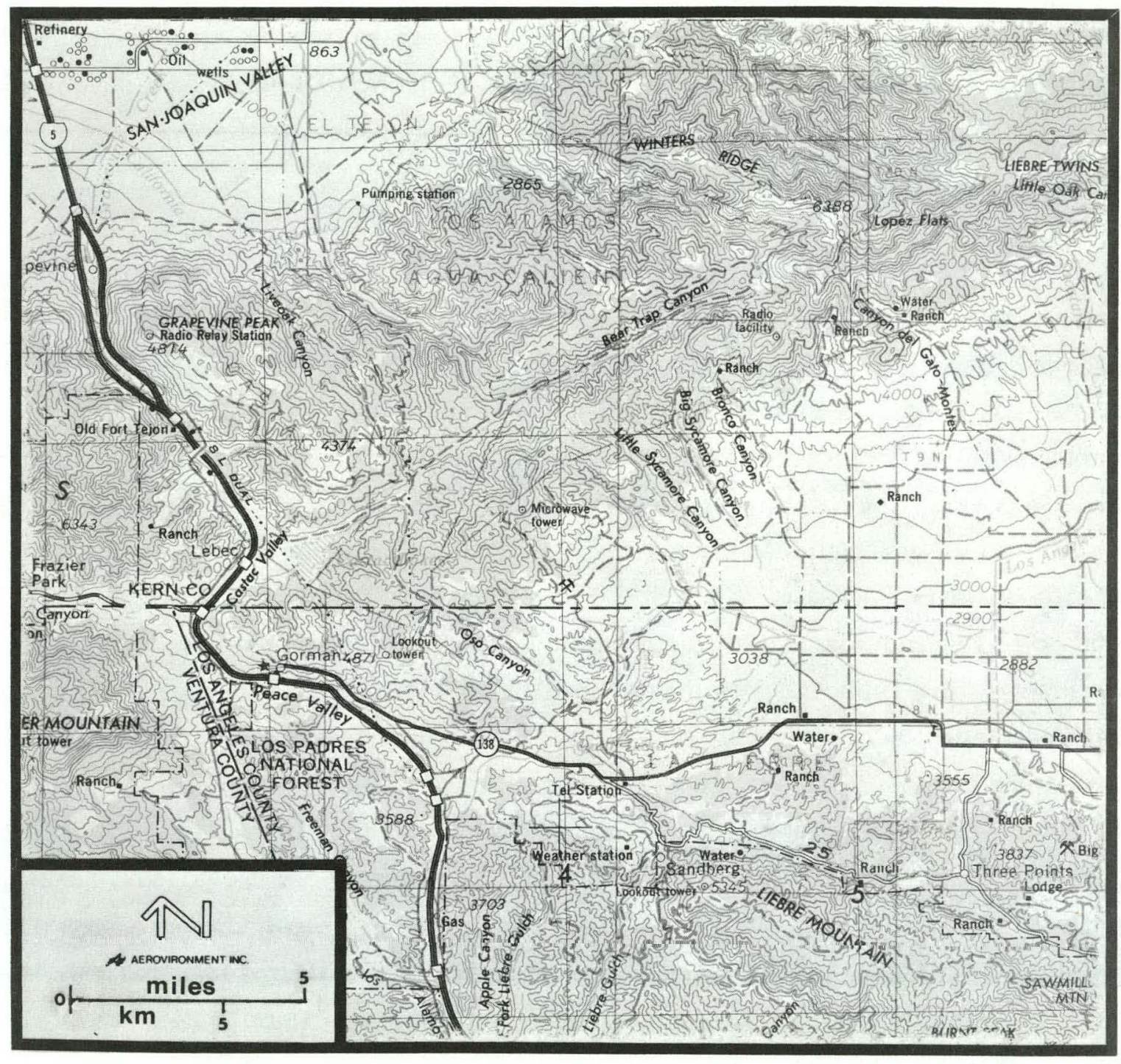

FIGURE 2. Detail of Tehachapi study area. 
of the Tehachapi Mountains making use of abundant limestone deposits accumulated on the slopes and valley floor.

Figure 3 is the same scale relief map of the study region as Figure 2 but with prominent ridgelines highlighted. The far northeast section of the study region is Winters Ridge (presumably named after Jim Winter, who having handled sheep on the moors of Scotland, where he was born, settled in the Tehachapis and surrounding deserts in the 1870s). This is the highest ridgeline; traversing west-northwest, its major axis is five miles long with peaks over $6000 \mathrm{ft}$ and is most inaccessible. In contrast to other portions of the study area, Winters Ridge is well forested to the northeast by very tall and straight Ponderosa pine, many of which have major limbs broken, presumably by strong icing and snow. Some sections of this ridge are completely inaccessible due to the density of trees. In some areas, snow has been seen accumulated under trees as late as July.

Intersecting Winters Ridge at the east-southeast is Purdie Ridge, an insignificant, heavily forested section. Proceeding on a straight southwest axis from Purdie Ridge is the "backbone" ridge of the area called Geghus Ridge (name origin unknown). This ridgeline, approximately nine miles long, is basically soft rolling hilltops covered with tight groves of California oak previously described. The ridgeline ascends from an elevation of around $3700 \mathrm{ft}$ at its southwest end to nearly $5000 \mathrm{ft}$ where it joins Purdie Ridge to the northeast. Under most conditions, the ridge is accessible with a conventional four-wheel-drive vehicle. Major cattle herds are also found in this area.

To the southeast of Geghus Ridge is a sharp drop (approximately a $40^{\circ}$ slope) down to a narrow canyon locally referred to as Bear Trap Canyon. About two miles to the southeast of Geghus Ridge running parallel to the ridge are the last major mountains before the Antelope Valley begins (for discussion purposes, this will be referred to as the La Liebre Ridge). These mountains are the highest and most exposed of any in the study region. Varying anywhere from 4200 to $6000 \mathrm{ft}$, these mountains vary in topography from sharp jutting peaks covered with Ponderosa pine, to flat tabletops with sharply carpeted scrub oak and fields of rubble. Two major radio relay stations are located on these mountains, and as affirmation of the exposed ridgeline, these facilities can be prominently seen far into southeast Antelope Valley. 


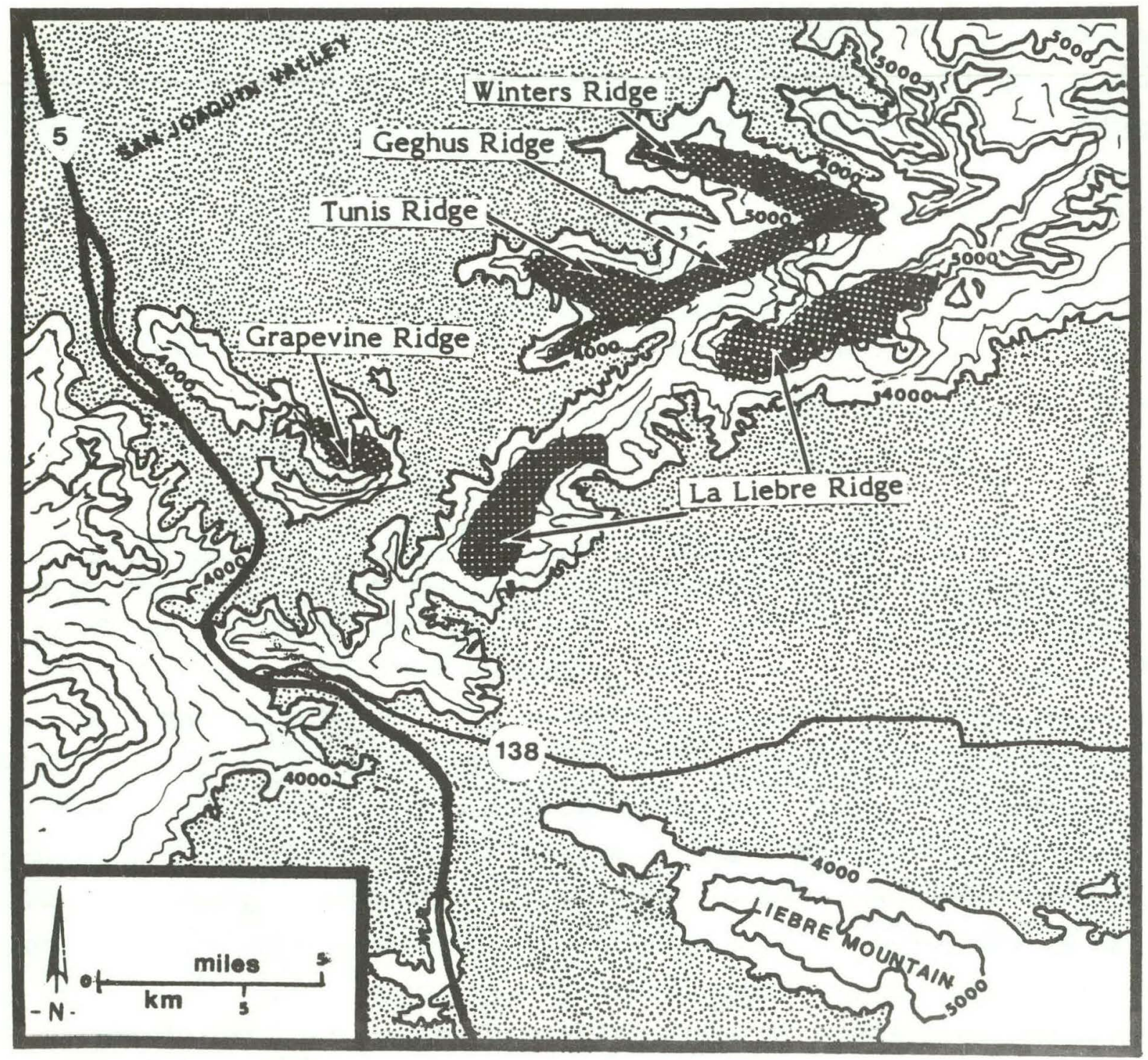

Below $3000 \mathrm{ft}$

$\square$ Above $4000 \mathrm{ft}$

FIGURE 3. Prominent ridgelines of Tehachapi study region. 
To the northwest of Geghus Ridge is another major ridgeline which juts out in a finger-like fashion almost midway along the axis of Geghus Ridge. This ridgeline, called Tunis Ridge, is named after the small wild cactus that once grew there. Tunis Ridge is very similar in topography to Geghus Ridge. Traversing approximately five miles, Tunis Ridge (although extending more westerly) is parallel to Winters Ridge, well exposed to the north-northeast about three miles away. Separating Tunis and Winters Ridge is a very deep and inaccessible arroyo which leads out to the northwest into the San Joaquin Valley.

On the basis of this topography, the mesoscale climatology obtained from previous reports and historical summaries from Bakersfield and Sandberg, two major wind-energy siting decisions were initially apparent. First, it would be useless to investigate the arroyos for wind-energy applications because of their disorientation to the prevailing north-northwest or summer convective southeast flows, and the inaccessibility of these regions. Second, with the exception of the tabletop fields of rubble on the La Liebre ridgeline, there is no single flat area which could support more than three or four large WECS. The only regions suitable for wind-energy applications would be the crests along the rolling hills of the Winters, Tunis, Geghus, and La Liebre ridgelines. From the use of 7.5-minute topographic maps, 16 sites were identified as "candidate" sites for WECS. These 16 sites are numbered on the relief map of Figure 4.

Considering the approximately 100 -square-mile area comprising the study region, approximately 20 square miles encompassing the major ridgelines was considered suitable for WECS investigation, or one in five square miles of complex terrain. Based upon preliminary site inspections, it was estimated that the remaining one square mile of the five would, most probably, have one orographic feature which would make a local area suitable for WECS siting.

\section{FIELD ASSESSMENT SURVEY PROCEDURES}

Ideally, all 16 candidate sites selected by the initial screening could be instrumented with some type of wind monitoring instrumentation to record one year of continuous windspeed and direction data used to decide the suitability of WECS in the region. Cost constraints may not permit this investigation; therefore, a technique was developed to 


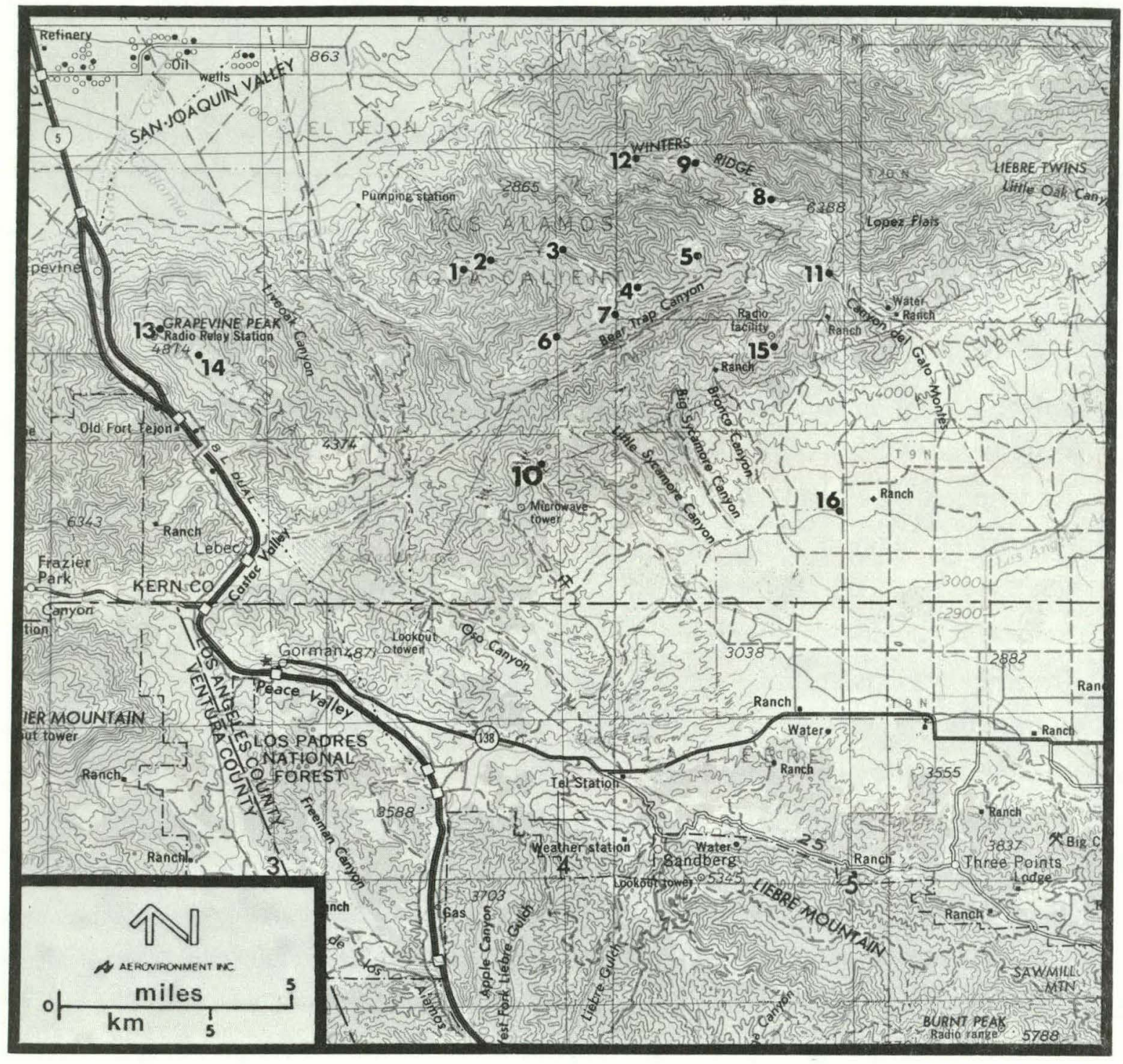

FIGURE 4. Candidate sites at the Tehachapi Study Region. 
judge the merits and disadvantages of wind monitoring at each respective site. For each observational criterion-- namely, check anemometry, ecological features, and serviceability -- each site was ranked in order of merit for the observational criterion with respect to the other 15 . The final result was a combination of three sets of rankings into a matrix to obtain, from best to worst, the sites most suitable for installing windmonitoring stations.

For this particular siting exercise, seven wind-speed monitoring stations and two wind-speed/direction monitors, which operated for six months collecting continuous data on strip-chart recorders, were used. (The consequences of this selection of number and type of instrumentation are discussed in the conclusions.) The following discussions concern the field assessment survey conducted to determine the ranking of the candidate sites. The field survey was conducted during one week in late April 1979 when winds were judged to be from the predominant direction, as recorded by the National Weather Service at Sandberg.

\section{Short-Term Field Measurement Survey}

The short-term field measurement survey involved three methods for measuring low-level winds. The first task was to set up continuous wind-speed monitoring stations at strategic locations. These base stations would provide a history of the diurnal variation of wind during the one-week field survey. The base stations were equipped with a simple cup anemometer that outputs a continuous voltage onto a strip-chart. Each anemometer was mounted atop a guyed pole high enough to be unobstructed by any ground effect (usually between 20 to 33 feet depending on the site). The base stations were portable and each required approximately two man-hours to install. Base stations were strategically placed at five candidate sites: Site 9, Winters Ridge; Site 3, Tunis Ridge; Site 4, Geghus Ridge; Site 10, La Liebre Ridge; and Site 14, Grapevine Hill. Data were to be recorded simultaneously at all five sites.

Each site was chosen to provide a base measuring point on each major ridge and selected for field operations convenience and accessibility during the course of the one-week field survey. 
The second check anemometry task involved the use of the TALA kite. The TALA kite was used to measure wind-speed profiles at all candidate sites. This instrument is composed of a small kite. The lift and drag forces exerted on the kite and string are transmitted to a recorder as line tension, which is converted to wind velocity via a correlation relationship. The basic measurement procedure has been verified in the National Bureau of Standards and NASA-Langley Air Force Base wind tunnels.

The kite, made of Tyvek by du Pont, is specially designed for high wind stability, with a tail stabilizing the kite. Specifications call for the kite to fly in winds from 7 to $12 \mathrm{mph}$ (approximately 3 to $4 \mathrm{~m} / \mathrm{sec}$ ) and reach a peak altitude of $1000 \mathrm{ft}$ in winds as low as $13 \mathrm{mph}$. Wind speeds up to $60 \mathrm{mph}$ may be measured. The height of the kite is determined from the corrected line length and elevation; the latter being measured by an inclinometer. The azimuth angle gives the wind direction. The initial model employed a hand-held reel and calibrated spring in a measurement tube (TALA base unit 151). A newer model utilizes a strain gauge for measuring cable tension and an analog recorder (TALA base unit 152). The overall accuracy of the system has been investigated by work performed by Baker et al. (1979) in which systems similar to those used in this siting exercise were flown in winds from 17 to $35 \mathrm{mph}$ against several towers equipped with anemometers at 17 to $200 \mathrm{~m}$, and in controlled comparison experiments by WMO and NOAA/WPL, where TALA systems and other low-level sensing equipment were compared against a 300-m meteorological tower. The general consensus is the TALA system would give a reliable estimate of mean wind speeds. A forthcoming WMO monograph will provide more accurate system capabilities.

The plan of operation for wind-field assessment was the following:

In a given region of interest, a centralized location was chosen to provide representative readings of the prevailing wind flow. These centralized locations were where the continuous wind-speed monitors were operating. Each centralized location was designated the base station and equipped with a TALA base unit (Model 152) and radio communications. Two teams, also equipped with TALA kites (Model 151) and radio communications, then went to the other candidate sites in the region, coordinating time and altitude with the base station by radio communications. This procedure enabled wind- 
profile transverses in the areas to be coordinated and compared to the base unit to identify temporal changes. Readings (10-minute averages) at 10-, 30-, 50-, and 100-m levels were attempted. Designated areas were visited several times during a working period of approximately one week. (a)

The third check anemometry survey task involved the use of a portable, hand-held Gill Model 271000 propeller anemometer. The Gill hand-held anemometer is a precision airspeed-measuring instrument using a propeller molded in the form of a true generated helicoid and extensively tested in a wind tunnel by the manufacturer. The propeller rotates 0.96 revolutions per foot for all wind speeds above $4 \mathrm{ft}$ per second. The propeller drives a miniature D.C. tachometer generator providing a voltage output directly proportional to the wind speed. These instruments were mounted on a short, approximately 10-foot, pole and the reading output on a pocket-size digital voltmeter with 5-second time constants.

The Gill propeller anemometer served two purposes: (1) to ensure that the TALA and portable base stations were operating properly, because of its accuracy and reliability; and (2) to estimate wind speed and direction at many spots on the side or top of an individual site where TALA kites would be difficult to use because of trees, sloping terrain, or light winds.

The results of the check anemometry are reported later.

\section{Ecological Survey - Vegétation Flagging}

The ecological survey was conducted at the same time the check anemometry measurements were made. At each candidate site several factors were noted about the surrounding trees. Many photographs were taken of bushes and trees exposed to persistently strong winds. Trees exhibiting a wind-swept form have most of the vegetation on the lee side of the main stem. From visual observation, measurements, and photographs, the various degrees of wind shaping, depending upon the wind's strength, can be obtained. Several investigators have developed a sensitive index defining, quantitatively, the degree of deformation for several types of trees. Relationships which correlate these tree rankings to an actual mean annual wind speed have also been ${ }^{(a)}$ R. M. Young Company, 2801 A1rpark Drive, Traverse City, MI 49684. 
developed. Although subject to some uncertainty (generally, about $\pm 20 \%$ ), these correlations can only become more refined by the continual addition to the "data base" -that is, more comparisons between recorded wind-speed and refinements in tree deformation indices. However, for this siting exercise, site comparison of the degree of tree deformation was the comparative factor used in ranking the 16 candidate sites. Since actual wind-speed measurements were made at nine of the sites, comparison of this data to predicted mean annual wind speeds obtained from vegetation indices correlation was an additional, valuable sidelight of this siting exercise.

Four vegetation indices were used to estimate mean annual winds from tree deformation. The two most significant indices for the type of vegetation seen in the study region were the Deformation Ratio and the Barsch Index. The following descriptions of these indices are paraphrased from a succinct account of their use given by Hewson et al. (1979).

The Deformation, Ratio (D) is a measure of the degree of crown asymmetry and main stem deflection (see Figure 5). This index can be calculated from photographs of the tree taken normal to the prevailing wind direction or by direct examination of the tree. Photographs are taken from the direction perpendicular to the direction of maximum asymmetry. The angles $\alpha, \beta$, and $Y$ are measured on the photographs. The value of $D$ is given by the equation:

$$
\mathrm{D}=\frac{\alpha}{\beta}+\frac{\gamma}{45^{\circ}} \quad 1 \leq \frac{\alpha}{\beta} \leq 5
$$

where $\alpha$ is the angle between the crown and the main stem on the leeward side, $\beta$ is the angle between the crown and the main stem on the windward side, and $\gamma$ is the angle of the main stem or trunk deflection.

For deciduous trees with hemispherical crowns the Deformation Ratio is given by:

$$
\mathrm{D}=\frac{\mathrm{a}}{\mathrm{b}}+\frac{\gamma}{45^{\circ}} \quad\left(1 \leq \frac{\mathrm{a}}{\mathrm{b}} \leq 5\right),
$$




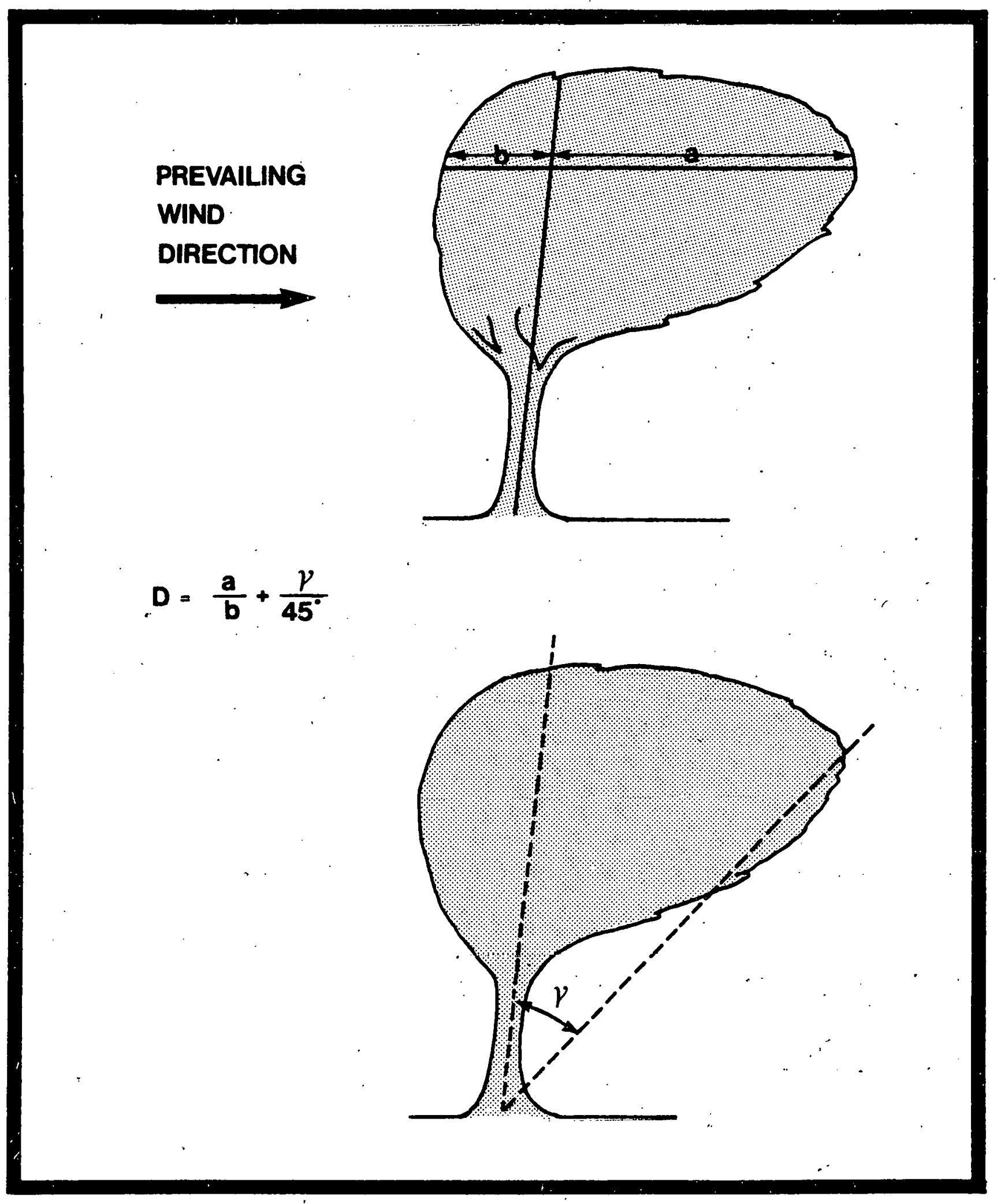

FIGURE 5. Deformation ratio definition. 
where $a$ is equal to the distance between the trunk and crown perimeter on the leeward side, and $b$ is the distance between the trunk and crown perimeter at the same height on the windward side. The parameter $\gamma$ is the same as in Equation (1). The variables $a$ and $b$ are measured in the top third of the tree crown.

A special index of wind deformation for deciduous trees with hemispherical crowns was developed by Barsch (1963). The index has seven steps and six deformation degrees:

0 no visible influence of winds

1 bending of the outer small twigs

2 stronger twigs and branches are bent leeward

3 strongly expressed crown asymmetry

4 all branches are bent leeward or have a flag form

5 throwing with trunk bent toward the leeward

6 carpet-form trees with main stem or trunk growing along the ground

Two other indices, the Griggs index for pines, and the compression ratio for pines, were used at some of the candidate sites, although insufficient trees of this type were available to use the indices for intersite comparisons. The Griggs index is a subjective rating scale in which each tree is given a rating based upon the observational characteristics of the wind deformation. The Griggs index is similar to the Barsch index but is used for conifers. The compression ratio is an indicator of the influence of the wind on the trunk's cross-section asymmetry. The compression ratio is calculated by taking the annual increment of growth of the bole or trunk on the windward side of the tree.

The results of the ecological survey are reported in a later section.

\section{Site Serviceability and Topography}

Site serviceability rankings were a subjective appraisal of general exposure and land constraints. It was felt this third ranking criterion would be important for effective operation of field-monitoring equipment, and also would incorporate the non-meteorological points to be considered. Vandalism, right-of-ways, public visibility, and wildlife were all parameters to be considered. Because the siting exercise was conducted on Tejon 
Ranch, land security was excellent and there was little restriction as to the placement of the wind-monitoring systems. Site serviceability, therefore, was based more on the candidate site's exposure and land area availability and access. The results of the site serviceability survey are reported later.

\section{INSTRUMENTATION}

Discussed here is the wind-monitoring instrumentation used at the nine selected stations. A description of equipment performance of all the instrumentation, including that used in the one-week field survey, is also discussed.

\section{General Description}

Because the intention of the study was to keep the instrumentation efficient but inexpensive, AeroVironment (AV) designed a $10-\mathrm{m}$ wind-monitoring station which made use of readily available parts which could be assembled, erected, and maintained with simplicity. The 10-m wind-monitoring station, complete with hardware and a flow diagram, is depicted in Figures 6 and 7.

The wind sensor used was a Model W200S three-cup anemometer manufactured by WeatherMeasure Corporation (see Figure 8$)^{(a)}$. The anemometer is mounted vertically on a stainless-steel shaft which rotates on ball bearings and is coupled to the permanent magnet of an A.C. generator. The anemometer cups and housing are polycarbonate; the cups are one-piece injection mold. Rotation of the cups occurs in direct proportion to wind speed. The A.C. generator, in turn, produces a voltage which is in direct proportion to the wind speed. The voltage produced by the generator is transmitted to a signalconditioning unit made by AV. A Rustrak, single-channel, strip chart recorder records the signal; power is supplied by a 12-volt rechargeable battery (Elpower Solid-Gel). The anemometer was mounted on a 30-foot telescoping guyed tower (one 16-gauge and two 18-gauge sections). The signal wires were run down the guyed tower and into a steel box containing the battery, the signal-conditioning unit, and Rustrak recorder.

The wind-direction sensor used was a Model W200D airfoil vane manufactured by WeatherMeasure Corporation (Figure 9). The vane is set on an anodized aluminum shaft
(a) WeatherMeasure Corporation, P.0. Box 41256, Sacramento, CA 95841.
(b) Rustrak Instruments Measurements and Control Systems Division, Gulton Industries, Inc.,
East Greenwich, RI 02818 .
Elpower Corporation, 2117-T S. Anne St., Santa Ana CA 92704. 


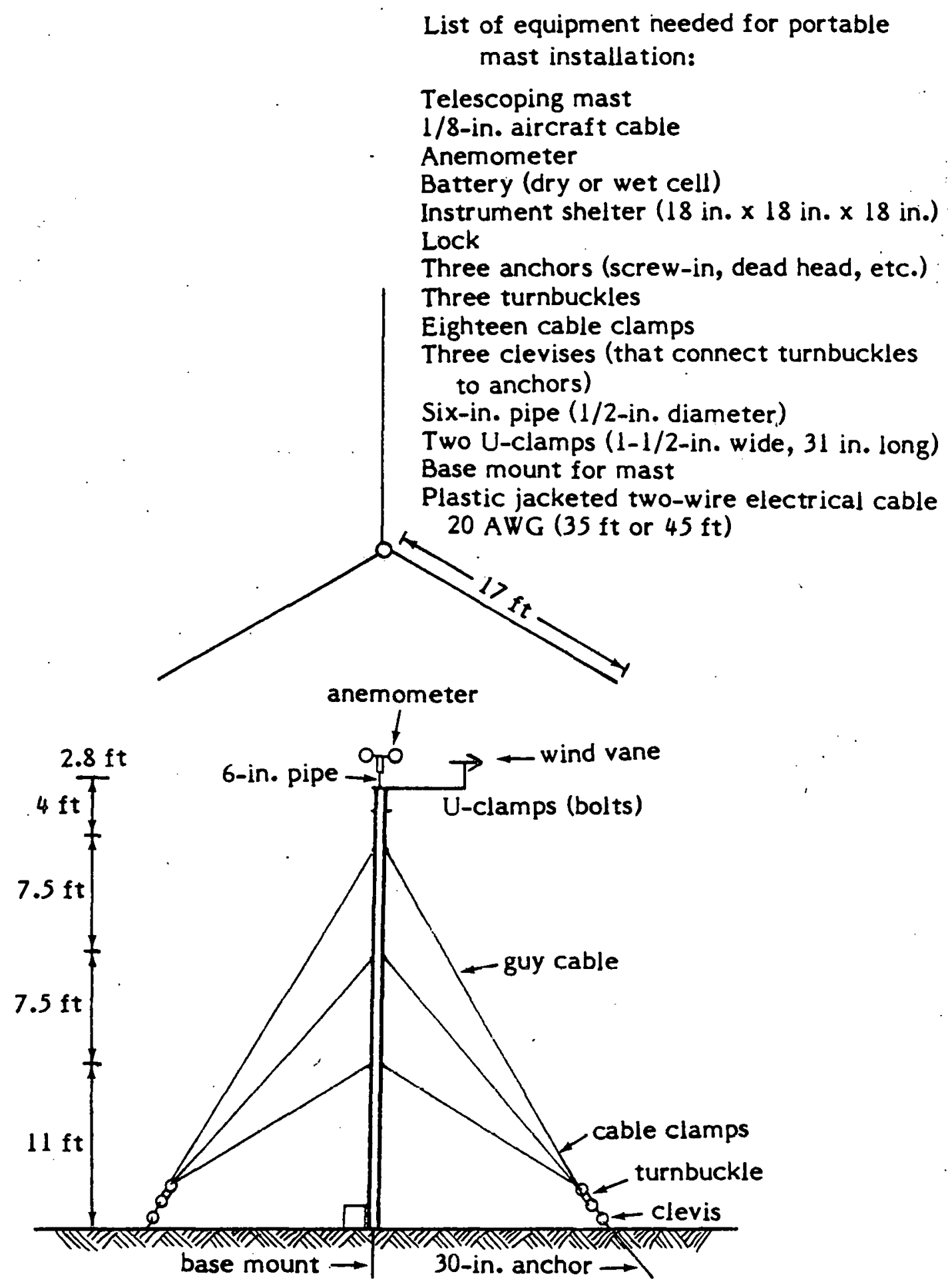

FIGURE 6. Ten meter (33-ft) wind monitoring station and hardware list. 


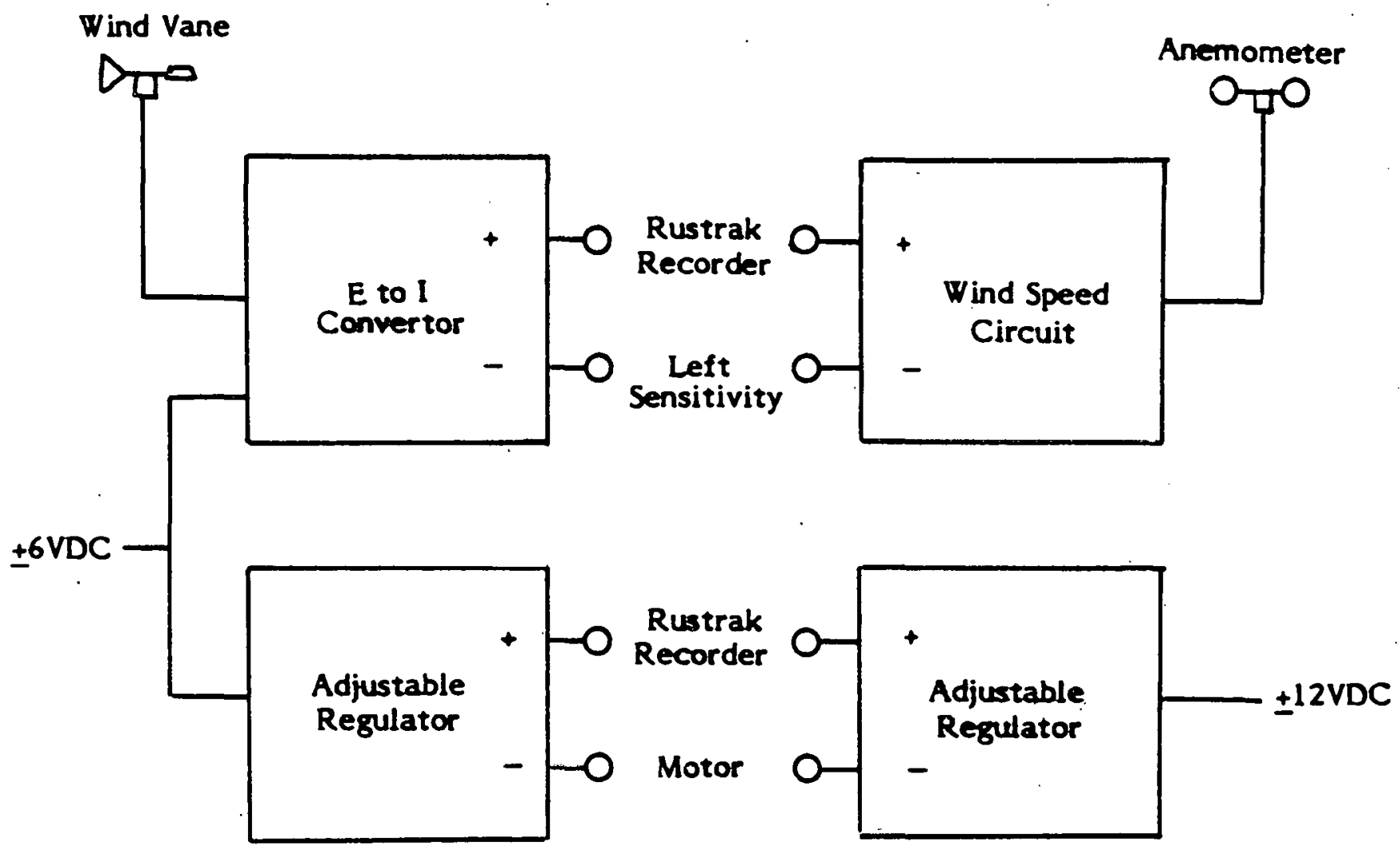

FIGURE 7. - Flow diagram of 10-m tower measuring station.

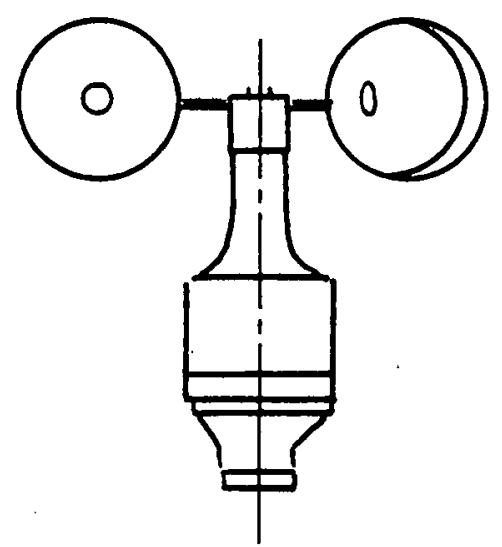

FIGURE 8. Cup anemometer.

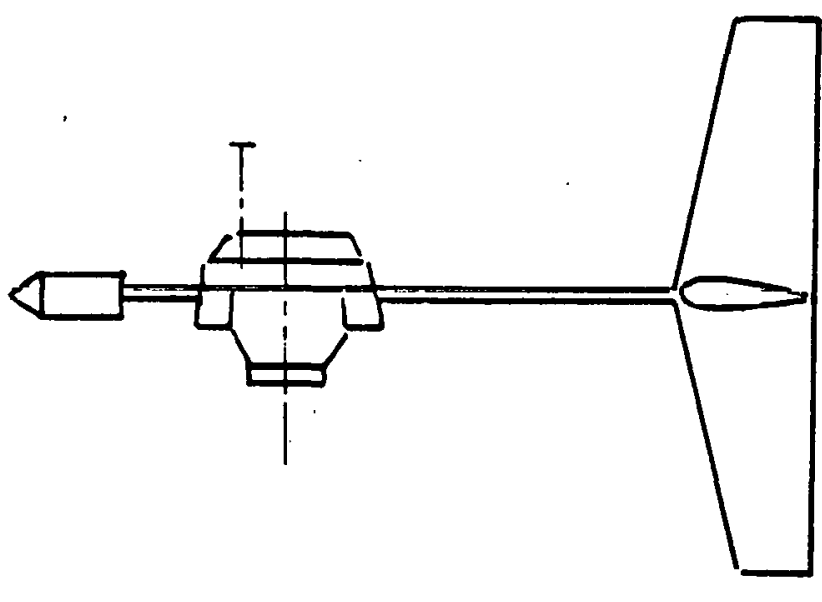

FIGURE 9. Wind vane. 
mounted on Teflon-type thrust bearings and rotates so that the counterbalance always points into the wind direction. Attached to the lower end of the vane is a dual-precious metal (gold-silver alloy) wiper which contacts a precision potentiometer to form a vol tage divider network. When a fixed D.C. voltage is applied to the potentiometer, the divider network produces an output voltage dependent upon the wiper (or vane) position. To indicate direction, power to the sensor and the returning voltage signal are transmitted by means of a three-wire cable, which exits through a hole in the bottom of the sensor housing. The output signal is stored on a Rustrak recorder. The sensor and instrumentation is mounted and stored on the same guyed tower-steel box configuration described for the wind-speed sensor.

\section{Calibration}

Although WeatherMeasure Corporation states, "These instruments (W200S, W200D) are factory calibrated and require no further adjustment," all new monitoring equipment were subject to a base check. Results from this test showed close agreement with instrument specifications.

\section{Site Checks and Data Retrieval Plan}

All sites were checked at three-week intervals by a two-man team from AV. The rugged terrain of the study region dictated the use of a four-wheel vehicle to gain access to the sites. To expedite maintenance tasks, sites were located near ranch roads, when possible.

The maintenance of on-site equipment was divided into three tasks:

1. Routine mainteriance required tö ensure proper operation of instruments; e.g., replacing strip charts and battery packs.

2. Preventive maintenance to maximize useful life of instruments; e.g., lubrication of bearings and replacement of anemometer cups.

3. Repair of malfunctioning equipment. 


\section{Equipment Performance}

Wind-speed and wind-direction sensors performed within the performance specifications set by WeatherMeasure Corporation; however, previous experience dictated replacement of cup assemblies after extended use. WeatherMeasure was aware of cup assembly fatigue problems and provided AV with replacement assemblies at no charge. As a preventive maintenance measure, all anemometer cups were replaced after three months of field use.

When occasional complete failure of sensors was experienced, the sensors were replaced by a new unit from an in-house inventory maintained by AV. This equipment inventory played a vital role in insuring minimum data loss attributed to sensor malfunction. Field plugs and components were specifically designed in modules, so replacement in the field was simple as possible.

The batteries used were Elpower Rechargeable Solid-Gel batteries. In moderate temperatures, the AV-designed battery pack can provide power to a site for well over a month. Allocation of two sets of battery packs for each site permitted one set to be fully charged while the other was in use. This practice helped keep battery failure to a minimum. The batteries performed to specification in the field.

The recorders used were Rustrak miniature strip recorders. The units were plotted on pressure-sensitive rectilinear chart paper by making a series of dots forming a continuous line representing the parameters being monitored. Recording occurs when a mechnical chopper bar presses the stylus against the pressure-sensitive chart paper.

The Rustrak recorder was found to be an erratic piece of field equipment. Nearly all da ta loss attributed to instrument malfunction was a direct result of Rustrak recorder failure. A major problem was that the stylus would break or the gears would slip. The Model 388 dual-channel recorder gave persistent problems with its drive motors from the onset of the field program and was eventually termed cost ineffective and returned to the manufacturer for replacement by single-channel recorders. To keep pace with the high instrument attrition rate, a large inventory of recorders was required. 
The TALA system proved to be a reliable field instrument for its basic application - - that is, it successfully measured wind velocity by exerting drag on the durable kite. Excellent results and field useability were obtained with the TALA Model 150 by observing the elongation of the spring scale, and obtaining the kite's elevation by recording the line count of kite twine let out.

However, problems occurred in proportion to the amount of analog equipment added to the basic unit. The TALA Model 151 is identical to the Model 150, with the exception of its recording capabilities. A strain gauge is included in the instrument's reel seat which outputs onto a Rustrak recorder. Both the strain gauge and Rustrak recorder were found to be too sensitive to the rugged treatment subjected to field-monitoring equipment. When they functioned, the calibration and paper-logging of the analog device and strip charts were more time-consuming than if the basic Model 150 was used. Also, since the instruments are used 8 to 12 hours per day, battery drainage became a problem.

The TALA Model 152 is a portable. recording, battery-operated, variable-altitude anemometer. Again, every addition to the basic Model 150 was more deleterious to field operation than a source of additional information. The strain gauge was erratic, as was the Rustrak recorder. (A major problem was that two parameters were designed to be recorded on the same strip chart; many times, data signals overlapped or went out of gain after a short period of time, sometimes in 5 minutes.) Batteries drained, the electric rewind motor was slow and sometimes too weak for the drag of the kite, and the mounting of the reel to the instrument casing was impractical.

Most of these design features would be useful, if they were operationally reliable. The manufacturer was attentive and responsive to design criticisms of these new instruments. Nevertheless, the TALA Model 150, in its simplicity, durability, and portability, proved to be the best of the three TALA systems tested in for this field survey.

\section{$\underline{\text { Related Field Operations }}$}

The field program was conducted within the confines of Tejon Ranch which provides grazing land for several thousand head of cattle. During summer, cattle are allowed to roam throughout the ranch, permitting the cattle to be in frequent contact with the 
monitoring sites. Barbed wire was draped around the sites to discourage the cattle from doing damage. However, the cattle ignored the barrier and entered the site to chew the instrument wires or scratch their backs against the guy wires. In one instance, the instrument tower was found stampeded and the instrument destroyed. (It was also apparent some cattle mistook our white instrument boxes for salt licks.)

During fall, cattle were transported to corrals at lower elevations, thus reducing the number of cattle frequenting the sites. After that no cattle damage was reported.

During summer, a southeast flow can spawn thunderstorms over the Tehachapis. A lightning strike near a site can cause an overload of the signal conditioning circuitry and recording instrumentation failure. This was discovered during site maintenance checks. The modular signal conditioning device was replaced and the damaged console was returned to AV for repair.

The TALA systems were not used when thunderstorm activity was apparent. Vandalism was not a factor, and the Tejon personnel were very cooperative and cordial.

\section{FIELD ASSESSMENT SURVEY RESULTS}

Reported are results obtained from the one-week field assessment survey. The objective of the field survey was to select nine sites at which temporary wind-monitoring stations would be installed.

\section{Short-Term Field Measurements}

Results of the TALA kite measurements are summarized in Table 1. The table lists the candidate site number, elevation, time of measurement, mean velocity after ten minutes of sampling (one sample every five seconds), standard deviation of the mean, turbulence intensity (defined as the standard deviation divided by the mean), prevailing wind direction, and the temperature at the ground.

The mean velocities and turbulence intensities measured by the TALA kites and plotted for the selected sites in Figure 10 reflect strong and gusty winds over 
TABLE 1. Summary of TALA wind speed measurements taken at candidate sites during 30 April 1979.

\begin{tabular}{|c|c|c|c|c|c|c|c|}
\hline $\begin{array}{c}\text { Candi- } \\
\text { date } \\
\text { Site } \\
\text { No. }\end{array}$ & $\begin{array}{l}\text { Time } \\
\text { (PST) }\end{array}$ & $\begin{array}{c}\text { Eleva- } \\
\text { tion } \\
\mathrm{ft}(\mathrm{m})\end{array}$ & $\begin{array}{c}\nabla \\
\mathrm{mph}(\mathrm{m} / \mathrm{s})\end{array}$ & $\sigma$ & I & $\begin{array}{c}\text { Direc- } \\
\text { tion } \\
\left(0-360^{\circ}\right)\end{array}$ & $\begin{array}{c}\text { Temper- } \\
\text { ature } \\
\left({ }^{\circ} \mathrm{F}\right)\end{array}$ \\
\hline $\begin{array}{l}1 \\
1 \\
1 \\
1\end{array}$ & $\begin{array}{l}1155 \\
1145 \\
1130 \\
1120\end{array}$ & $\begin{array}{rr}33 & (10) \\
99 & (30) \\
165 & (50) \\
330 & (100)\end{array}$ & $\begin{array}{ll}19.5 & (8.7) \\
19.5 & (8.7) \\
21.5 & (9.6) \\
21.0 & (9.4)\end{array}$ & $\begin{array}{l}1.7 \\
1.9 \\
1.6 \\
1.6\end{array}$ & $\begin{array}{l}0.19 \\
0.22 \\
0.16 \\
0.17\end{array}$ & $\begin{array}{l}310 \\
310 \\
305 \\
305\end{array}$ & $\begin{array}{l}68 \\
68 \\
68 \\
68\end{array}$ \\
\hline $\begin{array}{l}2 \\
2 \\
2\end{array}$ & $\begin{array}{l}1435 \\
1450 \\
1500\end{array}$ & $\begin{array}{rr}33 & (10) \\
165 & (50) \\
330 & (100)\end{array}$ & $\begin{array}{ll}29.8 & (13.3) \\
30.2 & (13.5) \\
28.4 & (12.7)\end{array}$ & $\begin{array}{l}2.6 \\
3.4 \\
3.1\end{array}$ & $\begin{array}{l}0.20 \\
0.25 \\
0.24\end{array}$ & $\begin{array}{l}330 \\
330 \\
330\end{array}$ & $\begin{array}{l}65 \\
65 \\
65\end{array}$ \\
\hline $\begin{array}{l}3 \\
3 \\
3\end{array}$ & $\begin{array}{l}1000 \\
0950 \\
0940\end{array}$ & $\begin{array}{rr}33 & (10) \\
165 & (50) \\
330 & (100)\end{array}$ & $\begin{array}{ll}17.9 & (8.0) \\
20.1 & (9.0) \\
21.5 & (9.6)\end{array}$ & $\begin{array}{l}1.6 \\
0.8 \\
1.0\end{array}$ & $\begin{array}{l}0.22 \\
0.10 \\
0.11\end{array}$ & $\begin{array}{l}315 \\
315 \\
315\end{array}$ & $\begin{array}{l}66 \\
66 \\
66\end{array}$ \\
\hline $\begin{array}{l}4 \\
4 \\
4 \\
4\end{array}$ & $\begin{array}{l}1215 \\
1200 \\
1150 \\
1135\end{array}$ & $\begin{array}{rr}33 & (10) \\
99 & (30) \\
165 & (50) \\
330 & (100)\end{array}$ & $\begin{array}{ll}31.3 & (14.0) \\
30.0 & (13.4) \\
25.9 & (11.6) \\
27.1 & (12.1)\end{array}$ & $\begin{array}{l}1.7 \\
1.7 \\
1.8 \\
1.3\end{array}$ & $\begin{array}{l}0.12 \\
0.13 \\
0.16 \\
0.11\end{array}$ & $\begin{array}{l}310 \\
310 \\
310 \\
305\end{array}$ & $\begin{array}{l}65 \\
65 \\
65 \\
65\end{array}$ \\
\hline $\begin{array}{l}5 \\
5 \\
5 \\
5\end{array}$ & $\begin{array}{l}1635 \\
1625 \\
1610 \\
1600\end{array}$ & $\begin{array}{rr}33 & (10) \\
99 & (30) \\
165 & (50) \\
330 & (100)\end{array}$ & $\begin{array}{ll}17.4 & (7.8) \\
22.6 & (10.1) \\
23.5 & (10.5) \\
28.0 & (12.5)\end{array}$ & $\begin{array}{l}3.0 \\
3.3 \\
2.9 \\
3.3\end{array}$ & $\begin{array}{l}0.39 \\
0.33 \\
0.27 \\
0.26\end{array}$ & $\begin{array}{l}310 \\
305 \\
310 \\
285\end{array}$ & $\begin{array}{l}64 \\
64 \\
64 \\
64\end{array}$ \\
\hline $\begin{array}{l}6 \\
6 \\
6 \\
6\end{array}$ & $\begin{array}{l}1455 \\
1445 \\
1430 \\
1419\end{array}$ & $\begin{array}{rr}33 & (10) \\
99 & (30) \\
165 & (50) \\
330 & (100)\end{array}$ & $\begin{array}{ll}19.5 & (8.7) \\
20.4 & (9.1) \\
21.5 & (9.6) \\
23.3 & (10.4) \\
\end{array}$ & $\begin{array}{l}2.5 \\
2.2 \\
2.8 \\
2.4 \\
\end{array}$ & $\begin{array}{l}0.29 \\
0.24 \\
0.29 \\
0.23 \\
\end{array}$ & $\begin{array}{r}300 \\
300 \\
.315 \\
310 \\
\end{array}$ & $\begin{array}{l}70 \\
70 \\
70 \\
70\end{array}$ \\
\hline $\begin{array}{l}7 \\
7 \\
7\end{array}$ & $\begin{array}{l}1620 \\
1555 \\
1610\end{array}$ & $\begin{array}{rr}33 & (10) \\
165 & (50) \\
330 & (100)\end{array}$ & $\begin{array}{ll}29.3 & (13.1) \\
34.4 & (15.4) \\
30.4 & (13.6)\end{array}$ & $\begin{array}{l}2.4 \\
3.1 \\
1.4\end{array}$ & $\begin{array}{l}0.18 \\
0.20 \\
0.10\end{array}$ & $\begin{array}{l}310 \\
305 \\
310\end{array}$ & $\begin{array}{l}58 \\
58 \\
58\end{array}$ \\
\hline 8 & \multicolumn{7}{|c|}{ not accessible } \\
\hline $\begin{array}{l}9 \\
9 \\
9 \\
9\end{array}$ & $\begin{array}{l}1855 \\
1845 \\
1835 \\
1825\end{array}$ & $\begin{array}{rr}33 & (10) \\
99 & (30) \\
165 & (50) \\
330 & (100)\end{array}$ & $\begin{array}{lr}22.6 & (10.1) \\
21.0 & (9.4) \\
19.5 & (8.7) \\
23.3 & (10.4)\end{array}$ & $\begin{array}{l}1.8 \\
1.2 \\
1.0 \\
0.9\end{array}$ & $\begin{array}{l}0.18 \\
0.13 \\
0.11 \\
0.08\end{array}$ & $\begin{array}{l}305 \\
290 \\
305 \\
305\end{array}$ & $\begin{array}{l}50 \\
50 \\
50 \\
50\end{array}$ \\
\hline
\end{tabular}


TABLE 1 (continued).

\begin{tabular}{|c|c|c|c|c|c|c|c|}
\hline $\begin{array}{l}\text { Candi- } \\
\text { date } \\
\text { Site } \\
\text { No. }\end{array}$ & $\begin{array}{l}\text { Time } \\
\text { (PST) }\end{array}$ & $\begin{array}{l}\text { Eleva- } \\
\text { tion } \\
\mathrm{ft}(\mathrm{m})\end{array}$ & $\begin{array}{c}\nabla \\
\mathrm{mph}(\mathrm{m} / \mathrm{s})\end{array}$ & $\sigma$ & I & $\begin{array}{c}\text { Direc- } \\
\text { tion } \\
\left(0-360^{\circ}\right)\end{array}$ & $\begin{array}{c}\text { Temper- } \\
\text { ature } \\
\left({ }^{\circ} \mathrm{F}\right)\end{array}$ \\
\hline $\begin{array}{l}10 \\
10 \\
10 \\
10\end{array}$ & $\begin{array}{l}1740 \\
1735 \\
1725 \\
1715\end{array}$ & $\begin{array}{rr}33 & (10) \\
99 & (30) \\
165 & (50) \\
330 & (100)\end{array}$ & $\begin{array}{ll}25.9 & (11.6) \\
25.5 & (11.5) \\
31.1 & (13.9) \\
33.8 & (15.1)\end{array}$ & $\begin{array}{l}2.3 \\
2.7 \\
2.4 \\
1.1\end{array}$ & $\begin{array}{l}0.19 \\
0.24 \\
0.18 \\
0.07\end{array}$ & $\begin{array}{l}285 \\
300 \\
305 \\
305\end{array}$ & $\begin{array}{l}50 \\
50 \\
50 \\
50\end{array}$ \\
\hline 11 & \multicolumn{7}{|c|}{ not accessible } \\
\hline $\begin{array}{l}12 \\
12 \\
12\end{array}$ & $\begin{array}{l}1620 \\
1830 \\
1840\end{array}$ & $\begin{array}{rr}33 & (10) \\
165 & (50) \\
330 & (100)\end{array}$ & $\begin{array}{ll}27.3 & (12.2) \\
28.6 & (12.8) \\
29.3 & (13.1)\end{array}$ & $\begin{array}{l}1.6 \\
1.0 \\
0.6\end{array}$ & $\begin{array}{l}0.13 \\
0.07 \\
0.05\end{array}$ & $\begin{array}{l}325 \\
320 \\
320\end{array}$ & $\begin{array}{l}44 \\
44 \\
44\end{array}$ \\
\hline 13 & \multicolumn{7}{|c|}{ not accessible } \\
\hline $\begin{array}{l}14 \\
14 \\
14 \\
14\end{array}$ & $\begin{array}{l}1430 \\
1445 \\
1445 \\
1430\end{array}$ & $\begin{array}{rr}33 & (10) \\
99 & (30) \\
165 & (50) \\
330 & (100)\end{array}$ & $\begin{array}{ll}13.2 & (5.9) \\
14.5 & (6.5) \\
15.0 & (6.7) \\
13.6 & (6.1)\end{array}$ & $\begin{array}{l}1.4 \\
1.1 \\
1.1 \\
1.5\end{array}$ & $\begin{array}{l}0.24 \\
0.16 \\
0.17 \\
0.24\end{array}$ & $\begin{array}{l}315 \\
315 \\
315 \\
335\end{array}$ & $\begin{array}{l}45 \\
45 \\
45 \\
45\end{array}$ \\
\hline $\begin{array}{l}15 \\
15 \\
15 \\
15\end{array}$ & $\begin{array}{l}1140 \\
1135 \\
1125 \\
1110\end{array}$ & $\begin{array}{rr}33 & (10) \\
99 & (30) \\
165 & (50) \\
330 & (100)\end{array}$ & $\begin{array}{ll}38.3 & (17.1) \\
40.0 & (17.9) \\
36.9 & (16.5) \\
34.4 & (15.4)\end{array}$ & $\begin{array}{l}1.4 \\
1.8 \\
1.7 \\
1.5\end{array}$ & $\begin{array}{l}0.08 \\
0.10 \\
0.10 \\
0.10\end{array}$ & $\begin{array}{l}305 \\
300 \\
310 \\
315\end{array}$ & $\begin{array}{l}46 \\
46 \\
46 \\
46\end{array}$ \\
\hline $\begin{array}{l}16 \\
16 \\
16 \\
16\end{array}$ & $\begin{array}{l}1220 \\
1235 \\
1245 \\
1220\end{array}$ & $\begin{array}{rr}33 & (10) \\
99 & (30) \\
165 & (50) \\
330 & (100)\end{array}$ & $\begin{array}{ll}33.1 & (14.8) \\
30.6 & (13.7) \\
31.8 & (14.2) \\
39.1 & (17.5)\end{array}$ & $\begin{array}{l}2.2 \\
2.7 \\
3.1 \\
1.7\end{array}$ & $\begin{array}{l}0.15 \\
0.20 \\
0.22 \\
0.10\end{array}$ & $\begin{array}{l}310 \\
315 \\
315 \\
320\end{array}$ & $\begin{array}{l}64 \\
64 \\
64 \\
64\end{array}$ \\
\hline
\end{tabular}

$\sigma=$ standard deviation of $\bar{\nabla}$

$I=$ turbulence intensity 


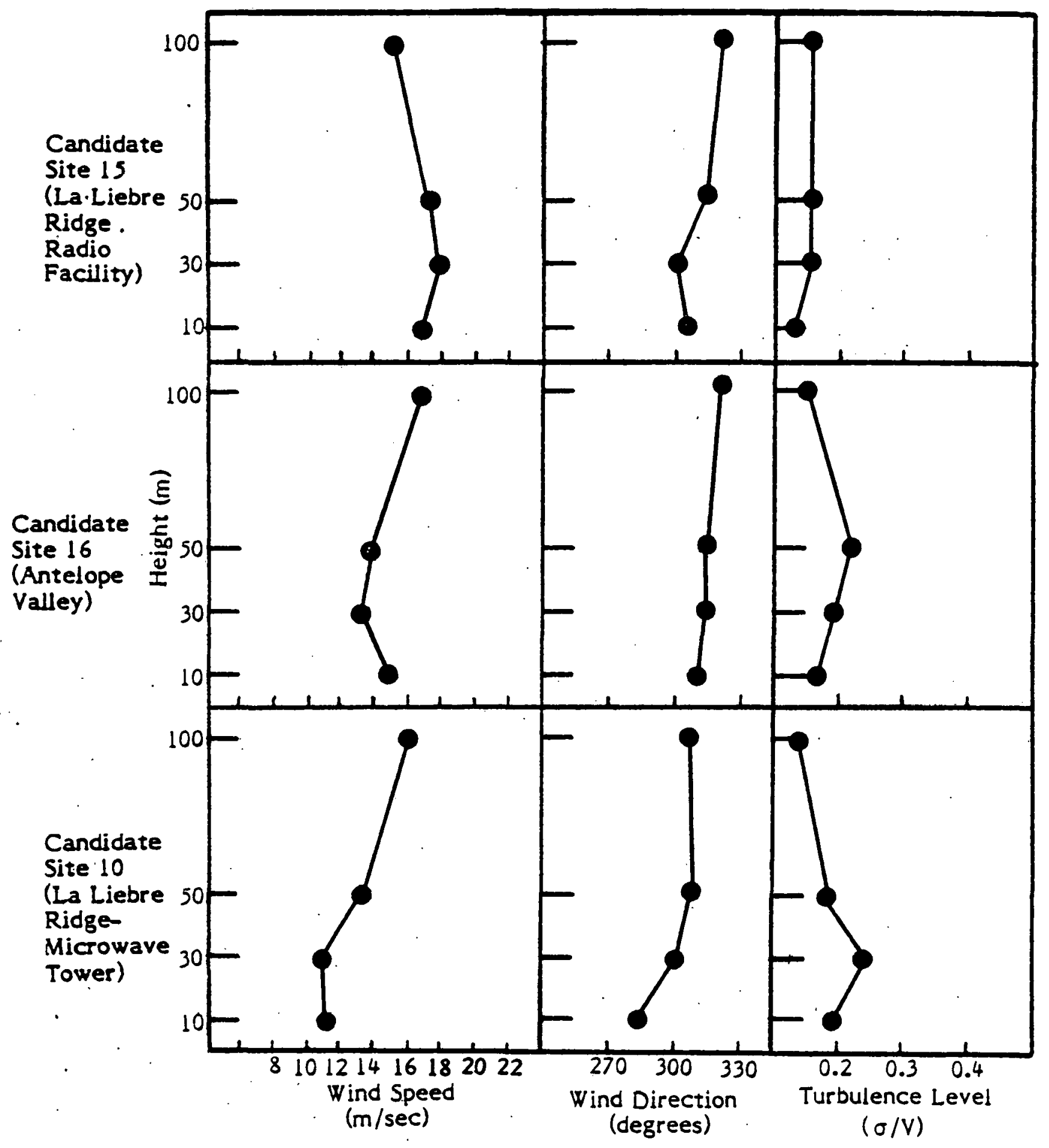

FIGURE 10. Velocity, direction, and turbulence profiles for selected sites using TALA measurements (1100 - 1700 PST 30 April 79) 
the study region. At candidate sites 2, 4, and 15, surface winds (10-m level) are of higher velocity than the winds aloft at $100 \mathrm{~m}$. At candidate sites $1,2,7,14$, and 15, the highest recorded winds were between 30 and $50 \mathrm{~m}$.

Such short-term readings need to be placed in perspective of the diurnal variation of the wind. As emphasized in the program procedure, the meteorological situations chosen for the field survey were of fairly neutral stability and free from frontal systems or significant mesoscale disturbances. Under these conditions, the diurnal pattern of windspeed should have a fairly consistent pattern: strong, gusty winds occurring in the early morning, rapidly decaying with solar heating at daybreak; constant, though relatively light winds through the afternoon with strong drainage flow conditions driven by radiative cooling after sunset; strong nocturnal winds after midnight. With these conditions being the case, it was anticipated that by conducting all site-comparative wind measurements within a four - to six-hour band from late morning to late afternoon, the diurnal variation would be at its minimal. The five portable anemometers installed for the duration of the field survey were to obtain hourly averages to check this assumption.

Table 2 summarizes the wind speed data recorded by strip chart recorders at Sites 3, 4, 10, and 14 for a typical day in-the-field survey. (The recorders at candidate sites 4 and 9 malfunctioned, resulting in loss of data.) Also listed is data obtained from Sandberg Weather Station for the same day. Figure 11 shows the diurnal cycle for this data. Sandberg shows more hour-to-hour variation in wind speed because, unlike the portable anemometers, the velocities reflect 5 -minute readings taken hourly, as opposed to 60-minute averages.

For all intents, it was judged that although there was some diurnal variation during the measurement period -- especially at Site 3 which is an isolated hill adjacent to a deep arroyo - no attempt would be made to scale or correct TALA velocity measurements for this effect. Concerning the mean velocity vertical profile, numerous investigations have been undertaken of airflow over hills based on atmospheric observations of small-scale embankments or wind tunnel measurements extrapolated to atmospheric scales. Field data is very limited so present measurements, although restricted in scope, are noteworthy as measurements in complex flow. 
TABLE 2. Summary of hourly averaged wind speeds obtained from portable recording stations at selected candidate sites in the Tehachapi study area.

\begin{tabular}{|c|c|c|c|c|c|}
\hline \multicolumn{6}{|c|}{ Monday, April 30, 1979} \\
\hline \multirow[b]{2}{*}{$\begin{array}{l}\text { Hour } \\
\text { (PST) }\end{array}$} & \multirow[b]{2}{*}{$\begin{array}{l}\text { Sandberg* } \\
(10 \mathrm{~m})\end{array}$} & \multicolumn{4}{|c|}{ Mean Velocities at Candidate Site $(\mathrm{m} / \mathrm{sec})$} \\
\hline & & $\begin{array}{l}\text { No. } 3 \\
(10 \mathrm{~m})\end{array}$ & $\begin{array}{l}\text { No. } 4 \\
(3 \mathrm{~m})^{4}\end{array}$ & $\begin{array}{l}\text { No. } 10 \\
(3 \mathrm{~m})\end{array}$ & $\begin{array}{l}\text { No. } 14 \\
(3 \mathrm{~m})\end{array}$ \\
\hline $\begin{array}{l}0100 \\
0200 \\
0300 \\
0400 \\
0500 \\
0600 \\
0700 \\
0800 \\
0900 \\
1000 \\
1100 \\
1200 \\
1300 \\
1400 \\
1500 \\
1600 \\
1700 \\
1800 \\
1900 \\
2000 \\
2100 \\
2200 \\
2300 \\
2400\end{array}$ & $\begin{array}{r}10.3 \\
4.5 \\
4.0 \\
7.6 \\
5.4 \\
1.8 \\
3.1 \\
1.7 \\
6.3 \\
7.2 \\
8.9 \\
9.8 \\
8.5 \\
4.9 \\
6.7 \\
7.6 \\
7.2 \\
5.5 \\
5.8 \\
8.5 \\
5.8 \\
9.4 \\
8.0 \\
6.3\end{array}$ & $\begin{array}{l}7.2 \\
6.7 \\
8.0 \\
6.7 \\
5.8 \\
5.8 \\
6.3 \\
6.2 \\
7.2 \\
7.2 \\
8.0 \\
8.9 \\
9.8 \\
11.2 \\
11.2 \\
10.7 \\
11.2 \\
12.5 \\
11.6 \\
13.4 \\
12.5 \\
10.3 \\
10.7 \\
10.3\end{array}$ & $\begin{array}{r}8.9 \\
10.3 \\
10.3 \\
9.8 \\
9.4 \\
8.9 \\
8.0 \\
7.9 \\
8.9 \\
9.8 \\
10.3 \\
10.3\end{array}$ & $\begin{array}{l}9.4 \\
9.8 \\
8.9 \\
8.0 \\
8.5 \\
8.0 \\
7.6 \\
7.6 \\
7.2 \\
7.6 \\
7.6 \\
8.0\end{array}$ & $\begin{array}{l}5.8 \\
4.5 \\
3.6 \\
5.4 \\
3.1 \\
2.2 \\
2.7 \\
2.7 \\
3.1 \\
4.5 \\
\\
3.6 \\
\\
\\
3.1 \\
3.1 \\
2.7 \\
5.4 \\
3.1 \\
5.4 \\
6.3 \\
8.0 \\
7.6 \\
6.3\end{array}$ \\
\hline
\end{tabular}

* Sandberg data based on five-minute observations each hour. 


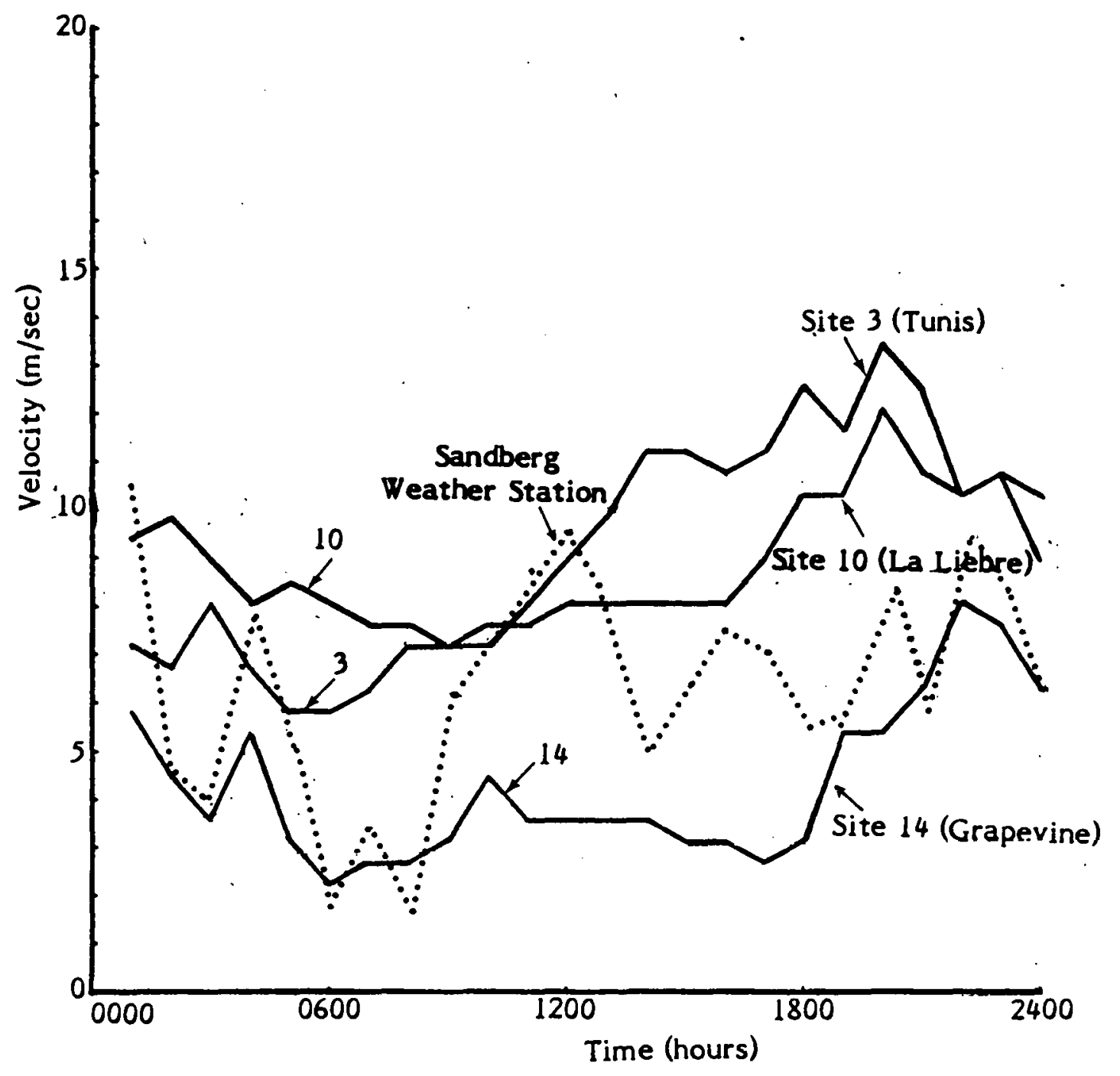

FIGURE 11. Diurnal cycle of wind speed for selected sites (data from Table 2). 
Vertical velocity profiles are usually described by a power law relation, $\left(U_{100} / U_{10}\right)=(100 / 10)^{\alpha}$, where $U_{100}, U_{10}$ are mean velocities at $100-m$ and $10-m$ heights, respectively, and is an empirical value. The power law wind-speed profile was not used as a comparative criterion among candidate sites because the differences were too small given the measurement accuracy. It is interesting to note that most values for $\alpha$ are near zero, which means a more uniform wind profile than what would be obtained, assuming the conventional $1 / 7$ power law wind-speed profile.

Another application of the TALA system novel to this study was for mean velocity horizontal profiles -- that is, to use the TALAs to locate the strongest region of local topographic speed-up at the $50 \mathrm{-m}$ height, which is approximately hub height for large WECS. The mean velocities obtained for the $50-\mathrm{m}$ level will then be a justifiable criterion for site comparisons.

Table 3 gives the highest mean wind recorded from the TALA system at each site; the ranking of the sites based on this column; the recorded velocity at the $50 \mathrm{~m} \mathrm{level}$; and the ranking based on that height. The rankings are very similar, with only Sites 4 and 9 showing a ranking difference of more than one place. Also listed is the $50-\mathrm{m}$ turbulence intensity level and its ranking. The overall ranking was determined by summing the best two of three rankings for each site, then averaging. This was decided because it was felt a site should have at least two of the three criterion for a good indication of wind.

In summary, given the time and physical constraints of field measurements, it would be of more significance to take as many readings as possible at the $50-\mathrm{m}$ level.

\section{Ecological Survey Results}

One major issue in the use of trees as a local climatic indicator is that tree deformation indices are an indication of annual, seasonal, or peak gust wind speed statistics. The subject has been reviewed and studied in length by Wade and Hewson. (1979). In their work, three indices -- the Griggs-Putnam index, the deformation ratio, and the comparison ratio -- were determined at over 60 locations which had Douglas fir and/or Ponderosa pine and a year or more of wind data. These indices were calibrated against a number of wind characteristics, including mean annual wind speed, mean growing-season wind speed, mean nongrowing wind speed, and percent of winds from the 
TABLE 3. Short-term wind measurement.

\begin{tabular}{|r|r|r|r|r|r|r|r|r|}
\hline Site & $\begin{array}{c}\nabla_{50} \\
(\mathrm{~m} / \mathrm{sec})\end{array}$ & Rank & $\begin{array}{c}\overline{\mathrm{V}}_{\text {peak }} \\
(\mathrm{m} / \mathrm{sec})\end{array}$ & Rank & $\mathrm{I}_{50}$ & Rank & $\alpha$ & $\begin{array}{c}\text { Overall* } \\
\text { Rank }\end{array}$ \\
\hline 1 & 9.6 & 9 & 9.6 & 10 & 0.16 & 4 & 0.03 & 9 \\
2 & 13.5 & 5 & 13.5 & 6 & 0.25 & 9 & -0.02 & 7 \\
3 & 9.0 & 10 & 9.6 & 10 & 0.10 & 2 & 0.11 & 8 \\
4 & 11.6 & 7 & 14.0 & 5 & 0.16 & 4 & 0.06 & 6 \\
5 & 10.5 & 8 & 12.5 & 8 & 0.27 & 10 & 0.20 & 10 \\
6 & 9.6 & 9 & 10.4 & 9 & 0.29 & 11 & 0.08 & 12 \\
7 & 15.4 & 2 & 15.4 & 3 & 0.20 & 7 & 0.02 & 3 \\
8 & - & - & - & - & - & - & - & - \\
9 & 8.7 & 11 & 10.4 & 9 & 0.11 & 3 & 0.11 & 8 \\
10 & 13.9 & 4 & 15.1 & 4 & 0.18 & 6 & 0.11 & 5 \\
11 & - & - & - & - & - & - & - & - \\
12 & 12.8 & 6 & 13.1 & 7 & 0.07 & 1 & 0.03 & 4 \\
13 & calm & 13 & calm & 12 & calm & 12 & - & 13 \\
14 & 6.7 & 12 & 6.7 & 13 & 0.17 & 5 & 0.01 & 11 \\
15 & 16.5 & 1 & 17.9 & 1 & 0.10 & 2 & -0.05 & 1 \\
16 & 14.2 & 3 & 17.5 & 2 & 0.22 & 8 & 0.07 & 2 \\
\hline
\end{tabular}

*Determined by summing the best two of three rankings for each site then averaging.

$\bar{\nabla}_{50} \quad=\quad$ mean velocity at $50-\mathrm{m}$ height $\nabla_{\text {peak }}=\begin{aligned} & \text { peak velocity measured between } 10 \text { - and } 100-\mathrm{m} \\ & \text { heights heights }\end{aligned}$

$\mathrm{I}_{50} \quad=\quad$ turbulence intensity at $50-\mathrm{m}$ height

$\alpha=$ power law exponent $v_{100} / v_{10}=(100 / 10)$ 
prevailing wind direction. The characteristic most highly correlated with these indices was the mean annual wind speed. The result was preliminary, though, and much more research into the biological effects of wind on trees is needed.

Table 4 sumarizes the vegetation indices and predicted mean annual wind speeds. Listed are the site number; Barsch index (B), deformation ratio (D), Griggs index (G), and the respective mean annual wind speed velocity correlations $\left(V_{b}, V_{d}\right.$, and $\left.V_{g}\right)$. The last column is the average mean annual wind speed (velocity) based upon all indices at a particular site.

The predicted mean wind speeds are primarily based on two indices ( $B$ and $D$ for oaks) which have not yet been validated. With this in mind, the predicted mean wind speeds will have a confidence band of near 50\%. Three locations had oak and conifers. Based upon the conifer indices, a comparison indicates, for the most part, lighter predicted winds. The average predicted wind for the three locations using conifers is $7.2 \mathrm{~m} / \mathrm{sec}$ and using deciduous indices is $7.8 \mathrm{~m} / \mathrm{sec}$. Greater confidence should be placed on conifer trees since they are more sensitive to winter winds than deciduous trees (Wade, 1979). A benefit of the one-year wind assessment study in the Tehachapi region will be more tree data and, hence, a better confidence band for the Griggs and Barsch indices for California oak.

Table 5 gives the ecological survey ranking results. Listed is the deformation ratio and $i t s$ ranking, and the averaged velocity from all indices and $i$ ts ranking. To obtain the ranking used for the site-selection criterion it was decided that the velocity average correlations be used as the first consideration, then use the deformation ratio as a "tie-breaker." In this way, more significance was given to the deformation ratio reflecting the more quantitative nature of the index.

\section{Site Topography and Serviceability Results}

An equally important factor in site selection is the availability of land, site accessibility, and the general exposure of the site vicinity. Table 6 summarizes the factors for each candidate site. These characteristics were observed during the field program and point out the savings in time and expense which could be gained by a (a) Personal conmunication. 
TABLE 4. Vegetation analysis for Tehachapi study region.

\begin{tabular}{|c|c|c|c|c|c|c|c|}
\hline $\begin{array}{c}\text { Candidate } \\
\text { Site } \\
\text { No. }\end{array}$ & $\begin{array}{c}\text { Barsch * } \\
\text { Index } \\
\text { B }\end{array}$ & $\begin{array}{c}\text { Correlated } \\
\text { Annual } \\
\text { Velocity } \\
V_{b} \\
\mathrm{mph}(\mathrm{m} / \mathrm{sec})\end{array}$ & $\begin{array}{c}\text { Deforma- } \\
\text { tion } \\
\text { Ratio } \\
\text { D }\end{array}$ & $\begin{array}{c}\text { Correlated } \\
\text { Annual } \\
\text { Velocity } \\
\mathbf{V}_{\mathbf{d}} \\
\mathrm{mph}(\mathrm{m} / \mathrm{sec})\end{array}$ & $\begin{array}{c}\text { Griggs * } \\
\text { Index } \\
\text { G }\end{array}$ & $\begin{array}{l}\text { Correlated } \\
\text { Annual } \\
\text { Velocity } \\
V_{g} \\
(\mathrm{~m} / \mathrm{s})\end{array}$ & $\begin{array}{c}v_{b}+v_{d}+v_{g} \\
m p h(m / s e c)\end{array}$ \\
\hline $\begin{array}{c}1 \\
2 \\
3 \\
4 \\
5 \\
6 \\
7 \\
8 \\
9 \\
10 \\
11 \\
12 \\
13 \\
14 \\
15 \\
\text { Sandberg Mtn. }\end{array}$ & $\begin{array}{rr}3 & (3) \\
3 & (3) \\
3 & (3) \\
4 & (2) \\
4 & (1) \\
3-4 & (3) \\
4 & (1) \\
4 & (1) \\
2 & (1) \\
& 4 \\
& \\
& \\
2 & (1) \\
3 & (2) \\
5 & (2) \\
& 2\end{array}$ & $\begin{aligned} 12.8 & (5.7) \\
12.8 & (5.7) \\
12.8 & (5.7) \\
15.7 & (7.0) \\
15.7 & (7.0) \\
14.3 & (6.4) \\
15.7 & (7.0) \\
15.7 & (7.0) \\
9.8 & (4.4) \\
15.7 & (7.0) \\
& \\
4.0 & (8.9) \\
5.7 & (12.8) \\
8.3 & (18.6) \\
4.4 & (9.8)\end{aligned}$ & $\begin{array}{l}4.0 \\
2.4 \\
4.1 \\
5.0 \\
5.0 \\
4.7 \\
5.0 \\
5.0 \\
1.4 \\
5.0\end{array}$ & $\begin{array}{rr}14.8 & (6.6) \\
11.0 & (4.9) \\
15.0 & (6.7) \\
17.2 & (7.7) \\
17.2 & (7.7) \\
16.3 & (7.3) \\
17.2 & (7.7) \\
17.2 & (7.7) \\
8.7 & (3.9) \\
17.2 & (7.7) \\
& \\
4.3 & (9.6) \\
5.1 & (11.4) \\
8.8 & (19.7) \\
4.2 & (9.4)\end{array}$ & $\begin{array}{ll}4 & (2) \\
3 & (1) \\
5,6 & (2)\end{array}$ & $\begin{array}{l}6.4 \\
5.5 \\
7.9\end{array}$ & $\begin{array}{l}13.9(6.2) \\
11.9(5.3) \\
13.9(6.2) \\
16.6(7.4) \\
16.6(7.4) \\
15.0(6.7) \\
16.6(7.4) \\
15.9(7.1) \\
10.5(4.7) \\
17.0(7.6) \\
\\
9.4(4.2) \\
12.1(5.4) \\
17.9(8.0)\end{array}$ \\
\hline
\end{tabular}

* Number ( ) of trees in sample. 
TABLE 5. Ecological survey ranking results.

\begin{tabular}{|c|c|c|c|c|c|}
\hline $\begin{array}{c}\text { Candidate } \\
\text { Site }\end{array}$ & $\begin{array}{l}\text { Average } \\
\text { Velocity } \\
\text { From All } \\
\text { Vegetation } \\
\text { Indicators } \\
\text { (m/sec) }\end{array}$ & Rank * & $\begin{array}{l}\text { Deformation } \\
\text { Index }\end{array}$ & Rank & $\begin{array}{c}\text { Overall } \\
\text { Rank }\end{array}$ \\
\hline 1 & 6.2 & 6 & 4.0 & 5 & 7 \\
\hline 2 & 5.3 & 8 & 2.4 & 7 & 9 \\
\hline 3 & 6.2 & 6 & 4.1 & 4 & 6 \\
\hline 4 & 7.4 & 3 & 5.0 & 2 & 3 \\
\hline 5 & 7.4 & 3 & 5.0 & 2 & 3 \\
\hline 6 & 6.7 & 5 & 4.7 & 3 & 5 \\
\hline 7 & 7.4 & 3 & 5.0 & 2 & 3 \\
\hline 8 & 7.1 & 4 & 5.0 & 2 & 4 \\
\hline 9 & 4.7 & 9 & 1.4 & 9 & 11 \\
\hline 10 & 7.6 & 2 & 5.0 & 2 & 2 \\
\hline 11. & - & - & - & - & - \\
\hline 12 & - & - & - & - & - \\
\hline 13 & 4.2 & 9 & 1.7 & 8 & 10 \\
\hline 14 & 5.4 & 7 & 2.5 & 6 & 8 \\
\hline 15 & 8.0 & 1 & 6.1 & 1 & 1 \\
\hline 16 & - & - & - & - & - \\
\hline
\end{tabular}

- Ranking is based from 1 to 12 by highest to lowest wind velocity for each respective category. Overall ranking is based on velocity average correlations as the first step (column 2) and deformation index rank (column 5) as a tie-breaker. 
TABLE 6. Site topography and serviceability.

\begin{tabular}{|c|c|c|c|c|}
\hline $\begin{array}{l}\text { Candidate } \\
\text { Site } \\
\text { No. }\end{array}$ & Comment & $\begin{array}{l}\text { Estimated } \\
\text { Usable } \\
\text { Land } \\
\text { Area }\left(\mathrm{m}^{2}\right)\end{array}$ & $\begin{array}{l}\text { Site } \\
\text { Elevation } \\
(\mathrm{m})\end{array}$ & Rank \\
\hline 1 & $\begin{array}{l}\text { Located on the far end of Tunis ridge- } \\
\text { line. Good exposure to San Joaquin } \\
\text { Valley (NW); } 4 \text {-wheel drive vehicle } \\
\text { required. }\end{array}$ & 12,000 & 1295 & 7 \\
\hline 2 & $\begin{array}{l}\text { Located in a saddle on Tunis Ridge. } \\
\text { Good exposure to NNW; poor exposure } \\
\text { other directions; } 4 \text {-wheel drive } \\
\text { vehicle required. }\end{array}$ & 6,000 & 1370 & 10 \\
\hline 3. & $\begin{array}{l}\text { Centrally located on Tunis Ridge. } \\
\text { Good northerly exposure; poor } \\
\text { exposure other directions; } 4 \text {-wheel } \\
\text { drive vehicle required. }\end{array}$ & 6,000 & 1510 & 8 \\
\hline 4 & $\begin{array}{l}\text { Located at juncture of Tunis and } \\
\text { Geghus ridgelines. Excellent } \\
\text { exposure to NW; } 4 \text {-wheel vehicle } \\
\text { required; grounds soft during } \\
\text { wet seasons. }\end{array}$ & 20,000 & 1580 & 9 \\
\hline 5 & $\begin{array}{l}\text { Located on a spur off Purdie Ridge. } \\
\text { Excellent WNW exposure; poor } \\
\text { exposure other directions; bad } \\
\text { accessibility. }\end{array}$ & 10,000 & 1670 & 12 \\
\hline 6 & $\begin{array}{l}\text { Located in a saddle on Geghus Ridge. } \\
\text { Good exposure to S; heavily } \\
\text { vegetated. }\end{array}$ & 54,000 & 1330 & 6 \\
\hline 7 & $\begin{array}{l}\text { Located on a spur off Geghus Ridge } \\
\text { at head of a canyon. Good exposure } \\
\text { to } W ; 4 \text {-wheel vehicle required. }\end{array}$ & 35,000 & 1490 & 11 \\
\hline 8 & $\begin{array}{l}\text { Located on apex of Winters Ridge. } \\
\text { Good exposure to NE and SW; } 4 \text {-wheel } \\
\text { vehicle required; inaccessible } \\
\text { during wet seasons. }\end{array}$ & 24,000 & 1950 & 15 \\
\hline
\end{tabular}


TABLE 6 (continued).

\begin{tabular}{|c|c|c|c|c|}
\hline $\begin{array}{l}\text { Candidate } \\
\text { Site } \\
\text { No. }\end{array}$ & Comment & $\begin{array}{l}\text { Estimated } \\
\text { Usable } \\
\text { Land } \\
\text { Area }\left(\mathrm{m}^{2}\right)\end{array}$ & $\begin{array}{l}\text { Site } \\
\text { Elevation } \\
(\mathrm{m})\end{array}$ & Rank \\
\hline 9 & $\begin{array}{l}\text { Centrally located on Winters Ridge. } \\
\text { Good exposure to } \mathrm{N} \text { and } \mathrm{S} ; 4 \text {-wheel } \\
\text { drive vehicle required; inaccessible } \\
\text { during wet seasons. }\end{array}$ & 12,500 & 1780 & 13 \\
\hline 10 & $\begin{array}{l}\text { Located on SW end of } \mathrm{La} \text { Liebre Ridge. } \\
\text { Excellent exposure to } \mathrm{NW} \text { and SW; } \\
4 \text {-wheel vehicle required. }\end{array}$ & 64,500 & 1645 & 1 \\
\hline 11 & $\begin{array}{l}\text { Located on NE end of La Liebre Ridge. } \\
\text { Good exposure to NW and SW; poor } \\
\text { accessibility. }\end{array}$ & 6,000 & 1990 & 16 \\
\hline 12 & $\begin{array}{l}\text { Located on W end of Winters Ridge. } \\
\text { Good exposure to NNW and S; } 4 \text {-wheel } \\
\text { vehicle required; inaccessible } \\
\text { during wet seasons. }\end{array}$ & 12,000 & 1600 & 14 \\
\hline 13 & $\begin{array}{l}\text { Located at } \mathrm{N} \text { tip of Grapevine Peak. } \\
\text { Good exposure to } \mathrm{NW} ; 4 \text {-wheel drive } \\
\text { vehicle required for access during } \\
\text { wet seasons. }\end{array}$ & 7,800 & 1450 & 5 \\
\hline 14 & $\begin{array}{l}\text { Centrally located on summit of } \\
\text { Grapevine Peak. Good exposure to } \\
\mathrm{N} ; 4 \text {-wheel drive vehicle recommended } \\
\text { for access during wet seasons. }\end{array}$ & 96,000 & 1400 & 4 \\
\hline 15 & $\begin{array}{l}\text { Located on NE end of La Liebre Ridge. } \\
\text { Excellent exposure to } \mathrm{NW} \text { and } \mathrm{SE} ; \\
\text { 4-wheel drive vehicle required; poor } \\
\text { accessibility during wet seasons. }\end{array}$ & 10,000 & 1815 & 3 \\
\hline 16 & $\begin{array}{l}\text { Located in NW end of Antelope Valley. } \\
\text { Valley. Excellent exposure to all } \\
\text { directions; } 4 \text {-wheel drive vehicle } \\
\text { required for access during wet seasons. }\end{array}$ & 200,000 & 990 & 2 \\
\hline
\end{tabular}


thorough investigation of a remote area using all available data and information, such as Landsat photographs and communication with local residents. The Tejon Ranch Company was extremely helpful in this respect.

\section{Station Selection}

The ranking matrix from which the nine wind monitoring stations were selected is given in Table 7. Listed are the candidate site number, and the survey rankings for vegetation, short-term measurements, and topography. The total ranking was obtained by the average of the best two out of three surveys for each site. "Ties" were broken by considering the wind survey rank. The final column lists the sites at which the windmonitoring stations were eventually installed.

The purpose of the ranking was to set up stations at the nine top-ranked candidate sites. Site 7 , with a total ranking of 4 , was not a practical siting choice due to the large herd of cattle grazing in that area which would have trampled the tower. Because of its roads, Site 5 , with a ranking of 8 , was totally unacceptable by the time instrumentation was to be erected. Thus, the next best site was chosen, Site 9, as it was necessary to have some input from Winters Ridge, although Site 8 was initially selected to obtain representative flows from Winters Ridge but fell victim to cattle.

The nomenclature used for selected sites is AVI through AV9. AV is an abbreviation for AeroVironment Inc. Figure 12 is a location map of the nine wind-monitoring stations. Site photographs are given in Appendix A. 
TABLE 7. Ranking matrix for Tehachapi study region.

\begin{tabular}{|c|c|c|c|c|c|}
\hline \multirow[b]{2}{*}{$\begin{array}{c}\text { Candidate } \\
\text { Site No. } \\
: \quad \cdot\end{array}$} & \multicolumn{4}{|c|}{ Survey } & \multirow[b]{2}{*}{$\begin{array}{c}\text { Site } \\
\text { Selection }\end{array}$} \\
\hline & Vegetation & Wind & Topography & $\begin{array}{c}\text { Total * } \\
\text { Ranking }\end{array}$ & \\
\hline 1 & 7 & . 9 & 7 & 10 & AV8 \\
\hline 2 & 9 & 7 & 10 & 12 & - \\
\hline 3 & 6 & 8 & 8 & 9 & AVI \\
\hline 4 & 3 & 6 & 9 & 5 & AV7 \\
\hline 5 & 3 & 10 & 12 & 8 & - \\
\hline 6 & 5 & 12 & 6 & 6 & A 6 \\
\hline 7 & 3 & 3 & 11 & 4 & - \\
\hline 8 & 4 & - & 15 & 15 & - \\
\hline 9 & 11 & 8 & 13 & 14 & A 33 \\
\hline 10 & 2 & 5 & 1 & 2 & Av9 \\
\hline 11 & - & - & 16 & - & - \\
\hline 12 & - & 4 & 14 & 13 & - \\
\hline 13 & 10 & 13 & 5 & 11 & - \\
\hline 14 & 8 & 11 & 4 & 7 & A 44 \\
\hline 15 & 1 & 1 & 3 & 1 & A 2 \\
\hline 16 & - & 2 & 2 & 3 & AV5 \\
\hline
\end{tabular}

* Total ranking was obtained by average of the best two of three surveys for each site. Ties were broken by considering the wind survey rank. 


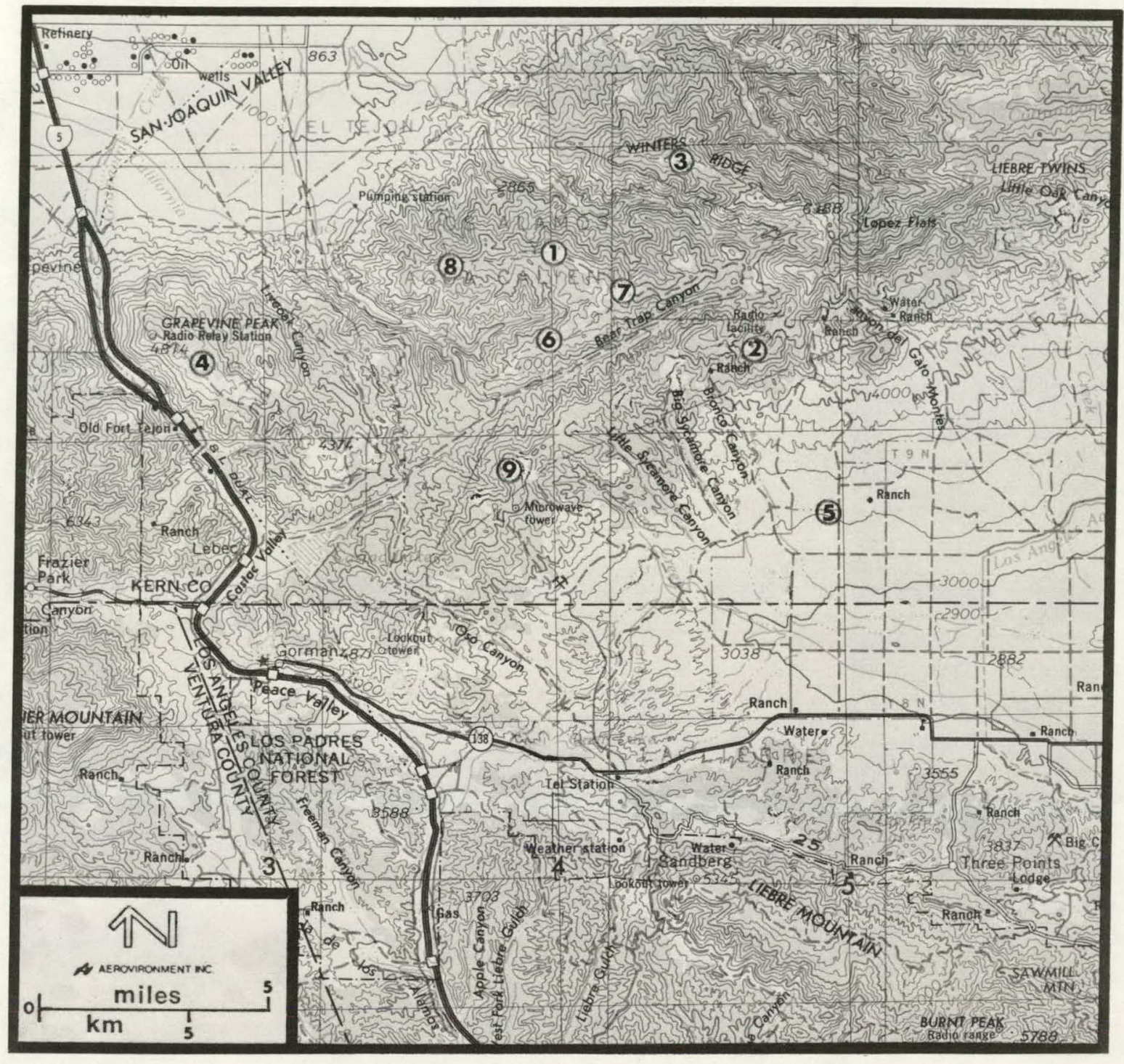

FIGURE 12. Station locations in the study area. 


\section{THIS PAGE WAS INTENTIONALLY LEFT BLANK}




\section{SIX-MONTH DATA RESULTS}

\section{DATA ANALYSIS}

The results from wind measurements obtained during the program year are reported in this chapter. Appendix B tabulates wind data and Appendix $C$ tabulates the data analysis for the six-month measurement period.

\section{Data Analysis Procedures}

These analysis steps were applied to data from most sites:

Step 1. Monthly summaries for wind speed (and direction, if applicable) were prepared for each site, and are tabulated in Appendix B. The wind-speed summaries yield the following:

- Average wind speed for the month.

- Standard deviation of wind speed for the month.

- Daily average wind speed.

- Daily hourly peak wind speed.

The wind-direction summaries yield the following:

- Prevailing-direction (16 compass points) diurnal-variation averages for the month.

- Prevailing direction for the month.

- Prevailing directions for each day.

Step 2. For sites which record both wind-speed and wind-direction, a joint frequency distribution was prepared, and tabulated in Appendix C.

The joint frequency distribution yields the following information: 
- Average wind speed for the time period by direction (16 compass points).

- Frequency distribution of direction.

- Wind-speed frequency distribution by a direction.

- Wind-speed frequency distribution for all directions.

Step 3. A wind-and power-frequency distribution analysis is generated. Wind speed is in $1-\mathrm{mile} / \mathrm{hr}(0.45 \mathrm{~m} / \mathrm{s})$ increments, and power is estimated for a hub-heightlevel of $50 \mathrm{~m}$ using a power law velocity profile and standard air-density corrections for site altitude as defined below. Tables for these values are reported in Appendix C.

- Estimation of 50-m-level wind speed

$$
\begin{aligned}
& v_{50}=v_{10}\left\{\frac{50}{10}\right\}^{\alpha} \\
& v_{50}=50 \text {-m-level wind speed } \\
& v_{10}=10 \text {-m-level wind speed } \\
& \alpha=\text { power law exponent (assumed to be } 0.14)
\end{aligned}
$$

- Air density corrections

$$
\begin{aligned}
\rho & =\rho \operatorname{SL}\{\exp (-Z / 8435) \cdots(\overline{\mathrm{T}}-15) / 288\} \\
\rho \mathrm{SL} & =\text { sea level density } \\
\mathrm{Z} & =\text { site altitude above sea level (meters) plus hub height } \\
\overline{\mathrm{T}} & =\text { temperature in }{ }^{\circ} \mathrm{C}
\end{aligned}
$$

- Power calculation at 50-m height

$\frac{\text { Power }}{\text { Unit Area }}=1 / 2 \rho \mathrm{V}^{3}$ 


$$
\mathrm{P} / \mathrm{A}=1 / 2 \rho \mathrm{V}_{50}^{3}
$$

Step 4. An estimate of wind-turbine power unit energy output is made using hypothetical wind-turbine specifications given in Figure 13. Results of these analyses applied at specific sites of interest are presented in a later chapter.

\section{MEAN WIND SPEEDS}

Table 8 is a summary of the monthly average wind speeds. Figure 14 plots the mean monthly hourly wind speed for selected stations and the historical summaries for Bakersfield and Sandberg. All mountainous-located monitoring stations exhibited a monthly wind pattern similar to Sandberg station -- a characteristic drop in mean speed during late summer and a steady rise in mean speed with the onset of winter. Although data have not been collected for late winter-early spring, an initial assumption is the monitoring stations would also be characteristic of Sandberg -- a leveling off of high winds throughout winter and into early spring, with a sharp drop of wind speed with the onset of summer. Site 5 in the Antelope Valley probably would not see this leveling off of high winds throughout winter but more likely would see a gradual drop during winter and a sharp increase with the onset of spring.

Data are being obtained to verify the predicted trends for the winter and spring seasons.

\section{FREQUENCY DISTRIBUTIONS}

Various statistical distributions have been used to approximate wind speed frequency distributions. Cliff (1977) and Justus et al. (1978) provide excellent reviews of various distributions based on the bivariate normal distribution.

Briefly reviewing these works, Justus simplifies the five parameter bivariate normal distribution into a unimodel (Weibull) distribution. The Weibull distribution requires only two parameters, the mean and the variance. Cliff bases his analysis on a special case of 


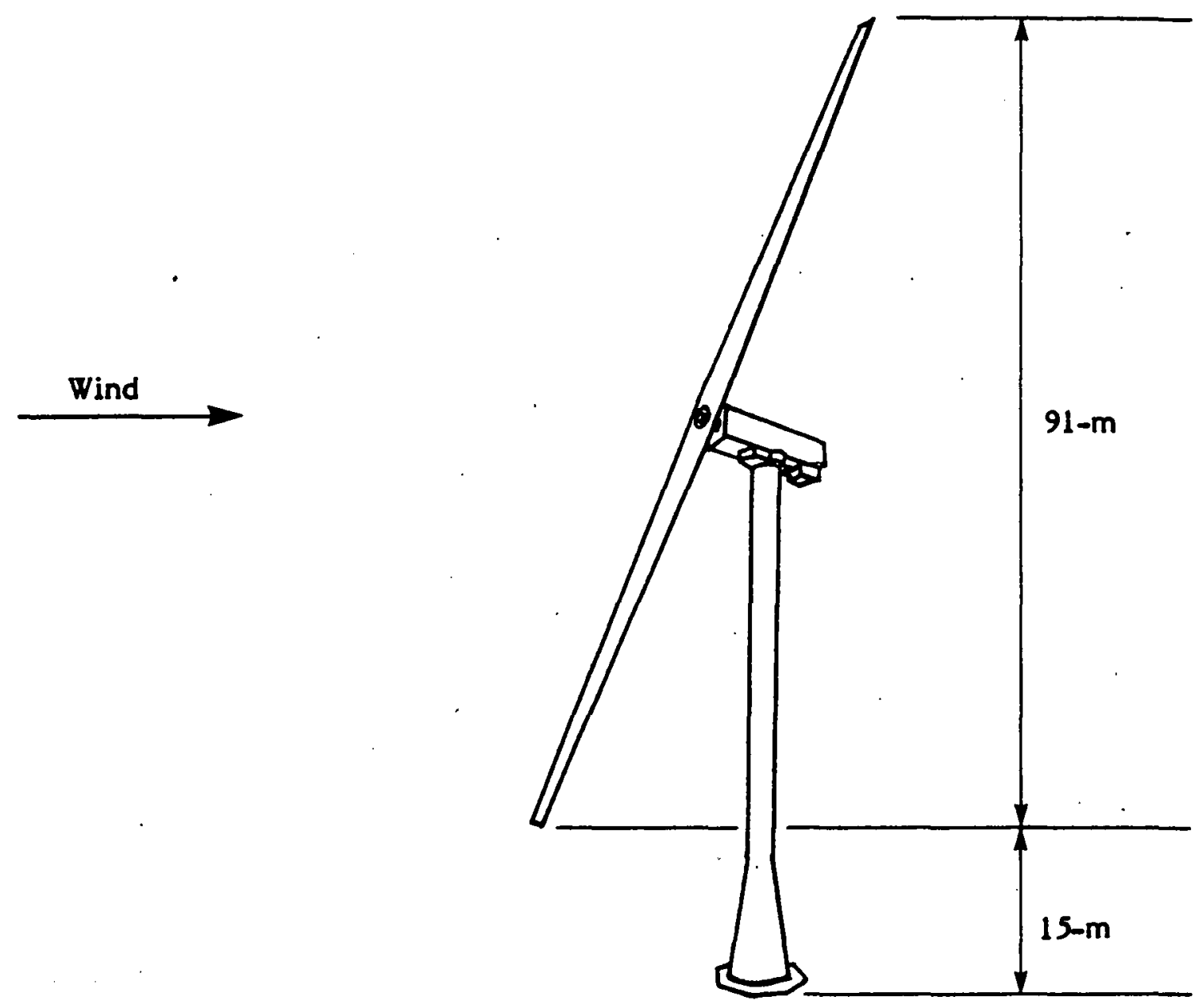

\begin{tabular}{|l|c|c|c|}
\hline \multicolumn{1}{|c|}{ Configuration No. } & I & II & III \\
\hline \hline Rotor Diameter meters (feet) & $91.0(300)$ & 91.0 & 91.0 \\
Cut-In Speed $\mathrm{m} / \mathrm{sec}(\mathrm{mph})$ & $6.3(14)$ & $6.3(14)$ & $6.3(14)$ \\
Rated Speed $\mathrm{m} / \mathrm{sec}(\mathrm{mph})$ & $12.4(27.7)$ & $12.4(27.7)$ & $14.3(32)$ \\
at hub height & $20.1(45)$ & $26.8(60)$ & $25.5(57)$ \\
Cut-Out Speed $\mathrm{m} / \mathrm{sec}(\mathrm{mph})$ & 2500 & 2500 & 4000 \\
Rated Power $\mathrm{kW}$ & & & \\
\hline
\end{tabular}

FIGURE 13. Wind turbine configurations. 
TABLE 8. Summary of monthly average wind speed (in mph) at monitoring stations in the Tehachapi study area (May-November 1979).

\begin{tabular}{|c|c|c|c|c|c|c|c|c|c|c|c|c|}
\hline \multirow[b]{3}{*}{ Site } & \multicolumn{12}{|c|}{ Month } \\
\hline & \multicolumn{8}{|c|}{1979} & \multicolumn{4}{|c|}{1980} \\
\hline & M & $\mathbf{J}$ & JI & A & $S$ & 0 & $\mathbf{N}$ & D & J & $\mathrm{F}$ & $M$ & A \\
\hline 1 & 5.3 & 5.2 & 5.1 & 4.7 & 3.9 & 5.6 & 10.0 & & & & & \\
\hline 2 & - & - & 18.4 & 15.6 & 11.1 & 15.7 & 16.5 & & & & & \\
\hline 3 & 7.0 & - & 6.7 & 7.0 & 8.1 & 8.4 & 8.7 & & & & & \\
\hline 4 & 6.2 & 6.5 & 5.5 & 4.6 & 5.8 & 7.1 & 10.4 & & & & & \\
\hline 5 & - & - & 10.2 & 9.5 & 5.7 & 10.3 & 8.4 & & & & & \\
\hline 6 & - & 8.6 & 7.9 & 6.8 & 5.0 & 8.4 & 12.4 & & & & & \\
\hline 7 & - & - & 11.6 & 9.5 & 8.5 & 10.6 & 11.4 & & & & & \\
\hline 8 & - & - & 3.7 & 4.0 & 4.0 & 6.2 & 10.4 & & & & & \\
\hline 9 & 11.7 & 14.5 & 13.3 & 11.1 & 10.3 & 13.2 & 17.2 & & & & & \\
\hline Bakersfield* & 8.0 & 8.0 & 7.2 & 6.8 & 6.3 & 5.6 & 5.1 & 4.9 & 5.2 & 5.8 & 6.6 & 7.2 \\
\hline Sandberg** & 15.1 & 15.1 & 12.8 & 12.6 & 12.9 & 14.9 & 16.1 & 16.4 & 17.0 & 16.4 & 16.7 & 16.4 \\
\hline
\end{tabular}




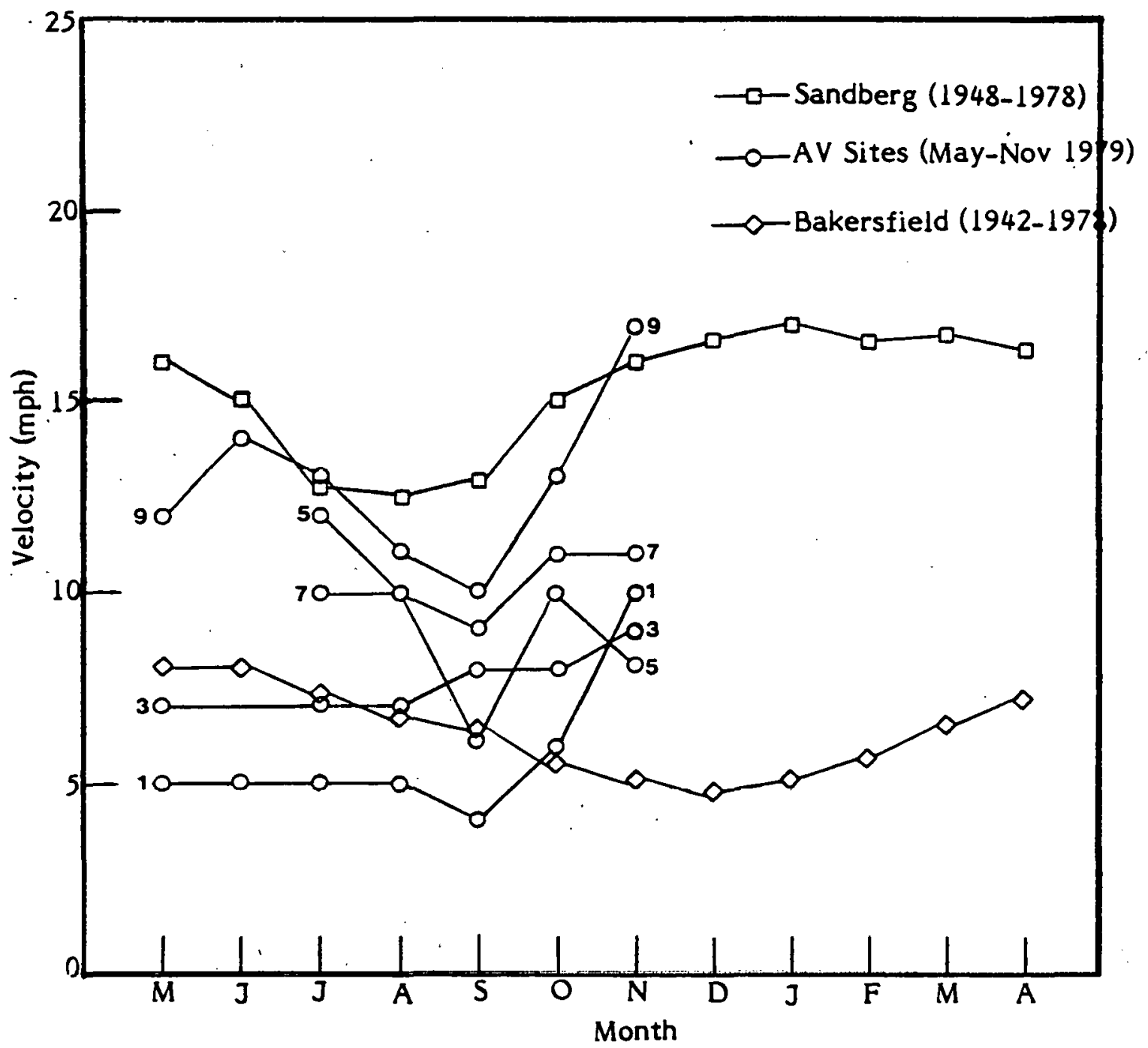

FIGURE 14. Comparison of mean hourly averages taken in Tehachapi Mountains with long-term mean hourly averages from Sandberg and Bakersfield stations. 
the Weibull distribution, which reduces the parameter characterization to a singie input, the mean. This is the Rayleigh distribution. Both researchers support the hypothesis that higher mean wind speeds tend to have a Rayleigh frequency distribution (annual mean greater than $4.5 \mathrm{~m} / \mathrm{sec}(10 \mathrm{mph}))$.

The Rayleigh distribution is

$$
P(v)=\frac{V \pi}{2 \bar{V}^{2}} \quad \exp -\left\{\frac{v^{2} \pi}{4 \bar{V}^{2}}\right\} .
$$

where

$$
\begin{aligned}
P(v) & =\text { frequency distribution of wind speed } \\
V & =\text { wind speed } \\
\bar{v} & =\text { long-term average (mean) wind speed }
\end{aligned}
$$

Cliff found that when calculating the long-term (annual) average extractable power by the measured wind speed probability distribution and by an assumed Rayleigh distribution, the Rayleigh distribution provided reasonable estimates of the average extractable power even though the actual distribution in some cases differed substantially from a Rayleigh distribution.

If this is the general case then for wind energy purposes data could be collected using a simple wind-run type anemometer. This would obtain the integrated average of the mean wind speed for a long averaging period (one month, or one year). A Rayleigh wind speed distribution would then be assumed, and results produced would have comparable monthly or annual wind energy statistics as that obtained by more costly time-series data collection systems.

A comparison of power output capacity generated by measured data and by Rayleigh distributions is done in a later chapter.

Figures 15 through 23 are plots of the actual frequency distributions for the month of November with an overlay of the Rayleigh distribution. November data were chosen 


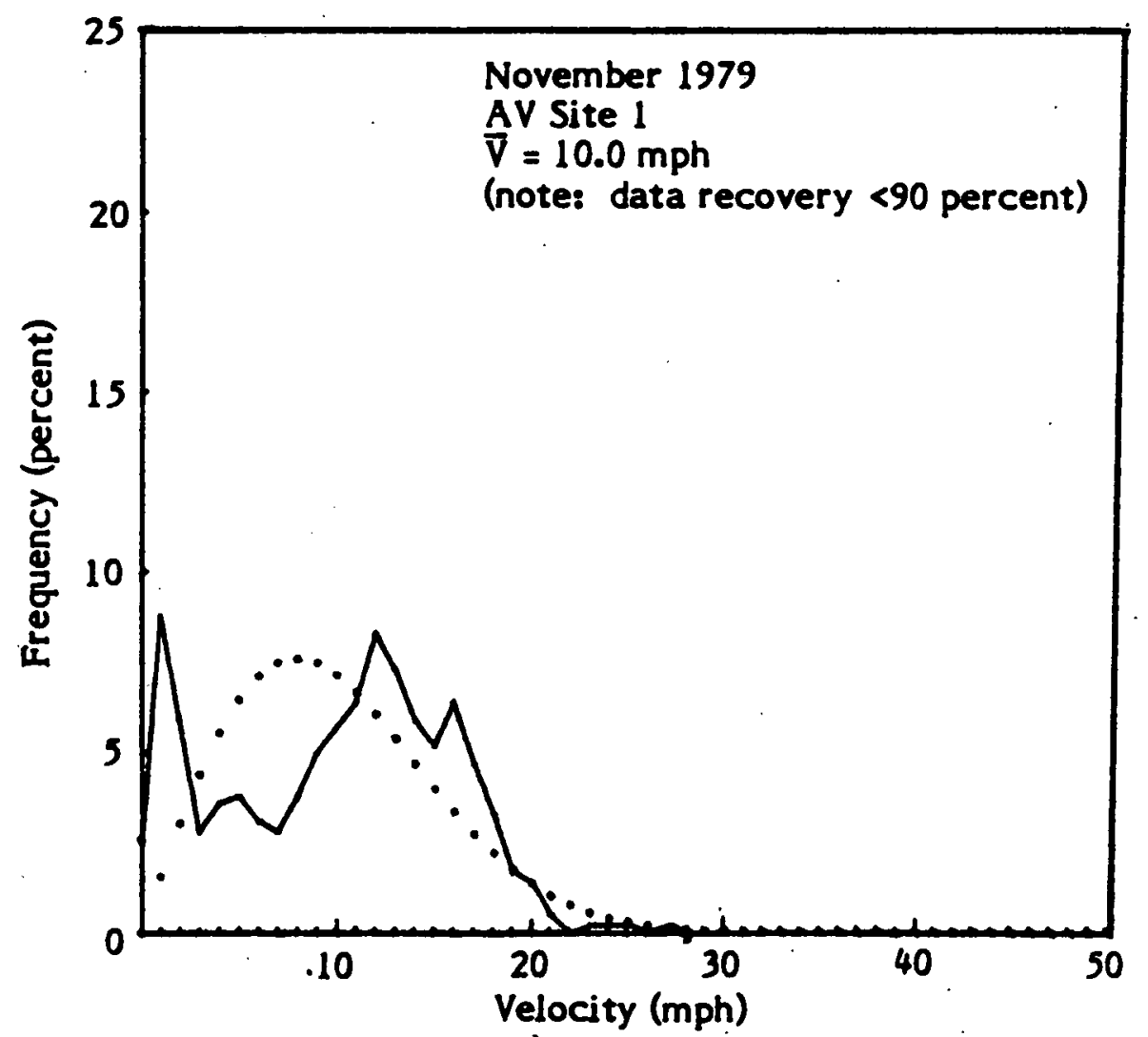

FIGURE 15. Frequency distribution for November 1979 - AV Site 1 (Tunis Ridge) .

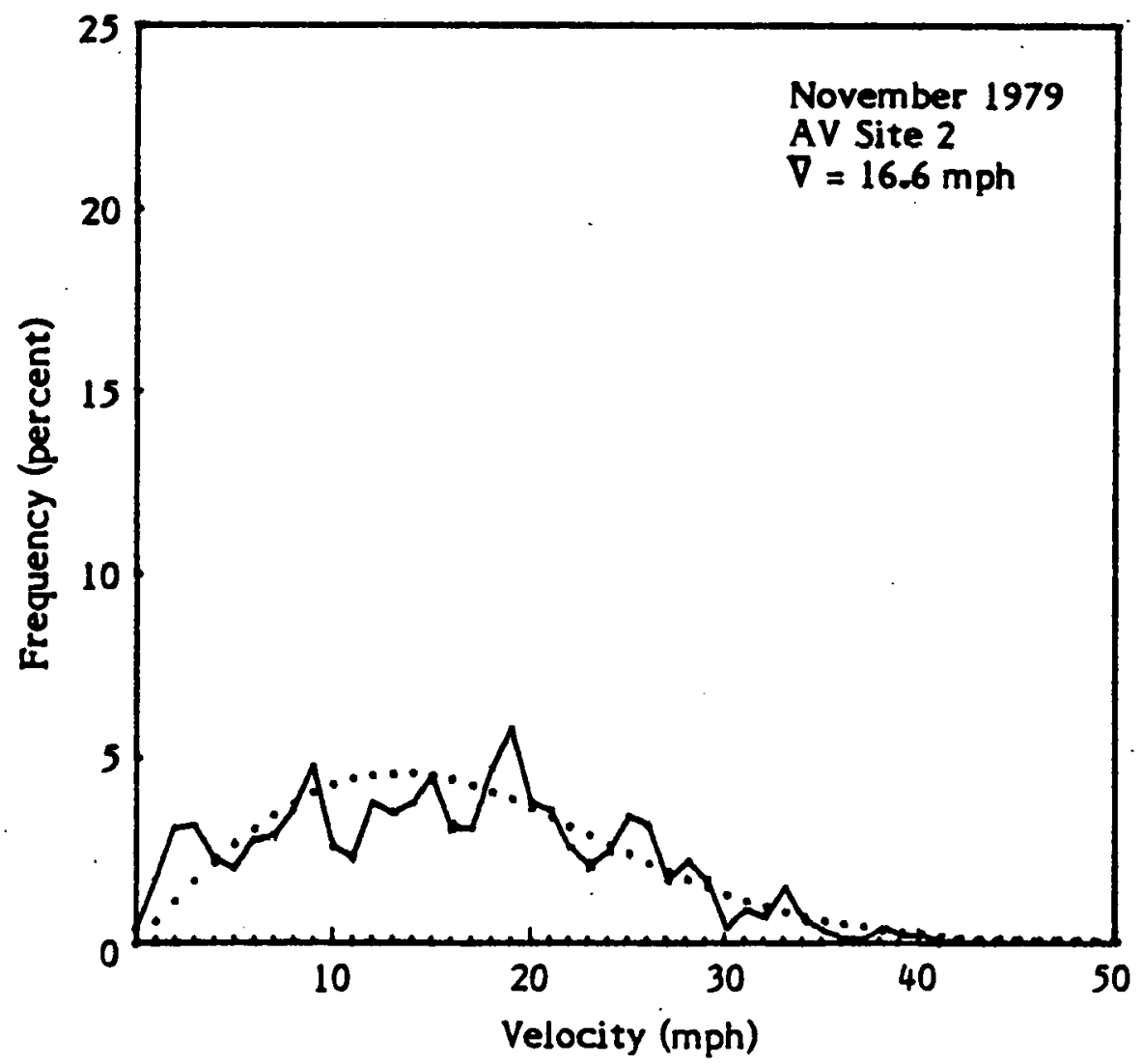

FIGURE 16. Frequency distribution for November 1979 - AV Site 2 (La Liebre Ridge). 


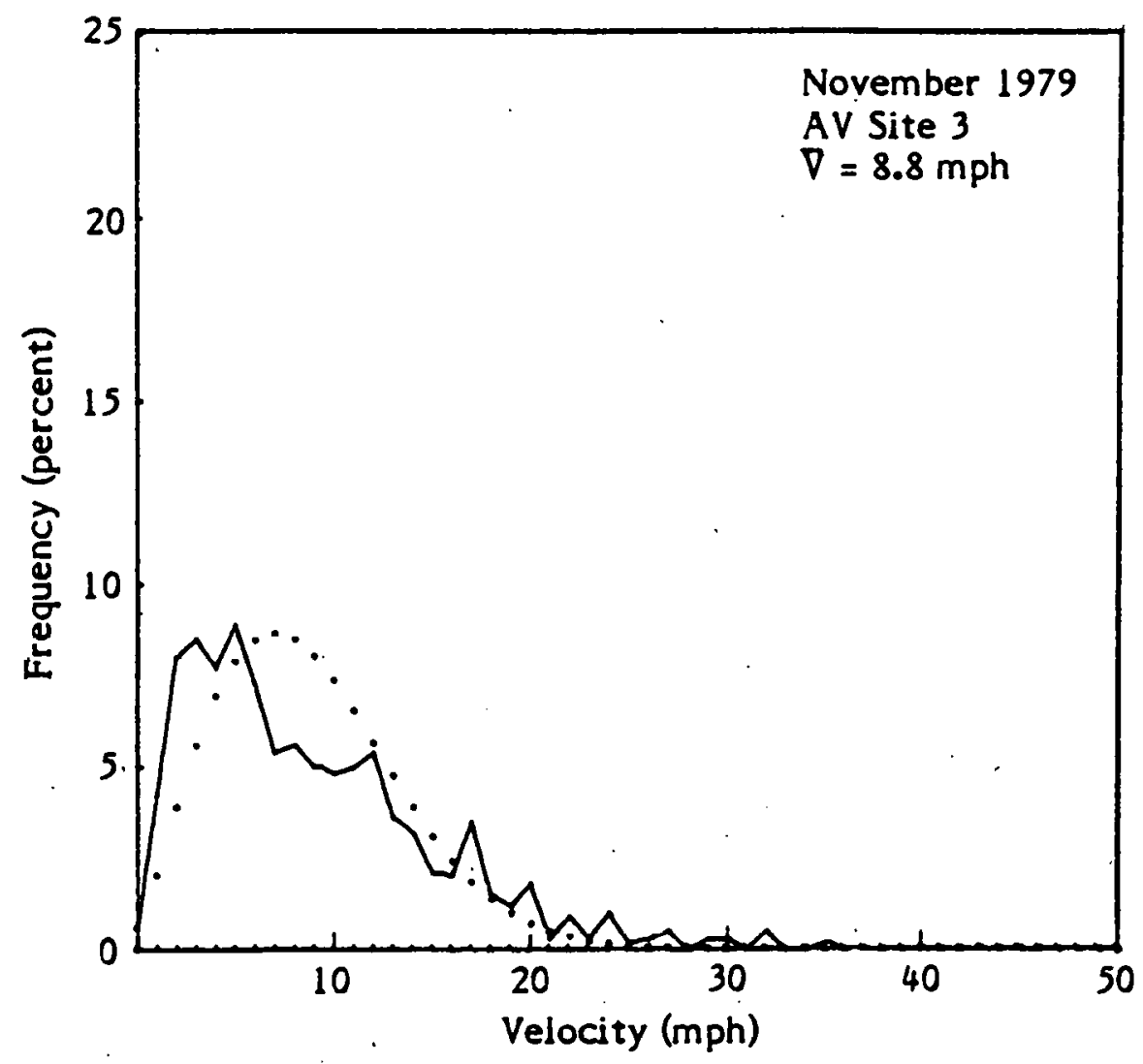

FIGURE 17. Frequency distribution for November 1979 - AV Site 3 (W inters Ridge).

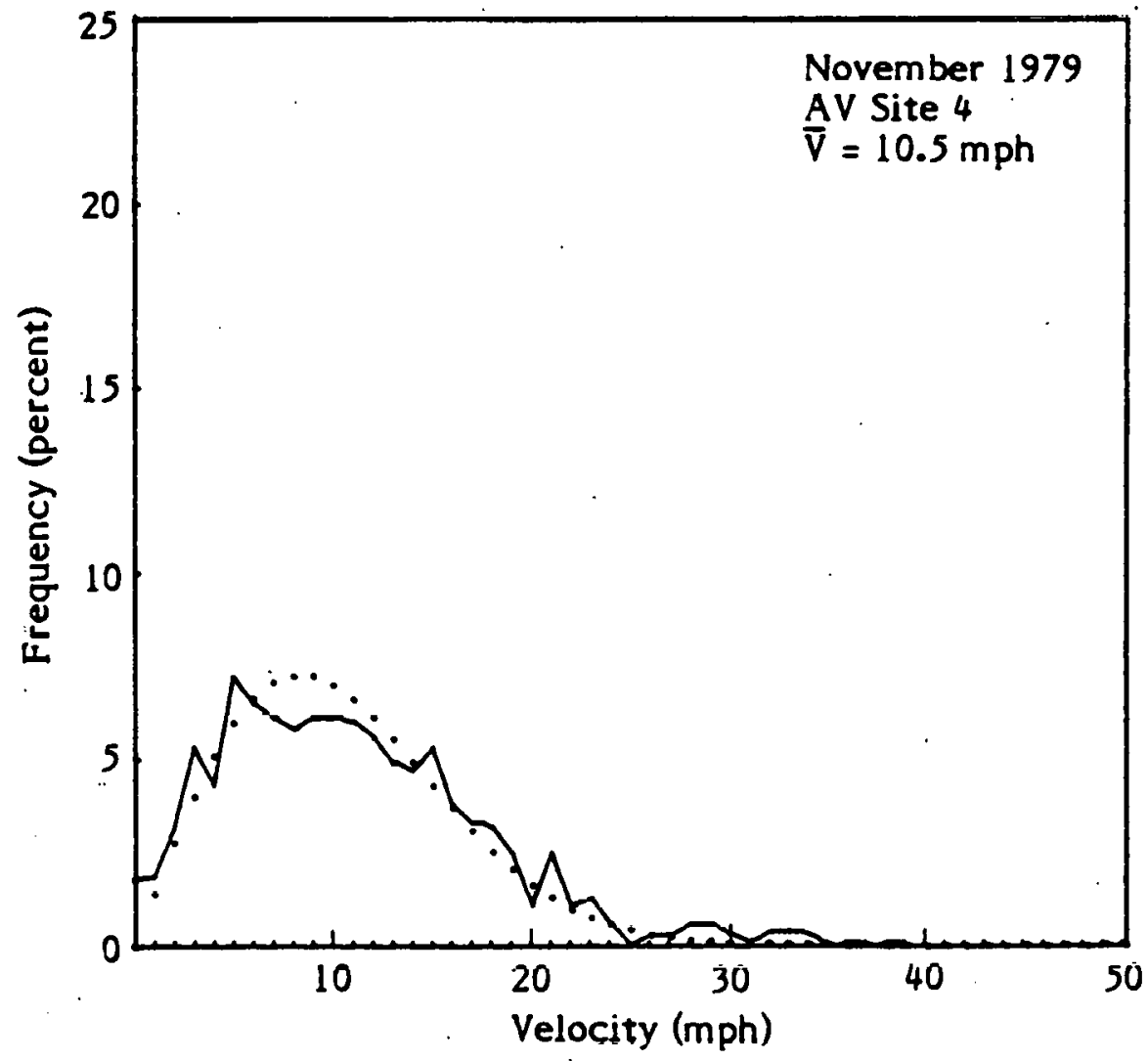

FIGURE 18. Frequency distribution for November 1979 - AV Site 4 (Grapevine Ridge). 


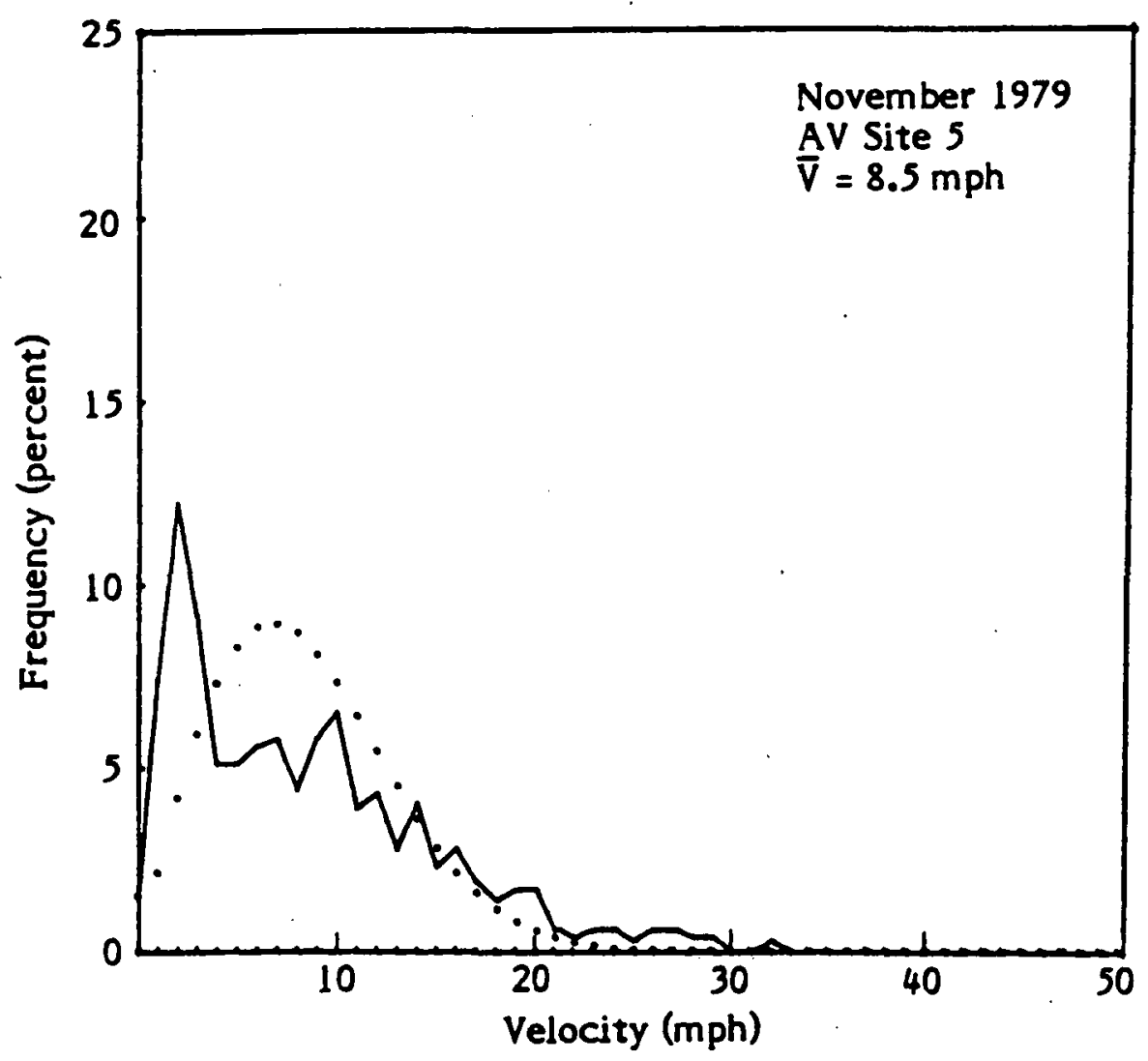

FIGURE 19. Frequency distribution for November 1979 - AV Site 5 (Antelope Valley).

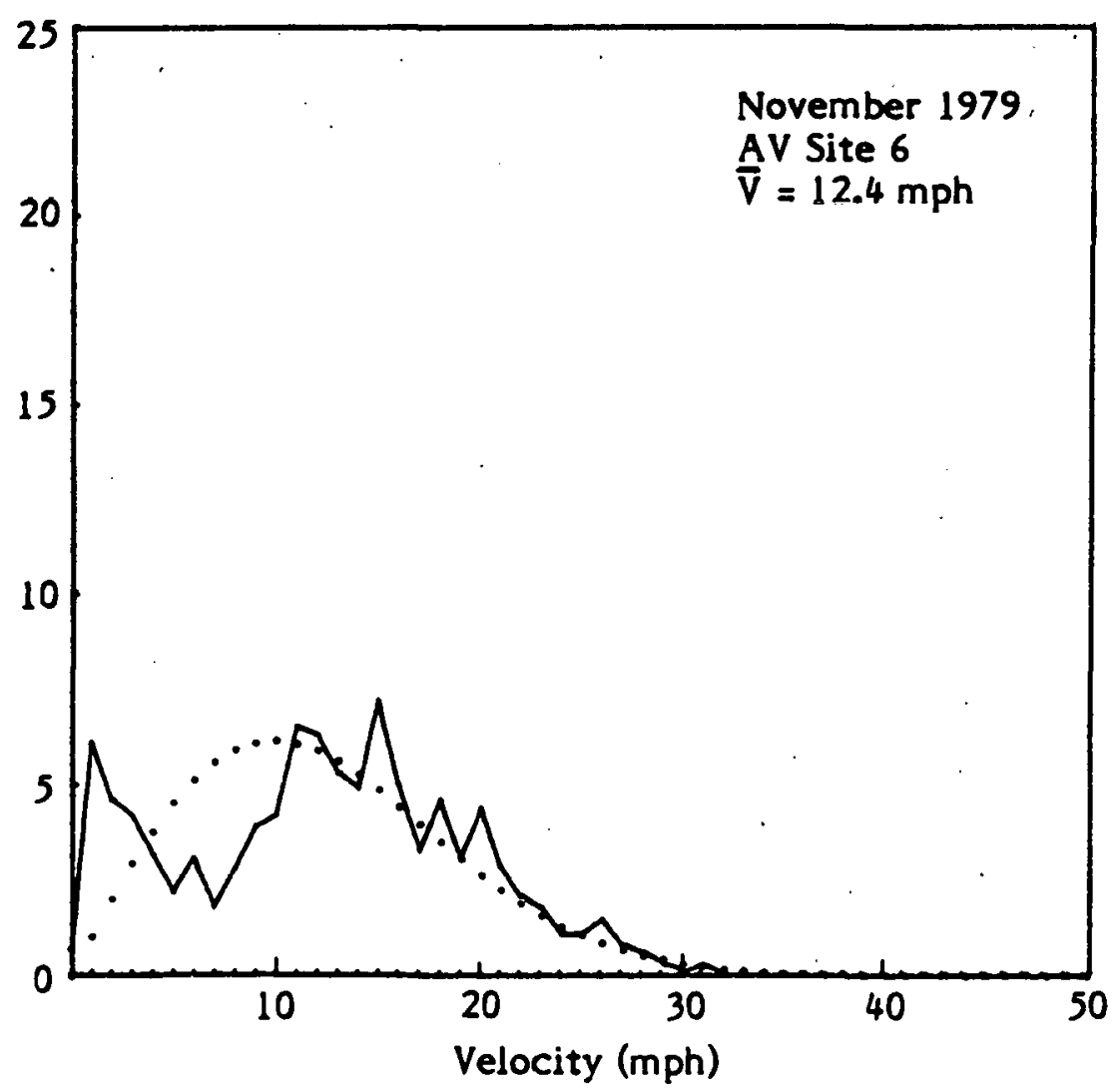

FIGURE 20. Frequency distribution for November 1979 - AV Site 6 (Geghus). 


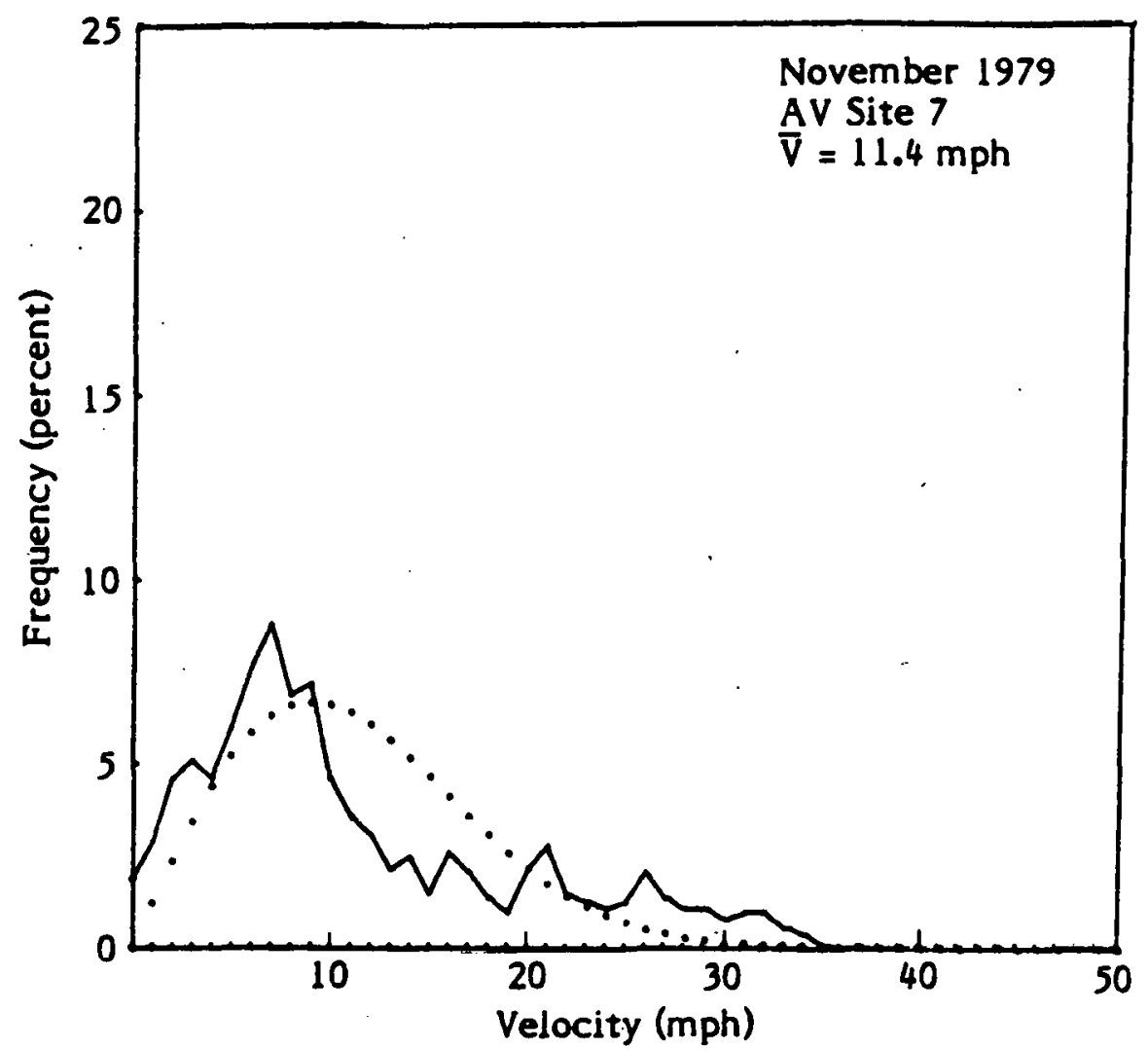

FIGURE 21. Frequency distribution for November 1979 - AV Site 7 (Tunis-Geghus).

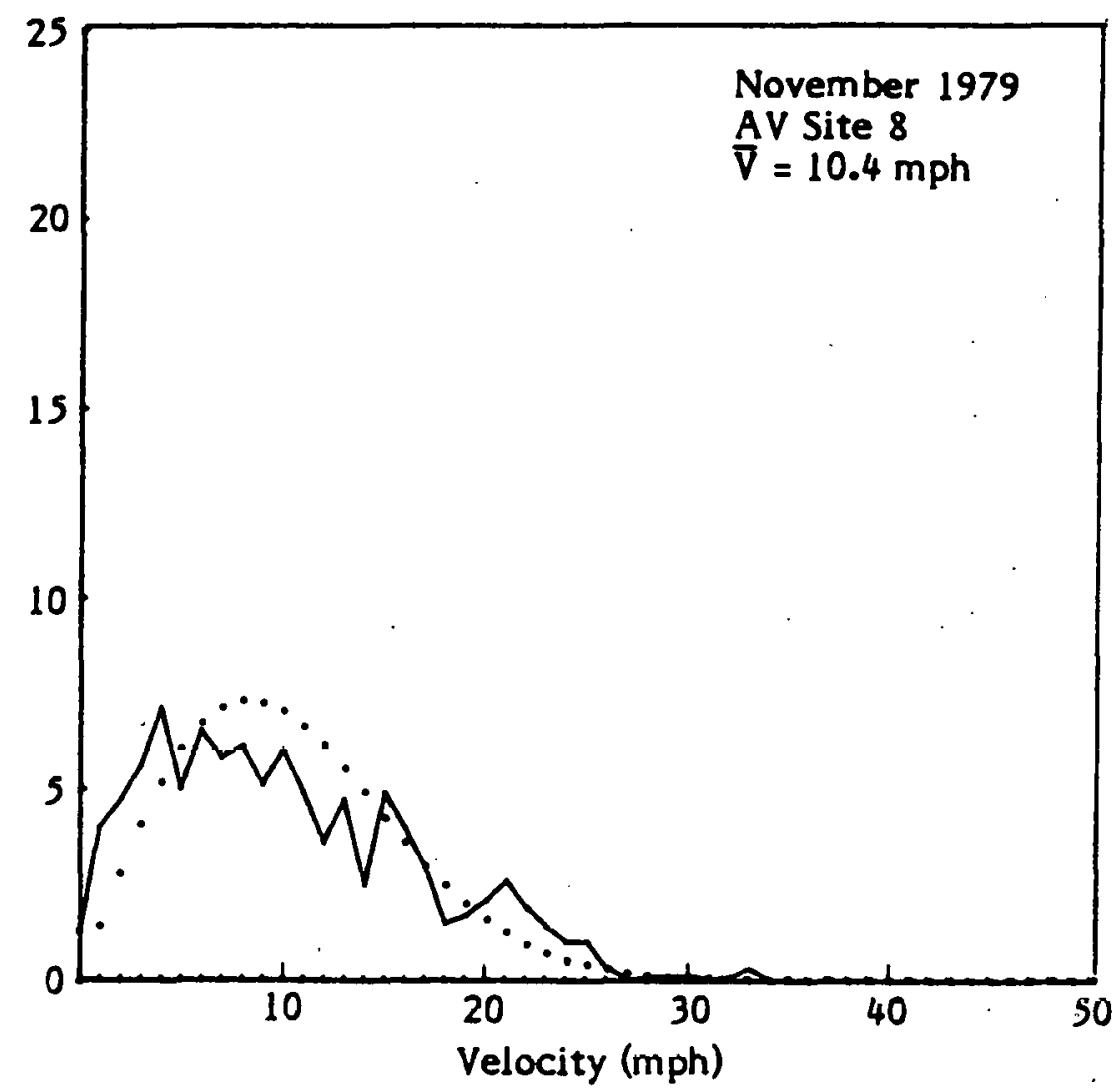

FIGURE 22. Frequency distribution for November 1979 - AV Site 8 (Tunis Ridge). 


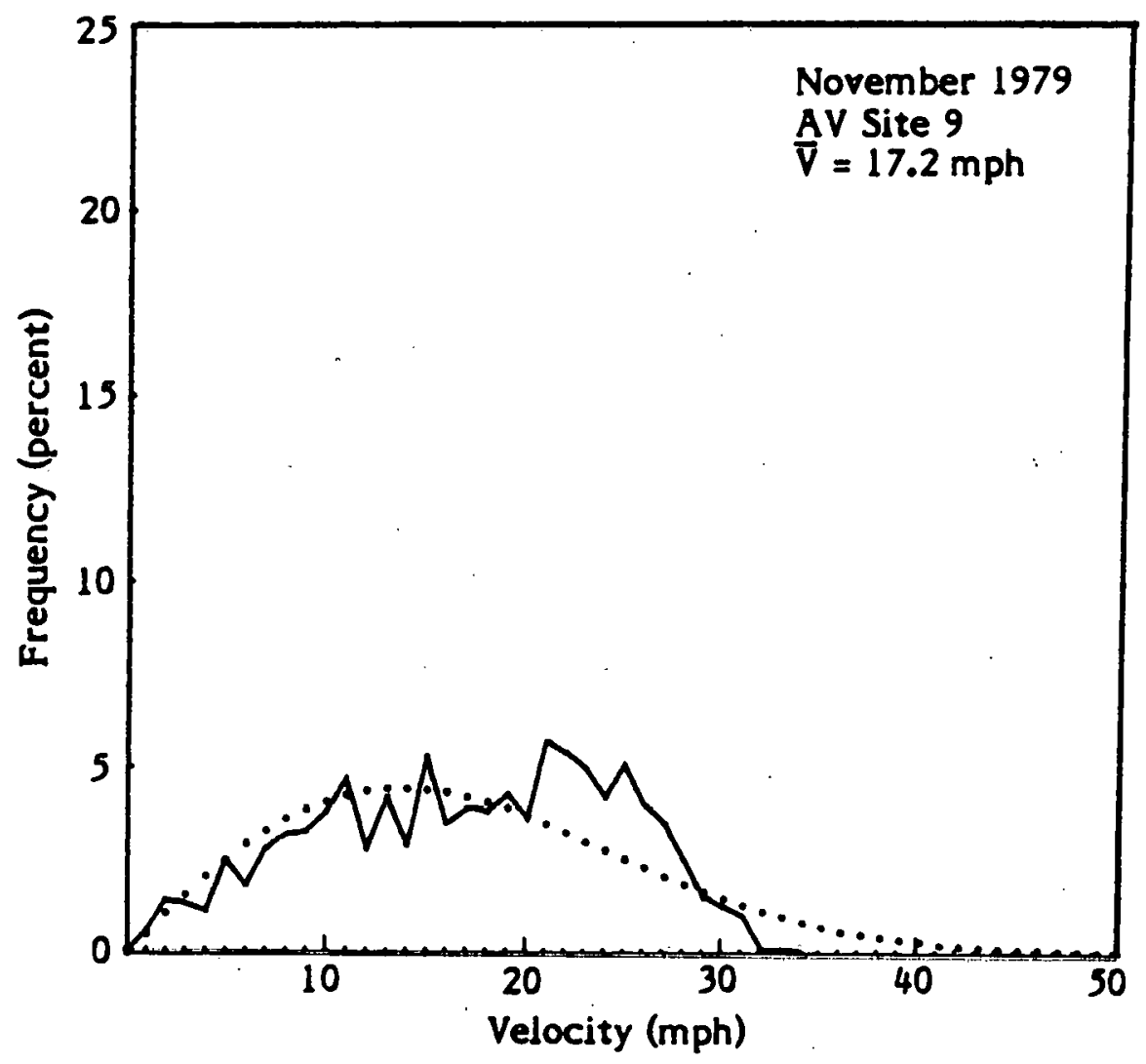

FIGURE 23. Frequency distribution for November 1979 - AV Site 9 (La Liebre Ridge). 
because of high monthly averages and data recovery greater than 90 percent at wind monitoring stations AV2 through AV9.

Figure 15 is the plot for Station AV1 where data recovery was only 60 percent, thus resulting in an uncharacteristic frequency distribution curve. Stations AV2 (Figure 16), AV4 (Figure 17), and AV8 (Figure 21) are reasonably approximated by the Rayleigh distribution.

Figure 24 is a similar plot of the actual frequency distribution for the period December 1977 - November 1978 at the Sandberg Weather Station. The data are the last year of continuous data taken at that monitoring station, and are based on three-hour averaged mean winds derived from hourly observations. 


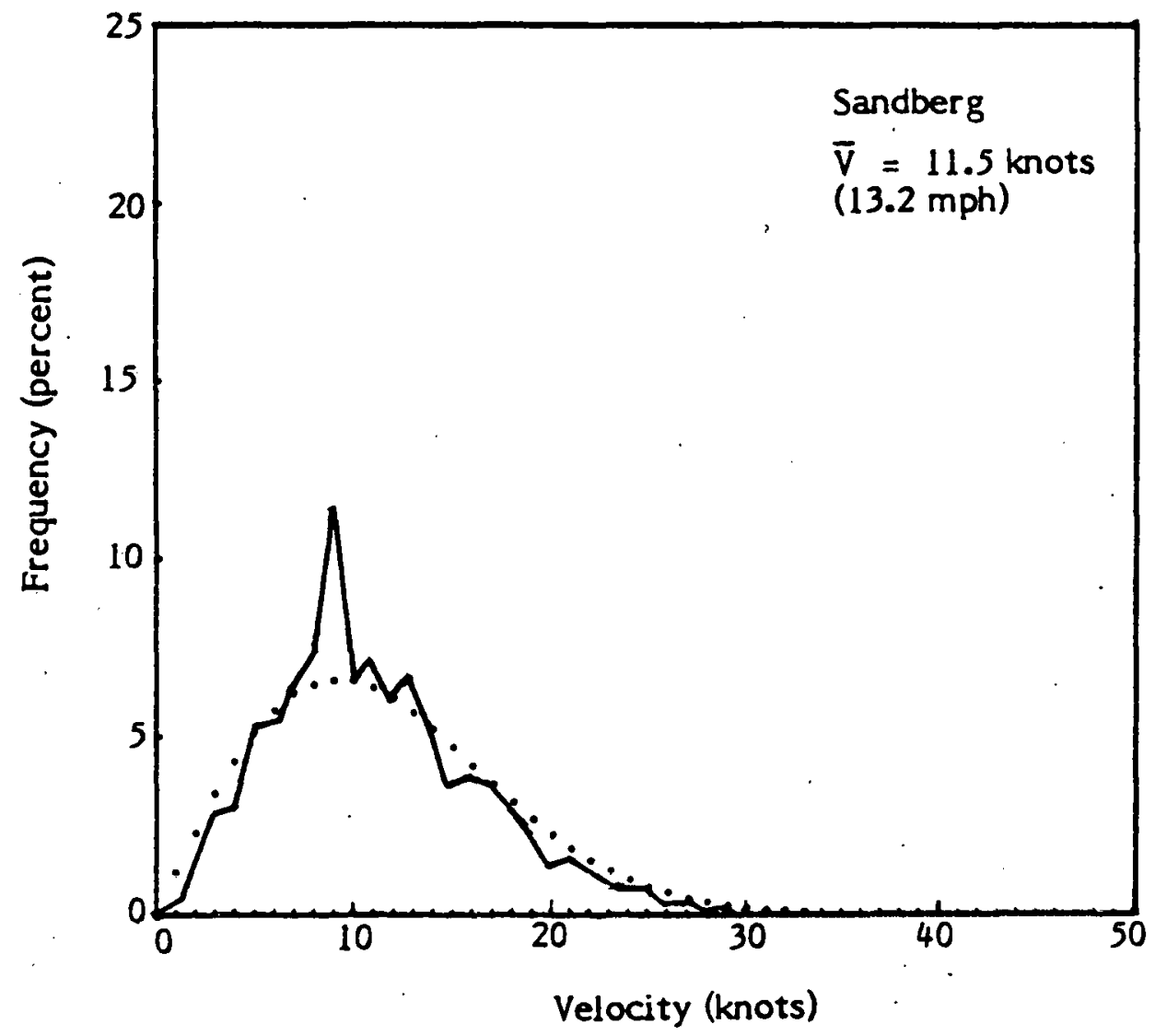

FIGURE 24. Frequency distribution for the period December 1977 - November 1978 for Sandberg Weather Station - based on three-hour averaged mean wind speed (knots) at 33-feet A.G.L. 


\section{WIND-FIELD ANALYSIS OF THE TEHACHAPI MOUNTAIN STUDY REGION}

The two wind characterizations required for WECS siting are the joint-frequency distributions of wind-speed and wind-direction, and the seasonal and annual variations of wind speed. This chapter examines the local mean airflow and its strength and variation over the study region. This is done by (1) characterizing the regional wind field into basic flow patterns observed over the Tehachapi study area during the six-month program; (2) comparing the recorded diurnal patterns from the nine wind-speed stations with the general weather patterns; and (3) analyzing these flow patterns and trends in view of the historical climatology of the Southern California region.

\section{GENERAL METEOROLOGICAL CONDITIONS}

The primary determining factor of Southern California weather is the location and strength of the semi-permanent, eastern-Pacific, high-pressure cell and a thermal lowpressure cell which occur over the southwestern desert area. In the Tehachapi Mountains, these phenomena do not produce the strong winds documented in other desert areas of Southern California (Zambrano et al., 1980) because the temperature gradient across the Tehachapis acts to diminish the pressure gradient that drives the prevailing flow. With this in mind, a review of upper atmospheric winds and surface synoptic features may provide insight into wind speeds observed along the ridgelines of the Tehachapi region.

\section{LARGE-SCALE SYNOPTIC PATTERNS}

Figures 25 and 26 show the location and size of the pressure cells which are the typical dynamic mechanisms influencing winds of Southern California. Figure 27 was obtained by summarizing 20 years of monthly weather data from the National Oceanography and Atmospheric Administration (NOAA) (1957-77) and illustrates the general trend of the centers of high and low pressure cells.

The basic flow in the free air above Southern California is from the west or northwest during most of the year. The complex terrain within the state, however, is 

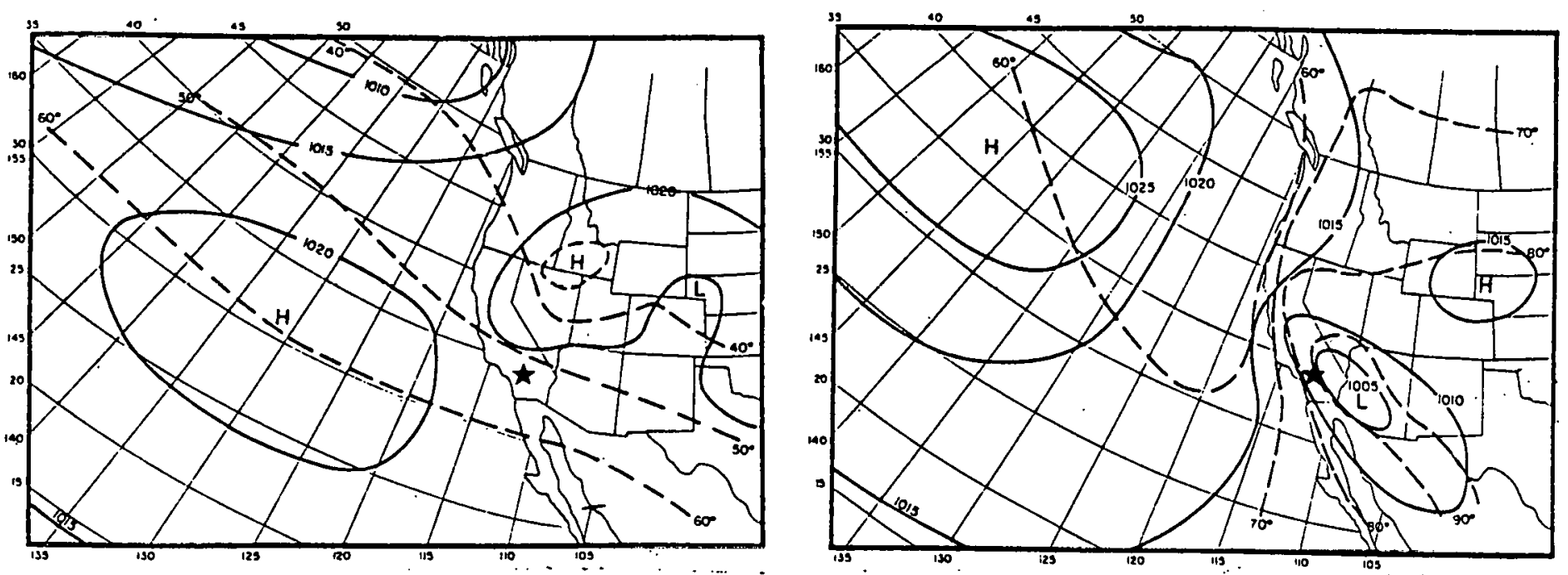

FIGURE 25. Normal January sea level pressure (solid lines) in millibars and temperature (dashed lines) in F. (Source: Smagorinsky, 1953).

FIGURE 26. Normal July sea level pressure (solid lines) in millibars and temperature (dashed lines) in F. (Source: Smagorinsky, 1953).

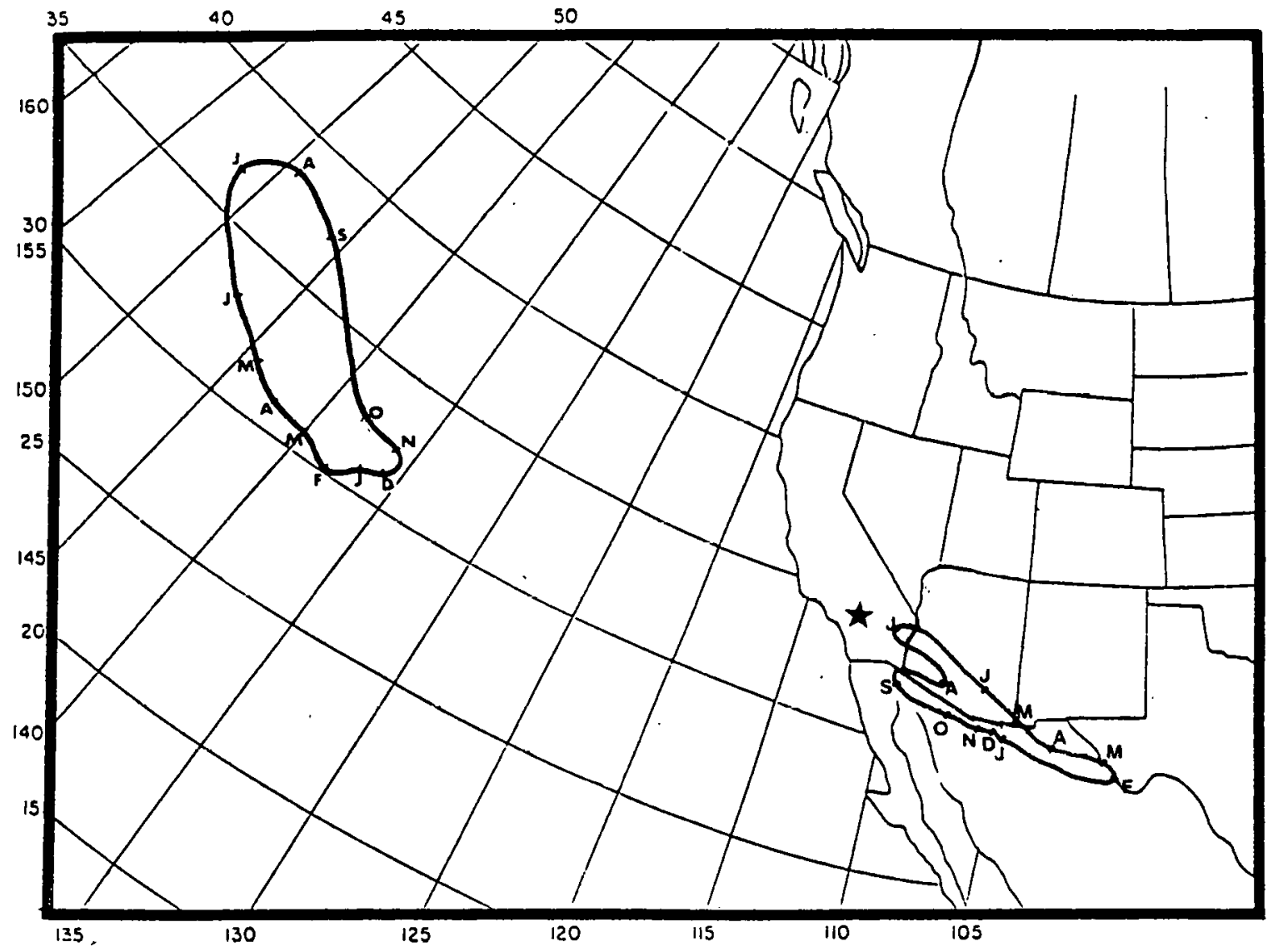

FIGURE 27. Trends of high and low pressure cell movement obtained from 20 years of monthly weather summaries. 
responsible for deflecting these winds and, except for the immediate coast, wind direction is likely to be more a product of local terrain than it is of prevailing circulation (see NOAA, 1978).

During summer and early fall free air flow can be channeled northwest up the axis of the San Joaquin Valley. The Tehachapi Mountains are located at the terminus of the valley and are thus recipient of a strong up-valley flow. At other times during summer and early fall, an inversion layer caps the San Joaquin Valley and inhibits the flow of air over the Tehachapi Mountains. During late evening, the high ridges of the Tehachapis can be exposed to upper-level flows. Periods of high winds on these ridges correspond to strong upper-level winds associated with weather fronts and active upper-level atmospheric circulation. These winds tend to be strongest during the winter and spring seasons when the atmospheric circulation is most active. Historically, Sandberg Station experiences the strongest winds during this period.

\section{BASIC FLOW PATTERNS}

The intensity and direction of air movement over the Tehachapis is governed by large-scale synoptics prevalent in the region and altered by local terrain. Winds tend to be strongest on well-exposed ridgelines, at the heads of canyons, and on the fringes of the Antelope Valley. Flow is generally perpendicular to the primary axis of the Tehachapi Mountain chain. Four basic flow patterns were observed and are now discussed.

1. Summer Northwest

2. Winter Northwest

3. Summer Southeast

4. Santa Ana

\section{Summer Northwest Flow}

The northwest flow is the most dominant flow pattern prevailing over the Tehachapi Mountains during summer. The northwest-southeast orientation of the San Joaquin Valley channels the up-valley northwest flow directly into the Tehachapi range. 
The height of the inversion layer in the San Joaquin Valley. has a significant role in the diurnal wind variation in the Tehachapi Mountains. The mean top of the inversion layer in the San Joaquin Valley reaches an average minimum height of $1700 \mathrm{~m}$ during May and a minimum of $500 \mathrm{~m}$ during December (Franson, 1979). Since the altitudes of the ridges being studied range between $1200 \mathrm{~m}$ and $1900 \mathrm{~m}$ (with the Antelope Valley site at $990 \mathrm{~m}$ ), diurnal heating and cooling expose the sites to varying degrees of inversion layer effects. Coupled with small scale terrain features, strikingly local diurnal wind-speed patterns result at each location in the Tehachapi study region.

Based on observations during site monitoring, the following scenario was drawn for summer northwest flow.

The temperature inversion in the morning near Bakersfield in the San Joaquin Valley is at a lower elevation than the ridges in the Tehachapi study region. This is evident by the smog trapped in the valley. The temperature inversion marks the top of the planetary boundary layer (PBL) over the San Joaquin Valley. Within the PBL the flow is turbulent and above it is nonturbulent. In the morning the smog is not flowing over the Tehachapis indicating that the valley PBL air is blocked and has insufficient kinetic energy to cross the potential energy barrier that the Tehachapis represent. The nonturbulent air above the valley PBL moves toward the Tehachapis. As this air interacts with the ridges, shear generated turbulence establishes the PBL over the Tehachapis. There are no measurements to verify how thick the PBL is over the Tehachapis. An initial estimate is that it may be several hundred meters thick by the time it reaches La Liebre Ridge.

As morning heating begins the PBL over the San Joaquin Valley begins to grow. As the valley $\mathrm{PBL}$ heats up and gains momentum by entrainment of the high mountain air above the inversion the valley air becomes no longer blocked by the ridges and so flows over the Tehachapis.

In general, minimum wind speeds occur in early afternoon. In the evening, radiative cooling at the earth's surface causes a near surface temperature inversion to form. The height of the PBL resets to near the surface, and the force balance on the winds at ridge level changes rapidly. The strongest winds, in general, occur after midnight. After 
midnight, there can be a small increase in wind speed caused by an upper level jet which flows through the San Joaquin Valley.

Based on the prevailing wind direction data from Bakersfield Weather Station and AV Station 9 (La Liebre Ridge), July 28, 1979, experienced summer northwest flow. Table 9 gives the hourly averaged wind speed data for selected stations (keeping in mind that the station columns are arranged left-to-right to correspond with wind flow from the northwest).

Station records from this day appear to agree with the scenario drawn for summer northwest flow. There is a diurnal trend towards strong nighttime winds which diminish with diurnal heating then pick up again with early evening cooling. Stations on the La Liebre ridgeline (AV2 and AV9) are significantly stronger than other stations. This is . probably due to a number of factors, most notably excellent exposure to the northwest and the sharp drop to the Antelope Valley in the southeast.

The lack of high wind statistics at Winters Ridge (AV3), Tunis Ridge (ÁV1), Grapevine (AV4), and Geghus Ridge (AV6) during episodes of prevailing summer northwest flow was an early signal in the six-month data period that the wind resource may be less than expected. This is significant when reviewing the historical data from Sandberg and Bakersfield. Sandberg experiences northwest or north-northwest flow approximately 50 percent of the summer; Bakersfield about 80 percent of the summer.

Figure 28 is a photo taken of La Liebre Ridge from the Antelope Valley looking to the northwest. Figure 29 is a photo taken of the San Joaquin Valley from La Liebre Ridge looking to the northwest.

\section{Winter Northwest Flow}

The winter season sees a cold lid of air clamp down on the San Joaquin Valley. The top of the inversion layer averages $460 \mathrm{~m}$, (Franson, 1979) well below the ridges of the Tehachapis $(1200 \mathrm{~m}$ to $1800 \mathrm{~m})$. This inversion elevation results in the ridges exposed to upper-level flow, which based on climatological summaries from Sandberg Weather Station (NOAA, 1978) is exceptionally strong during the winter season. Strongest winds 
TABLE 9. Summary of wind speed, wind direction, and temperature data obtained in the study region on July 28, 1979 during summer northwest flow conditions. (All wind speeds are in mph at 33 feet AGL.)

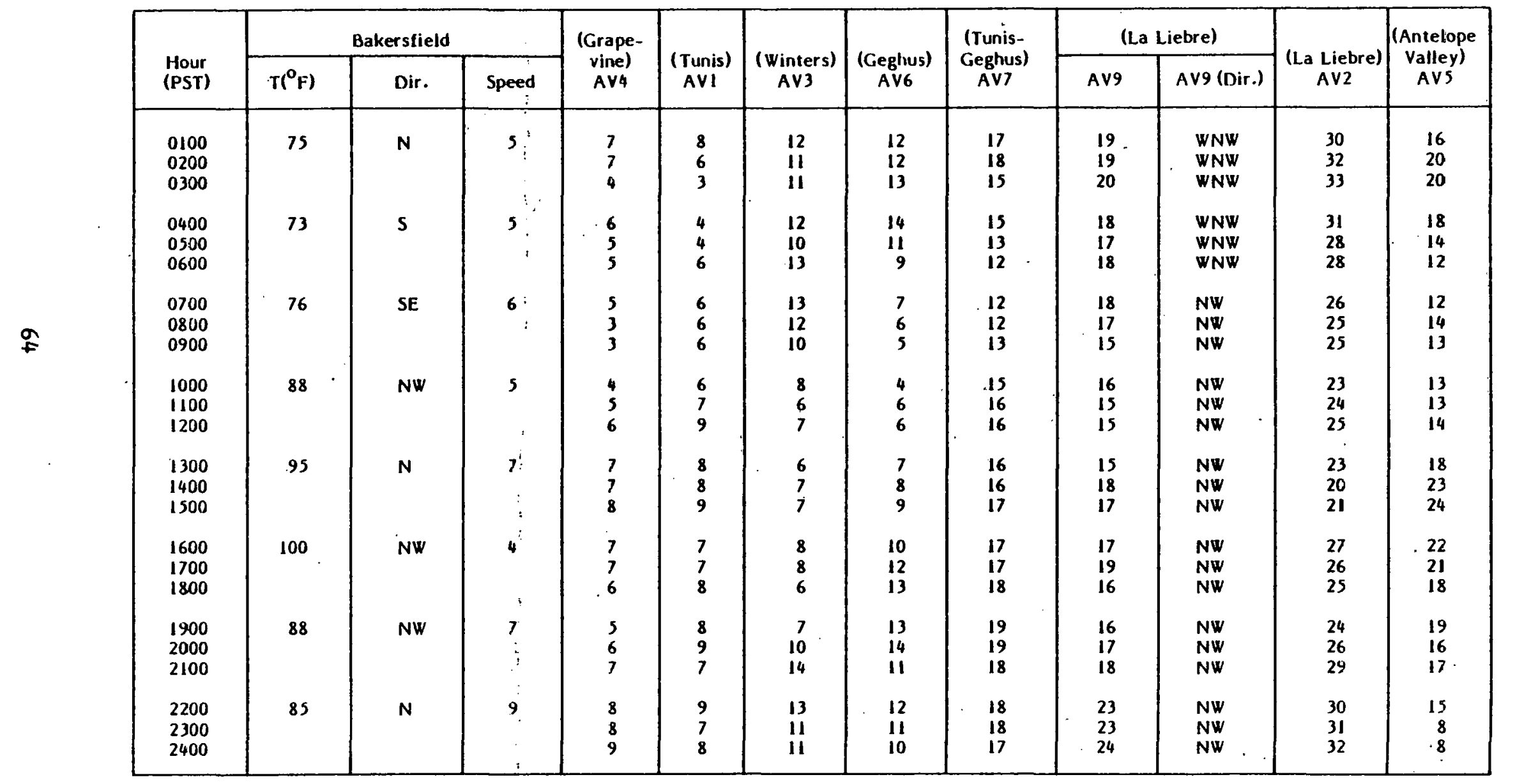




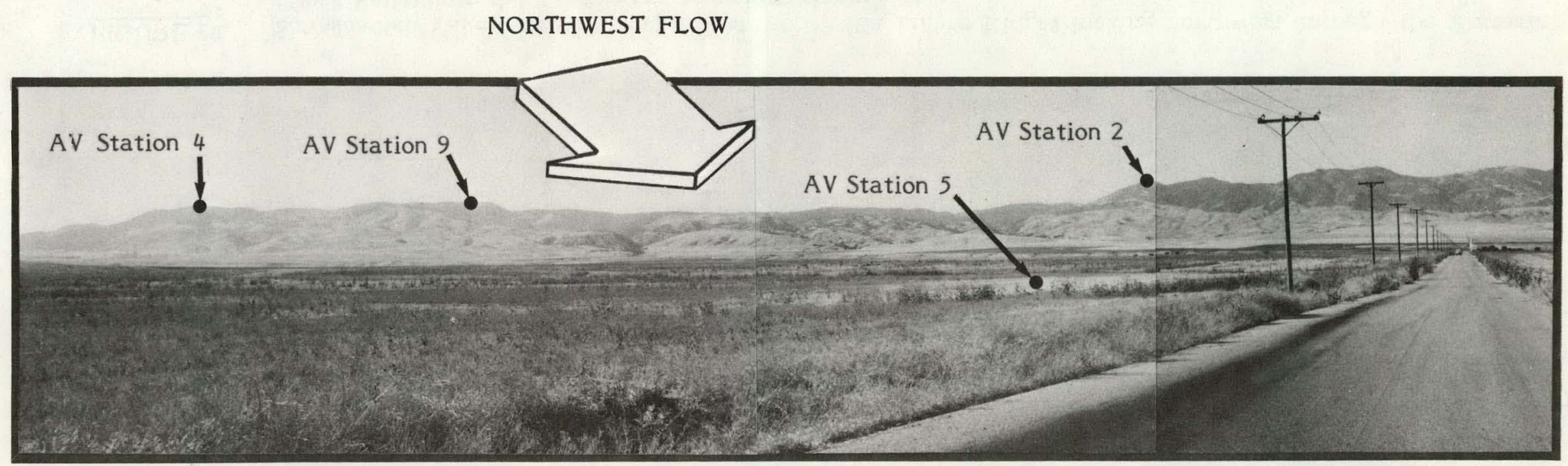

FIGURE 28. La Liebre Ridge viewed from the Antelope Valley looking northwest into the direction of prevailing summer flow. 


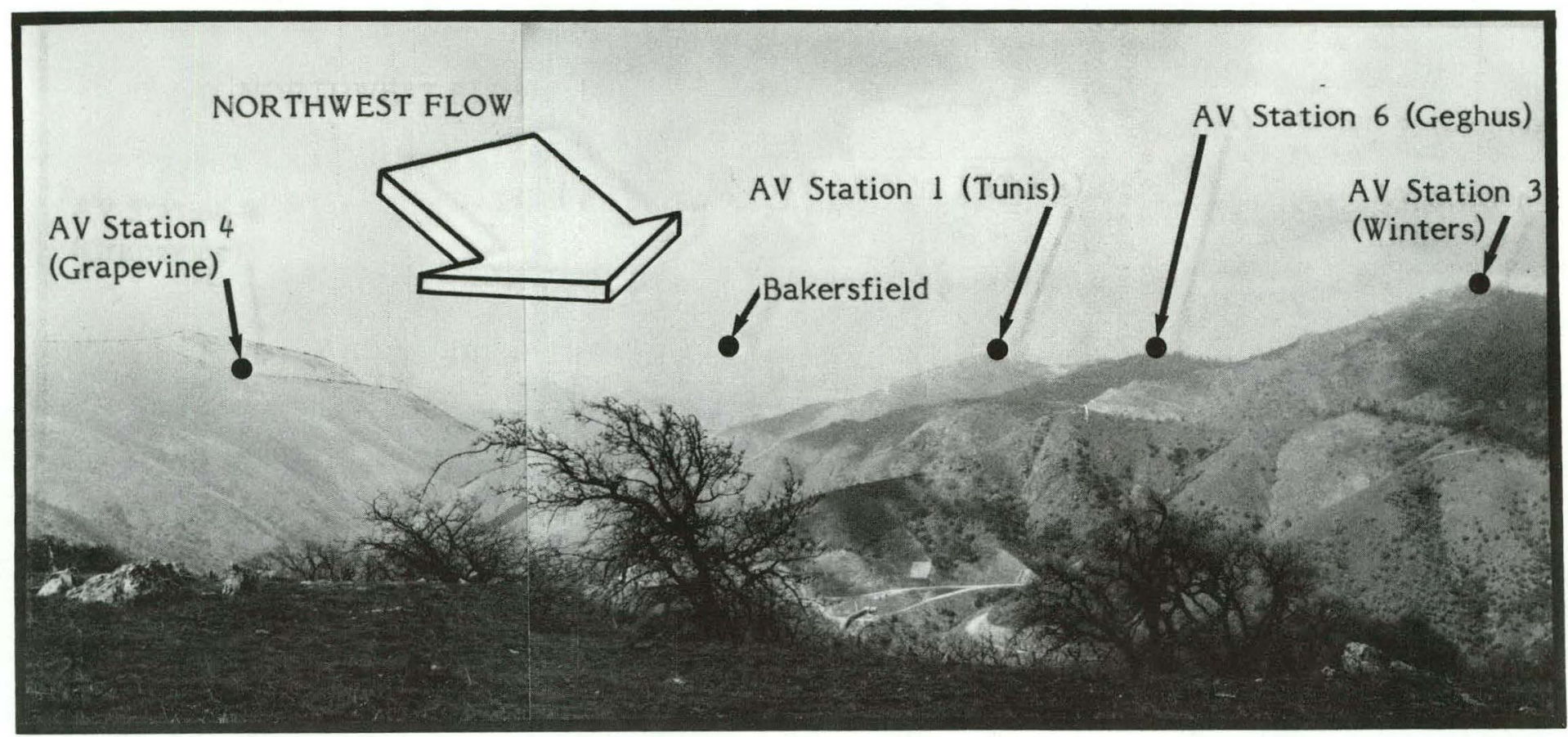

FIGURE 29. San Joaquin Valley viewed from AV Station 9 (La Liebre Ridge) looking northwest through the Pastoria Creek Valley into the direction of prevailing summer flow. 
are a consequence of synoptic features such as weather front passages or cut-off upperlevel low pressure cells. Winds associated with these storms are short in duration, very violent and often accompanied by severe rains or snow, resulting in tree damage as shown in Figures 30 and 31 in many regions. These flows tend to induce high turbulence levels in winds over ridgelines farthest from the San Joaquin Valley and strong downslope winds onto the floor of the Antelope Valley.

Table 10 is data recorded on November 26, 1979. Strong northwest winds were prevailing over Winters (AV3) and Geghus (AV6) ridges as well as La Liebre (AV2 and AV9). The Antelope Valley site recorded strong winds also from the northwest, most probably the result of strong downslope winds caused by the moving storm.

\section{Summer Southeast Flow}

On occasion, synoptic situations dictate a reversal of the prevalent flow pattern during late summer. A thermal low pressure cell can form over the San Joaquin Valley and produce temperature and pressure gradients that combine to reverse the flow over the Tehachapis. This circulation pattern causes an influx of warm, moist air from the southwest to infiltrate the Southern California desert regions. This moisture spawns thunderstorms and a storm front then creeps northwesterly across Southern California.

On September 24, 1979, thunderstorm activity was recorded at Bakersfield Weather Station in the evening. Table 11 records data obtained for that day. In general, winds from the southeast will be light over most of the Tehachapi region. When the storm front then develops and begins to move, northwest winds again dominate. Grapevine (AV4) and Winters (AV3) appear more influenced by storm activity than other ridges, possibly due to a more direct exposure to the San Joaquin Valley.

Another mechanism which can cause local southeast flow is daytime upslope mountain breezes. Observations of $12-15 \mathrm{mph}$ southeast winds in the late morning hours at AV9 (La Liebre), AV2 (La Liebre) and AV7 (Tunis-Geghus) were noted by our field crew quite frequently in the summer. Other stations experienced only faint southeast breezes during these times. 


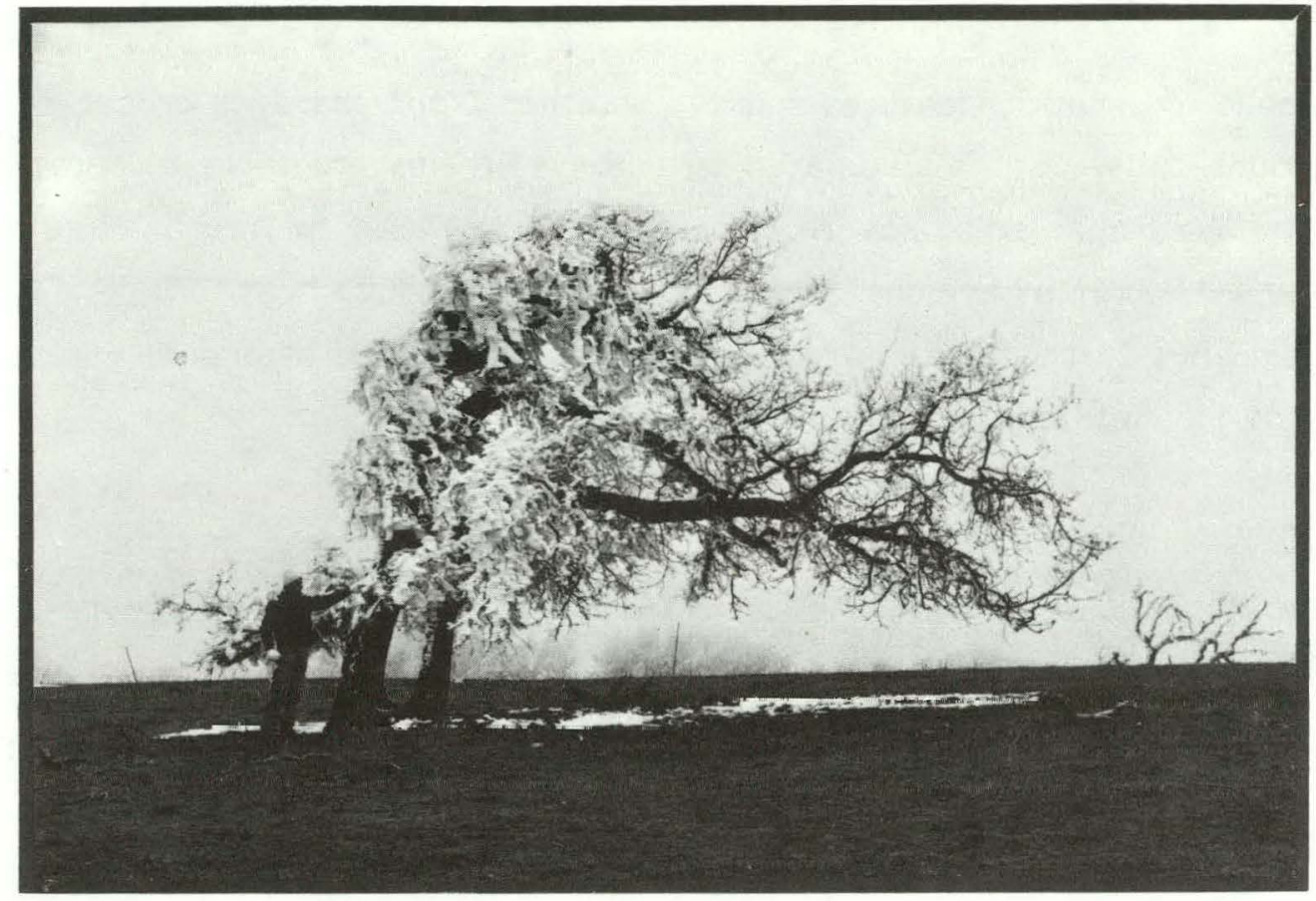

FIGURE 30. Rime icing on flagged California Oak tree located near AV Station 7 (Tunis-Geghus) in the Tehachapi Study Region.

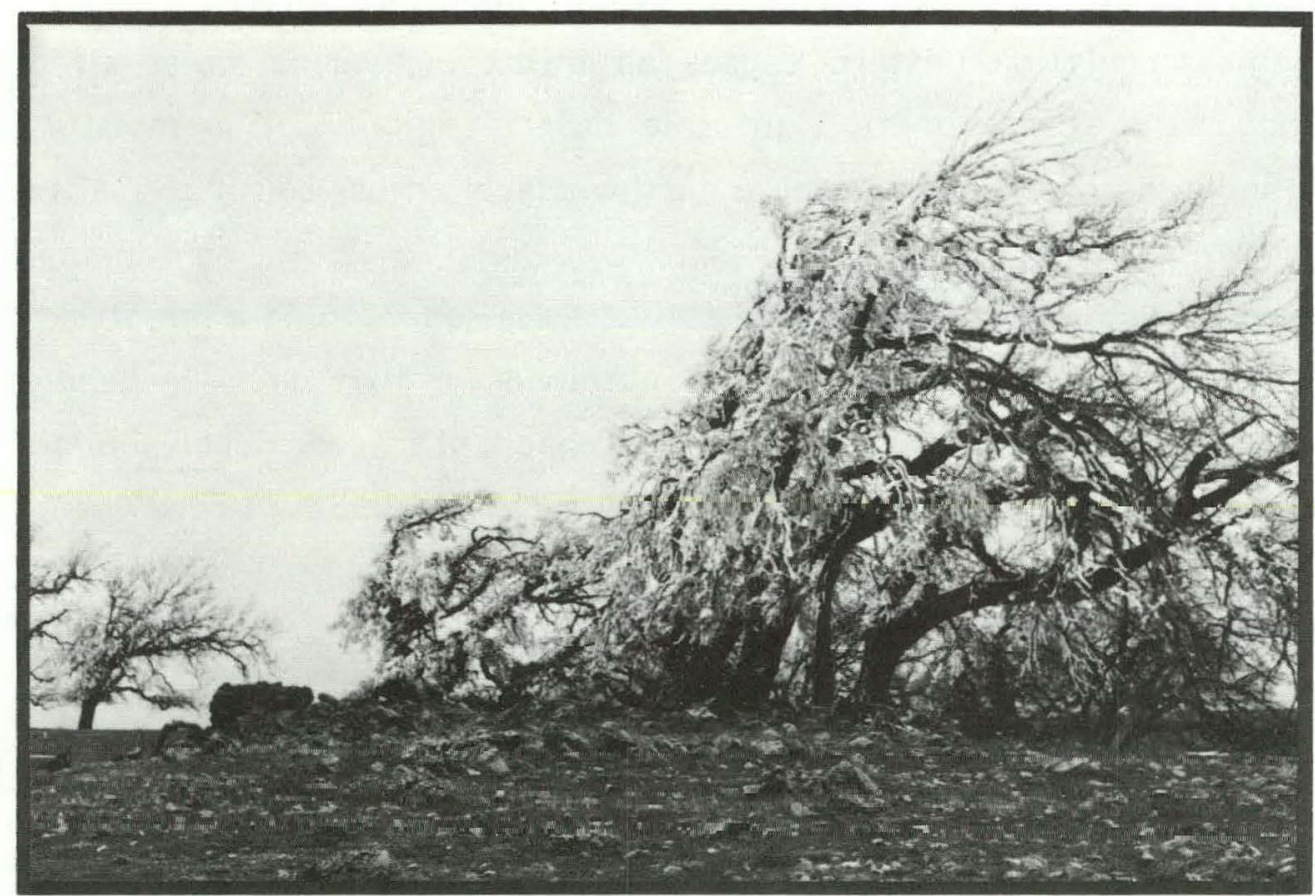

FIGURE 31. Rime icing on flagged (northwest) California Oaks located near AV Station 6 (Geghus) in the Tehachapi Study Region. 
TABLE 10. Summary of wind speed, wind direction, and temperature data obtained in the study region on

November 26, 1979 during winter northwest flow conditions. (All wind speeds are in mph at 33 feet AGL.)

\begin{tabular}{|c|c|c|c|c|c|c|c|c|c|c|c|c|c|}
\hline \multirow{2}{*}{$\begin{array}{l}\text { Hour } \\
\text { (PST) }\end{array}$} & \multicolumn{3}{|c|}{ Bakersfield } & \multirow{2}{*}{$\begin{array}{c}\text { (Grape- } \\
\text { vine) } \\
\mathrm{AV}_{4}\end{array}$} & \multirow{2}{*}{$\begin{array}{c}\text { (Tunis) } \\
\text { AVI }\end{array}$} & \multirow{2}{*}{$\begin{array}{c}\text { (Winters) } \\
\text { AV } 3\end{array}$} & \multirow{2}{*}{$\begin{array}{c}\text { (Geghus) } \\
\text { AV6 }\end{array}$} & \multirow{2}{*}{$\begin{array}{c}\text { (Tunis- } \\
\text { Geghus) } \\
\text { AV7 }\end{array}$} & \multicolumn{2}{|c|}{ (La Liebre) } & \multirow{2}{*}{$\begin{array}{c}\text { (La } \\
\text { Liebre) } \\
\text { AV2 }\end{array}$} & \multicolumn{2}{|c|}{ (Antelope Valley) } \\
\hline & $T\left({ }^{\circ} \mathrm{F}\right)$ & Dir. & Speed & & & & & & Av9 & Av9 (Dir.) & & Avs & AVS (Dir.) \\
\hline $\begin{array}{l}0100 \\
0200 \\
0300\end{array}$ & 56 & E & 6 & $\begin{array}{l}12 \\
12 \\
10\end{array}$ & $\begin{array}{l}13 \\
15 \\
16\end{array}$ & $\begin{array}{l}14 \\
13 \\
16\end{array}$ & $\begin{array}{l}21 \\
22 \\
25\end{array}$ & $\begin{array}{l}25 \\
26 \\
27\end{array}$ & $\begin{array}{l}31 \\
30 \\
30\end{array}$ & $\begin{array}{l}N W \\
N W \\
N W\end{array}$ & $\begin{array}{l}29 \\
30 \\
32\end{array}$ & $\begin{array}{l}17 \\
27 \\
26\end{array}$ & $\begin{array}{l}N W \\
N W \\
N W\end{array}$ \\
\hline $\begin{array}{l}0400 \\
0500 \\
0600\end{array}$ & 52 & ESE & 3 & $\begin{array}{l}10 \\
11 \\
11\end{array}$ & $\begin{array}{l}16 \\
14 \\
13\end{array}$ & $\begin{array}{l}13 \\
14 \\
18\end{array}$ & $\begin{array}{l}25 \\
24 \\
25\end{array}$ & $\begin{array}{l}27 \\
27 \\
27\end{array}$ & $\begin{array}{l}30 \\
32 \\
33\end{array}$ & $\begin{array}{l}\text { NW } \\
\text { NW } \\
\text { WNW }\end{array}$ & $\begin{array}{l}29 \\
29 \\
27\end{array}$ & $\begin{array}{l}26 \\
26 . \\
28\end{array}$ & $\begin{array}{l}N W \\
N W \\
N W\end{array}$ \\
\hline $\begin{array}{l}0700 \\
0800 \\
0900\end{array}$ & 55 & E & 4 & $\begin{array}{l}y \\
6 \\
7\end{array}$ & $\begin{array}{l}16 \\
15 \\
20\end{array}$ & $\begin{array}{l}17 \\
15 \\
20\end{array}$ & $\begin{array}{l}24 \\
23 \\
26\end{array}$ & $\begin{array}{l}29 \\
32 \\
31\end{array}$ & $\begin{array}{l}31 \\
30 \\
27\end{array}$ & $\begin{array}{l}\text { NW } \\
\text { WNW } \\
\text { WNW }\end{array}$ & $\begin{array}{l}26 \\
29 \\
32\end{array}$ & $\begin{array}{l}29 \\
26 \\
28\end{array}$ & $\begin{array}{l}\text { NW } \\
\text { NW } \\
\text { NW }\end{array}$ \\
\hline $\begin{array}{l}1000 \\
1100 \\
1200\end{array}$ & 64 & SW & 3 & $\begin{array}{l}8 \\
8 \\
8\end{array}$ & $\begin{array}{l}17 \\
14 \\
13\end{array}$ & $\begin{array}{l}20 \\
21 \\
20\end{array}$ & $\begin{array}{l}28 \\
26 \\
25\end{array}$ & $\begin{array}{l}29 \\
28 \\
31\end{array}$ & $\begin{array}{l}25 \\
23 \\
24\end{array}$ & $\begin{array}{l}N W^{-} \\
N W \\
N W\end{array}$ & $\begin{array}{l}26 \\
25 \\
22\end{array}$ & $\begin{array}{l}29 \\
27 \\
23\end{array}$ & $\begin{array}{l}N W \\
N W \\
N W\end{array}$ \\
\hline $\begin{array}{l}1300 \\
1400 \\
1500\end{array}$ & 71 & NW & 12 & $\begin{array}{l}\text { s } \\
3 \\
3\end{array}$ & $\begin{array}{l}12 \\
12 \\
12\end{array}$ & $\begin{array}{l}21 \\
24 \\
20\end{array}$ & $\begin{array}{l}25 \\
27 \\
29\end{array}$ & $\begin{array}{l}34 \\
32 \\
30\end{array}$ & $\begin{array}{l}24 \\
24 \\
25\end{array}$ & $\begin{array}{l}N W \\
N W \\
N W\end{array}$ & $\begin{array}{l}22 \\
23 \\
20\end{array}$ & $\begin{array}{l}19 \\
20 \\
19\end{array}$ & $\begin{array}{l}N W \\
N W \\
N W\end{array}$ \\
\hline $\begin{array}{l}1600 \\
1700 \\
1800\end{array}$ & 64 & NNW & 15 & $\begin{array}{r}4 \\
8 \\
12\end{array}$ & $\begin{array}{l}11 \\
10 \\
12\end{array}$ & $\begin{array}{l}18 \\
18 \\
16\end{array}$ & $\begin{array}{l}27 \\
23 \\
20\end{array}$ & $\begin{array}{l}28 \\
24 \\
22\end{array}$ & $\begin{array}{l}25 \\
26 \\
25\end{array}$ & $\begin{array}{l}N W \\
N W \\
N W\end{array}$ & $\begin{array}{l}19 \\
15 \\
20\end{array}$ & $\begin{array}{l}18 \\
16 \\
12\end{array}$ & $\begin{array}{l}N W \\
N W \\
N W\end{array}$ \\
\hline $\begin{array}{l}1900 \\
2000 \\
2100\end{array}$ & 59 & NW & 10 & $\begin{array}{l}15 \\
15 \\
17\end{array}$ & $\begin{array}{l}12 \\
13 \\
11\end{array}$ & $\begin{array}{l}10 \\
11 \\
13\end{array}$ & $\begin{array}{l}19 \\
20 \\
18\end{array}$ & $\begin{array}{l}26 \\
28 \\
25\end{array}$ & $\begin{array}{l}26 \\
26 \\
25\end{array}$ & $\begin{array}{l}\text { NW } \\
\text { NW } \\
\text { NW }\end{array}$ & $\begin{array}{l}34 \\
41 \\
33\end{array}$ & $\begin{array}{l}10 \\
16 \\
15\end{array}$ & $\begin{array}{l}\text { WNW } \\
\text { WNW } \\
\text { WNW }\end{array}$ \\
\hline $\begin{array}{l}2200 \\
2300 \\
2400\end{array}$ & 52 & NW & 6 & $\begin{array}{l}18 \\
16 \\
14\end{array}$ & $\begin{array}{l}4 \\
2 \\
5\end{array}$ & $\begin{array}{l}14 \\
17 \\
20\end{array}$ & $\begin{array}{l}15 \\
15 \\
14\end{array}$ & $\begin{array}{l}24 \\
21 \\
17\end{array}$ & $\begin{array}{l}24 \\
22 \\
23\end{array}$ & $\begin{array}{l}\text { NW } \\
\text { NW } \\
\text { NW }\end{array}$ & $\begin{array}{l}25 \\
20 \\
14\end{array}$ & $\begin{array}{l}19 \\
13 \\
22\end{array}$ & $\begin{array}{l}\text { WNW } \\
\text { WNW } \\
\text { WNW }\end{array}$ \\
\hline
\end{tabular}


TABLE 11. Summary of wind speed, wind direction, and temperature data obtained in the study region on September 24,1979 . (All wind speeds in mph at 33 feet AGL.).

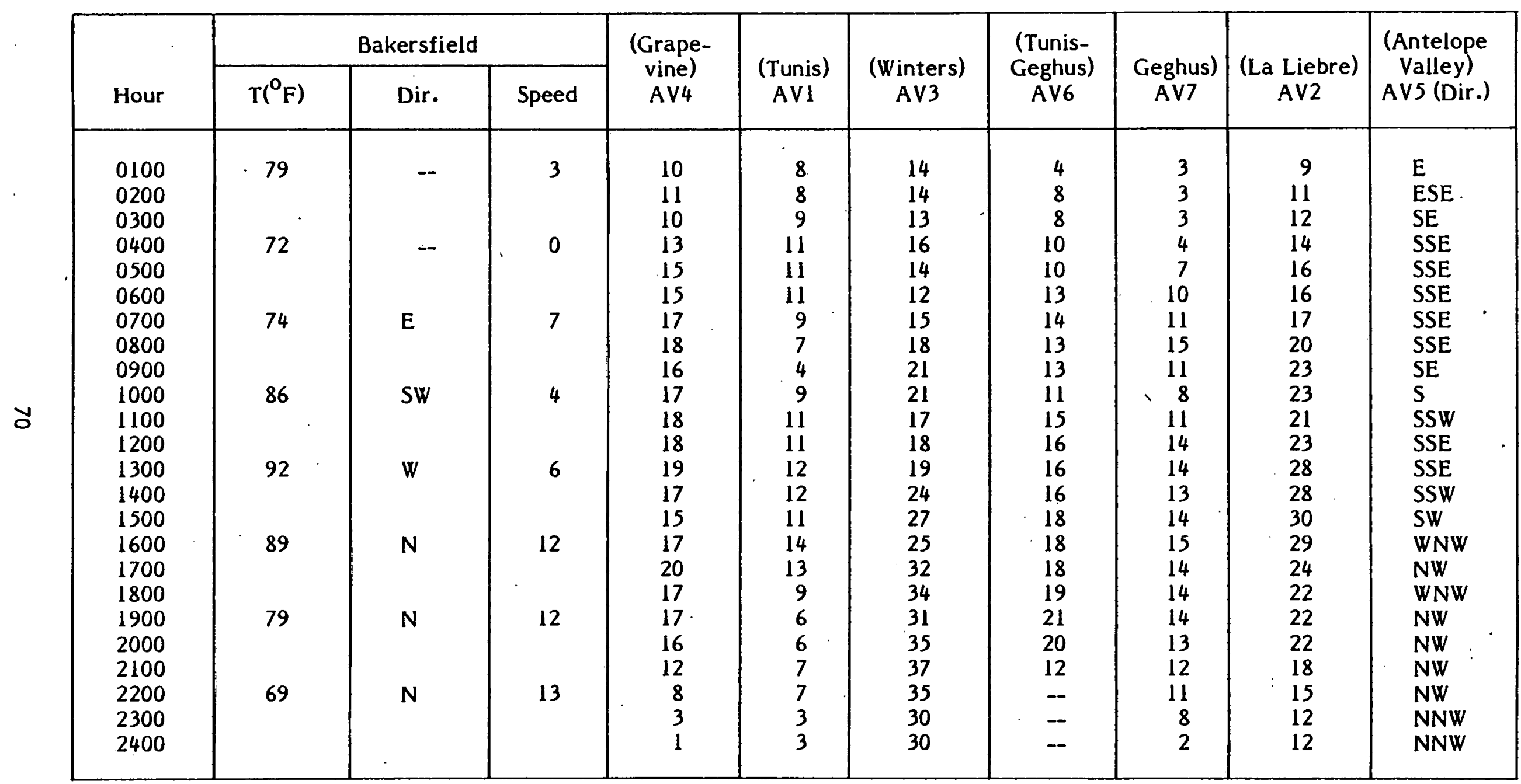




\section{Santa Ana Flow}

The Santa Ana flow is caused by a build-up of pressure over the Great Basin area of Nevada-Utah which occurs after frontal passages in winter. The strength of this flow is determined by the pressure differential between the Great Basin and that off the coast. Generally, the flow is from the east-southeast over the Tehachapi study region, but can be altered by terrain effects. Extremely strong winds can occasionally occur, as is described in the following account (U.S. Weather Service, 1977):

The storm started at Bakersfield during the early morning hours of December 20, 1977 and lasted until the evening of December 21st. The wind was southeasterly during this period at greater than $15 \mathrm{mph}$ both night and day. Blowing dust was reported during most of the period. The maximum sustained wind was $46 \mathrm{mph}$ on the 20 th and $38 \mathrm{mph}$ on the $21 \mathrm{st}$. According to our records, the $46 \mathrm{mph}$ wind recorded at - Bakersfield on the 20 th was the strongest ever recorded at that site for the period of record from 1948 through 1977. There were reports of extremely strong winds on the mountain ridges south of Bakersfield. A mechanical wind-measuring device located at Wheeler Ridge recorded $120 \mathrm{mph}$ just after 11 a.m. on December 20 th.

In perspective, Sandberg Weather Station recorded east-southeast winds of nearly $50 \mathrm{mph}$ on that day. Table 12 notes the number of Santa Ana cases in Southern California for a ten-year period by month.

\section{FREQUENCY OF STORMS}

Severe gusty winds observed in the Tehachapi Mountain region are associated with storms. As a result of such storms, precipitation of ten occurs; therefore, episodes of precipitation and storms are correlated. Table 13 lists the mean number of days with measurable precipitation and thunderstorm occurrences for Sandberg and Bakersfield. 
TABLE 12. Number of Santa Ana cases by months, Southern California region, 1951-1960:

\begin{tabular}{|c|c|c|c|c|c|c|c|c|c|c|c|c|c|}
\hline Month & Jan. & Feb. & Mar. & Apr. & May & Jun. & Jul. & Aug. & Sep. & Oct. & Nov. & Dec. & Total \\
\hline Frequency & 7 & 10 & 17 & 8 & 7 & 4 & $2 *$ & 0 & 11 & 19 & 26 & 18 & 129 \\
\hline Total days & 12 & 19 & 43 & 15 & 10 & 18 & $5 *$ & 0 . & 48 & 86 & 128 & 66. & 450 \\
\hline Range (days) & $1-3$ & $1-7$ & $1-9$ & $1-6$ & $1-2$ & $1-8$ & $1-4$ & 0 & $1-7$ & $3-8$ & $1-12$ & $1-10$ & $1-12$ \\
\hline Average (days) & 1.7 & 1.9. & 2.5 & 1.8 & 1.4 & 4.5 & 2.5 & 0 & 4.4 & 4.5 & 5.0 & 3.7 & 3.5 \\
\hline
\end{tabular}

*Cases affecting high elevations only

(Source: Pacific Southwest Forest Service, 1964) 
TABLE 13. Mean number of days with measurable precipitation and thunderstorm occurrences.

\begin{tabular}{|c|c|c|c|c|}
\hline \multirow[b]{3}{*}{ Month } & \multicolumn{4}{|c|}{ Mean Number of Days } \\
\hline & \multicolumn{2}{|c|}{ Measurable Precipitation } & \multicolumn{2}{|c|}{ Thunderstorms } \\
\hline & Sandberg & Bakersfield & Sandberg & Bakersfield ' \\
\hline Jan & 6 & 5 & * & * \\
\hline Feb & 6 & 6 & * & * \\
\hline Mar & 6 & 6 & * & * \\
\hline Apr & 4 & 5 & 1 & * \\
\hline May & 2 & 2 & 1 & * \\
\hline Jun & * & * & * & * \\
\hline Jul & * & * & 1 & * \\
\hline Aug & 1 & * & 1 & * \\
\hline Sep & 1 & 1 & 1 & * \\
\hline Oct & 2 & 2 & * & * \\
\hline Nov & 4 & 3 & * & * \\
\hline Dec & 6 & 5 & * & * \\
\hline Annual & 40 & 36 & 4 & 3 \\
\hline
\end{tabular}

Bakersfield ( 39 year period)

Sandberg ( 42 year period)

*denotes less than one 


\section{THIS PAGE WAS INTENTIONALLY LEFT BLANK}


This chapter will briefly identify related wind-energy development factors other than those involving the wind field.

\section{FAULTS}

The Tehachapi study region is on the southwest end of a major fault zone called the Garlock fault. The Garlock fault runs from the Death Valley region over 100 miles southwest along the southern rim of the Sierra-Nevadas through the Tehachapis., Near AV Station 4 on Grapevine Mountain, the Garlock fault is intersected by the San Andreas Fault, which traverses northwest throughout the state of California.

The Garlock fault, the most prominent fault in the region, is seismologically active -- that is, it shows continuous or intermittent movements. In the wedge between the Garlock and San Andreas fault zones (southwest of the study region) at least 10 smaller faults trend northeast.

The strongest earthquake ever recorded in California was centered near the Tehachapi Mountain study region at Fort Tejon on January 8 and 9, 1857. Estimated at a magnitude of greater than 8.0 on the Richter scale, the earthquake was felt strongly throughout most of California, from San Diego near the Mexican border to north of Sacramento, and from the Santa Barbara Channel to the high valleys of the Sierra-Nevada Mountains. The best account was that the 1857 earthquake opened a crevice in the earth at least 275 miles long (U.S. Geological Survey, 1950).

\section{ECONOMIC GEOLOGY}

In 1950, John Wiese compiled an extensive geological survey for the U.S. government on natural resources of the Tehachapi Mountain region. The following descriptions are summarized from his account. 
Although the mountainous area of the Tehachapi Mountains has been prospected for more than a century, few mineral deposits of value have been discovered. Colors of gold may be obtained by panning the granitic gravels on the slopes of the Liebre Mountain (south of the study region), and gold traces are fairly common along the south slope of the Tehachapi Mountains.

In the general vicinity, gold has been produced from only one property, the Riviera Mining Company, southeast of the study region. This gold discovery, coupled with finding silver near Mojave, by W.J. Rogers in about 1934 led to a small gold rush. Many claims were staked and hundred of pits put down in the foothills on both sides of the Antelope Valley, but no other deposits were discovered.

Tin

The discovery of tin in 1942 revived interest in the region's mineral resources, especially around the margins of limestone in the La Liebre Range of the Tehachapi Mountains. Several small deposits of high-grade ore were produced in 1942 but none after 1945.

\section{Marble and Limestone}

A number of small quarries were opened for furnishing crushed rock for construction of the Los Angeles Aqueduct at the base of the Tehachapis. Limestone, granite, andesite, and quartz monzonite were used. With the exception of the large Oso Cement Plant north of Quail Lake, most quarries are now idle.

\section{Petroleum}

Two unsuccessful borings for petroleum were made by the Tejon Ranch Oil Company in 1920 and have not been attempted again since then. Renewed interest in recent years may result in further petroleum exploration of the region in the next few years. 


\section{Endangered Species}

The California Condor, an endangered species, has been sited in the vicinity of the Tehachapi study area (Ortega, 1979). A strong interest exists among conservationists and within California to minimize human encroachment on the two remaining condor nesting areas in the Sespee-Piru region, which is about 30 miles southwest of the Tehachapis and in the Sisquoc condor sanctuary. Protection areas and Condor Management Areas are currently being examined by both state and federal government. Although it is unlikely that any of the major ridgelines studied would fall under this protective zoning, wind energy array size and height restrictions may be affected by such concerns.

\section{TRANSMISSION LINE PROXIMITY}

The Tehachapi study region is adjacent (less than 1 mile from AV Station 9) to the Southern California Edison Company "Big Crëek" Transmission line (500 kV). An excellent initial investigation into the cost of electrical power transmission alternatives for wind energy development of this general area was done by Lindley (1977). Readers should refer to his report for details. 


\section{THIS PAGE \\ WAS INTENTIONALLY \\ LEFT BLANK}




\section{POWER AVAILABILITY ESTIMATES}

This chapter concerns the available wind energy. at each area investigated on the Tehachapis and the amount of power which can be extracted given a wind turbine with defined power output parameters. There are two major simplifications made in the subsequent energy calculations.

The first involves the interpolation of surface $(10-\mathrm{m})$ wind speed data to hub height $(50-\mathrm{m})$ wind speed data. In a mountainous area the surface roughness varies appreciably between the various wind directions. The measured wind velocity at a small height $(10-\mathrm{m})$ translated to a larger height $(50-\mathrm{m})$ should take this into account. For this study, however, it is assumed that the translation of wind velocity to a larger height is uniformly scaled by, a power-law function, which will be the same for all site locations. Although TALA wind profile measurements were taken several times during the six-month field program, not enough reliable data were obtained to make a clear definition of the wind speed profile from $100-\mathrm{m}$ to ground level. As previously discussed, the field survey measurements did indicate a definite accelerated flow within the first 50 meters above the surface, but no data were taken in the evening, nor in winter flows to verify this as the general case. Instead, a power law exponent of 0.14 was chosen for scaling 10-m velocity data to $50-\mathrm{m}$ velocity data. This results in a velocity speed-up of approximately 25 percent from the $10-m$ velocity data.

The second simplification concerns the averaging time of the wind data and its consequence on energy flux. This study reports wind velocity as an average over a onehour period. Wind, however, fluctuates instantaneously and these fluctuations result in a difference between the true average energy flux and the calculated energy flux derived from hourly averaged data. de Vries (1979) does an excellent review of this statistical difference. Summarizing, the factor between the true average energy flux and the energy flux calculated for hourly averaged velocity can be approximated by

$$
\overline{U^{3}}=\bar{U}^{3}\left[1+3\left(\sigma^{2}\right)\right]
$$

where 


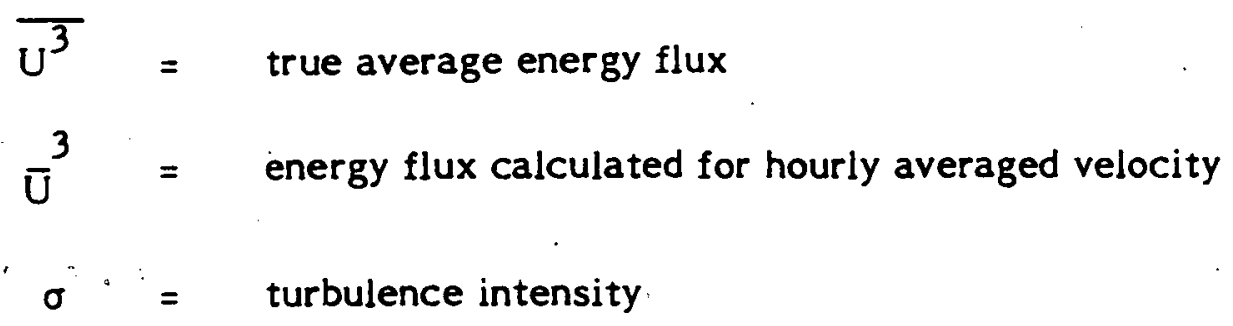

An initial guess for the turbulence intensity for the Tehachapis is 0.15 at the $50-\mathrm{m}$ level. This results in the energy flux calculated by hourly average velocity being about seven percent lower than the true energy flux.

\section{AVAILABLE WIND ENERGY}

As described in an earlier chapter wind velocity and wind energy frequency distributions were calculated for each month at the nine AV monitoring stations. These data are tabulated in Appendix C.

Table 14 gives the wind energy flux (watts $/ \mathrm{m}^{2}$ ) at the $50-\mathrm{m}$ level for a unit area through a vertical plane. Based entirely on the monthly trend of wind speed recorded at Sandberg Weather Station ( 30 years of historical data), an estimate for the winter-spring wind energy flux was made. This was done by scaling AV station data from November with historical Sandberg data. Continued wind monitoring is being conducted through these months to verify this assumption.

The wind energy availability for the Tehachapi mountain study area was carefully examined and summarized in Figure 32.

Area I is the region for which wind energy development is promising and where follow-on studies would be recommended. All of Area I shows an annual energy potential of greater than 400 watts $/ \mathrm{m}^{2}$, corresponding to an annual wind speed of about $16 \mathrm{mph}$. The annual wind is defined as the annual wind speed at 10-m AGL with a frequency distribution characterized by a Rayleigh distribution which would have the same energy as the actual wind distribution. Some local windy areas in this region, such as AV Station 2 - La Liebre can have average energy potential near 600 watts $/ \mathrm{m}^{2}$ during peak seasons, 
TABLE 14. Average wind energy flux (watts $/ \mathrm{m}^{2}$ ) for the Tehachapi Mountain study region (interpolated to 50-m AGL based on hourly averaged velocity data).

\begin{tabular}{|l|c|c|c|c|}
\hline AV Station No. & $\begin{array}{c}\text { (June-Aug) } \\
\text { Summer }\end{array}$ & $\begin{array}{c}\text { (Sep-Nov) } \\
\text { Fall }\end{array}$ & $\begin{array}{c}\text { (Dec-May) } \\
\text { Winter-Spring* }\end{array}$ & Annual Average** \\
\hline \hline 1 (Tunis) & 20 & 60 & 130 & 85 \\
2 (La Liebre) & 520 & 440 & 560 & 130 \\
3 (Winters) & 40 & 100 & 140 & 100 \\
4 (Grapevine) & 20 & 140 & 180 & 155 \\
5 (Antelope Valley) & 120 & 140 & 260 & 185 \\
6 (Geghus) & 70 & 200 & 290 & 230 \\
7 (Tunis-Geghus) & 140 & 80 & 190 & 120 \\
8 (Tunis) & 20 & 300 & 520 & 435 \\
9 (La Liebre) & 250 & & 90 & 130 \\
\hline
\end{tabular}

*Winter-Spring estimate based on monthly trend of wind speed recorded at Sandberg Weather Station (30 year historical data base).

**Based on recorded Summer and Fall data and estimated Winter-Spring data. 


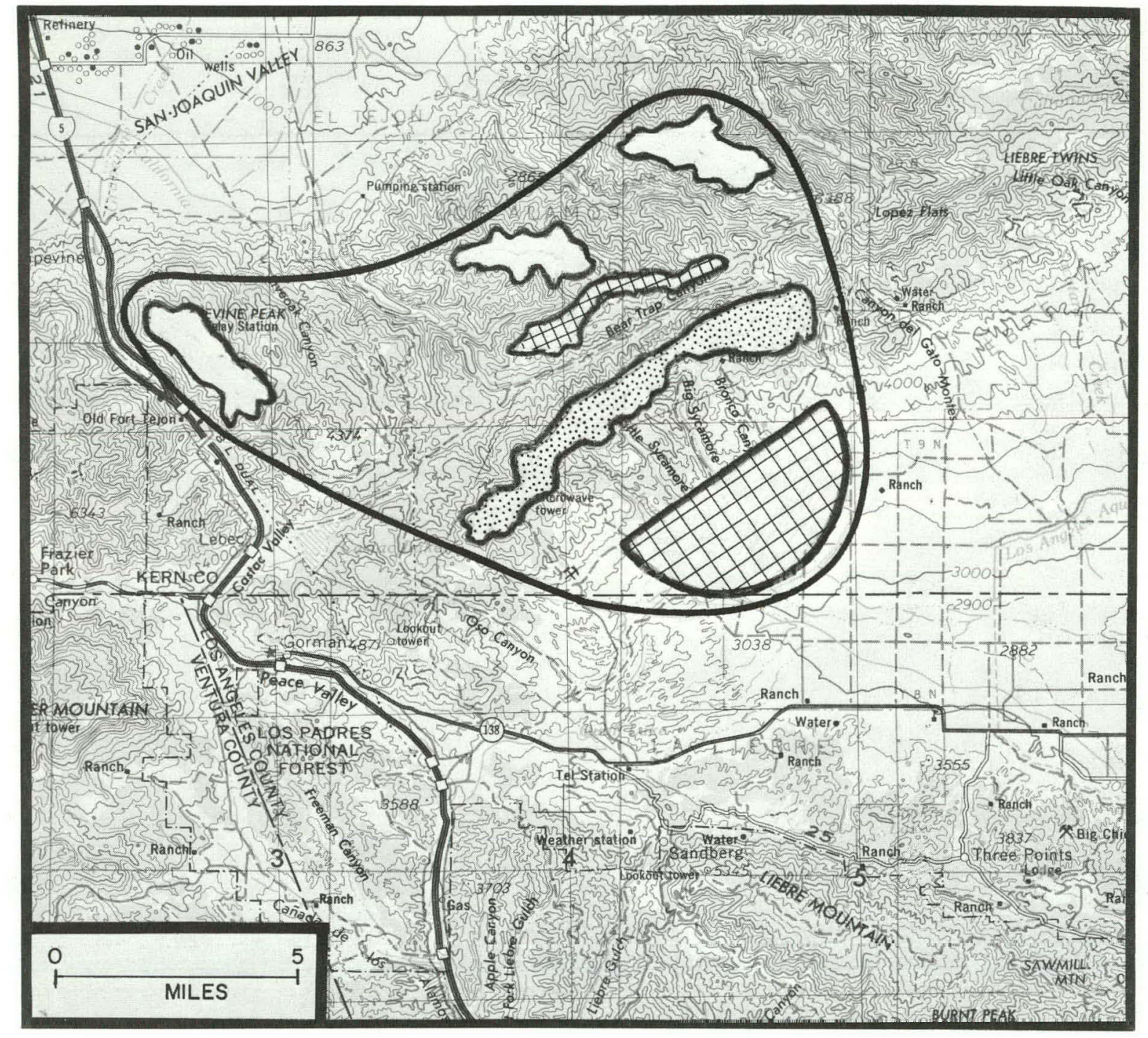
Area I
$>400$ watts $/ \mathrm{m}^{2} \quad$ (good wind energy potential) *
Area II
$>200$ watts $/ \mathrm{m}^{2}$ (fair wind energy potential) *
Area III $\square$
$>100$ watts $/ \mathrm{m}^{2} \quad$ (poor wind energy potential) *

* based on calculation of annual wind-energy density flux through a vertical plane at 50-m AGL

FIGURE 32. Areas suitable for wind turbine development. 
corresponding to an annual wind of about $18.3 \mathrm{mph}$. Also, it is probable that in this area there would not be less than 200 watts $/ \mathrm{m}^{2}$ during the low season (an annual wind of $12.7 \mathrm{mph})$.

Area II is the region for which wind energy development is fair. Although it is doubtful that any of the region would have an annual average energy potential greater than 300 watts $/ \mathrm{m}^{2}$ (a Rayleigh wind of $14.5 \mathrm{mph}$ ), all of the area can expect an annual energy potential of at least 150 watts $/ \mathrm{m}^{2}$ (a Rayleigh wind of $11.7 \mathrm{mph}$ ).

Area III is for regions with less than 100 watts $/ \mathrm{m}^{2}$ annual energy potential (a Rayleigh wind of $9.8 \mathrm{mph}$ ). Violent storms may cause significant increases in wind energy flux, but in general these regions would, at best, be marginal.

The actual capture of the energy in the wind depends upon wind turbine size and operating characteristics. For the study, a hypothetical large WECS design has been used. Specifications are similar to a design of the Boeing MOD-2, $2500 \mathrm{~kW}$ rated WECS.

Using the characteristics of this turbine and the wind speed frequency curves for specific sites, the average energy output can be determined by season and year.

The method for calculating energy output is straightforward. For the large WECS system chosen a typical wind turbine performance curve is specified and shown in Figure 33. For each AV Station where time-series data has been collected, wind speed frequency distribution curves can be generated. This has been done in this report and tabulated in Appendix $C$. The convolution of the machine output per unit speed with the probability density of wind speed per unit speed yields the power frequency distribution of a machines' output as a function of wind speed. The integral of this curve then yields the average expected power output of the wind turbine. This average expected power output divided by the rated power output of the particular machine yields a non-dimensional value, which is the capacity factor. Power outputs for five of the monitoring stations in the Tehachapis are shown in Table 15. For the best areas on La Liebre Ridge (AV Stations 2 and 9) the annual capacity factor is around 0.42. In perspective, annual capacity factors at the best locations in the Palm Springs-Whitewater Region vary between 0.40 and 0.45 (but assume a more conservative velocity ratio between $50-\mathrm{m}$ and $10 \mathrm{-m}$ of 17 percent (Zambrano et al., 1980). 


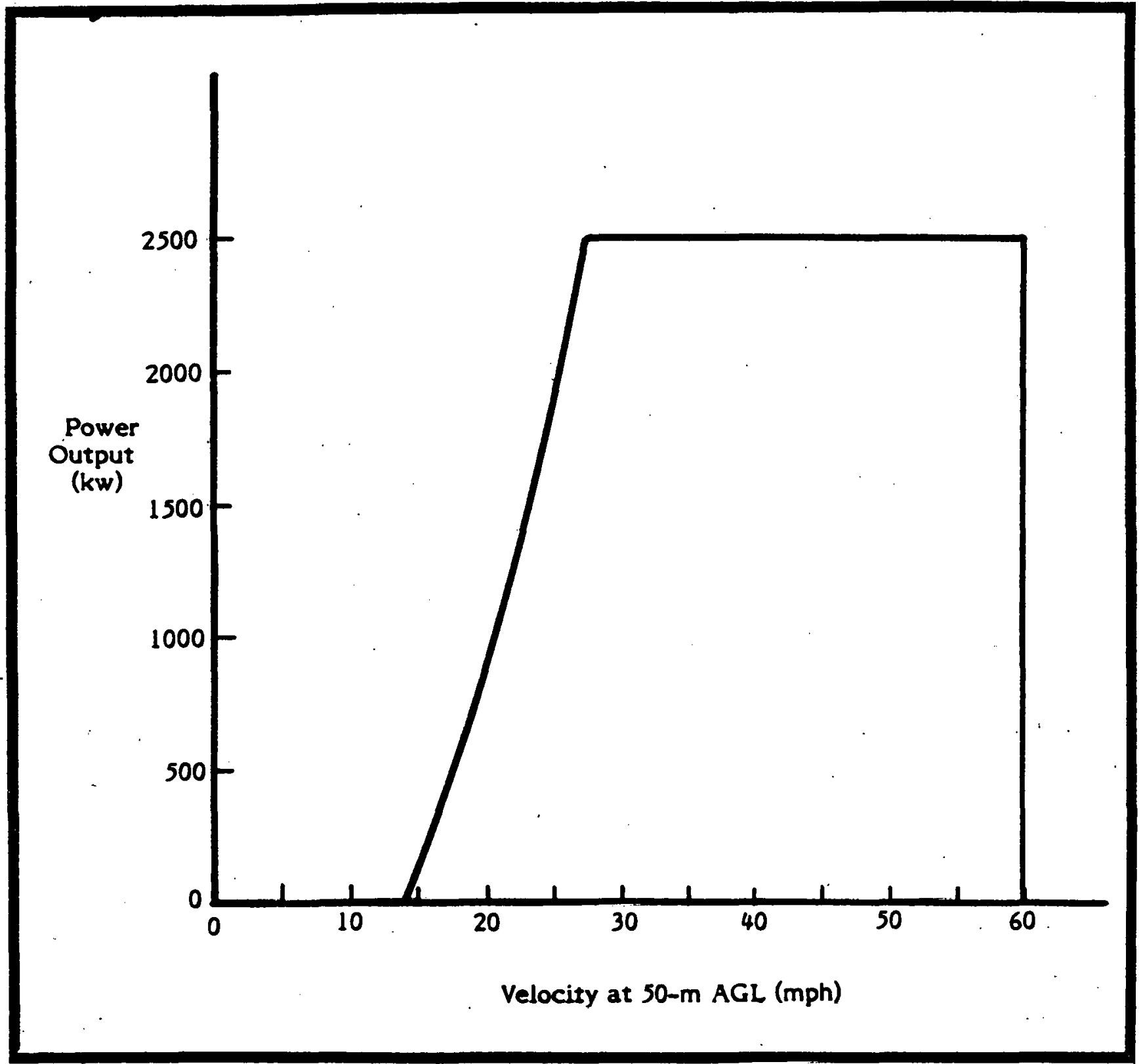

FIGURE 33. Typical Power Output curve for a large WECS. 
TABLE 15. Estimate of large WECS Average Seasonal Power and Total Energy Output $(\mathrm{kw})$ for Specific Sites in the Tehachapi Mountains

$$
V_{\text {cut-in }}=14 \mathrm{mph} ; V_{\text {rated }}=27.7 \mathrm{mph} ; V_{\text {cut-out }}=60 \mathrm{mph} ; \mathrm{P}=2500 \mathrm{~kW}
$$

(assuming velocity ratio of 1.25 between hub height winds and measured $10-\mathrm{m}$ AGL winds)

\begin{tabular}{|l|c|r|r|r|r|}
\hline \multicolumn{1}{|c|}{ AV Station No. } & $\begin{array}{c}\text { Summer } \\
(\mathrm{kW})\end{array}$ & $\begin{array}{c}\text { Fall } \\
(\mathrm{kW})\end{array}$ & $\begin{array}{c}\text { Predicted } \\
\text { Winter-Spring } \\
(\mathrm{kW})\end{array}$ & $\begin{array}{c}\text { Average } \\
\text { Total } \\
(\mathrm{kW})\end{array}$ & $\begin{array}{c}\text { Total Annual } \\
\text { Energy } \\
(\mathrm{kW}-\mathrm{hr})\end{array}$ \\
\hline \hline 2 (La Liebre) & 1,175 & 925 & 1,150 & 1,100 & $9.6 \times 10^{6}$ \\
5 (Antelope Valley) & 325 & 250 & 300 & 290 & $2.5 \times 10^{6}$ \\
6 (Geghus) & 150 & 325 & 700 & 470 & $4.1 \times 10^{6}$ \\
7 (Geghus-Tunis) & 400 & $400^{-}$ & 600 & 500 & $4.4 \times 10^{6}$ \\
9 (La Liebre) & 775 & 825 & 1,275 & 1,040 & $9.1 \times 10^{6}$ \\
\hline
\end{tabular}


The fluid mechanics involved in WECS array orientation has been investigated thoroughly by Lissaman (1979). An important influence in the WECS array performance is the distribution of wind-energy flux with wind direction. This is obtained by calculating the kinetic energy passing through a vertical plane in a unit time (which in our case is one hour). By multiplying this value, which has units of power/unit area (such as watts $/ \mathrm{m}^{2}$ ) by the percent of time wind is from a particular direction, a joint distribution of wind-energy and direction is obtained. These joint distributions are plotted for the month of November in Figures 34 and 35.

It must be remembered that wind-energy statistics are estimated for a hub-heightlevel of $50 \mathrm{~m}$ (165 feet) using a power law velocity profile, with an assumed power-law exponent fo 0.14 . This result is a scale-up of 25 percent in wind speed from measured $10 \mathrm{~m}$ (33 feet) AGL AV wind monitoring station data. Figure 34 is the: wind-energy direction distribution at AV Station 9 on La Liebre Ridge for November 1979. Wind direction is divided into 16 compass points, each direction representing a direction sweep of \pm 11.250. Referring to Figure 34,510 watts $/ \mathrm{m}^{2}$ is the total wind energy available for November at AV Station 9. Of that, approximately 200 watts $/ \mathrm{m}^{2}$ is from northwest winds $\left(315^{\circ} \pm 11.25^{\circ}\right)$, and the remaining energy flux is from south-southeasterly and. northwesterly winds. An interesting feature presented in Figure 34 is that even though the maximum winds for November were from the south (mean wind speed of $20 \mathrm{mph}$ at 33 feet AGL), south winds occur only 4 percent of the time and therefore have secondary wind energy potential.

Similar wind energy-direction distributions for AV Station 5 in the Antelope Valley are given in Figure 35. This distribution is most interesting when generated from annual data, since seasonal synoptic changes which many times result in prevailing wind direction changes can be put in perspective. Unfortunately wind direction data recovery at AV Stations 5 and 9 was insufficient to generate those plots. Instead, the joint distribution for wind energy and direction for Sandberg Weather Station for the 12-month period (December 1977-November 1978) was generated and is shown in Figure 36. The Sandberg data was plotted in ten degree increments due to the published format of that data. This refinement shows that wind directions can vary significantly ten degrees. For effective 


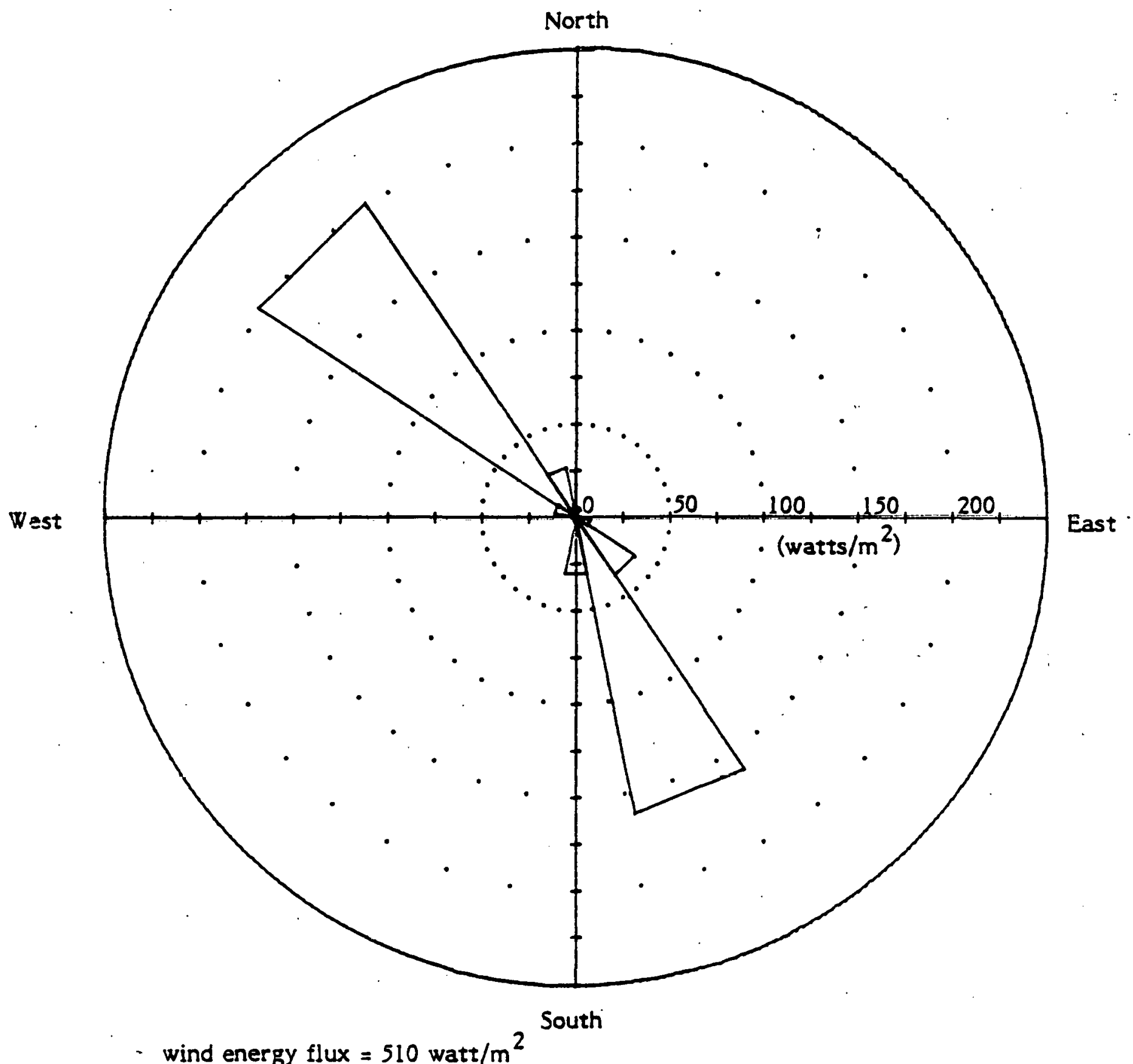

FIGURE 34. Wind energy-direction distribution for AV Station 9 - La Liebre, November 1979 (50-m AGL). 


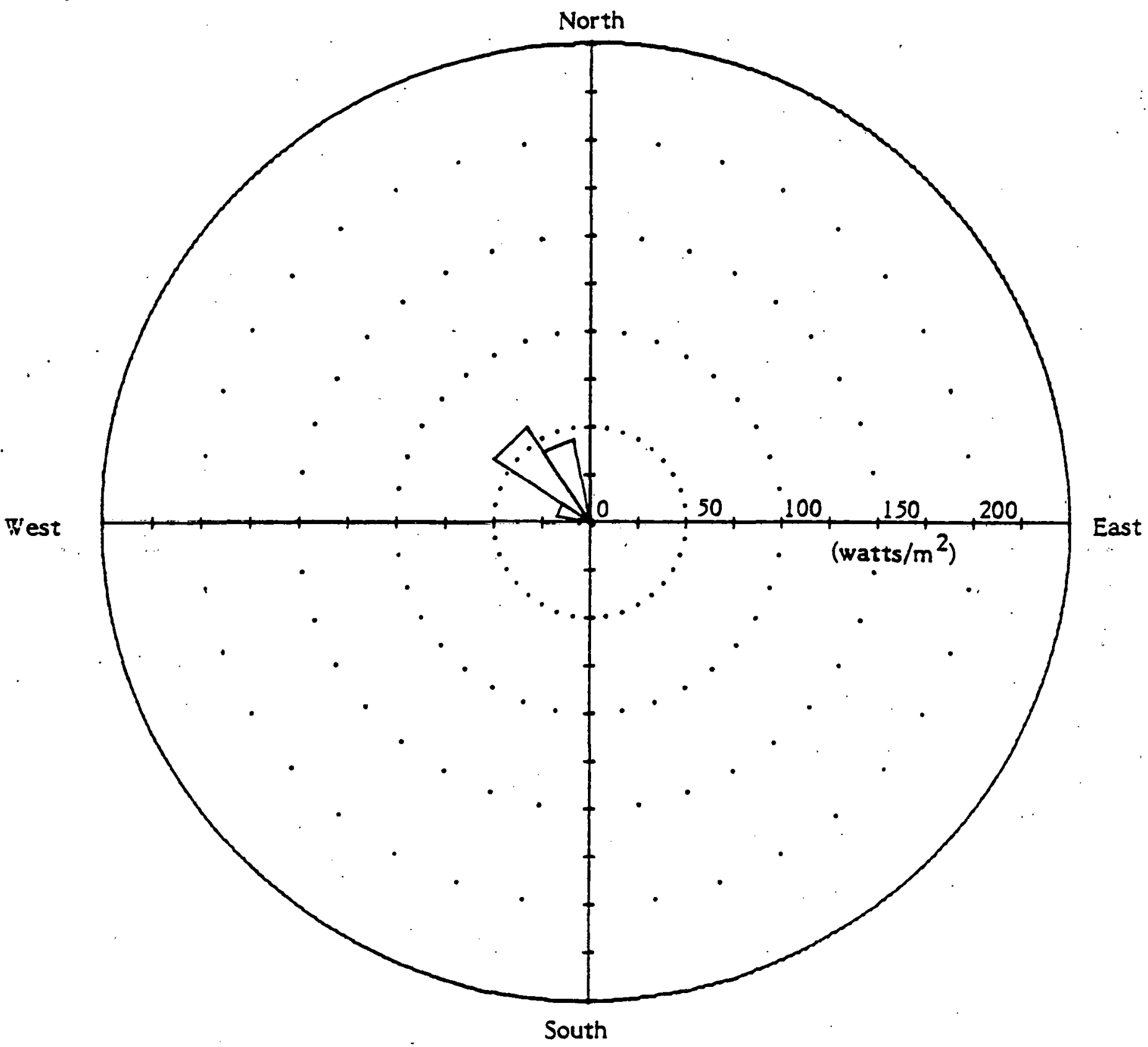

wind energy flux $=130 \mathrm{watt} / \mathrm{m}^{2}$

FIGURE 35. Wind energy-direction distribution for AV Station 5-Antelope Valley, November 1979 (50-m AGL). 


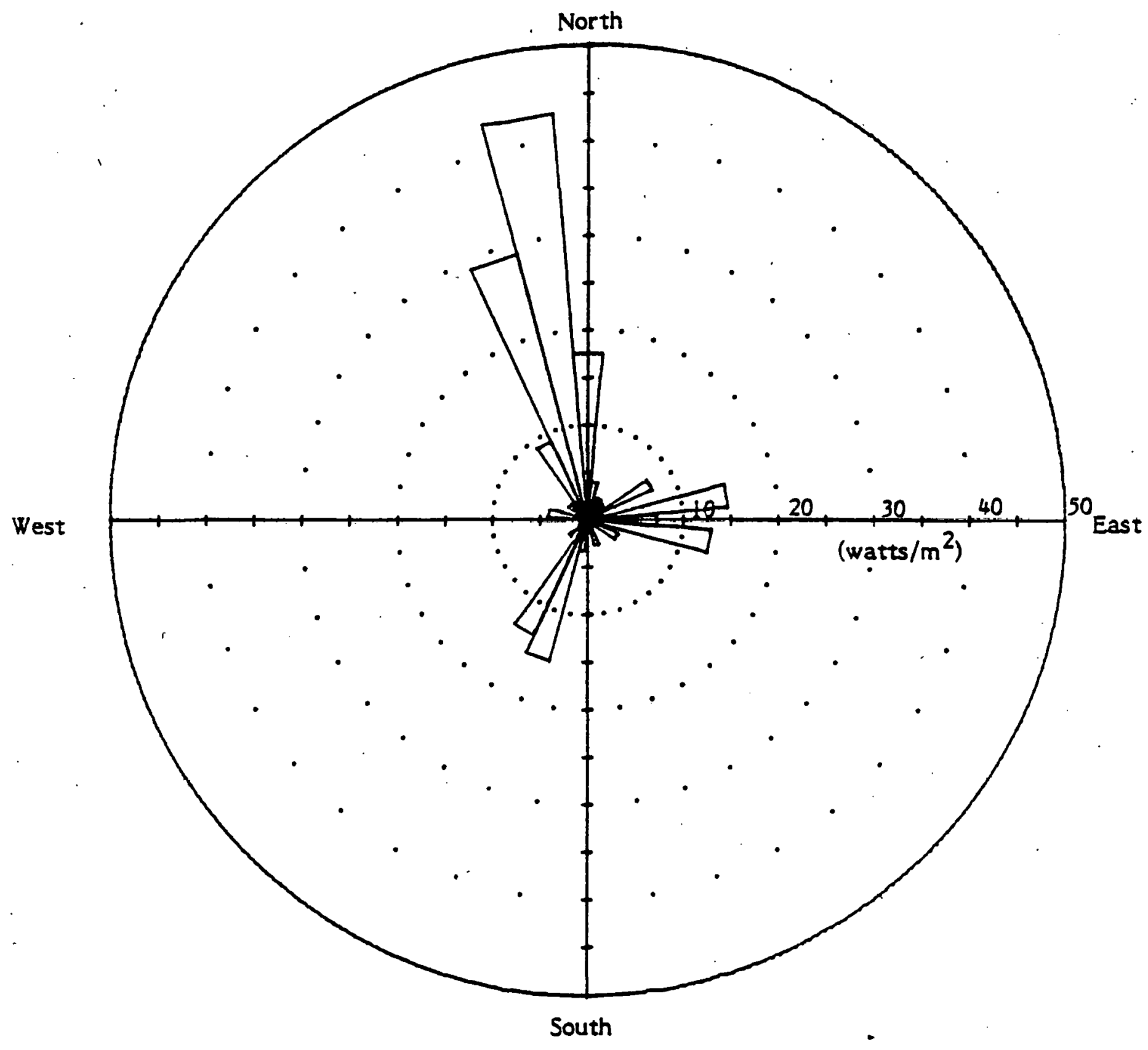

wind energy flux $=315$ watts $/ \mathrm{m}^{2}$

FIGURE 36. Wind energy-direction distribution for a 12-month period (Dec 77-Nov 78) at Sandberg Weather Station (50-m AGL). 
orientation of WECS, wind energy-direction distributions which discriminate per degree would be of value.

Since all sites are along ridgelines, the initial assumption is that turbines would be run along a one-dimensional array. Optimization of an array development is beyond the current level of this study; therefore, for informational purposes, a simplified single-line array of turbines will be considered. The array considered is assumed to be comprised of the same turbines corresponding to the configurations detailed previously. For each line mile, a 90\% land availability is assumed -- the result being that approximately eight turbines could be aligned on each mile with two diameter-spacing between hubs. From Figure 32 available land for Area I is approximately seven miles, traversing La Liebre Ridge between wind monitoring Stations 2 and 9. The available land for Area II is approximately three miles, traversing Geghus Ridge between wind monitoring Stations 6 and 7. Capacity factors for these regions for the respective ridges were averaged between two sets of wind monitoring stations. No other regions were considered in this initial array estimate. The result of these calculations is shown in Table 16. The last column in the table gives the average power output of any one single turbine in that region.

Again, it must be stressed that only with further refinement of wind measurements, along with turbine and spacing optimization, can Area I then be refined for actual turbine selection and location.

\section{USE OF THE RAYLEIGH DISTRIBUTION}

In an earlier chapter, Rayleigh distributions were obtained for wind speed frequency distributions associated with November monthly mean wind speed. Table 17 compares capacity factors generated by the actual wind speed frequency distributions with the Rayleigh distribution. The results are similar to that obtained by Cliff (1977). As shown earlier in Figures 15 through 23, some of the distributions appear to vary significantly from the Rayleigh distribution yet still lead to average power output values close to the estimates predicted using the Rayleigh distribution. 
TABLE 16. Estimated seasonal energy output ( $\left.\mathrm{KW}-\mathrm{hr} \times 10^{9}\right)$ for single-line wind turbine arrays on the Tehachapi Mountains.

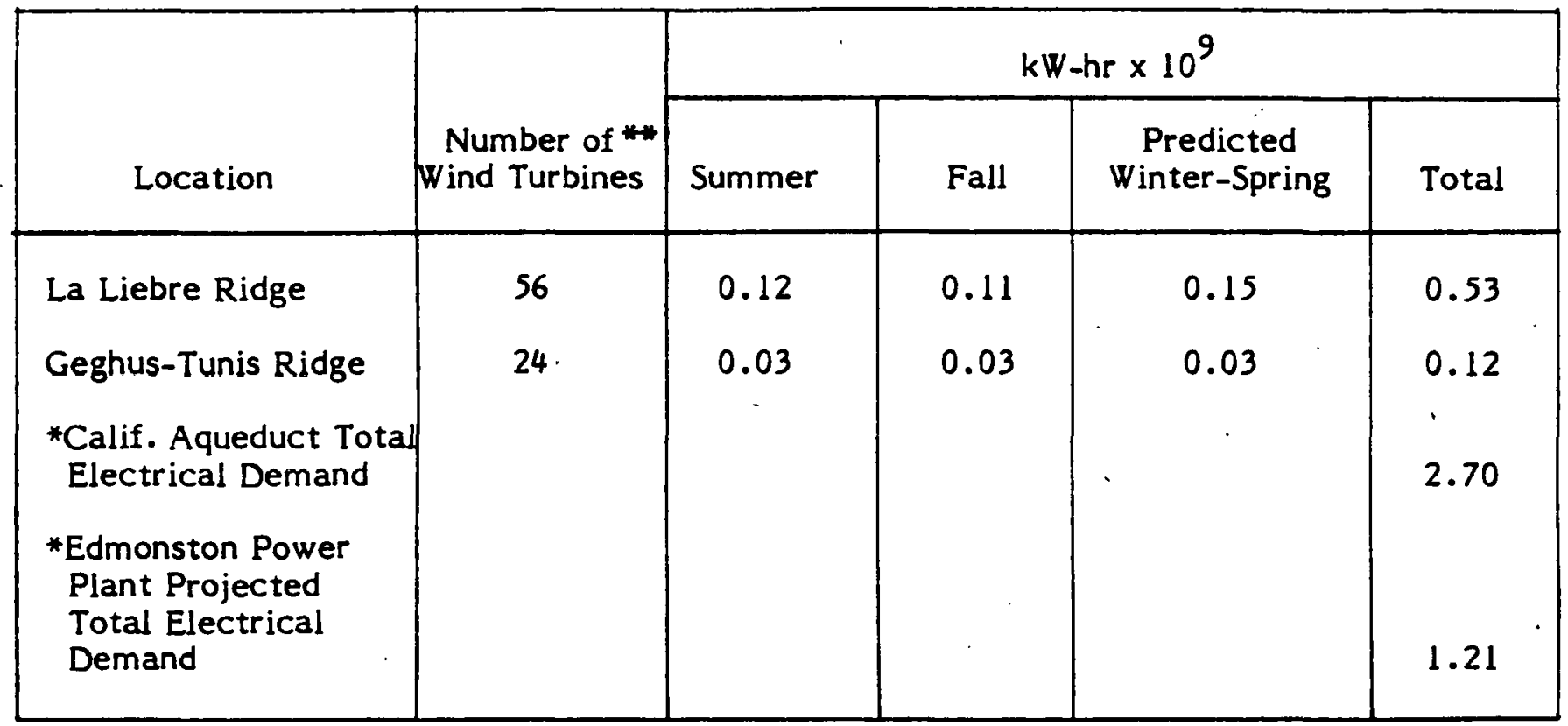

*Based on projections for 1990 (Lindley, 1977).

* single line array, two diameter spacing between hub, $90 \%$ land availability 
TABLE 17. Comparison of capacity factors for large WECS obtained from actual wind speed frequency distribution and Rayleigh distribution for November 1979.

$$
\mathrm{V}_{\text {cut-in }}=14 \mathrm{mph} ; \mathrm{V}_{\text {rated }}=27.7 \mathrm{mph} ; \mathrm{V}_{\text {cut-out }}=60 \mathrm{mph} ; \mathrm{P}=2500 \mathrm{~kW}
$$

\begin{tabular}{|c|c|c|}
\hline AV Station No. & Actual & Rayleigh \\
\hline \hline $1^{*}$ & .18 & .15 \\
2 & .49 & .46 \\
3 & .12 & .12 \\
4 & .20 & .16 \\
5 & .10 & .12 \\
6 & .31 & .28 \\
7 & .25 & .24 \\
8 & .20 & .19 \\
9 & .53 & .51 \\
\hline
\end{tabular}

less than 90 percent data recovery 


\section{COMPARISON OF FIELD ASSESSMENT SURVEY RESULTS WITH RECORDED DATA}

Table 18 summarizes the results from the initial field survey with the six month measurement program. The first column is the station number, the second is the preliminary field survey rank - defined in a previous chapter as the average rank of the best two out of three surveys (short term field measurements, vegetation indices, and topography). The third column is the estimated annual wind energy flux at 50-m AGL and the fourth is the estimated annual energy wind at $10-\mathrm{m} \mathrm{AGL}$, remembering the energy wind is the continuous wind which would have the same energy as the actual wind distribution.

AV Stations 2 and 9 (both on La Liebre Ridge) were initially judged to be the best sites and are further affirmed by the six-month data. AV Station 5 (Antelope Valley), which had a ranking of 3 , was initially judged to have better wind energy potential than was documented by the six-month data. Sites 6 (Geghus) and Site 7 (Geghus-Tunis) were initially judged to have good wind energy potential. Although the six-month data show these sites to be the next best sites to the stations on La Liebre Ridge, it was expected the difference in estimated annual energy flux would not have been as large.

In retrospect, it appears that the preliminary survey can successfully locate prime wind sites - those with expected annual energy winds greater than $15 \mathrm{mph}$ at the $10-\mathrm{m}$ level, and successfully locate poor wind sites - those with expected annual energy winds less than $9 \mathrm{mph}$ at the $10-\mathrm{m}$ level. The critical zone for wind energy potential (wind speed that can be between 10 and $14 \mathrm{mph}$ annually) is, basically, all remaining areas. Wind speed there can only be evaluated by actual field measurements with proper placement of monitoring equipment. Comparison of actual data with statistical distributions has also shown that obtaining an integrated average of the mean monthly wind speed can be a cost-effective method for obtaining first-order approximations of average power at a site.

From this experience, it is recommended that for future studies instrumentation be varied from monitors capable of wind speed and wind direction time-series data at sites located having potential annual wind speed of greater than $14 \mathrm{mph}$ at $33-\mathrm{ft} \mathrm{AGL}$, and 
TABLE 18. Comparison of Preliminary Field Survey Results with Data Obtained from the six month monitoring program.

\begin{tabular}{|l|c|c|c|}
\hline AV Station No. & $\begin{array}{c}\text { Preliminary } \\
\text { Field Survey } \\
\text { Rank }\end{array}$ & $\begin{array}{c}\text { Estimated Annual } \\
\text { Wind Energy } \\
\text { Flux (watts/m })\end{array}$ & $\begin{array}{c}\text { Estimated Annual } \\
\text { Wind * Speed } \\
\text { at 10-m AGL- } \\
\text { m/sec (mph) }\end{array}$ \\
\hline \hline 1 - Tunis & 9 & 85 & $4.4(9.8)$ \\
2 - La Liebre & 1 & 520 & $7.9(17.8)$ \\
3 - Winters & 14 & 100 & $4.4(10.1)$ \\
4 - Grapevine & 7 & 100 & $4.4(10.1)$ \\
5 - Antelope Valley & 3 & 155 & $5.3(11.9)$ \\
6 - Geghus & 6 & 183 & $5.4(12.3)$ \\
7 - Geghus-Tunis & 5 & 230 & $5.9(13.6)$ \\
8 - Tunis & 10 & 120 & $4.4 .(10.1)$ \\
9 - La Liebre & 2 & 400 & $7.3(16.4)$ \\
\hline
\end{tabular}

* energy wind is defined as the continuous wind which would have the same energy as the actual wind distribution. 
monitors capable of integrated monthly averaged wind speed data at sites located having potential annual wind speed between 10 and $14 \mathrm{mph}$ at 33-ft AGL.

The vegetation survey can be the only short-term evaluation technique which may provide a method for discerning between regions within this 10 to $14 \mathrm{mph}$ band. Results from the initial field survey compared with six-month results, however, show initial correlation attempts unsuccessful. Table 19 compares the predicted annual average velocity from the deformation index of California oak with the estimated annual wind speed derived from the six-month data.

The difference between the predicted annual velocity from the deformation index with the estimated annual energy wind speed was to be expected, given that any vegetation index now developed contains an error band of 20 percent to 40 percent (Hewson, Wade 1979). The correlation curve initially used for velocity estimates was a preliminary estimate, which was to be refined with the "calibrated" data obtained from the actual field measurements. Figure 37 plots the data obtained comparing six-month measurements with deformation ratio. The figure shows quite clearly that the scatter of mean velocities with deformation ratios renders the linear correlation meaningless.

The vegetation index insensitivity to the critical wind speeds may be a result of many factors, two of which will be discussed.

First, consider the simple but analogous case of uniform loading on a vertical cantilivered beam. Using basic statics (see Popov, 1952) and assuming the beam to be elastic and of uniform thickness, the deflection at any point $x$ distance from the base is

$$
\Delta_{x}=\frac{w}{24 E I}\left(x^{4}-4{ }^{3} x+3{ }^{4}\right)
$$

where $\quad w=$ uniformly distributed load per unit of length

$E=$ modulus of elasticity of the material (wood $\approx 1.6 \times 10^{6} \mathrm{psi}$ )

$1=$ moment of inertia of beam

$\ell=$ total length of beam 
TABLE 19. Comparison of Vegetation Survey Results with data obtained from the six-month monitoring program in the Tehachapi Study region.'

\begin{tabular}{|l|c|c|c|}
\hline AV Station No. & $\begin{array}{c}\text { California Oak } \\
\text { Calc. Deforma- } \\
\text { tion Index }\end{array}$ & $\begin{array}{c}\text { Predicted Annual } \\
\text { Vel. from Deforma- } \\
\text { tion Index (m/sec) }\end{array}$ & $\begin{array}{c}\text { Est. Annual } \\
\text { Wind Speed } \\
\text { (m/sec) }\end{array}$ \\
\hline \hline 1 - Tunis & 4.1 & 6.2 & 4.4 \\
2 - La Liebre & 6.1 & 8.0 & 7.9 \\
3 - Winters & 1.4 & 4.7 & 4.4 \\
4- Grapevine & 5.0 & 7.4 & 4.4 \\
5 - Antelope Valley & - & - & - \\
6- Geghus & 4.7 & 6.7 & 5.4 \\
7 - Geghus-Tunis & 5.0 & 7.4 & 5.9 \\
8 - Tunis & 4.0 & 6.2 & 4.4 \\
9- La Liebre & 5.0 & 7.6 & 7.3 \\
\hline
\end{tabular}




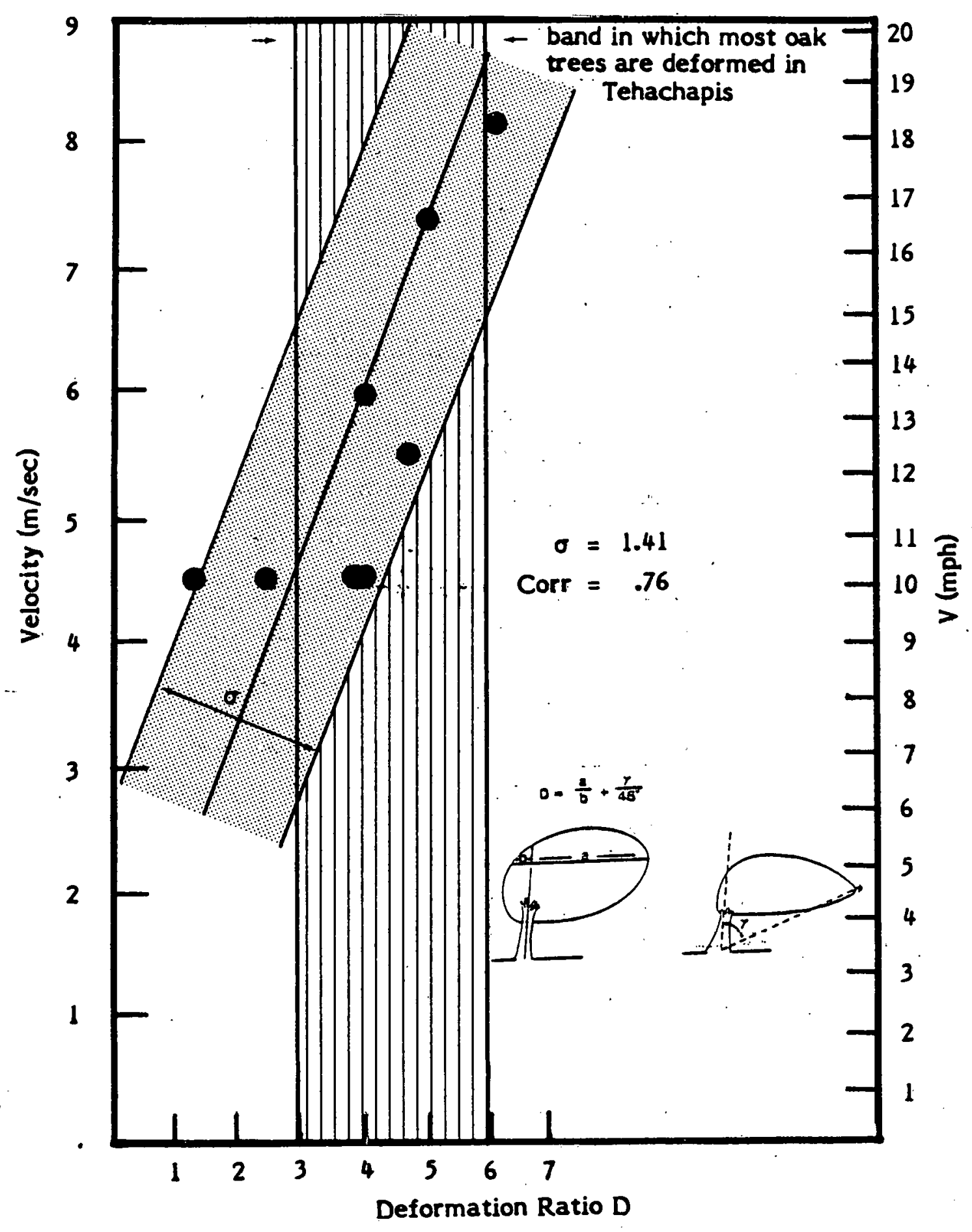

FIGURE 34. Comparison of Calculated Deformation Ratio (D) for California Oak with estimated annual wind speeds derived from six-month measurement program in the Tehachapis. 


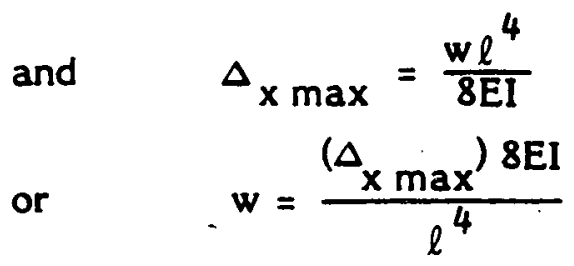

now for wind loading, the pressure of wind at different velocities is

$$
w=1 / 2 \rho v^{2}
$$

so

$$
\left.V=\left[\frac{\left(\Delta_{x \max }\right)^{16 E I}}{\rho \ell^{4}}\right]\right]^{1 / 2}
$$

This shows that the deflection of a beam is not linearly related to the wind velocity and is dependent on the beam length $\ell$. The same would be expected for tree deformation, but to a much greater degree because unlike the continuous vertical beam the tree will have a moment of inertia which would be varying with height, and the total force on the tree would be nonuniform.

A second factor is the comparative bending moment on a tree caused by wind and by snow or ice loading. Since the density of water is about 800 times that of air, the bending of branches caused by snow and icing may have greater effect than even violent wind loading on tree deformation. Figure 38 shows photographs of the same grove of California oaks during winter and spring. The severe deformation of the trees' top branches appears to be caused by the snow and ice loading. Wind forces are generally treated as deflecting a tree in the along-wind direction. Ice and snow loading however can be transmitting torsion loads on the tree and, in effect, cause warping. In the summer California oaks grow a dark, dense leaf covering which results in their characteristic oval appearance. The severity of the branch system bending or warping is then very difficult to detect from any far distance or photograph.

Because of these factors, it is recommended that a thorough analysis of the mechanics of tree deformation be done. This can be done in conjunction with a field program for obtaining tree data - which would include a systematic method for measuring tree height, solidity (summer and winter), circumference and along-wind and cross-wind eccentricity as well as other parameters which may relate to the mechanics of bending. 

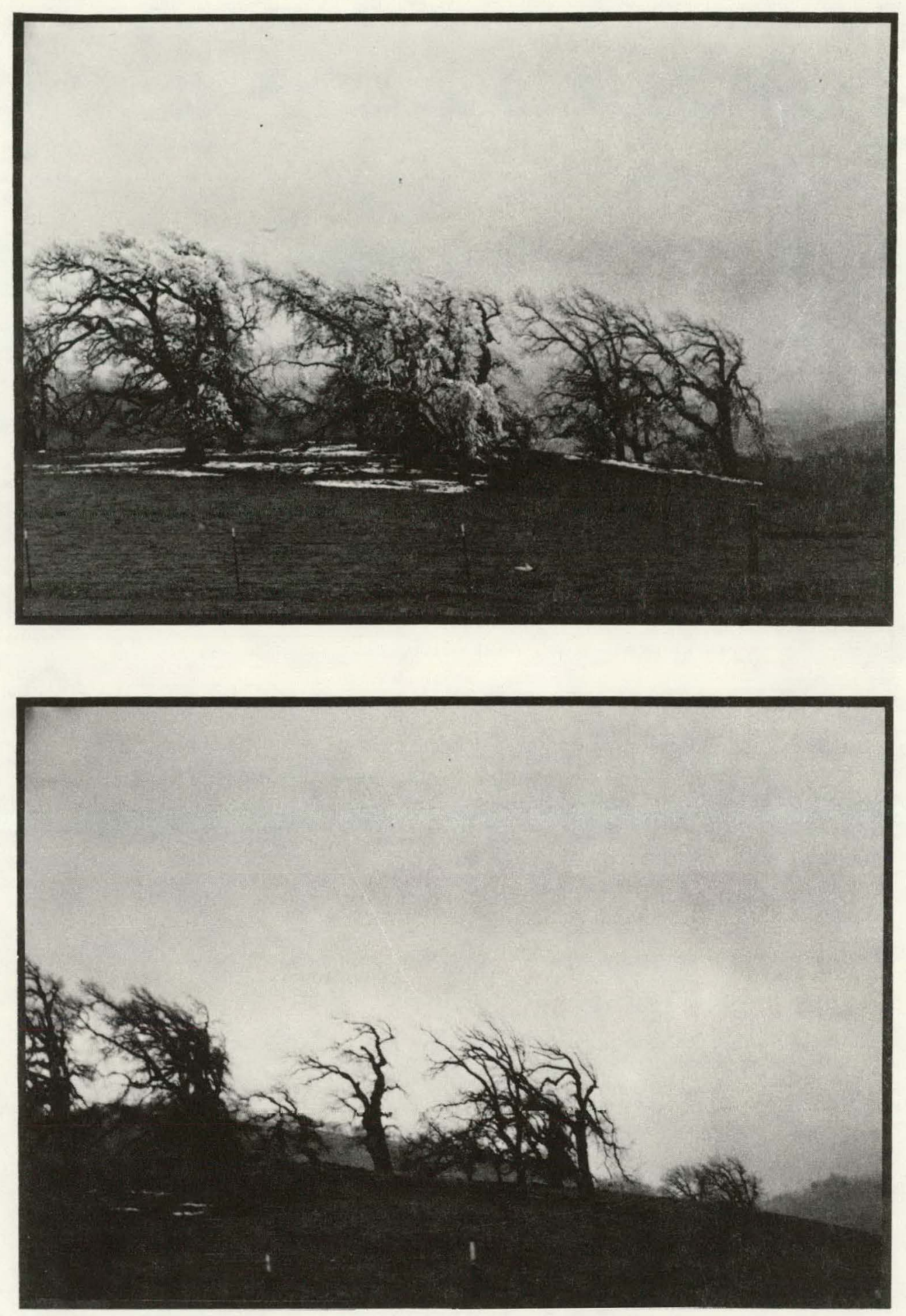

FIGURE 38. Identical trees in the study region during winter and early spring. 


\section{THIS PAGE WAS INTENTIONALLY LEFT BLANK}




\section{CONCLUSIONS AND RECOMMENDATIONS}

The general scope of work performed was to conduct a wind-site survey in the Tehachapi Mountain region; select, procure, and assemble the instrument systems and associated equipment for the monitoring program; conduct a six-month measurement program and reduce the meteorological data as one-hour averages and joint-frequency distributions of velocity and direction as applicable; analyze the data from the monitoring program in terms of wind-power statistics; and compare the monitoring program data with the field assessment data.

The task of wind-energy assessment in complex terrain requires an observational method for the initial screening and for the evaluation of potential WECS sites. The method employed in this program produced a detailed basic study of where WECS development should be further pursued. On the positive side, the combination of several survey techniques such as short-term measurements, vegetation indices, and site serviceability generated the desired criteria for selection of monitoring sites. The verification of the field assessment by actual instrumentation was governed by the level of effort of the project, but was sufficient to provide a basic comparison of the initial field survey results and documentation of the flow field and wind-energy flux.

There were no severe problems encountered with the operation of the field assessment program or subsequent data acquisition, al though several recommendations for improvements were discussed in previous chapters. A summary of these recommendations follows.

The TALA systems are a reliable, portable, wind-energy assessment device for remote regions. Horizontal velocity profiles over the surrounding terrain at the $50-\mathrm{m}$ level should be taken as often as possible and coordinated with simultaneous measurements taken with other TALA systems at adjacent ridgèlines. TALA measurements should be made with every station check during the study period. In times of low winds during station checks, deformation ratios for vegetation should be more extensively surveyed and logged. 
There is a need for refinement of the velocity correlation relations of tree deformation ratios. Data obtained from this survey should be viewed with caution because of the large scatter. Further research into the mechanics of tree bending can result in a more systematic method for obtaining a tree deformation index.

Sites identified from a preliminary survey as having a potential wind-speed annual average greater than $14 \mathrm{mph}$ near the surface should be monitored with stations having wind-speed and wind-direction capabilities. The amount of effort needed to acquire data from remote regions should outweigh the additional cost of instrumentation. Wind direction can be taken as simply as an instant reading over a given time period (one hour) and be very. useful in defining local flow fields for strong wind conditions, and would enable further analysis of wind power output. Sites identified from a preliminary survey as having a potential wind-speed annual average of less than $14 \mathrm{mph}$ can be costeffectively monitored with stations capable of obtaining integrated monthly averaged wind speed data.

One year's field monitoring is recommended for any wind-energy assessment program. After six months sufficient amount of information is obtained to generate an accurate interim assessment which can assist planners in WECS development as a potential energy system. As with any large-scale engineering project, there are additional specific questions which are to be addressed as the scope of the program becomes more hardware-oriented. This report introduced preliminary information on environmental issues, power estimates, and machine selection and array planning. Each of these areas will need immediate study as the next phase of WECS development and can be considered after the first six months of field monitoring.

On the basis of the insights gained during the course of this program, we conclude that with improvement of the vegetation indices and additional field experience with TALA systems, this program for assessing a local wind field consitutes a reliable, costeffective technique for WECS siting in complex terrain. 


\section{REFERENCES}

Baker, R.W., and J.E. Wade (1978): Wind field survey in Southern California. California Energy Commission, March.

Baker, R.W., R.L. Whitney; and E.W. Hewson (1979): A low level wind measurement technique for wind turbine generator siting. Oregon State University.

Barsch, D.W. (1963): Baumform and Lanschaft: Eine Untersuchung dew Windeinflusses auf Baumform and Kulterland Schaft am Berpiel des Mistralgebutes im Franzosischen Rhonetal. In Frieburger Geographische hefte, Heft 1 edited by F. Bartz and W. Weischet.

Cliff, W.C. (1977): The effect of generalized wind characteristics on annual power estimates from Wind Turbine Generators. U.S. Department of Energy, PNL-2463/UC-60.

de Vries, O. (1979): Fluid dynamics aspects of wind energy conversion. AGARDograph No. 243. NATO

Franson G. (1979): A study of inversion and mixing heights at Fresno, California. National Weather Service, Fresno, California.

Grant, L.O., C.F. Chappell, L.W. Crow, J.M. Fitch, and P.W. Mielke Jr. (1969): Weather modification -- A pilot project in the San Juan Mountains, Colorado River Basin. Final report -- February 1974, Bureau of Reclamation, Contract No. 14-06-D-6467.

Hewson, E.W., J.E. Wade, and R.W. Baker (1977): Vegetation as an indicator of high wind velocity. Oregon State University, ERDA Contract EY-76-2226.

Justus, C.G., W.R. Hargraves, A. Mikhail, and D. Graber (1978): Methods for estimating wind speed frequency distributions. J. App. Met., Vol. 17, No. 3, March, p. 350.

Lindley, C.A. (1977): Wind machines for the California Aqueduct. The AeroSpace Corporation, U.S. Department of Energy SAN/1101-76/2.

Lissaman, P.B.S. (1979): Energy effectiveness of arrays of wind turbines. AIAA 79-0114R, J. of Energy, Vol. 3, No. 6, November, p. 323.

Popov, E.P. (1952): Mechanics of materials, Prentice-Hall Inc., Englewood Cliffs, N.J.

Putnam, P.C. (1948): Power from the wind. Van Nostrand.

Smagorinsky, J. (1953): The dynamical influence of large-scale heat sources and sinks on the quasi-stationary mean motions of the atmosphere. J. of Roy. Aeron. Soc., Vol. 79.

Traci, R.M. and G.T. Phillips (1979): Wind prospecting in regions of complex terrain. Science Applications Incorporated. La Jolla, California. 
U.S. Weather Service (1977): California Air Resources Board-Air Quality Data. JanuaryMarch 1978, p. 14.

Wade, J.E., E.W. Hewson (1979): Trees as a local climatic wind indicator. J. of App: Met., Vol. 18, No. 9, September, p. 1182.

Weise, J.H. (1950): Geology and mineral resources of the Neenach Quadrangle, California. State of California Department of Natural Resources - Division of Mines. Bulletin 153.

Zambrano, T.G., S.N. Walker, and R.W. Baker (1980): Wind energy assessment of the Palm Springs - Whitewater Region. AeroVironment Inc., Pasadena, California. 


\section{APPENDIX A}

\section{Site Photographs}




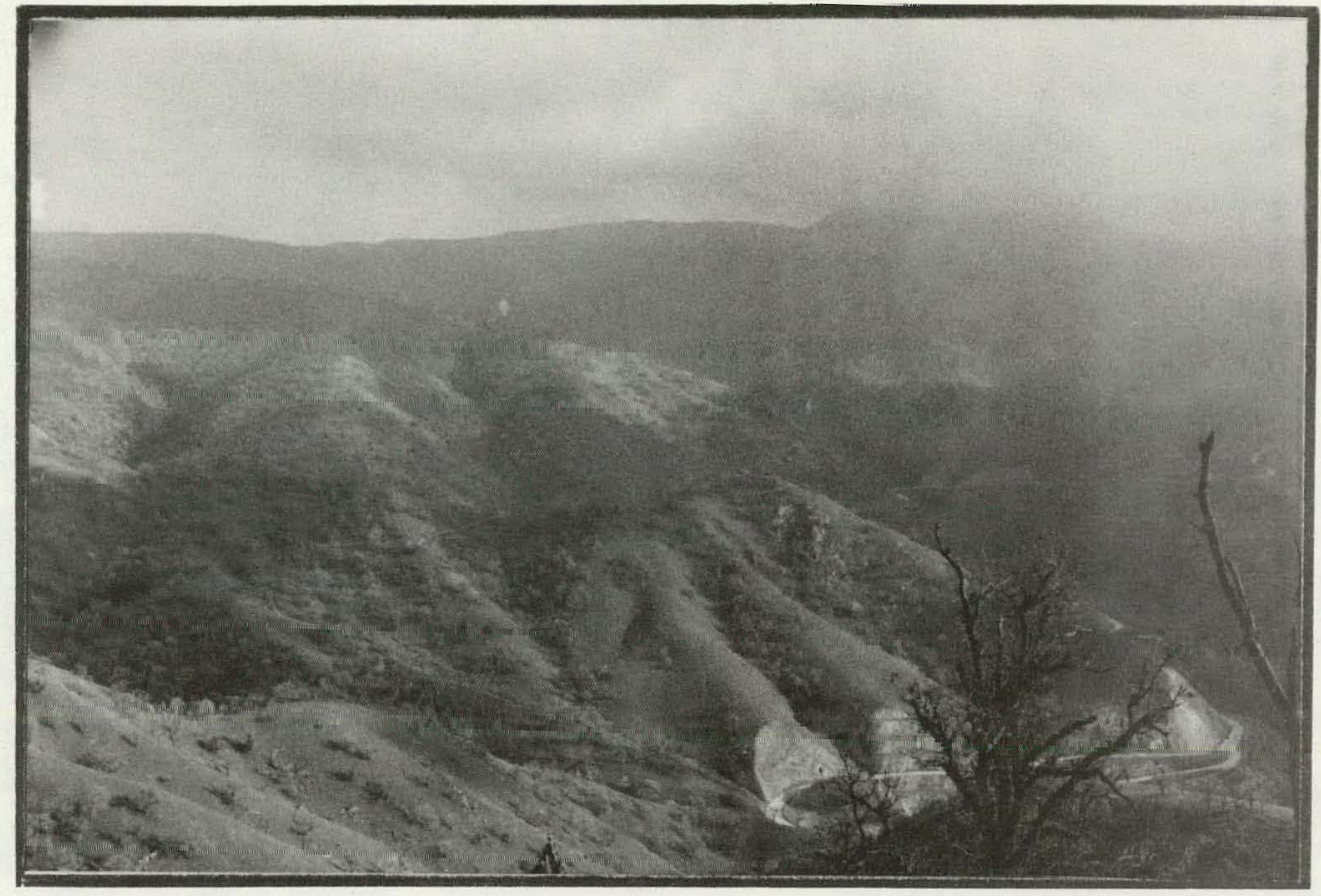

A1: View from AV Station 8 on Tunis Ridge looking south into Pastoria Creek Arroyo.

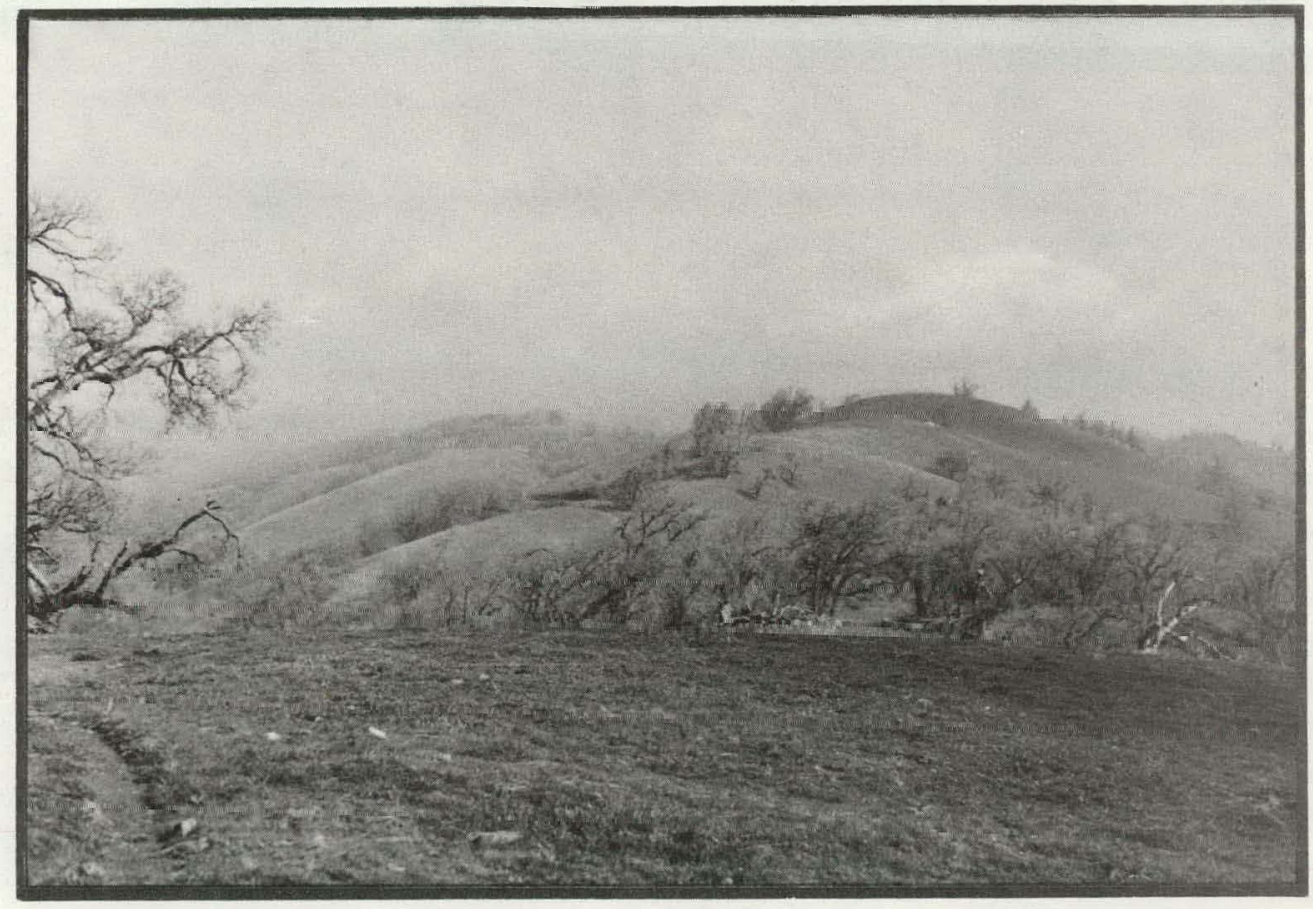

A2: Rolling terrain of Tunis Ridge near AV Station 8, looking northeast toward AV Station 1. 


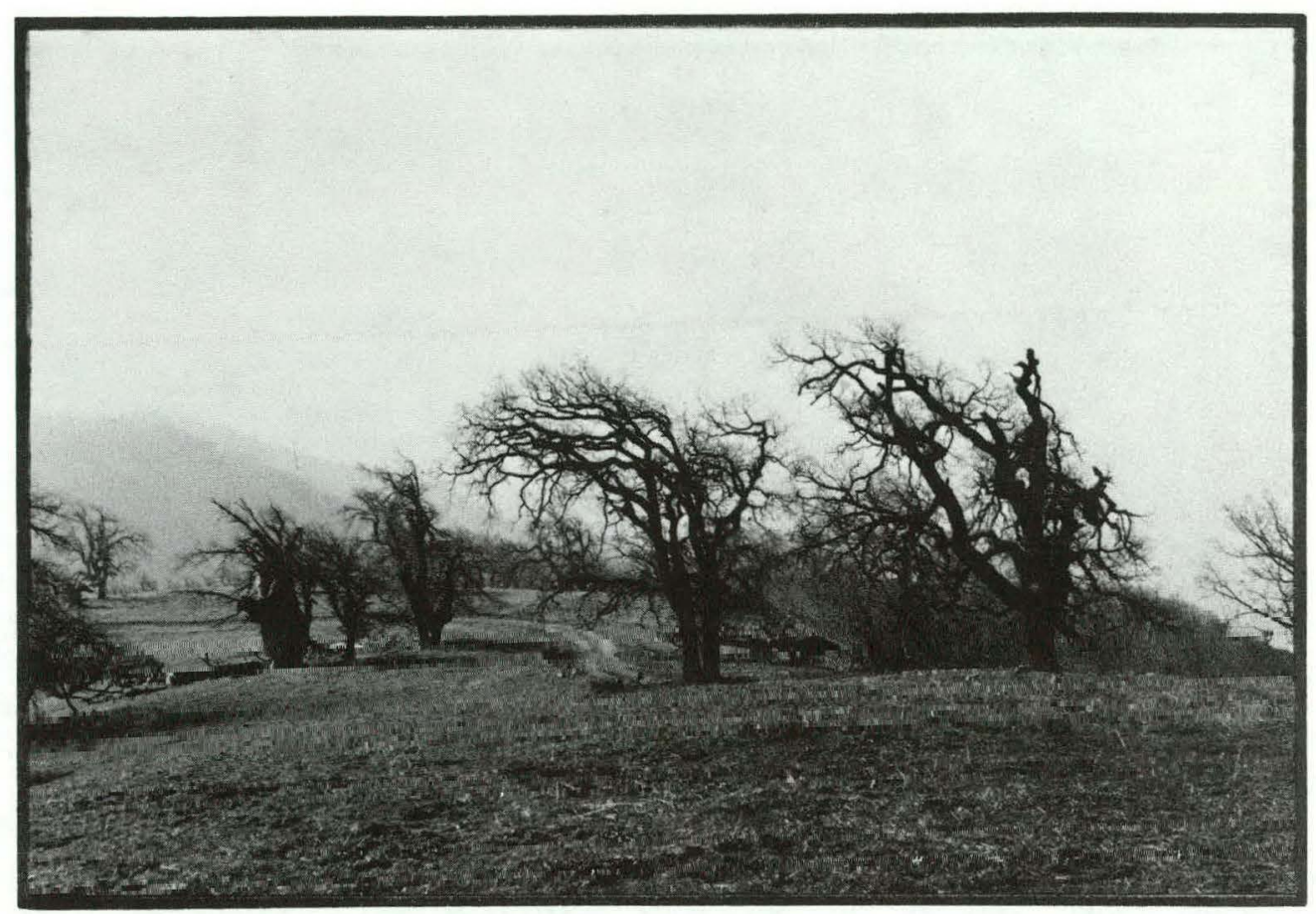

A3: Looking back (southwest) towards AV Station 8 from AV Station 1 on Tunis Ridge.

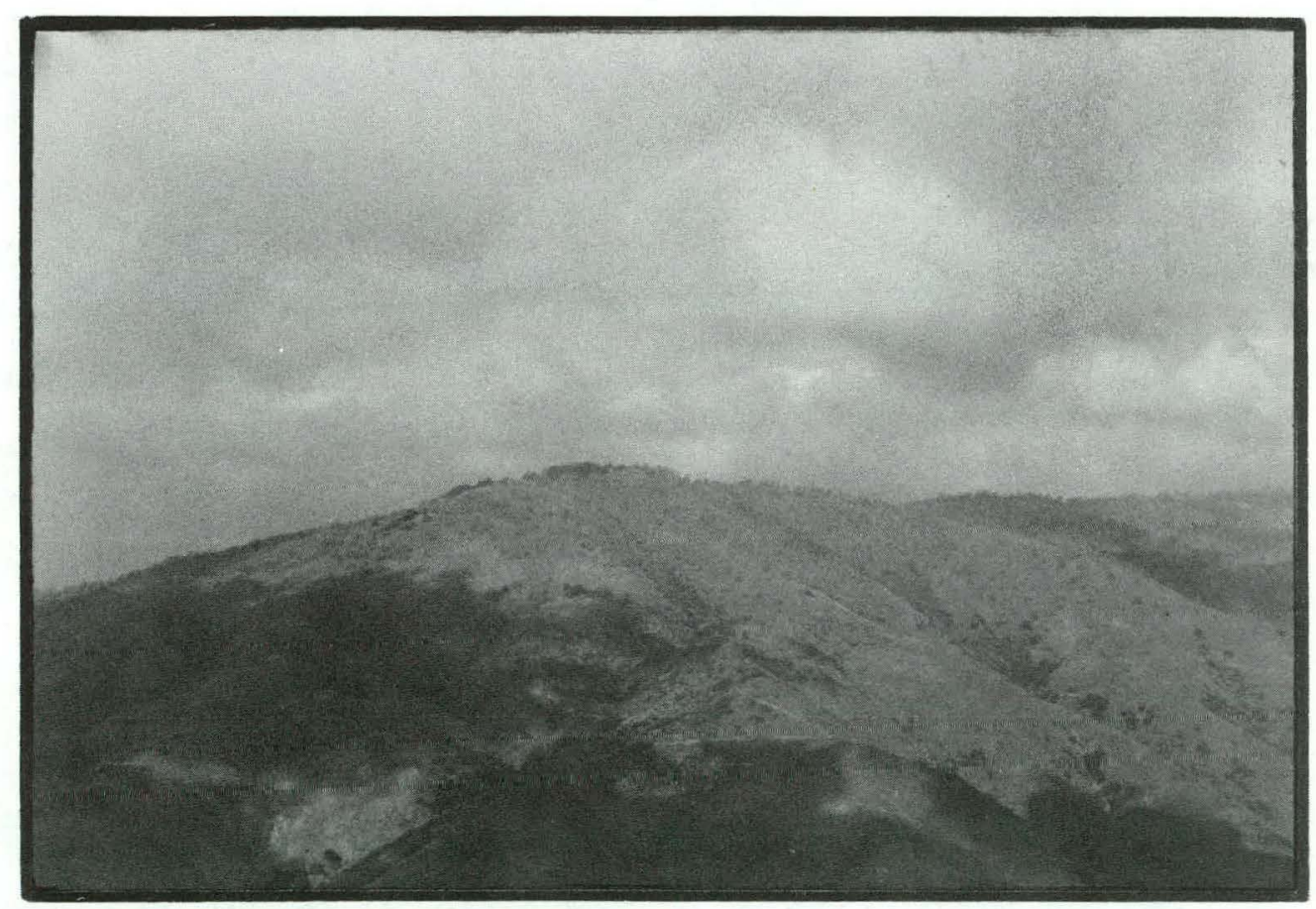

A4: View from AV Station 1 on Tunis Ridge looking north towards Winters Ridge and AV Station 3. 


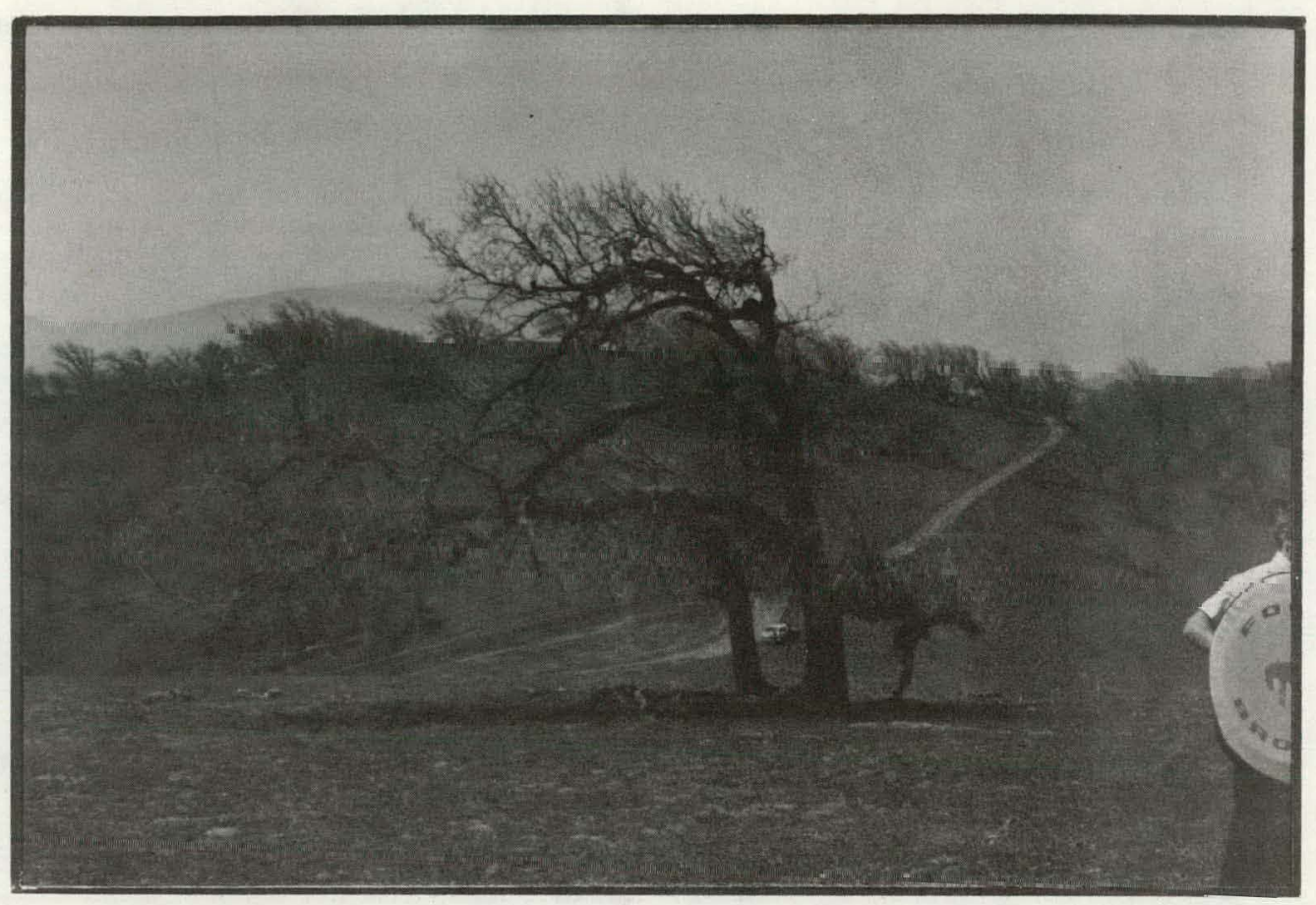

A5: View from AV Station 7 (Tunis-Geghus) looking down road (west) towards Geghus Ridge (AV Station 6).

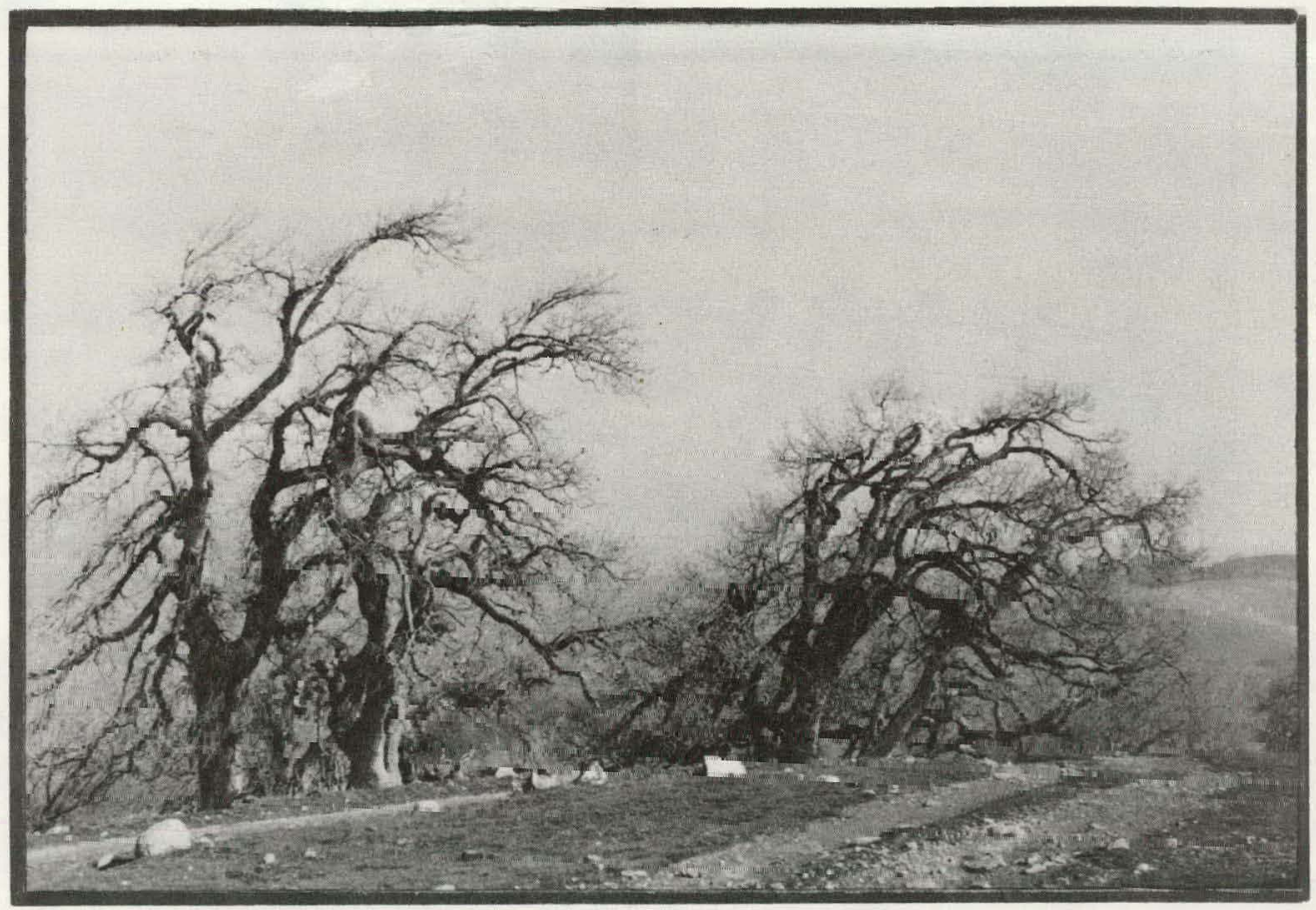

A6: Flagged trees on Geghus Ridge looking northeast from AV Station 6 towards AV Station 7. 


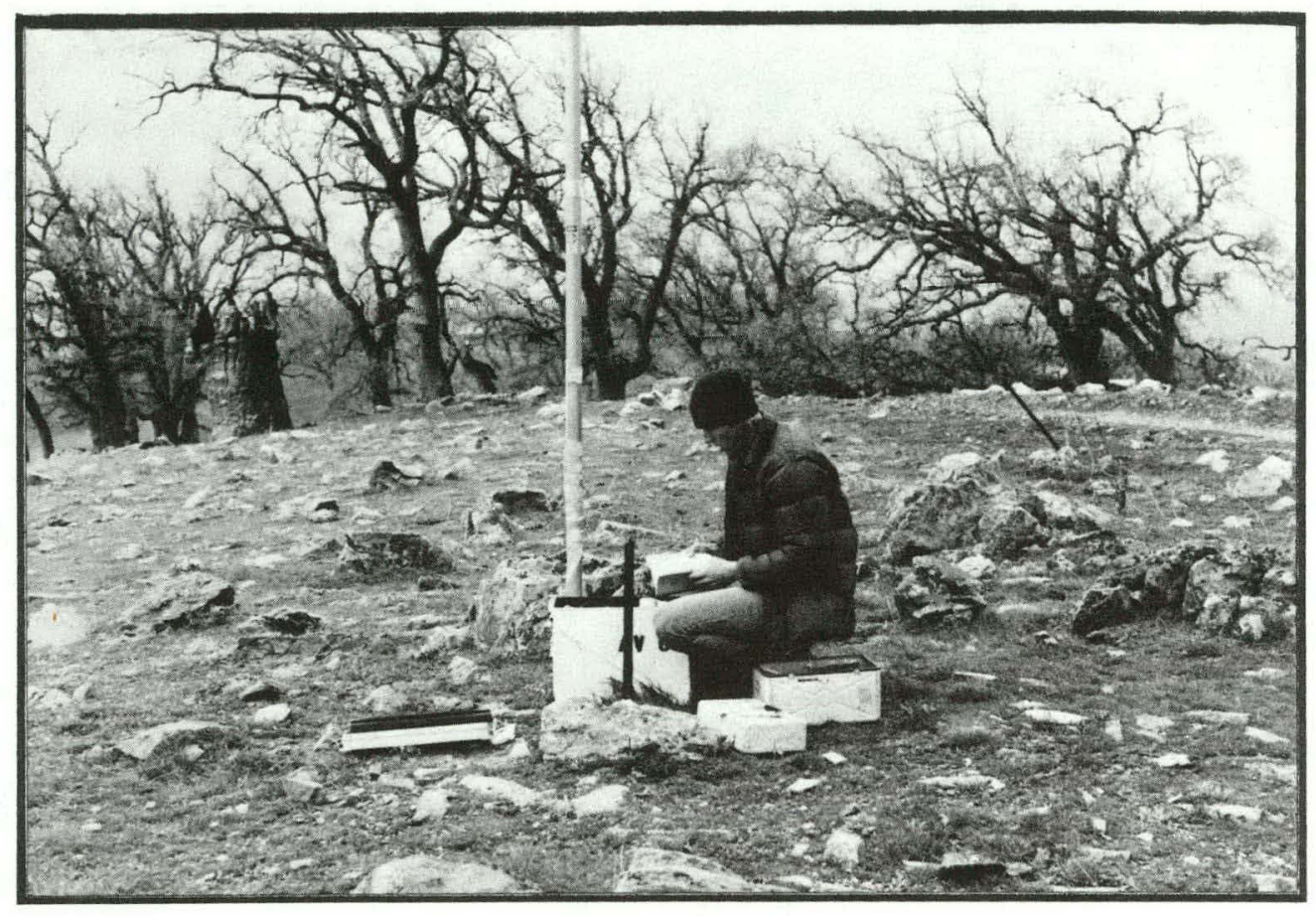

A7: Site check at AV Station 6 (Geghus Ridge).

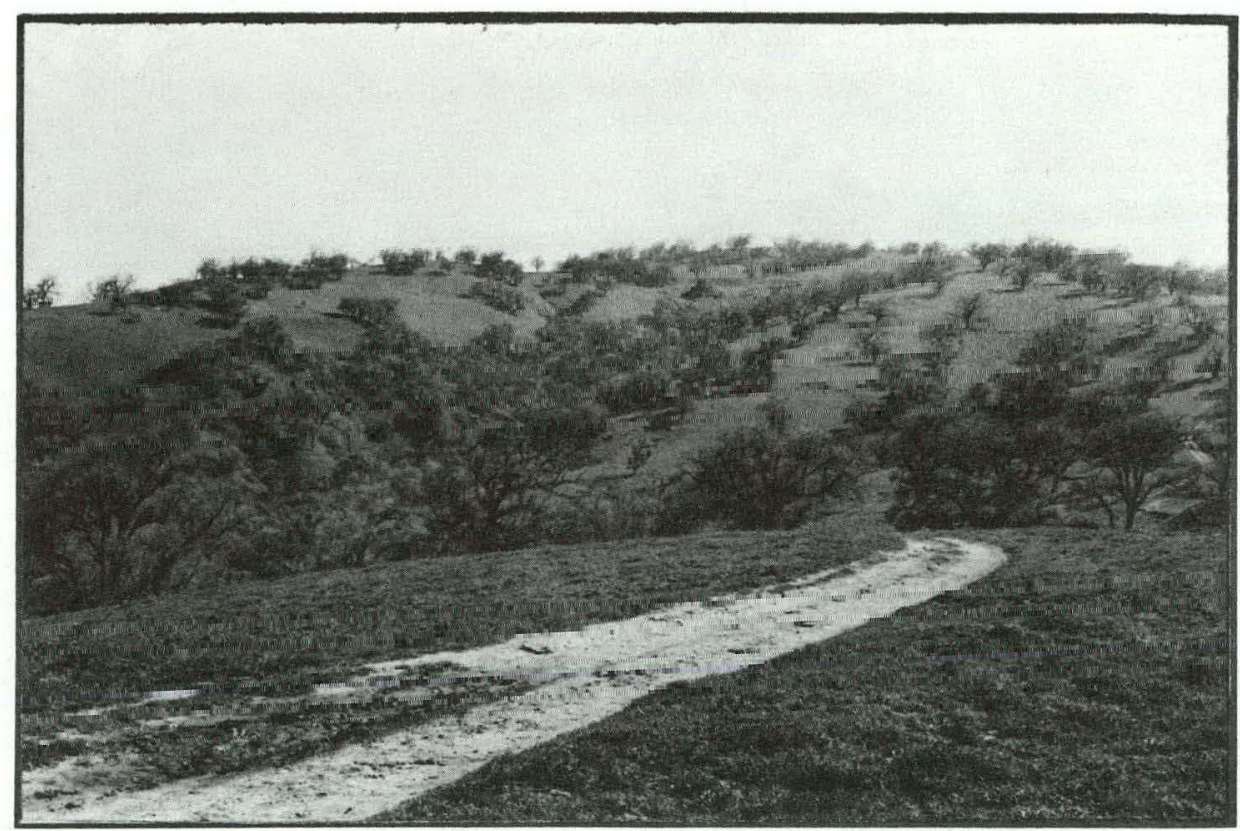

A8: Southern end of Geghus Ridge looking northeast towards AV Station 6. 


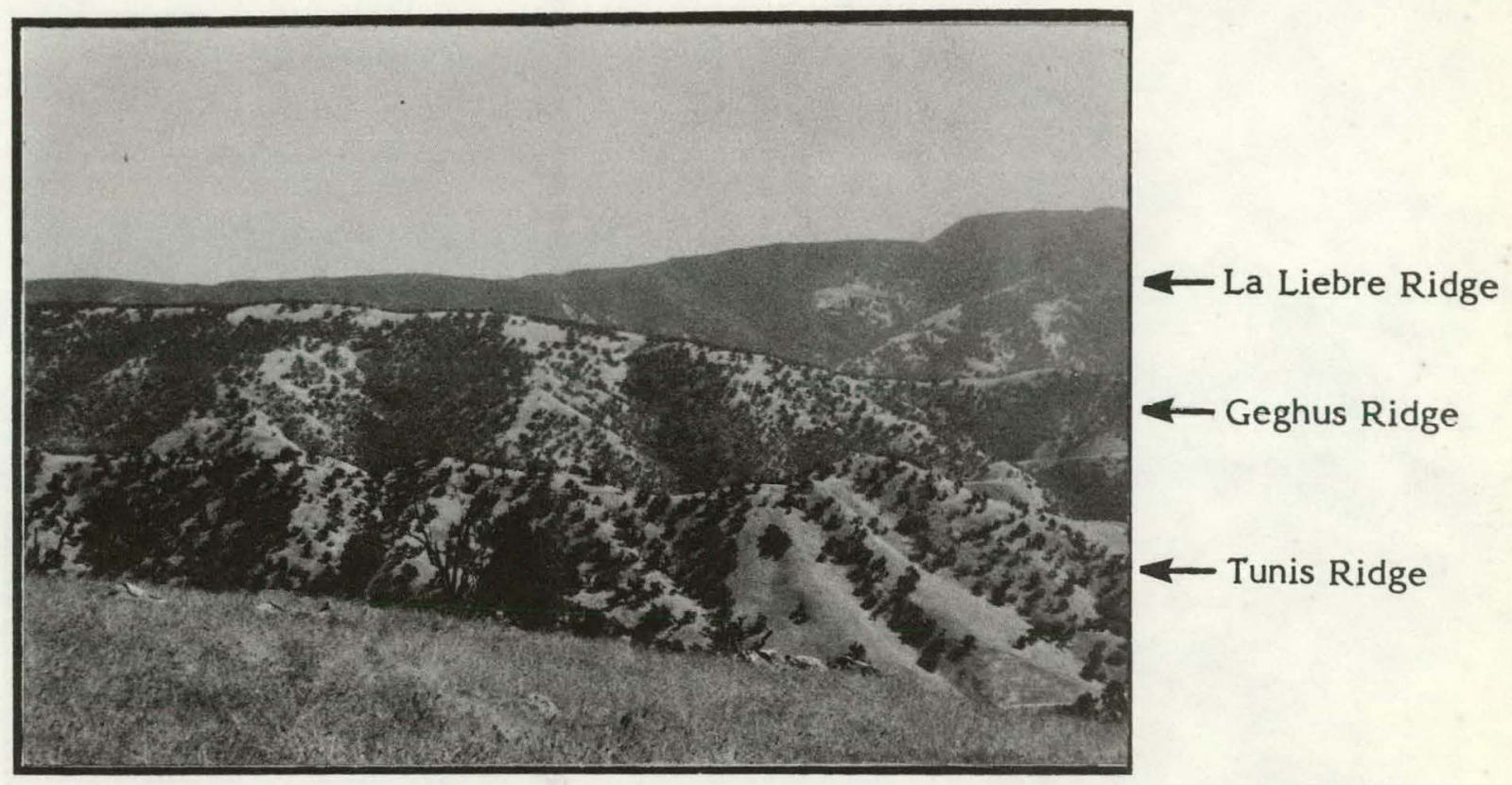

A9: Ridgelines of the study region looking south from Winters Ridge.

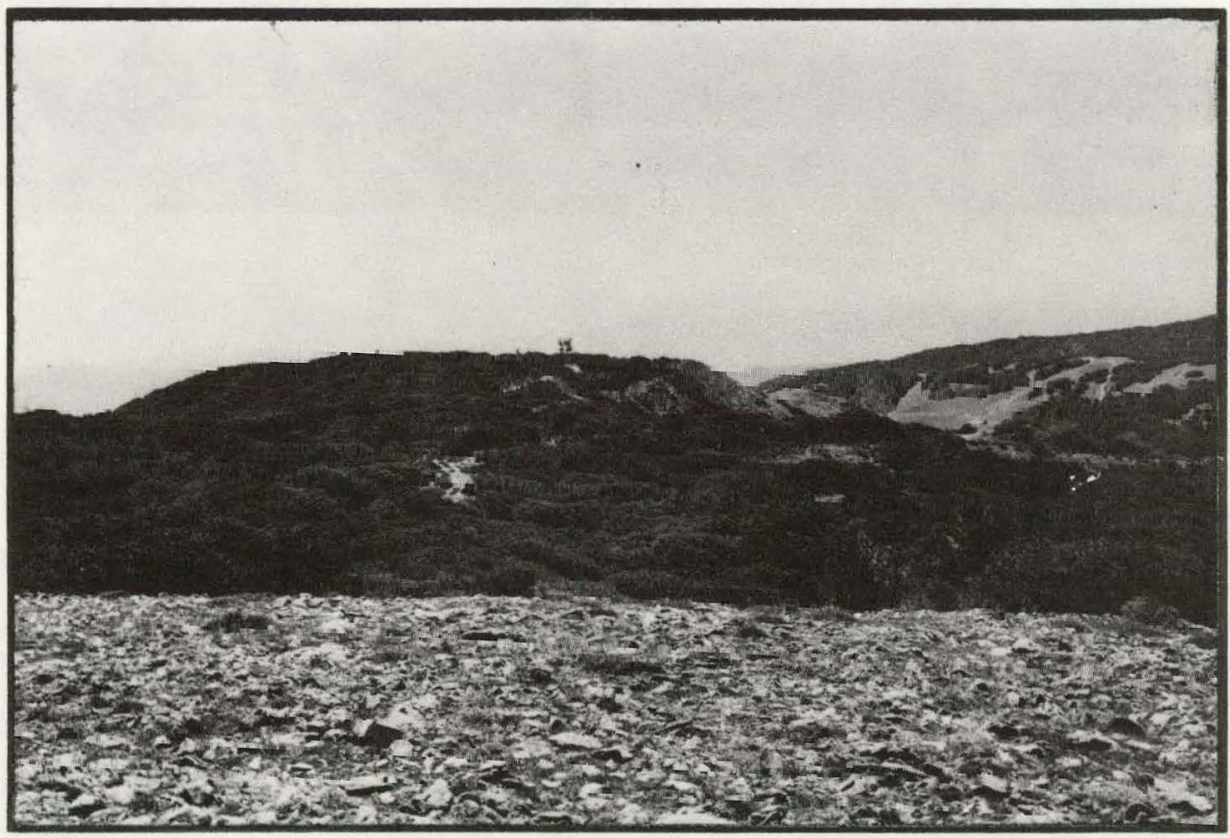

A10: Flat plateau of AV Station 9 (La Liebre Ridge) looking southwest towards microwave tower. 


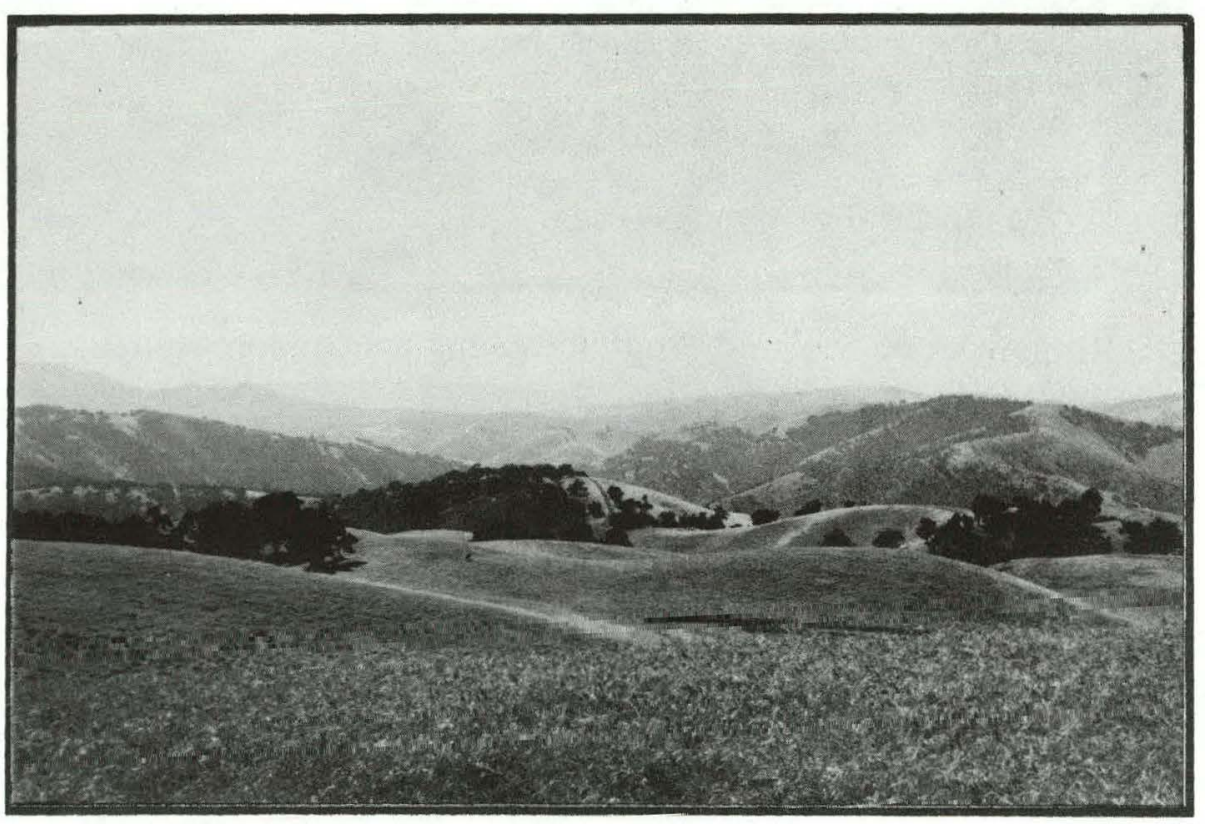

A11: Typical rolling terrain of Grapevine Hill. 
APPENDIX B

Wind Data Summary 
TABLE B-1. Total hours of published data for Tehachapi sites (May 1979 - November 1980).

\begin{tabular}{|l|r|r|r|r|r|r|r|r|c|}
\hline & May & June & July & Aug & Sep & Oct & Nov & Total & Percent \\
\hline \hline Site 1 & 139 & 540 & 744 & 744 & 656 & 512 & 422 & 3,618 & $76 \%$ \\
Site 2 & - & - & 318 & 456 & 582 & 201 & 686 & 2,243 & $61 \%$ \\
Site 3 & - & - & 158 & 744 & 715 & 707 & 662 & 2,986 & $81 \%$ \\
Site 4 & 714 & 720 & 684 & 631 & 720 & 741 & 720 & 4,930 & $96 \%$ \\
Site 5 & - & - & 154 & 731 & 425 & 202 & 720 & 2,232 & $61 \%$ \\
Site 6 & - & 542 & 744 & 744 & 573 & 711 & 720 & 4,034 & $92 \%$ \\
Site 7 & - & - & 299 & 744 & 720 & 744 & 720 & 3,227 & $88 \%$ \\
Site 8 & - & - & 156 & 696 & 559 & 470 & 720 & 2,601 & $71 \%$ \\
Site 9 & 709 & 720 & 744 & 378 & 563 & 686 & 720 & 4,520 & $88 \%$ \\
Site 10 & - & - & -- & - & - & -- & - & - & - \\
\hline Percent & $70 \%$ & $88 \%$ & $60 \%$ & $88 \%$ & $85 \%$ & $74 \%$ & $94 \%$ & & $77 \%$ \\
\hline
\end{tabular}

* percentage data recovery is made by assuming that each station should be operating for the full month regardless of equipment malfunction, start date, site inaccessibility or animal damage. 


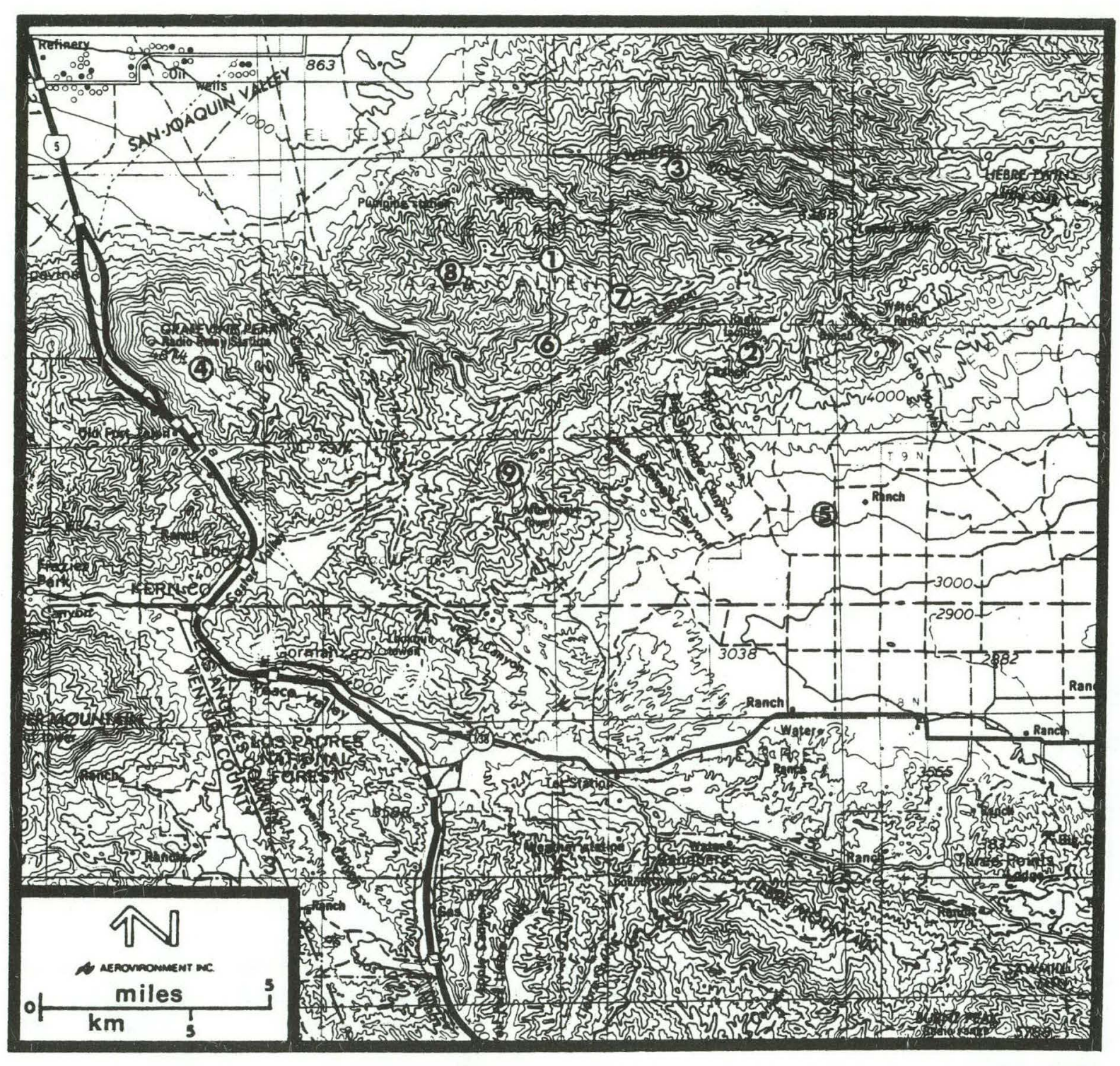

Station locations in the study area. 


\begin{tabular}{|c|c|c|}
\hline $\begin{array}{l}\text { Numerical } \\
\text { Entry Code }\end{array}$ & $\begin{array}{l}\text { Letter } \\
\text { Code }\end{array}$ & Description \\
\hline 900 & $\mathrm{CA}$ & Calibration (calibration, system check) \\
\hline 910 & MT & Maintenance ( changing paper, tape, charcoal) \\
\hline 920 & $\mathrm{FO}$ & Flame Out ( on the GC-THC, $\mathrm{HC}, \mathrm{CH}_{4}, \mathrm{CO}$ ) \\
\hline 930 & IM & Instrument Malfunction ( instrument failures ) \\
\hline 940 & PF & Power Failure (generator failure) \\
\hline 950 & RF & Recording System Failure ( chart jaris, runs out) \\
\hline 955 & NV & $\begin{array}{l}\text { Not Visible ( values were not within range of } \\
\text { instrument i. e. inver sion heights may exist beyond } \\
\text { the full scale of the Acoustic Radar) }\end{array}$ \\
\hline 960 & LI & Local Interference ( car nearby) \\
\hline 965 & OE & $\begin{array}{l}\text { Operator Error ( Field tech leaves switch in } \\
\text { wrong position out of } A V^{\prime} \text { 's control. ) }\end{array}$ \\
\hline 970 & OS & Off Scalc" ( at top of chart) \\
\hline 975 & IN & $\begin{array}{l}\text { Interference ( } \mathrm{CO}_{2} \text { interference on sulfur data, } \mathrm{SO}_{2} \\
\text { interference in oxidant readings) }\end{array}$ \\
\hline 980 & $\mathrm{SE}$ & Special Experiment \\
\hline 985 & OR & $\begin{array}{l}\text { Out for Repair ( instrument removed from site } \\
\text { with no replacement) }\end{array}$ \\
\hline 990 & $\mathrm{VA}$ & Variable Wind Direction \\
\hline 995 & CM & Calm ( no wind direction when wind speed $=0$ ) \\
\hline 998 & UN & Unlimited Ceiling ( reported by NWS Stations) \\
\hline 999 & & $\begin{array}{l}\text { Blank ( causes a space to be printed as in the } \\
\text { beginning of a new month before a component } \\
\text { starts) }\end{array}$ \\
\hline
\end{tabular}




\section{THIS PAGE \\ WAS INTENTIONALLY \\ LEFT BLANK}


WTNO SPEED ICCinIt

\section{MILES/HOUR}

LEVEL HEIGHT : 10 METERS
AATIEILF WINA STIIDY, HGOS

TEHACHAPI MTNS, CA.

SITE

MAY, 1979

AFROVIRONMFNT INC.

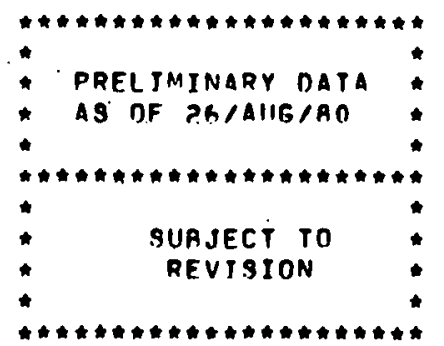

CLOCK HOUR ILNCAL STANDARO TIMES 
WTNR SPFFO rerinI

MILES/HOISR

LEVEL HEIGHT : 10 METERS
PATTFLIE WINN STIUYY H5NG TEHACHAPI MTNS, CA.

SITE

JUN, 1979

AFROVIRONMENT INC.

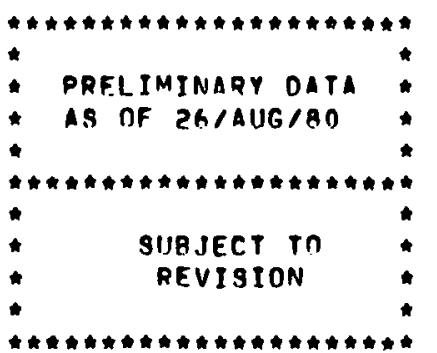

CLOCK HMIIR LLOCAL STANDARD TIMF]

no

01

02

03

04

$n 6$

07

DA 00

10

$11 \quad 12$

13

14

15 Ih

17

Iค

19

20

21

22

23

AVE PEAK

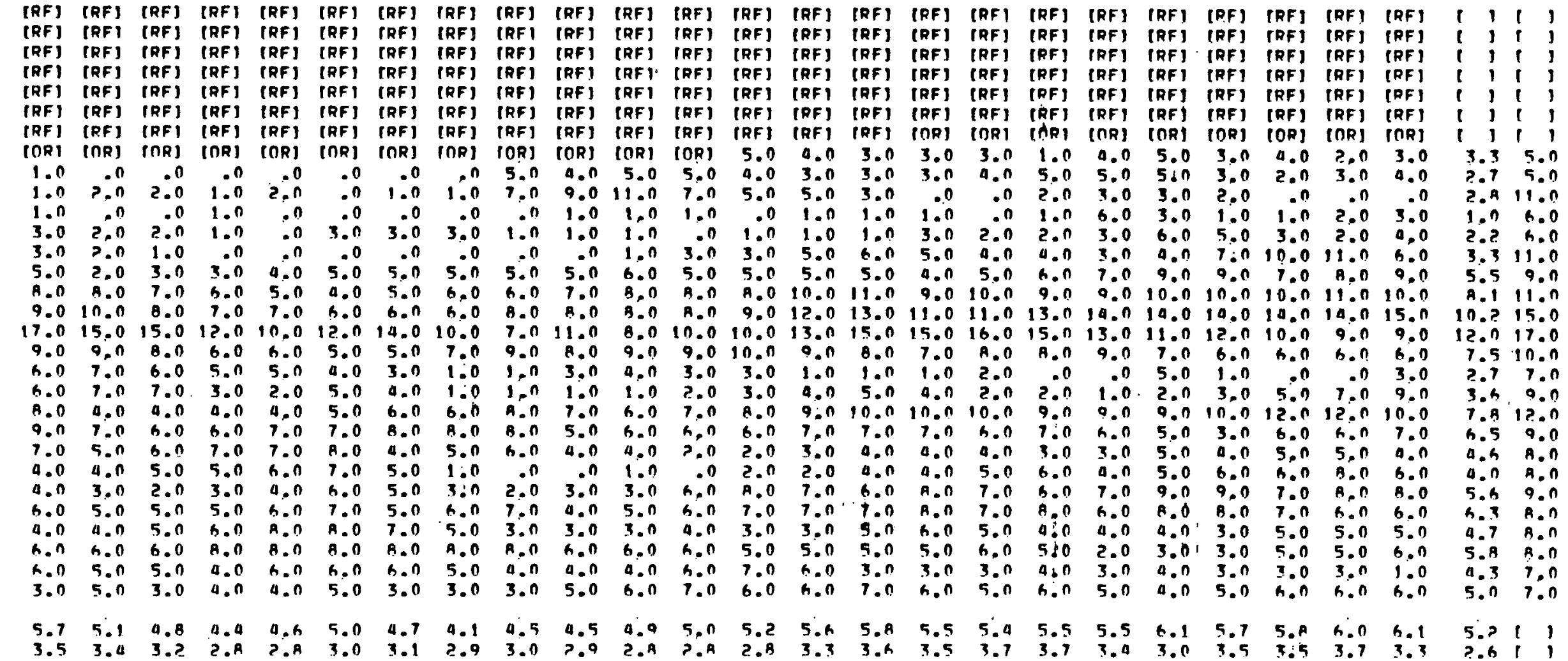


WINA SPFEn [Cring]

MILES/HOUR

LF.VEL HEIGHT : 10 METERS
AATTFILF WINI STIINY, W505

TEHACHAPI MTNS, CA.

SITE $I$

JIL .1979

AERT.VTRANMENT INC.

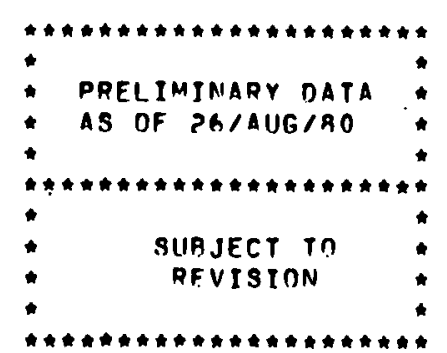

CLOCK HOIIR ILOCAL STANDARD TIME]

$3.57 . n$ $.9 \quad 0.0$ 4.a 12.n h.1 in.n 6.810 .0 $2.5 \quad 8.0$ 5.59 .0 1.45 .0 0.010 .0 0.015 .0 3.37 .0 $1.5 \quad 4.0$ 2. 0 a.n 1.53 .0 3.411 .0 6.319 .0 11.8210 7.97 .0 $5.0 \quad 9.0$ 7.311 .0 5.A 10.0 3.67 .0 5.A 13.0 7.A 10.0 $6.99 . n$ h.o 0.0 2.n a.n $5.1+1$ $? .511$ 
WTNR SPEEN [Crini]

MILES/HOUR

LEVEL HETGHT i' 10 METFRS
PATTELLE WIND STIINY, \#SAS

TEHACHAPI MTNS, CA.

SITE

116, 1979

AEROVIRONMFNT INC.

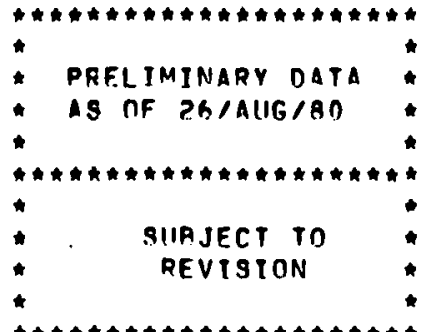

CLOCK HOLR ILOCAI. STANDARN TIMEJ

11.0 4.37 .0 4.9 .. 2.96 .0 25. 3.3 ค. a. 1.0 $3 . n$ ค. . 2.0 0.0 5.310 .0 a.n 10.0 6.9 10. . 1.03 .0 $.9 \quad 3.0$ 2.A A. 0 $4.0 \quad 10.0$ 4.310 .0 $3.7 \quad 3 . n$ 5 . 10.0 b.a 12.0 9.513 .0 A.3 11.0 5.B 9.0 3.39 .0 5.79 .0 4.0 . 0

4.711 3.01 
WINR SPEEn treinil

MILES/HOUR

LEVEL HEIGHT: 10 METERg
RATTELLE WINO STURY. $\$ 505$

TEHACHAPI MTNS, CA.

SITE

SEP. 1979

AEROVIRONMENT TNC.

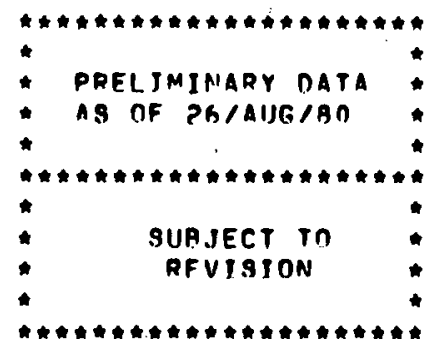

Clock hMUR [LDCAL STANDARN TIME)

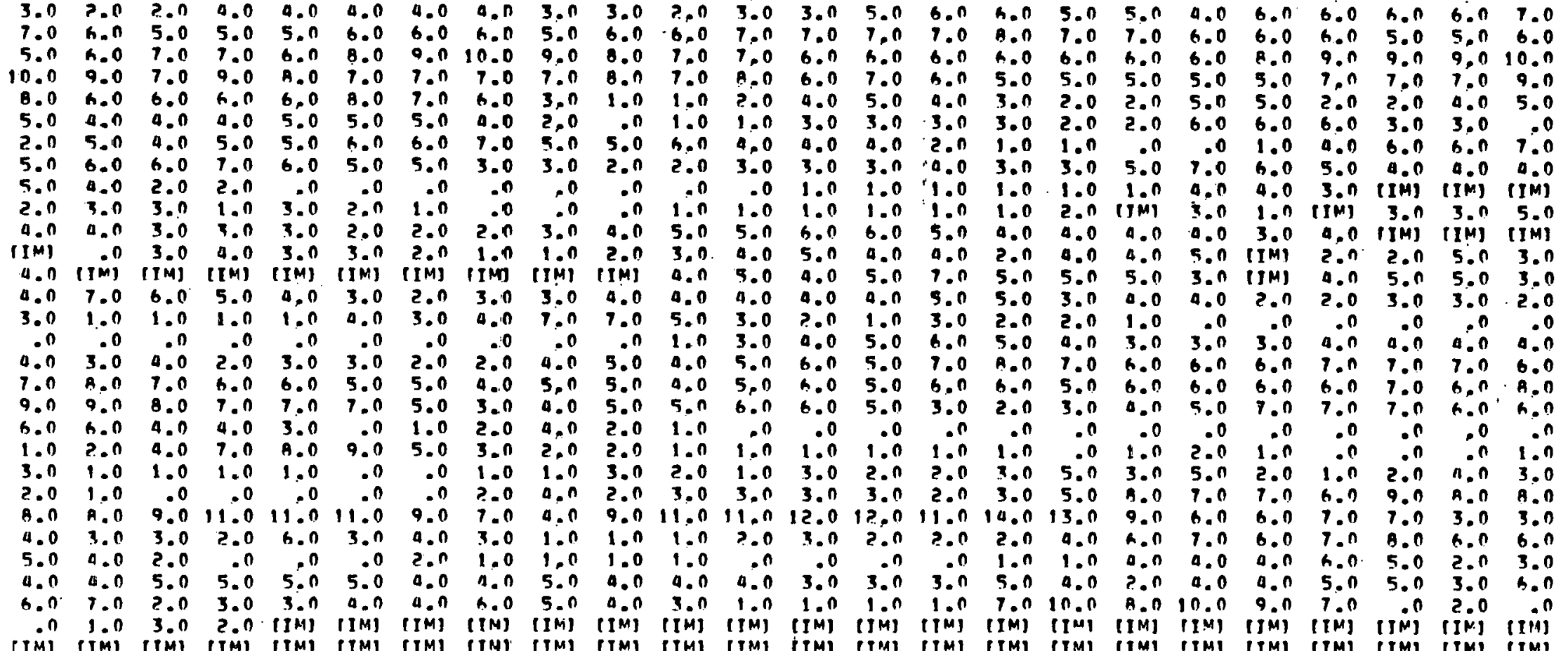

a. 7.0 6.1 2.0 $1.3 \ln .0$ 0.30 .0 $3.3 \quad .0$ $0.07,0$ a.3 $7 . n$ 1.45 .0 1.79 .0 3.0 $a-67.0$ 3.50 3.17 .0 2.26 .0 5.08 .0 5.B R. 0 .7 .0 .0 2.39 .0 2.15 .0 3.69 .0 B. 14.0 3.A A.n ?. $n$ h.n 4.? 6.0 4.310 .0

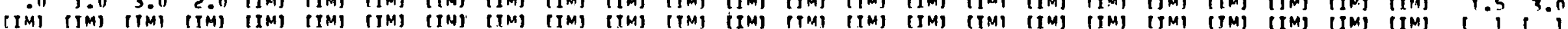

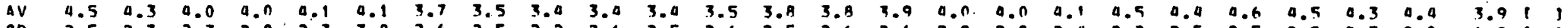
aOnUT 111 maY 791 
WTND SPEEN IrCinil

MILES/HOIIR

LEVEL HEIGHT: 10 METERS
BATTFLLE WTNA STIIDY.HSOS TFHACHAPI MTNS. CA.

SITE

OCT. 1979

AEROVIRONMENT INC.

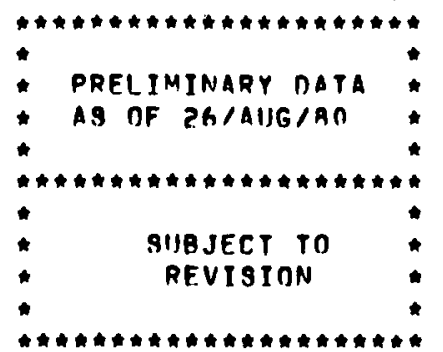

CLOCK HOIR ILOCAL STANDARD TIME]

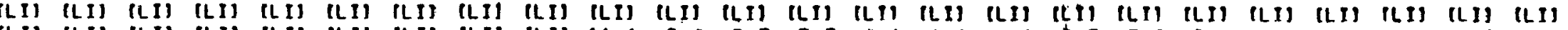

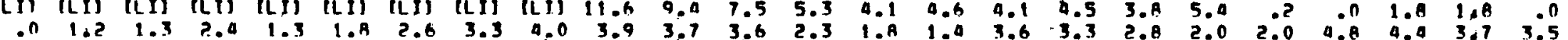

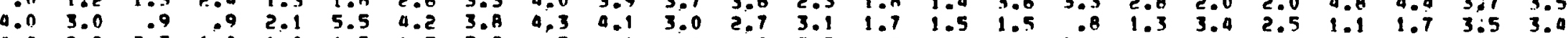

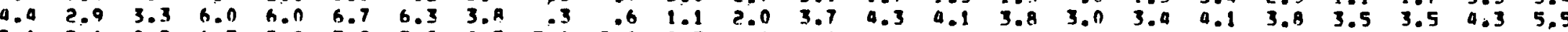

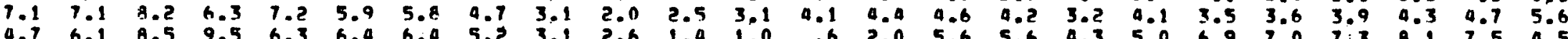

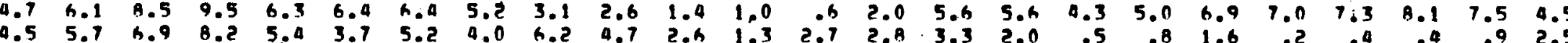

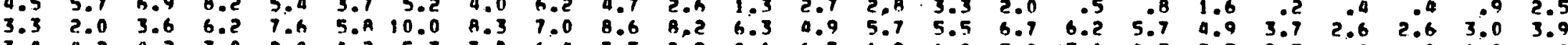

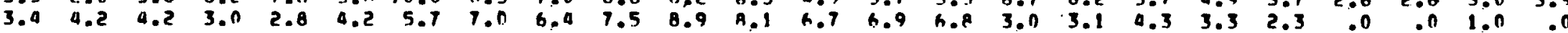

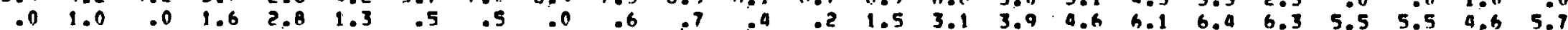

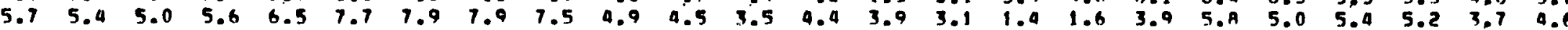

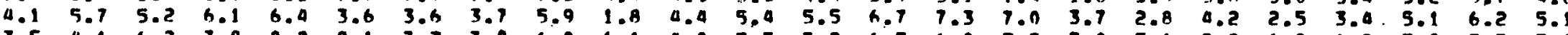

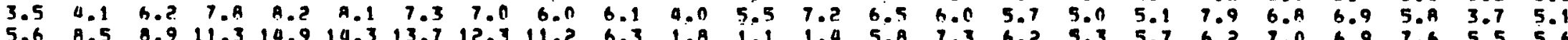

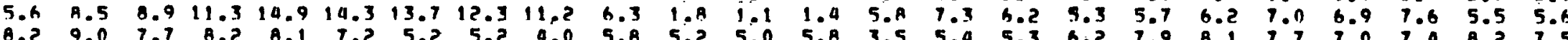

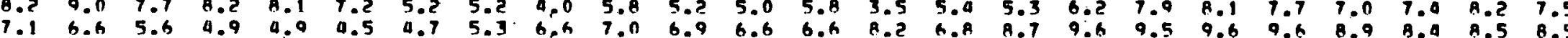

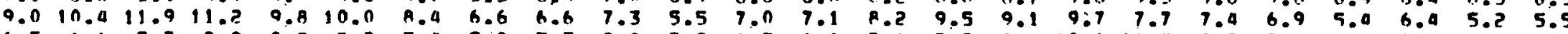

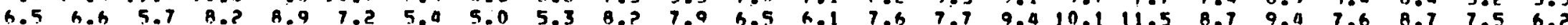

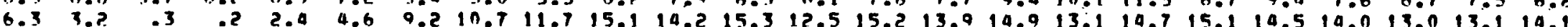

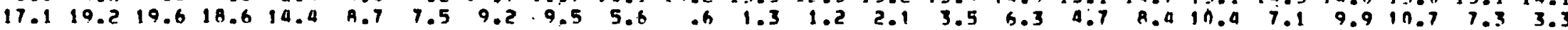

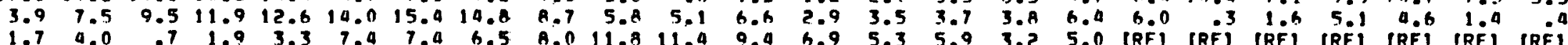

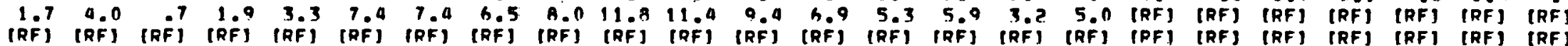
[RF] [RF] [RF] [RF] [RF] [RF] [RF] [RF] [RF] [RF] [RF] [RF] [RF] [RF] [RF] [RF] [RF] [RF] [RF] [RF] [RF] [RF] [RF] [RF]

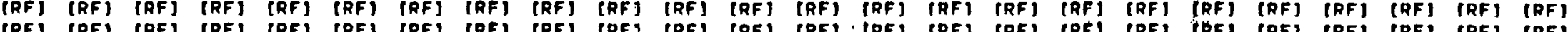

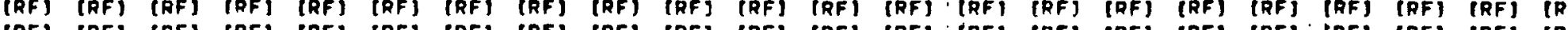

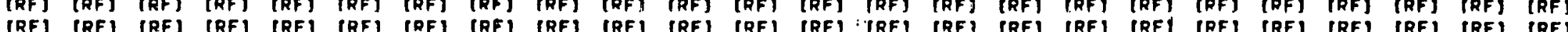

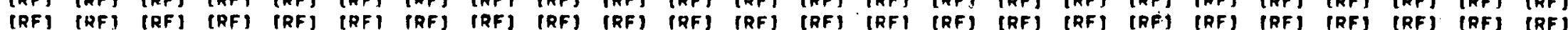

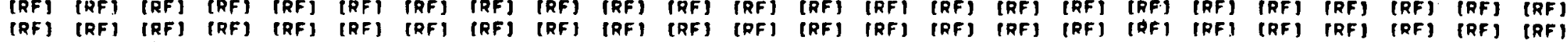

111 4.311 .6 $2.7 \quad 0.8$ 2.75 .5 $3.8 \quad 6.7$ 4.7 ค.? 5.? 9.5 3.52 .5 5.510 .0 4.39 .9 2.6 h. 5.07 .9 a.A 7.3 6.1 ค.? 7.514 .9 h.h 9.0 $7.3 \quad 9.6$ $8,011.9$ 7.611 .5 10.915 .3 8.h 19.6 6.515 .4 5.911 .8 1111 ( ) 13 (1) 1 1

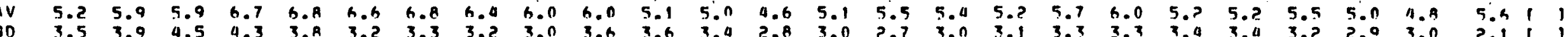

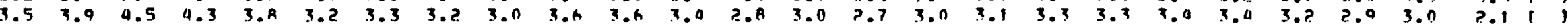


WTND SPFED recinll

MILES/HOUIR

LEVEL HEIGHT \& IO METERS
AATTELI.E WINO STIINY,H5OS

TEHACHAPT MTNS, CA.

TITE 1

NOV. 1979

AEROVIRONMFNT IMC.

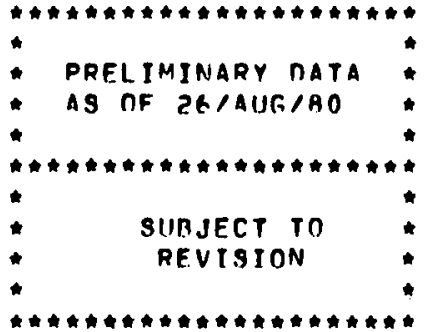

CLOCK HOUR ILOCAL STANDARD TIME. 
WTNR SPEEN ICCEOTI

MILES/HOUR

LEVEL HEIGHT : 10 METERS
BATTEILF WIND STIINY HSOS TEHACHAPI MTNS. CA.

SITE.

DEC, 1979

AEROVIRONMENT INC.

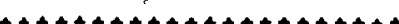

- preliminarir oata

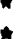

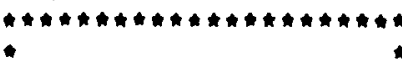

SIJEJECT TO

ISION

CLOCK HOIIR (LOCAL STANDARA TIME)

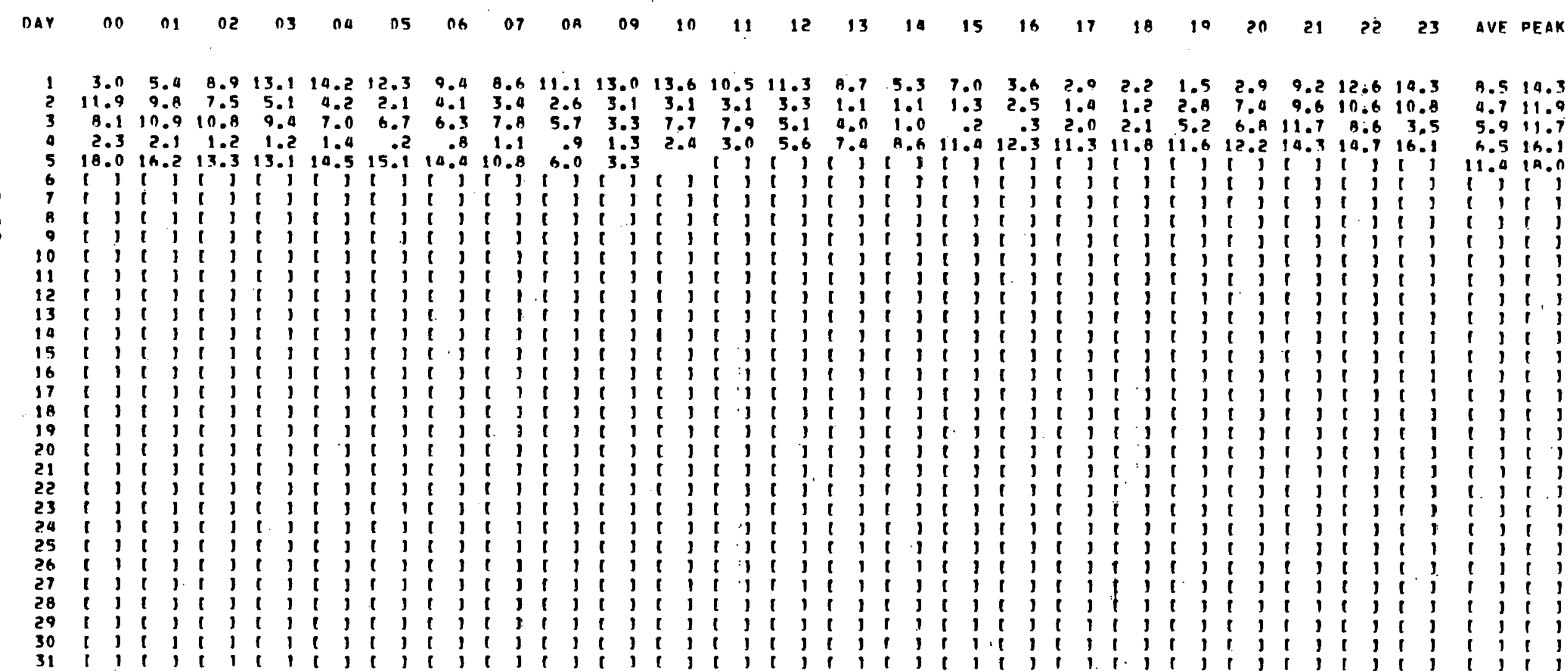

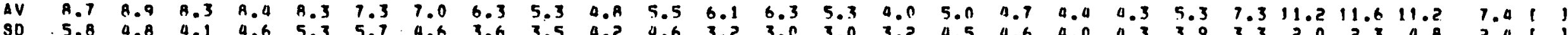


WTND SPEEN Ircinit

MILES/HOUR

LEVEL HEIGHT \& IN METERS
BATTELLE WINN STIINY, \#SOS

TEHACHAPI MTNS, CA.

SITE

JIIL. 1979

AEROVIRONMENT INC.

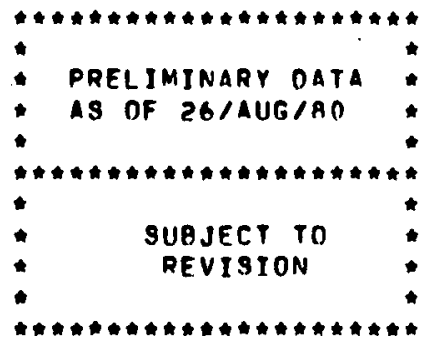

CLOCK hOIR ILOCAL STANMARD TIME]

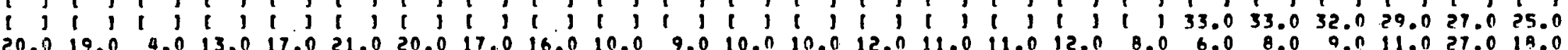

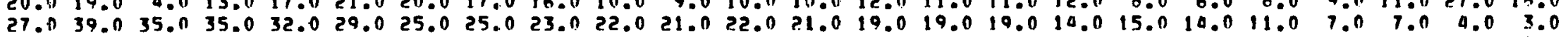

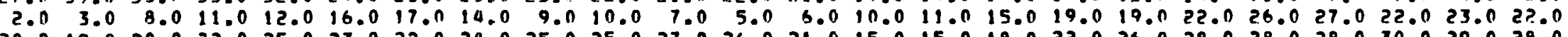

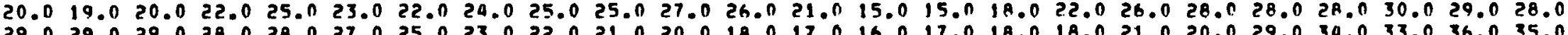

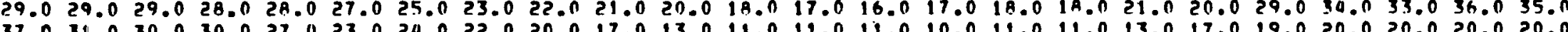

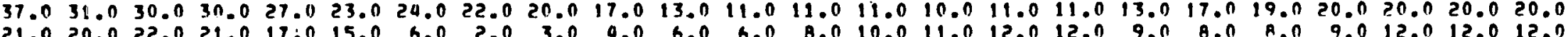

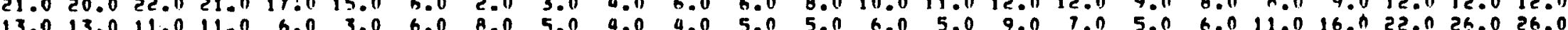
30.030 .030 .027 .026 .020 .023 .024 .021 .021 .019 .023 .021 .020 .023 .025 .024 .026 .032 .038 .031 .033 .035 .030 .0 30.032 .033 .031 .028 .028 .026 .025 .025 .023 .024 .025 .023 .020 .021 .027 .026 .025 .024 .026 .029 .030 .031 .032 .0

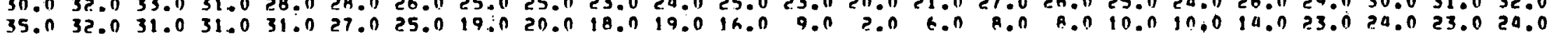

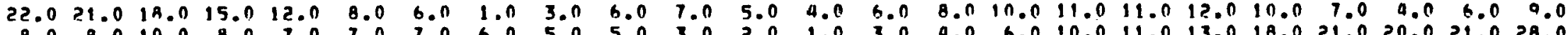

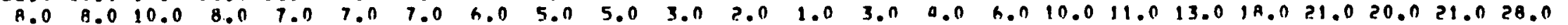

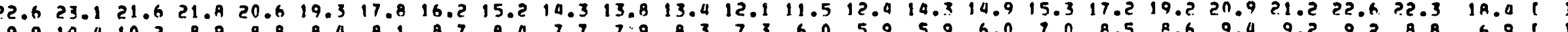


WIND SPEEn ricinal

MILES/HOUR

LEVEL HEIGHT I 10 METERS
PATTELLE WINO STIINY, HERS

TEHACHAPI MYNS, CA.

SITE $?$

AIJG. 1979

AEROVIRONMENT INC.

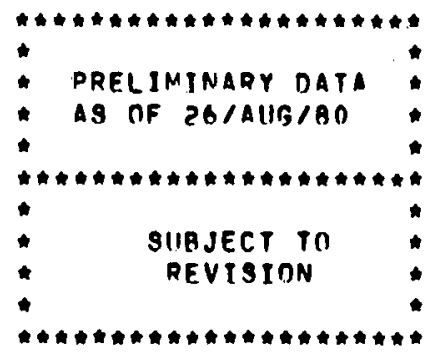

CLOCK HOUR ILOCAL STANHARD TIME

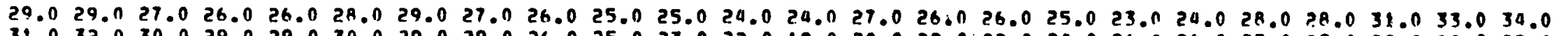

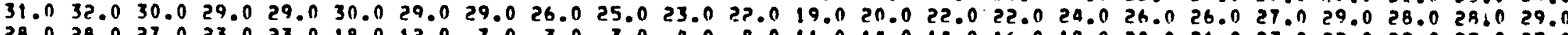

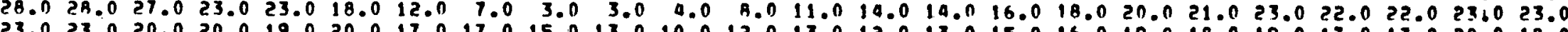

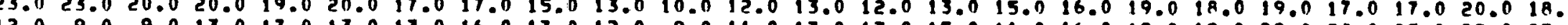

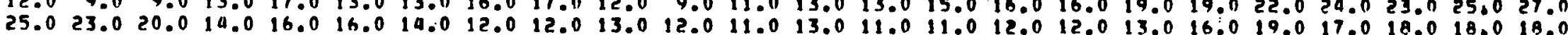

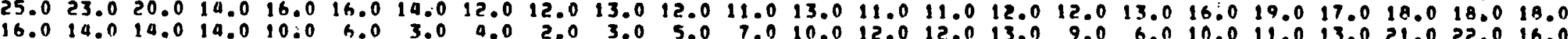

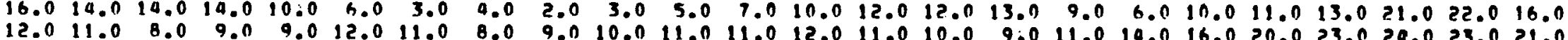

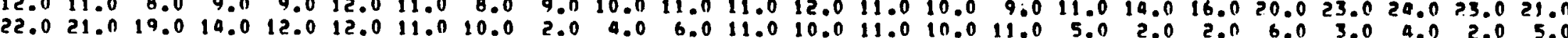

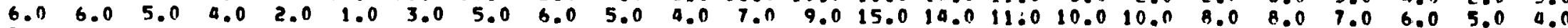

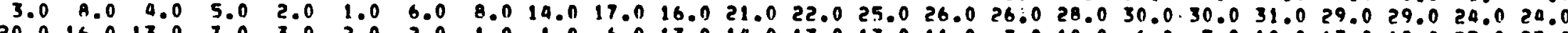

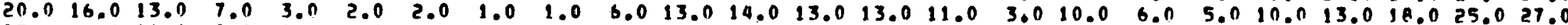
25.026 .021 .019 .017 .021 .026 .026 .023 .022 .018 .017 .019 .017 .016 .019 .018 .022 .025 .030 .028 .030 .029 .031 .0

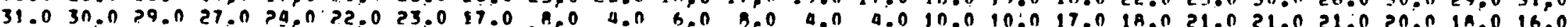

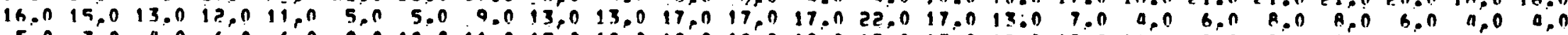

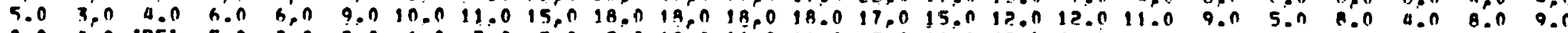

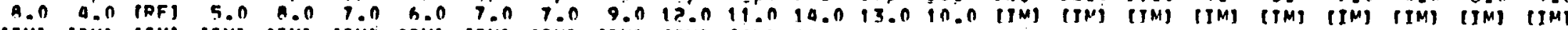
[IM] [IM] [IM] [IM] [IM] [IM] [IM] [IM] [IM] [IM] [IM] [IM] [IM] [JM] [IM] [IM] [IM] [IM] [IM] [IM] [IM] [IM] [IM] [IM] [IM] [IM] [IM] [IM] [IM] [IM] [TM] [IM] [IM] [IM] [TM] [TM] [IM] [IM] [IM] [TM] [IM] [TM] [IM] [IM] [IM] [IM] [IM] [IM] [IM] [TM] [IM] [JM] IIMI [IM] [IM] [IM] [IM] [TM] [IM] [IM] [IM] [IM] [IM] [IM] [IM] [IM] [IM] [TM] [IM] [IM] [IM] [IM] [IM] [JM] [TM] [IM] [IM] [IM] [IM] [IM] [IM] [IM] [IM] [IM] [IM] [IM] [JM] [IM] [IM] [IM] [TM] [IM] [IM] [IM] [IM] [IM] [IM] [IM] [IM] [IM] ITMI [IM] [IM] [IM] [IM] [IMI [TM] [IM] [IM] [IM] IIM] [IM] [IM] [IM] [IM] [IM] [IM] [IM] [TM] [IM]

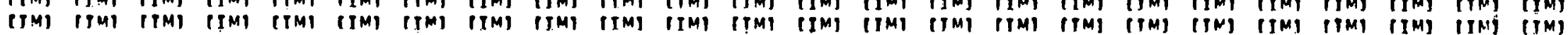
[IM] [IM] [IM] [IM] [IM] [JM] IIM] [IM] [IM] IIM] [IM] [IM] [IM] [IM] IIM] [IM] [IM] [IM] [IM] [IM] [JM] [IM] [IM] [IM]

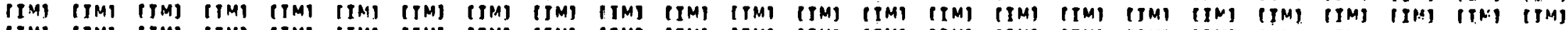
[IM] [TM] IIM] [IM] [IM] [IM] [IM] [IM] [IM] [IM] [IM] [IM] [IM] [IM] [IM] [IM] [IM] [IM] [IM] [IM] [IM] [IM] [IM] [IM] [IM] [TM] [IM] [TM] [IM] [IM] [IM] [IM] [IM] [IM] [IM] [IM] [IM] [IM] [IM] [IM] [IM] [IM] [IM] [IM] [IM] [IM] [IM] [IM]

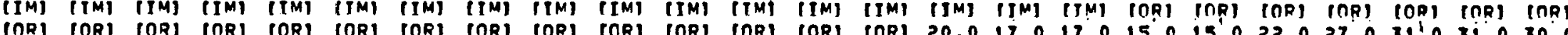

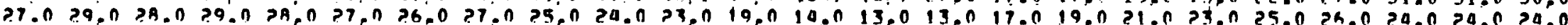

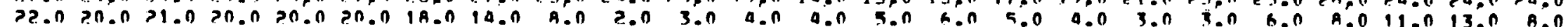


WTNR SPEEN rerinI

MTLES/HOUR

LFVFL HETGHT; IO MFTERS
BATTELLF WJNA STIINY,ESTS TEHACHAPI MTNS. RA.'

STTE

SEP. 1979

AERAUTRONMENT TNC:

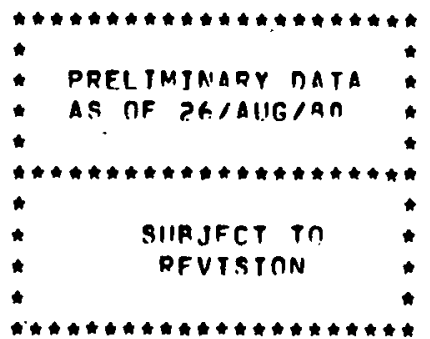

CLOCK HOIH RLORAL STANHARN TIMFI

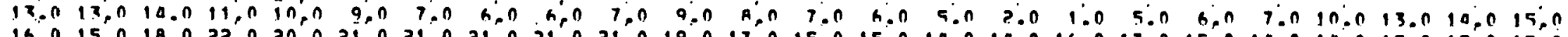

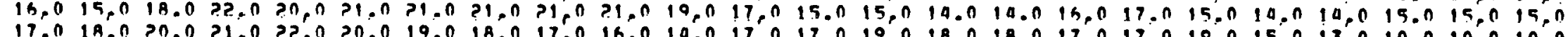

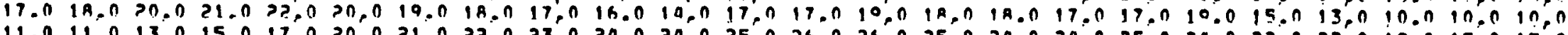

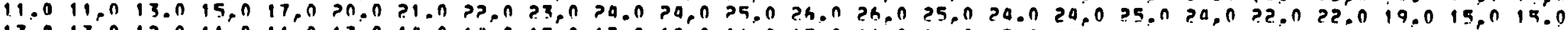

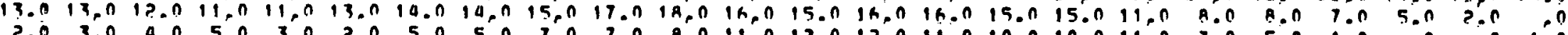

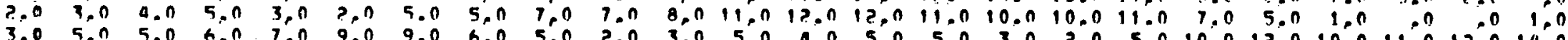

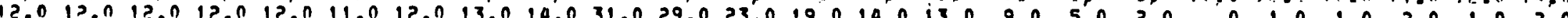

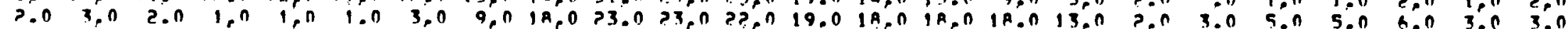

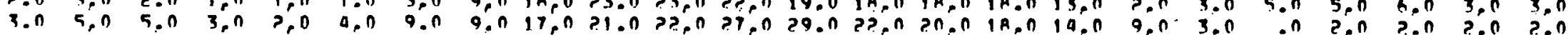

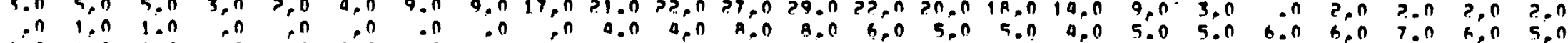

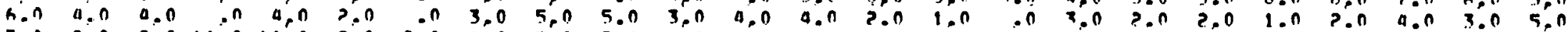

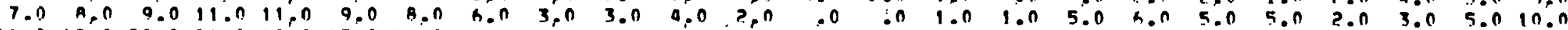

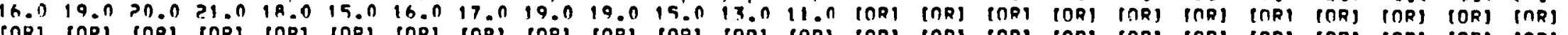

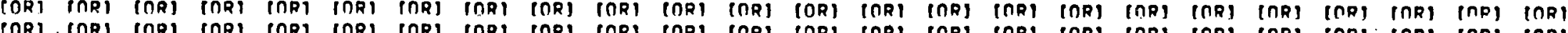

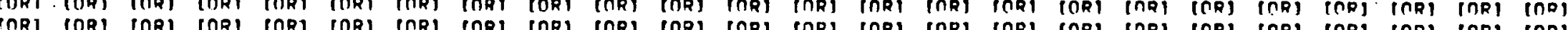

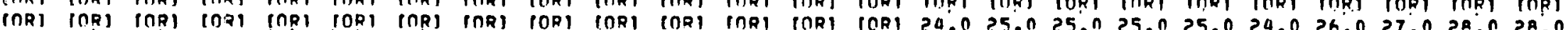

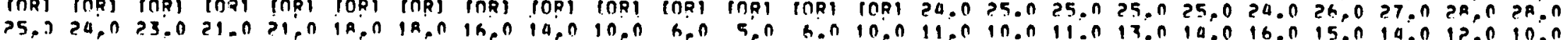

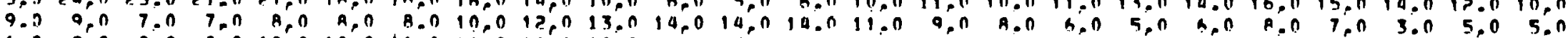

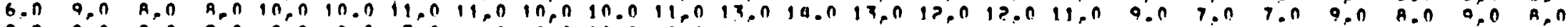

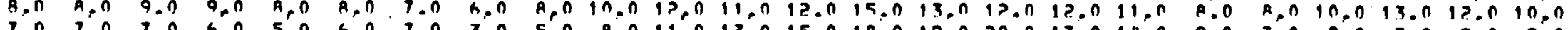

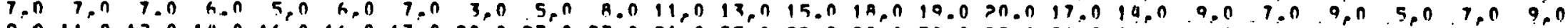

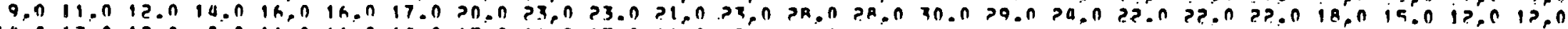

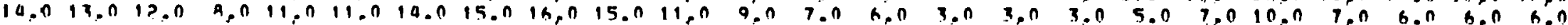

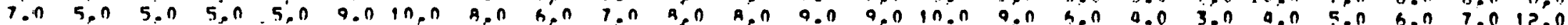

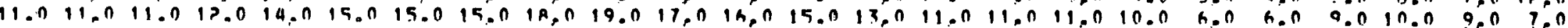

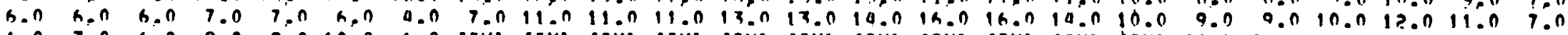

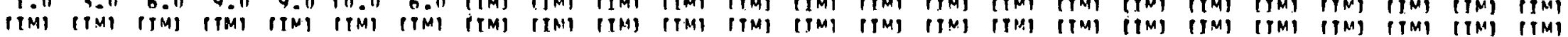

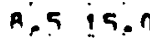
$17.1>?, 0$ h. A $2>, n$ $20,52 k, 0$ $5 \%$ is. 6.6 in. 10.931 .0 $0, ?>3 . n$ $\ln .0>0,0$ $3 . h$ A.n ?.9 h.? in 2100 1,1 , 1 1.11 25,7 ?a, $n$ $14,325 . ?$ a, $\mathrm{h} 10 . \mathrm{n}$ $0,214,0$ $10,015.0$ $9, a \geq n, 0$ $19,530.0$ 0.1 1a.n 7. $13, n$ $12, ?$ la.n Q.A IR.? h.? 1n.?

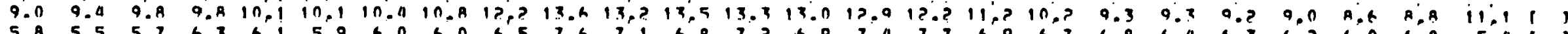
ABกIIT 
AATTEILE WIND STUNY Z5O5 TFHACHAPI MTNS. CA SITF ?

nct. 1979

AERTVIRONMFNT INC:

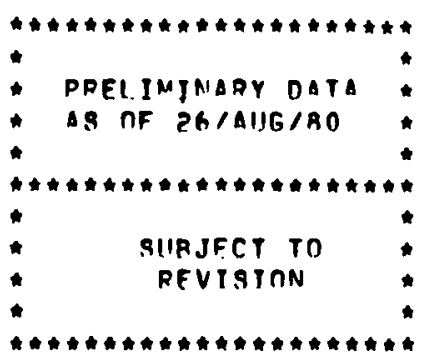

CLOCK HOUR ILOCAL STANMARD TJMEJ

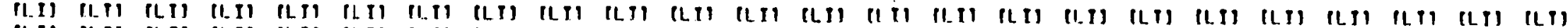

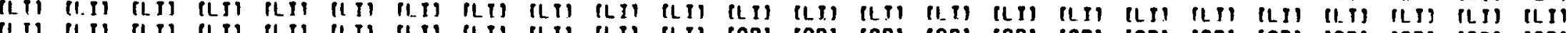

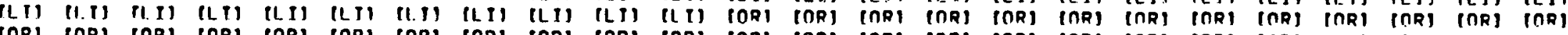

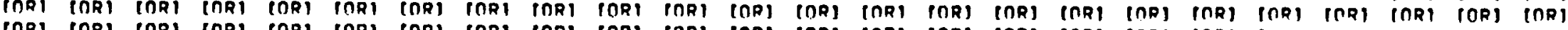

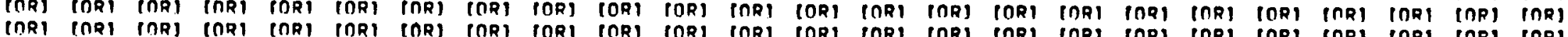

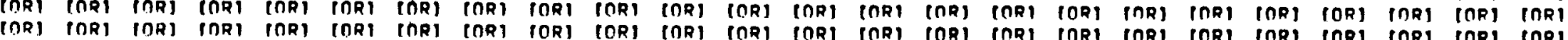

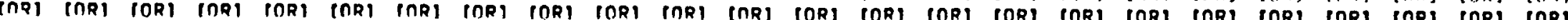

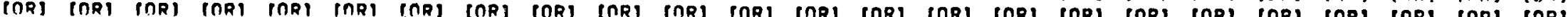

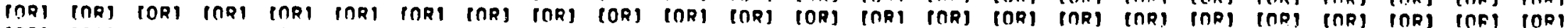

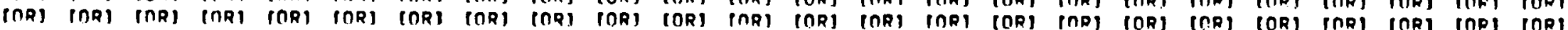

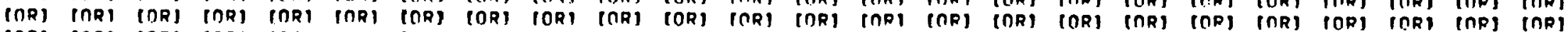

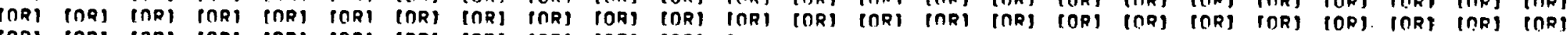

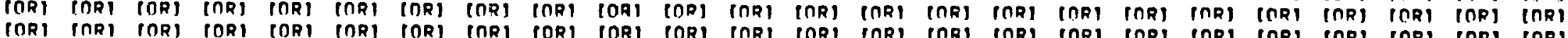

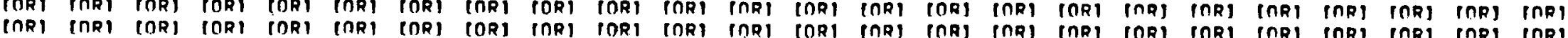

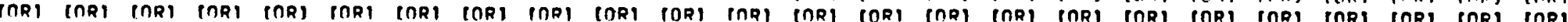

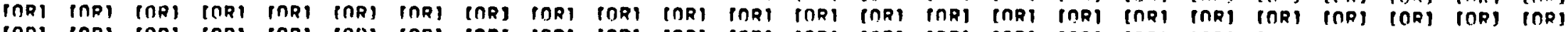

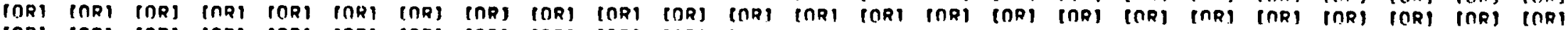

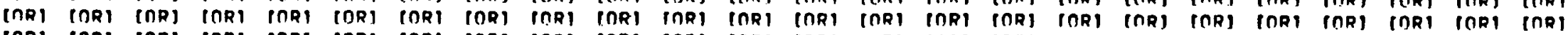

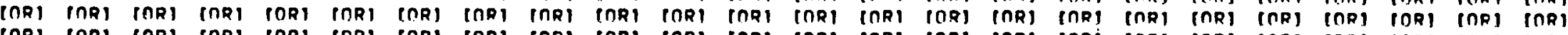

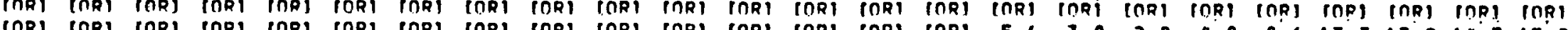

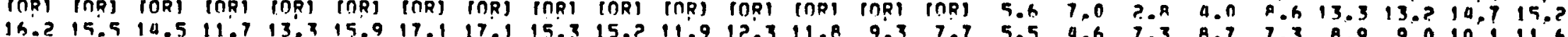

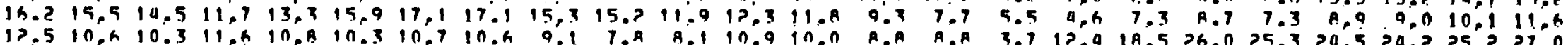

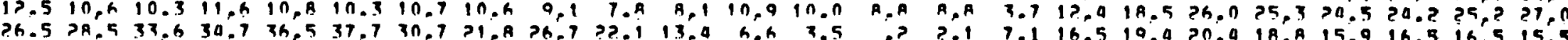

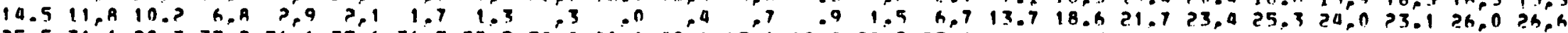

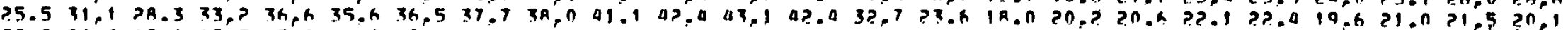

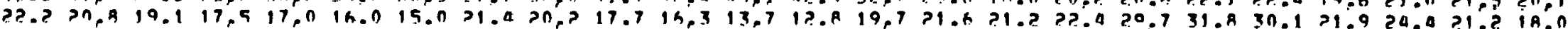

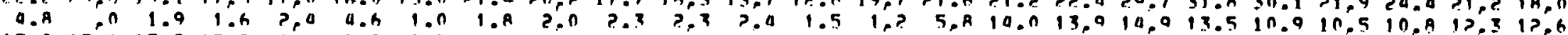

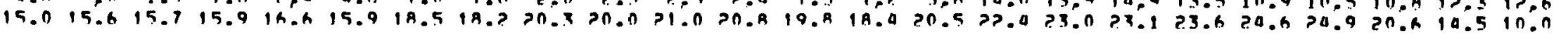


WINA SPEED ICrinil

MTI.FS/HOIIR

I.FVEL HETEHT: In MFTERS
RATTELLF WTNO STUNY. \#GOE TFHACHAPI MTNS, CA.

STTF

NnV. 1979

AFROUTROAMANT INC:

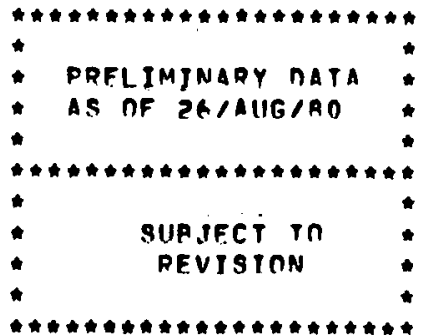

clonek holiR (l.oCal standaph tTME)

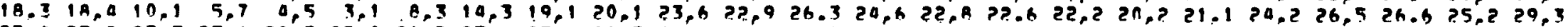

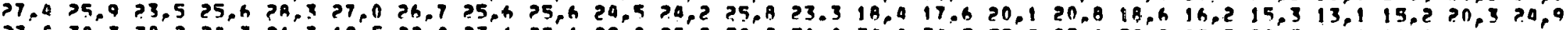

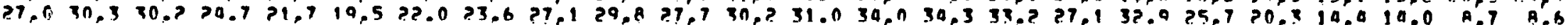

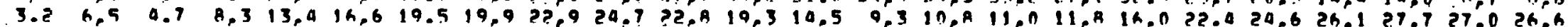

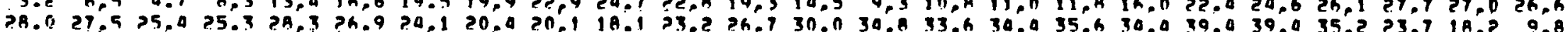

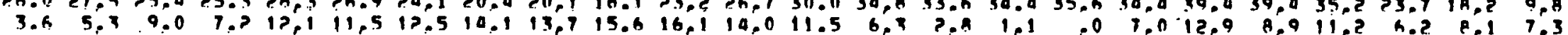

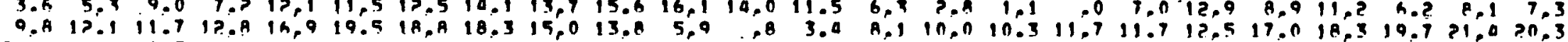

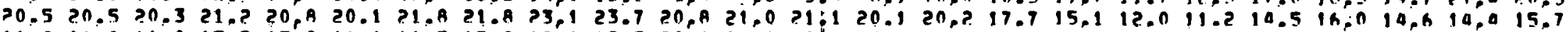

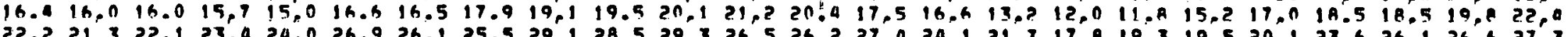

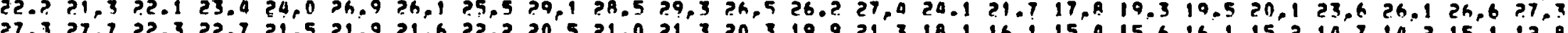

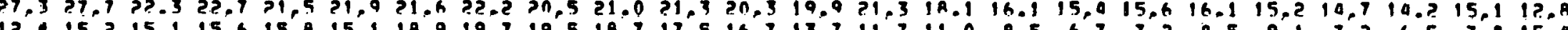

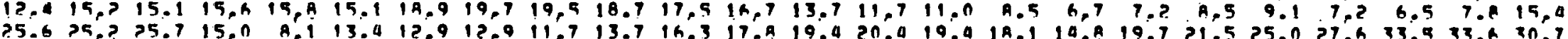

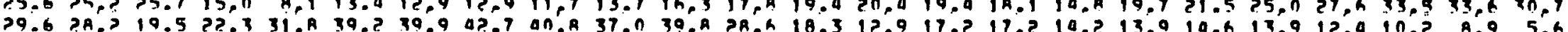

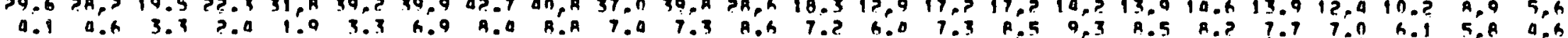

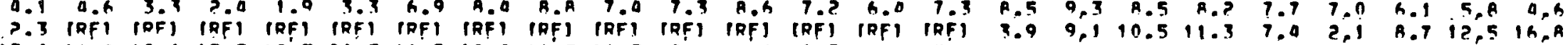

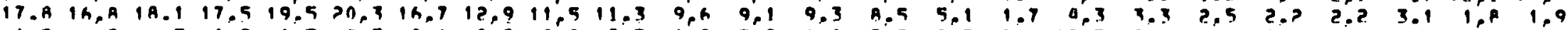

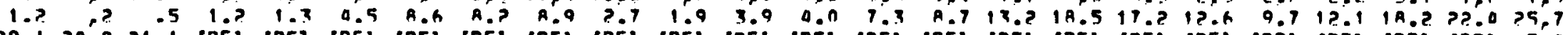

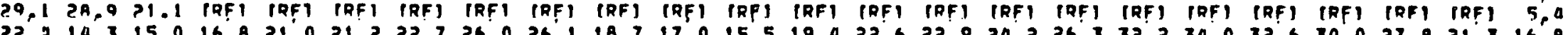

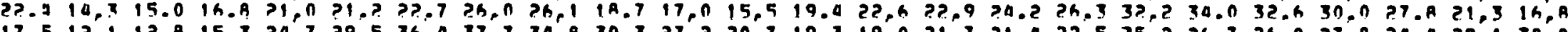

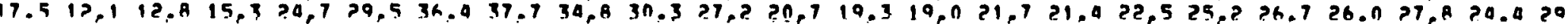

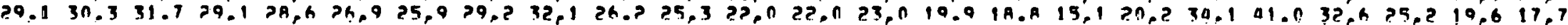

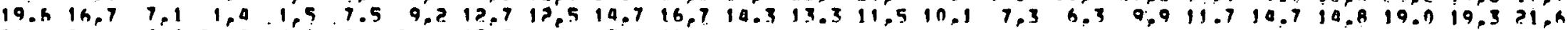

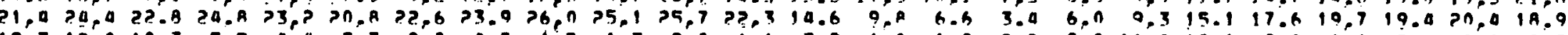

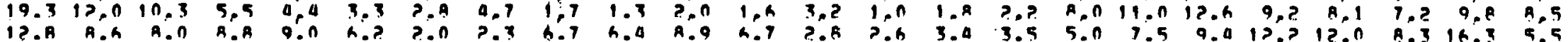

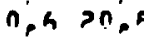
on 19,5 5., 30,4 $10.5>0.3$ ??,? PA, 3 24.970 .3 $17,97.7$ 37, is 39,4 $9,1 \quad \ln _{0,1}$ 13,3 ? 1.0 $19.7 ? 3.7$ $17, ? ? 2.0$ $3,4,430,3$ 10,4 ? 19 $12,19.7$ 30.135 $\begin{array}{ll}13 \\ 23.1 & 33.6\end{array}$ h. 9.3 A. 5 IR.A 9.5 ?, .3 A. $9 ? 5.7$ 2. 1.1 ?0.1 2? $3 a$ 5อ? 2h. 1 al. 1?.? ? ?. क IA. 5 SR. $6,310.3$

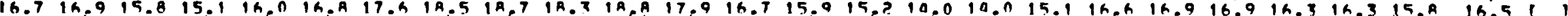

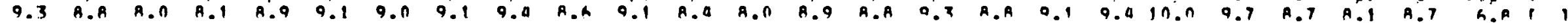


WTAN SPFEn ICCBnil

MTLES/HOIIR

LFVEL HEIGHT: in METFRS
RATTEILE WTNO SPIINY, HSOS

TEHACHAPI MTNS, CA.

SITF.

DFC. 1979

AFROUIPONMENT TNC:

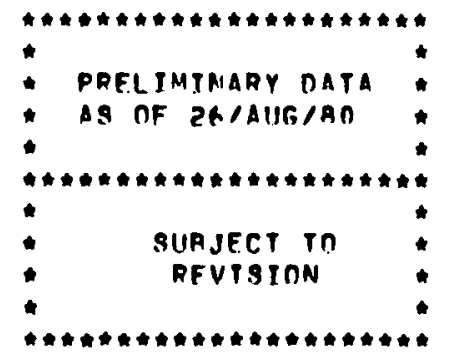

CLOCK HOIIR (LOCAL STANDARD TIME)

DAY

no 01 n? 03 na 05 06 07 na

nR

09

$1 i$

12

13

$14 \quad 1$

in

17

I 8

19

(

?)

AVE PFAK

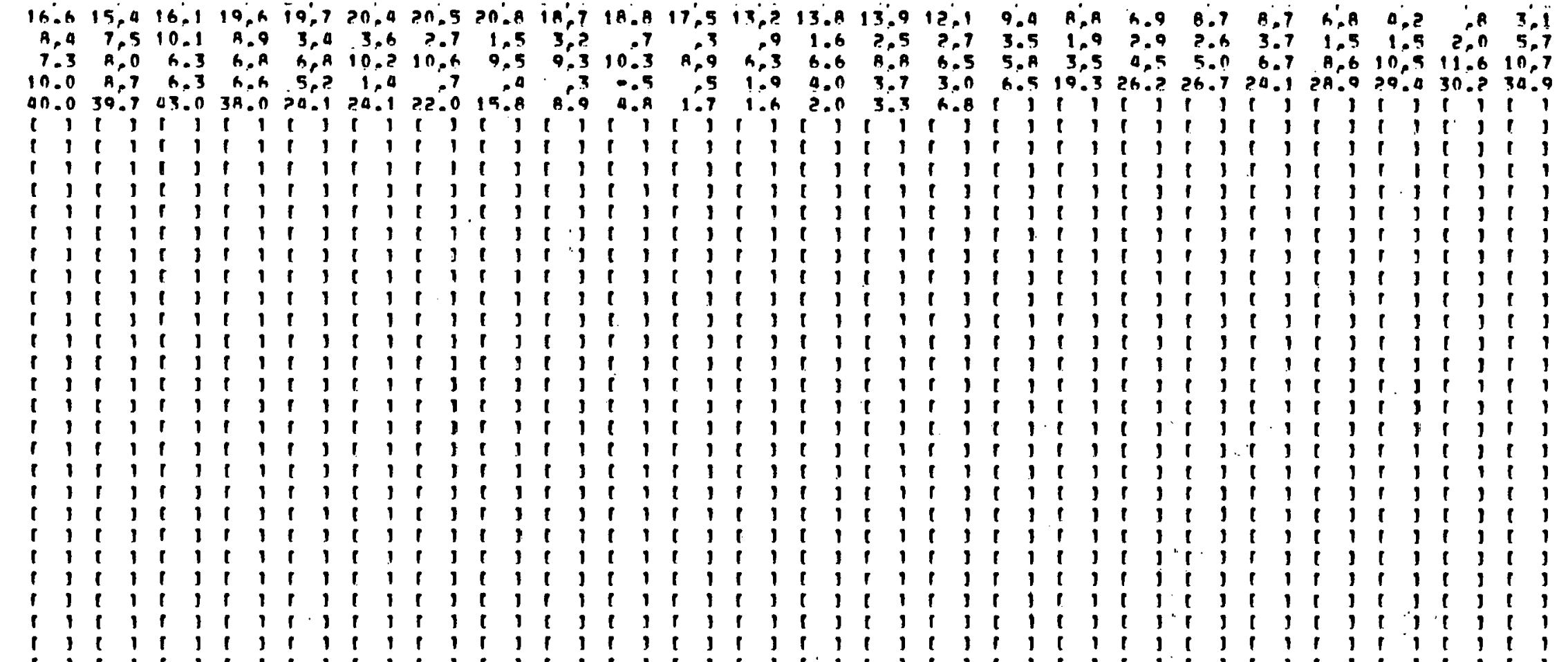

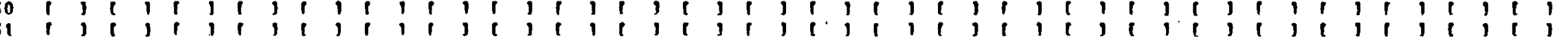

AV

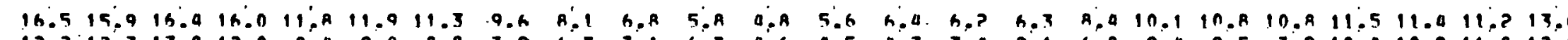

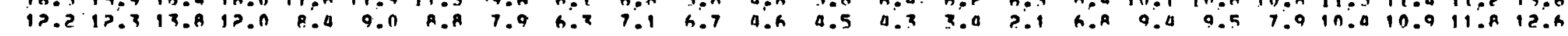

$13,1>0,8$ $3,510.1$ 11.6 >a.? 18.403 .0 (1) 1 ( 13 1 111 1 113 1) 15 i i 1 1,1 1,1 119 1113 1,13 (1) (1) 1, i 1 i 1,1 1,1 1111 1111 1313 (1) 19 , i i i i 111 10.911
5.011 
WINN SPEEN Irrosii

MTIES/HOUR

LEVFI. HETGHT: in MFTFRS
RATTEIIF WIND STIINY HQRE TFHACHAPI MTNA. CA.

STTF

MAY, 1979

AFROVIRONMENT INC:

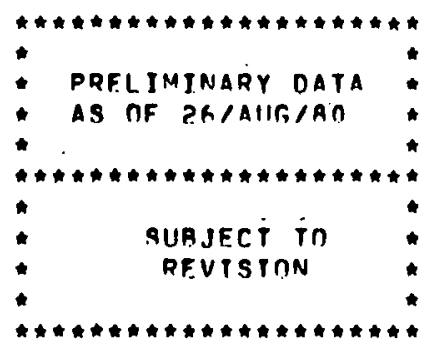

Clor, HMIIR (IOCCAL STANDARD TIME)

111 $\begin{array}{rrrrr}1 & 1 & 1 & 1 & 1 \\ 1 & 1 & 1\end{array}$ $\begin{array}{ll}1 & 1 \\ 1 & 1 \\ 1 & 1\end{array}$ 1,1111 $1,1,1,1$ l 1 $1,1,1,1,1$

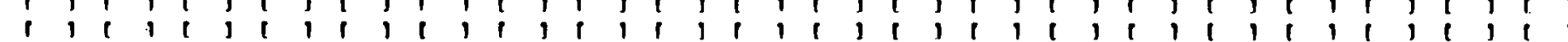

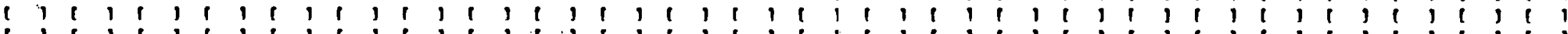

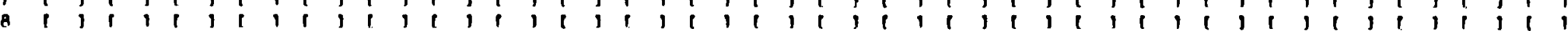

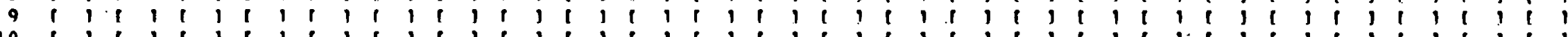

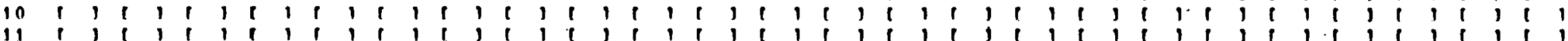

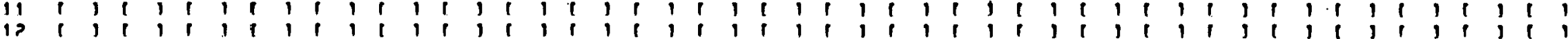

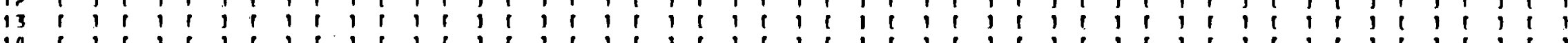

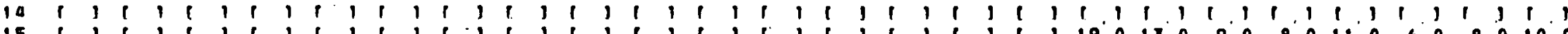

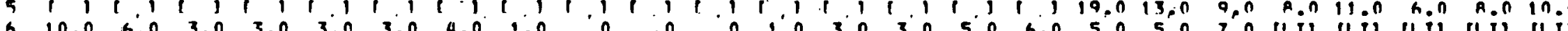

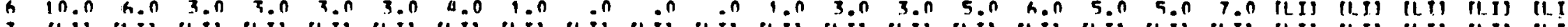

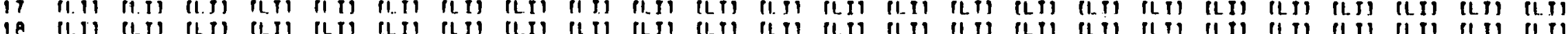

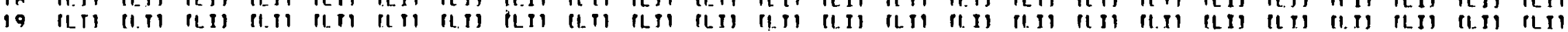

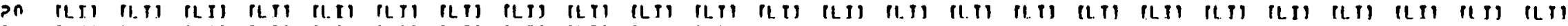

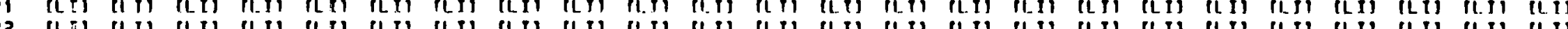

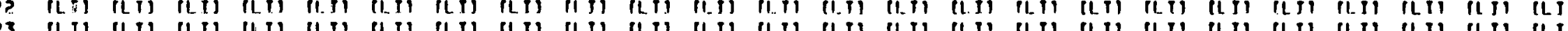

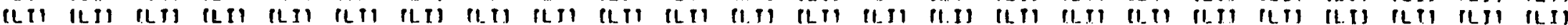

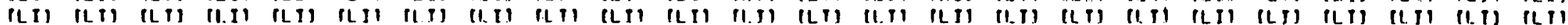

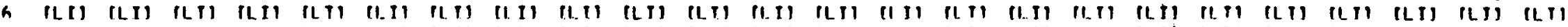

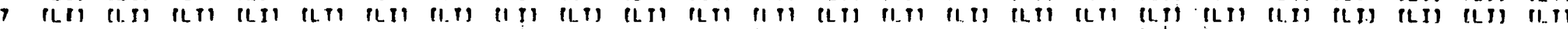

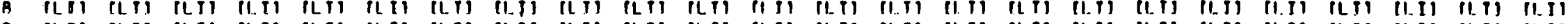

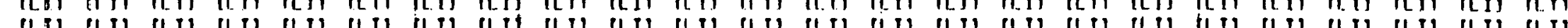

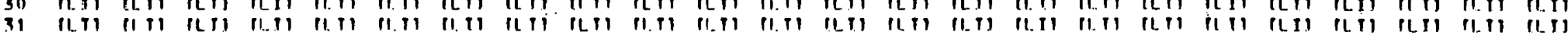

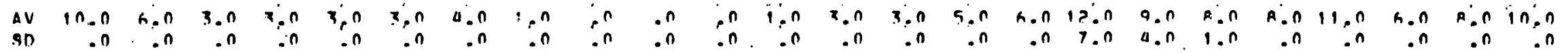


WTNO SPFEn ircinil

MTLFS HHOUR

LEVEL HEIGHT; in MFTFR.
RATTFLIE WTNO STUNY. HSOS TEHACHAPI MTNS. CA.

STTF.

IIIN, 1979

AEROVIRONMFNT INR:

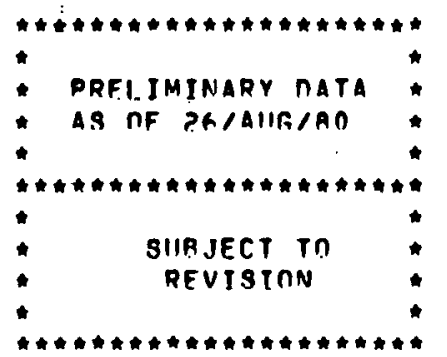

CLOCX HOIIR ILOCOL STANDARO TIME)

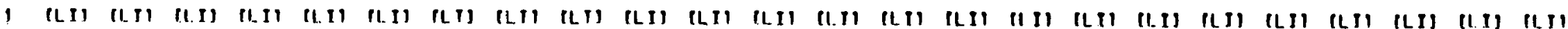

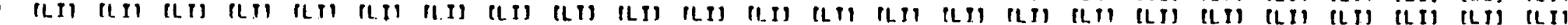

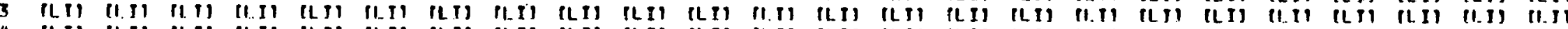

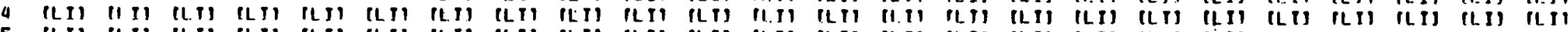

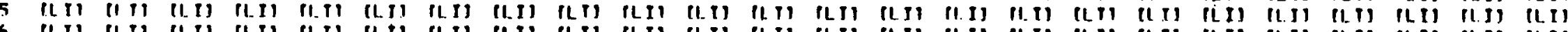

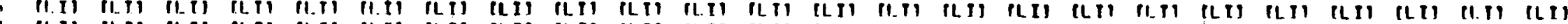

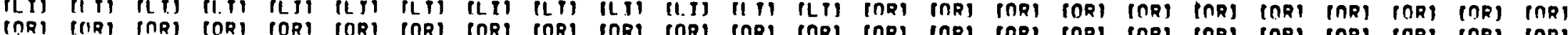

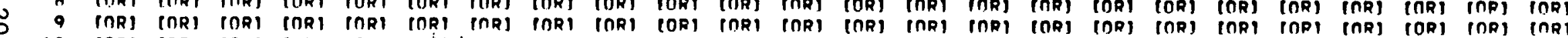

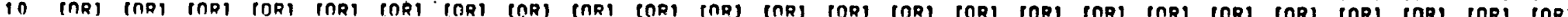

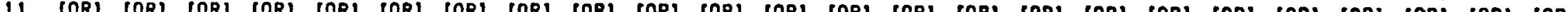

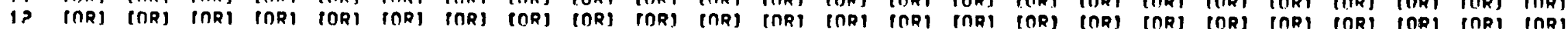

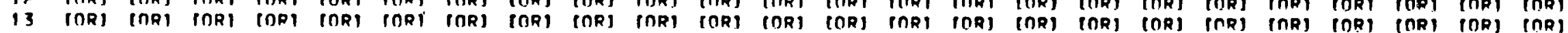

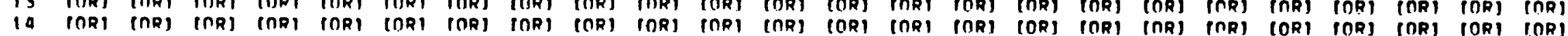

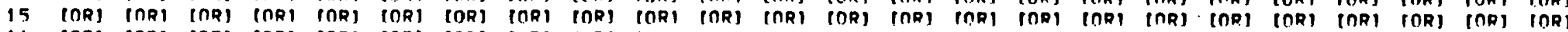

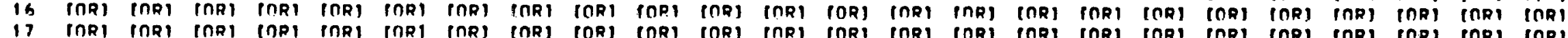

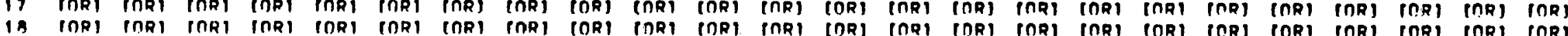

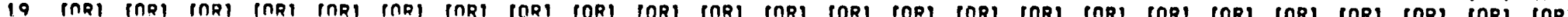

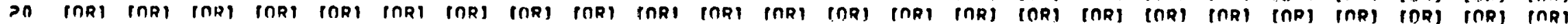

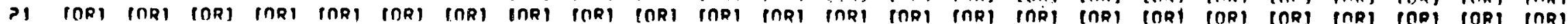

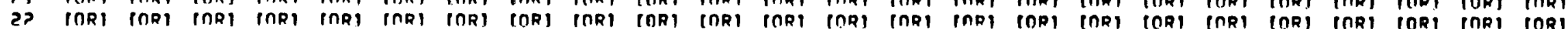

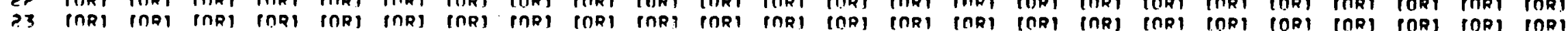

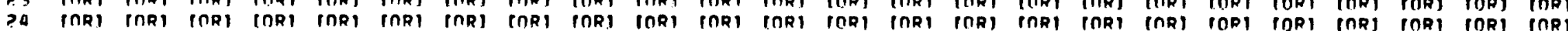

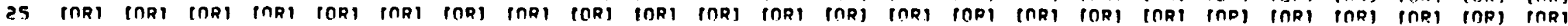

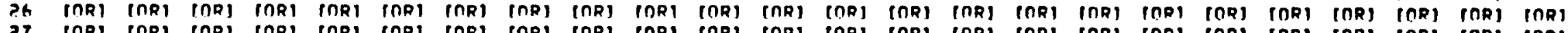

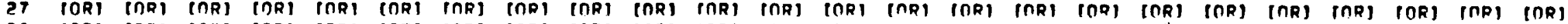

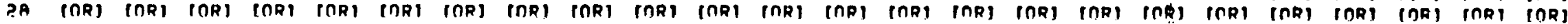

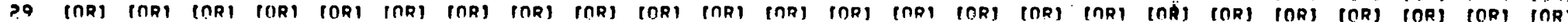

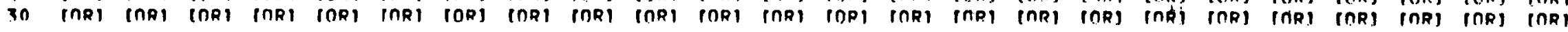

111 $1 \quad 11$ 15 1,1 111

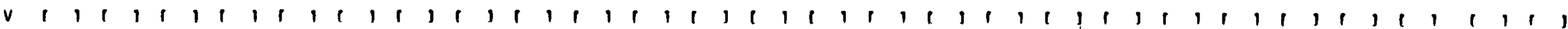

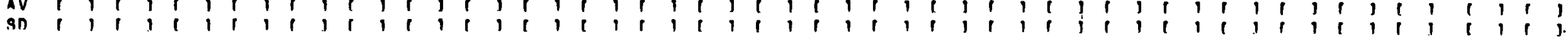


WTMI SPEFn recinil

MILES/HOUR

LEVFL HEIGHT: IO MFTERS
AATTFLLF WINO STIINY, \#505

TFHACHAPT MTNS. CA.

J111. 1979

AFROUTROAMENT TNC:

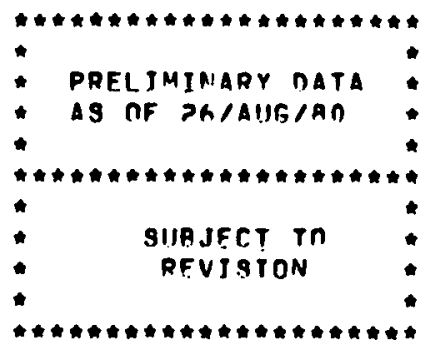

ClOCK hMIIR ILOCAl stannarD timf

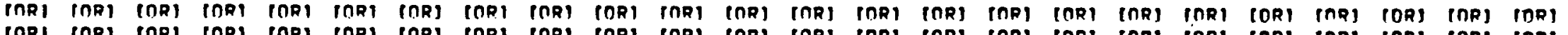

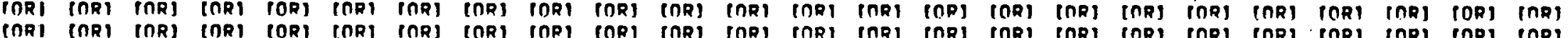

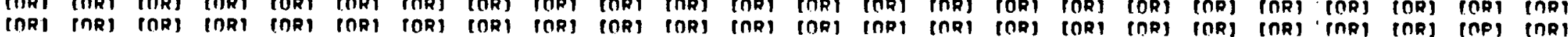

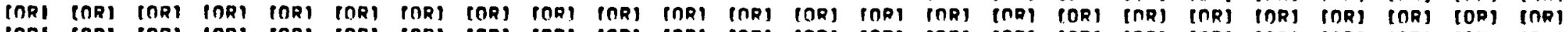

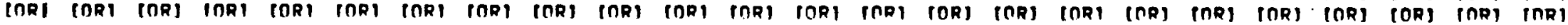

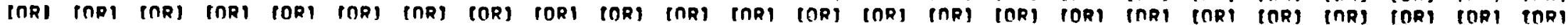

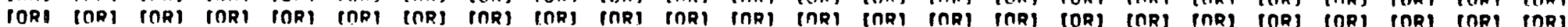

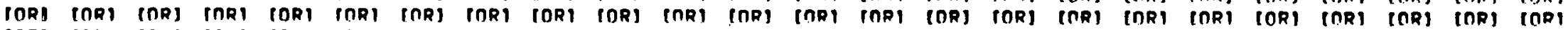

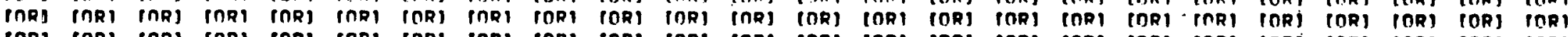

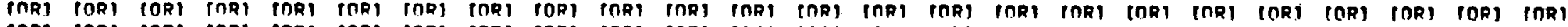

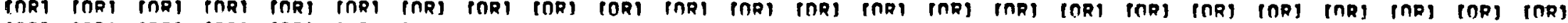

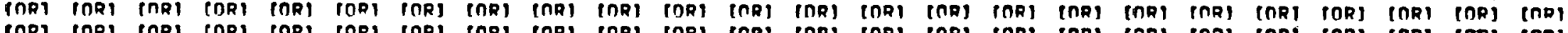

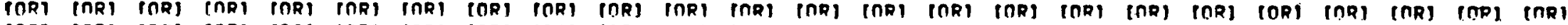

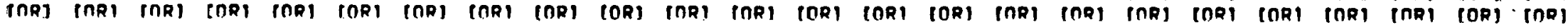

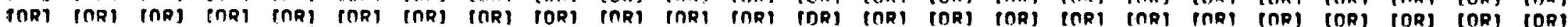

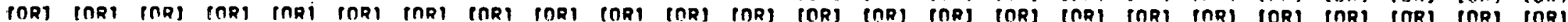

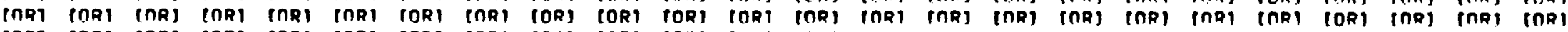

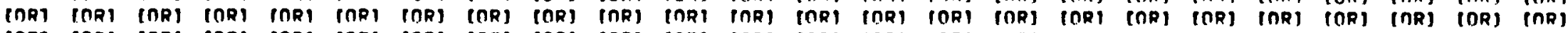

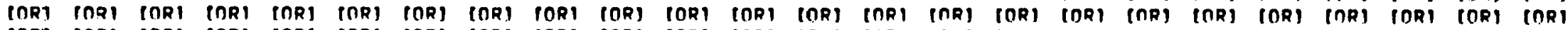

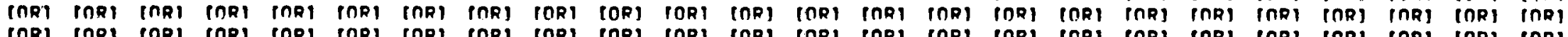

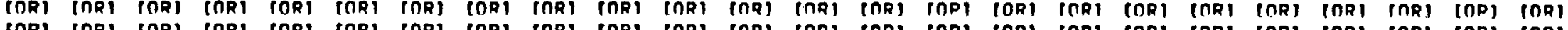

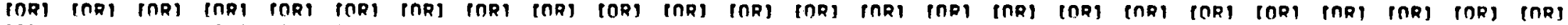

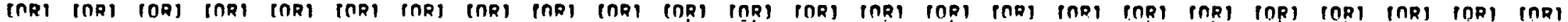

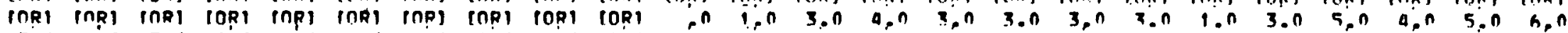

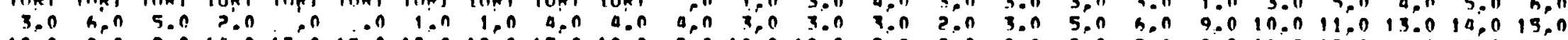

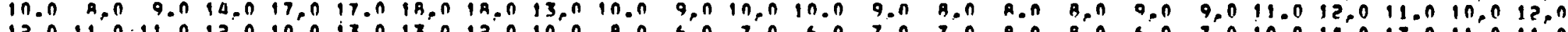

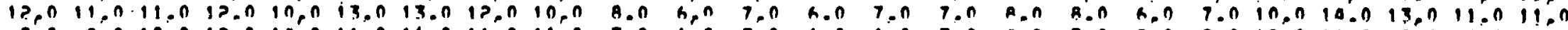

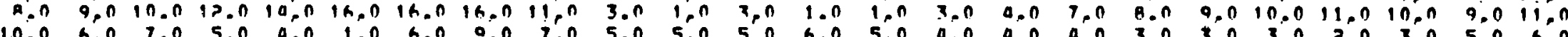

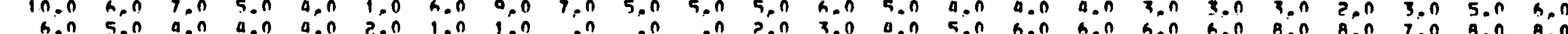

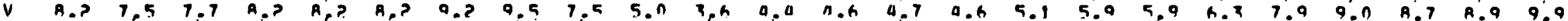


WTNO SPFFn recing

MTLES/HOUR

LEVEL MFTGHT I 10 MFTERS
PATTELIE WTAN STIINY. 505

TEHACHAPI MTNS. CA.

SITF 3

Alus. 1979

AFROVIRONMENT INC.

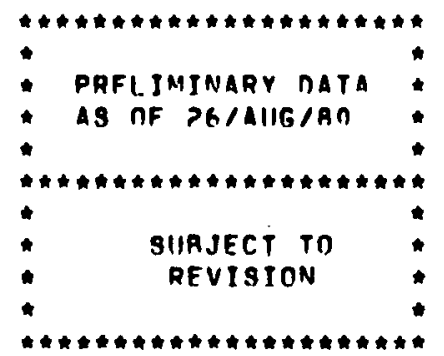

CI.OCK HOIJR LLOCAL STANDARO TIMEJ

0,1 i?.n a.h is.n A.7 in.? ค. 14.0 T.5 13.0 5,3 i1, o $0,713,0$ $0.5 \operatorname{lin}$ 5.5 in. 1,4 is.o 5.717 .0 $7.913,0$ 6.514 .0 5 , a 11.0 T.5 1h.n $4,9 \quad B, n$ 50 . i.j 1 ?. n a.n M., h.5 9.0 G.n 3.0 B.? 11.0 $0, ? 14.0$ 5.A 9.0 5.911 .0 ion ia.n T.n 12.0 4.514 .0

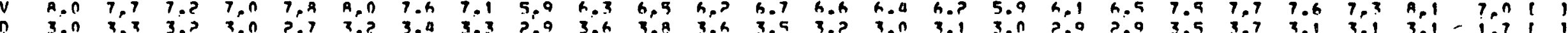


WINA SPEEn IrCinil

MTLES/HOIIP

LEVEL HEIGHT: in MFTFRS
AATTFLIF NTNO STIINY, \#5OS TFHACHAPI MTNA. CA.

GitF

SFP. 1979

AFROUTRONMFNT TNC.

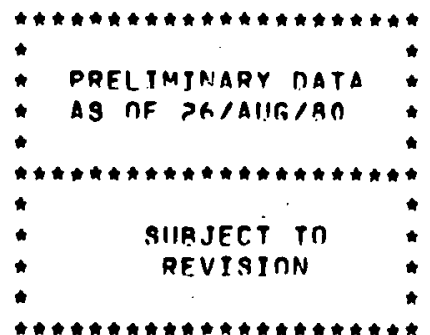

ClnCK hDIR (loñal stannapn times 
WTMN SPFEn rreint1

MILES/HOIR

LFVEL HEIGHT: In MFTFRS
PATTFI LE WTAN STIINY. HSOS

TEHACHAPI MTNS. CA.

STTE

oct. 1979

AFROVIRANMENT INC.

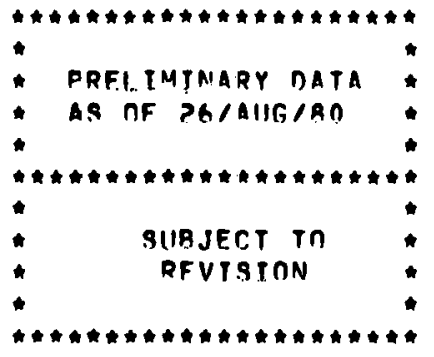

ClnCK hMUR rlncial. standarn tjuE,

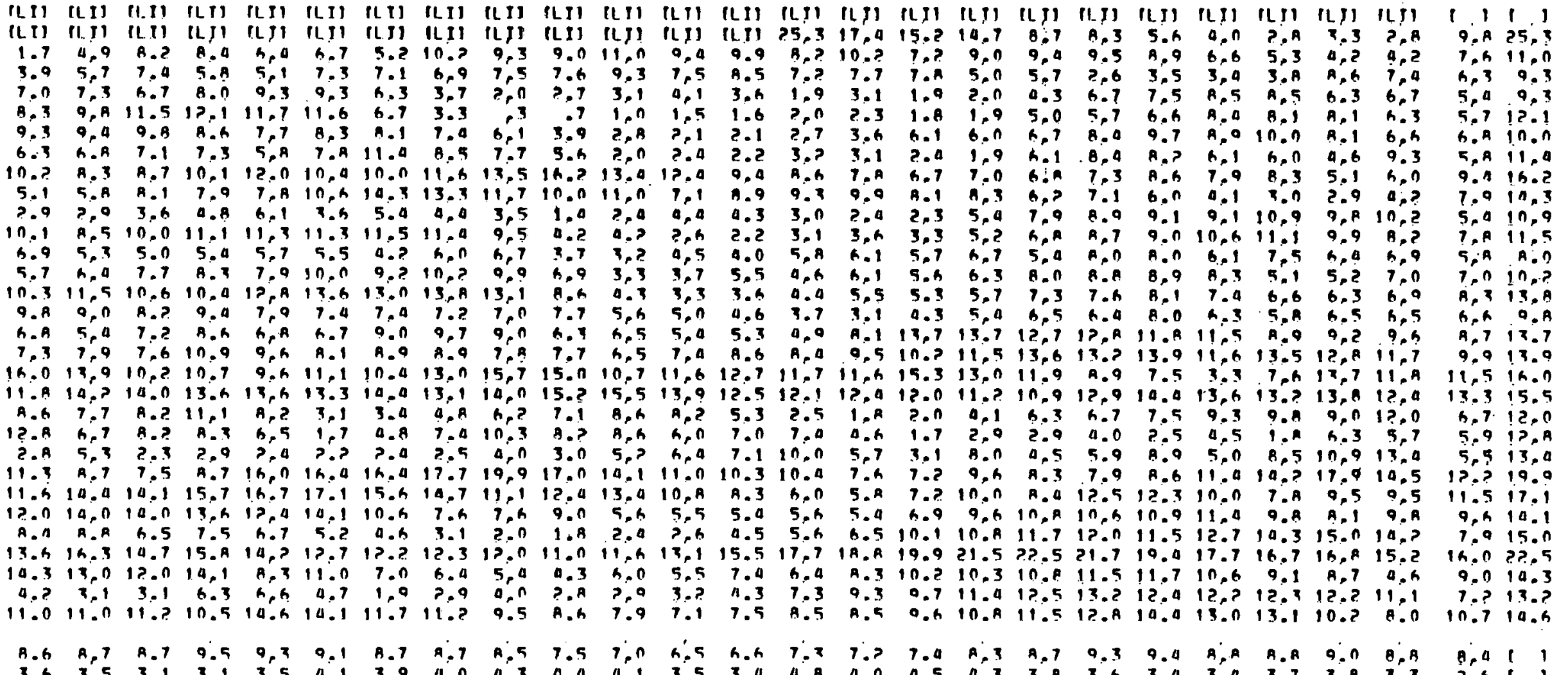

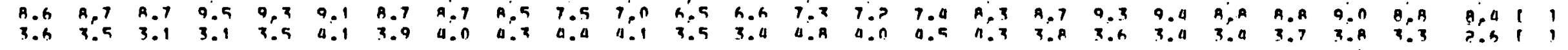


WTNO SPFED Ir.rin1)

MILFS/HOUIR

LFVFL HETFHT: In MFTFRS
PATTEILF WTND STIUPY H5OS TFHACHAPI MTNS. CA. SITF 3

NOV, 1979

AEROVTRONMENT INC.

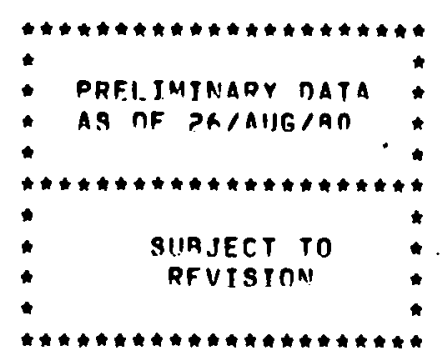

CLOCK HOIIR RLOEAL STANDARN TIME

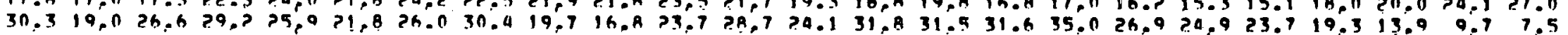

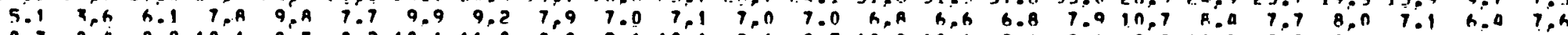

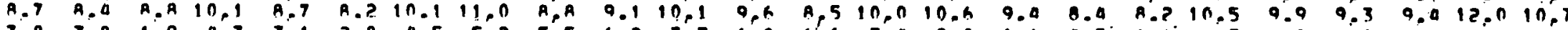

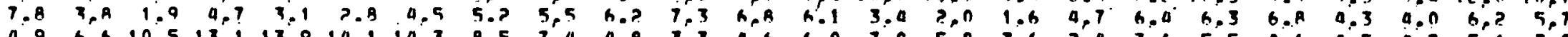

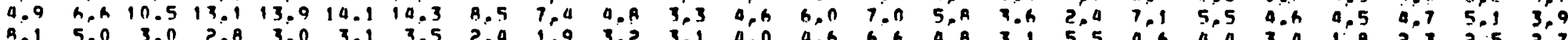

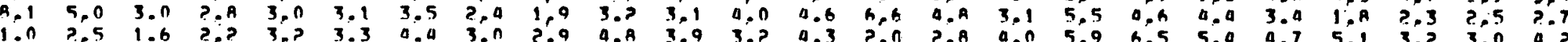

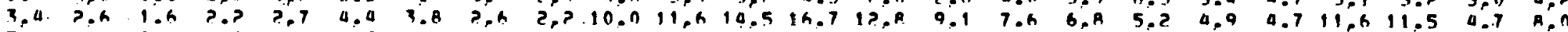

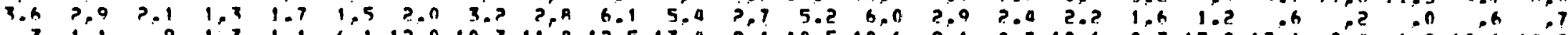

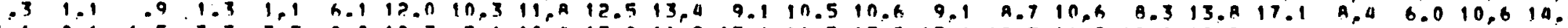

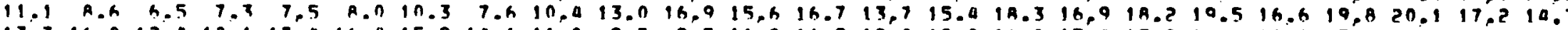

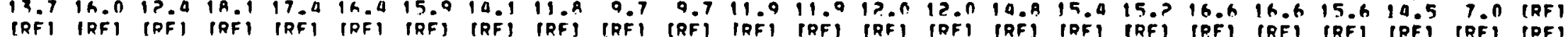

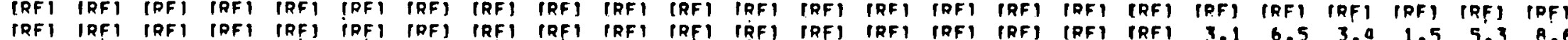

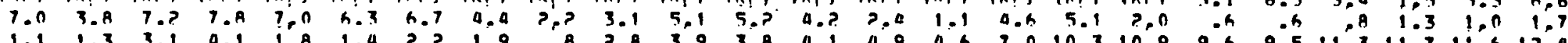

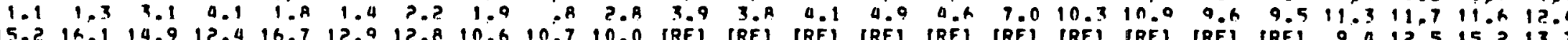

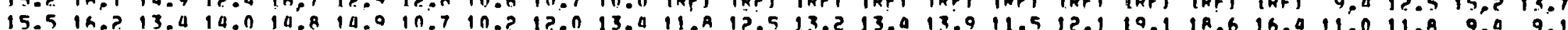

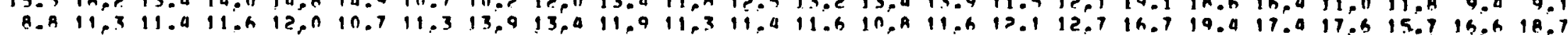

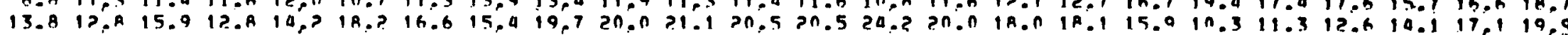

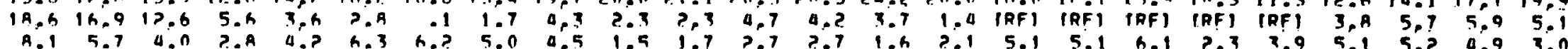

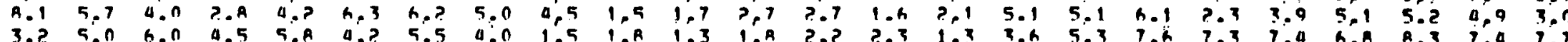

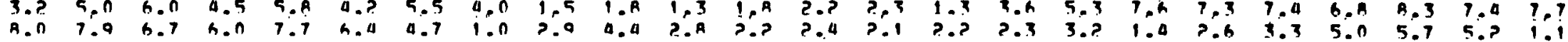

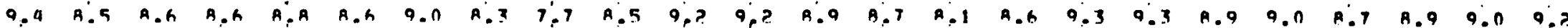

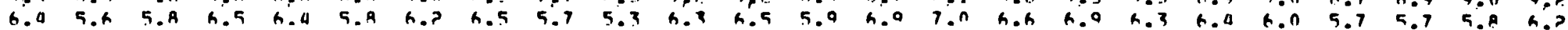


WTAn SPEFn [Crini)

MJLFS/HOIIR

LFVEL HEIGHT: In METFRS
RATTELLE WTNO STIIDY.

TEHACHAPI MTNS, CA.

DFC. 1979

AFROVIRONMENT INC.

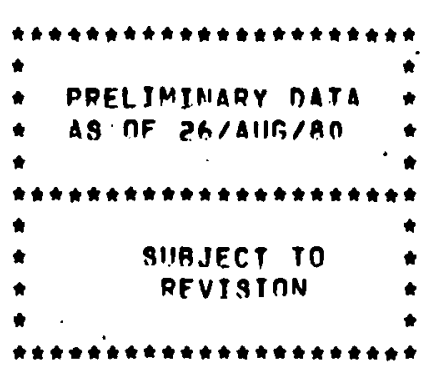

CLOCK HOIIR II.NCAL STAMDARN TIMEJ

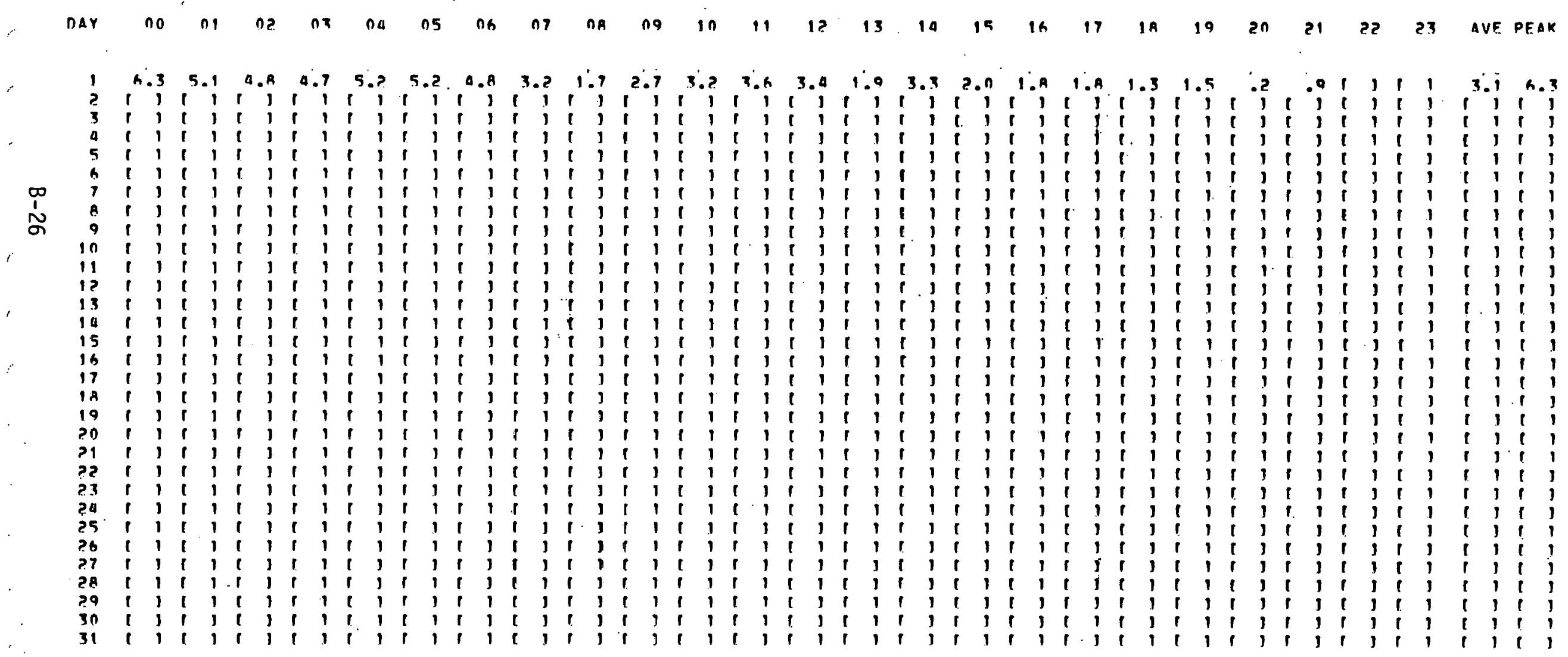

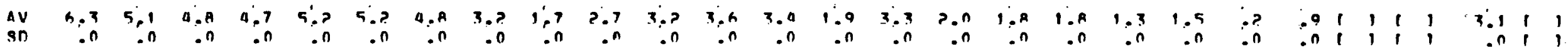


wIMn SPEFn Irring

MILESIHNIIR

I.FVFI. HEIRHT : IO MFTERS
AATTFIIF WTNR STIINY, HSOS

TFHACHAPJ MTNS. CA.

SiTF

MAY. 1079

AERTVIROAMFNT TNC.

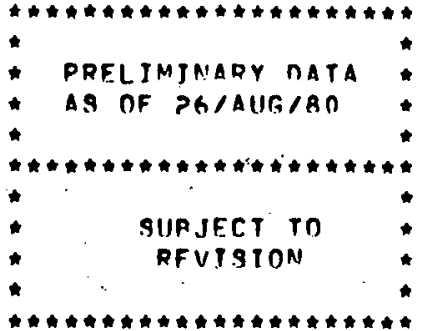

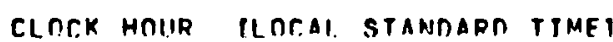

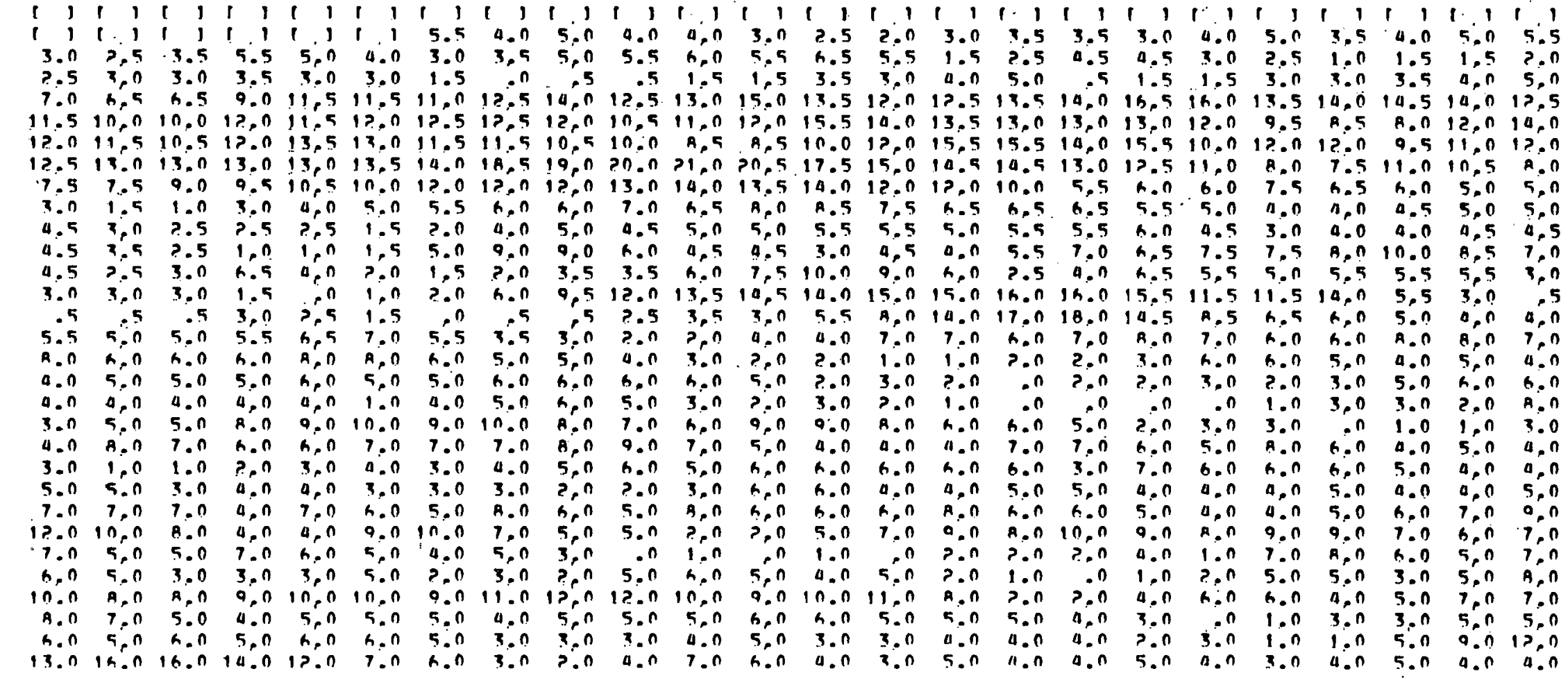


WTAM SPEFD Proingl

MTLES/HOIIR

LEVEL HEJGHT i In MFTERS
BATTFLIE WINI RTIINY, HSOS

TFHACHAPI MTNS. CA:

SITF a

JIIN. 1979

AEROVIRONMENT TNC:

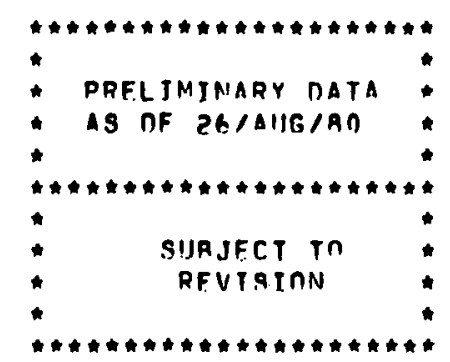

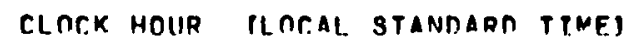

nar no

AคnแI 
WINR SPFFn IrCinis

MIIFS/HOIIR

LFVEL HEIGHT : 10 MFTFR
BATTEILE WJNA STIINY, \#505

TEHACHAPI MTNS, CA.

STTF

JIIL. 1079

AEROVIRTNMENT TNC:

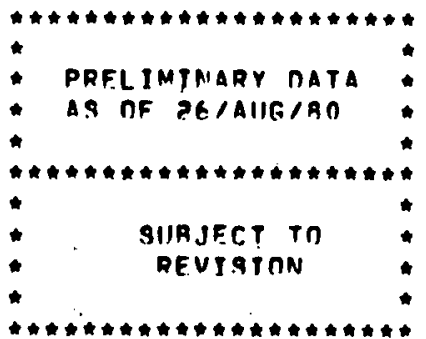

CLOCK HDIJR (IINCAL STANDARD TIMF.)

nay

กค 09

in

11

13

10

15

19

?ก

2)

23

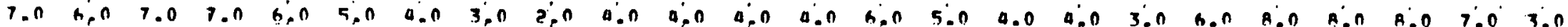

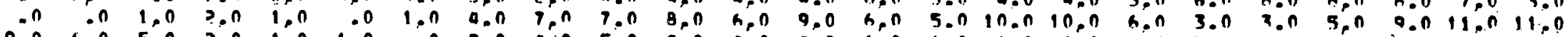

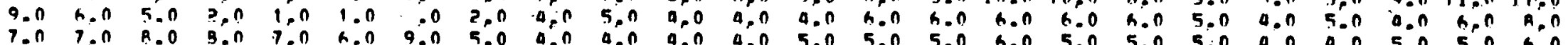

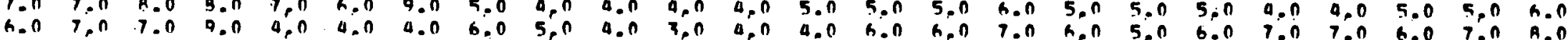

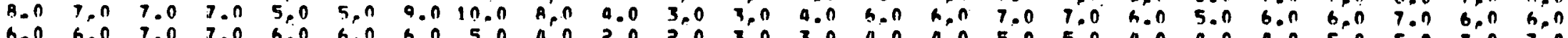

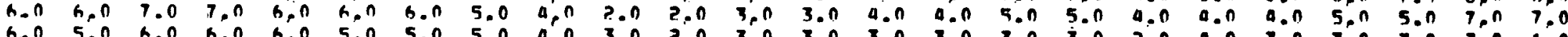

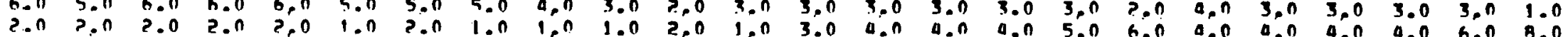

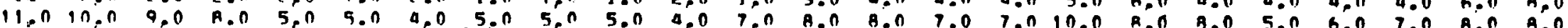

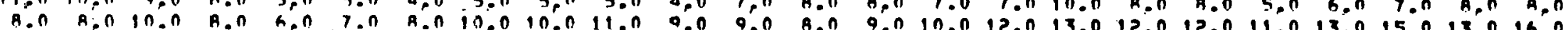

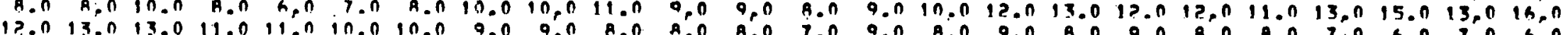

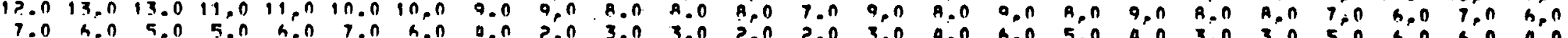

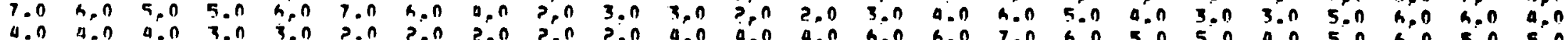

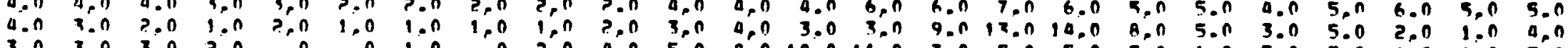

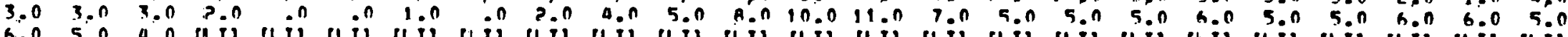

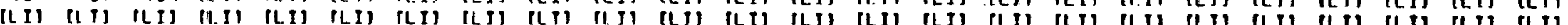

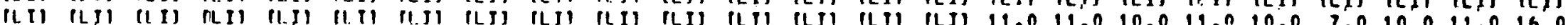

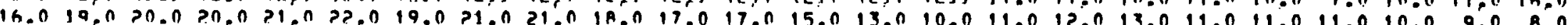

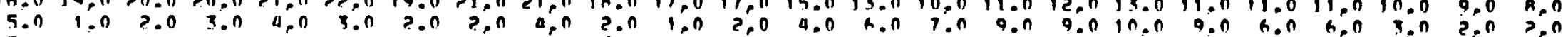

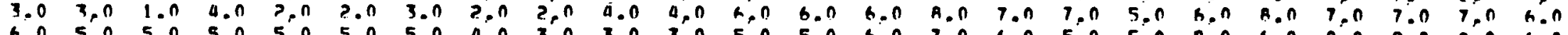

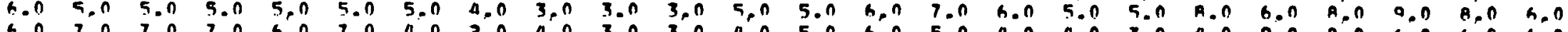

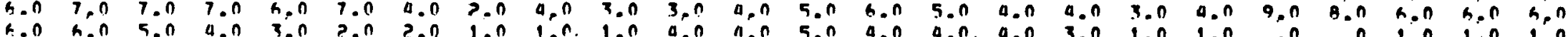

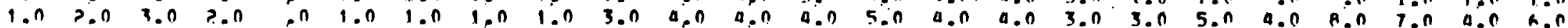

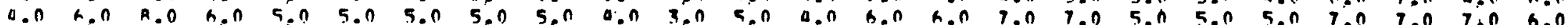

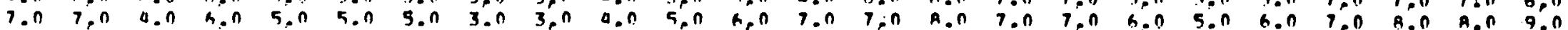

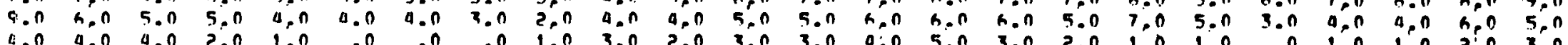

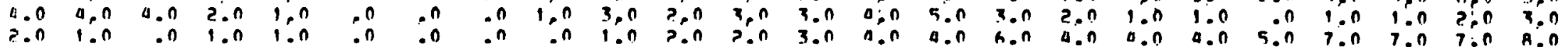

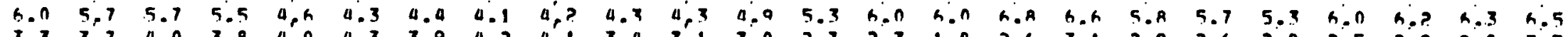

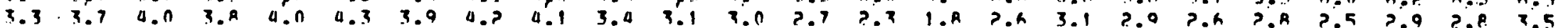

a.? A, 5.? 11.0 4. $9 . . n$ 5.50 .0 $2.8 \quad 0.0$ $\log , \ln . n$ a 70 ? 7.1 $3.1 \quad B .0$ $7.011 . n$ $10,316.0$ A, $013, n$ $0.57 . ?$

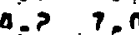
a 0 ia. Q.? 5.5 in 5.n h.n in:a is.n 15,2 ?? $n$ 4.3 in, n $3, A$ A., 5300 ?. 7 6. 3.0 a.n 5.5 ค. ก 6.0 9.n 4,9 9. 3.950 5.513 
WTAN SPEFn rerinil

MIIES/HOIR

LEVFI. HEIGHT IO METFRS
RATTEIIF WINA STIUNY, HEAS TFHACHAPI MTNS. C.A.

MTTF Q

AllG: 1979

AEROVTRONMENT INC.
PRELIMINARY DATA

AS DF PR/AIIG/RO

\section{SUPJECT Tn}

DEVISTON

Clock hOUR [loCAL STANDART TIME]

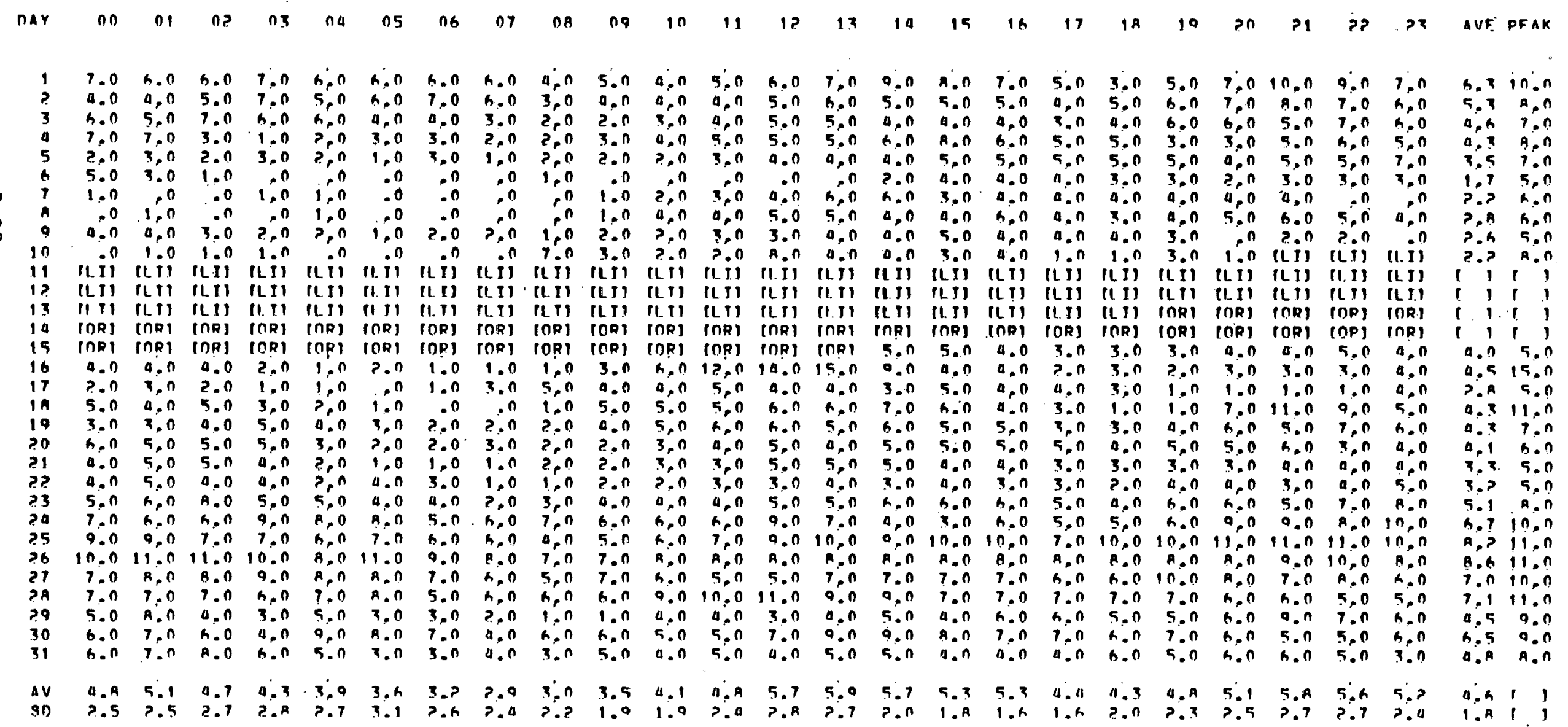


WTAN SPFFn PrCinil

MILES IHOUR

LEVFL HEITHT: IO MFTFRS
AATTFII.F WTNO STIINY, Z5AE

TENACHAPI MTNS. CA.

SITE

SFP. 1070

AEROUIRONMENT TINC:

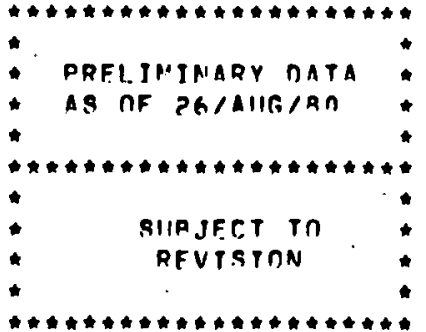

CIIDCK HOIIR ILOCAL STANDART TIMFI

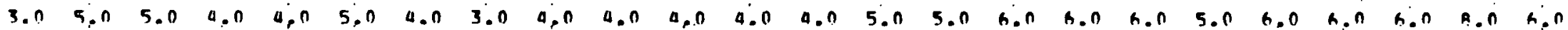

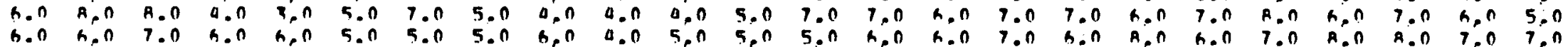

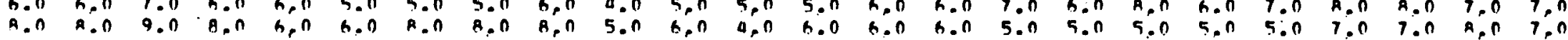

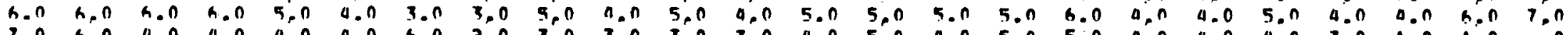

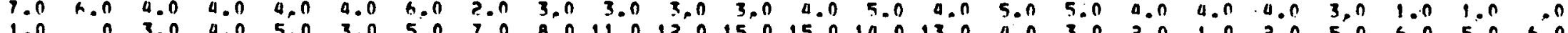

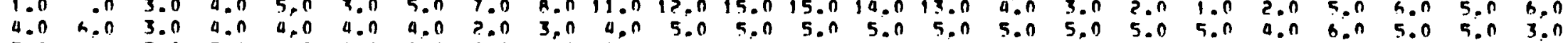

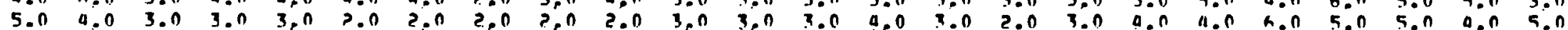
5.0 a. 2.0 3.0 3.0 3.0 3.0 3.0 ?.0

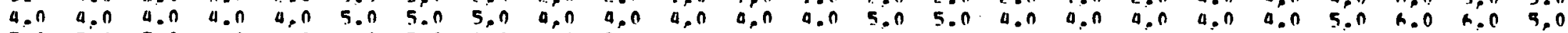

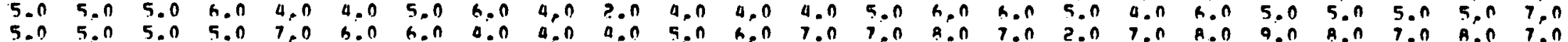

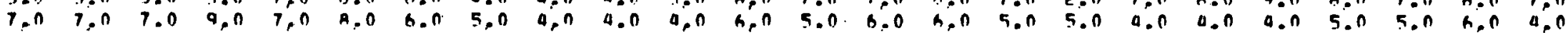

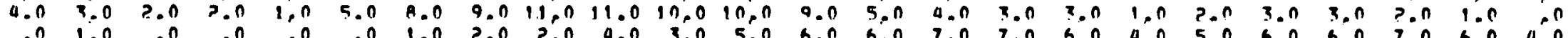

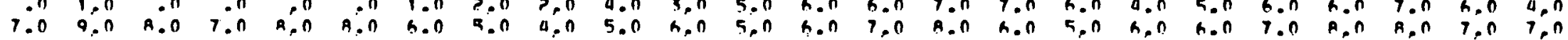

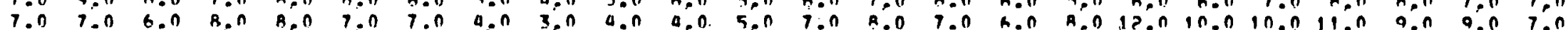

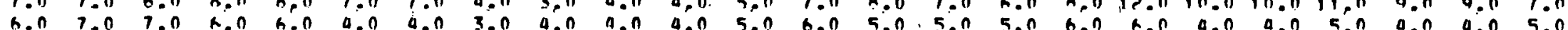

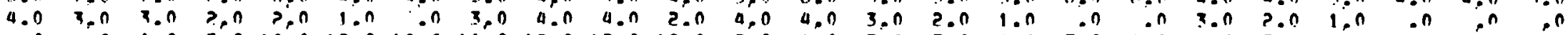

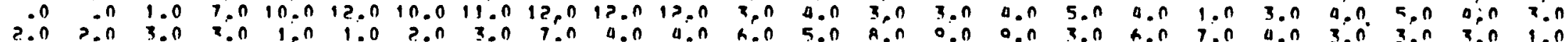
$3.0 \quad 3.0 \quad .0, .0 \quad .0 \quad .0 \quad 3.0 \quad 7.012 .016 .015 .014 .014 .014 .011 .010 .0 \quad A .0 \quad 9.0 \quad 9.010 .0 \quad 0.011 .013 .011 .0$

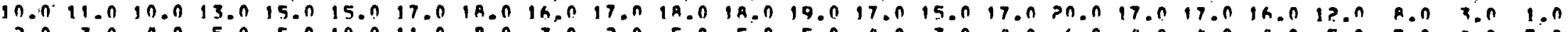

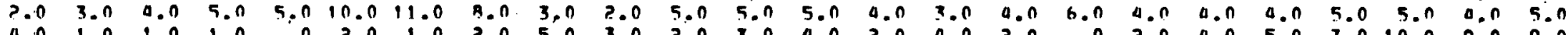

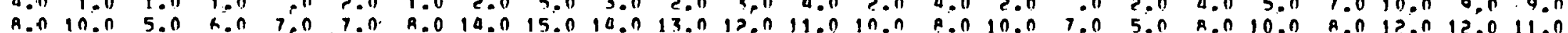
R.n

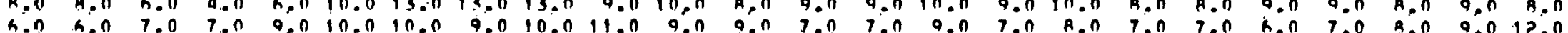

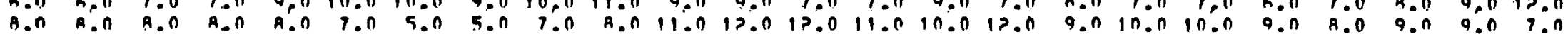

$.0 \quad 0.0$ $\therefore$ a. h.. .1 .0$ $\because .0,0$ 3.71 .0 h.3 15.0 I. a h. $n$ $3.4 \mathrm{h.n}$ . A h.n $.5 \mathrm{~h} . n$ n.9 7.0 h.1 0.1 .5 i. 377.0 h.t 0.0 $7.30 . n$ 5.n $7 . n$ b. 0.2 .0 5.512 .0 $.10 . n$ a. 1h.n la.? ?ก.n A. $11 . n$ 3.510. Q.h 15.0 A.9 13.0 A.? $1>. n$

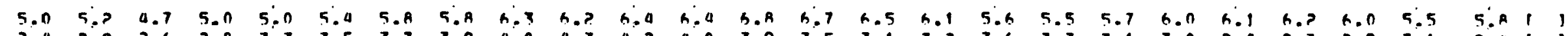

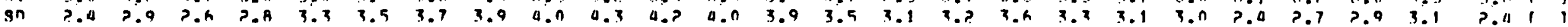


WINA SPEFA trrinil

MILESIHOUR

LEVEL HEIGHT; IN METFRS
AATTELLE WTNO STIINY. Z5OS

TEHAT.HAPI MTNS. CA.

STIF

nCt. 1979

AFROVIRONMFNT INC.

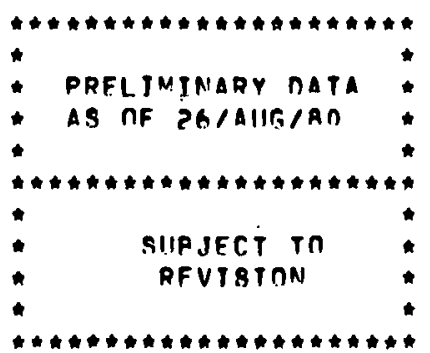

CLOCK HOHF ILOCAL STANDARO TIMFI

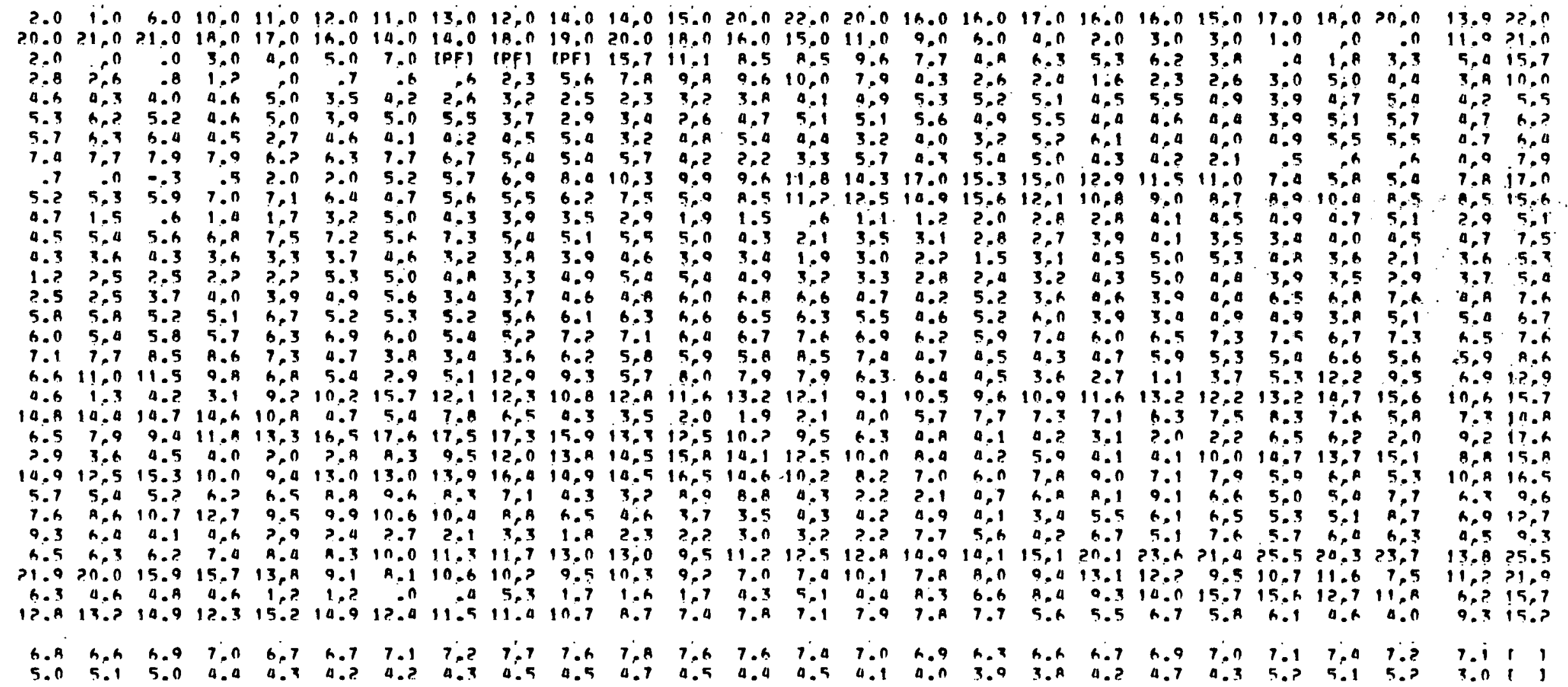


WINO SPEFn Proinil

MILES/HOIIR

LEVEL HEIGHT \& 10 MFTERS
AATTELIE WINA STIINY. WEAS

MTNS. CA:

SITE

Nov. 1979

AFRAVTRONMENT INC.

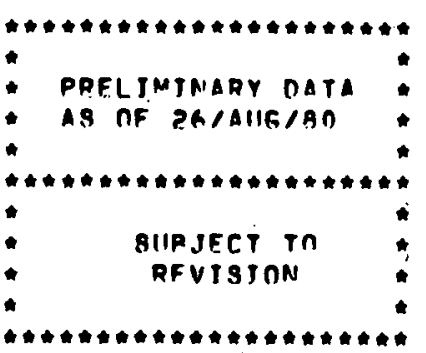

CLOCK HOHR II.DCAL STANDARN TTMEI

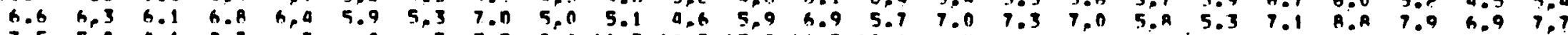

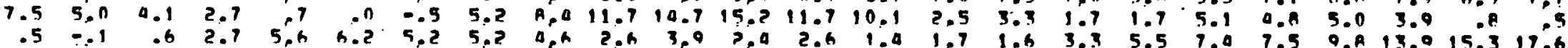

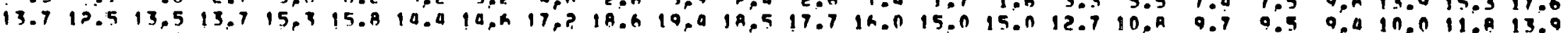

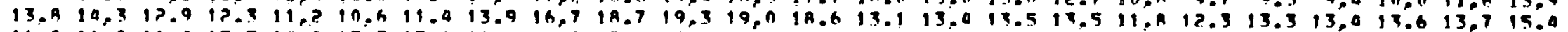

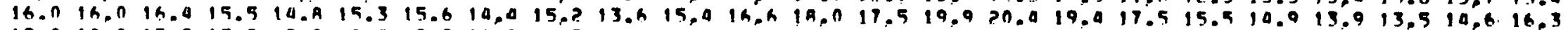

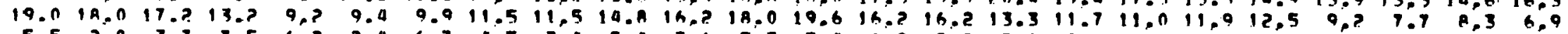

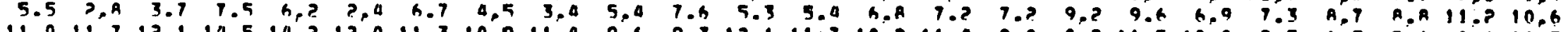

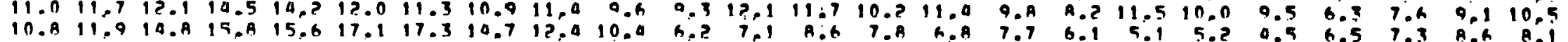

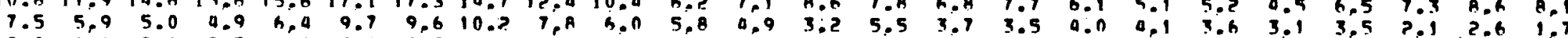

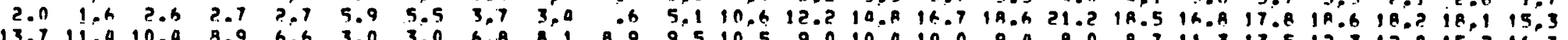

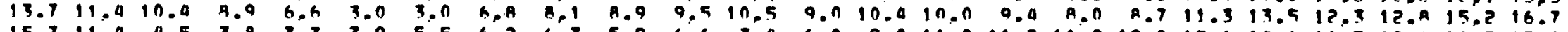

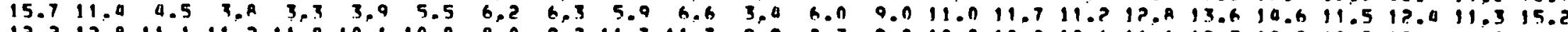

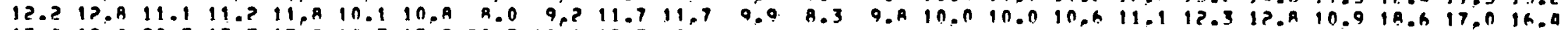

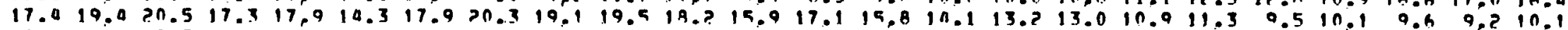

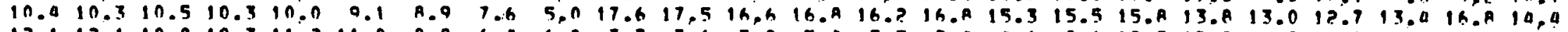

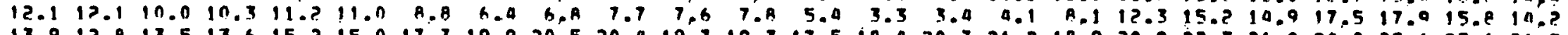

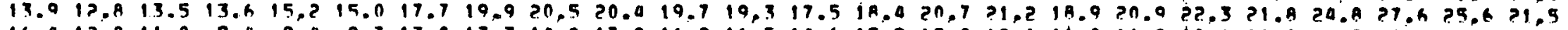

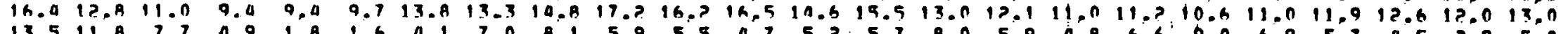

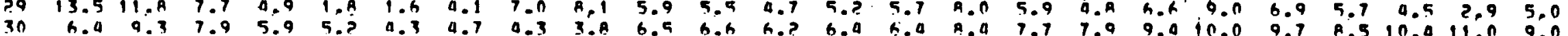


WTNA SPEEN Ircinit

MILES/HOUR

LEVEL HEIGHT: In MFTERS
RATTFLLF WINO STIINY, HERS

TEHACHAPI MTNS, RA.

STTE

DEC. 1079

AFROVTRONMENT INC.

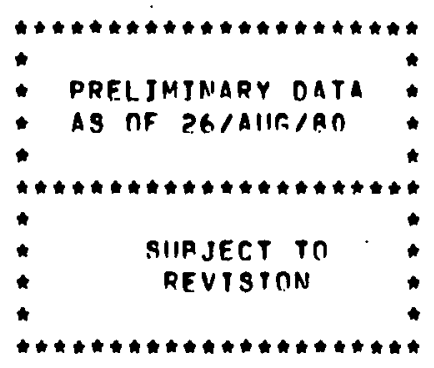

CLOCK HOUR [I.OCAL STANDARN TIME]

DAY

00

n) 02

03

05

OH

nT $O R$

$n 9$

1011

is.e 17.717 .017 .310 .910 .416 .015 .113 .113 .912 .610 .010 .9

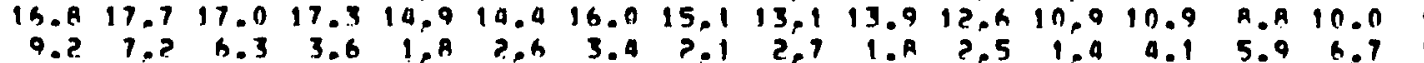

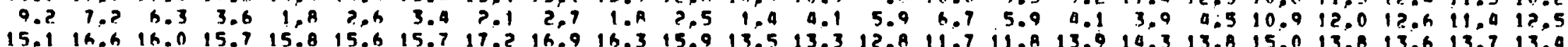

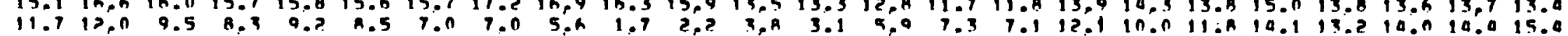

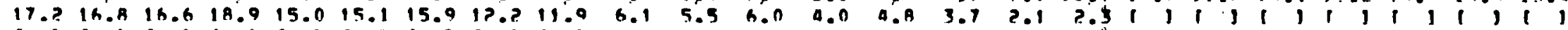

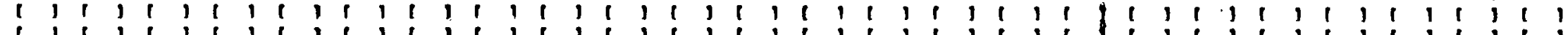


WINA SPEEA rrcinis

\section{MIIES/HOUR}

LFVEL HEIGHT: 10 MFTERS
BATTFILE WINO STIINY. FEAS

TEMACHAPI MTNS. R.A

SITF

JIL. 1979

AEROVIRONMFNT INC.

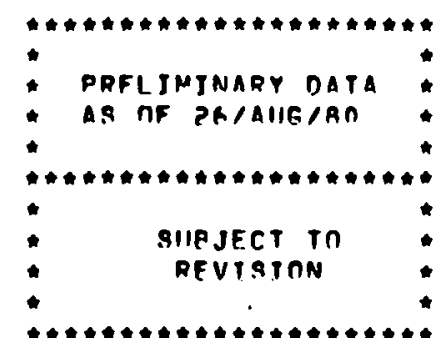

ClnCK hOUR IInCal stannarn tine]

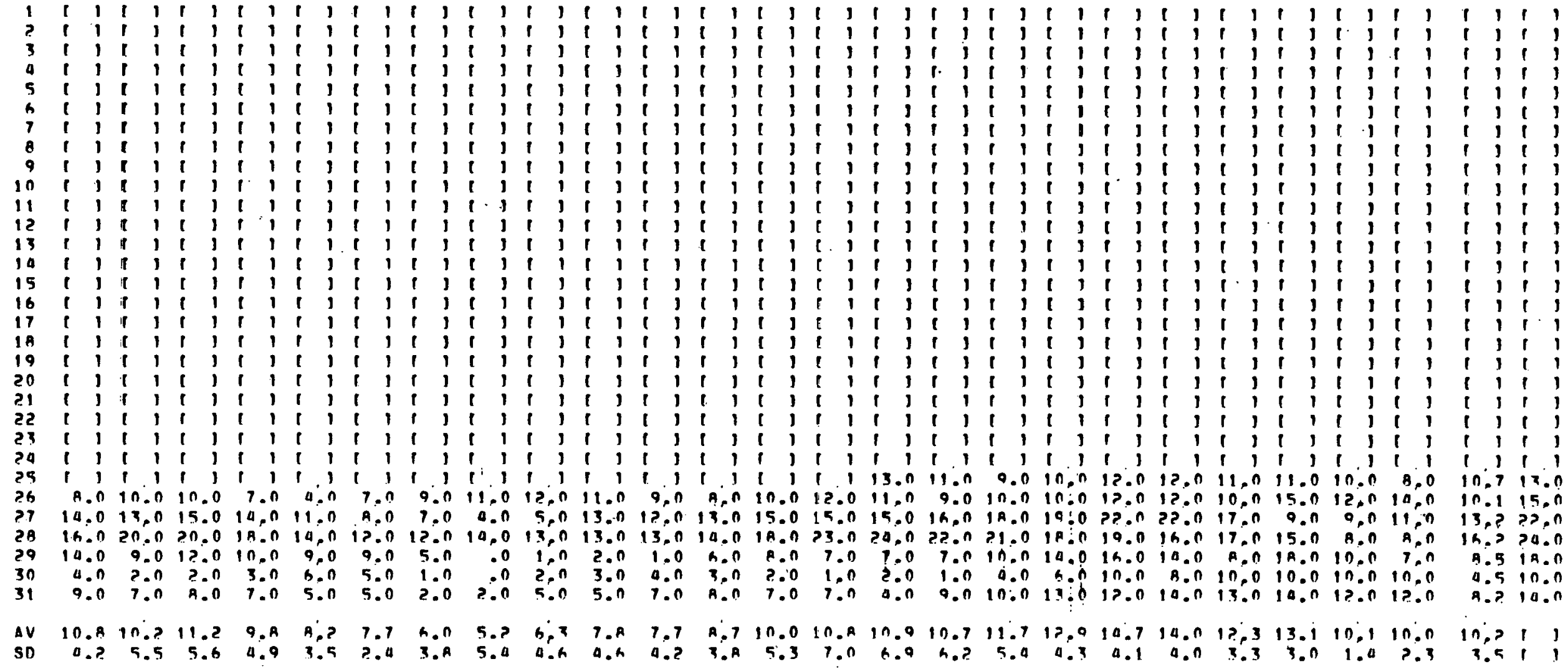


WTNO SPEEN Irrinil

MILES/HOIIR

I.EVEL HFIGHT : IO MFTERS
BATTFLLE WINO STUNY,WEOE TEHACHAPI MTNS, CA.

STTE

Al16. 1079

AEROUIRONMFNT INC.

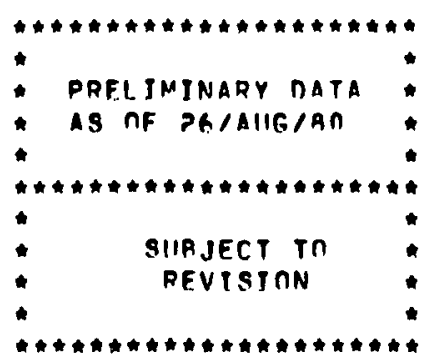

CI. HCK HOUR [LOCAL STANMARN TTMEJ

$1 \quad 14.013 .012 .013 .013 .015 .014 .010 .013 .013 .015 .019 .019 .018 .019 .019 .020 .022 .021 .020 .019 .016 .011 .013 .0$

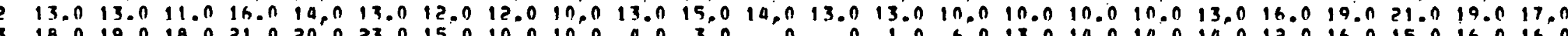

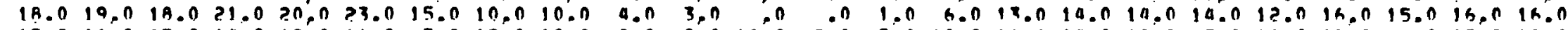

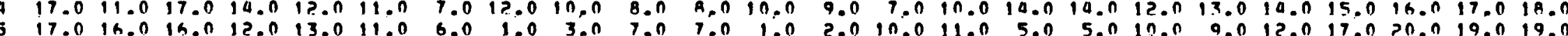

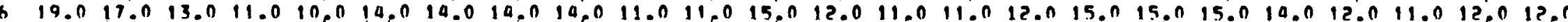

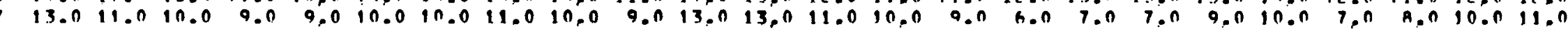

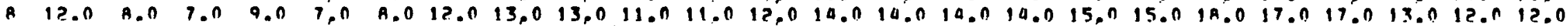

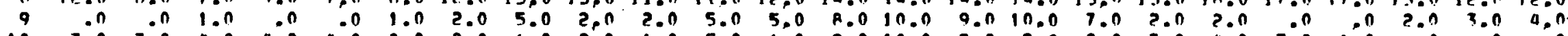

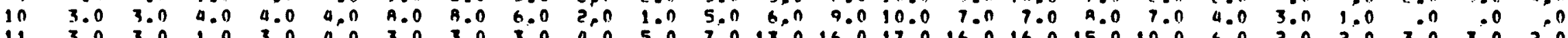

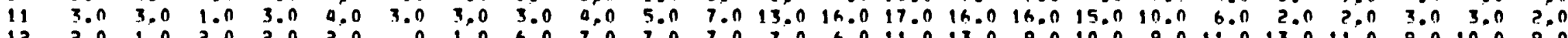

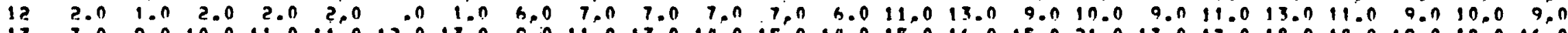
$137.0 \quad 9.0110 .011 .011 .012 .013 .0 \quad 9.011 .013 .014 .015 .014 .019 .016 .015 .0121 .017 .017 .018 .018 .019 .018 .016 .0$

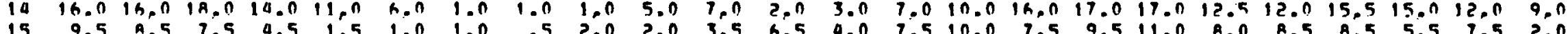

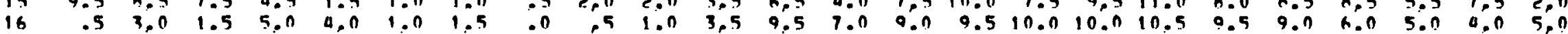

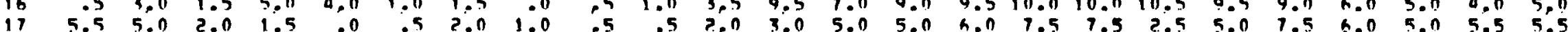

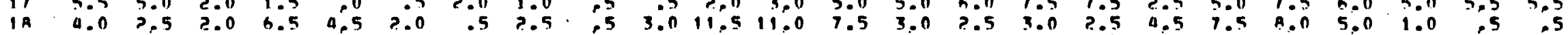

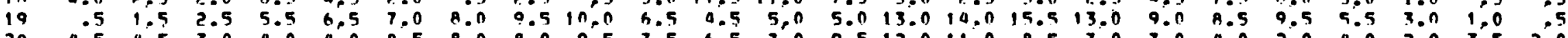

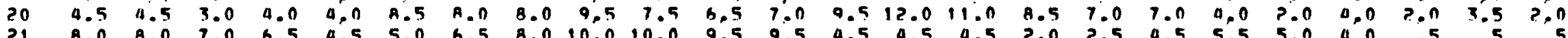

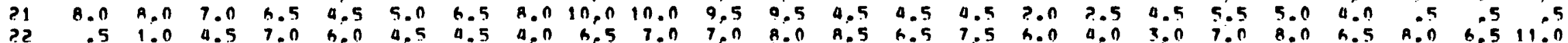

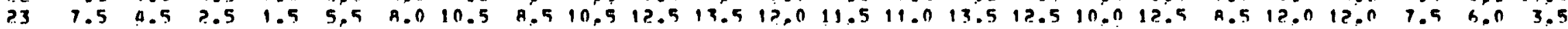

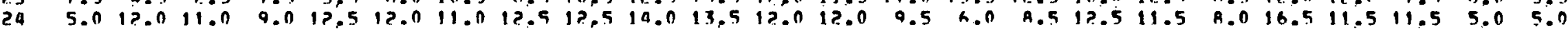

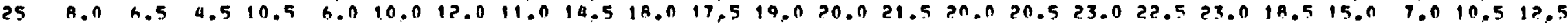

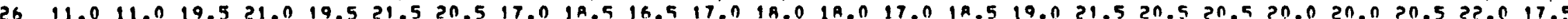

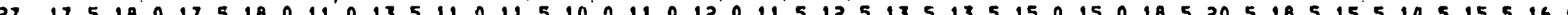
QA $15.015 .013 .013 .513 .510 .513 .011 .511 .012 .013 .016 .017 .016 .015 .515 .513 .511 .010 .510 .5 \quad 7.0 \quad 9.0 \quad 4.5 \quad 7.0$

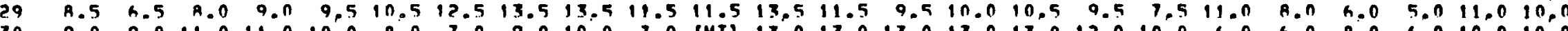

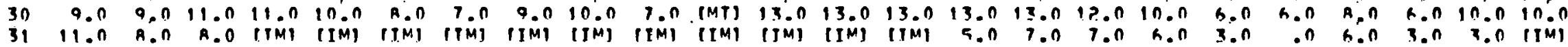

14,$0 ; 0,0$ $13.2 ? 1 . n$ $13.0,0.0 .0$ $13.318,0$ ln. 4 >n $13.1,19.0$ 12018.0 3.3 in.n a.e in.o h.7 $17 . n$ h. $013 . n$ $14.1>1.0$ ln.? IA, $5,711 . n$ 5.? 10.5 11.0 i 11.5 3.011 .5 h.o 15. h. 1 1?.? $5.510 . ?$ h. $011 . n$ 9.112 .5 10.616 .5 14.623 .0 IA.h ??. n 14.h ?n.5 17.317 .0 $9,013,5$ 9.713 .0 9.511 4.011 
WINA SPEEN rrcints

MTLES/HOUR

LEVEL HETGHT: 10 MFTERS
BATTELLF WINO STUNY, E505 TEHACHAPI MTA'S, CA.

STTE

SFP. 1999

AEROVIRONMENT TNE:

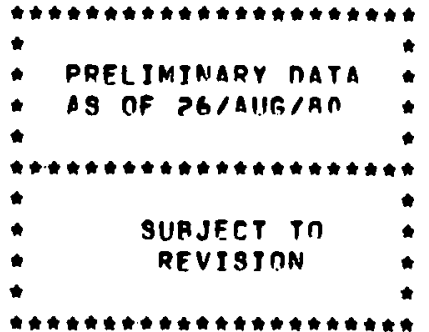

CLnCK HOUR ILDCAL STANBART TIMEI

Dar

$00 n 1$

n2

03 no

05

06

n)

nR

$09 \quad 10$

11

12

13

$14 \quad 15$

16

17

18

19

20

2

?3

AVE PEAK

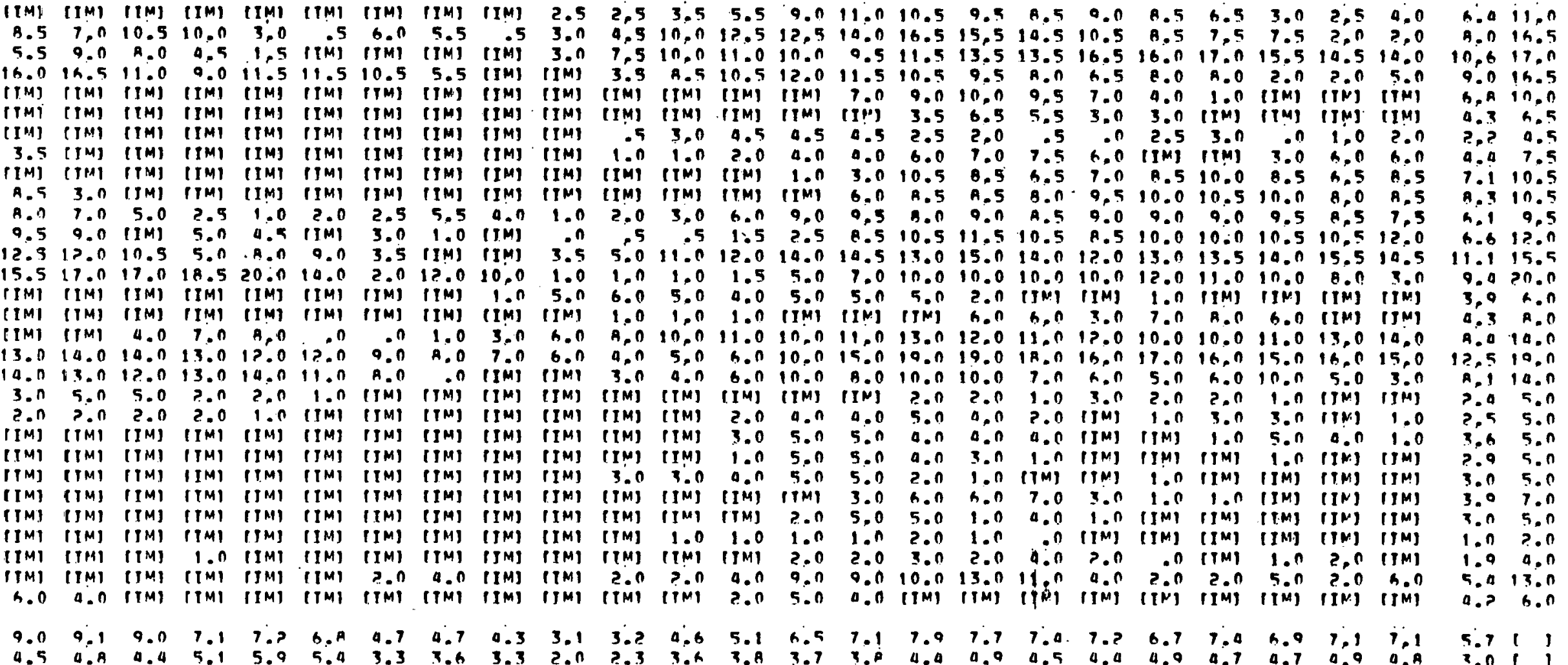

inour

I11 A:AY 791 
WTNA SPEFn icrinit

MILFS/HOIR

LEVEL HEIRHT : In MFTERS
RATTFLLE WTNN STIINY. \#ERE TEHACHAPI MTNS, CA.

SITE

OCT. 1979

AFROVIRTNMENT INC.
*

- preliminary outa

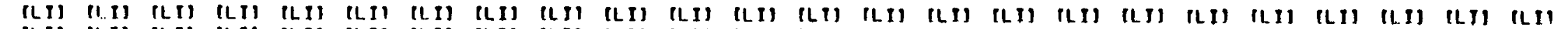

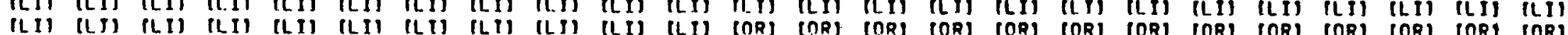

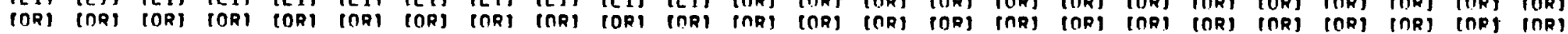

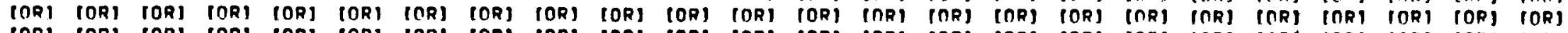

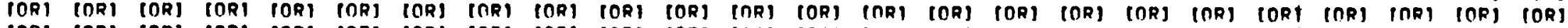

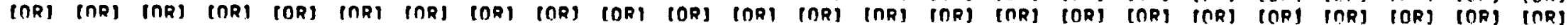

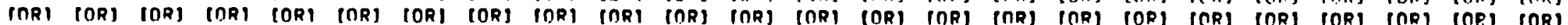

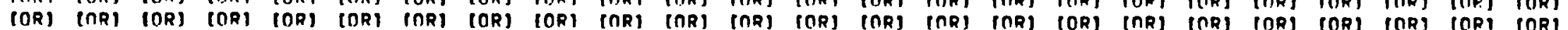

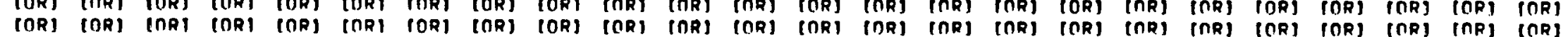

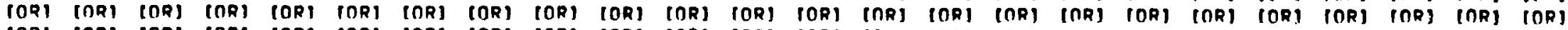

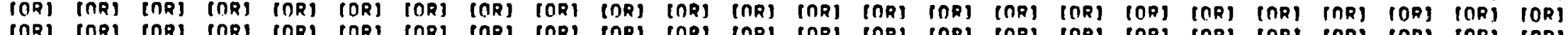

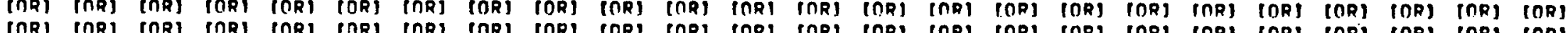

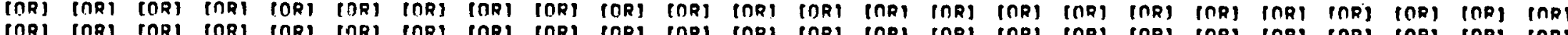

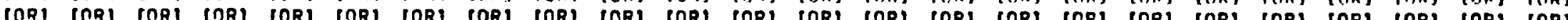

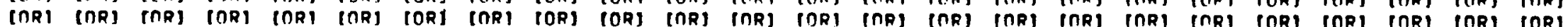

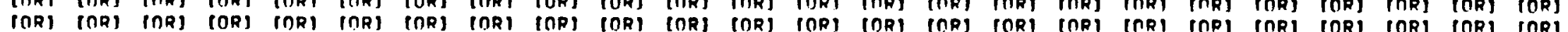

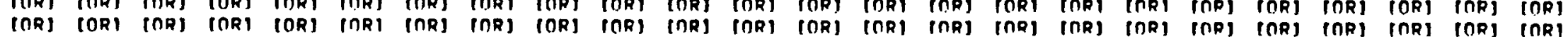

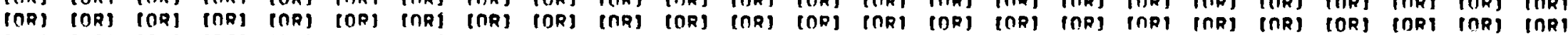
[OR] [OR] [OR] [OR] [OR] [OR] [DR] [OR] [OR] [OR] [OR] [OR] [OR] [OR] [OR] [OR] [OR] [OR] [OR] [OR] [OR] [OR] [OP] [OR]

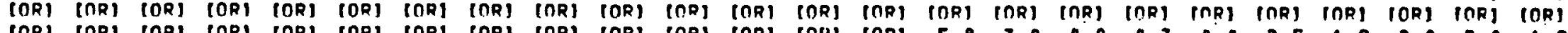

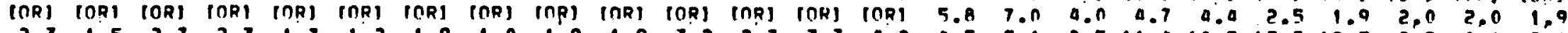

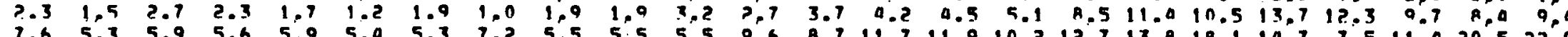

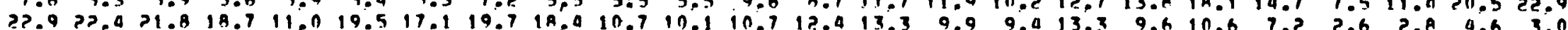

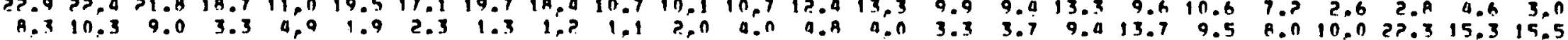

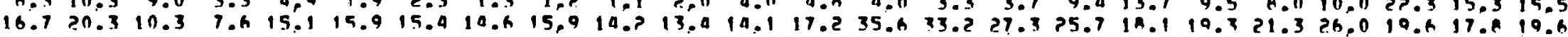

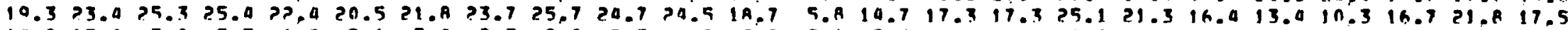

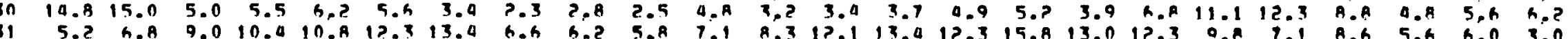


WTNA SPEF. Ir.cinil

\section{MILES/HOUR}

LEVFL HEIGHT \& 10 METERS
BATEILF WTNA STUDY HERS TFHACHAPJ MTNIS. CA.

STTF

NOV. 1979

AFROUTRONMENT INC:

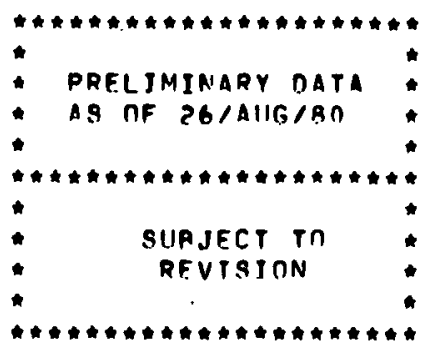

CLOCK HOIIR (LOCAL gTANDARO TIMEJ 
wiNn spFen recinis

MTI.ES/HOIIR

LEVEL HEIGHT: 10 METERS
RATTFILF WTNO STIINY. HSOS TFHACHAPI MTNS, CA.

SITF

JUN, 1979

AFROVIRONMENT INC.

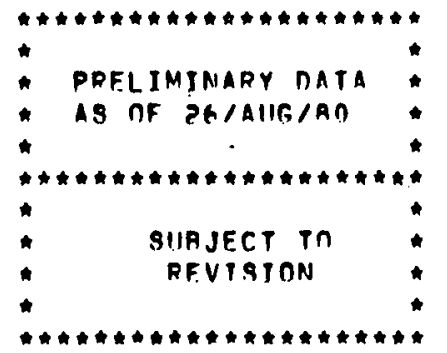

ClOCK hDIR ILDCAL STANDARO TINE)

DAY

on

0102

03

n4

$05 \quad n h$

n)

A 19

101

. 12

13

10

19

17

1 A

19

20

21

$2 \dot{2}$

23

AVF PEAK
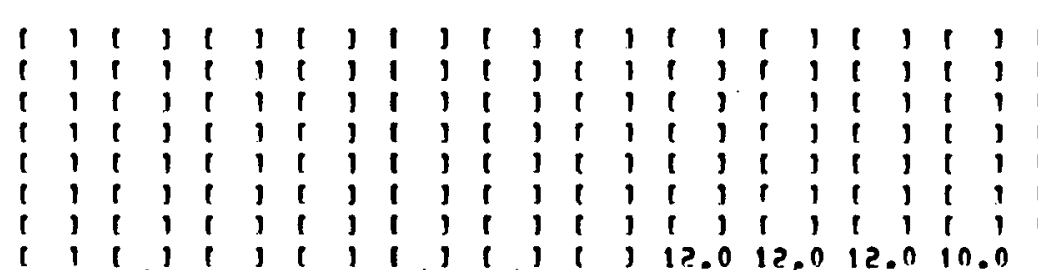

$\begin{array}{ll}1 & 1 \\ 1 & 1 \\ 1 & 1 \\ 1 & 1 \\ 1 & 1 \\ 1 & 1\end{array}$

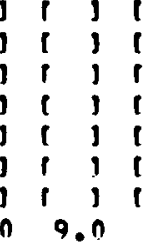

$\begin{array}{lllll}1.0 & .0 & .0 & .0 \\ 5.0 & 3.0 & 3.0 & 3.0 & 3 .\end{array}$

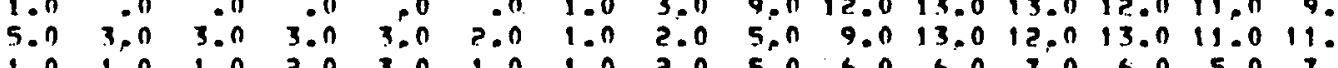

$\begin{array}{rlll}1.0 & 0.0 & 3.0 & 1.0\end{array}$

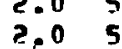

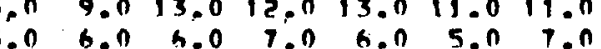

3.06 .03 .0

3.03 .03 .0

5.00 .0

$0,5, n$

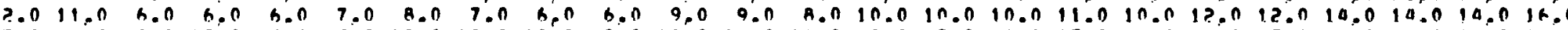

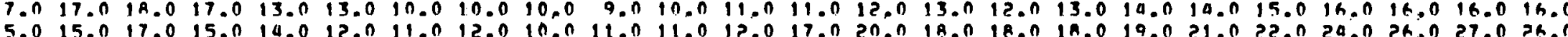

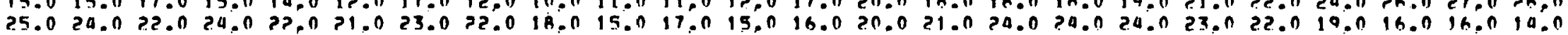
15.014 .015 .014 .012 .0 A.n B.0 10.013 .011 .013 .0 12.0 13.014 .018 .012 .013 .015 .014 .014 .011 .013 .010 .010 .0

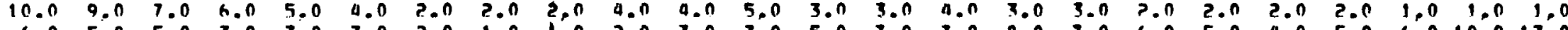
14.017 .015 .015 .015 .013 .011 .012 .010 .010 .012 .013 .013 .010 .015 .016 .016 .018 .016 .014 .019 .015 .019 .019 .0

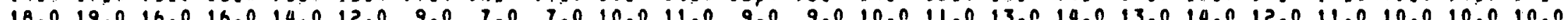

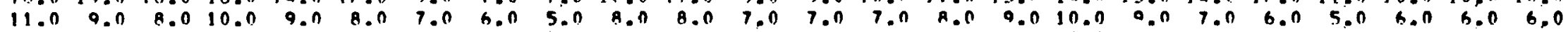

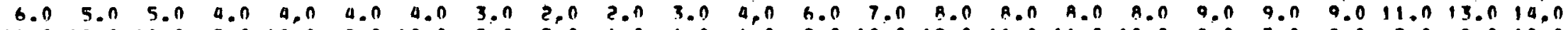

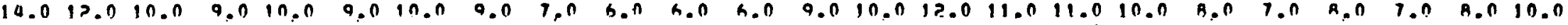

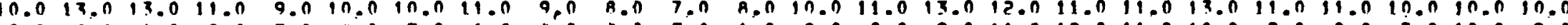

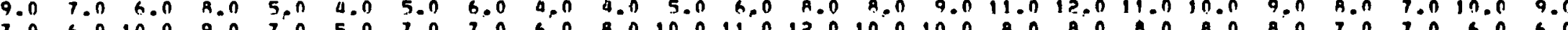

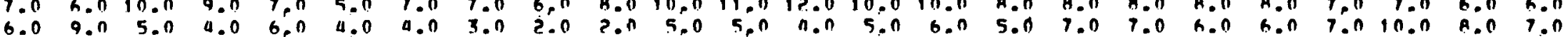

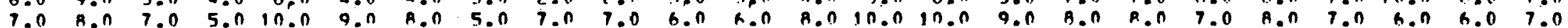

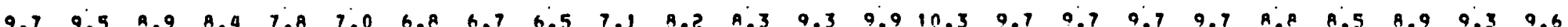

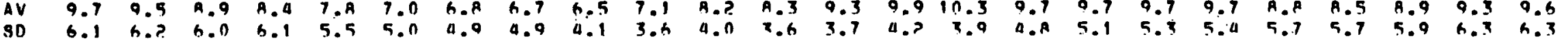
1111

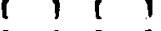
111 i 110 1 l 13 $\begin{array}{llll}1 & 1 & 1 & 1\end{array}$ $6.512 . n$ 5.013 .0 5.313 .0 $3.57 . n$ n.1 2.0 0.9 is.n 9.A Ih.n 12.5 IA.n 17.1 ?7. $2 n .325 . n$ 12.416 .0 3.610 .0 5.013 .0 $14.4+9.0$ 11.900 $7.611 . n$ 6.5 14.0 9.1 14.n 10.513 .0 7.512 .0 ค. $n 1 ? .0$ 5.510 .0 7.510 .0

ADกUT

111 MAY 791 
M:TLFS IHNIJR

LEVEL HEIGHT: 10 METFRS
HATTFLIE WIMN STIUNY ESES TEHACHAPI MTNS, CA. STTE $h$

JIL. 1979

AFROVIRTNMENT INC.

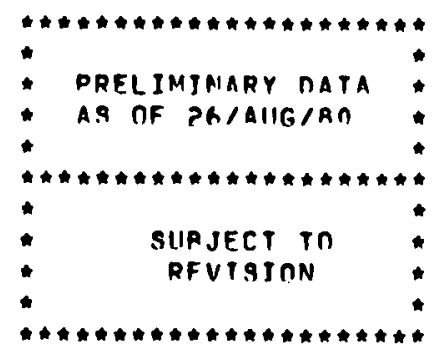

CLOCK HOII ILOCAL STANDART TIMEI 
WTNO SDEFN RCCONII

MULES/HOIIR

LEVEL HEIGHT: 10 METERS
RATTEIIF WTND STIINY,HSOS TFHACHAPI MTNS, CA:

SITE $h$

AIJE. 1979

AEROVIRONMENT INC.

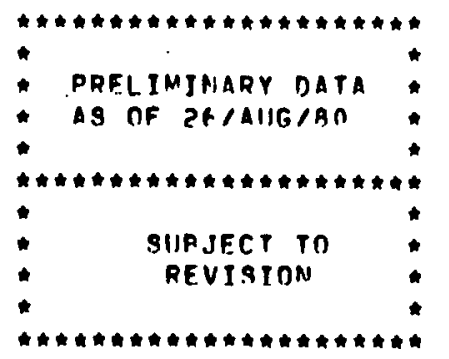

CLOCK HOUR (LOCAL STANDARO TTME)

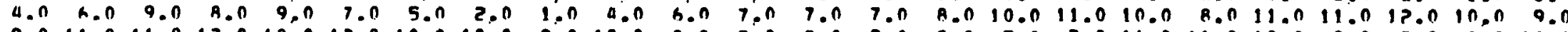

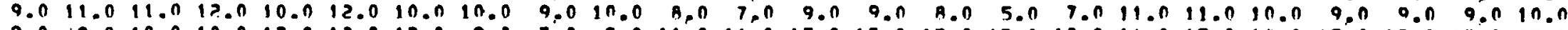

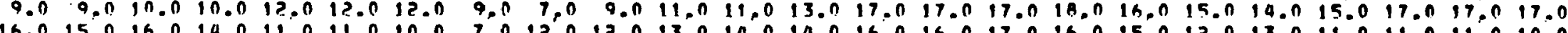

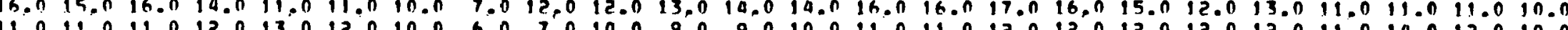

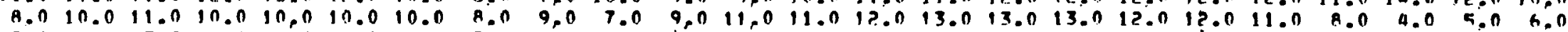

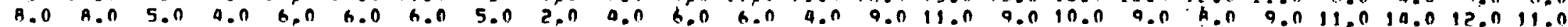

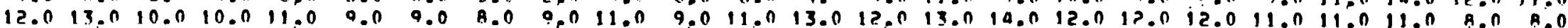

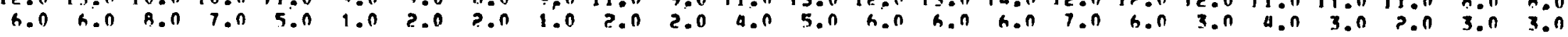


WIMT SPEFN rerintl

MII.ES/HOIIR

LEVEL HEIGHT : IO MFTERS
BATTFLIE WINA STIIDY. \#5NS TFHACHAPT MTNS, CA.

STTE.

SEP. 1979

AFROUIRONMENT INC.

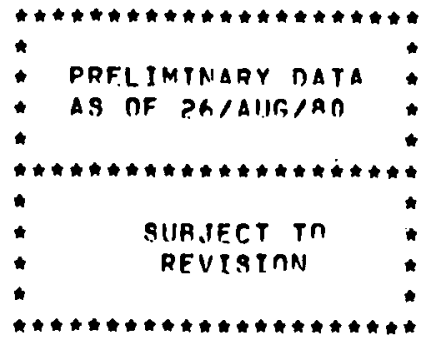

CLOCKK hOIIR ILOCAL STANIMAPD TIME]

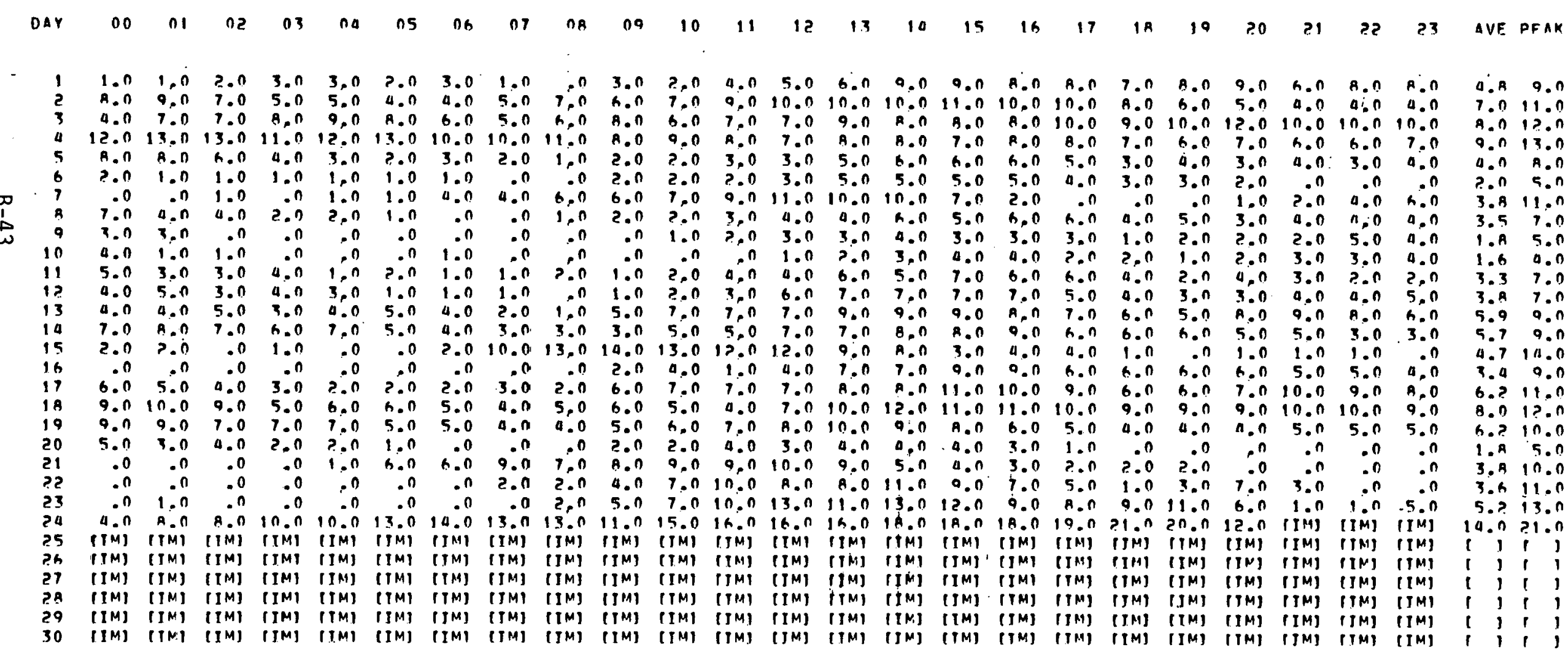

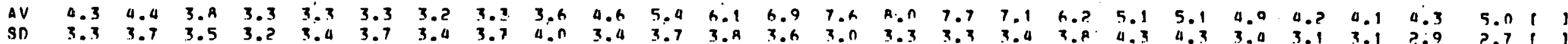


WTMn spFFn Irring

MTLES/HOIIR

LEVEL HEIGHT: IN METERS
RATTFILF WIJN STIJNY, \#ERE

TFHACHAPJ MTNS, CA.

STTE

nCt. 1979

AFROVIRONMFNT INC.

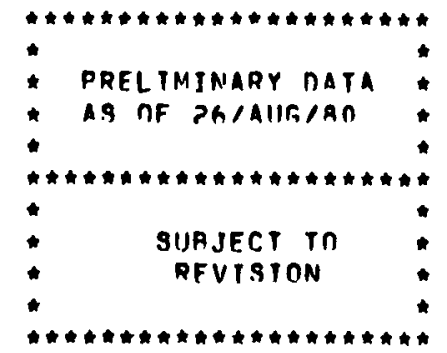

CLOCK HOLR LLOCAL STANDARD TIME]

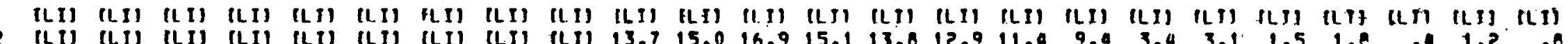

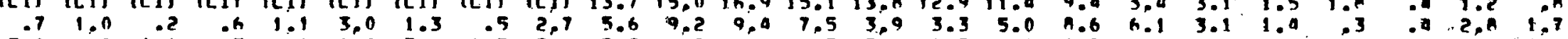

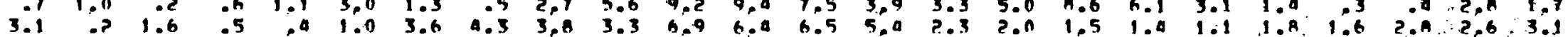

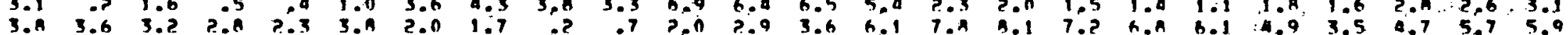

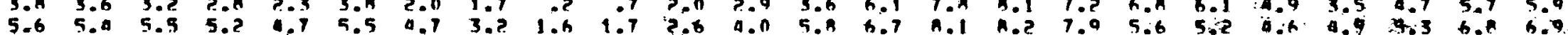

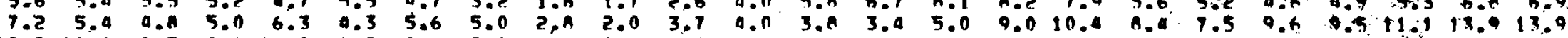

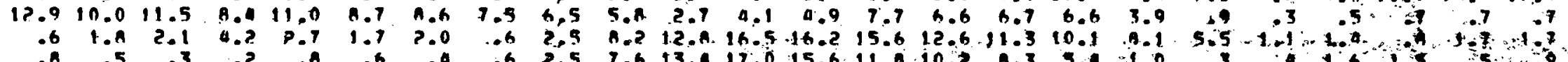

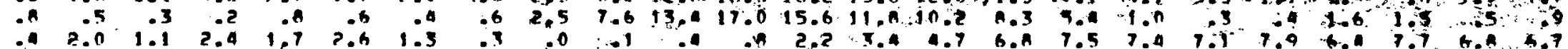

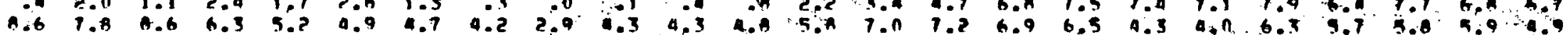

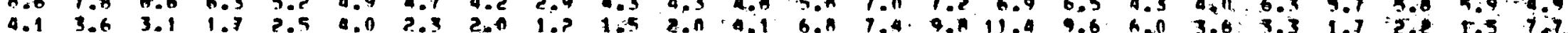

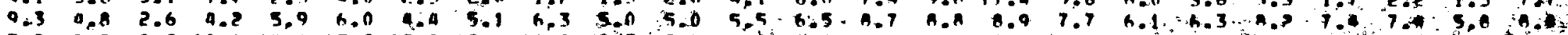

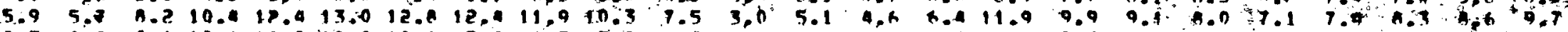

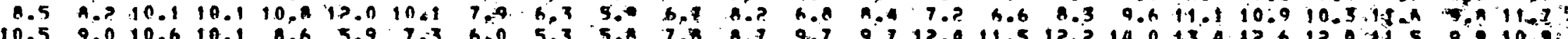

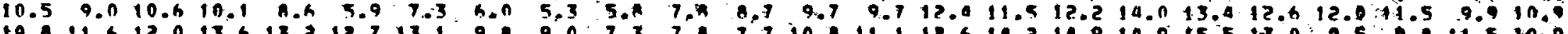

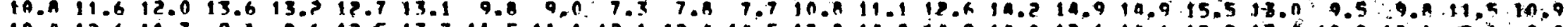

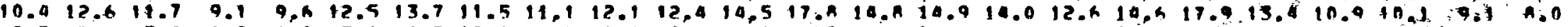

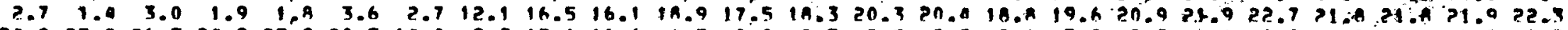

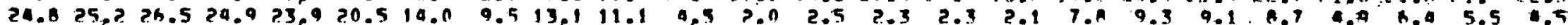

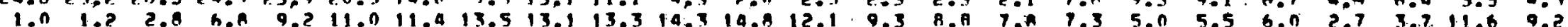

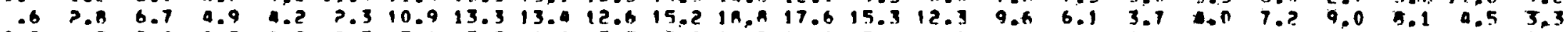

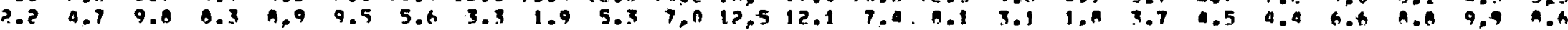

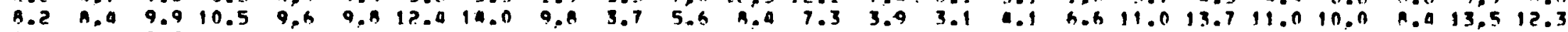

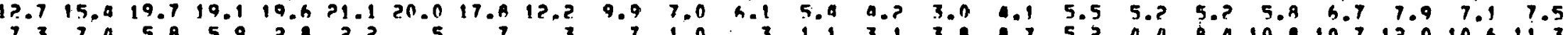

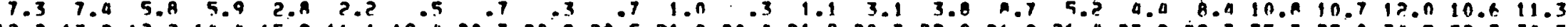

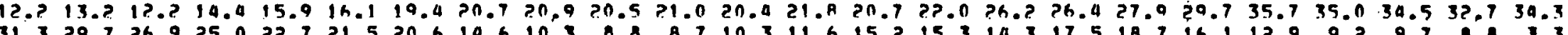

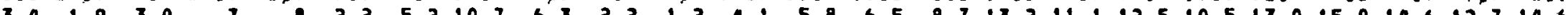

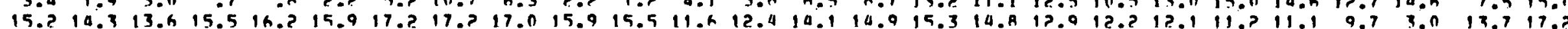

i l 1 h.t 14.9 3.39 .0 2.9. A.9 4.19 .1 5.> $A .2$ h.. 13.9 5.712. 5.4145 3.79 5.7 .66 1.t1: 6. 9.3 $=0.130$ $9.4=190$ 9.A 1.4. $11.6+1.5$ 18.517 .9 14.520 .7 11.134 .5 a ia 1.6 1A.A 6.5 17.5 9.019 .0 10.321 .1 5.712 .0 $23.1 \quad 35.7$ 16.931 .3 6.915 .3

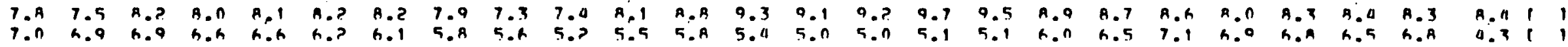


WIN!n SPFED Ir.r:OII

MIIFS/HOUP

LEVEL HEIGHT: 10 METERS
BATTFLLF WTHO STIINY, HERG

TEHACHAPI MTNS, CA

STTE

Nov, 1979

AEROVIRONMENT INR.

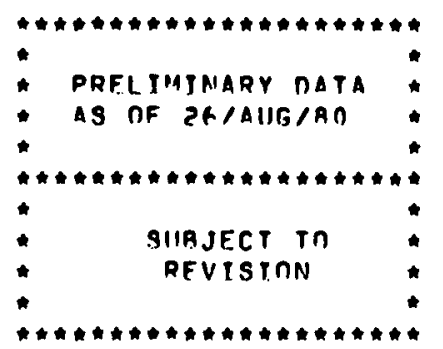

CLDCK HOIIR PLOCAL STANDARA TIME

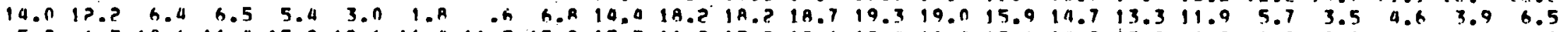

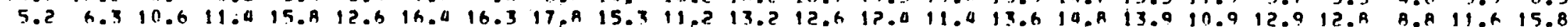

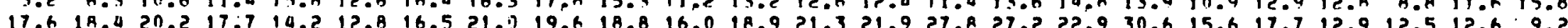

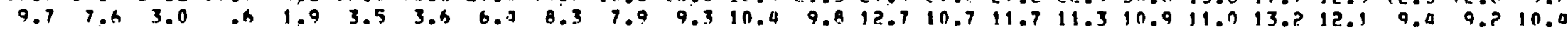

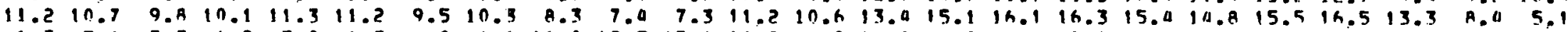

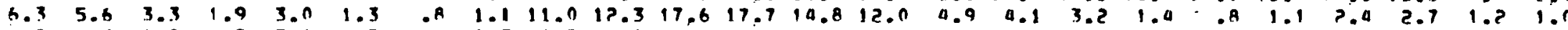

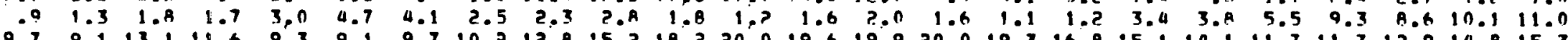

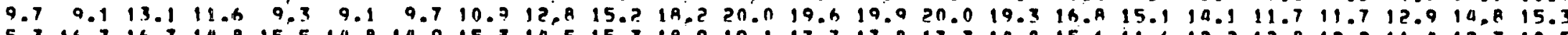
15.3 1h.7 16.7 14.A 15.5 14.A 14.9 15.3 10.5 15.3 18.9 19.1 17.7 17.A 17.3 10.A 15.h 11.A 1?.? 12.A 12.? 11.4 1?.3 10.5

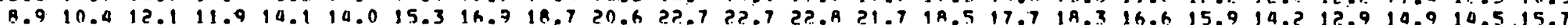

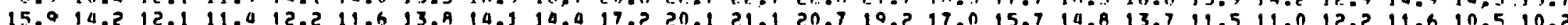

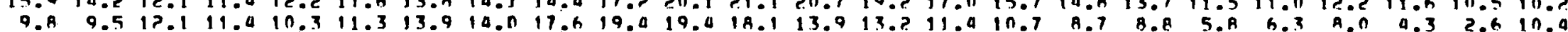

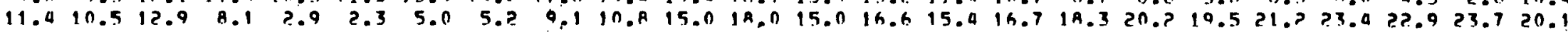

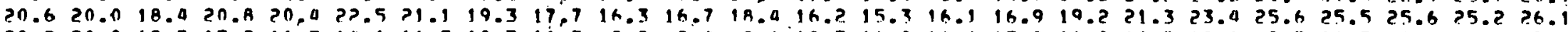

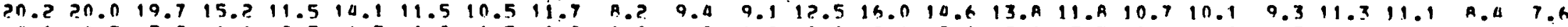

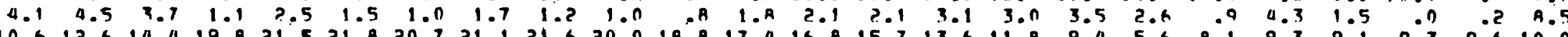

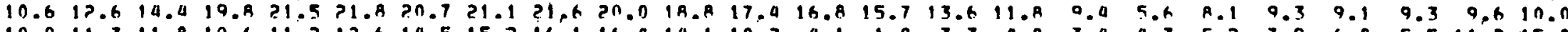

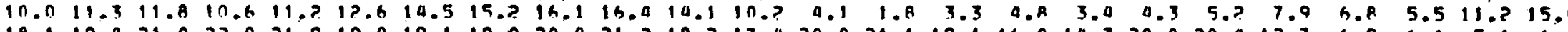

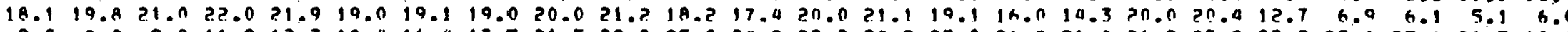

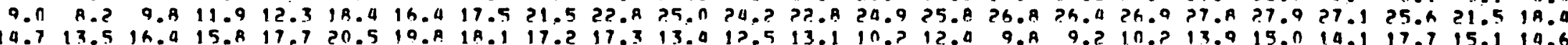

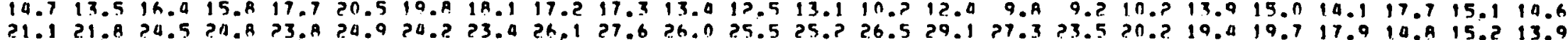

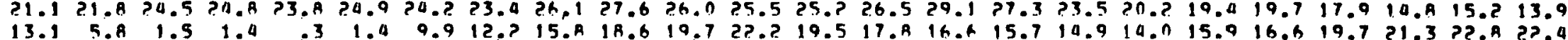

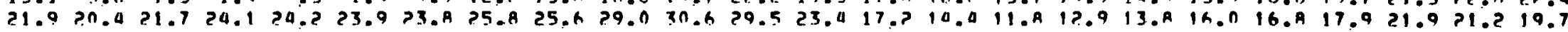

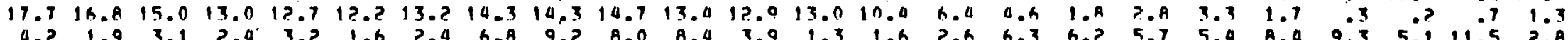

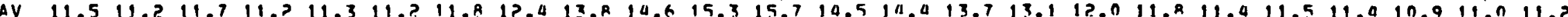


WINA SPEEN ercinil

MTLES/HOUR

LFVFL HEIGHT; 10 METERS
AATTEI.IE WINA STIINY. H5OS

TFHACHAPI MTNS. CA.

SITF

OEC. 1979

AFROVIRONGENT INC.

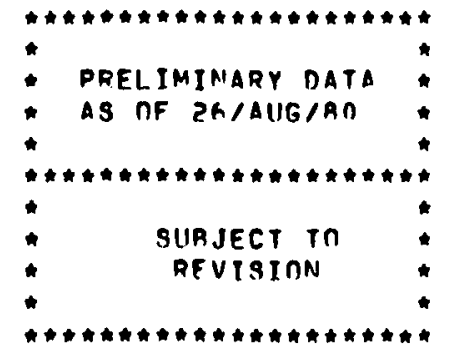

CLOCK HOIR ILOCAL STANDARO TJMFI

\section{5.}

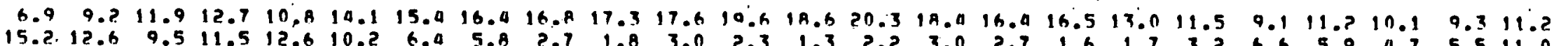

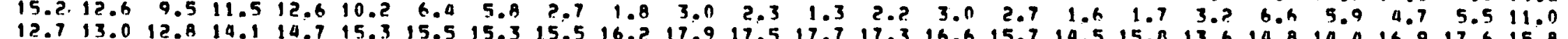

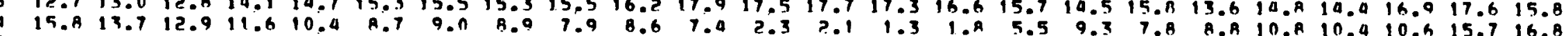

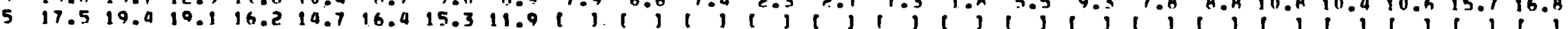

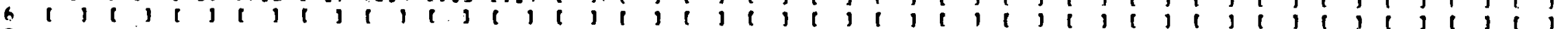


WTNO SPEEN Irrignil

\section{MTLES/HOUR}

LEVEL HEIGHT: 10 METFRS
PATTELLF WTNA STIINY. BSES

TEHACHAPI MTNS, CA.

SITF

JIIL. 1979.

AEROVIRTMAENT INC.

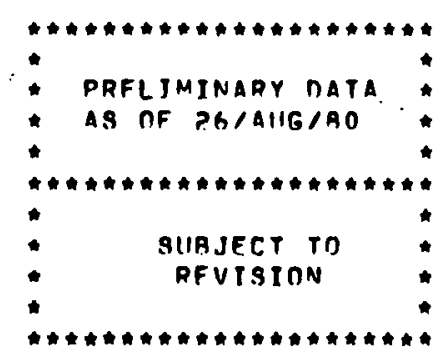

CLOCK HOIR [LOCAL STANDARD TIME] 16.016 .017 .016 .016 .016 .015 .015 .010 .013 .013 .015 .015 .016 .016 .019 .017 .017 .017 .022 .025 .021 .018 .021 .0 22.020 .019 .019 .019 .015 .013 .012 .0 9.0 10.011 .013 .012 .013 .013 .013 .013 .013 .010 .013 .011 .010 .010 .011 .0

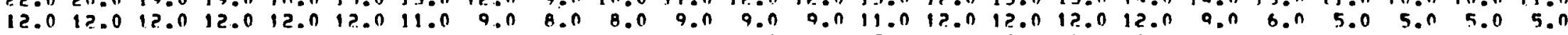

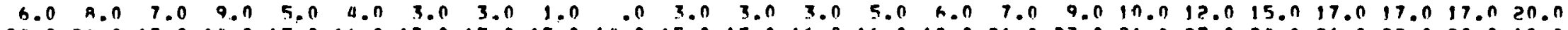

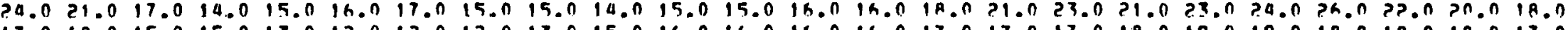

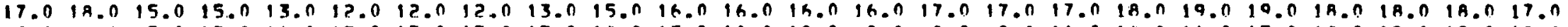

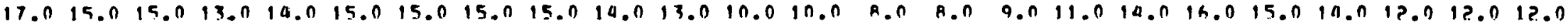

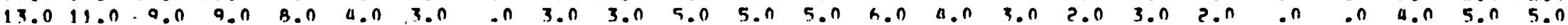

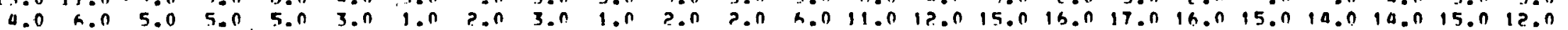


WTMD SPEFn rering

MILES/HOIIR

LEVEL HEIGHT: IO MFTFRS
PATTFLIE WTND STIINY, 5505

TEHACHAPI MTNS, CA.

SITF

AllG. 1079

AEROVIRANMENT INC.

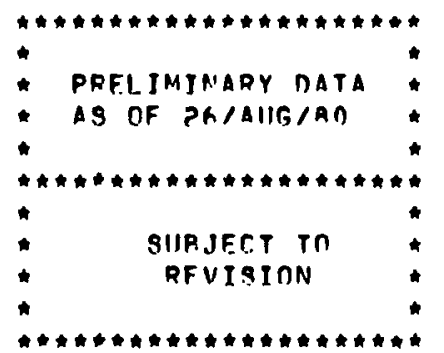

CLOCK HOIIR. ILOCAL STANDARO TIME

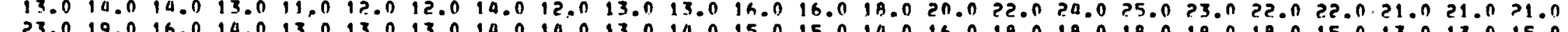
16.014 .015 .015 .014 .010 .014 .013 .012 .011 .010 .010 .010 .012 .012 .012 .012 .014 .014 .010 .019 .013 .014 .014 .0 12.013 .013 .013 .012 .012 .011 .011 .010 .010 .011 .012 .013 .014 .015 .015 .016 .016 .015 .014 .010 .015 .017 .013 .0

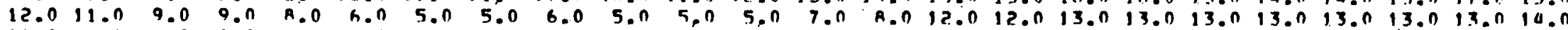

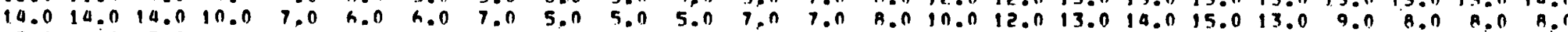

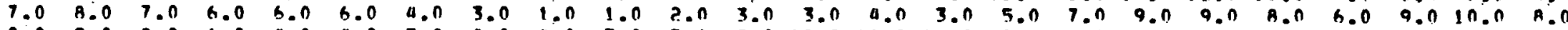

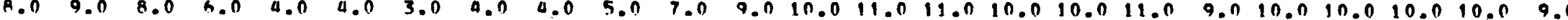

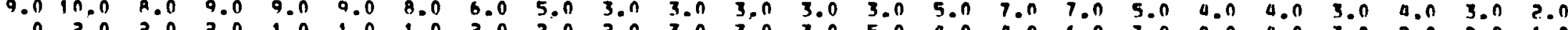

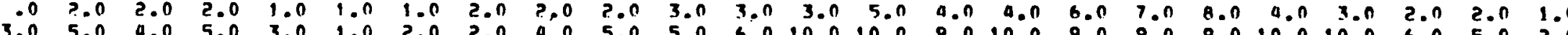

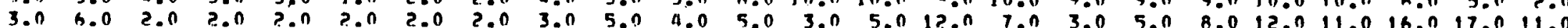

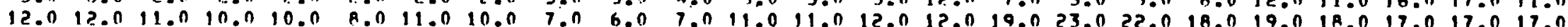

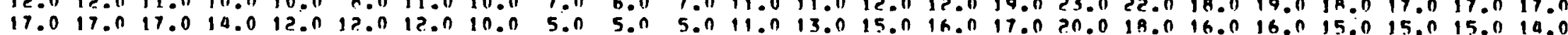

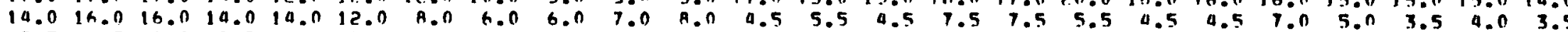
$\begin{array}{lllllllllllllllllllllllll}3.5 & 4.5 & 4.0 & 2.5 & 3.5 & 3.0 & 3.0 & 0.0 & 5.5 & 7.0 & 9.0 & 11.0 & 13.0 & 11.0 & 0.0 & 9.0 & 6.5 & 7.5 & 2.5 & 2.5 & 4.0 & 3.5 & 5.5 & 7.5 & \end{array}$

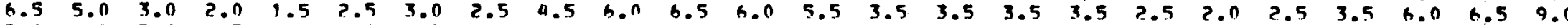

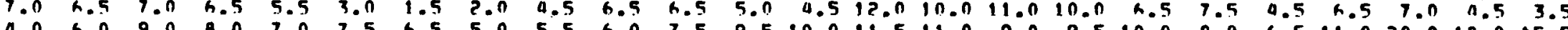

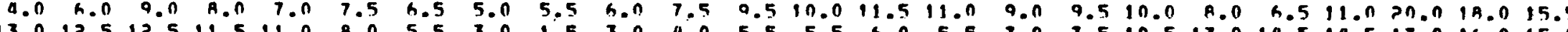
13.510 .5 .

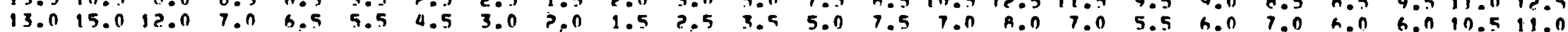

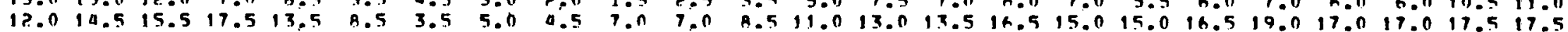

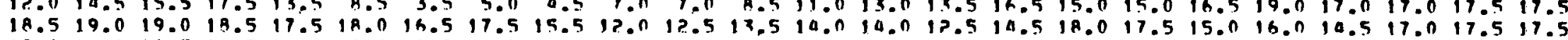

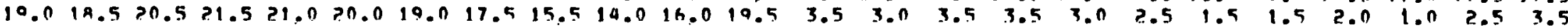

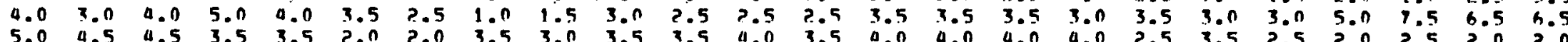

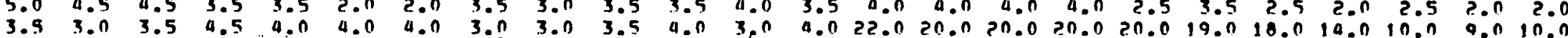
$10.014 .015 .010 .013 .013 .013 .011 .0 \quad 0.0 \quad 9.011 .019 .012 .015 .016 .016 .017 .017 .016 .017 .017 .021 .0$ ? 1.021 .0

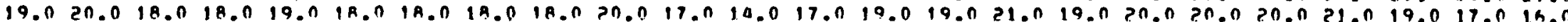

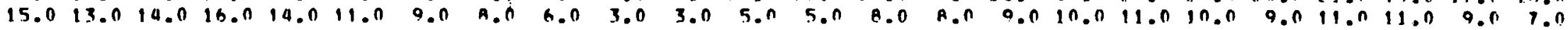

$17 . ? 25.0$ 15.533 .0 3.113 .0 $13.217 . n$ 9.514 .0 9.1 15.0 $5.4 \mathrm{in.n}$ ๑. 011.0 $5.510 . n$ 2.9 ..? 6. 10.0 6.? 17.0 13.352 .0 13.6 ?0.n 7.A in.n 5.913 .0 n.? $0 . n$ 6.? $1 ? .0$ $0.5>0.0$ 0.370 7.2 .13 .5 R.A 15.0 12.719 .0 16.119 .0 $10.5 ? 1.5$ 3.67 .5 0.253 .0 $14.5 ? 1.0$ 14.5 ? 1.0 9.416 .0

9.51
0.71 
WINN SPEFn ICrint1

MTLES/HOUR

LEVEL HEIGHT: 10 METERS
DATTFLLF WINA STIINY, ERAS

TFHACHAPJ MTNS, CA.

STTE

SEP. 1979

AEROVIRONMENT INC.

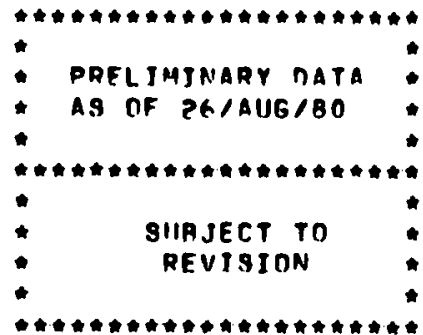

CLOCK HMUR ILOCAL STANDARN TJMEI

B.0 $9.0 \quad 7.0 \quad B .010 .010 .010 .0 \quad 7.0 \quad 6.0 \quad 5.0 \quad 4.0 \quad 6.0 \quad A .011 .015 .016 .015 .015 .013 .013 .014 .019 .013 .015 .0$ 19.010 .013 .013 .013 .014 .014 .014 .015 .015 .015 .014 .015 .019 .017 .019 .017 .014 .017 .015 .014 .013 .014 .014 .0

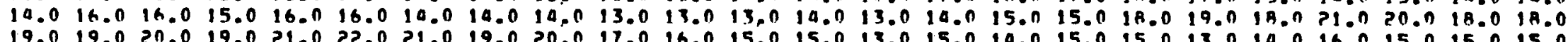
19.019 .0 ? 0.019 .0 ?1.0 2?.0 21.0 19.0 20.0 17.0 16.0 15.0 15.0 13.015 .014 .015 .015 .013 .019 .016 .015 .015 .015 .0

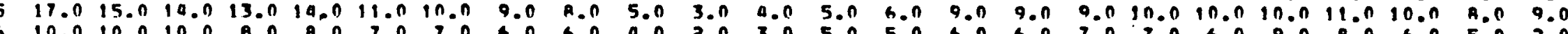

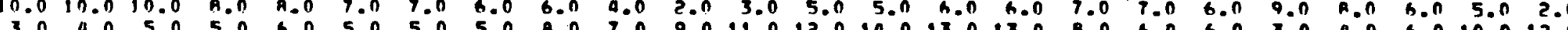
$13.012 .0 \quad 9.0 \quad 9.0 \quad 6.0 \quad 7.0 \quad 7.0 \quad 5.0 \quad 5.0 \quad 3.0 \quad 4.0 \quad 4.0 \quad 5.0 \quad 6.0 \quad 7.0 \quad 9.011 .0110 .010 .010 .010 .01 .011 .011 .0$

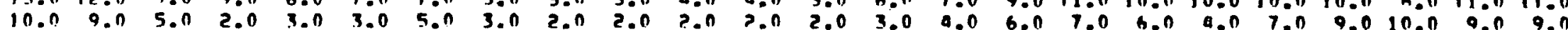

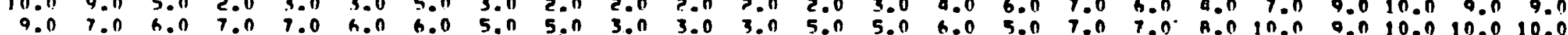

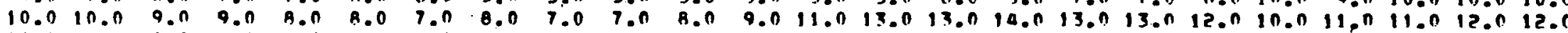
$12.011 .010 .010 .010 .011 .0 \quad 0.0 \quad A .0 \quad 7.07 .0 \quad 5.0 \quad h .0 \quad 4.0 \quad 9.012 .011 .013 .011 .010 .011 .012 .011 .011 .013 .0$

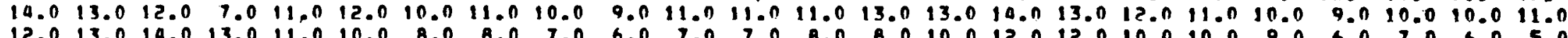

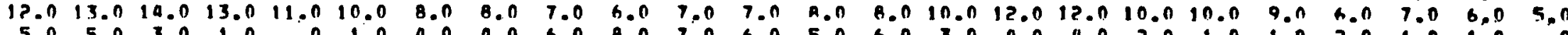

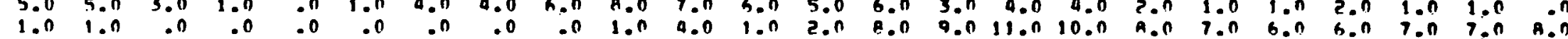

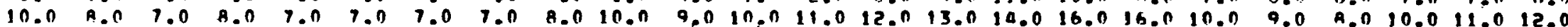
11.013 .013 .012 .013 .013 .010 .012 .011 .011 .012 .011 .012 .019 .013 .015 .014 .012 .011 .011 .013 .013 .015 .016 .0

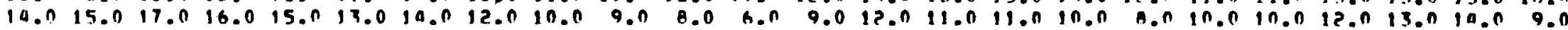

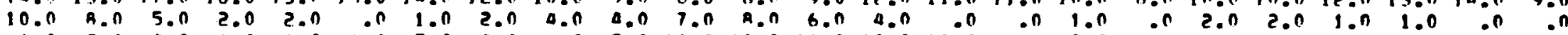

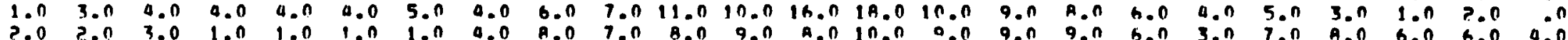

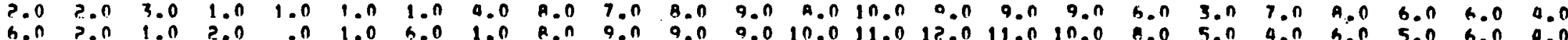

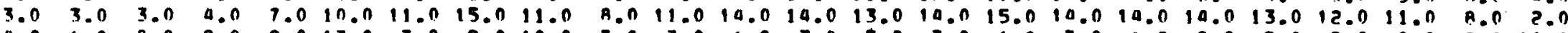

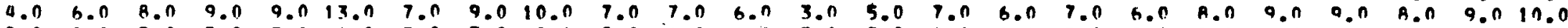

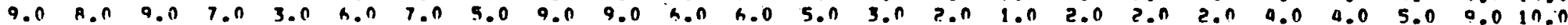

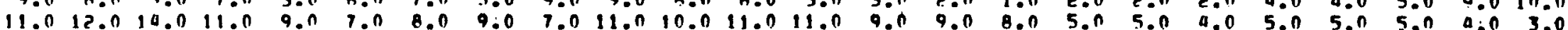

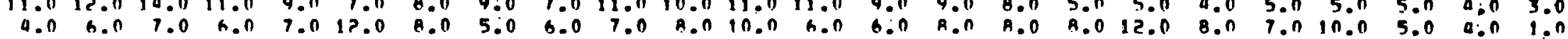

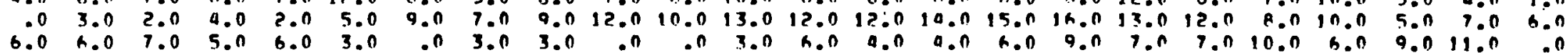

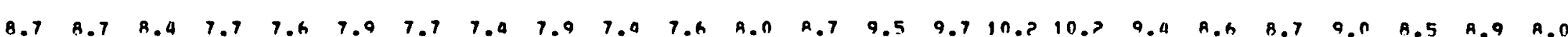

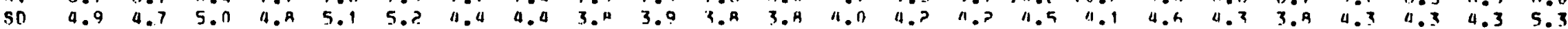

0.516 .0 10.918 .0 $15.7 ? 1.0$ 16.A P2. 9.517 .0 6. 11.0 7.510 .0 B.n $13 . n$ $5.210 . n$. b.t 10.0 10.? 14.n 9.017 .0 11.? 14.n 9.114 .0 3.7 R.A a.0 11.0 10.016 .0 12.515 .0
11.519 .0 2.910 .0 b. I IR.n 5.510 .0 h.1 1?.n 10.215 .0 7.613 .0 5.510 .0 a.0 10.0 7.n 12.n A. $16 . n$ 5.n 11.0 . 
WTNA SPFEn [reini]

MTLES/HOUR

LEVEL HEIGHT: 10 MFTERS
RATTFILF WYMN STIIDY,HSOE

TEHACHAPI MTNS, CA.

STTE

OCT. 1979

AEROVIRONMENT INC.
- prelimipapr nata as nf zg/allgian

CLOCK HOHR ILOCAL STANDARD TIME] 
WIND SPFEN IC:C:III

MILES/HOUR

LEVEL HEIGHT: IN METERS
PATTFILLE WINA STIINY, \#SOE TEHACHAPI MTNA. CA. STTE

NoV. 1979

AFROUIRONMENT INIC.

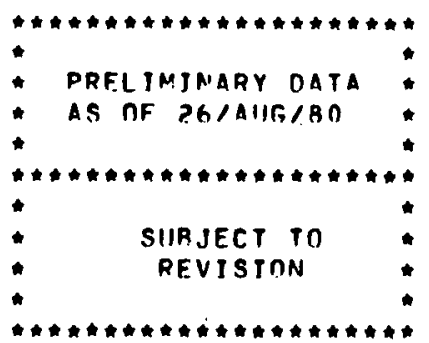

CLOCK HOJR ILOCAL STANHARN TIMEI

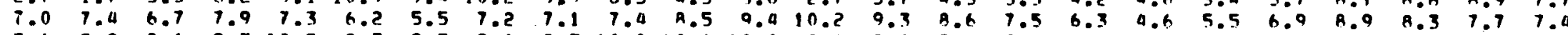

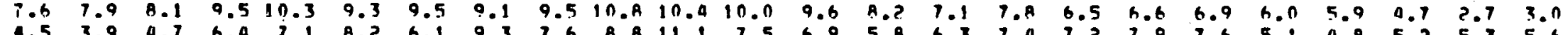

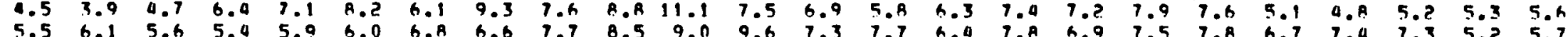

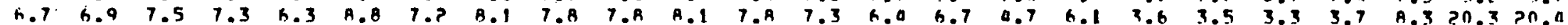

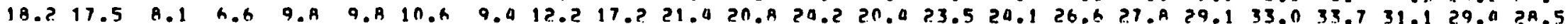

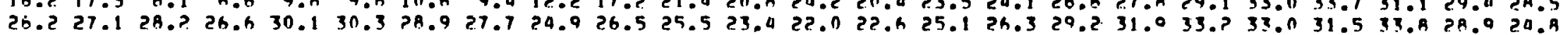

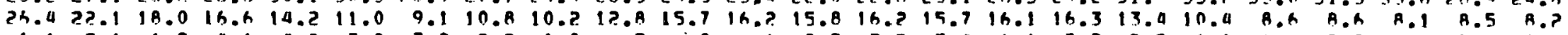

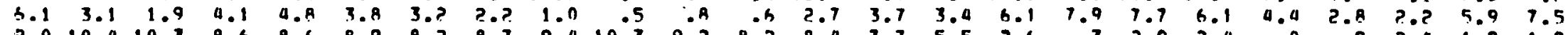

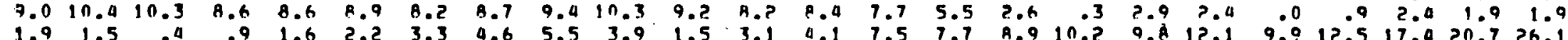

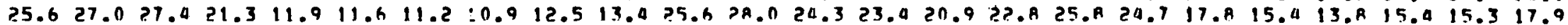

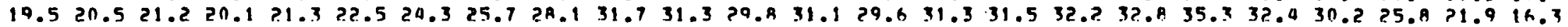

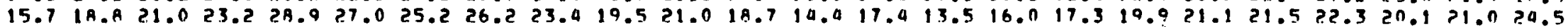
$25.526 .426 .627 .327 .327 .228 .6 \quad 31.6 \quad 31.129 .527 .830 .433 .931 .929 .625 .923 .922 .525 .627 .525 .023 .921 .017 .2$

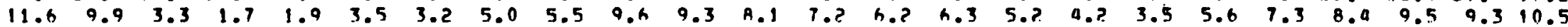

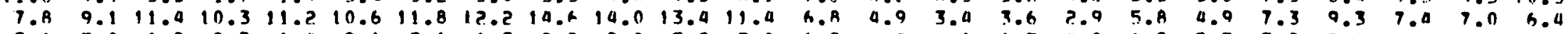

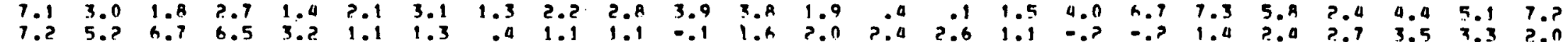


WINA SPEEN RCCINII

\section{MILES/HNUR}

LEVEL HEIGHT i In METFRS
BATTFELE WTNR STIINY, Z5OS

TEHAC.HAPI MTNS, CA.

SITE

JIIL. 1979

AFROVIRONMFNT INC.

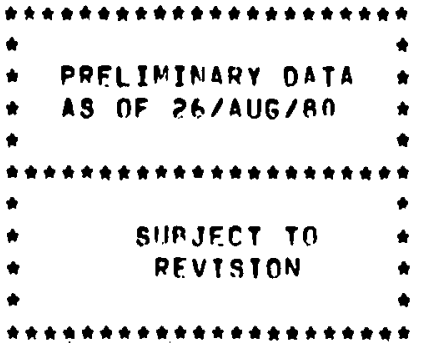

ClOCK hOUR ILOCAL STANDARD TTME

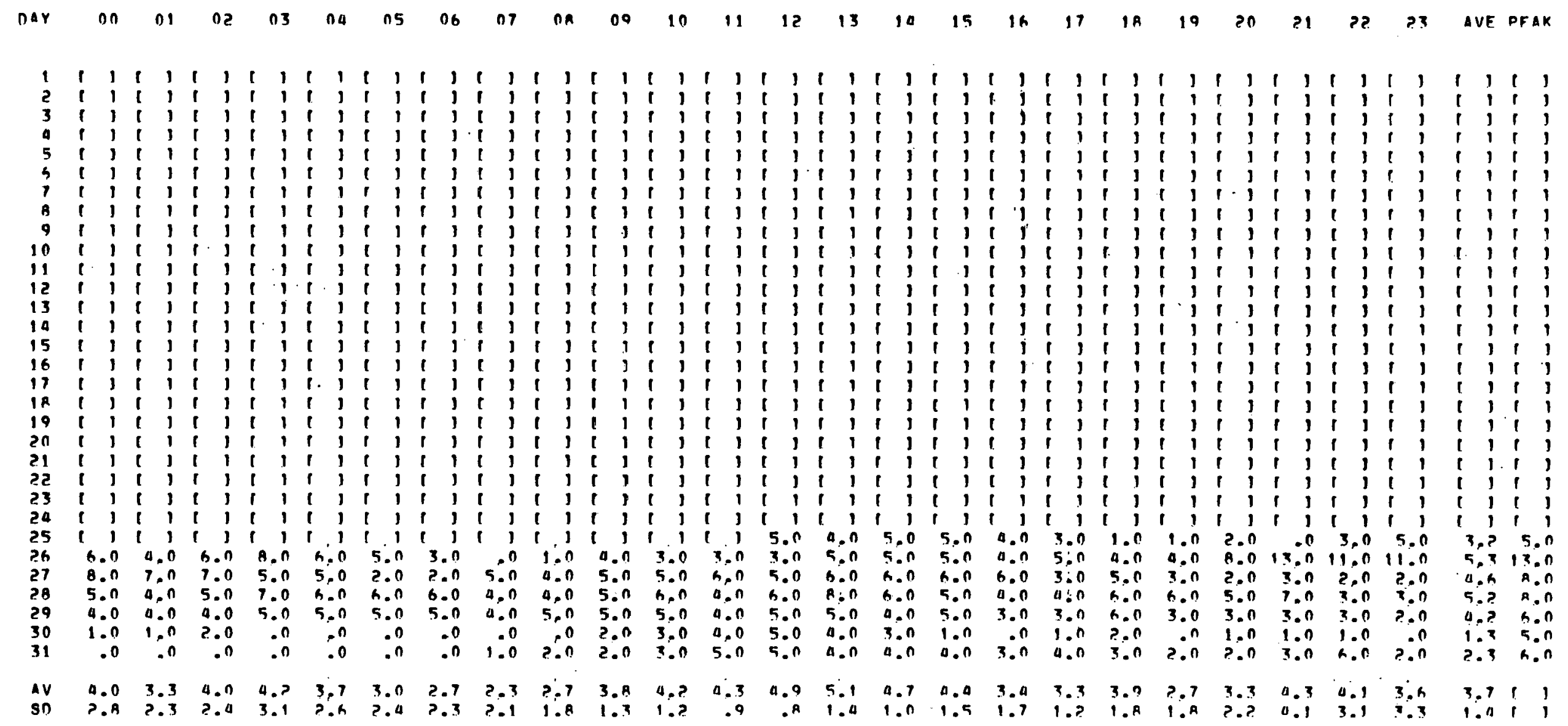


WTMI SPEED rCrinil

MILFS/HOUR

LEVEL HEIGHT: 10 MFTFRS
BATTFILF WTND STIIDY, ZGRG

TFHACHAPI MTNG, CA.

SJTE

Allg. 1079

AEROVTRONMENT INC

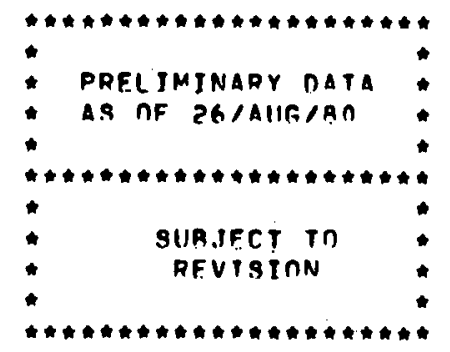

CLOC.K HOUR RLOCAL STAMDARD TIMF. 
WINR SPEFD ICrsnII

MTI.ES/HOIIR

LEVEL HETGHT： 10 MFTFR.9
RATTFLIF WIND STURY,HEOS TFHACHAPI MTNS, CA.

SITF

SFP. 1979

AFROVIRANMENT TNC.

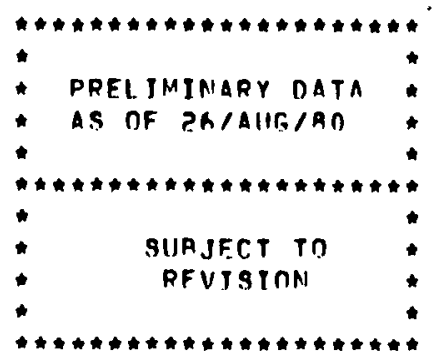

CLOCK HOUR ILOCAL STANDARO TIMFI

.08 09 10 111 ? 13 14 1514 17 
WIND SPEET IrCIOII

\section{MILES/HOIIR}

LEVEL HEIFHT : In MFTFRS
AATTEILF HIND STIIDY, Z5OS TEHACHAPI MTNS, CA.

STTE

OCT. 1979

AFROVIRANMFNT INC:

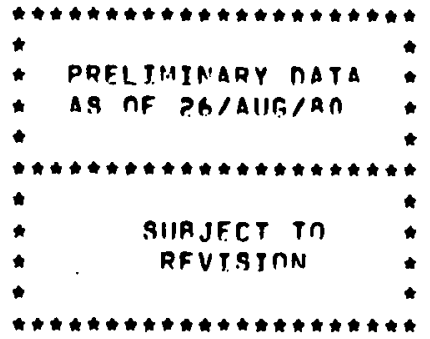

CLOCK hOIR [LDGAL STANDARD TIME]

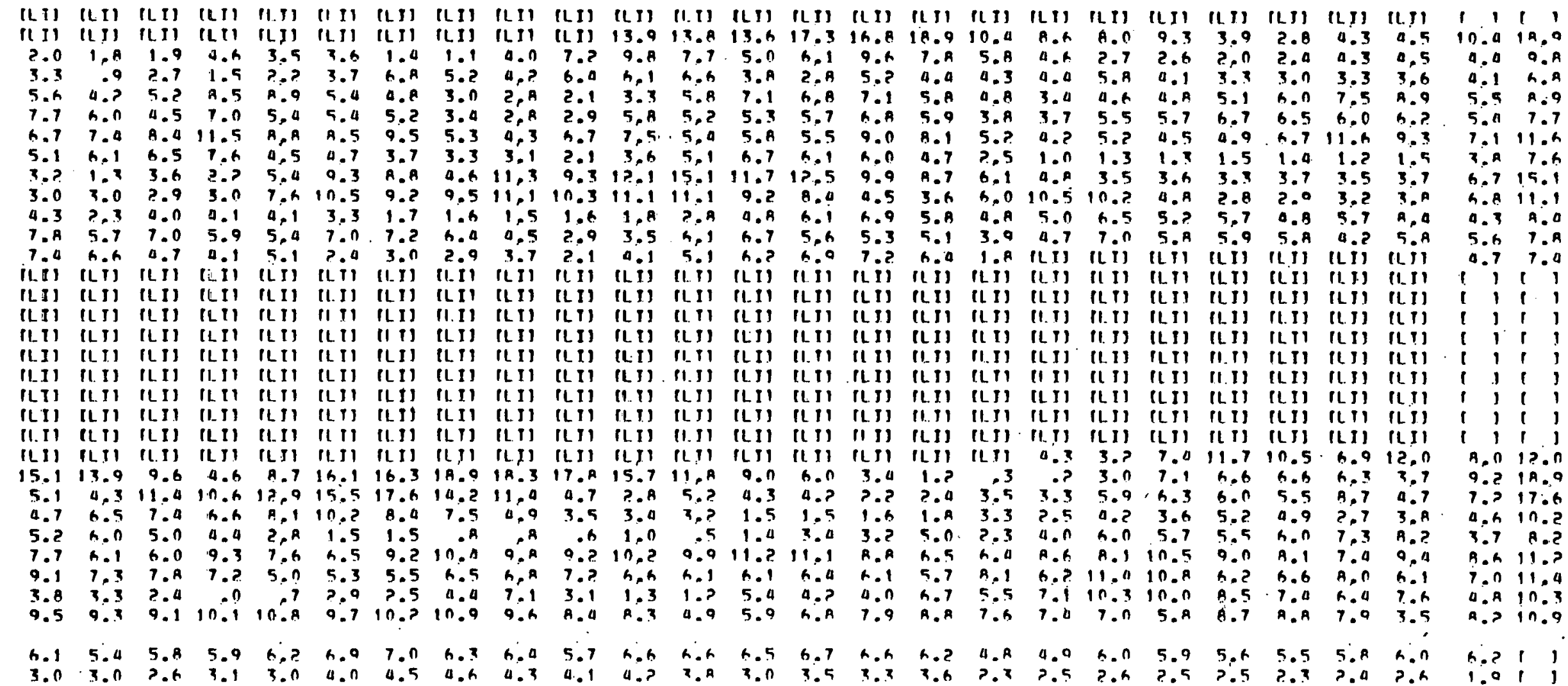


WTNA SPEEN ICr:BO11

\section{MTI.F.S/HOUR}

LEVEL HEIGHT i IN METERS
RATTELLE WTNA STIINY.HFOF

TEHACHAPI MTNS, CA.

SITF

NnV. 1979

AFROVIRONMENT INC.

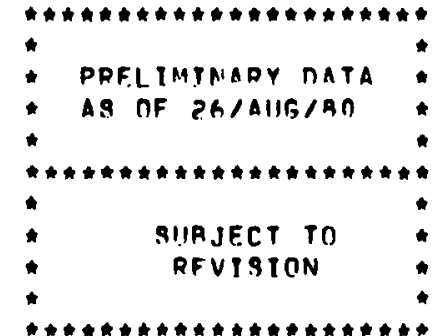

CLOCK HUIIP RLOCGAL STANDARD TTMEJ 
WTND SPEFD iCcinI

MILES/HOIIR

LFVFL HEIFHT: 10 METFRS
RATTELLE WTNA STIINY, \#505 TFMACHAPI MTNS, CA.

SITE

DFC. 1979

AFPRVIRONMENT INC.

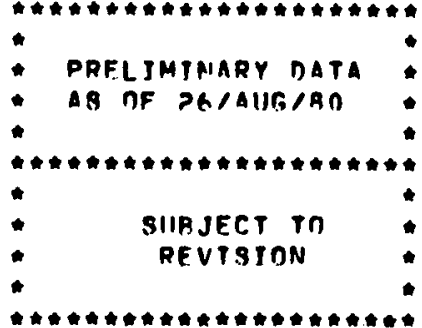

CLOCK HOIIR ILOCAL STANDARO TIMEJ

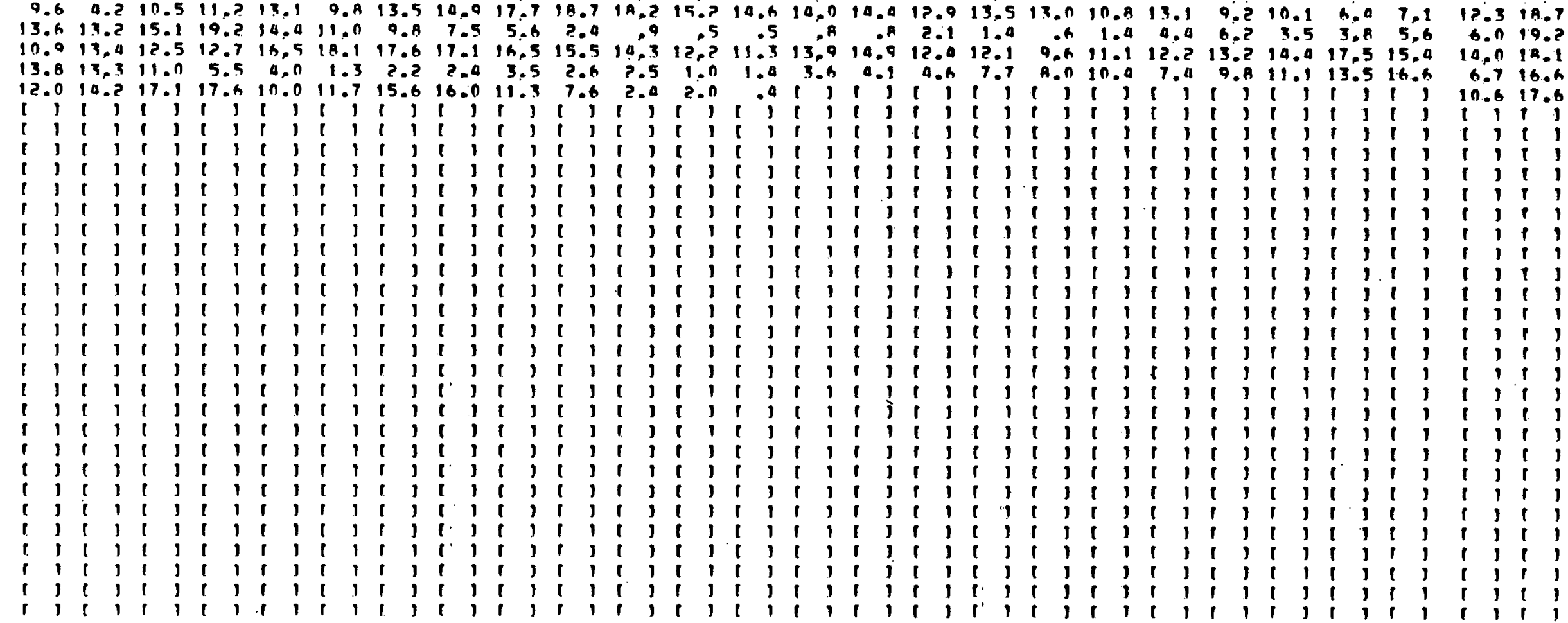


WTNR SPEEN IC,EOII

MILES/HOIIR

LEVEL HEIGHT : In METERS
PATTFLIE WTNO STINYY. \#505

TEHACHAPI MTNS. CA.

STTE 9

MAY. 1979

AFROVIRANHENT INC.

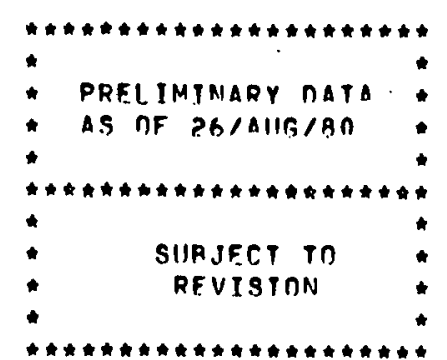

CLOCK HOUR (I.NCAL STANIDARD TIM.)

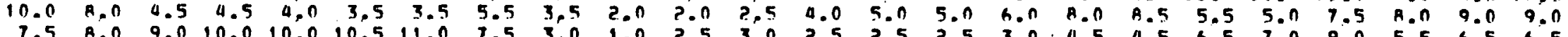

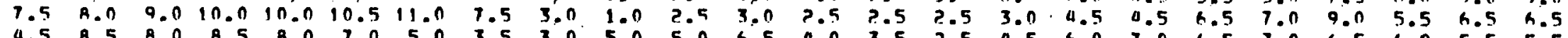

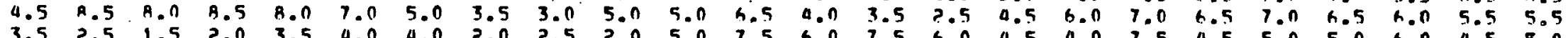

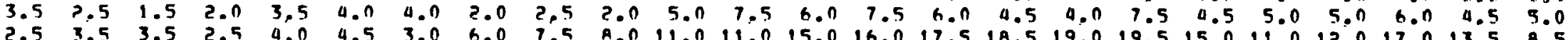

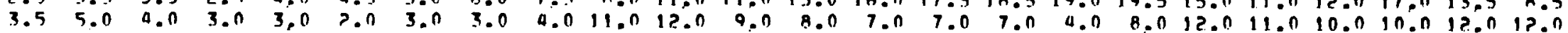

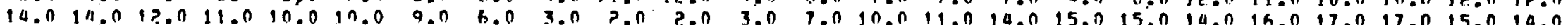

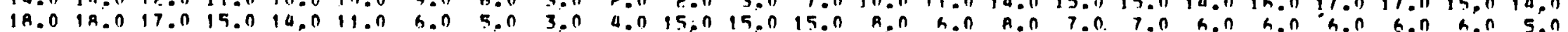

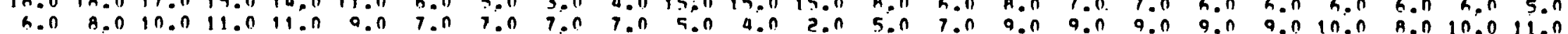

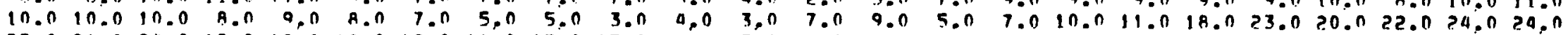

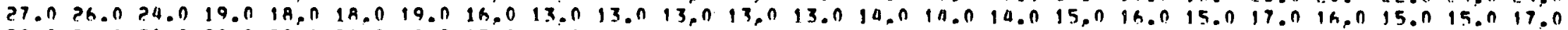

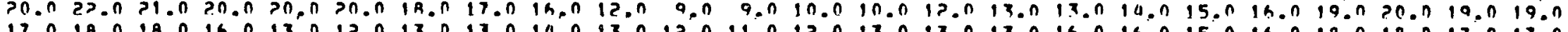

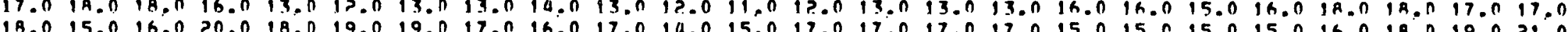

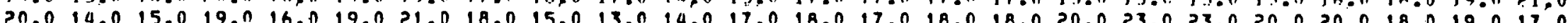

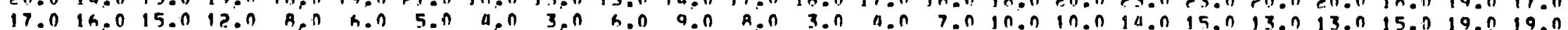

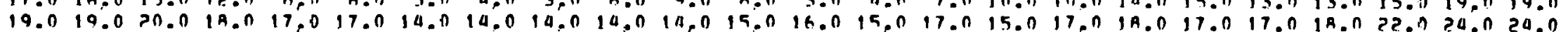

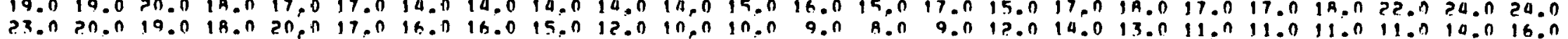

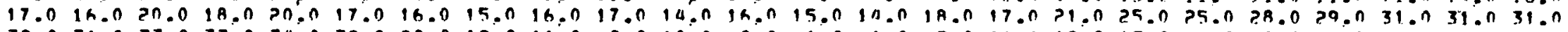

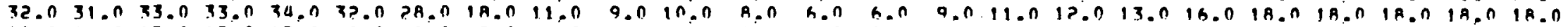

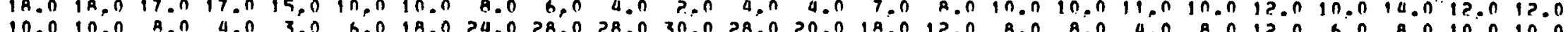
a.0 13.5 $10, a$ ? 0 10 , 5? 15.5 ? 1.5 $11.011 . n$ 0.713 .0 $5.5 \quad ! n .0$ h.0 11.n $5.7 \quad 2.5$ a.4 7.5 10.10 .5 ln. 19.5 1n.o 17.0 9.518 .0 7.011 .0 $10.0>0.0$ 16.727 .0 1h.n.??.n 14 , 1 A. 0 14. $16.921 . n$ $16.9 ? 1 . n$ $10^{2} .0$ ? 3.0 0.519 .0
17.324 .0 17.324 .0
$14 . n 23.0$ $20.3 \geqslant 1 . n$ 19.034 .0 $10.418 . n$

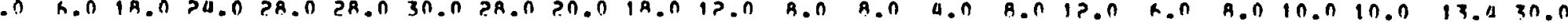


WTND SPEER [C.C:Oni

MILES/HOUR

LEVFL HEIFHT $\because$ IN MFTERS
RATTEIIE WTND STIIDY, H5OS

TFHACHADI MTNS. CA.

STTE

JIIN. 1979

AEROVIRANMENT TINC.

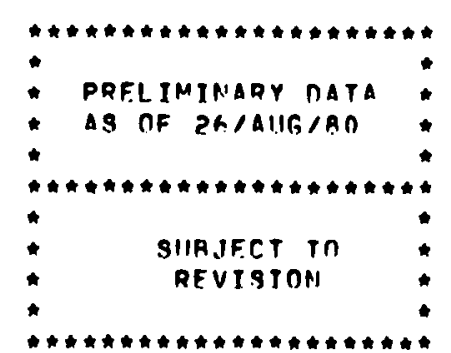

CLOCK HOLR ILOCAL STANBARO TIMFJ

GAY

1 1

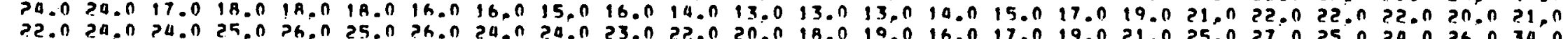
3?.0 30.0

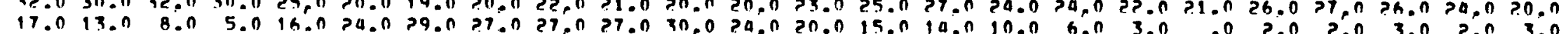

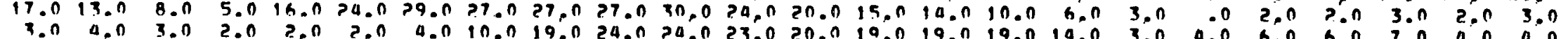

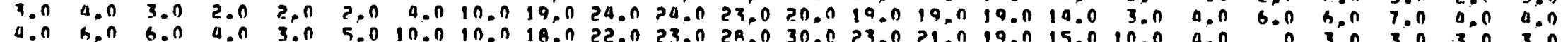

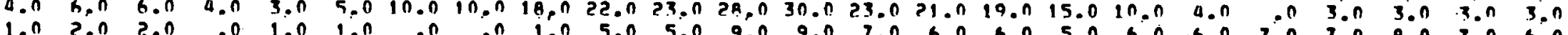

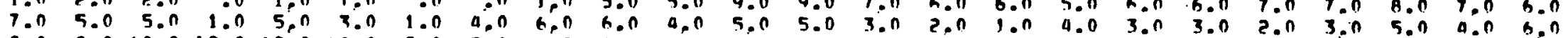

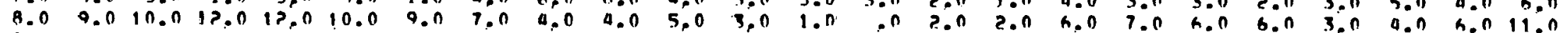

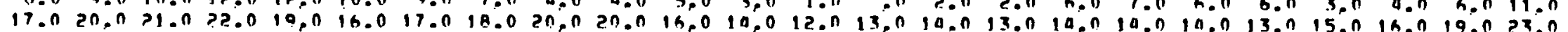

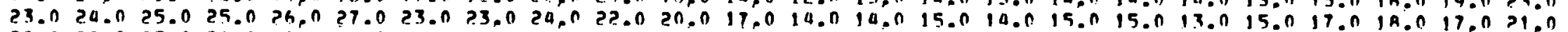

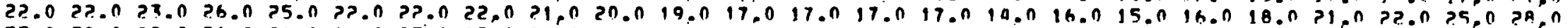

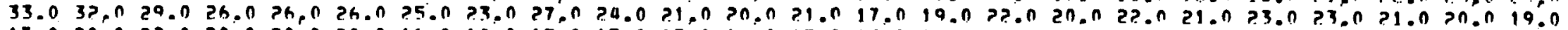

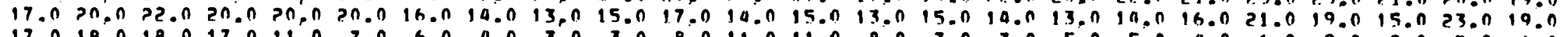

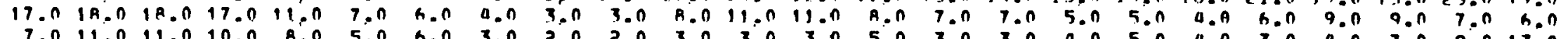

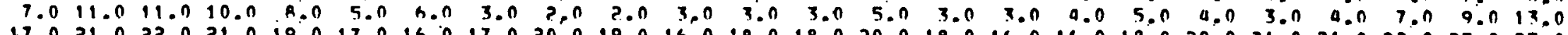
17.0 21.0 ?2.0 21.0 19.0 17.0 1h.n

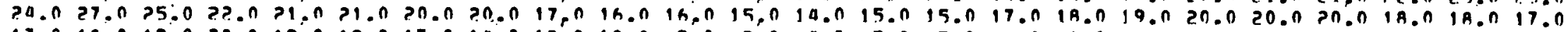

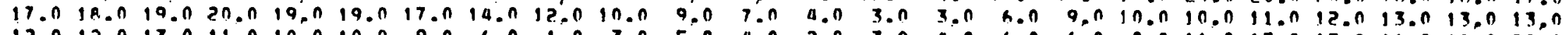

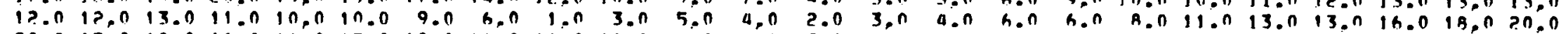

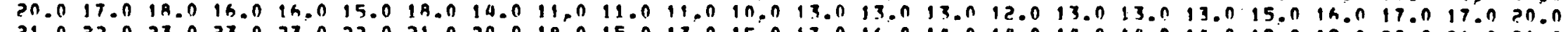

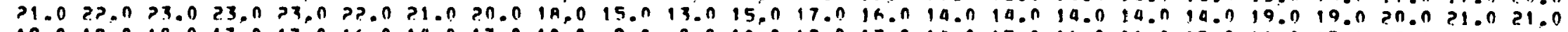
19.019 .018 .017 .017 .0 16.0 14.0 13.0 10.0 9.0 A.n 10.012 .013 .014 .015 .016 .016 .015 .016 .017 .017 .017 .019 .0

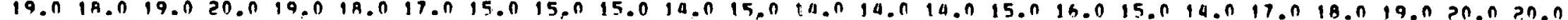

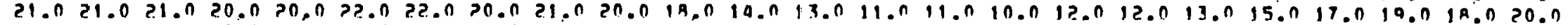

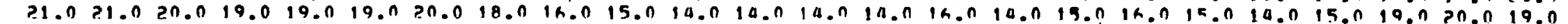

AV $16.917 .417 .216 .4 \quad 16.315 .7 \quad 15.214 .119 .013 .913 .913 .313 .112 .312 .012 .312 .712 .512 .613 .714 .415 .015 .716 .7$

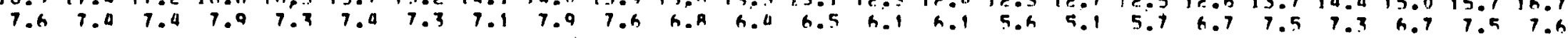
i1 $\operatorname{mar} 791$ 
WTNN SPEEN ICCinI1

MILES/HOIJR

LEVFL HETGHT i In METFRS
RATTELLE WINN STUNY, 505 TEHACHAPI MTNS, CA.

STTE.

JUL, 1979

AFROVIRONMFNT INC.
PPELIMTNARY DATA

as ne zh/allg ian

SUAJECT TO

REVISION

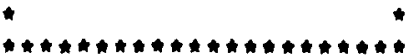

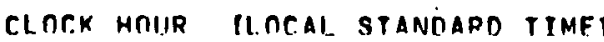

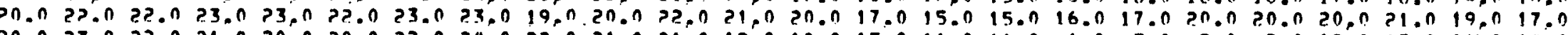

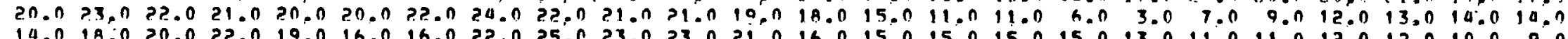

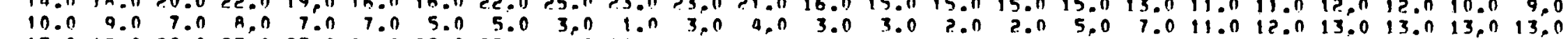

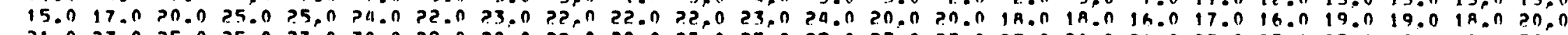

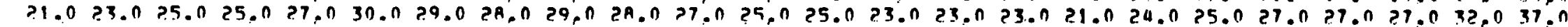

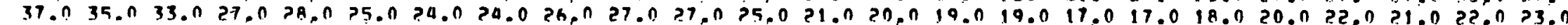

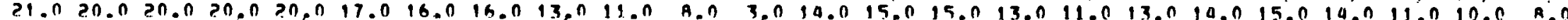

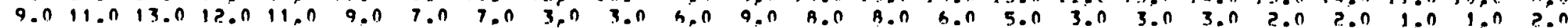

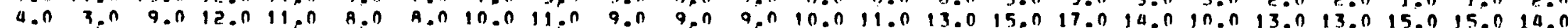

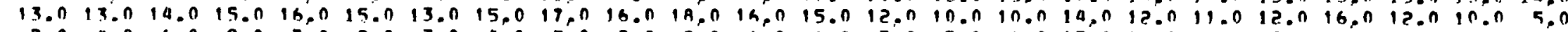

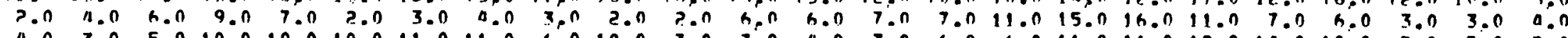

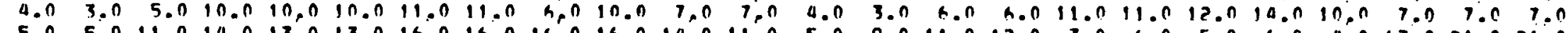

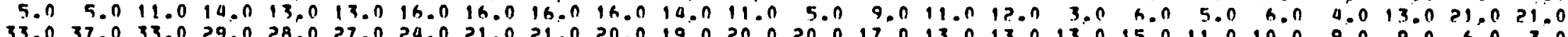

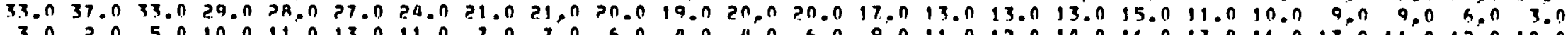

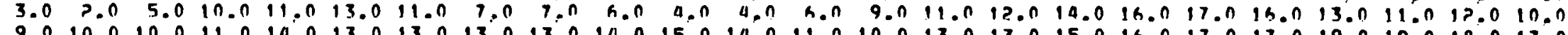

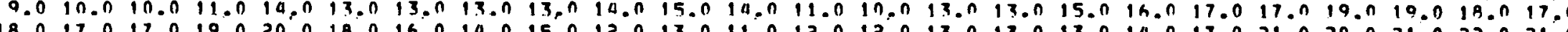

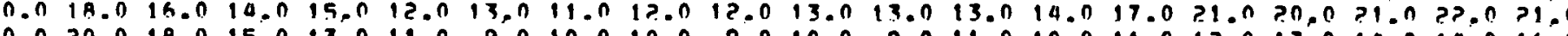

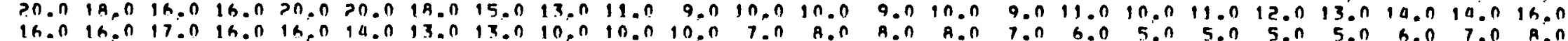

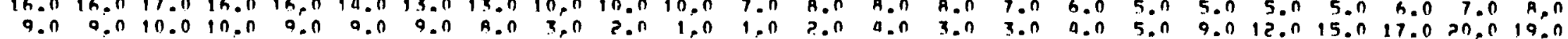

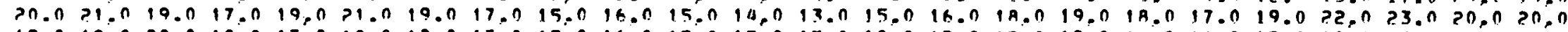

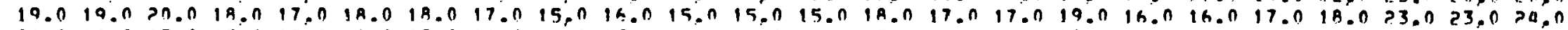

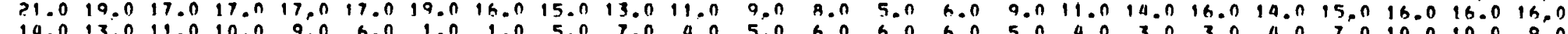

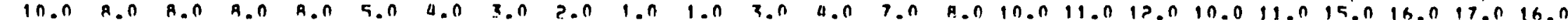

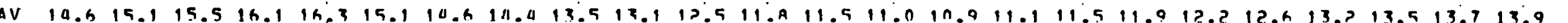

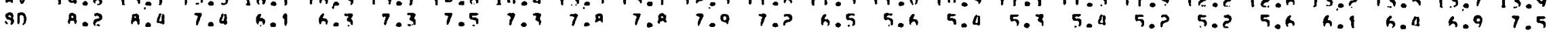


WTNO SPFEN Irringl

MIIFS/MOUR

LFVEL HEIGHT; IN MFTERS
AATTELI.F WTNA STIINY. H5O5

TFHACHAPJ MTNS, CA.

SITF

A116. 1979

AFROVIROMMENT INC:

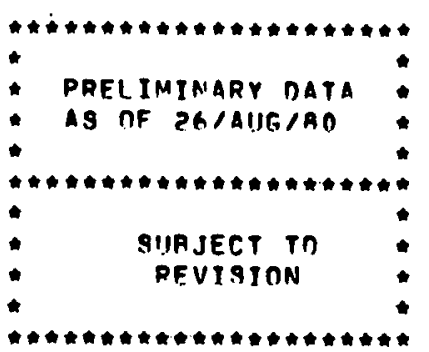

Clock holH [LOCAL stannaan trme] 12.010 .010 .011 .012 .012 .012 .012 .013 .010 .0 a.n A.n $0.011 .012 .012 .013 .012 .012 .012 .015 .015 .015 .015,0$

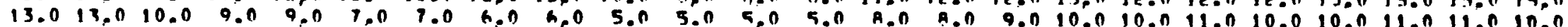

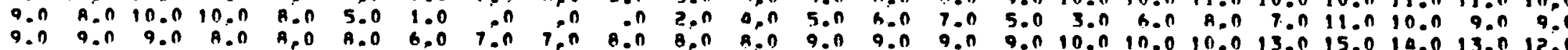

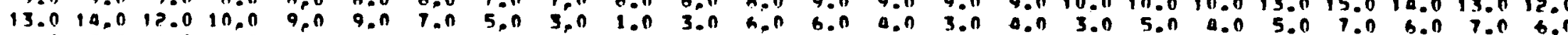

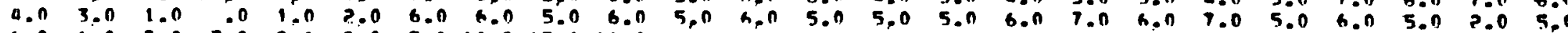

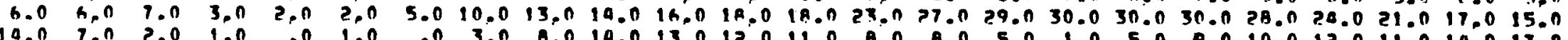

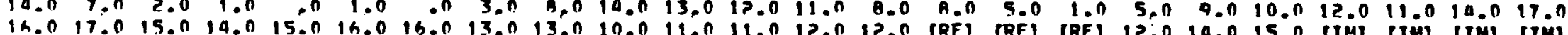

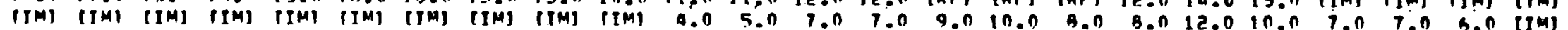
[IM] [IM] [IM] [IM] [IM] [IM] [IM] [IM] [IM] [IM] [IM] [IM] [IM] [IM] [IM] [IM] [IM] [IM] [IM] [IM] [IM] [IM] [IM] [IM] [IM] [IM] [JM] [IM] [IM] [IM] [TM] [IM] [IM] [IM] [IM] [IM] [IM] [IM] [IM] [IM] [JM] [IM] [IM] [IM] [IM] [IM] [IM] [IM] [IM] [IM] $[I M]$ [IM] [IM] [IM] [IM] [IM] [IM] [IM] [IM] [IM] [IM] [IM] [IM] [IM] [JM] [IM] [JM] [IM] [IM] [IM] [IM] [ITM] [IM] [IM] [IM] [IM] [IM] [IM] [IM] [IM] [IM] [IM] [IM] [IM] [IM] [IM] [IM] [IM] [IM] [IM] [IM] [IM] [IM] [IM] [JM] [IM] [TM] [IM] [IM] [TM] [TM] [IM] [TM] [IM] [IM] [IM] [IM] [IM] [IM] [IM] [JM] [IM] [IM] [IM] [IM] [IM] [TM] [IM] [JM] [IM] [IM] [IM] [IM] [IM] [IM] [TM] [IM] [IM] [IM] [IM] [IM] [IM] [IM] [IM] [IM] [IM] [IM] [IM] [IM] [IM] [TM] [IM] [IM] [IM] [IM] [TM] [IM] [IM] [IM] [IM] [IM] [TM] IIM] TIM] [TM] [TM] [IM] [IM] [JM] IIM] [IM]

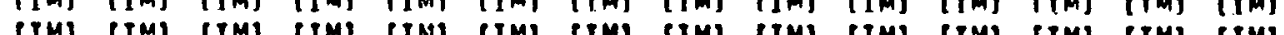
[IM] [TM] [IM] [IM] [IM] [IM] [IM] [IM] [IM] [IM] (IM] [IM] [JM] [IM] [IM] [IM] [IM] [IM] [IM] [IM] [IM] [IM] [IM] [IM] IIM] [IM] [IM] [IM] [IM] [IM] [IM] [IM] [IM] IIM] [IM] IIM] [IM] [IM] [IM] [IM] [IM] [IM] [IM] [IM] [IM] [IM] [IM] [IM] [IM] [TM] [IM] [TM] [IM] [IM] [IM] [IM] [IM] [IM] [IM] [IM] TIM] [IM] [IM] [IM] [IM] [IM].IIM] [IM] [IM] [IM] [IM] [IM] [IM] [IM] [IM] [IM] [IM] [IM] [IM] [IM] [IM] [IM] [IM] [TM] [IM] [IM] [IM] [IM] [IM] [IM] [IM] [IM] [IM] [IM] [IM] [IM] [IM] [IM] [IM] [TM] [IM] [IM] [TM] [IM] [IM] [IM] [IM] [IM] [IM] [IM] [IM] [IM] [IM] [IM] [IM] [IM] [IM] [IM] [IM] [IM]

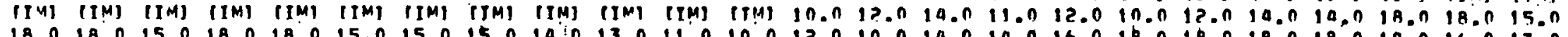
IA. 1 A.

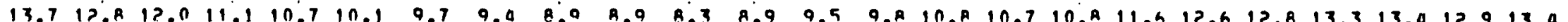

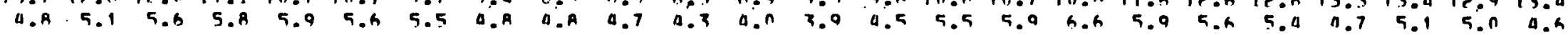


WIND SPEED ICCSOII

MTLES/HOUR

LFVEL HEIGHT i 10 METERS
RATTELLF WIND STIINY,WEOS

TFHACHAPI MTNS, CA.

SITE 9

SEP. 1970

AFROVTRONMFNT TNIS.

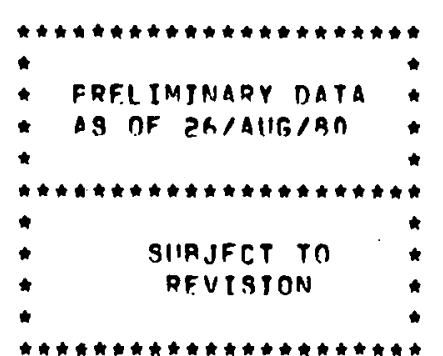

CLOCK hOIIR II Bral. STANHARN TIME

$10.5 \quad 9.511 .011 .012 .512 .512 .510 .0 \quad 6.5 \quad 5.0 \quad 4.0 \quad 6.0 \quad h .0 \quad 7.0 \quad 0.011 .512 .012 .513 .011 .014 .010 .016 .517 .0$

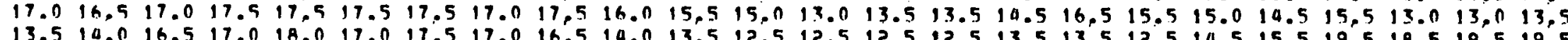

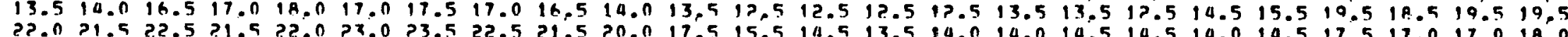

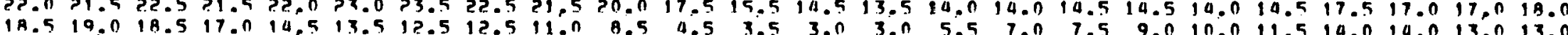

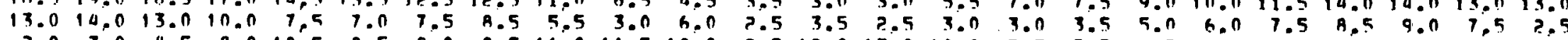
$2.0 \quad 3.0 \quad 4.5$ A.n 10.5 A.5 A.0 A.5 $11.011 .510 .0 \quad 0.512 .013 .010 .0 \quad 7.5 \quad 7.5 \quad h .5 \quad 4.5 \quad 2.0 \quad 3.5 \quad 7.010 .011 .5$

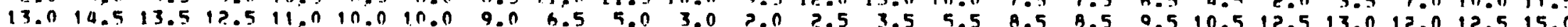

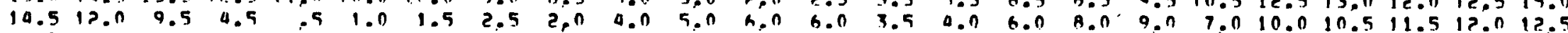

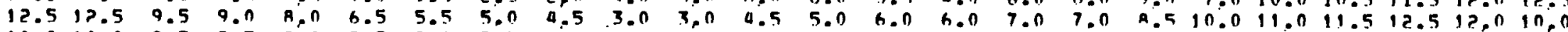

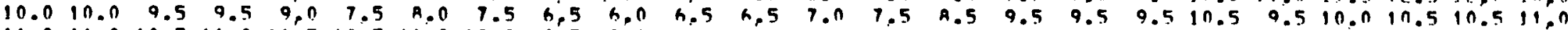
$11.011 .010 .511 .011 .510 .511 .012 .0 \quad 10.5$ 9.0 6.5 3.5 $4.0 \quad 4.5 \quad 5.5 \quad 9.5 \quad 9.010 .010 .010 .010 .010 .010 .511 .0$

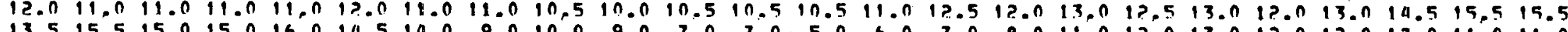

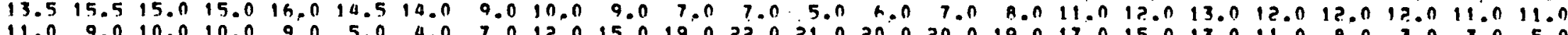

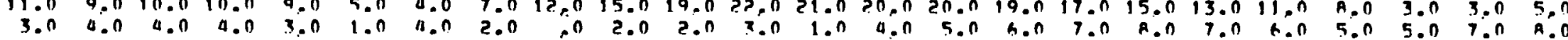

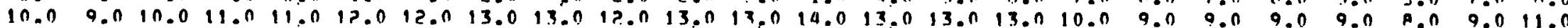

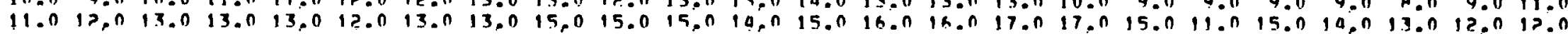

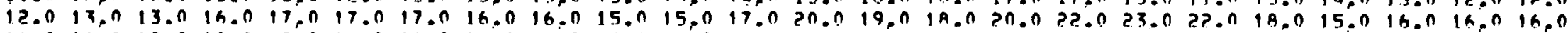
$14.011 .010 .010 .0 \quad 9.011 .014 .014 .014 .013 .012 .013 .014 .013 .013 .013 .013 .013 .013 .013 .012 .011 .010 .09 .0$

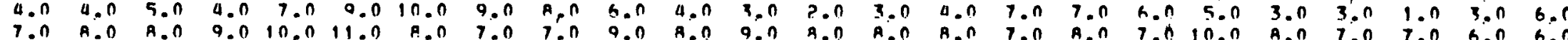

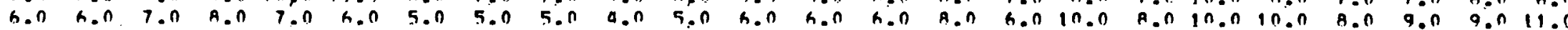
[ח.0 A.n. [TM] [TM] [TM] TIMI [TM] [IMI TIM] [IM] [IM] [IM] TIM] [IM] [TMI TIM]

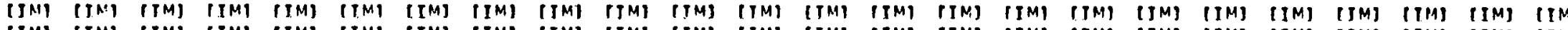

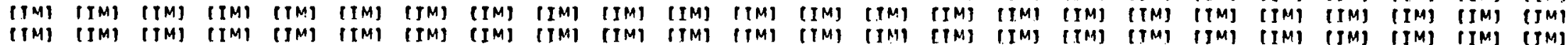

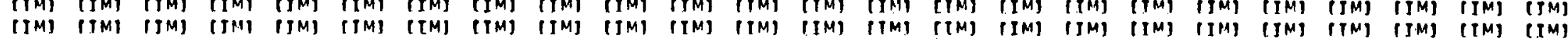
[TM] [TM] [TM] [IM] [IM] [IM] [IM] [IM] [TM] [IM] [IM] [TM] [TM] [IM] [IM] [IM] [IM] [IM] [IM] [IM] [TM] [JM] [IM] [JM]

10.717 .0 15.517 .5 15.519 .5 18.? 23.5 1., 14.0 $7.0,13.0$ 9.15 .0 h.8 14.5 7.912 .5 ค. A 11.0 9.P 1?.0 11.915 .5 11.116 .0 ?.ก ว?.n a.? . $n$ 13.1 19.0 $17.023 . n$ $1 ? .114 . n$ 5.110 .0 B. 11.0

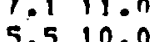
5.510 .0 1,11 1 1 1 !

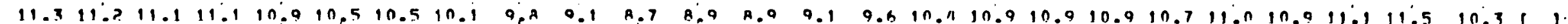

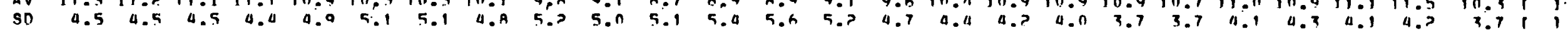


WTNR SPEEN ICCInII

\section{MTLES/HOIJR}

LFVEL HFITHT i In METERS
AATTFI.I.F WINA STIINY, \#505

TFHACHAPI MTNS, CA.

STTE

OCT. 1979

AEROVIRTNMENT INC.

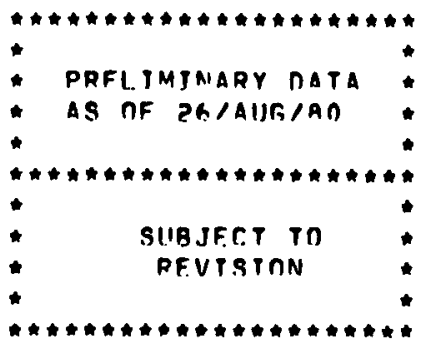

CLOCK HOIIR ILOCAL STANDARO TIMF.]

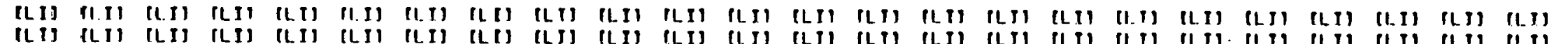

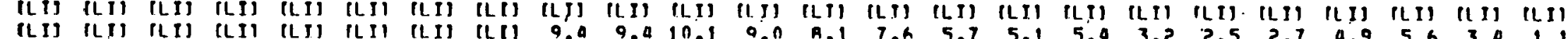

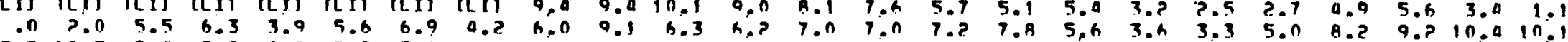

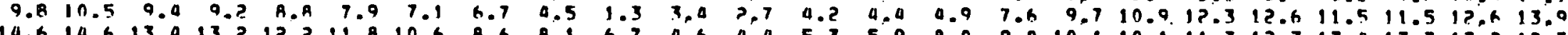

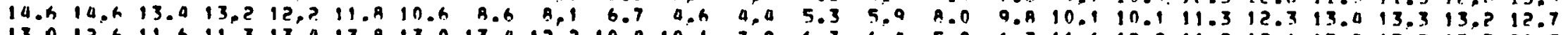

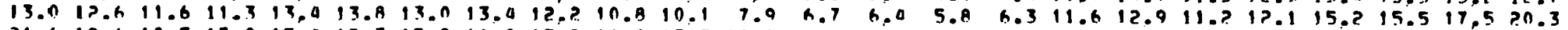

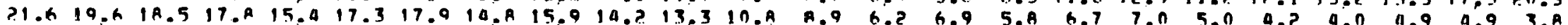

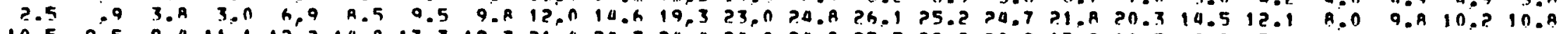

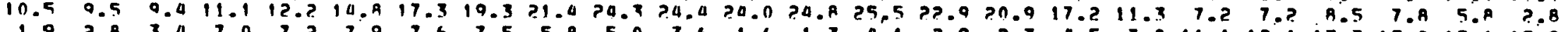

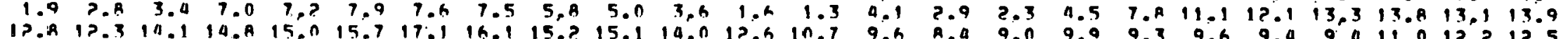

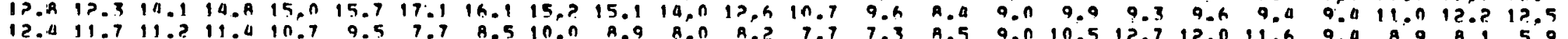

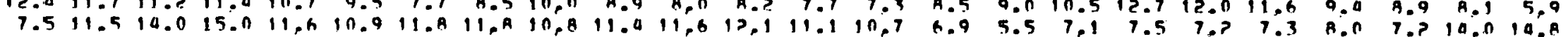

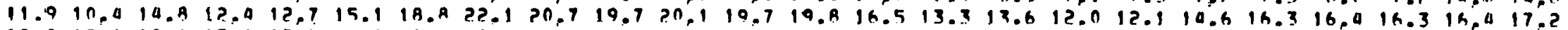

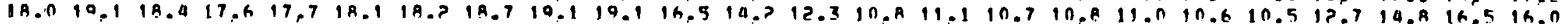

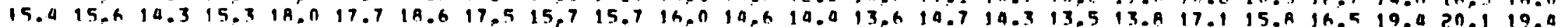

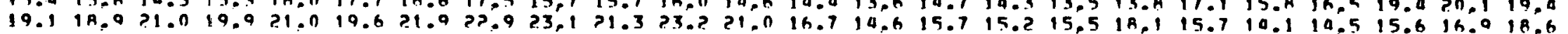

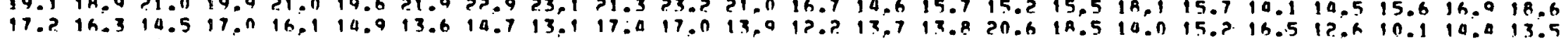

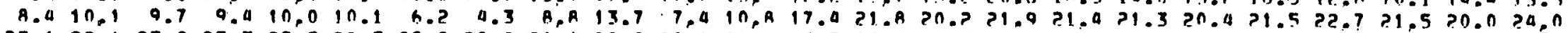

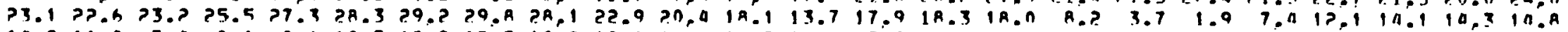

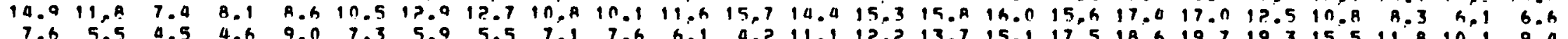

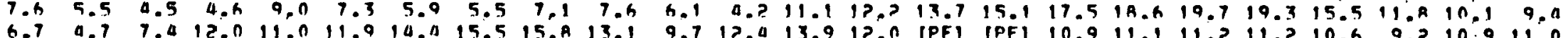

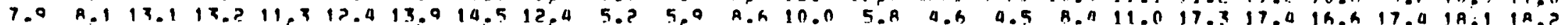

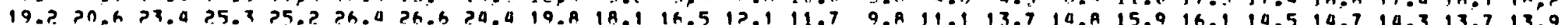

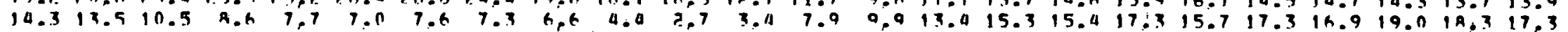

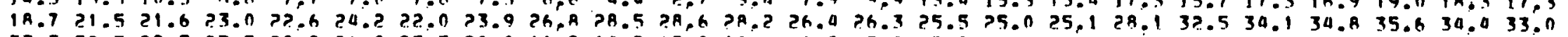

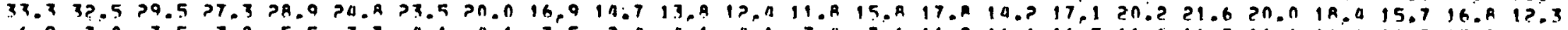

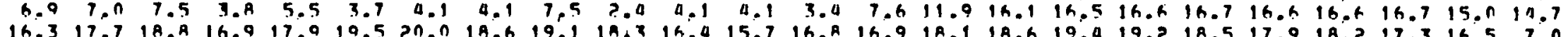


WINN SPEEN IrConil

MTLES/HOUR

LEVEI HEIGHT: IO NETERS
PATTFLLF WINA STIUY, \#505 TEHACHADI MTNS, CA. STTF

NOV. 1979

AFROVIRDNMENT TNC

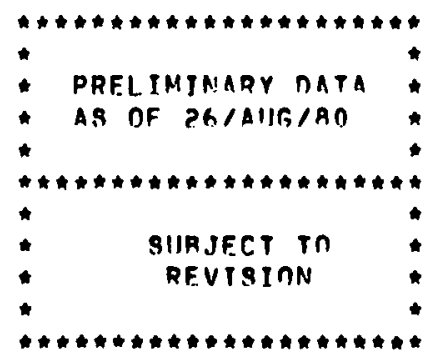

CLnEK HOIIR ILOCAL STANDARO TIMEI

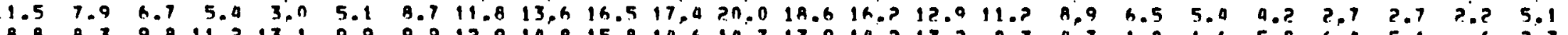

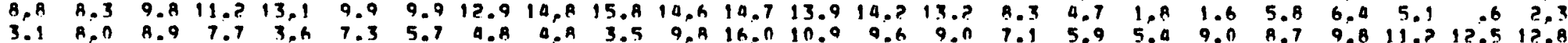

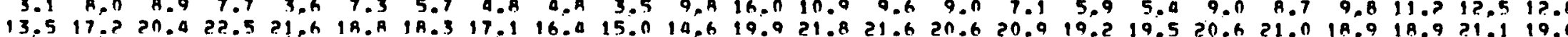

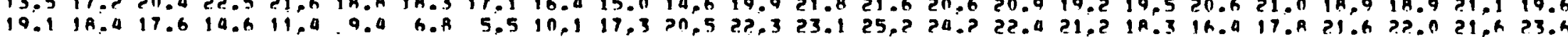

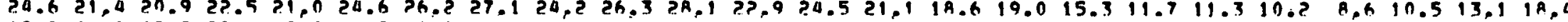

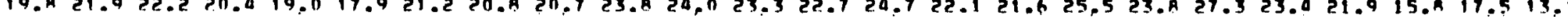

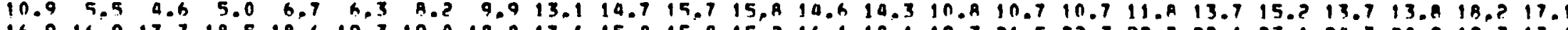
16.9 16.9 17.7 18.5 1A.h 19.3 19.0 1A.A 17.h 15.8 15.A 15.2 16.1 18.1 19.3 21.5 2?..3 ?.2.7 ??.1 23.1 24.7 P0.9 19.3 17.0

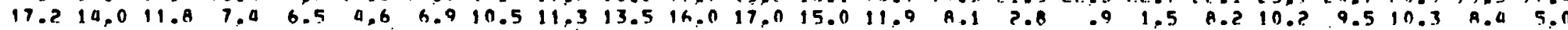

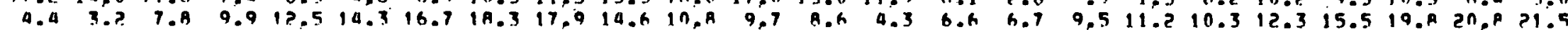

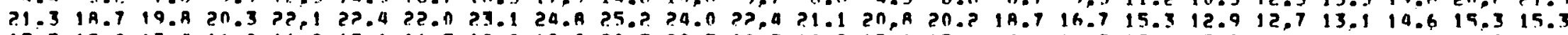

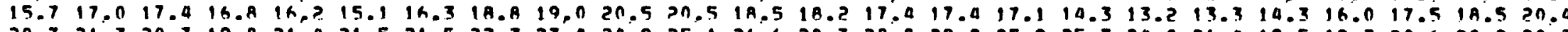

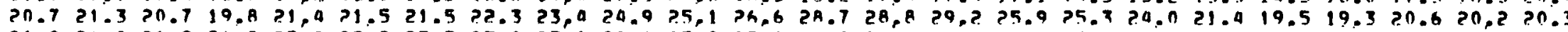

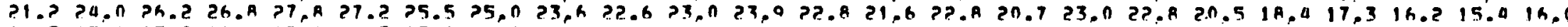

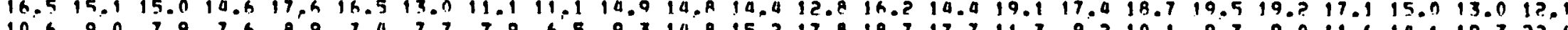

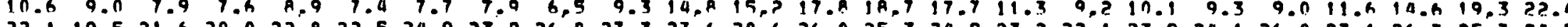

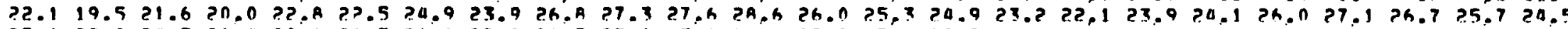

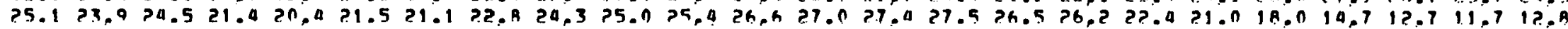

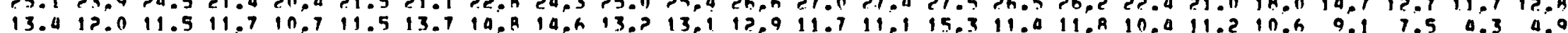

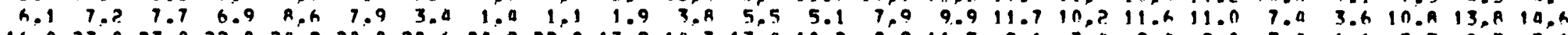

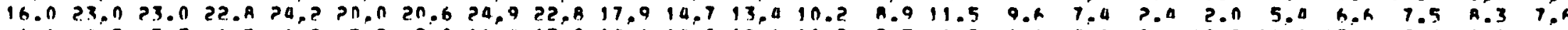

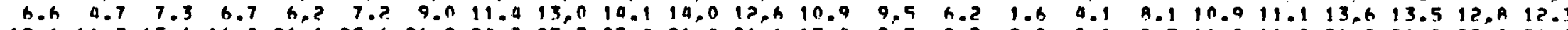

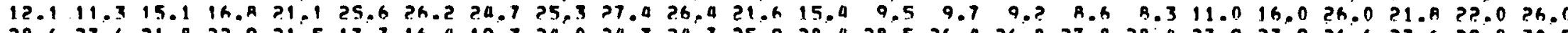

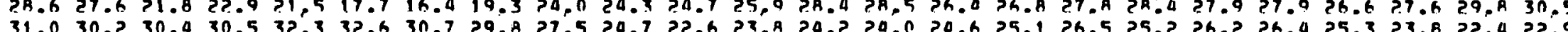

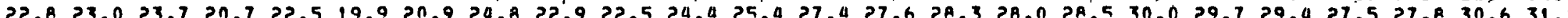

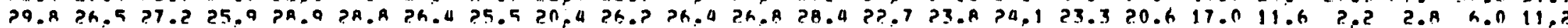

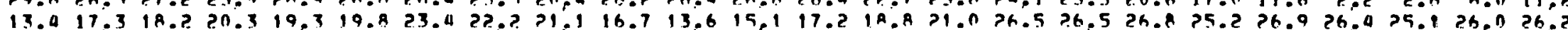

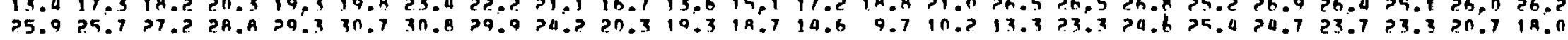


WINA SPEFE ICCIOH

MTLES/HOIIR

LFVEL HEIGHT; IO METERS
RATTELL.F WIAIN SPIINY, HEAS

TFHACHAP I MTNS. CA.

STTE

DEC, 1979

AFROVIRONMENT INC.

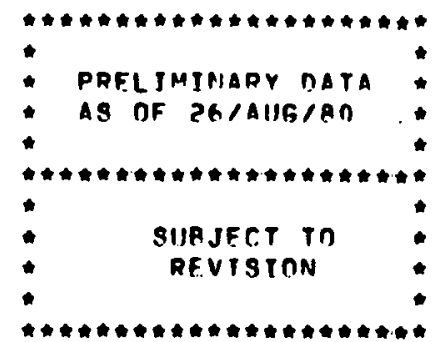

CLOCK hMIIR [LOCAL STANHARO TJMFJ

2.0.9 2.1. 521.9 13..? $13.511 .4 \quad 10.7 \quad 10.7$

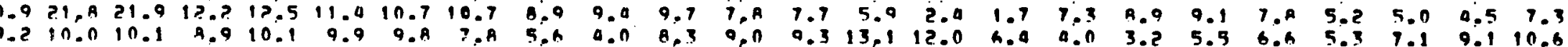

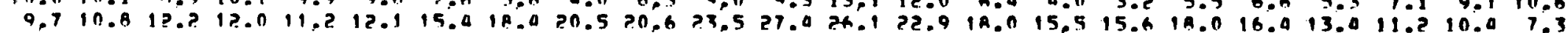

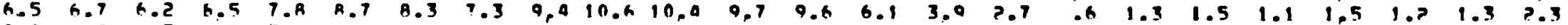

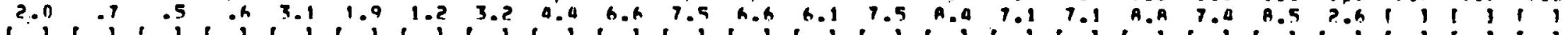

$$
\text { (1) }
$$


(V: 1:4) DTRECT IUR: ICC:(1)

\section{DEGREES}

LEVEL HEIGHT : 10 METERS
EATIELIE WIRIN STURY, H505

IEHACHAPI MINS, CA.

SITE

AIIG, 1979

AEROVJRONMENT INC.

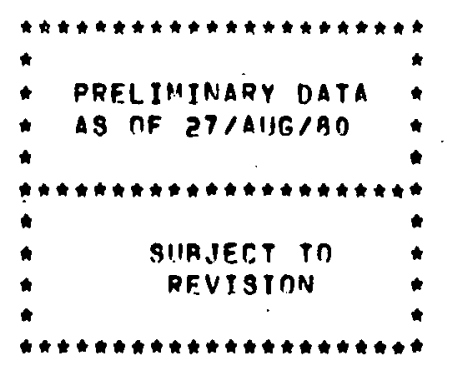

CLOCK HOIIR (LOCAL STANOARD TIME)

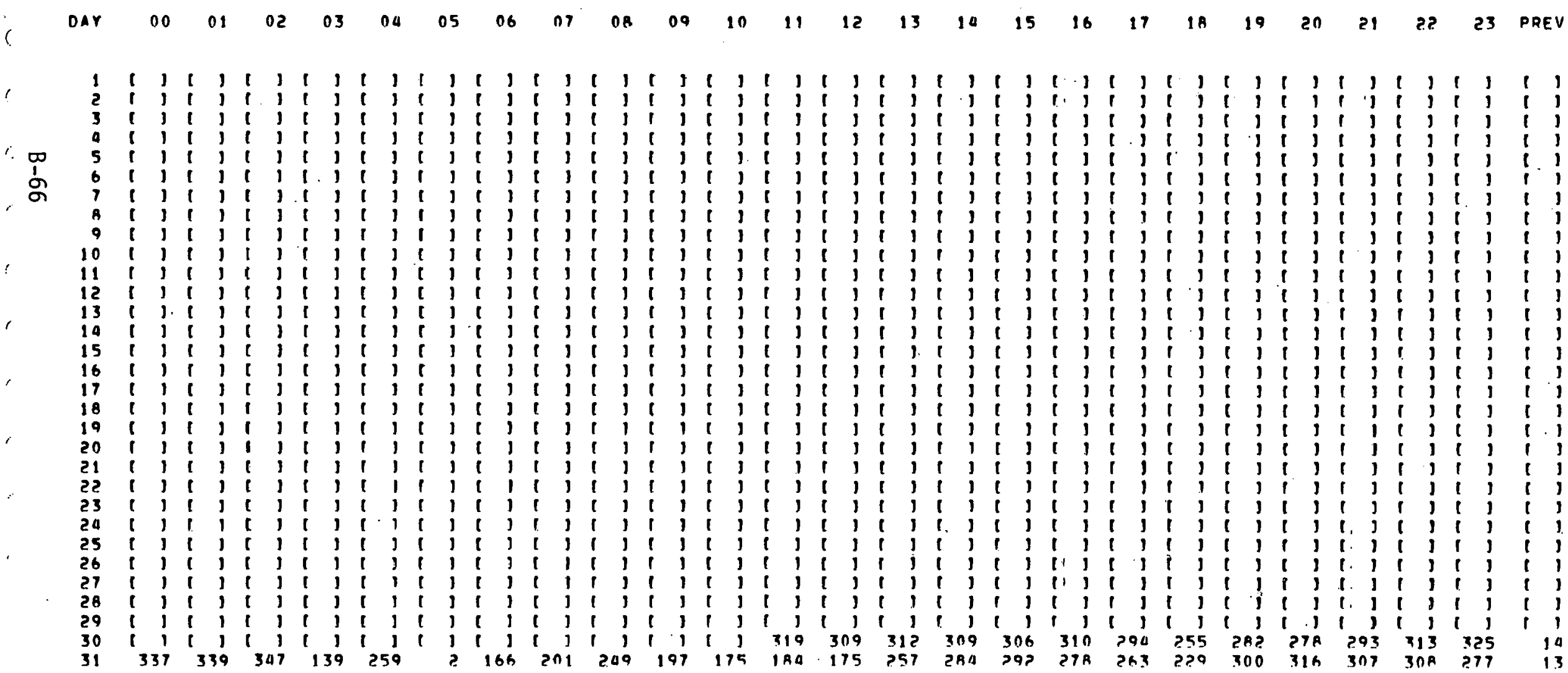


WINT DIPECTION ITCBOST

LEVEL HETTHT : 10 MFTERS
BATTELLE. WIND STUDV, \#SRE TFHACHAPI MTNS, CA.

SITE

AUG, 1979

AFROVIRONMENT INC.

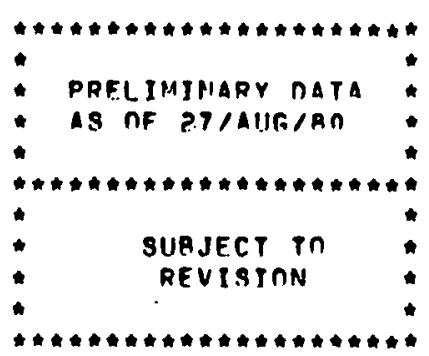

CLDCK HOIIG ILOCAL STANDARO TIMEJ 
WINO DIRECTION [CCIOP)

DEGREES

LEVEL HEIGHT 10 MFTERS
BATTELLE WTNO STUDY, 505

TEHACHAPI MTNS, CA.

SIT

SEP, 1979

AFROVIRONMENT INC.

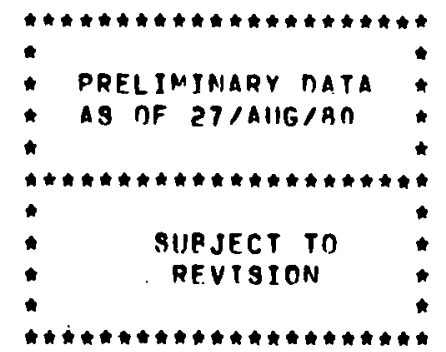

CLOCK HOUR (LOCAL STANDARD TIME)

\begin{tabular}{|c|c|c|c|c|c|c|c|c|c|c|c|c|c|c|c|c|c|c|c|c|c|c|c|c|c|}
\hline AY & 00 & 01 & 2 & 3 & 04 & 55 & 06 & 07 & ก. & 09 & 10 & 11 & 12 & 13 & 14 & 15 & 16 & 17 & $1 A$ & 19 & 20 & 21 & 22 & 23 & REV \\
\hline $\begin{array}{l}1 \\
2 \\
3 \\
4 \\
5 \\
6 \\
7 \\
8 \\
9 \\
10 \\
11 \\
12 \\
13 \\
14 \\
15 \\
16 \\
17 \\
18 \\
19 \\
20 \\
21 \\
22 \\
23 \\
24 \\
25 \\
26 \\
27 \\
28 \\
29 \\
30\end{array}$ & $\begin{array}{r}75 \\
312 \\
276 \\
316 \\
300 \\
39 \\
2 \\
300 \\
295 \\
341 \\
330 \\
327 \\
325 \\
317 \\
346 \\
119 \\
312 \\
329 \\
205 \\
119 \\
243 \\
264 \\
172 \\
96 \\
13 \\
33 \\
339 \\
307 \\
39 \\
279\end{array}$ & $\begin{array}{r}356 \\
318 \\
300 \\
320 \\
303 \\
312 \\
275 \\
312 \\
328 \\
87 \\
331 \\
333 \\
325 \\
311 \\
87 \\
137 \\
295 \\
294 \\
280 \\
127 \\
226 \\
235 \\
20 \\
99 \\
328 \\
333 \\
0 \\
309 \\
177 \\
328\end{array}$ & $\begin{array}{r}1 \\
321 \\
293 \\
334 \\
26 \\
312 \\
343 \\
317 \\
305 \\
252 \\
335 \\
319 \\
319 \\
312 \\
91 \\
143 \\
295 \\
310 \\
284 \\
110 \\
199 \\
216 \\
113 \\
113 \\
284 \\
301 \\
53 \\
301 \\
67 \\
332\end{array}$ & $\begin{array}{l}2 A 3 \\
120 \\
168 \\
202 \\
106 \\
125 \\
274 \\
283 \\
A 2 \\
305 \\
2 B 9 \\
32 A\end{array}$ & $\begin{array}{r}262 \\
207 \\
343 \\
323 \\
325 \\
110 \\
78 \\
308 \\
321 \\
296 \\
141 \\
179 \\
175 \\
136 \\
153 \\
2152 \\
270 \\
90 \\
286 \\
262 \\
58\end{array}$ & $\begin{array}{l}311 \\
299 \\
180 \\
192 \\
192 \\
192 \\
151 \\
249 \\
246 \\
106 \\
273 \\
302 \\
90\end{array}$ & $\begin{array}{r}178 \\
332 \\
32 \\
306 \\
14 \\
340 \\
49 \\
47 \\
108 \\
262 \\
343 \\
324 \\
132 \\
306 \\
97 \\
325 \\
327 \\
316 \\
295 \\
197 \\
184 \\
212 \\
191 \\
149 \\
221 \\
252 \\
115 \\
218 \\
199 \\
117\end{array}$ & $\begin{array}{r}263 \\
300 \\
59 \\
290 \\
13 \\
337 \\
90 \\
116 \\
107 \\
262 \\
337 \\
28 \\
38 \\
327 \\
36 \\
316 \\
327 \\
327 \\
292 \\
208 \\
217 \\
207 \\
187 \\
107 \\
234 \\
229 \\
123 \\
128 \\
213 \\
126\end{array}$ & $\begin{array}{l}322 \\
304 \\
246 \\
210 \\
201 \\
195 \\
162 \\
261 \\
223 \\
16 \\
137 \\
285 \\
117\end{array}$ & $\begin{array}{l}246 \\
331 \\
399 \\
70 \\
130 \\
120 \\
146 \\
245 \\
108 \\
245 \\
350 \\
114 \\
332 \\
96 \\
349 \\
316\end{array}$ & $\begin{array}{r}249 \\
344 \\
270 \\
275 \\
79 \\
128 \\
100 \\
247 \\
129 \\
259 \\
1 \\
119 \\
316 \\
125 \\
110 \\
18 \\
339 \\
322 \\
310 \\
301 \\
234 \\
207 \\
281 \\
174 \\
298 \\
193 \\
182 \\
139 \\
291 \\
93\end{array}$ & $\begin{array}{l}249 \\
333 \\
270 \\
275 \\
262 \\
120 \\
116 \\
259 \\
110 \\
276 \\
296 \\
134 \\
299 \\
96 \\
24 \\
234 \\
327 \\
329 \\
295 \\
300 \\
303 \\
260 \\
188 \\
195 \\
296 \\
216 \\
197 \\
109 \\
309 \\
02\end{array}$ & $\begin{array}{l}277 \\
313 \\
284 \\
287 \\
256 \\
144 \\
130 \\
267 \\
168 \\
298 \\
289 \\
96 \\
290 \\
293 \\
25 \\
242 \\
325 \\
332 \\
285 \\
311 \\
311 \\
289 \\
326 \\
165 \\
296 \\
282 \\
198 \\
142 \\
311 \\
108\end{array}$ & $\begin{array}{l}290 \\
316 \\
284 \\
2 A 9 \\
275 \\
134 \\
152 \\
27 A \\
239 \\
310 \\
298 \\
80 \\
298 \\
288 \\
20 \\
247 \\
328 \\
330 \\
298 \\
311 \\
314 \\
268 \\
324 \\
168 \\
287 \\
298 \\
209 \\
225 \\
324 \\
233\end{array}$ & $\begin{array}{l}287 \\
303 \\
291 \\
283 \\
281 \\
220 \\
198 \\
287 \\
284 \\
323 \\
296 \\
292 \\
311 \\
295 \\
18 \\
240 \\
330 \\
322 \\
314 \\
314 \\
301 \\
313 \\
323 \\
198 \\
285 \\
307 \\
293 \\
288 \\
330 \\
323\end{array}$ & $\begin{array}{l}P A A \\
302 \\
301 \\
285 \\
2 A 3 \\
280 \\
150 \\
298 \\
315 \\
322 \\
311 \\
299 \\
310 \\
297 \\
45 \\
274 \\
322 \\
330 \\
312 \\
320 \\
205 \\
323 \\
312 \\
? 28 \\
300 \\
304 \\
316 \\
310 \\
333 \\
335\end{array}$ & $\begin{array}{l}313 \\
326 \\
313 \\
307 \\
310 \\
310 \\
12 \\
324 \\
322 \\
310 \\
301 \\
327 \\
25 A \\
295 \\
342 \\
297 \\
313 \\
305 \\
284 \\
283 \\
30 A \\
323\end{array}$ & $\begin{array}{l}327 \\
325 \\
311 \\
313 \\
311 \\
331 \\
350 \\
327 \\
310 \\
304 \\
299 \\
329 \\
252 \\
286 \\
325 \\
315 \\
319 \\
313 \\
304 \\
300 \\
320 \\
303\end{array}$ & $\begin{array}{r}316 \\
328 \\
52 \\
342 \\
330 \\
308 \\
312 \\
328 \\
258 \\
270 \\
329 \\
292 \\
300 \\
318 \\
316 \\
285 \\
338 \\
327\end{array}$ & $\begin{array}{l}327 \\
328 \\
316 \\
329 \\
331 \\
193 \\
336 \\
317 \\
317 \\
329 \\
259 \\
279 \\
332 \\
325 \\
317 \\
305 \\
315 \\
322 \\
341 \\
337\end{array}$ & $\begin{array}{r}324 \\
270 \\
49 \\
341 \\
312 \\
355 \\
310 \\
313 \\
264 \\
307 \\
337\end{array}$ & $\begin{array}{r}312 \\
351 \\
7 \\
312 \\
308 \\
232 \\
7 \\
298 \\
330 \\
311 \\
307 \\
319 \\
291 \\
999\end{array}$ & $\begin{array}{l}132 \\
75 \\
319 \\
290 \\
232 \\
358 \\
332 \\
318 \\
320 \\
308 \\
310 \\
291 \\
45\end{array}$ & $\begin{array}{r}33 A \\
97 \\
8 B \\
301 \\
263 \\
231 \\
331 \\
332 \\
345 \\
326 \\
307 \\
39 \\
59 \\
59\end{array}$ & $\begin{array}{r}13 \\
15 \\
14 \\
14 \\
14 \\
16 \\
16 A \\
14 \\
16 \\
16 \\
15 \\
15 \\
15 \\
15 \\
2 \\
16 \\
15 \\
15 \\
14 \\
15 \\
11 \\
10 \\
16 \\
8 \\
15 \\
15 \\
15 \\
14 \\
15 \\
16\end{array}$ \\
\hline & 15 & 15 & 15 & 14 & 14 & 14 & 15 & a) & 16 & in & 15 & 1.7 & 14 & 10 & 15 & 15 & in & 15 & 19 & 15 & 5 & 15 & 15 & 15 & \\
\hline
\end{tabular}


WIND DIRECTION [CCIOSI

LEVEL HETGHT : 19 METERS
BATTELLE WIND STIBDY,ASOS TEHAC,HAPI MTNS, CA. SITF 5

SEP, 1979

AEROVIRONMENT INC. preliminary data

As DF $27 / 4 U G / B D$

SHEJECT TO
REVISION

CLOCK hOUR [LOCAL STANDARD TIME]

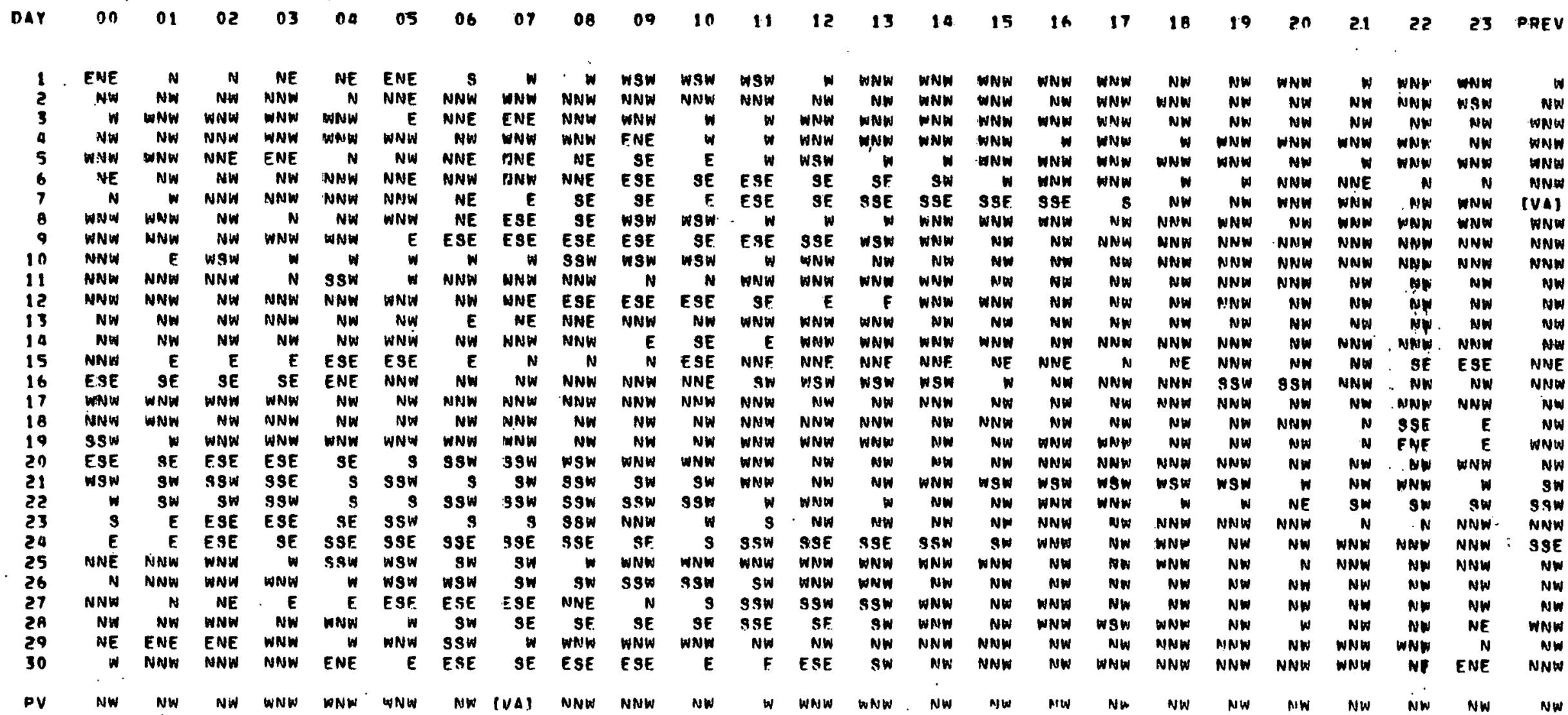


WIND MTRECTION [CC:OS]

DEGREES

LEVEL HETGHT , IO METERS
BATTELLE WIND STUDY, $\$ 5 \cap 5$

TEHACHAPI MTNS, CA.

SITE

OCT. 1979

AEROVIRONMFNT INC.

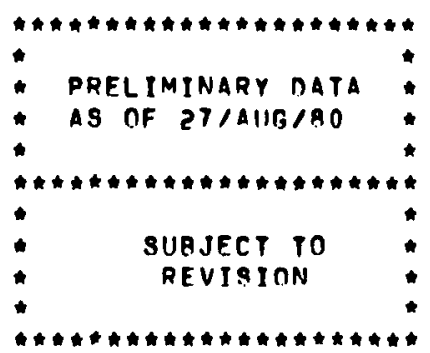

CLOCK HOUR [LICAL GTANHARD TJME]

\begin{tabular}{|c|c|c|c|c|c|c|c|c|c|}
\hline $\begin{array}{r}5 A \\
303\end{array}$ & $\begin{array}{r}28 \\
307\end{array}$ & $\begin{array}{r}40 \\
0\end{array}$ & $\begin{array}{r}35 \\
9\end{array}$ & $\begin{array}{r}39 \\
348\end{array}$ & $\begin{array}{r}47 \\
3\end{array}$ & $\begin{array}{r}49 \\
9\end{array}$ & $\begin{array}{l}98 \\
\text { A }\end{array}$ & $\begin{array}{l}111 \\
105\end{array}$ & $\begin{array}{l}96 \\
B A\end{array}$ \\
\hline 314 & 316 & 327 & 334 & 333 & 349 & 4 & 343 & 16 & 76 \\
\hline 314 & 342 & 345 & 332 & 334 & 340 & 325 & 231 & 199 & 168 \\
\hline 320 & 319 & 307 & 345 & 14 & 28 & 45 & As & $11 h$ & 119 \\
\hline 335 & 329 & 306 & $2 B$ & 107 & 110 & 111 & 109 & $5 A$ & 270 \\
\hline 298 & $3 \cap 2$ & 291 & 303 & 60 & 75 & 93 & 261 & 247 & 258 \\
\hline 306 & $30 a$ & 309 & $32 h$ & 342 & 319 & 308 & $2 B 8$ & 253 & 234 \\
\hline 2BA & 326 & 325 & 356 & 0 & 335 & 295 & 298 & 100 & 113 \\
\hline 17 & 26 & 60 & 73 & 65 & AB & 75 & 116 & $1 ? 0$ & \\
\hline 281 & 240 & 24? & 240 & 241 & 263 & 273 & 241 & 202 & 254 \\
\hline 311 & 325 & 314 & 312 & 350 & 296 & 42 & 69 & 97 & 115 \\
\hline 243 & 247 & 264 & 291 & 296 & 264 & ?56 & 247 & 261 & \\
\hline 253 & 257 & 254 & 299 & 279 & 25月 & 265 & 289 & $28 A$ & 269 \\
\hline 261 & 232 & 305 & 313 & 208 & 312 & 270 & ? 99 & 72 & 239 \\
\hline 342 & 346 & 1 & 356 & 304 & 341 & 341 & 339 & 336 & $29 a$ \\
\hline 333 & 336 & 344 & 334 & 336 & 340 & 26 & 15 & 298 & 337 \\
\hline 228 & 245 & 243 & 246 & 222 & 224 & 242 & 272 & 272 & 286 \\
\hline 234 & 236 & 230 & 241 & 244 & 245 & 237 & 223 & 234 & 222 \\
\hline 220 & 233 & 237 & 232 & 267 & 258 & 290 & $28 \mathrm{~A}$ & 296 & 291 \\
\hline 294 & 277 & 279 & टम1 & 270 & 2AB & 160 & 275 & 292 & 75 \\
\hline 18 & 20 & 20 & 39 & $5 h$ & $5 B$ & 85 & 117 & 101 & 92 \\
\hline $3 A$ & 47 & 39 & 42 & 350 & 22 & 61 & B) & 109 & 93 \\
\hline
\end{tabular}

$\begin{array}{ll}5 & 9 \\ 1 & A \\ 5 & 12 \\ 0 & 22 \\ 2 & 12 \\ 5 & 29 \\ 1 & 25 \\ 7 & 25 \\ 1 & 11 \\ 2 & 10 \\ 8 & 25 \\ 3 & 29 \\ ? & 25 \\ 0 & 28 \\ 9 & 29 \\ 8 & 29 \\ 7 & 32 \\ 3 & 30 \\ 5 & 230 \\ 9 & 28 \\ 5 & 11 \\ 0 & 97 \\ 0 & 90 \\ 1 & 18\end{array}$

$\begin{array}{lllllllllllll}111 & 136 & 143 & 148 & 151 & 130 & 55 & 64 & 76 & 51 & 311 & 306\end{array}$ $8 \quad 118$ 14? 141 143 167 $276 \quad 292 \quad 299 \quad 305 \quad 304 \quad 311$ 3?

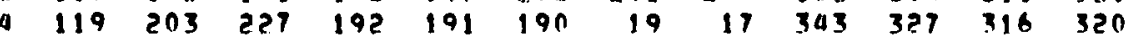

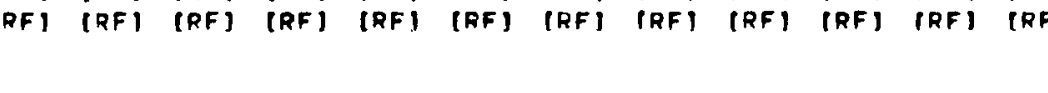


WIND DIRECTION ICCINST

LEVEL HEIGHT; IO METFRS
PATTELLE WINO STUDY, \#505

TEHACHAPI MTNS, CA.

SITF: 5

nCt, 1979

AEROVIRONMENT INC.

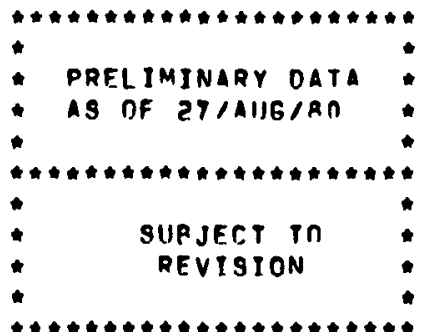

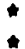

Clock hDUR (LOCAL STANDARO TIME)

\begin{tabular}{|c|c|c|c|c|c|c|c|c|c|c|c|c|c|c|c|c|c|c|c|c|c|c|c|c|c|}
\hline & 1) 0 & $n 1$ & 02 & 03 & 04 & 05 & 06 & 07 & $O B$ & $n 9$ & 10 & 11 & 2 & 3 & 4 & 5 & 6 & 17 & 18 & 9 & 0 & 21 & 22 & 23 & \\
\hline 1 & E VF: & NNE & NI & NE & NE & NE & NE & E & ESF & E & $E$ & $E$ & ES & s & & SSE & 3. & SE & We & NE & & NE & NW & $n$ & \\
\hline 2 & W VW & NW & $\mathbf{N}$ & 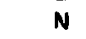 & NNW & iv & $N$ & E & 85 & E & $E$ & E & & 8 & & SE & SE & $w$ & WNW & WNW & NW & NW & NW & NW & \\
\hline 3 & VW & NW & NNW & NNW & NNW & $N$ & $N$ & NNW & NNE & ENE & ESE & SE & ESE. & s9w & sw & ssw & 9 & 3 & NNE & NNE & NNW & NNWI & NW & NW & \\
\hline a & vw & NNW & NNW & NNW & NNW & NNW & $N W$ & Sw & ssw & SSE & 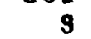 & sw & ssw & SW & SW & sw & w & INW & WNW & WNW & NW & NW & NW & NW & \\
\hline 5 & NW & NW & WW & NNW & NNE & NNE & NE & NE & E SE & ESE & SE & SE & SE & NNW & NW & WNW & WNW & ONW & WNW & NW & NW & NW & $N w$ & NW & \\
\hline 6 & NNW & NNW & NW & NNE & ESE & ESE & ESE & ESE & ENE & $w$ & WNW & WNW & WNW & WNN & WNW & NW & NW & NW & NNW & N & NE & NNW & NNW & NNW & \\
\hline 7 & WNW & WNW & WNW & WNW & ENE & ENE. & E & $w$ & WSW & wgw & $w$ & WSW & $w$ & WNW & WNW & NW & NW & NW & NW & NW & NW & NW & NW & WNW & \\
\hline 8 & N'W & NW & NW & NW & NNW & NW & NW & WNW & WSW & sw & WSW & Wsw & WNW & WNW & WNW & WNW & WNW & $w$ & $w$ & $w$ & wsw & $w$ & WNW & WNW & \\
\hline 9 & WNWW & NW & NW & $\mathbf{N}$ & $N$ & NNW & WNW & WNW & SSE & ESF. & ESE & ESE & ESE & ESE & ESE & ESE & ESE & FNE & $N$ & $\mathrm{~N}$ & NW & $N W$ & 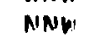 & $\mathbf{N}$ & \\
\hline 10 & NNE & NNE & ENE & ENE & ENE & ENE & ENE & E SE. & ESE & ESE & ESE & ESE & ESE & E.SE & E.AE & WSW & WNW & NW & WNW & WNW & WNW & WNW & WNW & WNW & \\
\hline 11 & $w$ & W.9W & WSW & WSW & WSW & $w$ & w & w gw & WSW & WSW & WSW & WRW & w & $w$ & WNW & WNW & WNW & NNW & NINW & NNW & NNW & NW & WNW & $N$ & \\
\hline 12 & NW & NW & NW & NW & $\mathbf{N}$ & WNW & NE & ENE & $\pi$ & ESE & D & WNW & WNW & WNW & WNW & WNW & WNW & WNW & WSW & SW & WSW & $\mathbf{N}$ & NW & $\boldsymbol{E}$ & \\
\hline 13 & wsw & W.SW & $w$ & WNW & WNW & $w$ & wsw & WaW & $w$ & WSW & sw & $W$ & WNW & WNW & $w$ & $w$ & W.9W & $w$ & WSW & W & $w$ & W9w & $w$ & Wsw & \\
\hline 14 & WB:V & Wsw & WSH & WNW & $W$ & WSW & $w$ & WNW & WNW & 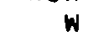 & $w$ & WNW & $w$ & $w$ & $w$ & WNW & $w$ & NINW & $w$ & WSW & WSW & $w$ & WNW & WNW & \\
\hline 10 & $w$ & sw & NW & NW & WNW & NW & $w$ & WNW & ENE & W9W & $\omega$ & WNW & WNW & WNW & NW & NW & NNW & NNW & NNW & NNW & NNW & NNW & NW & iw & \\
\hline 16 & NNW & NNW & $N$ & $N$ & NNW & NNW & NNW & NNW & NNW & WNW & WNW & WNW & WNW & WNW & WNW & NW & NW & NNW & NNW & NW & NNW & NNW & NNW. & NNW & \\
\hline 17 & NNW & NNW & NNW & NNW & NNW & NN: N & NNE & NNE & WNW & NNW & NNW & NNW & NW & NN!W & NNIW & NW & NW & Nk: & NW & NW & NNW & $w$ & WNA & $w$ & \\
\hline 18 & SW & W.9W & W\&W & WSW & sw & SW & พร & W & $w$ & WNW & WNW & WNW & WNW & WNWW & WNW & WNW & WNW & WNW & WNW & WNW & WNW & WNW & WN!W & $w$ & \\
\hline 19 & Sw & sw & SW & WSW & W9w & WSW & wsw & SW & sw & sw & SW & sw & sw & SW & sw & sw & sw & sw & SW & sw & . sw & SW & sw & $w$ & \\
\hline 80 & sw & SW & WSW & sw & $w$ & WSW & WNW & WNW & WNW & WNW & WNW & WNW & WNW & WNW & WNW & WNW & WNW & WNW & WNWW & WNW & WNW & NW & NW & WNW & \\
\hline & WNW & $w$ & $w$ & WNW & $w$ & WNW & SSE & $w$ & WNW & ENE & SE & ESE & ESF & ESE & E & E & ENE & NNF. & NW & NNW & $N$ & FNE & F & NE & \\
\hline & NNE & NNE & NNE & NE & NE & ENE & & ESF & E & $E$ & $E$ & $\underline{E}$ & ESE & E & ESE & ESE & & NE & NE & NNE & $\mathbf{N}$ & WNW & N & NNW & \\
\hline 28 & NE & NE & NE & NE & $\mathbf{N}$ & NNE & ENE & $\mathbf{E}$ & ESE & E & $E$ & E & [RF] & [RF] & [RF] & [RF] & (RF) & [RF] & (PF) & [RF] & RF I & [RF] & [RF] & [RF] & \\
\hline & (PF) & (RF) & (RF) & (RF) & (RF) & (RF) & (RF) & [RF ] & [RF] & (RF) & (RF) & [RF] & [RF ] & (RF) & [RF] & (RF) & [RF] & (PF) & IRFI & [RF]. & RF ] & RF I & RFj & RFI & \\
\hline 25 & (AF) & IRF] & (RF) & (RF) & [RF] & [RF] & [RF] & (RF) & (RF) & [RF] & [RF] & [RF] & (RF) & (PF) & (RF) & [RF] & [RF] & (RF) & |RF| & (RF) & (RF) & [RF j & IRF] & (RF) & $i$ \\
\hline 20 & [AF ] & [RF] & (RF) & (RF) & [RF] & [RF ] & [RF] & (RF) & (RF) & {$[R F]$} & {$[R F]$} & {$[R F\}$} & (RF) & [RF] & (RF) & [PF] & (RF) & (RF) & [RF] & [RF] & (RF) & (RF) & [RF] & [RF) & i \\
\hline & (RF) & [RF] & IRF I & [RF] & [RF] & [RF] & RF j & [RF] & [RF] & [RF] & [RF] & (RF) & [RF] & & & IR & [RF] & J & (RF) & (RF) & (RF) & (RF) & (RF) & & \\
\hline$e n$ & (RF) & [RF] & [RF] & |RF | & (RF) & (RF) & [RF] & [RF ] & [RF] & [RF) & [RF ] & (RF) & (RF) & (RF) & (RF) & (RF) & [RF] & (RF) & [RF] & (RF) & IRFi & (RF) & (RF) & [RF] & 1 \\
\hline 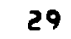 & (RF) & [AF] & (RF) & [RF] & (RF) & [RF ] & [PF] & (RF) & [RF] & [RF] & [RF] & [RF] & (RF) & [RF] & [PF] & [RF] & [RF] & (RF) & |RFi & (RF) & [RF] & [RF] & IDF ] & (RF) & \\
\hline 30 & PF J & (RF) & (RF) & [RF] & (RF) & (RF) & (RF) & (RF) & [RF] & [RF] & (RF) & $|R F|$ & [RF] & 1 & & (RF) & [RF] & [RF] & [RF] & (RF) & (RF) & (RF) & IPF I & (RF) & \\
\hline & QF J & [RF] & (RF) & [RF] & (RF) & [RF] & (RF) & (RF) & [RF) & [RF] & [RF] & $|P F|$ & (RF) & [RF] & |RFi & [RF] & (RF) & (DF) & |RFi & (RF) & (RF) & (RF) & IRF ] & (RF) & 8 \\
\hline
\end{tabular}


WINO DIRECTION [CCBOZ]

DEGREES

LEVEL HEIGHT: 10 METERS
AATTELLE WIND STIINY, \#SOS TEHACHAPI MTNS, CA.

STTE 5

NOV, 1979

AEROVIRONMENT INC.

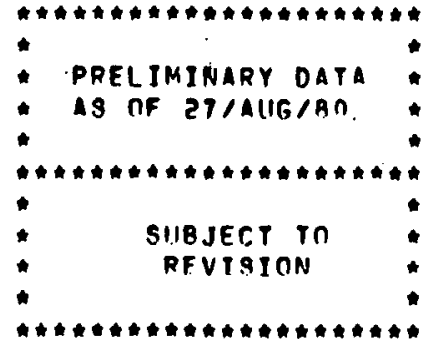

CLOCK HOUR ILDCAL STANDARO TIMEJ

DAY

\begin{tabular}{|c|c|c|c|c|c|c|c|c|c|c|c|c|c|c|c|c|c|c|c|c|c|c|c|c|}
\hline 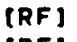 & 1 & & & F ] & & & [F] & 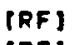 & (F) & 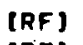 & 3 & & & 1 & & $=1$ & & [RF] & [RF] & [RF] & (RF) & (RF) & |RF| & l. \\
\hline$F$ & F] & (F) & RF I & IF) & RF I & IF I & [AF] & RF I & \{F \} & FI & PF J & F) & QF) & RF 1 & (RF) & [RF] & [RF] & (RF) & [RF] & (RF) & (RF) & (RF) & [RF] & i \\
\hline PF & (RF) & QF I & [RF] & [RF] & [RF] & [RF] & [RF] & (DF) & RF J & RF 1 & [RF] & RF I & AF J & (RF) & $\{R F\}$ & (RF) & [RF] & (RF) & (RF) & [RF] & (RF) & (RF) & (RF) & \\
\hline F] & F) & [F J & PF! & RF ! & FI & QF I & (RF) & (RF) & [RF ] & PFI & (RF) & (RF) & [RF] & [RF ] & (RF) & (RF) & [RF] & [RF] & (RF) & (RF) & (RF) & [RF] & RF I & I \\
\hline F! & [F] & [F J & $2 F 1$ & PF J & PF 1 & F) & [RF] & F I & [RF] & [F I & [RF ] & RF J & [RF] & (RF) & (RF) & [RF] & [RF] & (RF) & (RF) & (RF) & (RF) & [RF] & [RF] & \\
\hline [RF] & RF) & [RF] & [RF] & RF J & QF J & QFI & (RF) & (RF) & [RF] & RF J & [RF\} & RF $]$ & [RF] & [RF] & (RF) & [RF] & {$[R F]$} & [RF] & [RF] & [RF] & [RF ] & (RF) & [RF] & \\
\hline [RF ] & (F) & [RF] & RF & (RF) & [RF] & [RF] & (RF) & (RF) & [RF] & RF 1 & [RF] & [RF ] & [RF ] & (RF) & [RF] & [RF] & [RF] & (RF) & (RF) & (RF) & |RF] & (RF) & [RF] & I \\
\hline RF & F ] & F J & F 1 & [F] & RF 1 & $2 F$ & (RF) & [RF] & [RF] & RF J & [RF] & [RF ] & [RF] & [RF] & [RF] & (RF) & [RF] & (PF) & (RF) & (RF) & |RF| & [RF] & [RF ] & \\
\hline F] & F! & F) & [F] & {$[F]$} & [F $\}$ & [RF] & [RF) & (RF) & IRF I & RFI & [RF] & [RF] & [RF] & [RF ] & (RF) & (RF) & [RF] & (RF) & [RF] & [RF] & [RF ] & [RF ] & [RF] & 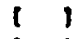 \\
\hline [RF) & [F] & [RF] & RF I & (RF) & [RF] & [RF] & [RF] & (RF) & [RF] & RF 1 & [RF] & (RF) & (RF) & (RF) & [AF ] & (RF) & [RF] & [RF] & [RF] & (RF) & (RF) & (RF) & [RF] & I \\
\hline [RF] & (RF) & (RF) & [RF ] & (RF) & (RF) & [RF] & (RF) & [RF] & [RF] & [RF] & [RF] & [RF] & [RF] & (RF) & [RF] & [RF] & (RF) & [RF] & (RF) & [AF I & [RF ] & [RF ] & [RF] & 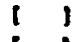 \\
\hline [RF] & F] & [RF] & [RF] & [RF] & [RF] & (RF) & (RF) & [RF] & [RF ] & (RF) & [RF] & [RF] & [RF] & (RF) & [RF] & [RF] & [RF ] & [RF] & (RF) & [RF] & (RF) & [RF ] & [RF ] & I \\
\hline [RF] & [RF] & (RF) & [RF] & [RF] & (RF) & (RF) & (RF) & (RF) & [RF] & RF I & [RF] & [RF] & [RF ] & [RF ] & 172 & 145 & $9 n$ & 73 & 83 & 216 & 239 & 103 & 11? & \\
\hline $\begin{array}{r}105 \\
92\end{array}$ & $\begin{array}{l}114 \\
121\end{array}$ & $\begin{array}{l}101 \\
111\end{array}$ & $\begin{array}{r}119 \\
69\end{array}$ & $\begin{array}{r}107 \\
68\end{array}$ & $\begin{array}{l}97 \\
71\end{array}$ & $\begin{array}{l}78 \\
99\end{array}$ & $\begin{array}{l}104 \\
118\end{array}$ & & & & $\begin{array}{l}144 \\
145\end{array}$ & $\begin{array}{l}141 \\
145\end{array}$ & $\begin{array}{l}142 \\
149\end{array}$ & $\begin{array}{l}101 \\
134\end{array}$ & $\begin{array}{l}130 \\
138\end{array}$ & $\begin{array}{l}190 \\
127\end{array}$ & $\begin{array}{l}115 \\
118\end{array}$ & $\begin{array}{l}71 \\
73\end{array}$ & $\begin{array}{l}66 \\
68\end{array}$ & $\begin{array}{r}66 \\
239\end{array}$ & $\begin{array}{l}166 \\
257\end{array}$ & 46 & 326 & \\
\hline 352 & 15 & 89 & 50 & 22 & ? & 49 & $9 n$ & 115 & 161 & 164 & 142 & 142 & 142 & 151 & 144 & 135. & 107 & $5 B$ & 34 & 23 & 10 & 350 & 327 & va \\
\hline $34 \mathrm{a}$ & 12 & 340 & 342 & 3?9 & 182 & 291 & 28 A & 276 & 323 & 323 & 327 & 327 & $3 P 2$ & 318 & 314 & 290 & $30 ?$ & 304 & 308 & 312 & 303 & 314 & 313 & \\
\hline 313 & 330 & 337 & 325 & 337 & 341 & 301 & 330 & 335 & 326 & 338 & 329 & 327 & 325 & 321 & 316 & 321 & $31 \mathrm{~A}$ & 305 & 316 & $\boldsymbol{n}$ & 331 & 8 & 8 & \\
\hline 321 & 332 & 334 & 326 & 340 & 341 & 329 & 307 & 347 & 5 & 33 & 339 & 321 & 334 & 335 & 321 & 307 & 258 & 340 & 353 & 346 & 344 & 196 & 336 & \\
\hline 327 & 329 & $35 A$ & 45 & 356 & 50 & 07 & $3 B$ & 107 & 142 & 15 & 109 & 124 & 134 & $12 A$ & 138 & 154 & 3?R & A & 249 & 26A & ha & 57 & 77 & \\
\hline 16 & A2 & 05 & 344 & 235 & 115 & 112 & 117 & 95 & 121 & 143 & 130 & 132 & 131 & 142 & 132 & 134 & 123 & 42 & $\Delta 1$ & 53 & ?? & 20 & ha & \\
\hline 222 & 223 & 222 & 292 & 41 & 85 & די & 56 & 61 & $9 n$ & 15 & IAY & 1BI & 146 & 100 & 148 & 152 & 142 & 286 & 2A4 & 970 & ?65 & 255 & 260 & \\
\hline 277 & 304 & 309 & 314 & 313 & PAI & 274 & 318 & 332 & 335 & 30 & 132 & 351 & 355 & 342 & 357 & 36 & 356 & $B$ & 262 & 272 & 293 & $3 n 7$ & 3 & \\
\hline 326 & $2 A 9$ & 2B2 & 2A1 & 10 & 252 & 336 & 321 & 309 & 330 & 32 & 2B9 & 299 & 305 & 316 & 303 & 295 & 300 & 09 & 3 & 311 & 301 & 303 & 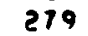 & \\
\hline 2BO & 2A5 & 299 & 299 & 303 & 303 & 304 & 299 & 300 & 2A? & $? 75$ & 259 & 264 & 309 & SiA & 316 & 315 & 311 & 2AB & & & 300 & 288 & & \\
\hline $30 ?$ & 320 & 318 & 317 & 321 & 317 & 326 & 317 & 321 & 31A & 32 & 312 & 305 & 310 & 313 & 304 & $3 n$ & 311 & 307 & 30.3 & 287 & 296 & 306 & 298 & \\
\hline 297 & 42 & 323 & 333 & 351 & 65 & 67 & 73 & 89 & 119 & 13 & 126 & 120 & 120 & 11 & 114 & 108 & 96 & 56 & 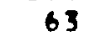 & 73 & 71 & A7 & 10 & \\
\hline BO & 133 & BA & 124 & 95 & 79 & 79 & $7 a$ & 91 & $13 \mathrm{~A}$ & 117 & 117 & 126 & 121 & 11 & 114 & 96 & 96 & 61 & & 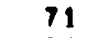 & 12 & 67 & 110 & \\
\hline 141 & 140 & 102 & $12 B$ & 108 & B9 & 89 & AO & Bn & 131 & 14 & 129 & 125 & 134 & 12 A & 134 & 132 & 109 & a 0 & 46 & 57 & $2 ? 1$ & 224 & 339 & \\
\hline 23 & $35 A$ & 19 & 70 & 29 & 18 & 7 & A & 15 & 7 & $35 a$ & 149 & 134 & 138 & 1 ? 1 & 113 & 117 & AA & 39 & 49 & 45 & in & 332 & 338 & \\
\hline
\end{tabular}


WINA DIRECTION ITCERZI

LEVEL HEIGHT; 10 METERS
BATTELLF WINO STỤN. Z5n5 TEHACHAPI MTNS, CA.

SITE

Nov, 1979

AEROVTRONMENT INC.

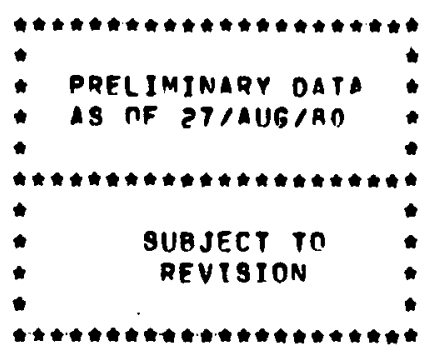

CLOCK HOUR ILOCAL STANDARD TIME] $\begin{array}{llllllll} & \\ \end{array}$

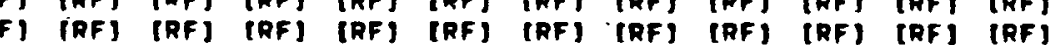

( 
WJND OIRECTION ICCBOZI

DEGREES

LEVEL HEISHT 10 METERS
AATTFLLE WJND STIINY, WEOS

TEHACHAPI MTNG, CA.

SITE

nEC, 1979

AEROUIRONMENT INC.

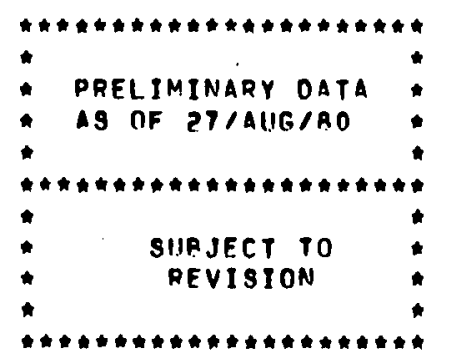

CLOCX HOUR ILDCAL STANDARO TIMEI.

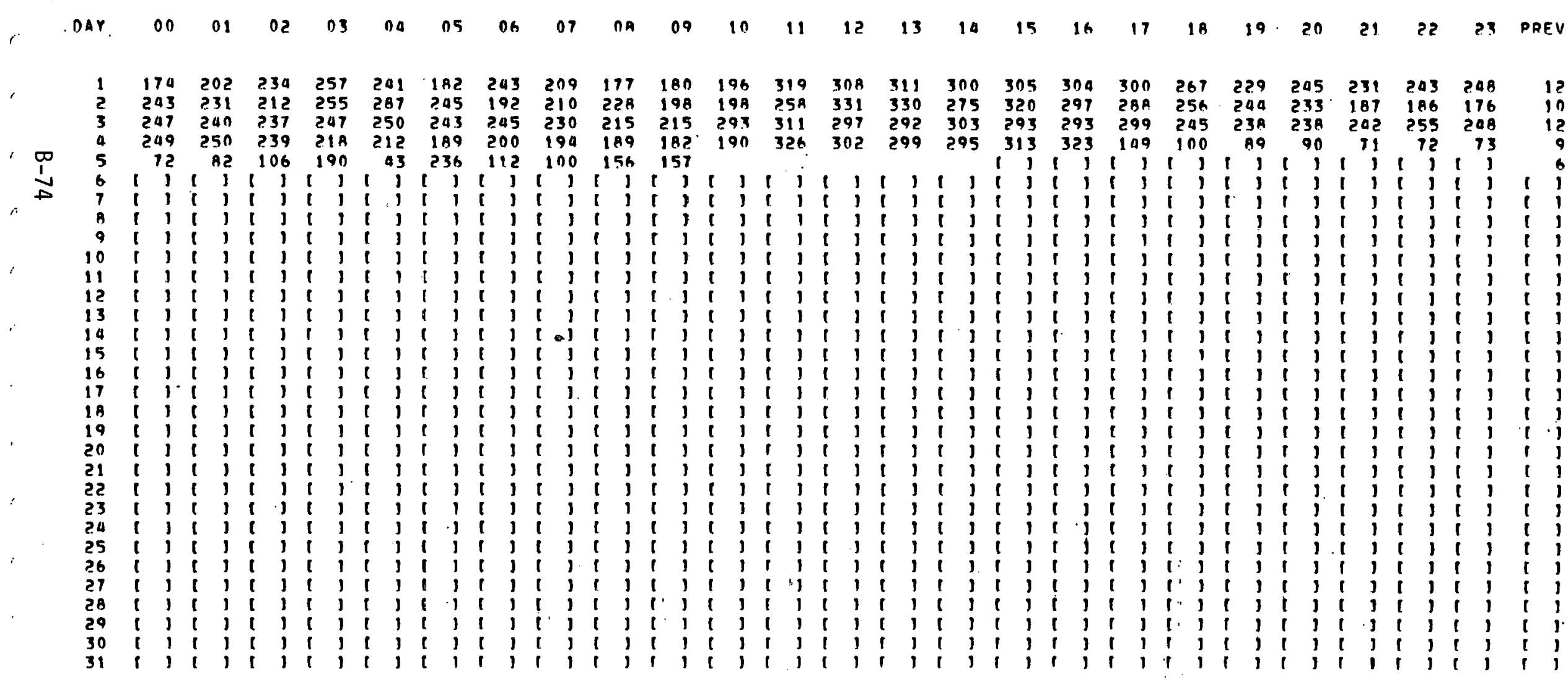


WIND DIRECTION ICCIDET

LEVEL HEIGHT i 10 METERS
PATTELLE WINO STUNY, \#505

TEHACHAPI MTNS, CA.

STIE

DEC, 1979

AEROVIRONMENT INC.

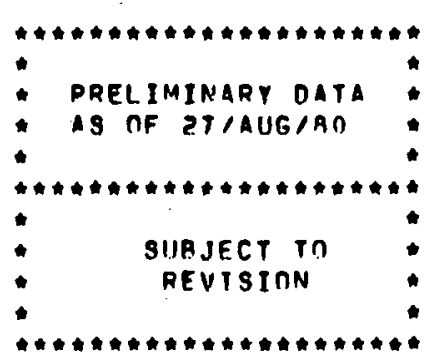

CLOCK HOIIR ILDCAL STANDARD TIME. 
WINO DIRECTION ICCSDII

DEGREES

LEVEL HEIGHT : 10 METERS
AATTFLLE WTNO STIIDY, HSOS TEHACHAPI MTNS, CA. SITE.

JIN, 1979

AEROVIRONMENT INC.

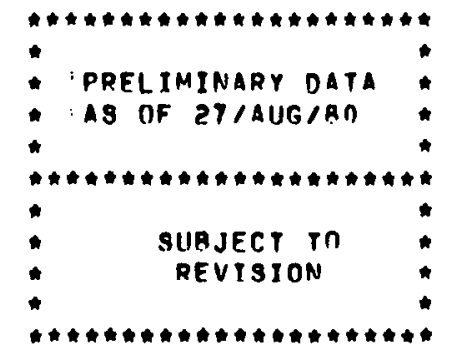

CLOCK HOIIR ILOCAL STANDARD TIME]

DAY 00 $n 1$ 02 030 05 on 07 Oค 09 10 11 13 14 15 16 I 19 20 12 P. PREV

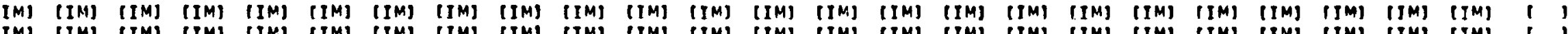
[IM] [IM] [IM] [IM] [IM] [IM] [IM] [IM] [IM] [IMM] [IM] [IM] [IM] [IM] [IM] [IM] [IM] [IM] [IM] [IM] [IM] [IM] [IM] [IM]

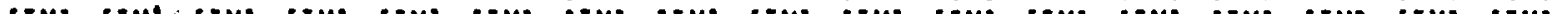
[IM] [IM] [IM] [IM] [IM] [IM] [IM] [IM] [IM] [IM] [IM] [IM] [IM] [IM] [IM] [IM] [IM] [IM] [IM] [IM] [IM] [IM] [JM] [IM] [IM] [IM] [IM] [IM] [IM] (IM] [IM] [IM] [IM] [IM] [IM] [IM] [IM] [IM] [IM] [IM] [IM] [IM] [IM] [IM] [IM] [JM] [IM] [IM]

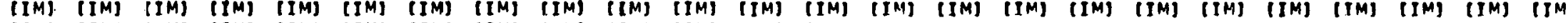
[IM] [IM] [IM] [IM] [IM] [IM] [IM] [IM] [IM] [IM] [IM] [IM] [IM] [IM] [IM] [IM] [IM] [IM] [IM] [IM] [IM] [IM] [IM] [IM] $[I M][I M]$ [IM] [IM] [IM] [IM] [IM] [IM] [IM] [IM] [IM] [IM] [IM] [IM] [IM] [IM] [IM] [IM] [IM] [IM] [IM] [IM] [IM] [IM] [IM] [IM] [IM] [IM] [IM] [IM] [IM] [IM] [IM] [IM]. [IM] [IM] [IM] [IM] [IM] [IM] [IM] [IM] [JM] [IM] [IM] [IM] [IM] [IM] [IM] [IM] [IM] [IM] [IM] [IM] [IM] [IM] [IM] [IM] [IM] [IM] [IM] [IM] [IM] [IM] [IM] [IM] [IM] [IM] [IM] [IM] [IM] [IM] [IM] [IM] [IM] [IM] [IM] [IM] [IM] [IM] [IM] [IM] [IM] [IM] [IM] [IM] [IM] [IM] [IM] [IM] [IM] [IM] [IM] [IM] [IM] [IM] [IM] [IM] [IM] [IM] [IM] [IM] [IM] [IM] [IM] [IM] [IM] [IM] [IM] [IM] [IM] [IM] [IM] [IM] [IM] [IM] [IM] [IM] [IM] [IM] [IM] [IM] [IM] [IM] [IM] [IM] [IM] [IM] [IM] [IM] [IM] [IM] [IM] [IM] [IM] [IM] [IM] [IM] [IM] [IM] [IM] [IM] [IM] [IM]
[IM]

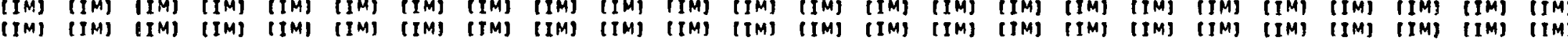
[IM] [IM] [IM] [IM] [IM] [IM] [IM] [IM] [IM] [IM] [IM] [IM] [IM] [IM] [IM] [IM] [IM] [IM] [IM] [IM] [IM] [IM] [IM] [IM] [IM] [IM] [IM] [IM] [IM] [IM] [IM] [IM] [IM] [IM] [IM] [IM] [IM] [IM] [IM] [IM] [IM] [IM] [IM] [IM] [IM] [IM] [IM] [IM] [IM] [IM] [IM] [IM] [IM] [IM] [IM] [IM] [IM] [IM] [IM] [IM] [IM] [IM] [IM] [IM] [IM] [IM] [JM] [IM] [IM] [JM] [IM] [IM] [IM] [IM] [IM] [IM] [IM] [IM] [IM] [IM] [IM] [IM] [IM] [IM] [IM] [IM] [IM] [IM] [IM] [IM] [IM] [IM] [IM] [IM] [IM] [IM] [IM] [IM] [IM] [IM] [IM] [IM] [IM] [IM] [IM] [IM] [IM] [IM] [IM] [IM] [IM] [IM] [IM] [IM] [IM] [IM] [IM] [IM] [IM] [IM] [IM] [IM] [IM] [IM] [IM] [IM] [IM] [IM] [IM] [IM] [IM] [IM] [IM] [IM] [IM] [IM] [IM] [IM] [IM] [IM] [IM] [IM] [IM] [IM] (IM)
$[I M]$

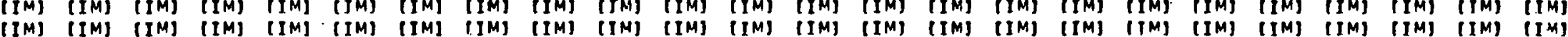
[IM] [IM] [IM] [IM] [IM] [IM] [IM] [IM] [IM] [IM] [IM] [IM] [IM] [IM] [IM] [IM] [IM] [IM] [IM] [IM], [IM] [IM] [IM] [IM] [IM] [IM] [IM] [IM] [IM] [IM] [IM] [IM] [IM] [IM] [IM] [IM] [IM] [IM] [IM] [IM] [IM] [IM] [IM] [IM] [IM] [IM] [IM] [IM] [IM] [IM] [IM] [IM] [IM] [IM] [IM] [IM] [IM] [JM] [IM] [IM] [IM] [IM] [IM] [IM] [IM] [IM] [IM] [IM] [IM] [IM] [IM] [IM] [IM] [IM] IIM] [IM]

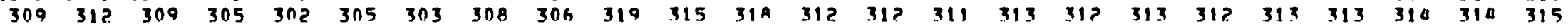
$\begin{array}{lllllllllllllllllllllllll}15 & 15 & 15 & 15 & 14 & 15 & 14 & 15 & 15 & 15 & 15 & 15 & 15 & 15 & 15 & 15 & 15 & 15 & 15 & 15 & 15 & 15 & 15 & 15 & 15\end{array}$ 
WIND DIRECTION ICCIOZI

LEVEL HEIGHT, 10 METERS
RATTELLE WIND STIIDY, ESAS TEHACHAPI MTNS, CA.

SITE

Jun. 1979

AEROVIRTNMENT INC.

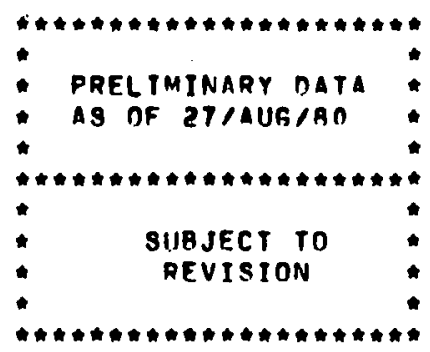

CLOCK HNUR ILOCAL STANDARO TIMF]

[IM] [IM] [IM] [IM] [IM] [IM] [IM] [IM] [IM] [IM] [IM] [IM] [IM] [IM] [IM] [IM] [IM] [IM] [IM] [IM] [IM] [IM] [IM] [IM] I ]

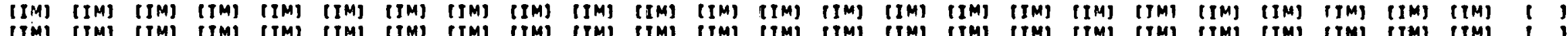
[IM] [IM] [IM] [IM] [IM] [IM] [IM] [IM] [IM] [IM] [IM] [IM] [IM] [IM] [IM] [IM] [IM] [IM] [IM] [IM] [IM] [IM] [IM] [IM] [IM] [IM] [IM] [IM] [IM] [IM] [IM] [IM] [IM] [IM] [IM] [IM] [IM] [IM] [IM] [IM] [IM] [IM] [IM] [IM] [IM] [IM] [IM] [IM]
[IM] [IM] [IM] [IM] (IM) [IM] [IM] [IM] [IM] [IM] [IM] (IM] [IM] [IM] [IM] [IM] [IM] [IM] [IM] [IM] [IM] [IM] [IM] [IM] [IM] [IM] [IM] [IM] [IM] [IM] [IM] [IM] [IM] [IM] [IM] [IM] [IM] [IM] [IM] [IM] [IM] [IM) [IM] [IM] [IM] [IM] [IM] [IM] [IM] [IM] [IM] [IM] [IM] [IM] [IM] [IM] [IM] [IM] [IM] [IM] [IM] [IM] [IM] [IM] [IM] [IM] [IM] [IM] [IM] [IM] [IM] [IM] [IM] [IM] [IM] [IM] [IM] [IM] [IM] [IM] [IM] [IM] [IM] [IM] [IM] [IM] [IM] [IM] [IM] [IM] [IM] [IM] [IM] [IM] [IM] [IM] [IM] [IM] [IM] [IM] [IM] [IM] [IM] [IM] [IM] [IM] [IM] [IM] [IM] [IM] [IM] [IM] [IM] [IM] [IM] [IM] [IM] [IM] [IM] [IM] [IM] [IM] (IM] [IM] [IM] [IM] (IM] [IM] [IM] [IM] [IM] [IM] [IM] [IM] [IM] [IM] [IM] [IM] [IM] [IM] [IM] [IM] [IM] [IM] [IM] [IM] (IM] [IM] [IM] [IM] [IM] [IM] [IM] [IM] [IM] [IM] [IM] [IM] [IM] [IM] [IM] [IM] [IM] [IM] [IM] [IM] [IM] [IM] [IM] [IM] [IM] [IM] [IM] [IM] [IM] [IM] [IM] [IM] [IM] [IM] [IM] [IM] [IM] [IM] [IM] [IM] [IM] (IM] [IM] [IM] [IM] [IM] [IM]

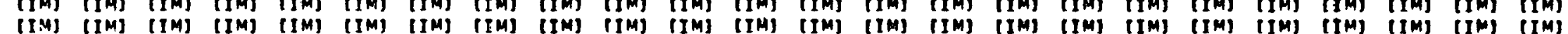

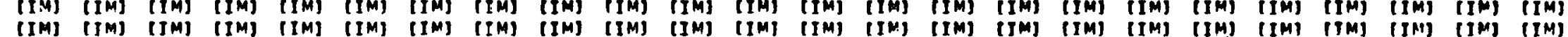
(IM] [IM] [IM] [IM] [IM] [IM] [IM] [IM] [IM] [IM] [IM] [IM] [IM] [IM] [IM] [IM] [IM] [IM] [IM] [IM] [IM] [IM] [IM] [IM] [IM] [IM] [IM] [IM] [IM] [IM] [IM] [IM] [IM] [IM] [IM] [IM] [IM] [IM] [IM] [IM] [IM] [IM] [IM] [IM] [IM] [IM] [IM] [IM] [IM] [IM] [IM] [IM] [IM] [IM] [IM] [IM] [IM] [IM] [IM] [IM] [IM] [IM] [IM] [IM] [IM] [IM] [IM] [IM] [IM] [IM] [IM] [IM] [IM] [IM] [IM] [IM] [IM] [IM] [IM] [IM] [IM] [IM] [IM] [IM] (IM] [IM] [IM] [IM] [IM] [IM] [IM] [IM] [IM] [IM] [IM] [IM] [IM] [IM] [IM] [IM] [IM] [IM] [IM] [IM] [IM] [IM] [IM] [IM] [IM] [IM] [IM] [IM] [IM] [IM] [IM] [IM] [IM] [JM] [IM] [IM] [IM] [IM] [IM] [IM] [IM] [IM] [IM] [IM] [IM] [IM] [IM] [IM] [IM] [IM] [IM] [IM] [IM] [IM] [IM] [IM] [IM] [IM] [JM] [IM]
[IM]

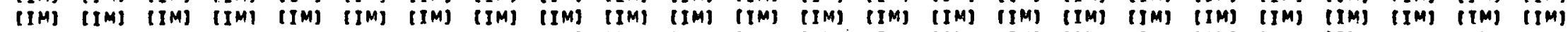
[IM] [IM] [IM] [IM] [IM] [IM] [IM] [IM] [IM] [IM] [IM] [IM] [IM] [IM] [IM] [IM] [IM] [IM] [IM] [IM] [IM] [IM] [IM] [IM] [IM] [IM] [IM] [IM] [IM] [IM] [IM] [IM] [IM] [IM] [IM] [IM] [IM] [IM] [IM] [IM] [IM] [IM] [IM] [IM] [IM] [IM] [IM] [IM] [IM] [IM] [IM] [IM] [IM] [IM] [IM] [IM] [IM] [IM] [IM] [IM] [IM] [IM] [IM] [IM] [IM] [IM] [IM] [IM] [IM] [IM] [IM] [IM] [IM] [IM] [IM] [IM] [IM] [IM] [IM] [IM] [IM] [IM] [IM] [IM] [IM] [IM] [IM] [IM] [IM] [IM] [TM] [IM] [IM] [IM] [IM] [IM]

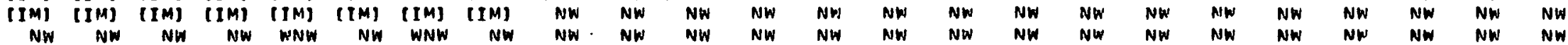
NW NW NW NW WNW NW WNW NW NW. NW NW NW NW NW NW NW NW NW NW NW NW NW NW NW 
WIND OIRECTITN ICCIN?!

DEGREES

LEVEL HEIGHT 10 METERS
BATTELLE WIMN STIIDY, HSOS

TEHACHAPJ MTNS, CA.

SITE

JUL, 1979

AEROVIRONMENT INC.

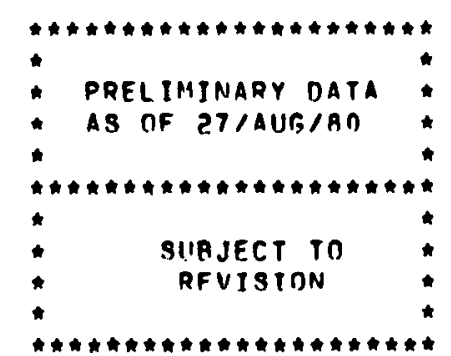

CLOCK HIIIR (LOCAL. STANDARD TIME]

\begin{tabular}{|c|c|c|c|c|c|c|c|c|c|c|c|c|c|c|c|c|c|c|c|c|c|c|c|c|c|}
\hline & 00 & 1 & 02 & 03 & $a$ & 05 & 6 & 1 & 08 & 9 & 0 & 1 & 2 & 3 & 4 & 5 & 6 & 7 & 18 & 9 & $n$ & 1 & 2 & 3 & \\
\hline 1 & & & & & & & & & & & & & & & & & & & & & & & & & \\
\hline$c$ & IIN & II & l & IIM & IIM & IIM & $11 \mathrm{M}$ & I IM & IIM & IIM & IIM & IIN & & III & 111 & & & & & & & & & & 1 \\
\hline 3 & I M & {$[T M]$} & [M] & [IM] & [M] & [IM] & [M] & [M] & IM] & $\{I M]$ & [M] & {$[\mathrm{IM}]$} & {$[I M]$} & {$[I M]$} & [IM] & [IM] & (M) & [IM] & (JM) & [IM] & []M] & {$[I M]$} & [M] & III & \\
\hline 4 & $M$ & [M] & [M] & [M] & [ M] & $\{M\}$ & [M] & [M] & [M] & {$[\mathrm{M}]$} & [ M] & [IM] & (IM) & (IM) & [IM] & [IM] & IM] & [IM] & [IM] & (IM) & [IM] & $\{\mid M\}$ & J) & II & 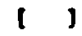 \\
\hline 5 & [IM] & (IM] & {$[I M]$} & (IM] & [IM] & (IM) & {$[[M]$} & $\{M\}$ & [MA] & [IM] & (IM) & {$[\{M]$} & [IM] & $(I M)$ & [IM] & (IM) & [IM] & (IM) & (IM) & [IM] & (IM) & {$[I M]$} & (IM) & II & t \\
\hline 6 & $(I M)$ & (IM) & {$[[14]$} & [IM] & IMI & {$[I M]$} & $\{I M]$ & $(M)$ & $\mid M I$ & [IM] & [IM] & [IM] & [IM] & (IM) & $\mid[M]$ & (IM) & & [IM] & [IM] & II & [IM] & {$[\{\mathrm{M}]$} & [IM] & ITI & J \\
\hline 7 & [M] & [IM] & [IM] & IM] & [ M] & (M) & [M] & (M) & JM] & (IM] & [IM] & (IM) & {$[I M]$} & [IM] & [IM] & [IM] & [IM] & [IM] & [JM] & [IM] & [IM] & [IM] & [IM] & II & t \\
\hline 8 & [IM] & (IM] & [IM] & (M) & IM & {$[M]$} & $T N$ & J & [M] & IM] & IM] & [ [M] & [IM] & {$[I M]$} & II & [IM] & [IM] & {$[\mid M]$} & [IM] & [IM] & II & II & [IM] & II & I \\
\hline 9 & {$[I M]$} & [IM] & (IM) & [M] & IIN & [M] & [M] & [M] & rM! & IM) & [M] & [IM] & [IM] & [JM] & II & [IM] & & (IM) & [SM] & II & 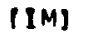 & & [IM] & & J \\
\hline 10 & (IM) & IM & II & [IM] & II & ] & [M] & J & [IM] & IIM & [M] & (IM) & II & III & lI & (IM) & [I & {$[I M]$} & [IM] & II & II & II & {$[\mid M]$} & II & $t$ \\
\hline & [IM] & IIM & IIM & IMI & IN & [IM] & [M] & & 1 & & [IM] & (IM) & II & (I) & II & [IM] & II & [IM] & [IM] & II & (1) & II & [IM] & & I \\
\hline 1 & IIM & [IM] & (IM) & IN & IM & {$[[\mid A]$} & III & 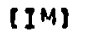 & & & & IIM & (II) & III & & [IM] & II & II & II & & & 11 & [] & & J \\
\hline 1 & [IM] & [IM] & [IM] & [IM] & IIM & [IM] & IIN & IIN & IIN & IIN & [IM] & (IM) & {$[I M]$} & [IM] & {$[\mid M]$} & {$[J M]$} & 313 & 321 & 31 & 31 & 320 & $31 \mathrm{~A}$ & $32 n$ & $31 \mathrm{~A}$ & 15 \\
\hline 10 & 319 & 319 & 31 & 32 & & 319 & & & & & 31 A & $3 ? 0$ & 320 & 317 & 317 & 317 & & 31 & 31 & 31 & 3 & 7 & $31 \mathrm{~A}$ & 32 & 15 \\
\hline 15 & & & 318 & & & & & 3 & & & 326 & 3?. & 326 & & 31 & & & & $3 \cap 8$ & & & & [IM] & II & \\
\hline 16 & {$[I M]$} & [IM] & 【IM] & (IM) & (IM] & [IM] & [IM] & [IM] & [IM] & {$[[N]\}$} & [IM] & (IM) & [IM] & [IM] & ||$M]$ & {$[I M]$} & [IM] & [IM] & (JM) & II & [IM] & [IM] & $30 R$ & 306 & \\
\hline 17 & 308 & 308 & 304 & 305 & 308 & 309 & 307 & 306 & 307 & 310 & 30A & 311 & 310 & 313 & 312 & 313 & 313 & 311 & 311 & 3 & 3 & 304 & 303 & 30 & \\
\hline 16 & & & & & & & & & & & 302 & 301 & 300 & & & & & $3 n 1$ & 296 & & 30 & 309 & 310 & 306 & 4 \\
\hline 19 & 3 & 304 & 5 & 14 & $n a$ & 94 & 317 & 3? 2 & 3 & 35 & $3 ? 0$ & 321 & $3 ? 4$ & 31 & $31 \mathrm{~A}$ & 318 & 3 & $31 \mathrm{~A}$ & 318 & 318 & 316 & 318 & 316 & & is \\
\hline 20 & 316 & 301 & [IM] & (IM) & [IM] & [IM] & {$[\{M]$} & [IM] & [IM] & [IM] & [IM] & [IM] & {$[I M]$} & [JM] & [IM] & [IM] & [IM] & \{IM! & [IM] & IN & $\mathrm{J!}$ & [M] & {$[J M]$} & & 14 \\
\hline 21 & [IM] & [IM] & [IM] & [M] & [IM] & [IM] & [IM] & [M] & II & II & $\{[M]$ & [IM] & IIM & 114 & (I) & {$[\mid M]$} & [I & [IM] & [IM] & [IM] & [IM] & IIMI & {$[I M]$} & [IM] & 1 \\
\hline ב & []M] & [IM] & [IM] & TMI & & & & & & & & {$\left[I^{M}\right]$} & [IM] & & & & & [IM] & & & & [IM] & [JM] & & I \\
\hline 23 & & 8 & 8 & J & III & & & & t th & & 11 & $\{[M]$ & [IM] & IIN & l1 & 11 & & {$[I M]$} & [IM] & II & II & II & (IM) & II & ? \\
\hline 24 & {$[I M]$} & [JM] & [IM] & (IM) & (IM) & [IM] & [IM] & {$[I M]$} & [IM] & II & [IM] & {$\left[I^{M}\right]$} & [IM] & {$[[M]$} & (I) & [IM] & {$[I M]$} & [IM] & [IM] & [IM] & $\{I M\}$ & [IM] & (JM) & {$[\mid M]$} & I \\
\hline 25 & [IM] & (IM] & (IM] & (IM] & [IM] & [JM] & {$[[M]$} & [IM] & & & [IM] & {$[J M]$} & [IM] & II. & & & & & [IM] & [IM] & II & [IM] & {$[J, M]$} & [IM] & 1 \\
\hline 26 & l & [IM] & IIM & [IM] & $11 \%$ & 11 & & & ( I) & II & {$[\mid M]$} & {$\left[I^{M]}\right.$} & IIN & IIN & 114 & III & II & 111 & 29 & & & 303 & $3 \cap 1$ & & 14 \\
\hline 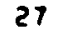 & 295 & 293 & 292 & 295 & 30 & 307 & 307 & 307 & 303 & $3 n$ & $3 \cap 6$ & 304 & 298 & 300 & 302 & 303 & 302 & 30 & 29 & 2 & 20 & 301 & $29 A$ & & $\because$ \\
\hline & 30 & & $3 n$ & $3 n$ & & & & & & & & 300 & 31 & & & & & & 314 & 310 & & $3 n 6$ & 307 & & 15 \\
\hline$c$ & 30 & 308 & 30 & $3 \cap 4$ & 30 & 315 & 31 & 31 & 309 & $3 n$ & $3 n 9$ & 297 & 29 & 29 & 29 & 29 & 293 & ?.9 & 29 & 20 & & D & 307 & $3 \cap 9$ & 5 \\
\hline & 31 & 31 & $3 n$ & $3 n$ & 30 & 301 & & 31 & 310 & 312 & 321 & & 316 & 30 & 307 & 304 & $? 03$ & 313 & 31 & 32 & $32 n$ & 319 & 317 & 316 & 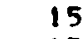 \\
\hline & & & & & & & & & & & & & & 116 & 115 & & & & & & & & & & \\
\hline
\end{tabular}


WIND DIRECTION ICCIOPI

LEVEL HEIGHT: 10 METERS
BATTELLE WIND STIINY, 505

TEHACHAPI MTNS, CA.

SITE

J11L, 1979

AEROVIRONMENT INC.

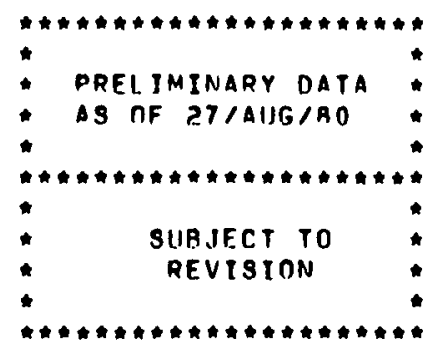

CLOCK HOIJR ILOCAL STANDARD IIMEJ 
WINT MIRECTION (CCIOP)

DEGRFES

LEVEL HEIGHT : 10 METERS
RATTELLE WTND STIUY, $\$ 505$

TEHACHAPI MTNS, CA.

SITE

Aur. 1979

AEROVIRONMENT INC.

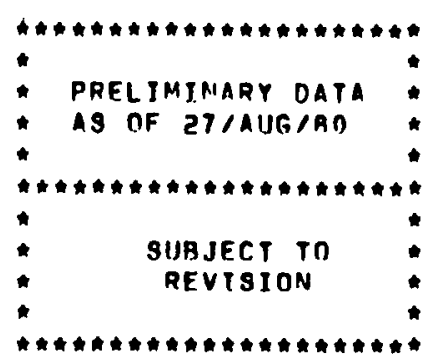

CLICK HOUR (LOCAL STANDARD TIME)
on 01
$0 ?$
304
0506
070
080
10
12
1319
1516
17
18
19
3
22
?3 PREV

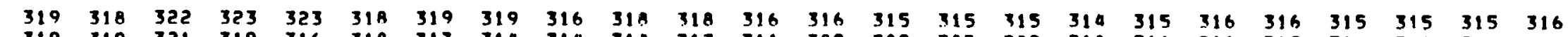

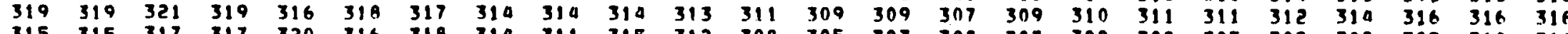

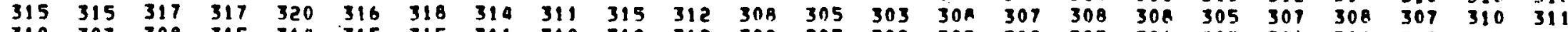

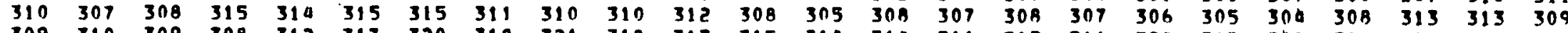

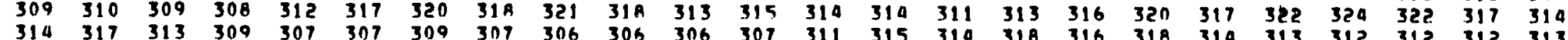
$\begin{array}{llllllll}313 & 311 & 311 & 312 & 313 & \text { [IM] [IM] [IM) [IM] [IM] [IM] [IM] [IM] [IM] [IM] [IM] [IM] [IM] [IM] [IM] [IM] [IM] [IM] [IM] }\end{array}$ [IM] [IM] [IM] [IM] [IM] [IM] [IM] [IM] [IM] [IM] [IM] [IM] [IM] [IM] [IM] [IM] [IM] [IM] [IM] [IM] [IM] [IM] [IM] [IM] [IM] [IM] [IM] [IM] [IM] [IM] [IM] [IM] [IM] [IM] [IM] [IM] [IM] [IM] [IM] [IM] [IM] [IM] [IM] [IM] [IM] [IM] [IM] [IM] [IM] [IM] [IM] [IM] [IM] [IM] [IM] [IM] [IM] [IM] [IM] [IM] [IM] [IM] [IM] [IM] [IM] [IM] [IM] [IM] [IM] [IM] [IM] [IM]
[IM]

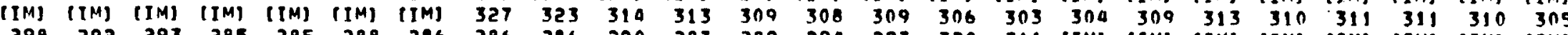

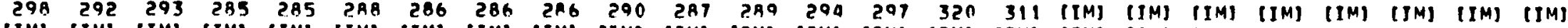
[IM] $I I M]$
$[I M]$ [IM] [IM] [IM] [IM] [IM] [IM] [IM] [IM] [IM] [IM] [IM] [IM] [IM] [IM] [JM] [IM] [IM] [IM] [IM] [IM] [IM] [IM] [IM] [IM]

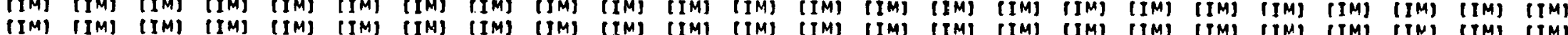
[IM] [IM] [IM] [IM] [IM] [IM] [IM] [IM] [IM] [IM] [IM] [TM] [IM] [IM] [IM] [IM] [IM] [IM] [IM] [IM] [IM] [IM] [IM] [IM] [IM] [IM] [IM] [IM] [IM] [IM] [IM] [IM] [IM] [IM] [IM] [IM] [IM] [IM] [IM] [IM] [IM] [IM] [IM] [IM] [IM] [IM] [IM] [IM] [IM] [IM] [IM] [IM] [IM] [IM] [IM] [IM] [IM] [IM] [IM] [IM] [IM] [IM] [IM] [IM] [IM] [IM] [IM] [IM] [IM] [IM] [IM] [IM] [IM] [IM] [IM] [IM] [IM] [IM] [IM] [IM] [IM] [IM] [IM] [IM] [IM] [IM] [IM] [IM] [IM] [IM] [IM] [IM] [IM] [IM] [IM] [IM]

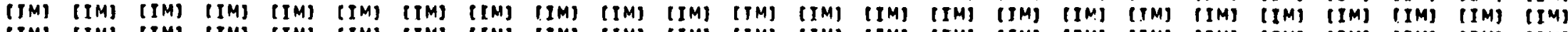
[IM] [IM] [IM] [IM] [IM] [IM] [IM] [IM] [IM] [IM] [IM] [IM] [IM] [IM] [IM] [IM] [IM] [IM] [IM] [IM] [IM] [IM] [IM] [IM] [IM] [IM] [IM] [IM] [IM] [IM] [IM] [IM] [IM] [IM] [IM] [IM] [IM] [IM] [IM] [IM] [IM] [IM] [IM] [IM] [IM] [IM] [IM] [IM] [IM] [IM] [IM] [IM] [IM] [IM] [IM] [IM] [IM] [IM] [IM] [IM] [IM] [IM] [IM] [IM] [IM] [IM] [IM] [IM] [IM] [IM] [IM] [IM] [IM] [IM] [IM] [IM] [IM] [IM] [IM] [IM] [IM] [IM] [IM] [IM] [IM] [IM] [IM] [IM] [IM] [IM] [IM] [IM] [IM] [IM] [IM] [IM] [IM] [IM] [IM] [IM]. [IM] [IM] [IM] [IM] [IM] [IM] [IM] [IM] [IM] [IM] [IM] [IM] [IM] [IM] [IM] [IM] [IM] [IM] [IM] [IM] [IM] [IM] [IM] [IM] [IM] [IM] [IM] [IM] [IM] [IM] [IM] [IM] [IM] [IM] [IM] [IM] [IM] [IM] [IM] [IM] [IM] [IM] [IM] [IM] [IM] [IM] [IM] [IM] [IM] [IM] [IM] [IM] [IM] [IM] [IM] [IM] [IM] [IM] [IM] [IM] [IM] [IM] [IM] [IM] [IM] [IM] [IM] [IM] [IM] [IM] [IM] [IM] [IM] [IM] [IM] [IM] [IM] [IM] [IM] [IM] [IM] [IM] [IM] [IM] [IM] [IM] [IM] [IM] [IM] [IM] [IM] [IM] [IM] [IM] [IM] [IM] [IM] [IM] [IM] [IM] [IM] [IM] [IM] [IM] [IM] [IM] [IM] [IM] [IM] [IM] [IM] [IM] [IM] [IM] [IM] [IM]
[IM] 
WIND DIRECTION ICCINST

LEVEL HEIGHT : 10 METERS
RATTELLE WINO STUDY, 505 TEHACHAPJ MTNS, CA.

SITE

Al16. 1979

AEROVIPONMENT INC.

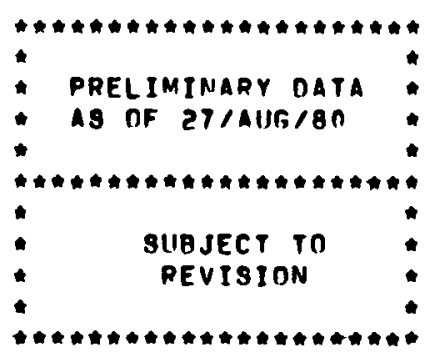

CLOCK HOUR (LOCAL STANDARD TIME)

D.r.

$\begin{array}{llllll}00 & 01 & 02 & 03 & 04 & 05\end{array}$

0607

$08 \quad 09 \quad 10$

$\begin{array}{llll}0 & 11 & 12 & 1\end{array}$

314

1516

$16 \quad 17$

18

192

o 2

22

23 PREV

$\begin{array}{lllll}\text { NW } & \text { NW } & \text { NW } & \text { NW } & \text { N } \\ \text { NW } & \text { NW } & \text { NW } & \text { NW } & \text { NW } \\ \text { NW } & \text { NW } & \text { NW } & \text { NW } & N \\ \text { NW } & \text { NW } & \text { NW } & \text { NW } & N \\ \text { NW } & \text { NW } & \text { NW } & \text { NW } & N \\ \text { NW } & \text { NW } & \text { NW } & \text { NW } & N W \\ \text { NW } & \text { NW } & \text { NW } & \text { NW } & \text { NW }\end{array}$

NW
NW
NW
NW
NW NW
NW NW
NW [IM]

[IM] IIM] [IM]

[IM] IIM] [IM] [IM] [IM] [IM] [IM] (IM] (IM] [IM] IIM] [IM] [IM] (IM) [IM] [IM] (IM] [IM] [IM] [IM] [IM] [IM] [IM] [IM]

[IM] [IM] [IM] [IM] [IM] [IM] [IM] [IM] [IM] [IM] [IM] [IM] [IM] [IM] [IM] [IM] [IM] [IM] [IM] [IM] [IM] [IM] [IM] [IM] [IM] [IM] [IM] [IM] [IM] [IM] [IM] NNW NW NW NW NW NW NW NW WNW NW NW NW NW NW NW. NW NW WNW WNW WNW WNW WNW WNW WNW WNW WNW WNW WNW WNW WNW WNW NW NW [IM] [IM] [IM] [IM] [IM] [IMI [IM] [IM] [IM] [IM] [IM] [IM] [IM] [IM] [IM] [IM] [IM] [IM] [IM] [IM] [IM] [IM] [IM] [IM] [IM] [IM] [IM] [IM] [IM] [IM] [IM] [IM] [IM] [IM] [IM] [IM] [IM] [IM] [IM] [IM] [IM] [IM] [IM] [IM] [IM] [IM] [IM] [IM] [IM] [IM] [IM] [IM] [IM] [IM] [IM] [IM]

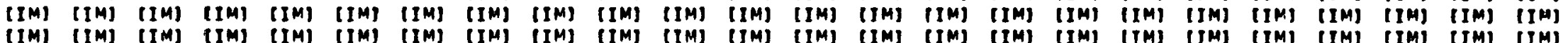

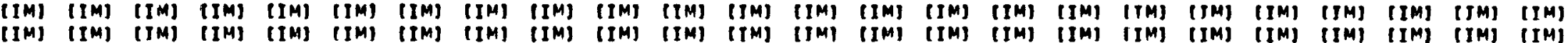
[IM] [IM] [IM] [IM] [IM] [IM] [IM] [IM] [IM] [IM] [IM] [IM] [IM] [IM] [IM] [IM] [IM] [IM] [IM] [IM] [IM] [IM] [IM] [IM] [IM] [IM] [IM] [IM] [IM] [IM] [IM] [IM] [IM] [IM] [IM] [IM] [IM] [IM] [IM] [IM] [IM] [IM] [IM] [IM] [IM] [IM] [IM] [IM] [IM] [IM] [IM] [IM] [IM] [IM] [IM] [IM] [IM] [IM] [IM] [IM] [IM] [IM] [IM] [IM] [IM] [IM] [IM] [IM] [IM] [IM] [IM] [IM] (IM] [IM] [IM] [IM] [IM] [IM] [IM] [IM] [IM] [IM] [IM] [IM] [IM] [IM] [IM] [IM] [IM] [IM] [IM] [IM] [IM] [IM] [IM] [IM]

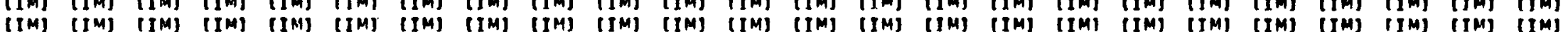

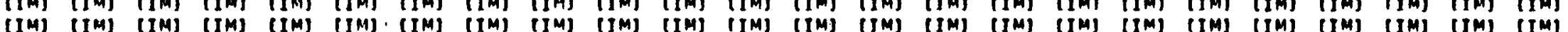
[IM] [IM] [IM] [IM] [IM] [IM] [IM] [IM] [IM] [IM] [IM] [IM] [IM] [IM] [IM] [IM] [IM] [IM] [IM] [IM] [IM] [IM] [IM] [IM] [IM] [IM] [IM] [IM] [IM] [IM] [IM] [IM] [IM] [IM] [IM] [IM] [IM] [IM] [IM] [IM] [IM] [IM] [IM] [IM] [IM] [IM] [IM] [IM] (IM) [IM] [IM) [IM] [IM) [IM] (IM) [IM] [IM] [IM] [IM] [IM] [IM] [IM) [IM] [IM] [IM] [IM] [IM] [IM] [IM] [IM] [IM] [IM] [IM] [IM] [IM] [IM] [IM] (IM) [IM] [IM] IIM] [IM] [IM] [IM] [IM] [IM] [IM] [IM] [IM] [IM] [IM] (IM] [IM] [IM] [IM] [IM]

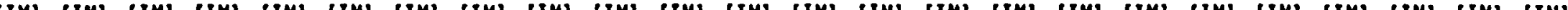
[IM] [IM] [IM] [IM] [IM] [IM] [IM] [IM] [IM] [IM] [IM] [IM] [IM] [IM] [IM] [IM] [IM] [IM] [IM] [IM] [IM] [IM] [IM] [IM] [IM] [IM] [IM] [IM] [IM] [IM] [IM] [IM] [IM] [IM] [IM] [IM] [IM] [IM] [IM] [IM] [IM] [IM] [IM] [IM] [IM] [IM] [IM] [IM] 
WINO DIRECTION (CCIOZ)

\section{DERREES}

LEVEL HEIGHT, 10 METERS
BATTELLE WJNO STUDY, $\$ 505$

TEHACHAPI MTNS. CA.
SITE 9

SEP, 1979

AEROVIRONMENT INC.

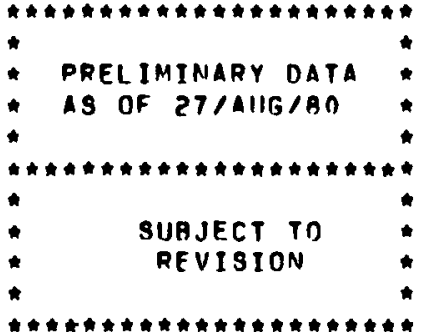

CLOCK HOUR ILOCAL STANDARO TIMEJ 
WINO DIRECTION ICCIOT)

LEVEL HEIGHT: 10 METFRS
BATTFLLE WIND STUNY, \#5OS

TEHACHAPI MTNS, CA.

SITE

SEP, 1979

AEROVIRONMENT INC.

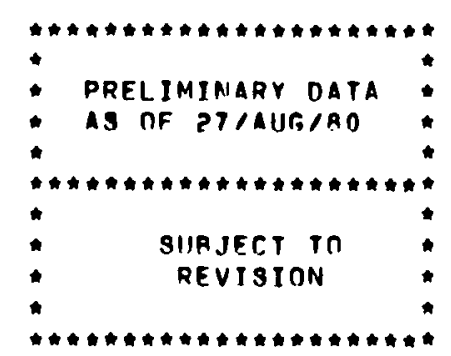

CLOCK HOUR (LOCAL STANDARO TIME] [IM] [IM] [IM] [IM] [IM] [IM] [IM] [IM] [IM] [IM] [IM] [IM] [IM] [IM] [IM] [IM] [IM] [IM] [IM] [IM] [IM] [JM] [IM] [IM]
[IM] [IM] [IM] [IM] [IM] [IM] [IM] [IM] [IM] [IM] [IM] [IM] [IM] [IM] [IM] [IM] [IM] [IM] [IM] [IM] [IM] [IM] [IM] [IM] [IM]

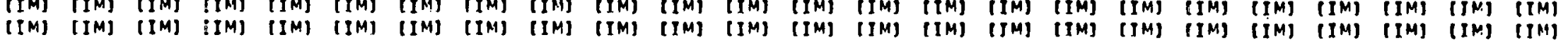
[IM] [IM] [IM] [IM] [IM] [IM] [IM] [IM] [IM] [IM] [IM] [IM] [IM] [IM] [IM] [IM] [IM] [IM] [IM] [IM] [IM] [IM] [IM] [IM]
[IM] [[M] [IM] [IM] [IM] [IM] [IM] [IM] [IM] [IM] [IM] [IM] [IM] [IM] [IM] [IM] [IM] [IM] [IM] [IM] [IM] [IM] [IM] [IM] [IM]

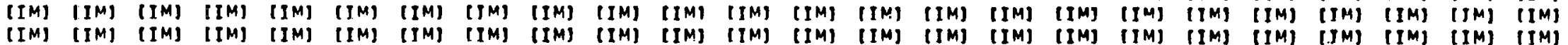
[IM] [IM] [IM] [IM] [IM] [IM] [IM] [IM] [IM] [IM] [IM] [IM] [IM] [IM] [IM] [IM] [IM] [IM] [IM] [IM] [IM] [IM] [IM] [IM] [IM] [IM] [IM] [IM] [IM] [IM] [IM] [IM] [IM] [IM] [IM] [IM] [IM] [IM] [IM] [IM] [IM] [IM] [IM] [IM] [IM] [IM] [IM] [IM] [IM] [IM] [IM] [IM] [IM] [IM] [IM] [IM] [IM] [IM] [IM] [IM] [IM] [IM] [IM] [IM] [IM] [IM] [IM] [IM] [IM] [IM] [IM] [IM] [IM] [IM] [IM] [IM] [IM] [IM] [IM] [IM] [IM] [IM] [IM] [IM] [IM] [IN] [IM] [IM] [IM] [IM] [IM] [IM] [IM] [IM] [IM] [IM] [IM] [IM] [IM] [IM] [IM] [IM] [IM] [IM] WNW NW NW WNW WNW WNW NW NW WNW WNW WNW WNW WNW WNW WNIW WNW

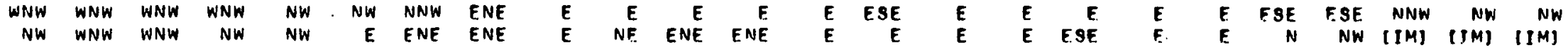
[IM] [IM] [IM] [IM] [IM] [IM] [IM] [IM] [IM] [IM] [IM] [IM] [IM] [IM] [IM] [IM] [IM] [IM] [IM] [IM] [IM] [IM] [IM] [IM] [IM] [IM] [IM] [IM] [IM] [IM] [IM] [IM] [IM] [IM] [IM] [IM] [IM] [IM] [IM] [IM] [IM] [IM] [IR:] [IM] [IM] [IM] [IM] [IM] [TM] [IM] [IM] [IM] [IM] [IM] [IM] [IM] [IM] [IM] [IM] [IM] [IM] [IM] [IM] [IM] [IM] [IM] [IM] [IM] [IM] [IM] [IM] [IM] [IM] [IM] [IM] [IM] [IM] [IM] [IM] [IM] [IM] [IM] [IM] [IM] [IM] [IM] [IM] [IM] [IM] [IM] [IM] [IM]. [IM] [IM] [IM] [IM] [IM] [IM] [IM] [IM] [IM] [IM] $S W$ SSW [IM] [IM] [IM] [IM]. [IM] [IM] [IM] [IM] [IM] [IM] [IM] [IM] [IM] [IM] [IM] [IM] (IM] [IM] [IM] [IM] [IM] [IM] [IM] [IM] [IM] [IM] $S$ S :SSW $9 W$ [IM] [IM] [IM] [IM] [IM] [IM] [IM] [IM] [IM] SW
[IM] SW $S$ SSE [IM] [IM] [IM] [IM] IIM] [IM] SE SE SSF ISSE S (IM] [IM] [IM] (IM) [IM] [IM] [IM] [IM] [IM] (IM] (IM) [IM] [IM] [IM] [IM] [IM] [IM] IIM] [IM] [IM] [IM] [IM] [IM] [IM] [IM] [IM] [IN] [IM] [IM] [IM] [IM] [IM] [IM] [IM]
[IM] [IM] [IM] [IM] [IM] [IM] [IM] [IM] IIM] [IM] [IM] [IM] [IM] [IM] [IM] [IM] [IM] [IM] [IM] SSF SSF. S S SSW SW

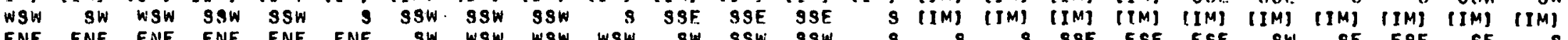
ENE ENE ENE ENE ENE ENE SW WSW WSW WSW SW SSW SSW $S$ S S SSE ESE FSE SW SE ESE SE S

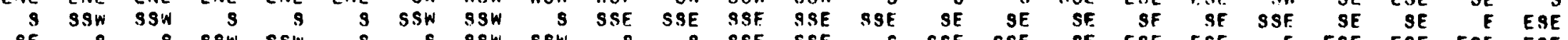

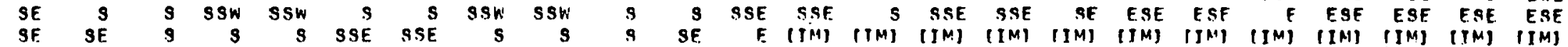
(VA) S S S SSW S SSW SSW S SSF SSF SSF 
WINI DIRECTION ICCBDSI

DEGREES

LEVEL HEIGHT \& 10 METERS
AATTELLE WTND STUDY. $\# 505$ TEHACHAPI MTNS, CA.

SITF.

OCT, 1979

AEROVIRONMENT INC.

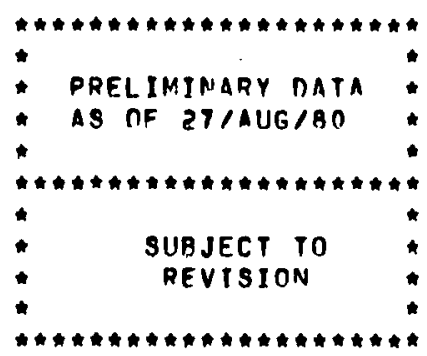

CLOCK HOLIR [LOCAL STANDARD TIME]

$\begin{array}{lllllll}00 & 01 & 02 & 03 & 04 & 05 & 06\end{array}$

07

$08 \quad 09$

10

11 t

13

14

15

16

17

18

19

20

21

22

23 PREV

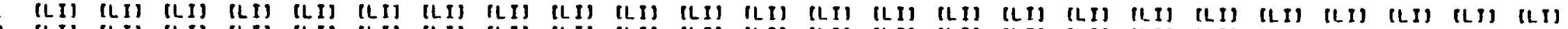

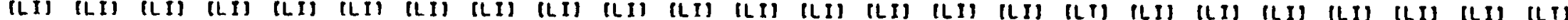
[LI] [LI] [LI] [LII [LI) [LI] [LI] [LI] [IM] [IM] [IM] [IM] [IM] [IM] [IM] [IM] [IM] [IM] [IM] [IM] [IM] [IM] [IM] [IM] [IM] [IM] [IM] [IM] [IM] [IM] [IM] [IM] [IM] [IM] [IM] [IM] [IM] [IM] [IM] [IM] [IM] [IM] [IM] [IM] [IM] [IM] [IM] [IM] [IM] [IM] [IM] [IM] [IM] [IM] [IM] [IM] [IM] [IM] [IM] [IM] [IM] [IM] [IM] [IM] [IM] [IM] [IM] [IM] [IM] [IM] [IM] [IM]
[IM] [IM] [IM] [IM] [IM] [IM] [IM] [IM] [IM] [IM] [IM] [IM] [IM] [IM] [IM] [IM] [IM] [IM] [IM] [IM] [IM] [IM] [IM] [IM] [IM]
[IM] [IM] [IM] [IM] [IM] [IM] [IM] [IM] [IM] [IM] [IM] [IM] [IM] [IM] [IM] [IM] [IM] [IM] [IM] [IM] [IM] [IM] [IM] [IM] [IM]

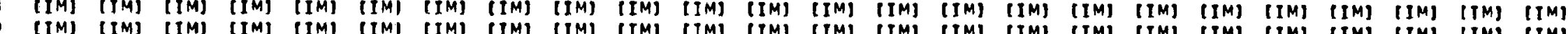
[IM] [IM] [IM] [IM] [IM] [IM] [IM] [IM] [IM] [IM] [IM] [IM] [IM] [IM] [IM] [IM] [IM] [IM] [IM] [IM] [IM] [IM] [IM] [IM] [IM] [IM] [IM] [IM] [IM] [IM] [IM] [IM] [IM] [IM] [IM] [IM] [IM] [IM] [IM] [IM] [IM] [IM] [IM] [IM] [IM] [IM] [IM] [IM] [IM] [IM] [IM] [IM] [IM] [IM] [IM] [IM] [IM] [IM] [IM] [IM] [IM] [IM] [IM] [IM] [IM] [IM] [IM] [IM] [IM] [IM] [IM] [IM]
[IM] [IM] [IM] [IM] [IM] [IM] [IM] [IM] [IM] [IM] [IM] [IM] [IM] [IM] [IM] [IM] [IM] [IM] [IM] [IM] [IM] [IM] [IM] [IM] [IM]
[IM]

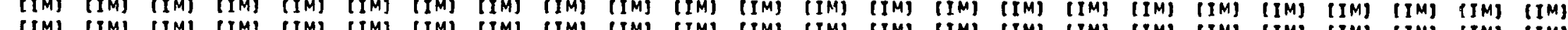

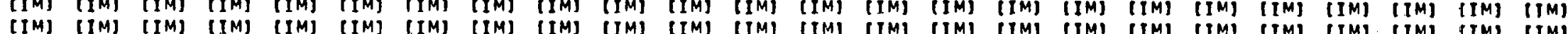

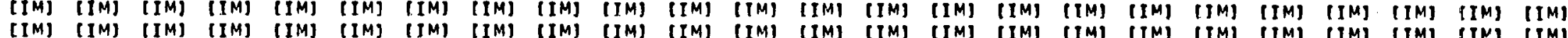

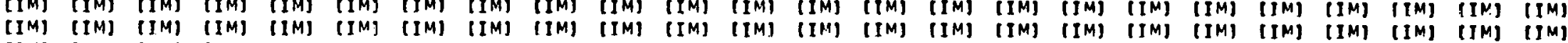
[IM] [IM] [IM] [IM] [IM] [IM] [IM] [IM] [IM] [IM] [IM] [IM] [IM] [IM] [IM] [IM] [IM] [IM] [IM] [IM] [IM] [IM] [IM] [IM] [IM] [IM] [IM] [IM] [IM] [IM] [IM] [IM] [IM] [IM] [IM] [IM] [IM] [IM] [IM] [IM] [IM] [IM] [IM] [IM] [IM] [IM] [IM] [IM] [IM] [IM] [IM] [IM] [IM] [IM] [IM] [IM] [IM] [IM] [IM] [IM] [IM] [IM] [IM] [IM] [IM] [IM] [IM] [IM] [IM] [IM] [IM] [IM]
[IM] [IM] [IM] [IM] [IM] [IM] [IM] [IM] [IM] [IM] [IM] [IM] [IM] [IM] [IM] [IM] [IM] [IM] [IM] [IM] [IM] [IM] [IM] [IM] [IM]
[IM] [IM] [IM] [IM] [IM] [IM] [IM] [IM] [IM] [IM] [IM] [IM] [IM] [IM] [IM] [IM] [IM] [IM] [IM] [IM] [IM] [IM] [IM] [IM] [IM] [IM] [IM] [IM] [IM] [IM] [IM] [IM] [IM] [IM] [IM] [IM] [IM] [IM] [IM] [PF] [PF] 259 260 260 26] 26126026026

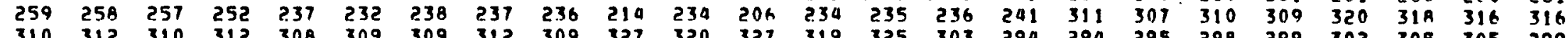

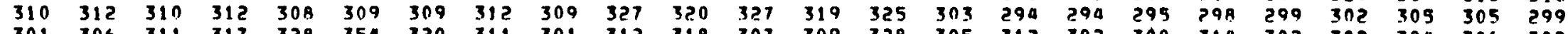

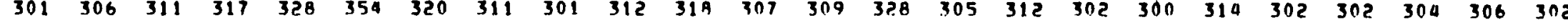

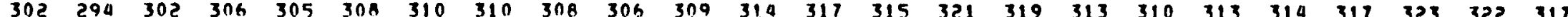

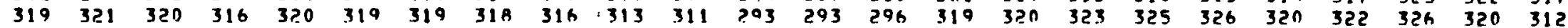

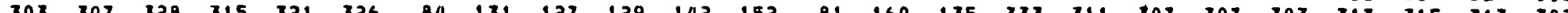

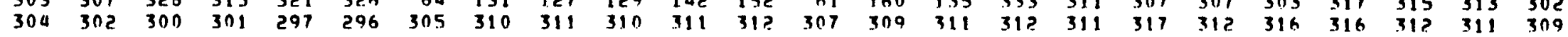


WIND DIRECTINN rCCINZJ

LEVEL HEIGHT: 10 METERS
BATTELLE WINO STUNY, A5NG TEHACHAPI MTNS, CA.

SITE

net. 1979

AEROVIRONMENT INC.

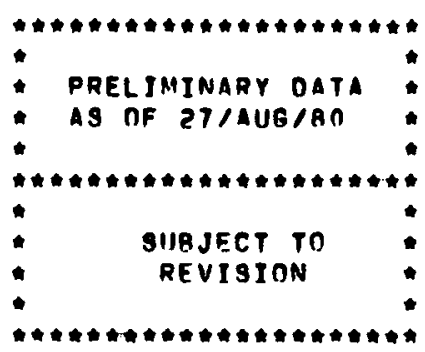

Clock hOUR ILDCAL stantapo timej

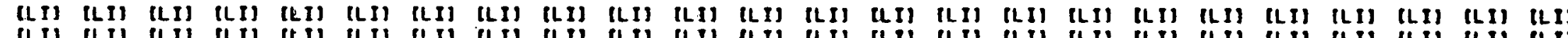

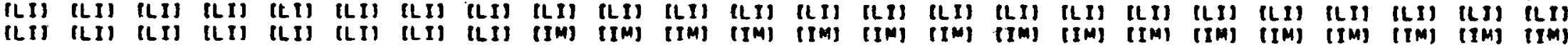
[IM] [IM] [IM] [IM] [IM] [IM] [IM] [IM] [IM] [IM] [IM] [IM] [IM] [IM] [IM] [IM] [IM] [IM] [IM] [IM] [IM] [IM] [IM] [IM] [IM] (IM] [IM] [IM] [IM] [IM] [IM] [IM] [IM] [IM] [IM] [IM] [IM] [IM] [IM] [IM] [IM] [EM] [IM] [IM] [IM] [IM] [IM] [IM]

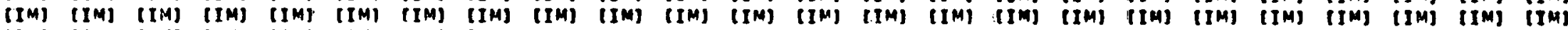
[IM] [IM] [IM] [IM] [IM] [IM] [IM] [IM] [IM] [IM] [IM] [IM] [IM] [IM] [IM] [IM] [IM] [IM] [IM] [IM] [IM] [IM] [IM] [IM] [IM] [IM] [IM] [IM] [IM] [IM] [IM] [IM] [IM] IIM] [IM] [IM] [IM] [IM] [IM] [IM] [IM] IIM] [IM] [IM] [IM] [IM] [IM] [IM]

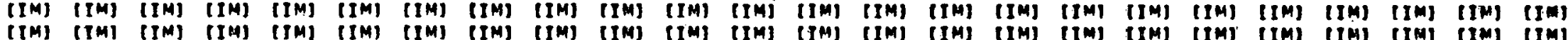

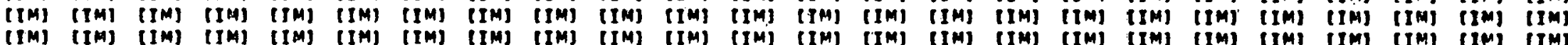
[IM] [IM] [IM] [IM] [IM] [IM] [IM] [IM] [IM] [IM] [IM] [IM] [IM] [IM] [IM] [IM] [IM] [IM] [IM] [IM] [IM] [IM] [IM] [IM] (IM) [IM] [IM] [IM] [IM] [IM] [IM] [IM] [IM] [IM] [IM] [IM] [IM] [IM] [IM] [IM] [IM] [IM] [IM] [IM] [IM] [IM] [IM] [IM] [IM] [IM] [IM] [IM] [IM] [IM] [IM] [IM] [IM] [IM] [IM] (IM] [IM] [IM] [IM] [IM] [IM] [IM] [IM] [IM] [IM] [IM] [IM] [IM] [IM] [IM] [IM] [IM] [IM] [IM] [IM] [IM] [IM] [IM] [IM] [IM] [IM] [IM] [IM] [IM] [IM] [IM] [IM] [IM] [IM] [IM] [IM] [IM] [IM] [IM] [IM] [IM] [IM] [IM] [IM] [IM] [IM] [IM] [IM] [IM] [IM] [IM] [IM] [IM] [IM] [IM] [IM] [IM] [IM] [IM] [IM] [IM] [IM] [IM] [IM] [IM] [IM] [IM] [IM] [IM] [IM] [IM] [IM] [IM] [IM] [IM] [IM] [IM] [IM] [IM] [IM] [IM] [IM] [IM] [IM] [IM] [IM] [IM] [IM] [IM] [IM) (IM] [IM] (IM) [IM] [IM] [IM] [IM] [IM] [IM] [IM] [IM] [IM] [IM] [IM] [IM] [IM] [IM] [IM] [IM] [IM] [IM] [IM] [IM] [IM] (IM] [IM] [IM] [IM) [IM] [IM] [IM] [IM] [IM] [IM] [IM] [IM] [IM] [IM] [IM] [IM] [IM] [IM] [IM]

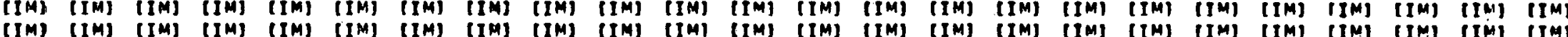
(IM] [IM] [IM] [IM] [IM] [IM] [IM] [IM] [IM] (IM] [IM] [IM] [IM] [IM] [IM] [IM] [IM] [IM] [IM] [IM] [IM] [IM] [IM] [IM] [IM] [IM] [IM] [IM] [IM] [IM] [IM] [IM] [IM] (IM] [IM] [IM] [IM] [IM] [IM] [IM] [IM] [IM] [IM] [IM] [IM] [IM] [IM] [IM] [IM] [IM] [IM] [IM] [IM] [IM] [IM] [IM] [IM] (IM] [IM] [IM] [IM] [IM] [PF] [PF]

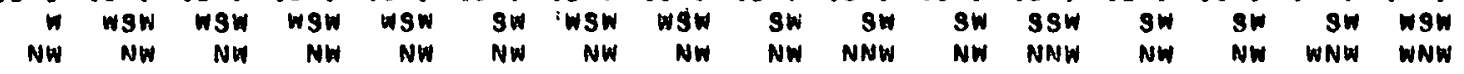
WNW NW NW NW NNW N NW. NW WNW NW WNW WNW WNW NW NW NW NW NW NW NW $N W N W N W N W N W N W N W N W$ NW NW WNA WNW WNW NWW NW NW NW NW NW NW NNW NW NW WNW WNW WNW WNW WNW NW NW NW NW NW NW NW NW NW NW NW NH. WNW WNW WNW NW NH NW WNW WNW 
WIND DIRECTION (CCIDE) DEGREES

LEVEL HEIGHT \& IN METERS
RATTELLE WINA STIJOY, HSOS

TENACHAPI MTNS, CA.

SITE

NnV. 1979

AFROVIRONMENT INC.

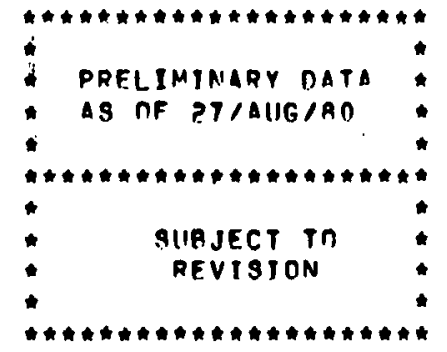

ClOCK HOUR [LDCAL STANDARN TIME]

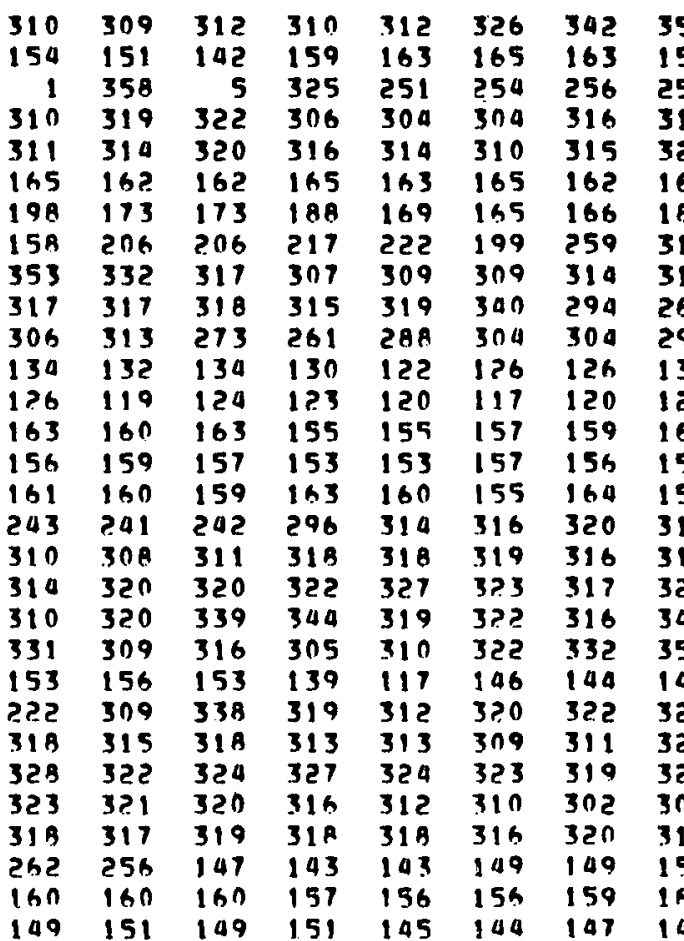

\begin{tabular}{|c|c|c|c|c|c|c|c|c|}
\hline $\begin{array}{l}147 \\
162 \\
259\end{array}$ & $\begin{array}{l}160 \\
157 \\
258\end{array}$ & $\begin{array}{l}158 \\
161 \\
256 \\
500\end{array}$ & $\begin{array}{l}152 \\
157 \\
258 \\
213\end{array}$ & $\begin{array}{l}150 \\
153 \\
244 \\
115\end{array}$ & $\begin{array}{l}157 \\
156 \\
211 \\
206\end{array}$ & $\begin{array}{l}157 \\
166 \\
276 \\
307\end{array}$ & $\begin{array}{l}159 \\
161 . \\
234\end{array}$ & $\begin{array}{l}159 \\
155 \\
235 \\
213\end{array}$ \\
\hline $\begin{array}{l}318 \\
320\end{array}$ & $\begin{array}{l}316 \\
334\end{array}$ & $\begin{array}{l}320 \\
341\end{array}$ & $\begin{array}{r}312 \\
23\end{array}$ & $\begin{array}{l}315 \\
145\end{array}$ & $\begin{array}{l}306 \\
150\end{array}$ & $\begin{array}{l}307 \\
163\end{array}$ & $\begin{array}{l}313 \\
161\end{array}$ & $\begin{array}{l}31 ? \\
168\end{array}$ \\
\hline $\ln 3$ & 164 & 170 & 175 & 171 & 166 & 160 & 158 & 165 \\
\hline 143 & 181 & A9 & 217 & 203 & 190 & 174 & 16? & \\
\hline 304 & 302 & 306 & 300 & 310 & $3 \cap 8$ & 307 & 307 & 314 \\
\hline $31 \mathrm{~h}$ & 315 & 317 & 316 & 314 & 319 & 315 & 317 & 318 \\
\hline 260 & cin & 151 & 143 & $13 A$ & 138 & 132 & 136 & 143 \\
\hline $30 B$ & 316 & 32 & $31 \mathrm{~A}$ & 316 & $31 n$ & 94 & 125 & 139 \\
\hline 127 & 125 & $12 B$ & 133 & 136 & 133 & 133 & 133 & 129 \\
\hline 125 & 12 & 123 & $16 \mathrm{~A}$ & 167 & 161 & ISA & 164 & IGR \\
\hline 161 & $15 A$ & 163 & 166 & 163 & 160 & 169 & 167 & 165 \\
\hline $14 \mathrm{R}$ & 151 & 159 & 159 & 162 & 161 & $16 \mathrm{~h}$ & 172 & 167 \\
\hline 154 & 16 & 159 & 163 & 166 & 169 & 170 & 168 & 164 \\
\hline 276 & 301 & 310 & $31 n$ & 299 & 304 & $3 \cap 3$ & 309 & 310 \\
\hline 310 & 319 & 321 & 119 & 317 & 312 & 309 & 313 & 317 \\
\hline 336 & 352 & 5 & 11 & a & 35 & 330 & 322 & 304 \\
\hline 339 & 328 & 341 & $3 ? 2$ & 325 & 310 & 313 & 313 & 311 \\
\hline 135 & 161 & 157 & 157 & 157 & 153 & 155 & 159 & IS? \\
\hline 140 & 100 & 146 & 153 & 150 & 153 & IOA & 147 & 146 \\
\hline 316 & 312 & 313 & 305 & $30 n$ & 301 & 313 & 313 & 317 \\
\hline 28 & 325 & 317 & $31 A$ & 307 & $3 n$ & & 3? 1 & ם جכן \\
\hline 325 & 327 & 326 & 3?1 & 323 & 32 & 323 & 320 & 311 \\
\hline 7 & 30 & $3 n$ & 313 & 316 & 30 & 312 & 311 & 309 \\
\hline 320 & 311 & 31 & 31? & 316 & & IIA & 306 & $3 \cap 3$ \\
\hline 155 & 15 & 15 & $15 \AA$ & 158 & 15 & 153 & 153 & 149 \\
\hline 157 & 16 & 15 & 155 & $15 n$ & 15 & 157 & 152 & $1 \Delta 6$ \\
\hline & 15 & 155 & 155 & 150 & 47 & 346 & $31 h$ & $31 \mathrm{~A}$ \\
\hline
\end{tabular}

$\begin{array}{llllll}161 & 168 & 163 & 163 & 163 & 15 A\end{array}$ 
WTNO MTRECTION ICCINDI

LFVEL HEISHT: 10 METERS
BATTELLE WIND STUDY, 505 TEHACHAPI MTN'S, CA.

$$
\text { SITE }
$$

NOV. 1979

AEROVIRONMFNT INC.

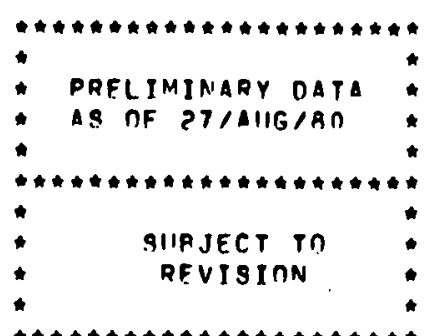

CLnCK HDIJR ILOCAL STANOARN TIMEI

\begin{tabular}{|c|c|c|c|c|c|c|c|c|c|c|c|c|c|c|c|c|c|c|c|c|c|c|c|c|c|}
\hline$\Delta Y$ & no & $n 1$ & 02 & 03 & 04 & 05 & 06 & 07 & 08 & 09 & 10 & 11 & $1 ?$ & 13 & 14 & 15 & $1 \mathrm{~h}$ & 17 & 18 & 19 & $2 n$ & 21 & ?? & 23 & REV \\
\hline 1 & NW & NW & $N W$ & NW & NW & NW & NNW & $N$ & S.SE & S9F & SSE & S.9E & SSE & SSE & SSE & S SE & S.9E & SSE & SSF & SSE & SSE & SF. & SSE & SE & S9F. \\
\hline$?$ & SBE & SSE & $S E^{\prime}$ & SSE. & SSE & SSE & SSE & SSE & SE & SSE & SSE & SSE & SSE & SSE & SSE & SSF. & SSE & SSF & SSF & SSF & $s$ & sw & SF & $N$ & SSE \\
\hline 3 & $N$ & $N$ & $N$ & NW & WSW & W.SW & WSW & WSW & W & WSW & Wsw & W.SW & WSw & SW & $s w$ & SW & SW & SSW & SW & Wsw & NNW & NW & NW & NW & WSW \\
\hline 4 & NW & NW & NW & NW & NW & NW & NW & NW & NW & NW & NW & $N W$ & NW & NW & NW & NW & NW & NW & NW & NW & NW & NW & NW & $N W$ & NW \\
\hline 5 & NW & NW & NW & NW & NW & NW & NW & NW & NW & NNW & NNW & NNE & SE & SSE & S.SE & SSF & SSE & SSE & S.9F & SSF & SSF & SSE & SSE & SSE & S.9E \\
\hline 6 & SSE & SSE & SSE & SSE & SSF & SSE & SSE & SSE & SSF & SSE & $\mathbf{s}$ & 9 & $s$ & SSE & SSE & SSE & SSE & SSE & SSE & SSE & SSE & 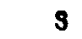 & ssw & SSW & $s$ \\
\hline 7 & SSW & s & 9 & s & 9 & SSE & $3 S E$ & $s$ & s & 9 & s & sw & ssw & 3 & 19 & SSE & 9 & SSF & $\mathbf{s}$ & 9 & SSE & s & 3 & 3 & s \\
\hline B & SSE & s.sw & SSiv & SW & SW & SS:N & W & NW & NiW & WNW & NW & NW & NW & NW & NW & NW & NW & NW & NW & NW & NW & NW & $N W$ & $N$ N & Niv \\
\hline 9 & $\mathbf{N}$ & NNW & NW & NW & NW & NW & NW & NW & NW & NW & NW & NW & NW & NW & NW & NW & NW & NW & NW & $N W$ & NW & NW & NW & $N W$ & NNW \\
\hline 10 & $N W$ & NW & NW & NW & NW & NNW & WNW & $w$ & $w$ & SSW & SSE & SF & SE & SE & SE & SE & SE. & SE & WSW & Sw & WNW & WNW & WNW & $N W$ & NW \\
\hline 11 & NW & NW & $w$ & $w$ & WNW & NW & NW & WNW & NW & NW & NW & NW & $N W$ & NW & $E$ & $S E$ & SE & SE. & SF & $9 F$ & SE & SE & SE & SE & NW \\
\hline 12 & SE & SE & SF & SF & F SE & SE & SE & SE & SE & s & SE & SE & SE & SE & SE & SE & sf. & SF & SE & SE & ESE & ESE & ESE & F.SE & SE \\
\hline 13 & SF & F.SE & SE & $\Xi S E$ & ESE & ESE & ESE & SE & SF & SE & ESE & SSE & SSE & SSE & SSE & SSE & SsE & SSF & S.SE & SSE & SSF & SSE & SSE & SSE & SSE \\
\hline 14 & S.SF. & SSE & SSE & SSE & SSE & SSE & SSE & SSE & SAE & SSE & SSE & SSE & SSE & SSE & SSE & SSF & SSE & SSF & SSF & SSF & SSE & SSE & SSE & SSE & SSE \\
\hline 15 & SSE & SSE & SSE & SSE & SSE & SSF & SSE & SSE & S9E & S.S & 39E & SSE. & ss & S.EE & SSE & $s$ & S.9E & 3 & SSE & $s$ & SSE & SSF & SSF & SSE & SSE \\
\hline 16 & SSE & SSE & SSE & S9E & SSE & SSE & SSE & SSE. & SF. & SSF & SSE & SSF. & SSE & 8 & 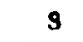 & SSE & S SF. & $s$ & $s$ & 8 & $\mathbf{s}$ & ssw & $\mathbf{S W}$ & sw & $\mathbf{s}$ \\
\hline 17 & WSW & WSW & WSW & NNW & NW & $\mathrm{NW}$ & NW & NW & $w$ & WNW & NW & NW & WNW & NW & WNW & NW & NW & NW & NW & NW & NW & NW & NW & NW & WNW \\
\hline 18 & NW & NW & NW & NW & $N W$ & NW & NW & NW & NW & $N W$ & NW & NW & NW & NW & NW & NW & NW & NH & NW & NIW & NW & NW & $\mathrm{NW}$ & $N W$ & NW \\
\hline 19 & $N W$ & $N W$ & $N W$ & $\mathrm{NWI}$ & NNW & $N ! N$ & NW & NW & NNW & $N$ & $\mathbf{N}$ & $N$ & $N$ & $\mathbf{N}$ & N'NW & NW & NW & WNW & NW & NW & NW & $N W$ & NW & JW & $N$ II \\
\hline 20 & NW & NW & NNW & NNW & NW & NW & NW & WNW & NNW & NNW & NN/W & $N \mid W$ & NW & NW & NW & NW & NW & NW & NNE & $N$ & $w$ & $w$ & $w$ & NNW & NNWW \\
\hline 21 & NNW & NW & NW & $N W$ & NW & NW & NNW & $N$ & SF. & SSE & SSE & SSE & SSE & S.SE & SSE & SSE & SSE & SsE & SSF. & SE & SSE & S9E & SSE & SSE & SSE \\
\hline 22 & SSE & S.SE & SSE & SF & ESF. & SF & $S E$ & SE & SE & SE & SF. & SSE & SSE & SSE & SSE & SSE & SE & SF & SE & SE & SSE & SSE & SSF & SSE & SE \\
\hline 23 & SW & NW & NNW & $\mathrm{NW}$ & NW & NW & NW & NW & NW & NW & $N W$ & NW & WNW & WNW & NW & NW & $\mathrm{NW}$ & NW & NW & NW & $N W$ & $N W$ & NW & NW & N(W) \\
\hline 24 & NW & NW & NW & NW & $\mathrm{NWW}$ & $\mathrm{NW}$ & NW & NW & NNW & NW & $\mathrm{NW}$ & $N W$ & $N W$ & $N W$ & NW & NW & $\mathrm{NW}$ & NNW & Nw & NNW & NNW & NNW & . NNW & NNW & NW \\
\hline 25 & NNW & NW & NW & NNW & NW & NW & NW & $N W$ & NW & NNW & NW & Niv & Nu & NW & $N$ & N & NW & $N W$ & NW & $N W$ & NIW & NIV & $n n$ & NW & $\mathrm{N} / \mathrm{W}$ \\
\hline 26 & NW & NW & NW & NW & NW & NW & WNW & NW & WNW & WNW & $N$ & NW & Nh & $\mathrm{NW}$ & $N$ & $\mathbf{N}$ & NW & NW! & NW & $N W$ & NW & NW & NIW & NW & NW \\
\hline 27 & NW & NW & NW & NW & $N W$ & NIN & NW & NW & NW & NW & NW & NW & $\mathrm{NW}$ & NW & NW & NIN & WNW & WNW' & NW & NNW & NINW & NNW & NNW & $w$ & NW \\
\hline 28 & $w$ & WSW & SSE & SE & SE & SSE & SSE & 3SF & SE & SSF. & SSE & SSE & SSF & SSE & SSE & SSE & S9E & SSF & S.9F & SSF & SSE & SSE & SSE & SSE & SSE \\
\hline ?9 & SSE & SSE & SSE. & SSE & SSE & S.SE & SSE & SSF & SSE & ss & SSE & SSE & Ss & SSF & SSF & S.9F & SF & SSE & SF & SSF & SSE & SSE & $8 E$ & SSE & SSE \\
\hline $3 n$ & SSE & S9F & SSE & SSE. & SE & SE & SSE & SE & SSE & SSE & S.SE & SSF & SSE & FNE & NNW & NW & NW & NW & NNW & NW & NNW' & $\mathbf{N}$ & . N & NNF. & SSE \\
\hline PV & $\mathrm{N}: \mathrm{N}$ & $\mathbf{W}$ & IN & NW & NWI & NIV & Aw & NW & 98 & SF & SE & SF & isf. & SF & SF & QF & SF & QF & SF & SSF & VAI & NW & A'W & Now & \\
\hline
\end{tabular}




\section{APPENDIX C}

Wind Analysis Summary 


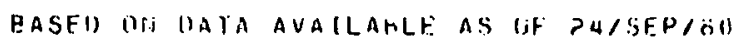

FUK THE PEKIOD AUG, 1979 TU AIIG, 1979

OIRECTION

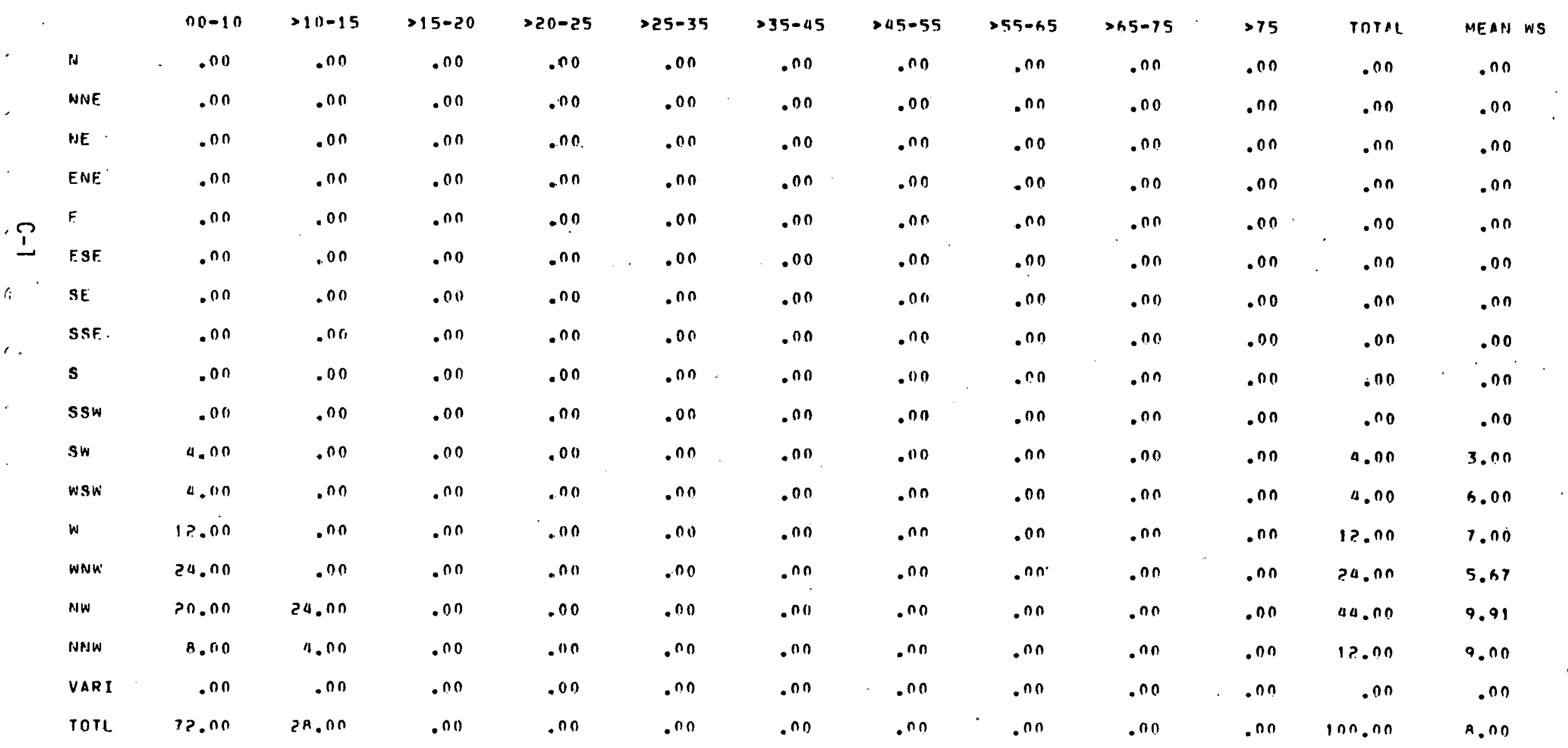

WINO SPEEO [MILES/HOUN] 
GASED DN DATA AVATLABLE AS IF ZM/SFP/RO

FOR THE PERION SEP, 1979 TO SEP, 1979

\section{DIRECTION}

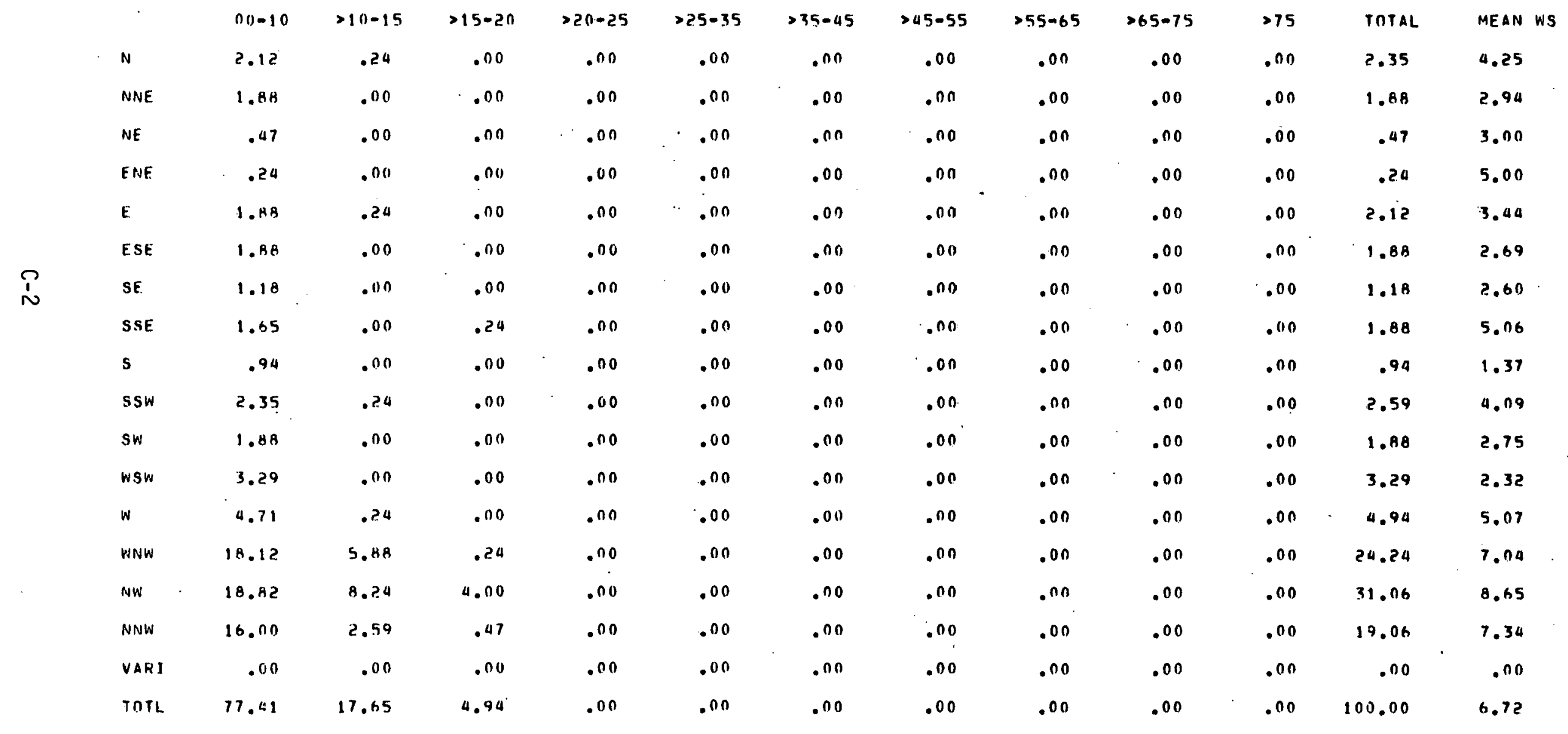

WINN SPEED [MILES/HOIR] 
HASEO IIT MATA AVAJLARLE AS OF ZIISEP/HO

FOR THE PENJOD NCT, $! 479$ TO OCT, 1979

WINA SPEED [MILES/HOIIRI

\begin{tabular}{|c|c|c|c|c|c|c|c|c|c|c|c|c|}
\hline & $00-10$ & $>1 i 1=15$ & $>15-20$ & $-20-25$ & $>25-35$ & $>35-45$ & $>45-55$ & $>55-6.5$ & $>65-75$ & $>75$ & TOTAL & MFAN WS \\
\hline $\mathbf{N}$ & $\operatorname{sss} s \$$ & SSSAss & $\$ \$ \$ \$ 5 \$$ & $\$ \$ \$ \$ \$$ & $5 \$ \$ \$ \$ S 5$ & S\$S\$s\$ & $5 s \$ 5 s s$ & $\operatorname{sisss}$ & $\$ 85 \$ 55$ & $535 s 5 s$ & $5.5 \$ \$ 5 \$$ & .00 \\
\hline NNE & 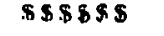 & $\$ 5 \$ \$ \$ \$ S 5$ & 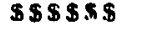 & 55.5558 & 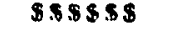 & s\$sssis & S\$S\$\$S & 535535 & 535355 & S5s5s.5 & 5.83555 & .00 \\
\hline NE & $5 \$ \$ \$ \$ \$$ & $\$ \$ \$ 5 \$ 8$ & $\$ \$ \$ \$ \$ \$$ & SSSS\$S & 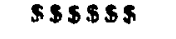 & $\$ 55355$ & $\operatorname{sississ}$ & 355855 & S5S\$\$S & $555 \$ \$ \$$ & S.S.S.S\$5 & $.0 n$ \\
\hline F $\mathrm{NE}$ & 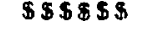 & 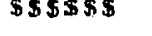 & 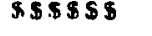 & \$S\$SSS & 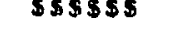 & sississs & 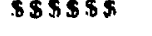 & S\$S\$S\$ & S35s \$s\$ & S\$\$\$S.8 & 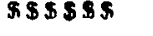 & .00 \\
\hline E. & $\$ \$ \$ \$ \$ \$$ & 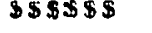 & 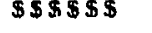 & S\$\$\$S\$ & 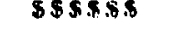 & 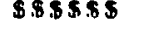 & 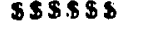 & \$.S5S\$S & $35 \$ \$ \$ \$$ & 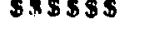 & \$\$\$\$\$\$ & .00 \\
\hline ESE & $\$ \$ 8.5 \$ 5$ & 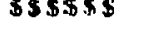 & SSSSS\$ & $\$ 5 \$ 5 \$ \$$ & $\$ \$ \$ \$ \$ \$ \$$ & $\$ \$ \$ \$ \$ \$$ & $\operatorname{sis} s \sin$ & 553555 & $\operatorname{sissss}$ & SSSSSS & 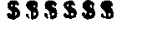 & .00 \\
\hline SE & \$SGS5 S & \$\$\$S\$\$ & S\$S\$\$\$ & SSTSBS & 5555.53 & $\operatorname{sinssss}$ & $\$ \$ \$ 55 \$$ & $583.5 \$ 5$ & 938555 & 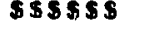 & $5 \$ \$ 5 \$ 3$ & .00 \\
\hline SSE. & $\$ \$ .85 . \$ \$$ & \$\$\$\$\$ & $\mathbf{S S S \$ S \$ ~}$ & $\$ \$ 5 \$ S 5$ & $35 \$ \$ S 5$ & $\$ \$ \$ \$ \$ \$$ & $5 \sin 53$ & $55 \$ 5 \$ \$$ & 235958 & 538558 & 55,5538 & .00 \\
\hline $\mathbf{S}$ & $\$ \$ \$ \$ 55 \$$ & \$\$\$\$S\$ & $\$ \$ \$ \$ \$ \$$ & $\$ .8 \$ 5 \$$ & $\$ 5.5 \$ 5 \$$ & 355959 & \$\$\$\$\$\$ & 553535 & $\$ 85 \$ 85$ & $5 \$ 8835$ & $355 \$ \$ 5$ & .00 \\
\hline SSW & 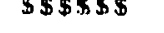 & 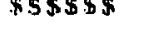 & 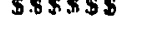 & 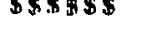 & $5 \$ 35358$ & 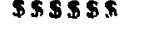 & 585953 & 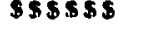 & 553355 & $\operatorname{sis} 5 \sin$ & 553555 & $.0 n$ \\
\hline SW & $\$ \$ 5 \$ \$ \$$ & $\$ 5.5 \$ \$ \$$ & 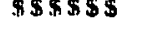 & 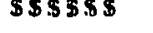 & \$S\$S.5. & 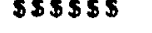 & $5 \$ \$ 5 \$ \$$ & \$\$S\$\$\$ & \$S\$S\$S & S95\$S\$S & 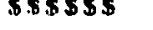 & .00 \\
\hline wSW & 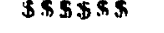 & $\$ \$ \$ \$ \$ \$$ & 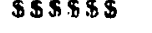 & $\$ \$ \$ 5 \$ \$$ & $\$ \$ \$ \$ \$ S \$$ & S\$SS\$S & 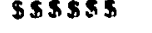 & 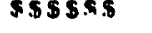 & $58 \$ \$ 35$ & 585553 & $5 \$ 5555$ & .00 \\
\hline $\mathbf{w}$ & 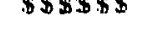 & $\$ \$ 5 \pi \$ \$$ & $\operatorname{sis} \$ 5 s$ & 555555 & 355553 & $\$ 35553$ & $\$ 55.558$ & 5.55555 & s5s5s & ssiss sis & SSSSSS & .00 \\
\hline WNW & 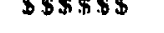 & S\$SSSS & $\operatorname{sis} 558$ & SSTSSS & $3 \$ 5.5 \$ 5$ & MSSSSS & 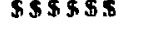 & SSTSSS & $\operatorname{siss} 35$ & 58539.5 & S\$SSS5 & .00 \\
\hline NW' & $\$ \$ \$ \$ \$ \$$ & 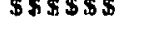 & $\$ \$ \$ \$ \$ \$$ & $\$ 5 \$ 5.3 \$$ & $\$ \$ \$ \$ 559$ & $\$ \$ 355 \$$ & $\$ 5 \$ 3 \$ 5$ & 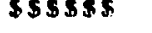 & $\$ \$ 5 \$ \$ 8$ & S\$S\$S\$ & 855535 & .00 \\
\hline NNW & $\$ \$ \$ .5 \$ 5 \$$ & $\$ \$ 5.8 \$ 5$ & 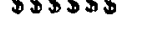 & 535555 & $35585 \$$ & $\$ 35 \$ \$ 55$ & S\$S\$S\$ & $585 \$ 58$ & $\$ \$ 5 \$ 55$ & $\$ 3 \$ \$ \$ \$$ & 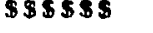 & .00 \\
\hline VARI & 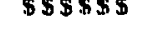 & 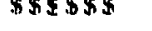 & $\$ \$ \$ \$ \$ \$$ & 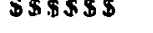 & $\operatorname{sis} \$ \$ \$ \$ \$ 3$ & $\$ \$ \$ \$ \$ \$$ & \$\$\$ \$\$\$ & S\$S\$S\$ & $\operatorname{ssssss}$ & SSSSSS & $\$ \$ \$ \$ \$ S \$$ & .00 \\
\hline ToTl. & 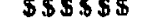 & $\$ . \$ 5 \$ \$ \$$ & \$\$\$\$\$\$ & $\$ \$ \$ \$ \$ \$ \$ S$ & $\$ S \$ S \$ S \$$ & \$\$\$\$\$\$ & $5 \$ \$ 5 \$ 5$ & $\operatorname{sisss} 4$ & $.855 \$ \$$ & $\$ \$ \$ \$ \$ \$$ & \$\$\$\$\$\$ & .00 \\
\hline
\end{tabular}


based In Data availahle as mf ra/sfp/an

FOR IHE PERIOO NIIV, 1979 TO NOV ,1979

DIRECTION

N

NNE

NE

ENE

E

E.SE

SE

SSE

$\mathbf{s}$

ssw

sw

WSW

w

WNW

NW

NNW

VAR I

TOTL

TOTAL OCCURS
3.12

$$
>10-15
$$
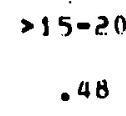

$>20-25$

$>29-35$

$3.36 \quad .00$

$4.56 \quad .24^{\circ}$

$8.15 . .24$

$6.00 \quad .00$

$8.39 \quad .96$

11.03

3.84

96

.24

1.92

1.20

1.68

1.92

1.20

3.12

.00

60.67

417

.24

$$
.24
$$

.01

$.24 \quad .00$$$
.00 \quad .00
$$$$
.00 \quad .00
$$$$
.00 \quad .00
$$$$
.00
$$$$
.0
$$$$
.00
$$$$
.000
$$$$
.00
$$$$
.00 \quad .00
$$$$
.00 \quad .00
$$$$
.00
$$$$
.00
$$$$
.00
$$

WIND SPEED [MILES/HOUIR]

.00

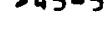

$>55-6$

.00

$>65-75$

$>75$

TOTAL

MEAN WS

.nn

$$
\text { .no }
$$

.00$$
.00
$$$$
.00
$$$$
5.04
$$$$
\text { 8. } 49
$$$$
.00 \quad .00
$$$$
.00
$$$$
.0
$$$$
.00
$$$$
3.60
$$$$
3.11
$$$$
\text { .no .no }
$$$$
\text { .no . }
$$$$
.00
$$$$
.00
$$$$
.00
$$$$
4.80
$$$$
4.0 \text { ? }
$$$$
.00
$$$$
.00
$$$$
.00
$$$$
.00
$$$$
8.39
$$$$
5.36
$$$$
.00 \quad .00
$$

.00

$$
.00
$$$$
6.00
$$$$
4.09
$$$$
.00
$$$$
.00
$$$$
.00
$$$$
.00
$$$$
.00
$$$$
.00
$$$$
9.59
$$$$
5.31
$$$$
.00
$$$$
\text { . nn }
$$$$
.00
$$$$
.00
$$$$
.00
$$$$
12.71 \quad 5.93
$$$$
.0 n
$$$$
.00
$$$$
.00
$$$$
.00
$$$$
.00
$$$$
.00
$$$$
.0 n
$$$$
3.843 .25
$$$$
.963 .54
$$$$
.00
$$$$
.00
$$$$
.00
$$$$
.00
$$

$.00 \quad .00$

.00

.00

.00

.00

.00

. no

.00

.00

.0

.00

.00

.00

.00

.00

.00

.00

$$
.00
$$$$
.00
$$$$
.24 \quad 7.86
$$$$
1.92 \quad .65
$$$$
1.04 \quad 5.67
$$$$
4.08 \quad 11.42
$$$$
9.11 \quad 12.73
$$$$
15.83 \quad 15.89
$$$$
12.47 \quad 15.58
$$$$
3.84 \quad .00
$$$$
.00
$$

.00

.00

$100.00 \quad 9.05$ 
RASED NN DATA AVATLABLE AS OF $24 / 9 E P / a O$

FOA THF PERIOD MAY, 1979 TO MAY, 1979

DIRECTION

$n n-10 \quad>10-15 \quad>15-20$

NNE S\$S.\$\$

NE $\quad \$ \$ \$ \$ \$ 5$

EHE SSSSSS

EH

8
E

SE

SSE

$\mathbf{s}$

s.sw

sw

NS

$N$

WNW

NW

NNW

VAR I

TOTL
Sकs

S.R.STs

$\operatorname{sis} 5 \sin$

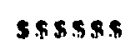

$\operatorname{ssc} 5 s 8$

sssiss

ssssiss

S.5.5.5s

ossess.s

s.5.s.5.

s\$ses

sossse

S\$S\$\$S

SSSSTS

S.S\$ $\$ 5$.

$\operatorname{ses} \operatorname{ses}$

$\$ \$ \$ \$ \$ \$ \$$

$\operatorname{sis} 5 \operatorname{sis} 5$
WIND SPEED [MILFS/HOHR]

\begin{tabular}{|c|c|c|c|c|c|c|c|c|}
\hline$>20-2.5$ & $>25=35$ & $>35-0.5$ & $>05-55$ & $>55-65$ & $>65-75$ & $>75$ & TOTAL & MEAN WS \\
\hline$\$ 5.95 \$ 5$ & S.S45\$.5 & 595.5 .95 & - Sss.sss.s & SSSGRS & 95835.8 & 598535 & SM9S5s & $.0 n$ \\
\hline $5 \$ \$ .8 .85$ & $\operatorname{sis} 5 s 5$ & 58.8555 & S\$\$\$S & s s.sess & 5354.85 & 5.8385 .5 & $35 \$ \$ 53$ & .00 \\
\hline $\operatorname{sssss} 5$ & $\sin 5 \sin 8$ & 5.5 .855 .5 & ssss.s.s & 5.53955 & 559.8 .5 .5 & 9.8 .85 .55 & 895955 & .00 \\
\hline $5.5 \leq 585$ & SGSSSS & $\operatorname{sinssst}$ & $\operatorname{sissis}$ & SAs.4. & $5 \$ 5 \$ 5 \$ 35$ & 3935.55 & 85855.8 & .00 \\
\hline s.4.s.5ss & sssss: & $5.5 .58 \$ 5$ & SSAsss & $\leq \leqslant \leq \leqslant \$ 3$ & 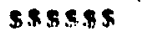 & S\$SSSS & SSSSSS & .00 \\
\hline $55 \$ 5 \$ 5$ & $\$ 55.855$ & S.8.85s 5 & sassest & $\operatorname{sins} 55$ & Massss & s.ssssist & S\$S\$s.8 & $.0 n$ \\
\hline SSARSS & STSSSS & $\$ 9545 s$ & SS\$\$S\$ & $5.85 s .5$ & \$33.9.5 & SM\$\$\$\$ & $\operatorname{sss} 5.5 .5$ & .00 \\
\hline STSSTSS & anssss & S\$N\$SS & $\operatorname{sss} 5,5$ & SSSSSTS & 5953.65 & 5,59989 & $\operatorname{sis} 4 \pi s$ & .00 \\
\hline Kasks & sinssss & s.sisss & $5 \$ 5 \$ 5.8$ & S.8SAS9 & $5 \$ 85.8 \%$ & 985558 & 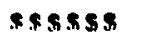 & .00 \\
\hline SSS.5.5 & 95.8555 & 35585.5 & 5.8 .85 .95 & S.5.5.85 & S\$5\$.8.45 & 55.58 .53 & S.5.5.5. &.$n 0$ \\
\hline SSSSSS & SSSSAS & $\$ \$ \$ \$ \$ S$ & 5.85959 & S.54595 & s.s.s.s. & SSSSSS & $5.595 .8 \%$ & .00 \\
\hline $5 s 5 s 53$ & s.5.5.5s. & S\$S\$S\$ & 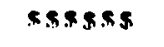 & 5.555 .55 & S\$s.s.5 & $\operatorname{sss} \operatorname{sins}$ & S.5.5.55 & .00 \\
\hline $\operatorname{sinss}$ & \$STS5.9 & x.9555.5 & $\operatorname{sss} 5 \sin$ & $\operatorname{sessas}$ & s\$ss.s. & S.\$S\$.5.5 & 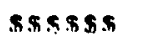 & .00 \\
\hline S\$SSSS & $\operatorname{sssssa}$ & SSS\$S\$ & $\$ \$ \$ \$ \$ \$$ & $\$ 5 \$ \$ 4 \$$ & $5 \$ 55 \$ 5$ & $5 s .5 s \$$ & 545554 & .00 \\
\hline $\operatorname{sinss.5s}$ & S5s.5s. & S.S.SSS\$ & sassss & 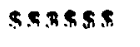 & SASSSR & S.S.S.5.5 & $\$ 5 \$ 5 \$ 5$ & $.0 n$ \\
\hline S.TSSSS & FSTSS5S & SSOSES & $\operatorname{sesess}$ & sass.5.5 & 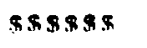 & s.s.s.s & S\$.S.S.5. & $.0 n$ \\
\hline 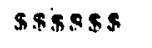 & $\$ \$ \$ \$ \$ \$$ & 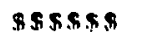 & $\$ S \$ S \$ S$ & 5.959 .55 & 5.5 .85 .8 .5 & S.S\$S\$S.S & $9.5,5,5.5$ & .00 \\
\hline $\operatorname{sins\$ \$ \pi }$ & $x \$ \leqslant \$ \$$ & $\$ \$ \$ \$ \$ \$$ & sss $s \leqslant \pi$ & 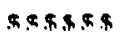 & $5 \$ \$ \$ \$ \$$ & $\$ \$ \$ \$ \$ \$$ & $5 \times \$ \$ \$ \$ S B$ & .00 \\
\hline
\end{tabular}


[PROGRAM: FOWSD] [VERSTON: AOOMSI [IL AUE TR] BASED ON DATA AVATLABLE AS OF ?M/SEP/RÓ

FOR THE PERTOR JUN .1970 TO JIIN, 1979
DIRECTION

\begin{tabular}{|c|c|c|c|c|c|c|c|c|c|c|c|c|}
\hline . & $00-10$ & $>10-15$ & $>15-20$ & $>20-25$ & $>25-35$ & $>35-45$ & $>45-55$ & $>55-69$ & $>65-75$ & $>75$ & TOTAL. & MEAN WS \\
\hline$N$ & .00 & .00 &.$n 0$ & .00 & .00 & .00 & $.0 n$ & .00 & .00 & $.0 n$ & .00 & .00 \\
\hline NNE. & .00 & .00 & .00 & .00 & $.0 n$ & $.0 n$ & .00 &.$n n$ & . nn & .00 &.$n n$ & .00 \\
\hline NE & .00 & .00 & .00 & .00 & .00 & . on & $.0 n$ & .00 & .00 & .00 & .00 & .00 \\
\hline ENE & .00 & $.0 n$ & .00 & .00 & .00 & .00 &.$n n$ &.$n n$ & $.0 n$ & $.0 n$ & $.0 n$ & .00 \\
\hline$E$ & .00 & .00 & .00 & .00 & .00 & .00 & $.0 n$ & .00 & .00 & .00 & .00 & .00 \\
\hline ESE & .00 & $.0 n$ & .00 & .00 & $.0 n$ &.$n 0$ &.$n 0$ & .00 & .00 & .00 & .00 & .00 \\
\hline SF & . nn & $.0 n$ & .00 & .00 & $.0 n$ & .00 & .00 & .00 & .00 & $.0 n$ & .00 & .00 \\
\hline SSF & .00 & .00 & .00 & .00 & $.0 n$ &.$n n$ & $.0 n$ & $.0 n$ & $.0 n$ & .00 &.$n n$ & .00 \\
\hline 9 & .00 & .00 & $.0 n$ & .00 & .00 & .00 & .00 & $.0 n$ & .00 & $.0 n$ & .00 & $.0 n$ \\
\hline ssw & .00 & .00 &.$n 0$ &.$n n$ & .00 & $.0 n$ & $.0 n$ & .00 &.$n n$ & $.0 n$ & $.0 n$ & .00 \\
\hline sw & .00 &. no & .00 & .00 & . no & .00 & $.0 n$ & $.0 n$ & $.0 n$ & $.0 n$ &.$n 0$ & . nn \\
\hline WSW & .00 & .00 & .00 & .00 &.$n 0$ & .00 & $.0 n$ & .00 & $.0 n$ & .00 &.$n n$ & .00 \\
\hline$w$ &.$n 0$ & $.0 n$ & .00 &.$n 0$ &.$n 0$ &.$n n$ & .00 & .00 &.$n n$ & .00 &.$n n$ &.$n n$ \\
\hline WNW & .00 & .00 & 5.00 & .00 &.$n n$ & .00 &..$n n$ & .00 & .00 & $.0 n$ & 5.00 & 19.50 \\
\hline$N W$ & $2.5 n$ & 45.00 & 40.010 & 7.50 & $.0 n$ & $.0 n$ & $.0 n$ & .00 &.$n n$ & .00 & 95.01 & 13.11 \\
\hline NNW & .00 &.$n n$ & .00 &.$n n$ & .00 & .00 & .00 &.$n n$ &.$n n$ & $.0 n$ &.$n n$ & . \\
\hline VARI & .00 & . no & .00 & $.0 n$ & .00 & . & $.0 n$ & .00 & .00 & $.0 n$ & $.0 n$ & .00 \\
\hline TOTL & 2.50 & 45.00 & 15.00 & 7.50 & .00 & .00 & $.0 n$ & $.0 n$ & $.0 n$ &.$n n$ & 100.00 & IG.?A \\
\hline
\end{tabular}

WIND SPEED RMILES/HOUR I 
BASED DN DATA AVAILABLE AS DF $24 /$ SEP/AO

FOR THE PERION JUL .1979 IO JILL. 1979

\section{DIRECTIIIN}
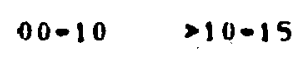

.00

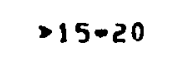

N

NNE

NE

ENE

E

E.SE

I SE

SSE. $.00 \quad .00$

S . .00 .00

S5W $\quad .00 \quad .00$

SW .00 .00

WSW .00 .00

$w$

WNM

NW

NNW

VAR I

TOTL
$.00 \quad .0$

$10.00 \quad 6.67$

$37.78 \quad 17.78$

$.37 \quad .37$

$.00 \div .00$

24.81

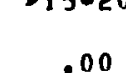

.0

.00

.00

.00

.00

.00

.00

.nn

$\because 00$

.00

.00

.00

.00

9.63

12.96

$.0 n$

.00

$2 ? .59$
WINI) SPEED [MILES/HOIIR]

\begin{tabular}{|c|c|c|c|c|c|c|c|c|c|}
\hline$>20-25$ & $>25-35$ & $>35-45$ & $>45-55$ & $>55-65$ & $>65-75$ & & $>75$ & TOTAL & MEAN WS \\
\hline .00 & .00 & $.0 n$ &.$n 0$ & .00 & .00 & & .00 & .00 & .00 \\
\hline .00 & .00 & .00 & .00 & .00 & .00 & & .00 & .00 & .00 \\
\hline .00 & .00 & .00 & $: n 0$ & .00 & .00 & $\therefore$ & .00 & .00 & .00 \\
\hline .00 & .00 & .00 & .00 & .00 & .00 & & .00 & .00 & .00 \\
\hline .00 & .00 & .00 & .00 & .00 & .00 & & .00 & .00 & .00 \\
\hline .00 & .00 & .00 & .00 & .00 & .00 & & .00 & $.0 n$ & .00 \\
\hline .00 & .00 & .00 & .00 & .00 & .00 & & .00 & .00 & .00 \\
\hline .00 & .00 &.$n 0$ & .00 & .00 & .00 & & .00 & .00 & .00 \\
\hline .00 & .00 & $.0 n$ &.$n n$ & $: 00$ & .00 & & .00 & .00 & .00 \\
\hline .00 & .00 & .00 & .00 & .00 & .00 & & .00 & .00 & .00 \\
\hline .00 & .00 & .00 & .00 & .00 & .00 & & .00 & .00 & .00 \\
\hline .00 & .00 & .00 &.$n_{0}$ & .00 & .00 & & .00 & .00 & .00 \\
\hline .00 & .00 & .00 & .00 & .00 & .00 & $\cdot$ & .00 & .00 & .00 \\
\hline 1.11 & .100 & .37 & .00 & .00 & .00 & & .00 & 27.78 & 13.09 \\
\hline 2.59 & .37 & .00 & .00 & .00 & .00 & & .00 & 71.48 & 10.39 \\
\hline .00 & .00 & .00 & .00 & .00 & .00 & & .00 & .74 & 10.00 \\
\hline .00 & .00 & $.0 n$ & .00 & - nn & .00 & & .00 & .on & .00 \\
\hline 3.70 & .37 & .37 & .00 & .00 & .00 & & .00 & 100.00 & 11.14 \\
\hline
\end{tabular}


BASED OH DATA AVAILAHLE AS UF $24 /$ SFP/BO)

FOR THE NERIOD AUG. 1979 TO AUG. 1979

DIRECTION

\begin{tabular}{|c|c|c|c|c|c|c|c|c|c|c|c|c|}
\hline & $00-10$ & $>10-15$ & $=15-20$ & $>20-25$ & $>25-35$ & $>35-45$ & $>45-55$ & $>55-65$ & $\times 65-75$ & $>75$ & TOTAL & MEAN IVS \\
\hline N & .00 & .00 & .00 & .00 & .00 & .00 & .00 & .00 & .00 & .00 & .00 & .00 \\
\hline NNE & .00 & .00 & .00 & .00 & .00 & .00 & .00 & .00 & .00 & .00 & .00 & .00 \\
\hline NE & .00 & .00 & .00 & .00 & .00 & .00 & .00 & .00 & .00 & .00 & .00 & .00 \\
\hline ENE & .00 & .00 & .00 & .00 & .00 &. no & $.0 n$ & .00 & .00 & .00 & .00 & .00 \\
\hline E & .00 & .00 & .00 & .00 & .00 & .00 & .00 & .00 & .00 & .00 & .00 & .00 \\
\hline ESE & .00 & $\because 0 n$ & .00 & .00 & .00 & .00 & $.0 n$ & .00 & .00 & .00 & .00 & .00 \\
\hline SE & .00 & .00 & .00 & .00 & .00 & .00 & .00 & .00 & $.0 n$ & .00 & .00 & .00 \\
\hline SSE & .00 & .00 & .00 & .00 & .00 & .00 & .00 & .00 & $.0 n$ & .00 & .00 & .00 \\
\hline $\mathbf{s}$ & .00 & .00 & .00 & .00 & .00 & .00 & .00 & .00 & .00 & .00 & .00 & .00 \\
\hline SSW & .00 & .00 & .00 & .00 &. no & .00 &. no & .00 & .00 & .00 & .00 & .00 \\
\hline SW & .00 & .00 & .00 & .00 & .00 & .00 & .00 & .00 & .00 & .00 & .00 & .00 \\
\hline WSW & .00 & .00 & .00 & .00 & $.0 n$ & .00 & .00 & .00 &. no & .00 & .00 & .00 \\
\hline$w$ & .00 & .00 & .00 & .00 & .00 & .00 & .00 & .00 & .00 & .00 & .00 & .00 \\
\hline WNW & 4.95 & 3.30 & .00 & .00 & 1.10 & .00 & $.0 n$ & .01 & .00 & .00 & 9.34 & 9.65 \\
\hline NW & 25.82 & 35.16 & 23.63 & 3.30 & 2.20 & .00 & .00 & .00 & .00 & .00 & 90.91 & 13.66 \\
\hline NNW & .55 & .00 &. no & .00 & .00 & .00 & .00 & .00 & .00 & .00 & .55 & 10.00 \\
\hline VARI & .00 & .00 & .00 & .00 & .00 & .00 & .00 & $.0 n$ & .00 & .00 & .00 & .00 \\
\hline TORL & 31.32 & 38.46 & 23.63 & 3.30 & 3.30 & .00 & .00 & .00 & .00 & .00 & 100.00 & 13.26 \\
\hline
\end{tabular}

WINI] SPEED [MILES/HOIIR]

TOTAL OCCUHS $=182$ 
HASEO ON DATA OVAILAHLE AS UF ZU/SEP/BO

FOR THE PERIIU SEP, 1970 IO SFP, 1979

GIRECTION

\begin{tabular}{|c|c|c|c|c|c|c|c|c|c|c|c|c|}
\hline & $00-10$ & $>10-15$ & $>15-20$ & $>20-25$ & $>25-35$ & $>35-45$ & $>45-55$ & $>55-65$ & $>65-75$ & 275 & TOTAL & MEAN W \\
\hline A & 1.32 & .00 . & .00 & .70 & .00 & .00 & $.0 n$ & .00 & .00 & .00 & 1.32 & 6.00 \\
\hline NNE & .00 & .00 & .00 & .00 & .00 & .00 & .00 & .00 & .0 . & $.0 n$ & .00 & .00 \\
\hline NE & 1.32 & .00 & .00 & .00 & $.0 n$ & .00 & .00 & .00 & .00 & $.0 n$ & 1.32 & 2.00 \\
\hline ENE & $6.5 A$ & .00 & .00 & $.0 n$ & .00 & .00 & .00 & .00 & .00 & $.0 n$ & $6.5 A$ & 3.60 \\
\hline$E$ & 10.53 & 5.26 & 5.26 & 2.63 & .00 & .00 & .00 & .00 & .00 & .00 & $23.6 \mathrm{~A}$ & 11.39 \\
\hline E SE & 2.63 & 1.3? & 1.32 & .00 & .00 & $.0 n$ & .00 & .00 & .00 & .00 & 5.26 & 11.50 \\
\hline SE & 2.63 & .00 & .00 & .00 & .00 & .00 & .00 & .00 & .00 & .00 & 2.63 & 4.50 \\
\hline SSE & 3.95 & .00 & .00 & .00 & .00 & .00 & .00 & $.0 n$ & .00 & .00 & 3.95 & 6.33 \\
\hline s. & 5.20 & .00 & .00 & .00 & .00 & .00 & .00 & .00 & $\because 00$ & .00 & 5.26 & 7.25 \\
\hline SSW & 2.63 & .00 & .00 & .00 & .00 & .00 & .00 & .00 & .00 & .00 & 2.63 & 8.50 \\
\hline sw & 5.26 & .00 & .00 & .00 & .00 & .00 & .00 & $.0 n$ & .00 & .00 & 5.26 & 7.50 \\
\hline NSW & .00 & .00 & .00 & $.0 n$ & .00 & .00 & .00 & .00 & .00 & .00 & .00 & .00 \\
\hline$v$ & .00 & .01 & . 00 & .00 & .011 &. no & .00 & .00 & .00 & .00 & .00 & .00 \\
\hline WNW & 13.16 & 11.84 & .00 & .00 & .00 & .00 & .00 & .00 & .00 & .00 & 25.00 & 9.37 \\
\hline $1 / 6$ & 14.47 & .00 & .00 & .00 & .00 & .00 & .00 & $.0 n$ & .00 & .00 & 14.47 & 5.45 \\
\hline NNW & 2.63 & .00 & .00 & 、.0? & .00 & $!^{n n}$ & .00 & .00 & .00 & .00 & 2.63 & 3.50 \\
\hline VAR I & .00 & .00 & .00 & .00 & .10 & .100 & .00 & .00 & .00 & $.0 n$ & .00 & .00 \\
\hline TOTL & 72.37 & 18.42 & 6.58 & 2.63 & .00 & .00 & .00 & .00 & .00 & $.0 n$ & 100.00 & B. 24 \\
\hline
\end{tabular}

WINO) SPEEI) [MILES/HOUR] 
BASED ON DATA AVALLARLE AS OF ?H/SFP/HO

FOH THE PERIOD OCT, 1979 TO OCT.1979

DIRECTION

\begin{tabular}{|c|c|c|c|c|c|c|c|c|c|c|c|c|}
\hline & $00-10$ & $>10-15$ & $>15-20$ & $=20-25$ & $225-35$ & $>35-45$ & $>45-55$ & $>55-45$ & $>65-75$ & $>75$ & TOTAL & MEAN WS \\
\hline N & .57 & .00 & .00 & $.0 n$ & .00 & .00 & $.0 n$ & .00 & .00 & .00 & .57 & 7.00 \\
\hline NNE & .00 & .00 & .00 & .00 & .00 & .00 & .00 & .00 & .00 & .00 & $.0 n$ & $.0 n$ \\
\hline NE. & .00 & $.0 n$ & .00 & .00 & .110 & $.0 n$ & .00 & .00 & .00 & .00 & .00 & .00 \\
\hline ENE & .00 & $.0 n$ & .00 & .00 & .00 & .00 &.$n 0$ & .00 & .00 & .00 & .00 &.$n 0$ \\
\hline$E$ & 1.14 &. no & .00 & .00 & .00 & .00 & .00 & .00 & $.0 n$ & .00 & 1.14 & 3.75 \\
\hline ESE & .00 & $.0 n$ & .00 & .00 & .100 & .00 & .00 & .00 & .00 & .00 & .00 & .00 \\
\hline SE & 2.27 & .57 & .00 & .00 & .00 & .00 & .00 & .00 & .00 & .00 & 2.84 & 6.00 \\
\hline SSE & 1.14 & .00 & .00 & .00 & .00 & .00 & .00 & .00 & .00 & .00 & 1.14 & 5.87 \\
\hline s & .00 & .00 & .00 & .00 & .00 & .00 & .00 & .00 & .00 & .00 & .00 & .00 \\
\hline ssw & .57 & .00 & .00 & .00 & $: 00$ & .00 & .00 & $.0 n$ & .00 & .00 & .57 & 8.63 \\
\hline sw & 2.84 & 1.14 & .00 & .00 & .00 & .00 & .00 & .00 & .00 & .00 & 3.98 & 8.02 \\
\hline IVSW & 1.70 & 3.41 & .00 & .00 & .01 & .00 & .00 & .00 & .00 & .00 & 5.11 & 10.81 \\
\hline$w$ & .57 & 3.41 & $.0 n$ & . no & .00 & .00 & .00 & .00 & .00 & $.0 n$ & 3.98 & 10.73 \\
\hline WNW & 1.14 & $5.6 H$ & 8.52 & 1.14 & .00 & .00 & .00 & .00 & .00 & .00 & 16.48 & 15.53 \\
\hline NW - & 7.95 & 6.25 & 25.00 & 7.95 & 13.07 & .57 & .00 & .00 & .00 & .00 & 60.80 & 18.92 \\
\hline NNW & 1.70 & .57 & 1.14 & .00 & .00 & .00 & .00 & .00 & .00 & .00 & 3.41 & 11.88 \\
\hline VARI & .00 & .00 & .00 & .00 & .00 & .00 & .00 & .00 & .00 & .00 & .00 & .00 \\
\hline TOTL & 21.59 & 21.0 .2 & 34.66 & 9.119 & 13.07 & .57 & .00 & .00 & .00 & .00 & 100.00 & 16.13 \\
\hline
\end{tabular}

WIND SPEE.D [MILES/HOHR] 


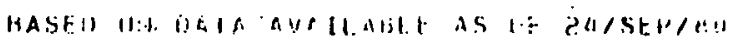

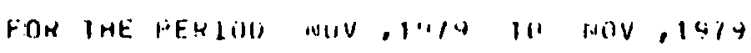

[i. IRECTIUAS

$$
00-10>10-15
$$

$>15-20$
.14

$>20-25$

$.69 \quad .28$$$
14
$$

WNE.

.00

.14

iafe

ENE

F

F. SF

I

.00

.00

.00

.00

.28

.47

$1 . \mathrm{HI}$

SSF

$\mathrm{s}$

SSเv

sw

visiv

m

WNN

Niv

NNW

VARI

IIIL

6.25

.14

.42

.28

$$
.56
$$

.42

. 2 B

$$
1.53
$$$$
.97
$$$$
.28
$$$$
.43 .69
$$

$5.97 \quad 7.92$

$1.11 \quad i .1$

.0

20.00

19.3

19.31

TOTAL NCCURS

\begin{tabular}{|c|c|c|c|c|c|c|c|}
\hline$>25=35$ & $>35-45$ & $>45-55$ & $>55-65$ & $>65-75$ & $>75$ & TOTAL & MEAN WS \\
\hline .42 & .00 & .00 & .00 & .00 & .00 & 1.B1 & 14.70 \\
\hline $.10^{\circ}$ & . no & .00 & .00 & $.0 n$ & .00 & .69 & 19.74 \\
\hline .00 & .00 & .00 & .00 & .00 & .00 & .00 & .00 \\
\hline .00 & .00 & .00 & .00 & .00 & .00 & .10 & 9.69 \\
\hline .00 & .00 & .00 & $.0 n$ & .00 & $.0 n$ & .14 & 6.58 \\
\hline .00 & .00 & .00 & $.0 n$ & .00 & .00 & 1.67 & 17.21 \\
\hline .97 & .00 & .00 & .00 & .00 & .00 & 0.33 & 16.84 \\
\hline 5.14 & .00 & .00 & .00 & .00 & .00 & 31.39 & 17.61 \\
\hline .42 & .00 & .00 & .00 & .00 &.$n n$ & 4.03 & 20.10 \\
\hline .00 & .00 & .00 & .00 & .00 & .00 & 1.39 & 12.44 \\
\hline .00 & .00 & .00 & .00 & .00 & $.0 n$ & 1.81 & 9.42 \\
\hline .14 & .00 & $.0 n$ & .00 & .00 & .00 & .2 .08 & 9.14 \\
\hline .28 & . no &. no & .00 & .00 & .00 & 1.53 & 12.36 \\
\hline .56 & .00 & $.0 n$ & .00 & .00 & .00 & 2.78 & 16.57 \\
\hline 6.94 & .00 & $.0 n$ & .00 & .00 & $.0 n$ & $37.0 \mathrm{~A}$ & 17.95 \\
\hline 1.39 &.$n n$ & .00 & .00 & .00 & .00 & 5.14 & 17.82 \\
\hline .00 & .00 & .00 & .00 & .00 & .00 & .00 & .00 \\
\hline 16.39 & .00 & . &.$n n$ & .00 & .00 & 100.00 & 17.21 \\
\hline
\end{tabular}

$7 \geq 0$

VIIND SHEEO [MILES/HOHK] 


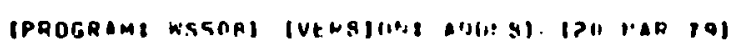

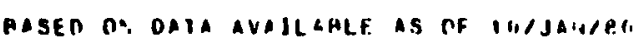

FOR THE PEKJIIL DAY .1074 10 MAY .1474

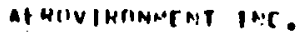

SITF ALITHISE AQSOFT SITE EXPONENTE IAON

ave HaGF IFMPFKAIIHE C. 813.3

InTAL. HIIILS RHSF HUEN -. 139

\begin{tabular}{|c|c|c|c|c|c|c|c|}
\hline 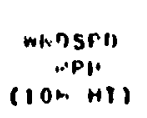 & $\begin{array}{l}P(1, E R \\
(1, / M=02)\end{array}$ & $\begin{array}{l}\text { HOilRs } \\
\text { pFugur }\end{array}$ & $\begin{array}{l}\text { RELATIVF } \\
\text { FREDOIF NICY }\end{array}$ & $\begin{array}{l}\text { CIIMULATIVE } \\
\text { MNIJUS }\end{array}$ & 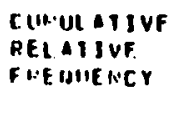 & 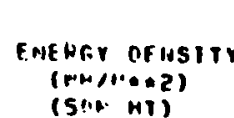 & $\begin{array}{l}\text { TOYAL } \\
\text { ENERGY NENSITY } \\
\text { (WH/MEDS) } \\
\text { (SOM NTI) }\end{array}$ \\
\hline
\end{tabular}

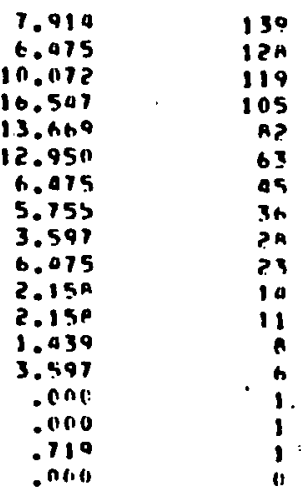

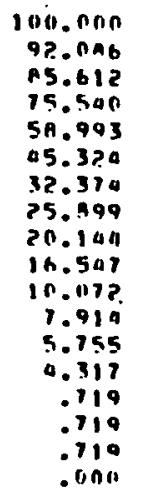

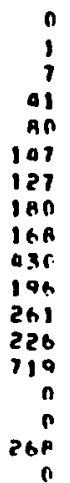

0
1
129
$12 A$
276
013
582
750
1190
11376
1638
1160
2583
2583
2583
2851
2851 


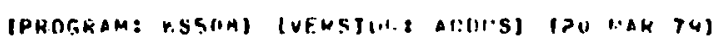

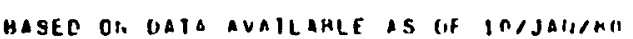
FOF IHE PERIUL; JII: .1970 TII JIII, .1074

IOIAL MLIIIHS nHSEGVEN -. S4O

\begin{tabular}{|c|c|c|c|c|}
\hline $\begin{array}{c}\text { P:ATSPI: } \\
\text { :APR } \\
\text { (IRI: HT) }\end{array}$ & (WNWEA & $\begin{array}{l}\text { HIIIISS } \\
\text { PFH:DOD }\end{array}$ & $\begin{array}{l}\text { RELATIVE } \\
\text { FPE TIIENCY }\end{array}$ & $\begin{array}{c}\text { CINAIILAYIVE } \\
\text { HUIIRS }\end{array}$ \\
\hline
\end{tabular}

achivintinenef IT:C.

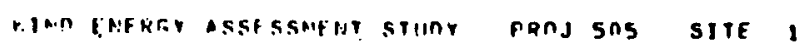

SIIF ALTITHMR. OQSOFI SITE EXPONENT: .1900

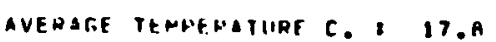

\begin{tabular}{|c|c|c|c|c|}
\hline ! & 0 & 3.4 & 7.037 & 540 \\
\hline 1 & 0 & 4,4 & 7.407 & $5 \cap 2$ \\
\hline$?$ & 1 & 29 & 3.185 & $a+2$ \\
\hline 3 & 2 & 65 & 12.031 & 43.4 \\
\hline 4 & $a$ & 54 & 10.000 & $3+9$ \\
\hline 5 & $B$ & is: & 14.074 & 315 \\
\hline a & 14 & 15 & 13.649 & 239 \\
\hline 7 & 22 & $\Delta \mathbf{b}$ & 0.519 & 164 \\
\hline M & 33 & 4.1 & 7.593 & 116 \\
\hline 9 & a) & $2 n$ & $4 . A 15$ & ו \\
\hline 10 & ha & 14 & 3.519 & 51 \\
\hline 11 & Bo & $a$ & $1.4 \mathrm{H1}$ & 32 \\
\hline 12 & 111 & a & 1.111 & 20 \\
\hline $1 \%$ & 101 & 4 & .741 & 10 \\
\hline ia & 176 & 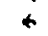 & 1.111 & 10 \\
\hline 15 & 217 & 6 & 1.111 & $B$ \\
\hline it & $2+3$ & i & .185 & 2 \\
\hline 17 & 316 & 1 & ins & i \\
\hline if & 375 & $n$ & . nino & 0 \\
\hline
\end{tabular}

RIHMIILATIIVE

PELATIVF

FWE GIIENCY
$100.0 \mathrm{in}$
92.963
B5. 556
00.370
$6 \mathrm{H.} .333$
56.333
40.259
30.370
30.01370
14.250
14.059
0.040
5.926
0.440
3.733
2.593
1.491
37
ins

EDE HEY CIEHSITY ENFRGY DENSTIY

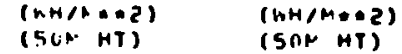

\begin{tabular}{|c|c|}
\hline 0 & 0 \\
\hline 3 & 3 \\
\hline 90 & 17 \\
\hline 113 & $13 n$ \\
\hline 222 & 352 \\
\hline . 10 & 962 \\
\hline 1001 & 2003 \\
\hline $\ln 19$ & 3017 \\
\hline 1309 & 4366 \\
\hline $121 \mathrm{~A}$ & 5583 \\
\hline 1221 & HBOA \\
\hline 604 & 7288 \\
\hline Goth & 1155 \\
\hline $5 \times 5$ & A>19 \\
\hline INSA & דוזי \\
\hline 1301 & Diora \\
\hline 263 & 11301 \\
\hline 316 & 11651 \\
\hline 0 & 11657 \\
\hline
\end{tabular}




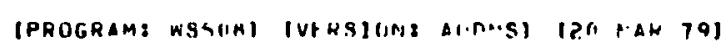

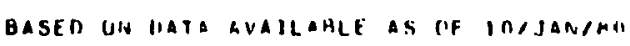

FOR INE PEKIIII: JILL ,1970 III IIIL .1970
QERIDUIRTIDART INT.

TOIAL HOIIHS OHSEHVEO -. TU4

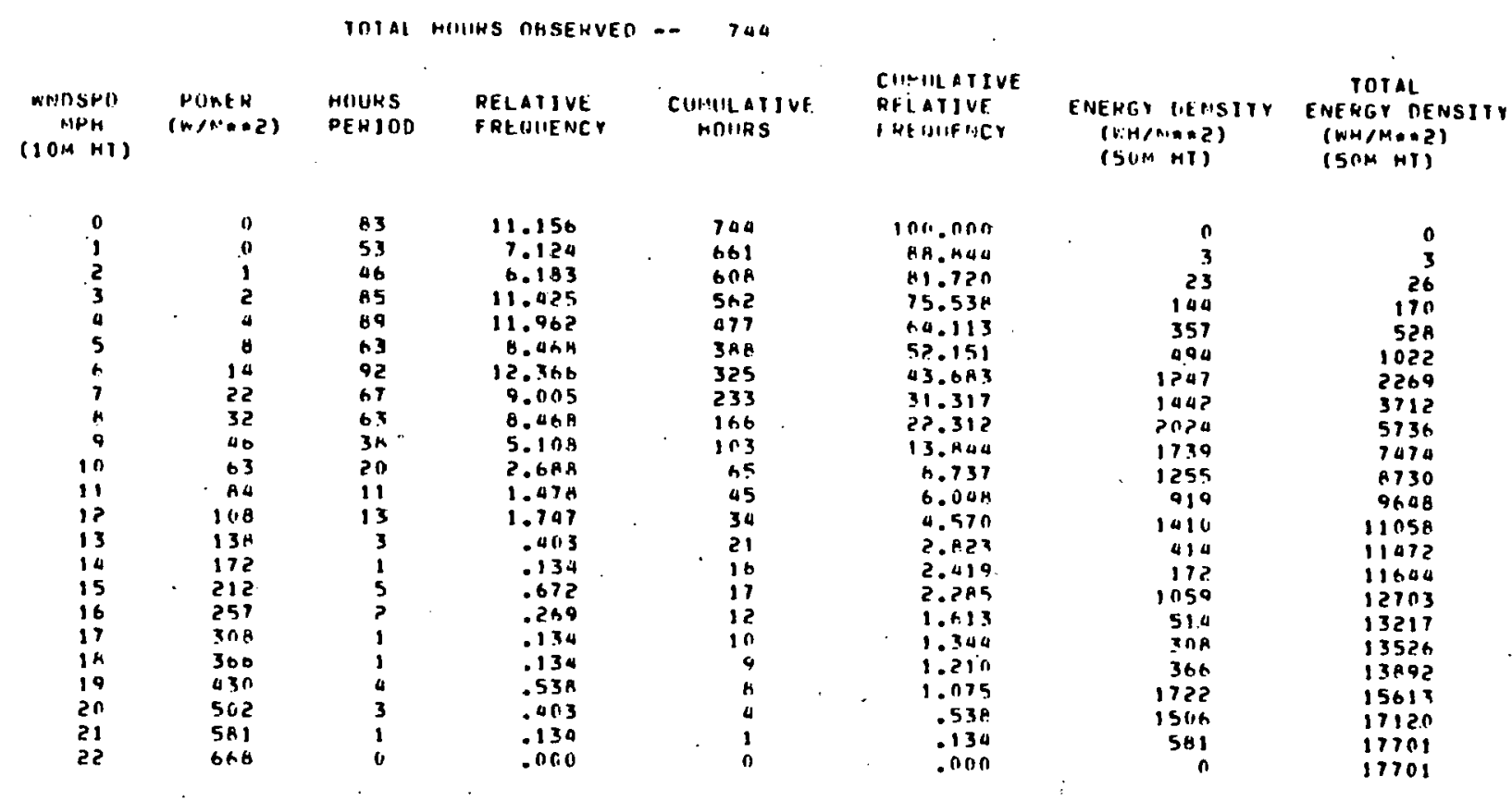

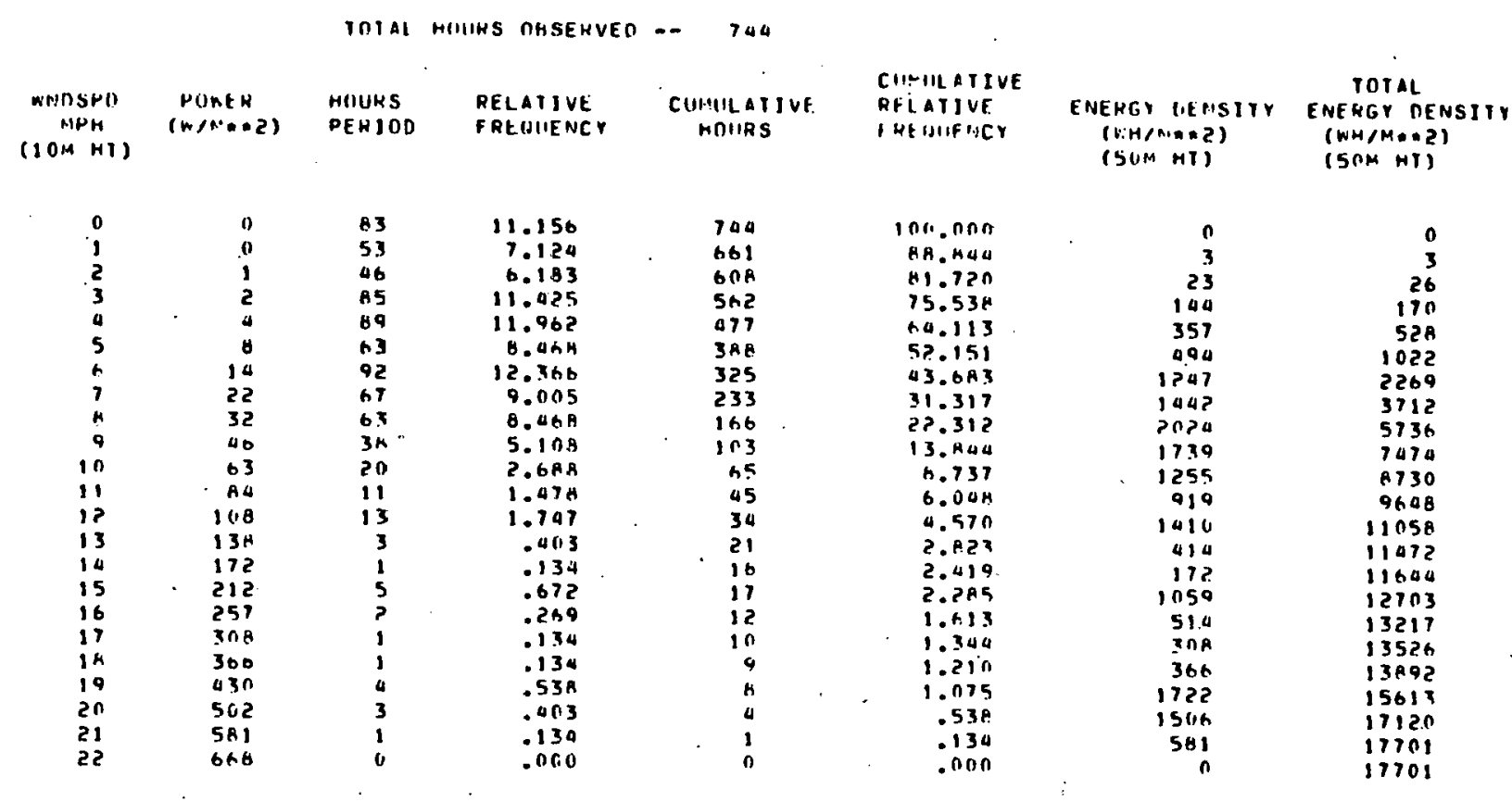

SIIE ALTIIITE: $4950 F T$ SITE EXPONENTS 1400

A.NFAGE TEAPFatura $C_{0}: 23.3$ 


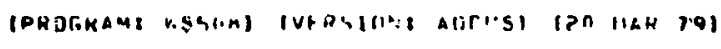

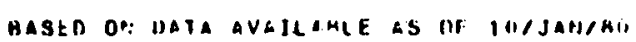

FOE THE PEAIIIO ALE, 1479 IN ALIG, 1979

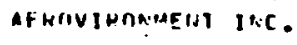

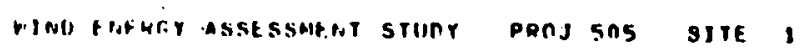

SITF ALTHUIDE: Q9SOFT SITE EXPONENTI .1000

aviparie tempfrature $C$. 22.8

TITAL HBIHS MIMSERVFD -. 744

\begin{tabular}{|c|c|c|c|c|c|c|c|}
\hline $\begin{array}{l}\text { MNIYSPR: } \\
\text { MPH } \\
\text { (I:OM NT) }\end{array}$ & $\begin{array}{l}\text { POWER } \\
(n / N \cdot A+2)\end{array}$ & $\begin{array}{l}\text { MOUKS } \\
\text { PERIDU }\end{array}$ & $\begin{array}{l}\text { RELATIVE } \\
\text { FREIIIENCY }\end{array}$ & $\begin{array}{l}\text { CIIMULAIIIVE } \\
\text { MRURS }\end{array}$ & $\begin{array}{l}\text { CHMALATIVE } \\
\text { RELATIVE } \\
\text { FRF UIIETCY }\end{array}$ & $\begin{array}{l}\text { ENEREY DENSITY } \\
\text { (WM/MOAL) } \\
\text { (SAR HT) }\end{array}$ & $\begin{array}{l}\text { TOTAL } \\
\text { ENERGY DENSITY } \\
\text { (WHAMEL) } \\
\text { (SOM HT) }\end{array}$ \\
\hline
\end{tabular}

$\begin{array}{ll}0 & 0 \\ 1 & 0 \\ 2 & 1 \\ 3 & 2 \\ 4 & 9 \\ 5 & 0 \\ 6 & 14 \\ 1 & 22 \\ 6 & 32 \\ 4 & 06 \\ 10 & 83 \\ 11 & 84 \\ 12 & 169 \\ 13 & 138 \\ 14 & 173 \\ 15 & 212 \\ 15 & 258 \\ 17 & 3129 \\ 17 & 347 \\ 19 & 431 \\ 20 & 553 \\ 21 & 562 \\ 22 & 670 \\ 23 & 725 \\ 24 & 849 \\ 25 & 983 \\ 26 & 1105 \\ \end{array}$

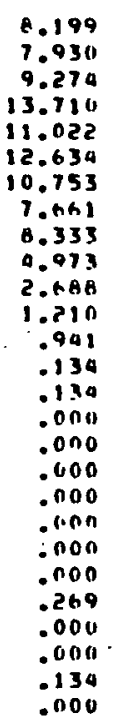

740

100.000

91. AC1

A3.A71

74.597

\begin{tabular}{|c|c|}
\hline ? & o \\
\hline 35 & 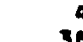 \\
\hline 173 & 212 \\
\hline 330 & saz \\
\hline 139 & 1281 \\
\hline 1087 & 2368 \\
\hline 1230 & 3597 \\
\hline 1997 & 5590 \\
\hline 1nos & 1290 \\
\hline $175 A$ & 0548 \\
\hline 753 & 9301 \\
\hline 761 & 10062 \\
\hline $13 \mathrm{~A}$ & 10200 \\
\hline 173 & $1031 ?$ \\
\hline o & 10373 \\
\hline 0 & 10373 \\
\hline 0 & 10313 \\
\hline 0 & 10373 \\
\hline 0 & 10373 \\
\hline 0 & 1037 \\
\hline 0 & 10313 \\
\hline 1339 & 11712 \\
\hline 0 & 11712 \\
\hline 0 & iivia \\
\hline 983 & 12695 \\
\hline & 12695 \\
\hline
\end{tabular}

60. BA7
$09 . A$ AS

90. Aht
37.231

$26.47 \mathrm{e}$

26.478
10.017

li.una

5.511

2.823

1.613
.672

.53

.003

.003
.003

.003

$.4 n \pi$

0.043

ans

139

.134

.0130 


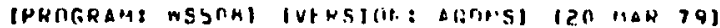

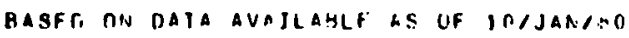

FOR IME PENIOU, StP. 1474 I11 SEP.1479
AEHOVTKMMEAFNT INC.

GeY asstssment stunt

SIIF ALIIIUIIE: 495 OFt

PNO.1 505 SITE 1

averare ithethature $C$.: 20.0

TOTAL HMUES OHSERVEA -. 656

HOLPS PEKIOU

RELATIVE

FRE OHENCY

CumULATIVE Houlks

(10: P:PH

PORER (ninas) perion
CIIMIIL ATIVE WELATIVE FRE DUENCY

ENERTY DENSTTY

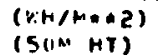

TOTAL ENERGY DENSITY (WHANAL)

100.000
89.787
79.726
69.665
56.250
41.764
24.963
16.416
6.079
9.674
2.247
1.524
.410
.305
.152
.010

0
4
34
151
387
668
1114
1223
694
789
318
508
220
100
175
0

0
30
$3 A$
189
576
1244
2358
3581
0265
5054
5372
5891
6101
6241
6015
6415

$\begin{array}{rr}1 & 0 \\ 1 & 0 \\ 2 & 1 \\ 3 & 2 \\ 4 & 4 \\ 5 & 0 \\ 5 & 14 \\ 7 & 22 \\ 8 & 33 \\ 4 & 40 \\ 111 & 64 \\ 11 & 85 \\ 12 & 110 \\ 13 & 140 \\ 14 & 175 \\ 13 & 215\end{array}$

636
589
523
457
369
27.4
190
109
53
32
15
10
4
2
1
0




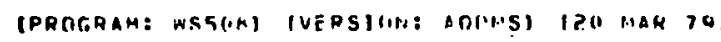

BASER ON DATA AVAJLAHLF AS IIF IOIJAI.JAI

FIR IHE PERINI) NCT .1979 VII OCT .1979 afrivingnatiat juc.

Tutal miluh OHSERVEn -- 512

\section{POV:FR} (r:IMA: 2$)$ (ION HT)
MIIIKS PFETIOS

\section{RELATIVE} r RERUEINCY COMULATIVE
MOURS
CINILATIVE GRLATIVE
FPETIEHCY

$$
\begin{array}{r}
4.102 \\
6.445 \\
5.859 \\
10.156 \\
13.477 \\
11.414 \\
13.067 \\
10.742 \\
0.590 \\
4.297 \\
2.734 \\
1.172 \\
1.367 \\
.977 \\
1.758 \\
1.754 \\
.080 \\
.145 \\
.0110 \\
.391 \\
.105 \\
.106
\end{array}
$$

512
991
458
428
376
317
246
175
120
70
54
46
34
77
37
13
4
4
33
3
1
0

$$
\begin{aligned}
& \text { iun.nnn } \\
& \begin{array}{l}
95.89 \mathrm{H} \\
89.453
\end{array} \\
& \begin{array}{l}
\text { A9. } 453 \\
0.5 .594
\end{array} \\
& 73.437 \\
& \begin{array}{l}
59.96 .1 \\
48 . n 07
\end{array} \\
& \begin{array}{l}
48.007 \\
34.1811
\end{array} \\
& \begin{array}{l}
34.1811 \\
23.437
\end{array} \\
& 14.444 \\
& 10.547 \\
& \begin{array}{l}
\text { T.t. } \\
\text { A.tal }
\end{array} \\
& \text { S. } 273 \\
& \begin{array}{r}
5.293 \\
4.297 \\
2.534
\end{array} \\
& 2.534 \\
& \text { IPI } \\
& \text {. } 5 \text { Ha } \\
& \text {. } 5 \text { HA } \\
& 095
\end{aligned}
$$

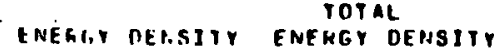
$($ III/MENC)
$(5 O H A T)$

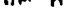

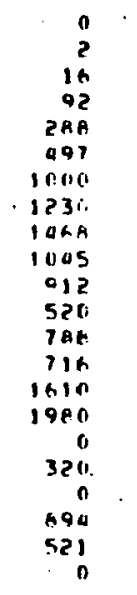

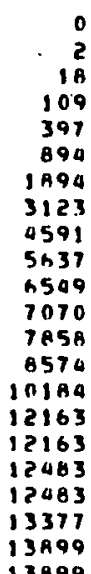


[PHORRAM: WSSHA) IVENSIIINI ARIOMSI I20 MAH 191

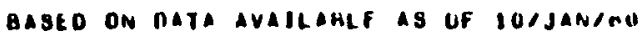

FOR IHE PERIOD NOV, 1974 IN NUV, 1974
AERIIVIKONAENT JNC.
RIIID EHFGY ASAESSMENT STHIDY

SIIE ATITUDE Q950FT

PROJ SOS BITE

SITE EXPONENT: 1400

0.9

TOTAL HUIRS OHSEAVED -- QZZ

\begin{tabular}{|c|c|}
\hline $\begin{array}{c}\text { WNOSPD } \\
\text { MPH } \\
(10 M N T)\end{array}$ & $\begin{array}{c}\text { POrEER } \\
(m / M=A 2)\end{array}$ \\
\hline 0 & 0 \\
\hline 1 & 0 \\
\hline ? & ! \\
\hline 3 & ? \\
\hline $\begin{array}{l}A \\
5\end{array}$ & $\begin{array}{l}4 \\
8\end{array}$ \\
\hline 6 & 14 \\
\hline 7 & 23 \\
\hline 8 & 34 \\
\hline 9 & 09 \\
\hline 10 & 6) \\
\hline ii & 89 \\
\hline 12 & 115 \\
\hline 13 & $1+6$ \\
\hline 14 & ins \\
\hline 15 & 225 \\
\hline 16 & 273 \\
\hline 17 & 328 \\
\hline is & 309 \\
\hline 19 & 057 \\
\hline 20 & 533 \\
\hline 21 & 617 \\
\hline 22 & 710 \\
\hline 23 & \\
\hline 24 & 922 \\
\hline 25 & 1042 \\
\hline 26 & 1172 \\
\hline 27 & 1312 \\
\hline
\end{tabular}

HOUR 8 PERI IND

RELATIVE FRE OIIENCY

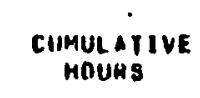

CUMIIL ATIVE

RELATIUE

FHEOUENCY

4.22

2.607

6.764

5.924
2.809

3.555

3.191

3. 1989

3.791

4.916

5.647

1.390
0.240

r. 346

5.924

5.213

6.390

3.318

3.316

1.022

.474

.160
.237

.237

.237

.1100
.237
.000

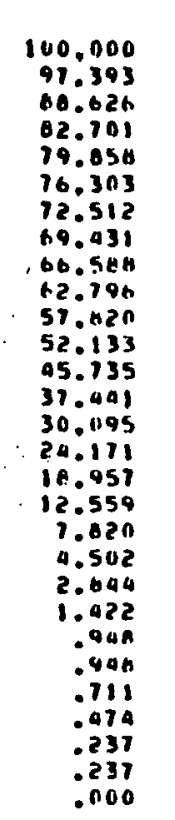

avellage tempenaturif $c$,

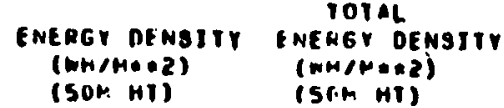

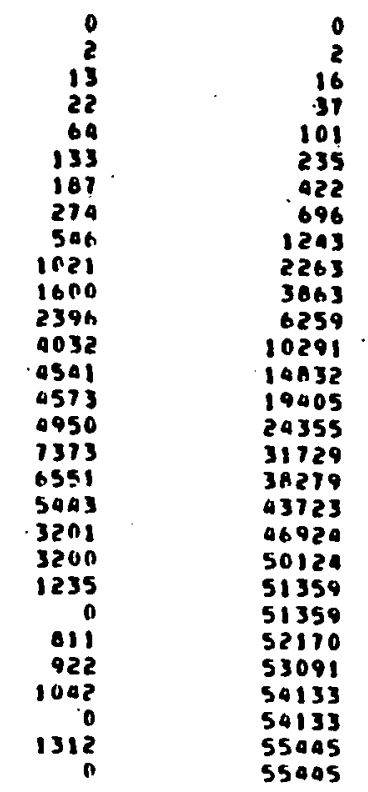




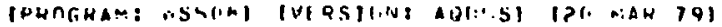

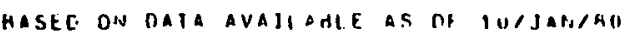

FOR THE PENIIIO JIIL . 1070 TO JIL , i470

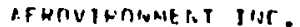

tITAL mIIIIRS naselved -. 31 a

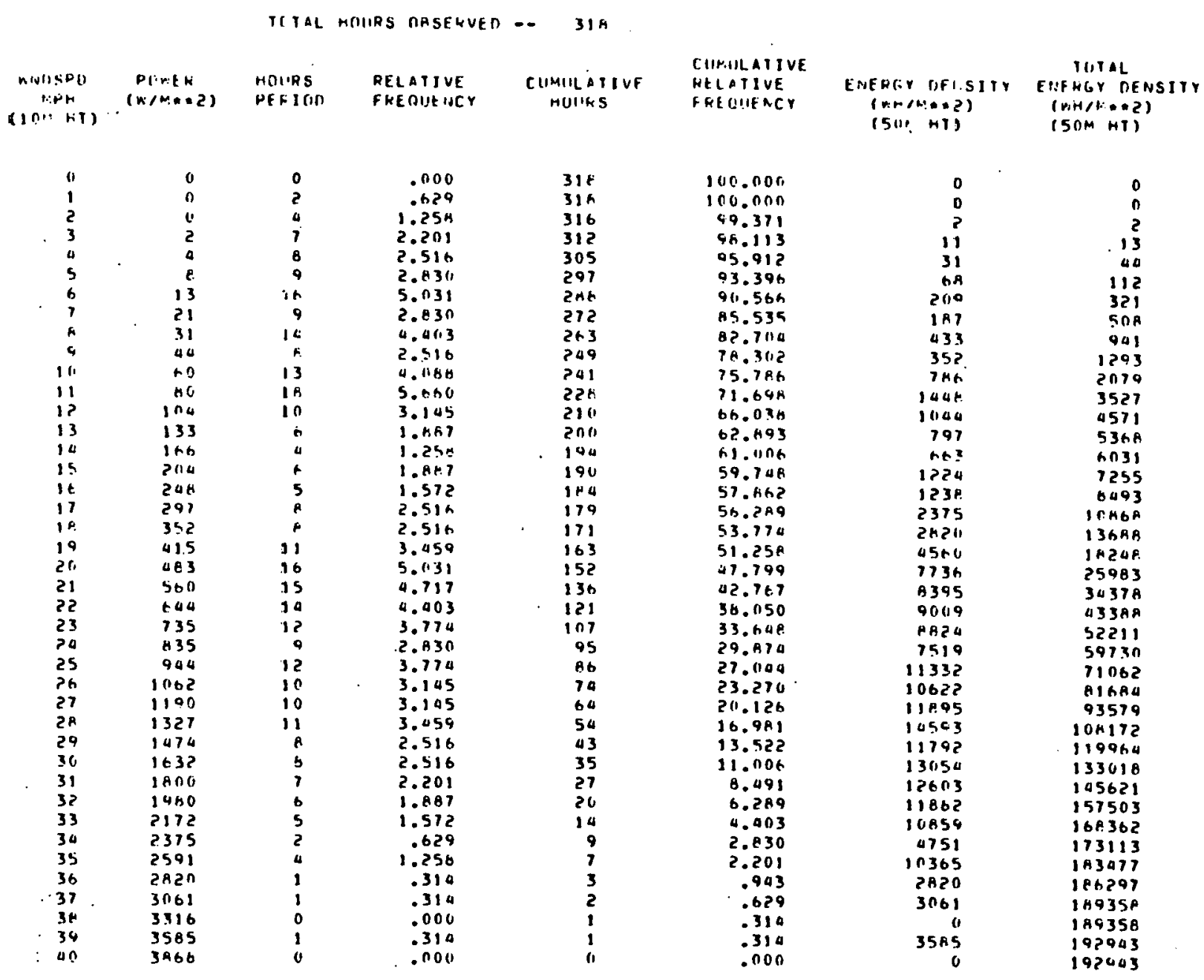

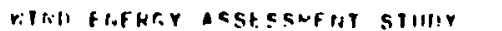

PROJ SOS SITE $?$

SITF AITITIEE: SQGTFT SITE FYPOHENT: .1000 avenabif. tenathatilat $C .:$ P3.3 


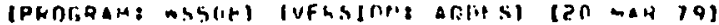

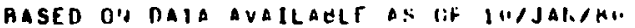

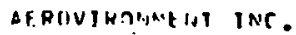

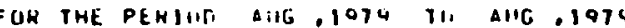

WING ENEWGY ASSESSMFLIT STURY PROJ 505 SITE

SITE ALTIIIIF: SUSTFT SITF EXPONENT: .IUOO

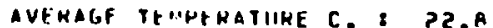

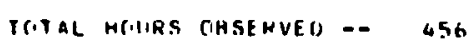

\begin{tabular}{|c|c|c|c|c|}
\hline 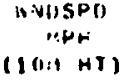 & $\begin{array}{l}\text { PrRER } \\
(\because: A: A * 2)\end{array}$ & $\begin{array}{l}\text { HIIIRS } \\
\text { PEFIODD }\end{array}$ & $\begin{array}{l}\text { RELATIVE } \\
\text { FREGUENCY }\end{array}$ & $\begin{array}{c}\text { CIIMULATIVE } \\
\text { mOUES }\end{array}$ \\
\hline
\end{tabular}

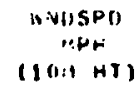

\begin{tabular}{|c|c|}
\hline 0 & 0 \\
\hline 0 & 4 \\
\hline 0 & 10 \\
\hline 2 & 13 \\
\hline 4 & 20 \\
\hline 8 & is \\
\hline 13 & io \\
\hline 21 & $y$ \\
\hline 31 & $1 \mathrm{H}$ \\
\hline 44 & is \\
\hline (b) & 17 \\
\hline AI & 23 \\
\hline 1115 & 1) \\
\hline 133 & Ph \\
\hline ith & is \\
\hline 200 & 9 \\
\hline $24 \mathrm{~A}$ & 10 \\
\hline 298 & 21 \\
\hline 353 & 17 \\
\hline 415 & is \\
\hline 485 & is \\
\hline $5+1$ & 12 \\
\hline 645 & 15 \\
\hline 137 & 37 \\
\hline 437 & 13 \\
\hline 946 & 12 \\
\hline 1005 & is \\
\hline 1102 & i? \\
\hline 1330 & ii \\
\hline 1471 & is \\
\hline $1+35$ & 8 \\
\hline 1804 & I \\
\hline $19 A 5$ & 1 \\
\hline 2177 & ; \\
\hline 23 A1 & j \\
\hline 2597 & o \\
\hline
\end{tabular}

.000
.877
2.193
2.851
4.386
3.509
0.167
1.974
3.947
3.117
3.728
3.144
4.615
5.7122
3.289
1.974
3.509
0.615
3.728
2.851
3.249
2.632
3.284
3.728
2.851
2.632
3.289
2.632
2.012
3.269
1.754
1.535
.219
.219
.219
.000

456
456
452
442
424
409
393
374
345
347
313
316
293
272
246
231
222
214
185
148
155
140
128
113
46
83
11
56
44
33
18
10
38
28
1
0

Cunulative PELATIVE
FHEIIIEMCY

$\log 000$

100.000 101.000
94.123 94.123
96.930 96.930
94.079 90.693 Bo. 194 B?. 110 Bo. 144 $16.114 n$ 73.n2h 09.298 50.250 59.640
53.047 53.947
$50.65 \mu$ $50.65 \mu$
48.680 48.680
05.175 40.570 40.570
36.042

33.991

33.991
30.712

30.7170
$2 A, 070$

24.7A1 21.053
$1 \mathrm{~A} .202$ 15.570 12.211

9.649
7.237

7.237
.3 .947

2.193

.658

.439
.219 (I.MAMEEL)
(SNA. HT)

TOTAL

ENERGY DENSITY.

(50\% HT)

\begin{tabular}{|c|c|}
\hline 0 & 0 \\
\hline$n$ & 0 \\
\hline 5 & 5 \\
\hline 21 & 26 \\
\hline 7月 & 104 \\
\hline $\begin{array}{l}121 \\
249\end{array}$ & $\begin{array}{l}225 \\
470\end{array}$ \\
\hline 187 & 661 \\
\hline $55 \%$ & 1219 \\
\hline 614 & $1 A 37$ \\
\hline 11130 & 2AB? \\
\hline 1854 & a 721 \\
\hline $219 h$ & 0919 \\
\hline 3460 & 111379 \\
\hline 2493 & 12872 \\
\hline 1840 & 19712 \\
\hline 3970 & |AGBI \\
\hline $6 ? 40$ & 24931 \\
\hline 6005 & 30936 \\
\hline 5001 & 36337 \\
\hline 1264 & 43605 \\
\hline 6731 & 50336 \\
\hline 9679 & tons1 \\
\hline 12528 & 72539 \\
\hline 1 OAFS & B3 420 \\
\hline 11351 & 94781 \\
\hline 15069 & 110750 \\
\hline $1430 t$ & 125057 \\
\hline $14 t 26$ & 139683 \\
\hline 22154 & 161841 \\
\hline 13083 & 174925 \\
\hline 12631 & 187556 \\
\hline 1985 & 189541 \\
\hline 2177 & 191717 \\
\hline 2381 & 194098 \\
\hline & 190090 \\
\hline
\end{tabular}




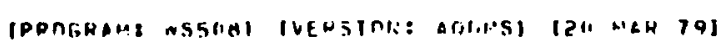

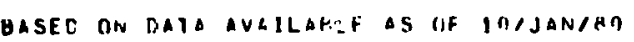

FOR IHE PEKIIII SEP, IOT4 IN SEP, 1Y74 ifulivionniafint jur.

TIIAL HOLIS LIFSEYVET, --

$58 ?$

\begin{tabular}{|c|c|c|c|c|}
\hline $\begin{array}{c}\text { NMISPC } \\
\text { NPH } \\
(10 \times N H)\end{array}$ & $\begin{array}{l}\text { PU:Nt:R } \\
\left(r, / M_{*} \neq 2\right)\end{array}$ & $\begin{array}{l}\text { HNIIRS } \\
\text { PENIO) }\end{array}$ & $\begin{array}{l}\text { RELATIVE } \\
\text { FEAUIUE INCY }\end{array}$ & $\begin{array}{l}\text { CIIMILLATIVE } \\
\text { HOUHS }\end{array}$ \\
\hline
\end{tabular}

CIIMIII ATIVE FHEQUENCY

100.000

100.000 97.079
94.330 9.561
90.506

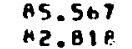
A.
15.858 . OA. 4 ORO $+3.115$ SA.67\% $52.116 ?$ 46.967 40.376
35.739 85.736
$31.7 \mathrm{~A}$ 19.137
$57.10 A$ 22.337

$19.5 \mathrm{HP}$

17.010

14.1149
12.027

12.027
10.053

10.591
10.801

6.701

5.326
3.7911

2. 905

1.490

1.546
.059

.859
.344
.172

112
.0110
POA.J 505 SITE?

SIIF ALTIUIIE: \$95\%

SITE FXPONENT: .1400 


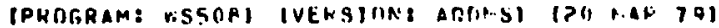

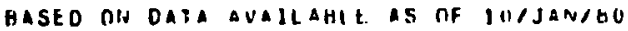

FOR THE PERJIO UCT .1979 IN OCT, 1979

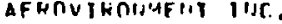

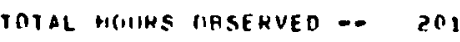

\begin{tabular}{|c|c|}
\hline WIUASPD & $\begin{array}{l}\text { POWER } \\
(\text { (V./MAZ) }\end{array}$ \\
\hline & \\
\hline 6 & 0 \\
\hline 1 & 0 \\
\hline 2 & 1 \\
\hline 3 & $i$ \\
\hline 4 & 4 \\
\hline 5 & 8 \\
\hline 6 & 10 \\
\hline 7 & 22 \\
\hline A & 32 \\
\hline 9 & 40 \\
\hline 10 & 63 \\
\hline is & 84 \\
\hline 12 & 109 \\
\hline 13 & 136 \\
\hline 14 & 172 \\
\hline 15 & 212 \\
\hline if & 257 \\
\hline 17 & 3 no \\
\hline is & 367 \\
\hline 19 & 431 \\
\hline 20 & $3 \mathrm{n}^{3}$ \\
\hline 21 & SBZ \\
\hline 22 & 649 \\
\hline 23 & 765 \\
\hline 20 & HoO \\
\hline 25 & QA? \\
\hline 24 & 1105 \\
\hline 37 & 1237 \\
\hline $2 k$ & 1380 \\
\hline P० & 1533 \\
\hline 36 & 1697 \\
\hline 31 & 1872 \\
\hline 32 & 2060 \\
\hline 33 & 2259 \\
\hline 34 & 2470 \\
\hline 35 & \\
\hline 36 & 2932 \\
\hline 37 & 3184 \\
\hline 38 & 3449 \\
\hline 39 & 3728 \\
\hline 40 & 4023 \\
\hline 01 & 4332 \\
\hline 42 & 4657 \\
\hline 43 & 4997 \\
\hline
\end{tabular}

V:THE RNEKG ASSFSSHENT STHIIY PHOJ SOS SITE

SITF AllTHE: SOBPT SITE TXPDNENT: 1900

AVERAGF tFMPERATIIEF, C.: 19.0

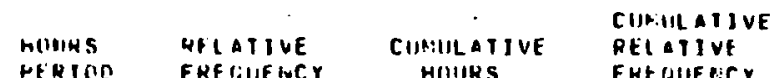
FRE IIJE IOC Y HOIIKS

FHE IUER:C

EINERGY IIERSITY EITE (WM/MAC?) (SOI: HT)

TOTAL

B.ERG OFNSJTY

$\left(\begin{array}{ll}(K H) M+R T) \\ (50+H T)\end{array}\right.$

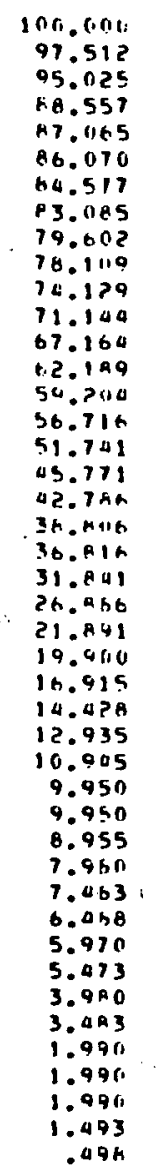

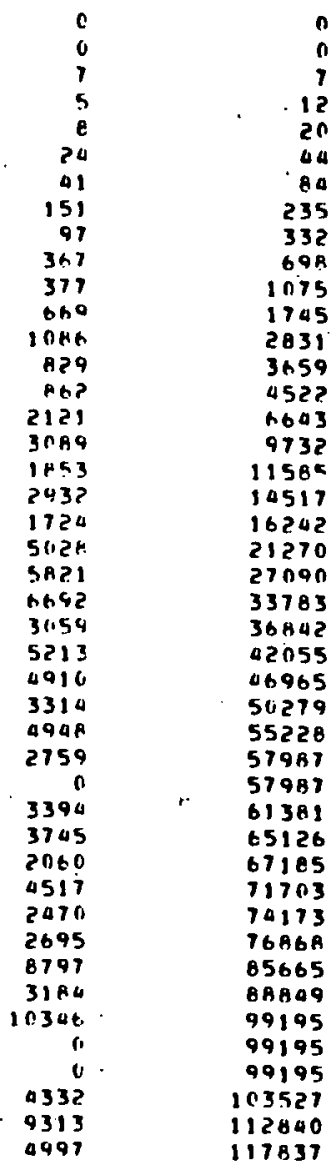


$00 \quad 5854 \quad .010$

o

.nno

(

[17ค37

$\stackrel{i}{\tilde{\omega}}$ 


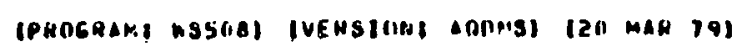

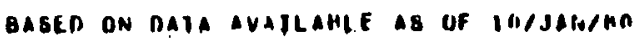

FOR IHE PEHJUD wOV ,1979 IO NOV , 1970
AF HOVIRDNMENT INC.

TOTAL MAURS ORgERVEO --

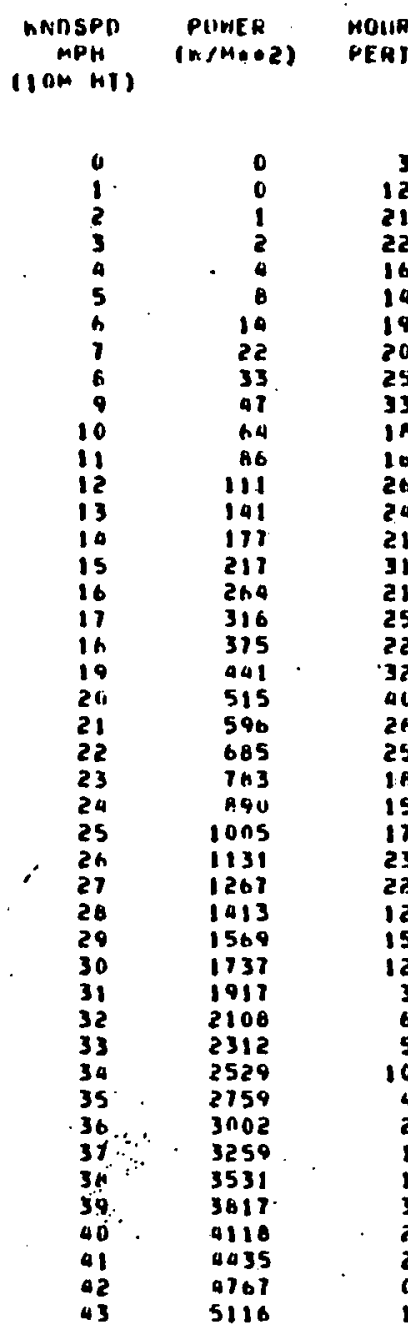
RELAIIVE
FHEDUENCY

CIIMILLATIVE HoUns

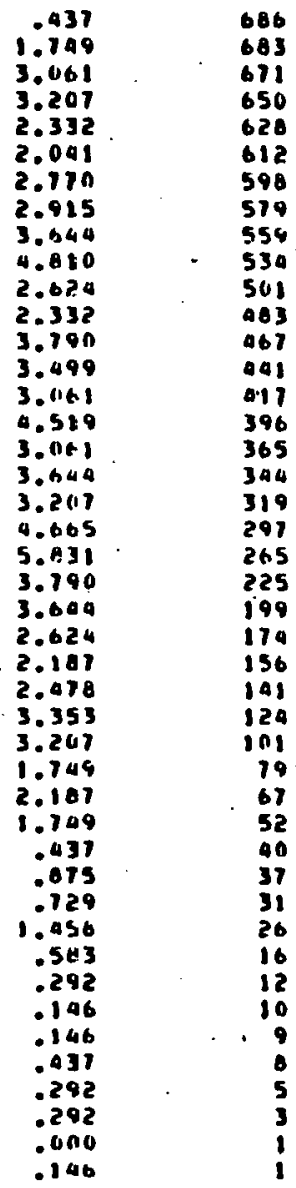

Climillative REL IIVE

$$
\text { Feouen }
$$

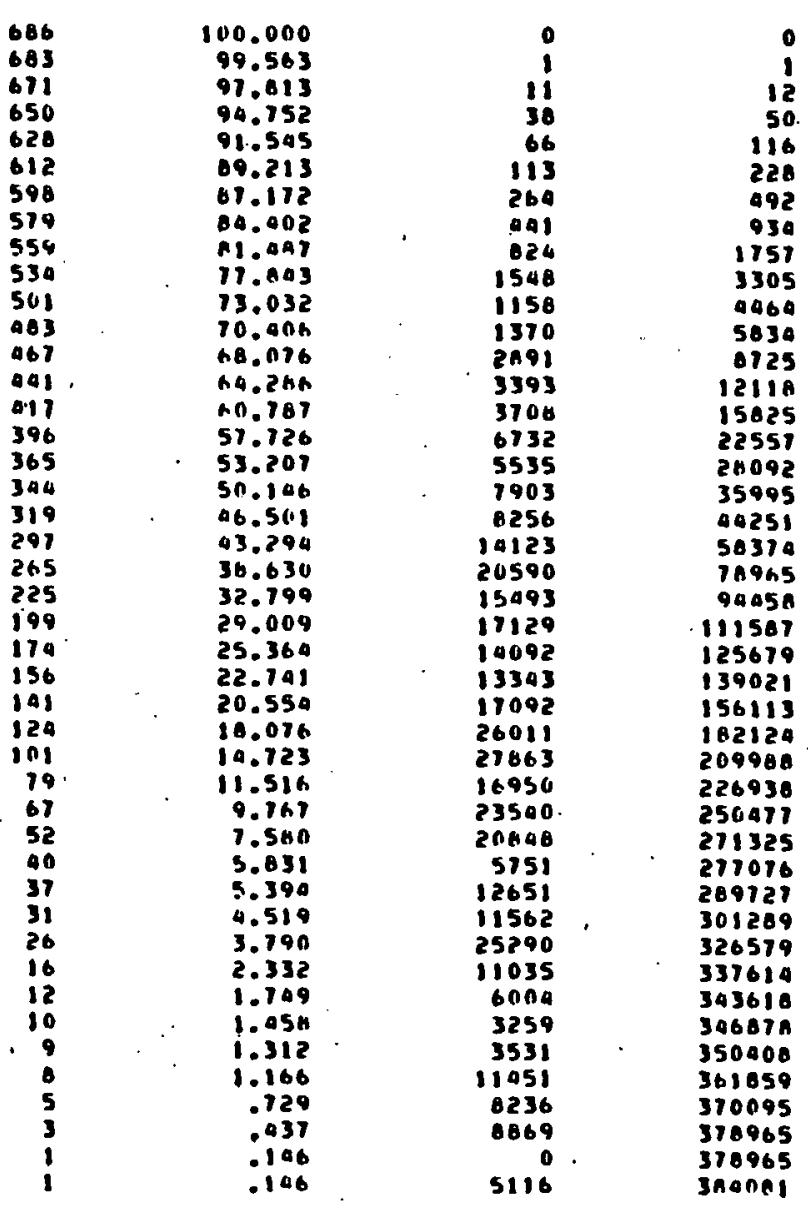

InTAL

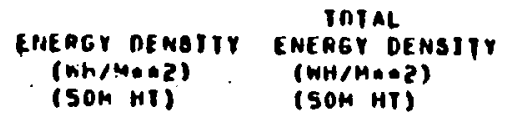

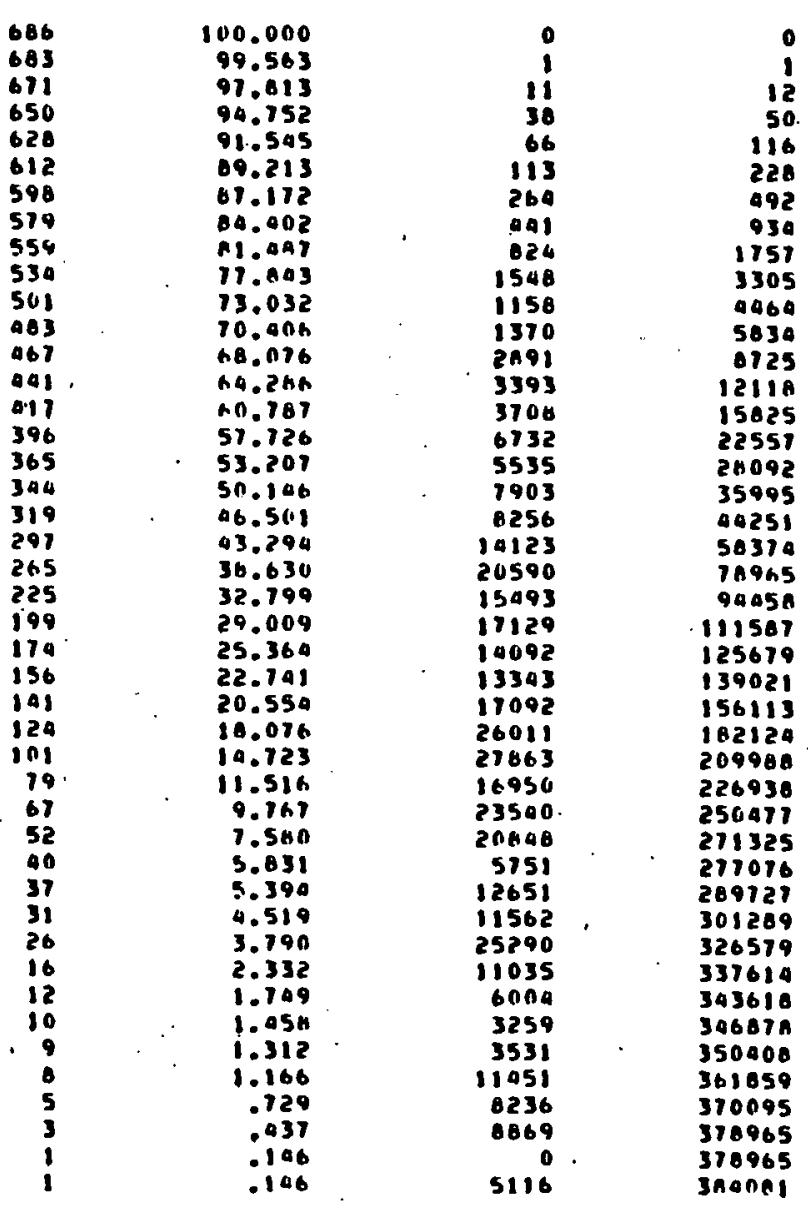

SITE ALTIHINES S95TFT

PHOJ 5ng BITE 2

avenage igmperatuRe $C$. 1.9 


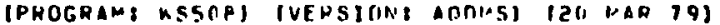

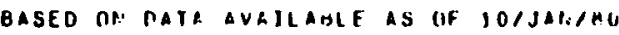

AERTVIROAHFAT INC.

FOR THE PEKIOI MAY 1974 in maY 1470

\section{- jhip pheper assissmant stumer \\ PROJ SOS SITE \\ suit Al Tlllits sesofi \\ SITE IXPONFAT: . 1000 \\ AUFAAGE TEMFFPATHEF $C .813 .3$}

TOTAL HOINS OHSERVED -. 27

\begin{tabular}{|c|c|c|c|c|c|c|c|c|}
\hline $\begin{array}{l}\text { AANSPPO } \\
\text { MPH } \\
(10 N M I)\end{array}$ & 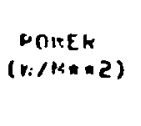 & $\begin{array}{l}\text { HUIIRS } \\
\text { PERION }\end{array}$ & 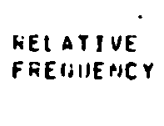 & $\begin{array}{l}\text { CUMILLAIIVE } \\
\text { MOLIRS }\end{array}$ & $\begin{array}{l}\text { CINIII ATIVE } \\
\text { HELATIVF } \\
\text { FHE TIUE INCY }\end{array}$ & $\begin{array}{l}\text { ENERSY. WF HSITY } \\
\text { (KH/MAOP) } \\
\text { (SOH HI) }\end{array}$ & $\begin{array}{c}\text { TOTAL } \\
\text { ENEHTYY OENSIT } \\
\text { (WH/M.OZ) } \\
\text { (SOH: HT) }\end{array}$ & \\
\hline$n$ & $n$ & 3 & 11.111 & ? & 100.1000 & $n$ & 0 & \\
\hline 1 & 0 & 2 & 7.407 & 24 & AK.AAQ & $n$ & 0 & \\
\hline . 2 & 1 & " & .000 & 22 & A1. $4 \mathrm{HI}$ & 0 & 0 & \\
\hline 3 & 2 & $:$ & 22.222 & 22 & $61.4 \mathrm{Al}$ & 10 & 10 & \\
\hline 4 & 4 & 1 & 3.704 & 16 & 59.759 & 4 & 14 & \\
\hline 5 & A & 3 & 11.111 & 15 & $55.55 t$ & 20 & $3 A$ & \\
\hline 6 & 14 & 3 & 11.111 & 12 & 44.444 & 41 & 19 & . \\
\hline 7 & 22 & 1 & 3.704 & 9 & 33.333 & ?? & 101 & \\
\hline A & 32 & 2 & 7.007 & A & $29 .+38$ & 65 & 106 & \\
\hline 9 & 46 & 1 & 3.704 & $\circ$ & ??.ร?? & 46 & ? $1 ?$ & \\
\hline 11 & 63 & 2 & $7.41 ; 7$ & 5 & $1 \mathrm{n} .519$ & 127 & 339 & \\
\hline 11 & Ba & $\begin{array}{l}1 \\
0\end{array}$ & 3.7614 & 3 & 11.111 & HA & 023 & \\
\hline 12 & 1110 & 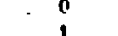 & $\therefore \ln 20$ & 5 & 7.407 & 0 & 423 & \\
\hline 13 & $\begin{array}{l}139 \\
174\end{array}$ & 1 & 3.7114 & ? & 7.4117 & 134 & 563 & \\
\hline 14 & 174 & 0 & - now & 1 & 3.7610 & $n$ & 563 & \\
\hline 15 & 214 & 0 & .000 & 1 & 3.700 & $n$ & 563 & \\
\hline 16 & 2no & $n$ & .0100 & 1 & 3.7114 & 0 & 563 & \\
\hline 11 & 311. & o & .0110 & 1 & 3.7114 & 0 & 563 & \\
\hline $1 A$ & $37 ! !$ & " & - noro & 1 & 3.7110 & $n$ & 563 & \\
\hline 16 & 435 & 1 & 3.704 & 1 & 3.71 .0 & 435 & 997 & \\
\hline 20 & 507 & 0 & .000 & $n$ & . & 0 & 997 & \\
\hline
\end{tabular}




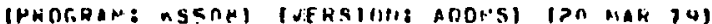

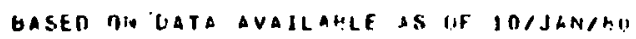

FOH THE PERIOI: JUL, 197 T 16 JIIL , 1479

TOIAL MIIIKS OHSERVED -. ISH

\begin{tabular}{|c|c|}
\hline RAUSPI & $\begin{array}{c}P(\text { InER } \\
(W / \text { Hin*2) }\end{array}$ \\
\hline
\end{tabular}

HOUKS PEAIOU

- RELATIVE FHEOUENCY

CUMIII.ATIUE

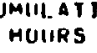

CIMBILATIVE PELATIVE
FECINECT

\begin{tabular}{|c|c|}
\hline 0 & 0 \\
\hline I. & 0 \\
\hline 2 & 0 \\
\hline$\geq$ & 2 \\
\hline 4 & 4 \\
\hline 5 & 8 \\
\hline$E$ & 13 \\
\hline$i$ & 1 \\
\hline F & 31 \\
\hline 9 & 44 \\
\hline 16 & 6) \\
\hline$i:$ & Ai \\
\hline 12 & $\ln 5$ \\
\hline 13 & 133 \\
\hline 10 & 167 \\
\hline 15 & 205 \\
\hline in & 249 \\
\hline 11 & 290 \\
\hline $1 \mathrm{~h}$ & 354 \\
\hline 17 & 416 \\
\hline
\end{tabular}

3.797
0.329
3.165
12.025
8.661
7.595
9.494
5.063
6.224
6.324
6.224
6.326
3.791
3.165
2.332
.633
1.499
1.266
1.266
.060

\begin{tabular}{|c|c|}
\hline 158 & ח tur. \\
\hline 152 & 96.2113 \\
\hline 142 & 49.073 \\
\hline 137 & 86.769 \\
\hline 118 & 74.684 \\
\hline 164 & 65.823 \\
\hline 92 & SH.22A \\
\hline 77 & AE.734 \\
\hline 69 & $43 . n 71$ \\
\hline 50 & 35.443 \\
\hline$\Delta 6$ & 29.114 \\
\hline 33 & P0.Bng \\
\hline 23 & 10.557 \\
\hline 17 & 10.750 \\
\hline 12 & 1.505 \\
\hline 0 & $5.0 \times 3$ \\
\hline 7 & $4.43 r$ \\
\hline 4 & $2.53 ?$ \\
\hline 2 & $1.2 \mathrm{HH}$ \\
\hline 0 & .000 \\
\hline
\end{tabular}

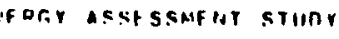

SIIT ALTITUIEE: SASOFI

aVEWAGE TEMPFGaTURE $C$.
PUNJ 5 S SITE 3

SITE EXFOANENT: . 1400

23.3 


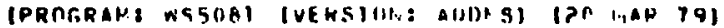

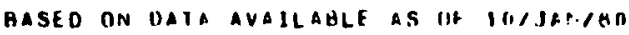

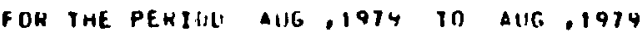

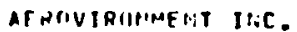

TOTAL HIUHS OHSERVEO -- 744

\begin{tabular}{|c|c|}
\hline $\begin{array}{c}\text { WNOSPO } \\
\text { :APR } \\
(10 \% \mathrm{HY})\end{array}$ & $\begin{array}{l}\text { PIMER } \\
(m / M * 12)\end{array}$ \\
\hline 0 & 0 \\
\hline 1 & 0 \\
\hline ? & 0 \\
\hline 3 & 2 \\
\hline 4 & 4 \\
\hline 5 & A \\
\hline 6 & 13 \\
\hline 7 & ? 1 \\
\hline H & 31 \\
\hline 4 & 44 \\
\hline $1 n$ & hI \\
\hline 11 & (i) \\
\hline 12 & 105 \\
\hline 13 & 134 \\
\hline 14 & 167 \\
\hline 15 & $2 n s$ \\
\hline it & 240 \\
\hline 17 & 294 \\
\hline if. & 355 \\
\hline 19 & 417 \\
\hline
\end{tabular}

RELATIVE FHEGUEHC
CURILLAJUE RELATIVE
FHE OIIENCY nouks

$$
\begin{array}{r}
.003 \\
2.205 \\
2.704 \\
6.455 \\
8.333 \\
11.554 \\
19.651 \\
11.426 \\
9.677 \\
8.333 \\
6.452 \\
5.511 \\
3.360 \\
2.265 \\
1.478 \\
1.075 \\
.403 \\
.463 \\
.463 \\
.060
\end{array}
$$

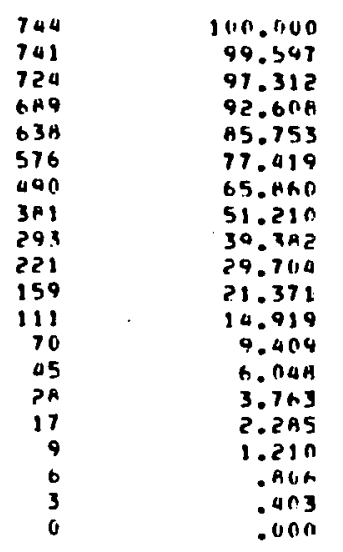

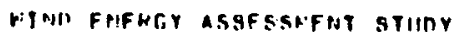

SITE ALTIIHII: SASOFT

PRIIJ 5N5 SITE

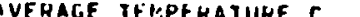

SITE EXPONENT: 1400

23.8
ENERG LIENSITY ENEGTS DERSITY (WHABADS
(SOH: HT)

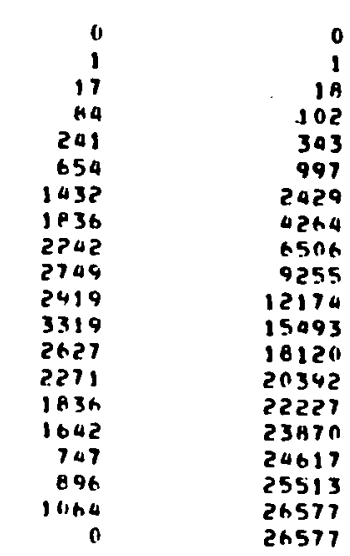




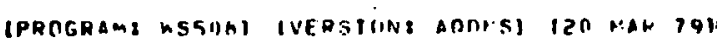

Based oiv Data avallahle as ni liljariara

FOR IHE PERIIII SEP ,1970 JO SEH .1970 m.rovironment jac.

TUTAL moliHS Baserved -.
I IAN FNEHGY ASSE SSMFUT STHNIV

SITE ALTIJURE: SASOFT

PRIJ SIS S.ITE 3

SITE EXPONENT: .1400

avfaAge tempfaAtLRE $C$. 20.0

\begin{tabular}{|c|c|c|c|c|}
\hline 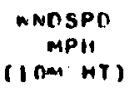 & $\begin{array}{l}P(1, N F A \\
(r, / M A D\end{array}$ & $\begin{array}{l}\text { HOLUHS } \\
\text { PERIOG }\end{array}$ & $\begin{array}{l}\text { RELATIVE } \\
\text { FKE IJIENCY }\end{array}$ & $\begin{array}{l}\text { CIUMHLL DT } \\
\text { H(IiNS }\end{array}$ \\
\hline 0 & $n$ & 20 & 2.147 & 715 \\
\hline .1 & 0 & $3 n$ & 5.315 & 645 \\
\hline 2 & n & 39 & 5.455 & .57 \\
\hline 3 & 2 & 57 & $7.97 ?$ & bin \\
\hline$a$ & 4 & 56 & 7.032 & 561 \\
\hline 5 & A & 60 & B. 392 & 505 \\
\hline 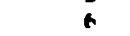 & 13 & 56 & 7.032 & 045 \\
\hline 7 & 21 & 63 & B.A11 & 389 \\
\hline A & 32 & 49 & 6.A53 & 326 \\
\hline 9 & 45 & 43 & 6.014 & 271 \\
\hline 10 & 62 & 44 & 6.154 & 230 \\
\hline i1 & 82 & 20 & ?.797 & 190 \\
\hline 12 & 100 & 31 & 0.336 & $i 70$ \\
\hline 13 & 135 & 20 & 2.747 & 139 \\
\hline 10 & 169 & 32 & $4.47 \mathrm{~h}$ & 119 \\
\hline 15 & 2116 & 21 & 2.937 & (17 \\
\hline 16 & 252 & 17 & $2.37 \mathrm{~h}$ & ba \\
\hline 17 & $3 n 3$ & 7 & .979 & 49 \\
\hline in & 354. & In & 1.394 & 42 \\
\hline 19 & 422 & 4 & .550 & 32 \\
\hline 20 & 493 & 3 & .020 & 26 \\
\hline 21 & 576 & $B$ & 1.114 & 25 \\
\hline 22 & 656 & 4 & .559 & 11 \\
\hline 23 & 744 & 1 & .140 & 13 \\
\hline 24. & A51 & i & 100 & 12 \\
\hline 25 & $9+2$ & $?$ & $.2 \times n$ & 11 \\
\hline 2t. & 1082 & 0 & .000 & 9 \\
\hline 27 & 1212 & 1 & .1911 & 9 \\
\hline $2 r$ & 1352 & n & . rino & p \\
\hline 29 & is0? & i & . noo & p \\
\hline 30 & 1663 & 2 & . 2A0 & $\theta$ \\
\hline 31 & 1034 & $i$ & .100 & 6 \\
\hline 32 & 2018 & $i$ & .100 & 5 \\
\hline 33 & 2213 & 0 & OONO & $a$ \\
\hline 30 & 2420 & j & .140 & 4 \\
\hline 35 & 2640 & 2 & .280 & 3 \\
\hline 36 & 2873 & 0 & .600 & $i$ \\
\hline$=37$ & 3119 & j & .140 & $i$ \\
\hline $36^{\circ}$ & 3379 & 0 & . non & 0 \\
\hline
\end{tabular}

CIIMULATIVE PELATIVF FREBITENCY

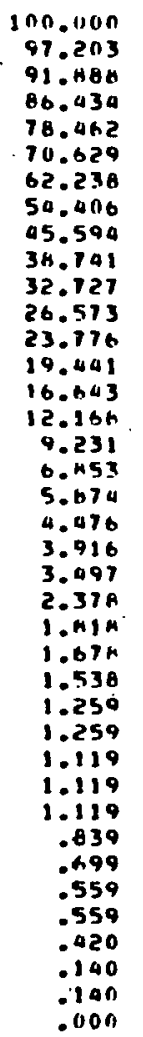

ENEAGT DENSITY ENERGY DENSITY

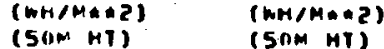

\begin{tabular}{|c|c|}
\hline 0 & n \\
\hline 2 & 2 \\
\hline 14 & 22 \\
\hline 95 & 116 \\
\hline 221 & 337 \\
\hline 462 & 199 \\
\hline 705 & 1500 \\
\hline 1331 & 2670 \\
\hline 1505 & 0419 \\
\hline 1930 & 6399 \\
\hline 2700 & 9059 \\
\hline 1639 & $1069 \mathrm{~A}$ \\
\hline 3299 & 13996 \\
\hline 2706 & 16702 \\
\hline Sani & 22109 \\
\hline 0364 & 26073 \\
\hline D2BB & 30761 \\
\hline 2118 & 32A19 \\
\hline 3542 & sharn \\
\hline 1689 & 38150 \\
\hline $107 \mathrm{~A}$ & 39631 \\
\hline 0.562 & 90190 \\
\hline $2+23$ & 06A22 \\
\hline 749 & 07571 \\
\hline A51 & 00422 \\
\hline $192 \mathrm{a}$ & 50306 \\
\hline & 50306 \\
\hline 1212 & 51559 \\
\hline & 51559 \\
\hline & 51559 \\
\hline 3325 & SARAQ \\
\hline 1834 & 56718 \\
\hline 2018 & $5 A 736$ \\
\hline & 58736 \\
\hline 2420 & 61156 \\
\hline 5280 & 66436 \\
\hline & 66036 \\
\hline 3119 & 69555 \\
\hline 0 & 69555 \\
\hline
\end{tabular}


(PAOGRAM: MSSOE) (VEFSIOH: AORMS) (20 MEH TO)

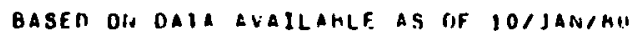

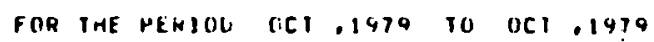

AFRIVIPRAMANT INC.

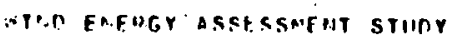

SIIE ALIITHE: SASOFI

PUII. SRS SITE 3

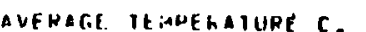

SITE EXPINENT: .1400

4.4

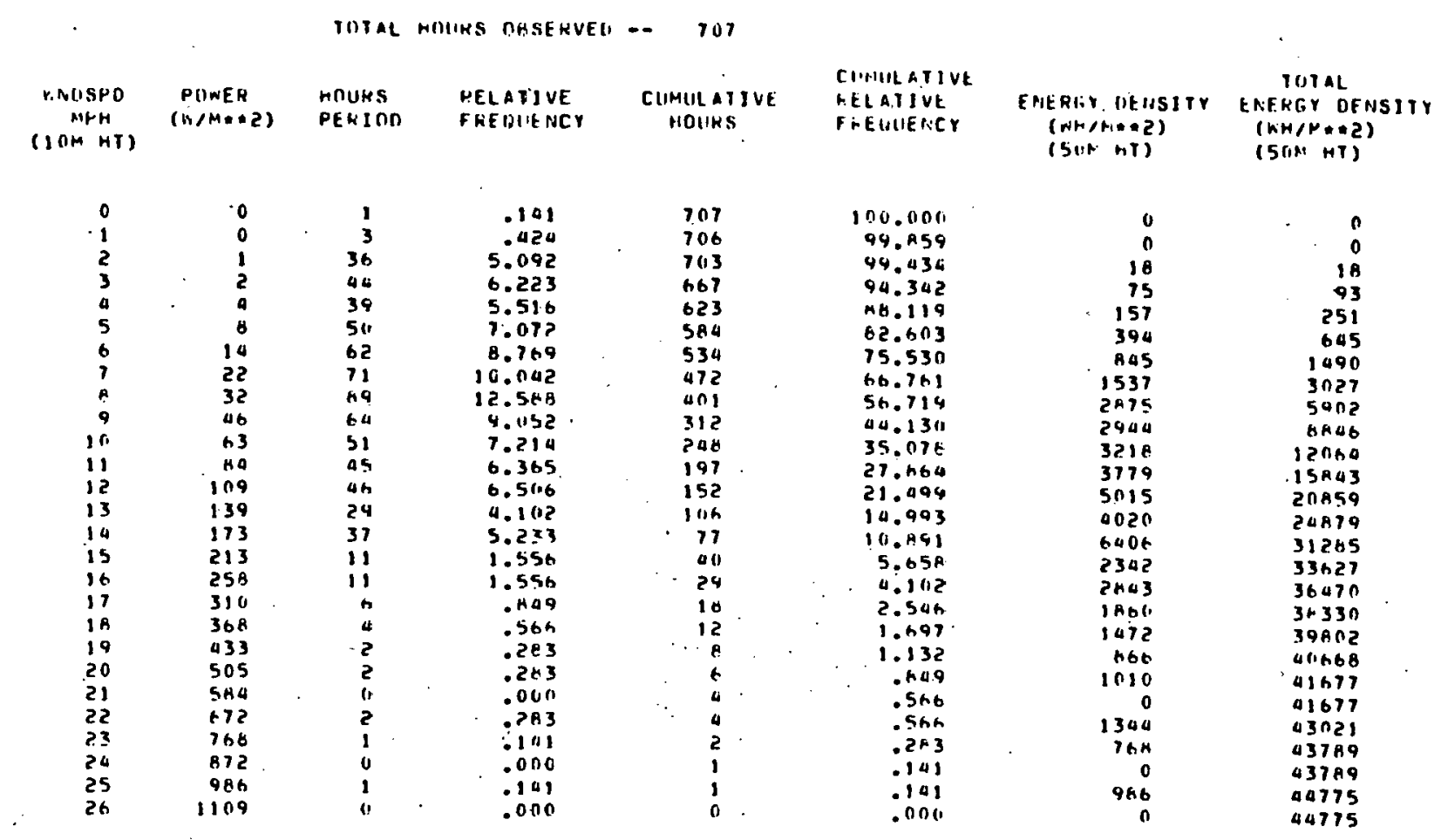




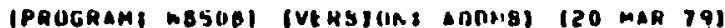

baged on daIa avallagle as of lojJanjod

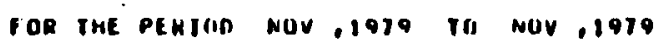

AFARVIRTMNERT JNC.

TOTAL HOHGS OABEAVEO - 662
WJ'NI ENFHEY ASSFSSMENT STUOY

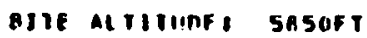

PHOJ SOS GTE,

Avenage ietPeratuge $c$.

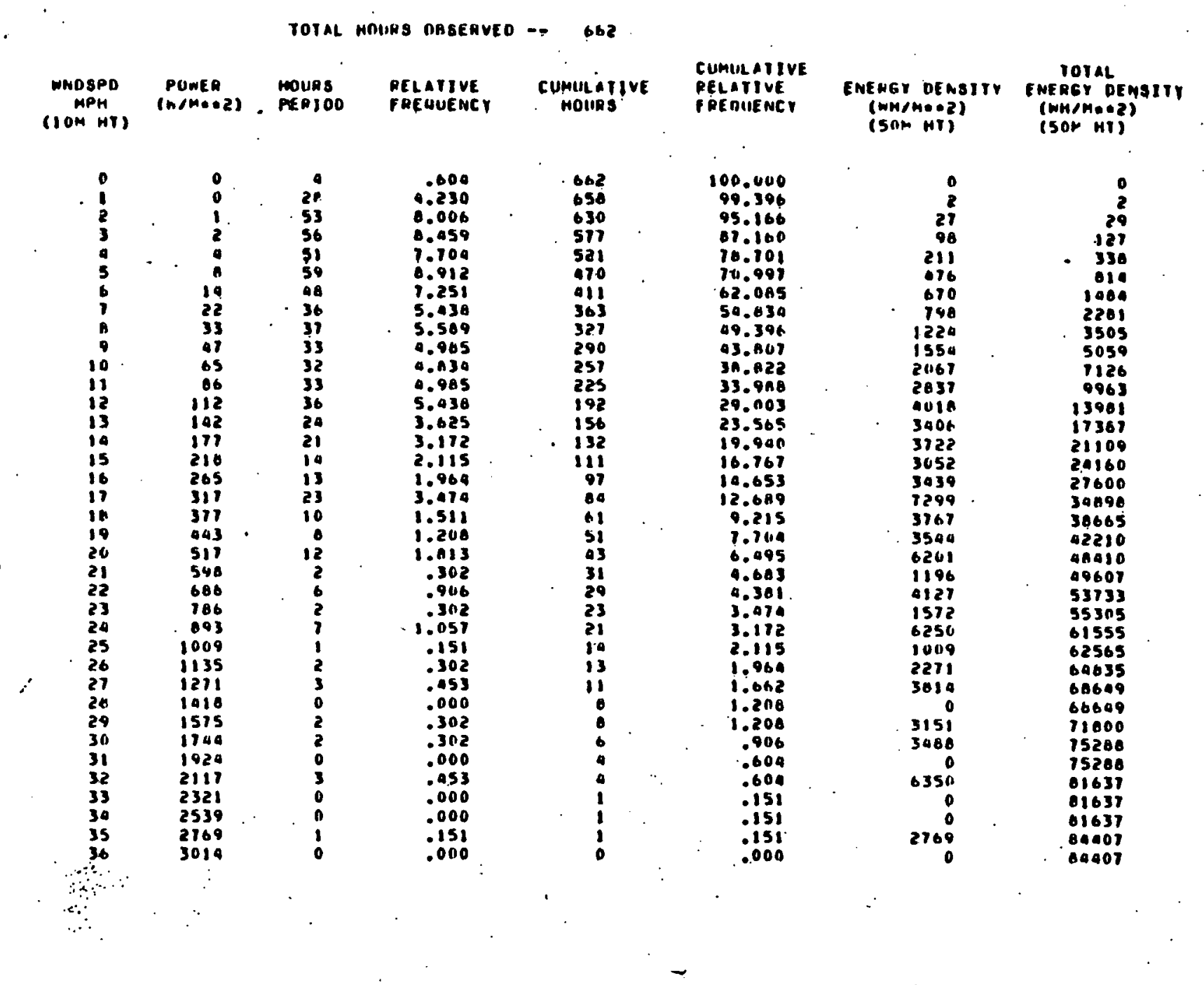




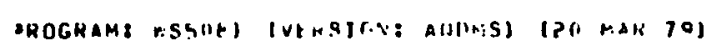
ISED ON OATA AVALAHLE AS UF IIJJAIMGI

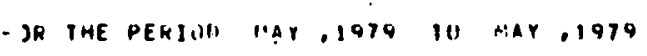

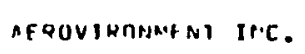

TOTAL HOIIKS OHSERVED -. 714

\begin{tabular}{|c|c|}
\hline${ }_{M P H}$ & $\begin{array}{l}\text { PNINER } \\
\text { (1:/AMA }\end{array}$ \\
\hline$(1$ ON. HT $)$ & \\
\hline 0 & 0 \\
\hline 1 & 0 \\
\hline 2 & 1 \\
\hline 3 & 2 \\
\hline a & 4 \\
\hline 5 & A \\
\hline 6 & 14 \\
\hline 7 & 23 \\
\hline i & 34 \\
\hline ö & $\Delta A$ \\
\hline 10 & 66 \\
\hline 11 & AO \\
\hline 12 & 115 \\
\hline 13 & ian \\
\hline 10 & 182 \\
\hline 15 & 220 \\
\hline in & 272 \\
\hline 17 & 326 \\
\hline is & 367 \\
\hline 10 & 455 \\
\hline ?o & 5311 \\
\hline 21 & 6) 4 \\
\hline 22 & 9106 \\
\hline
\end{tabular}

HUINS

RELATIVE FHE QUENCY

CUAMLATINE HOURS RELATIVF
FREUIENCY

ENERTYY OENSITY

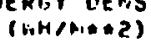

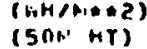

TOTAL

ENERGY DENSIT(SOMM HI)

\begin{tabular}{|c|c|c|c|c|}
\hline 1.961 & 714 & 100.000 & 0 & 0 \\
\hline 4.342 & 700 & 98.039 & 2 & 2 \\
\hline 1.143 & 669 & 93.697 & 27 & 29 \\
\hline 1.204 & bIA & 86.555 & 14.3 & iie \\
\hline 2.325 & 530 & 75.350 & 373 & 546 \\
\hline 4.566 & 450 & 63.025 & B62 & 1008 \\
\hline 3.025 & 346 & Qn. 450 & 1332 & 2740 \\
\hline 7.003 & 253 & 35.434 & 1137 & 3 З \\
\hline 5.462 & 203 & $2 n .431$ & 1324 & 5201 \\
\hline 3.641 & ind & 22.960 & 1257 & ba51 \\
\hline 3.221 & 134 & 19.328 & is25 & $79 A 2$ \\
\hline 1.ABI & 115 & 10.1106 & 1059 & 9041 \\
\hline 4.622 & 103 & 14.426 & 37A1 & 12822 \\
\hline 2.6011 & 70 & Q.enE & 2013 & $1573 \mathrm{~A}$ \\
\hline $3 . n 81$ & 50 & 7.003 & 4003 & 19738 \\
\hline 1.261 & $2 \theta$ & 3.972 & 2010 & 21752 \\
\hline $1.0 n i$ & 19 & $? .661$ & $271 n$ & $2040 A$ \\
\hline $.2 \mathrm{NO}$ & 9 & $1.2+1$ & +52 & 25120 \\
\hline .280 & 7 & .780 & 773 & 25893 \\
\hline .280 & 5 & .700 & 910 & 26003 \\
\hline .140 & 3 & .420 & $53 n$ & 27333 \\
\hline .280 & 2 & $.2 \mathrm{HO}$ & $122 \mathrm{~A}$ & 28561 \\
\hline .0110 & $n$ & noo & & 30501 \\
\hline
\end{tabular}




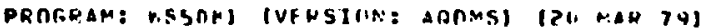

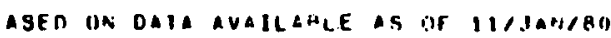

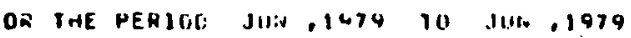

AERIIVIHTNIFET IHC.

TIITAL hMIINS OASERVEO -. 720

\begin{tabular}{|c|c|c|c|}
\hline $\begin{array}{l}\text { MNDSPR } \\
\text { HPH } \\
\text { (104 HT) }\end{array}$ & $\begin{array}{c}\text { POWER } \\
(r, M M * Q P)\end{array}$ & $\begin{array}{l}\text { HOWIRS } \\
\text { PERI IOD }\end{array}$ & $\begin{array}{l}\text { GELAIJVE } \\
\text { FREOUEN:C }\end{array}$ \\
\hline " & $"$ & 14 & 2.639 \\
\hline 1 & 0 & 24 & 0.028 \\
\hline 2 & $i$ & $3 n$ & 5.000 \\
\hline 3 & $\mathbf{2}$ & 45 & 0.250 \\
\hline$a$ & $\Delta$ & 75 & 10.017 \\
\hline 5 & 0 & BO & 11.111 \\
\hline n & 14 & na & ii.shi \\
\hline 7 & 22 & 41 & 12.639 \\
\hline$\mu$ & 33 & 04 & 11.667 \\
\hline$\dot{a}$ & 47 & 63 & e. 751 \\
\hline 10 & 65 & 33 & $0.5 A 3$ \\
\hline 11 & A7 & 25 & 3.472 \\
\hline 12 & 112 & 23 & 3.194 \\
\hline 13 & 103 & 12 & $1,+68$ \\
\hline is & 119 & 11 & i.s?o \\
\hline is & 230 & 3 & .017 \\
\hline 16 & 267 & 5 & .694 \\
\hline 17 & 320 & 2 & $.27 \mathrm{~A}$ \\
\hline & & & \\
\hline
\end{tabular}

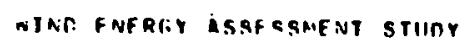

SITE Al TIIUOE: 4hOnFI

PROJ SOS SITE.

AVERAGE TE.PERATHUE $C$, 17.0
ClMULATIVE

RELATIVE

FREDIIENCY

HOURS

720
701
701
672
636
591
516
436
352
261
177
114
114
91
56
33
21
10
10
7
0
0

$$
\begin{aligned}
& 100.000 \\
& 97.361 \\
& 93.333 \\
& 68.333 \\
& 92.083 \\
& 71.067 \\
& 60.556 \\
& 44.889 \\
& 36.256 \\
& 24.583 \\
& 15.833 \\
& 11.25 n \\
& 7.778 \\
& 4.583 \\
& 2.917 \\
& 1.389 \\
& .972 \\
& .278 \\
& .810
\end{aligned}
$$

EMEQLT DETAL SETIT ENEEG DENSITY

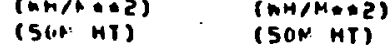




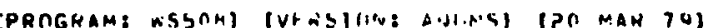

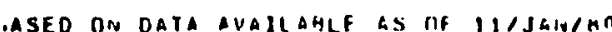

OR IHE PEHIOI JIL .1479 IO JIIL .1479

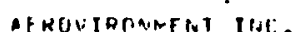

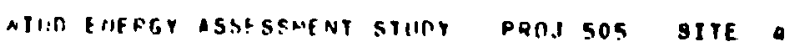

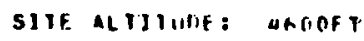

SIIF EXPONENT:. 1900

TUIAL HIIIKS OHSEKVED -- TRU

\begin{tabular}{|c|c|}
\hline $\begin{array}{c}\text { MNOSPD } \\
\text { I:PH } \\
(10 \mathrm{MT})\end{array}$ & $\begin{array}{l}\text { POate } \\
\text { ingute }\end{array}$ \\
\hline 0 & \\
\hline 1 & \\
\hline 2 & \\
\hline 3 & \\
\hline 5 & . \\
\hline 6 & 1 \\
\hline ? & 3 \\
\hline $\begin{array}{l}8 \\
4\end{array}$ & \\
\hline 10 & \\
\hline is & \\
\hline 12 & 11 \\
\hline 13 & \\
\hline 14 & \\
\hline 15 & \\
\hline $1 \mathrm{~h}$ & \\
\hline 17 & \\
\hline is & \\
\hline 10 & \\
\hline 20 & \\
\hline (1) & \\
\hline 22 & 0 \\
\hline 23 & \\
\hline
\end{tabular}

HCIIRS
PEHIOR,

RELATIVE

FREDIENCY

CIMMULATIVE

HMLPS

CINAILAYIVE

RELPINE

AVERAGI THIHEGATIINE C.

23.3

ENERGY DENSITY ENERGY DENSITY

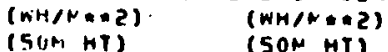

$\begin{array}{rrr}0 & 19 & 2.718 \\ 0 & 04 & 6.433 \\ 1 & 53 & 7.744 \\ 2 & 66 & 9.649 \\ 8 & 109 & 15.789 \\ 8 & 95 & 14.327 \\ 14 & 97 & 14.181 \\ 22 & 64 & 9.649 \\ 33 & 45 & 6.579 \\ 46 & 24 & 3.509 \\ 64 & 11 & 2.632 \\ 85 & 16 & 2.339 \\ 110 & 5 & .731 \\ 140 & 41 & 1.170 \\ 174 & 1 & .146 \\ 215 & 2 & .292 \\ 200 & 3 & .439 \\ 312 & 2 & .242 \\ 371 & 1 & .140 \\ 436 & 2 & .292 \\ 509 & 2 & .292 \\ 589 & 3 & .439 \\ 677 & 1 & .146 \\ 174 & 0 & .100\end{array}$

684
665
621
568
502
390
296
190
133
88
24
46
30
25
17
16
14
11
9
8
6
4
1
0

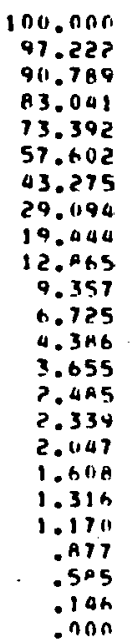

$\begin{array}{rr}0 & \\ 3 & 0 \\ 27 & 3 \\ 113 & 30 \\ 440 & 193 \\ 179 & 583 \\ 1332 & 1362 \\ 1140 & 2694 \\ 1465 & 6133 \\ 1113 & 5598 \\ 11145 & 6711 \\ 1354 & 1856 \\ 549 & 9210 \\ 1118 & 9759 \\ 174 & 10877 \\ 429 & 11751 \\ 711 & 11480 \\ 425 & 12262 \\ 371 & 12887 \\ 872 & 13258 \\ 1117 & 14130 \\ 1767 & 15197 \\ 677 & 16919 \\ 0 & 17591 \\ & 17591\end{array}$


(PROGRAP: WS5NHI IVFFSINH: ART:NSI IPU WAR 79)

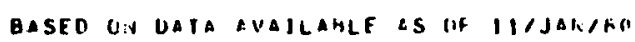

FOW IME PEKIII. AUG .1979 III AlIS .1979
AEROVIROVIMERT late.

TOTAL HIIIRS IIHSERVEO -. O31

\begin{tabular}{|c|c|c|c|c|}
\hline $\begin{array}{l}\text { RIVSPO } \\
\text { MPH } \\
(16: 41)\end{array}$ & 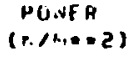 & $\begin{array}{l}\text { MTURS } \\
\text { PEKIOO }\end{array}$ & $\begin{array}{l}\text { FELATIVE } \\
\text { FHE OIIETCY }\end{array}$ & $\begin{array}{l}\text { CLIMIILAT } \\
\text { HOIIRS }\end{array}$ \\
\hline$(16.4 \mathrm{kT})$ & & & & \\
\hline$n$ & $u$ & 35 & 5.547 & 631 \\
\hline 1 & 0 & a 2 & 0.656 & 596 \\
\hline ? & $t$ & 47 & $7.44 \mathrm{n}$ & 554 \\
\hline 3 & 2 & i1 & 12.203 & 507 \\
\hline 4 & 4 & 111 & 17.591 & $43 n$ \\
\hline 5 & 3 & 103 & 16.323 & 319 \\
\hline 6 & 14 & A) & 12.437 & 216 \\
\hline 7 & 22 & 55 & 0.116 & 135 \\
\hline . & 33 & 34 & $5.3+\mathrm{A}$ & BO \\
\hline 9 & 46 & 22 & $3.4 \mathrm{A7}$ & 196 \\
\hline 30 & 64 & 13 & 2.060 & 20 \\
\hline 11 & es & $\theta$ & $1.2 \mathrm{ha}$ & 11 \\
\hline 12 & 110 & 1 & .158 & 3 \\
\hline 13 & $14 n$ & $n$ & .0611 & 2 \\
\hline I4 & 175 & 1 & .159 & . 2 \\
\hline 15 & 215 & 1 & .158 & 1 \\
\hline in & 261 & 0 & .000 & i \\
\hline
\end{tabular}

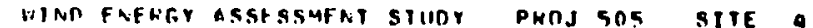

SIIF ALTIUURE: OOOOFT SITE EXPONENTI IONO AVERAGE IEMPERATIIRE C. 22.0

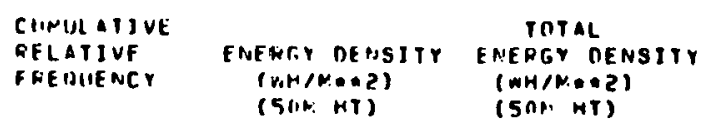

$$
\begin{array}{r}
100.006 \\
90.453 \\
87.797 \\
80.349 \\
68.146 \\
50.555 \\
30.231 \\
21.395 \\
12.670 \\
7.2941 \\
3.063 \\
1.703 \\
.475 \\
.317 \\
.317 \\
.154 \\
.0110
\end{array}
$$

$\begin{array}{rr}0 & 0 \\ 3 & 3 \\ 24 & 27 \\ 132 & 159 \\ 453 & 612 \\ 820 & 1932 \\ 1115 & 2547 \\ 1202 & 3799 \\ 11109 & 9859 \\ 1022 & 5881 \\ 824 & 6709 \\ 679 & 7388 \\ 110 & 7098 \\ 70 & 7098 \\ 175 & 7673 \\ 215 & 7889 \\ 0 & 7988\end{array}$




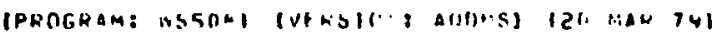

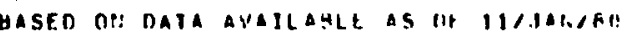

FON IHE PERIUI SEP, 1979 TII SEP, 1474
AEMUVIOOR:HEA,T INE.
"JPE? FIJPFEY ASSSPSHFNT STILOY PROJ 505 SITE a

SIIF ALIITUIIF: W6ONF

SITE EXPONENTI. . 1000

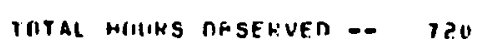

\begin{tabular}{|c|c|c|c|c|c|c|c|}
\hline $\begin{array}{l}\text { WNOSHD } \\
\text { APPN } \\
\text { (1OA: MI) }\end{array}$ & 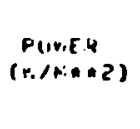 & $\begin{array}{l}\text { Mititis } \\
\text { PFRIOC }\end{array}$ & $\begin{array}{l}\text { RELATIVE } \\
\text { FEEQYHF IAS. }\end{array}$ & $\begin{array}{c}\text { CUMIILAYIVE } \\
\text { HOURS }\end{array}$ & $\begin{array}{l}\text { CUMIILATIVE } \\
\text { HELAIIVE } \\
\text { FREDIIENCY }\end{array}$ & $\begin{array}{l}\text { ENERGY HENSITY } \\
\text { (W:HIM\#EZ) } \\
\text { (SOM HT) }\end{array}$ & $\begin{array}{l}\text { TOTAL } \\
\text { ENERGY DENSIT } \\
\text { (WH/MAEL) } \\
\text { (5OM HI) }\end{array}$ \\
\hline
\end{tabular}

\begin{tabular}{|c|c|c|c|c|c|c|c|}
\hline 0 & 0. & 22 & 3.050 & 720 & 1no.nno & $n$ & 0 \\
\hline 1 & 0 & $2 \alpha$. & 3.611 & 698 & 96.940 & 2 & 2 \\
\hline 2 & 1 & 45 & 6.250 & 672 & 93.333 & 23 & 25 \\
\hline 3 & 2 & 59 & 8.190 & 627 & $87.0 B 3$ & 103 & 128 \\
\hline 4 & 4 & 123 & 17.083 & 568 & $7 H .489$ & 508 & 635 \\
\hline 5 & 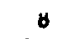 & i1s & 15.972 & 445 & G1.A11n & 927 & 1562 \\
\hline 6 & 14 & 85 & $11.80 \mathrm{~h}$ & 330 & 45.833 & lina & 2706 \\
\hline 1 & 32 & 67 & 9.306 & 205 & 30.025 & IAR2 & $422 A$ \\
\hline A & 33 & 56 & $1.71 \mathrm{~A}$ & $17 \mathrm{H}$ & 24.722 & 1849 & 6077 \\
\hline 9 & 47 & 32 & 4.444 & 122 & 16.944 & 13114 & 7581 \\
\hline 10 & ha & 26 & 3.611 & on & 12.500 & 1677 & 9258 \\
\hline 11 & no & 15. & 2.063 & ha & H.BAG & 1247 & 10545 \\
\hline 12 & 11.1 & $1 n$ & 2.272 & 49 & C.Ant & 1783 & 12328 \\
\hline 13 & 142 & $n$ &.$A 33$ & 33 & $4.5 \times 3$ & A50 & $1317 \mathrm{~A}$ \\
\hline 14 & 171 & 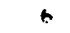 &.$A 33$ & 27 & 3.750 & $\ln 62$ & 14240 \\
\hline 1s & 215 & $?$ & .972 & 21 & 2.917 & is 23 & 15763 \\
\hline 16 & $2+4$ & 3 & .417 & 14 & $1.94 a$ & 792 & \\
\hline 11 & 311 & t & .833 & 11 & $1.52 \mathrm{H}$ & 1001 & $\begin{array}{l}\text { 10451 } \\
1045\end{array}$ \\
\hline 10 & $37 t$ & 3 & .417 & 5 & .694 & 1128 & 19585 \\
\hline 10 & 442 & 1 & .139 & 2 & .278 & auz & 20027 \\
\hline 20 & 510 & 1 & .239 & 1 & .110 & 510 & 20543 \\
\hline 21 & 597 & " & $.10 \mathrm{il}$ & o & . nno & 0 & 20543 \\
\hline
\end{tabular}




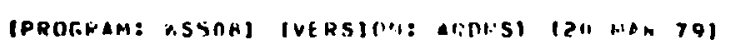

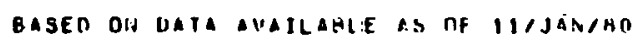

For the PERJIIO OCT.1479 IO ICT, 1479

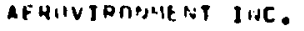

\begin{tabular}{|c|c|}
\hline ANCSPI & $\begin{array}{l}\text { POnER } \\
(M / M * \cdots 2)\end{array}$ \\
\hline & \\
\hline (1 & 0 \\
\hline 1 & (1) \\
\hline 2 & 1 \\
\hline 3 & 2 \\
\hline a & 4 \\
\hline 5 & 8 \\
\hline 6 & 19 \\
\hline 7 & 23 \\
\hline h. & 34 \\
\hline 4 & an \\
\hline 10 & 66 \\
\hline 11 & $A B$ \\
\hline 12 & 110 \\
\hline 13 & 145 \\
\hline 14 & IA 1 \\
\hline is & 223 \\
\hline is & 270 \\
\hline 17 & 324 \\
\hline 78 & 385 \\
\hline 19 & 453 \\
\hline$>0$ & 520 \\
\hline 21 & 611 \\
\hline 22 & 703 \\
\hline 23 & 863 \\
\hline 20 & 912 \\
\hline 25 & 1031 \\
\hline 26 & 1160 \\
\hline
\end{tabular}

TUIAL HOLIRS OHSEHVEO

HOINS

MOIIHS
PENInI)

RELATIVE
FREUIIEICY

CIMAULATJVE Hollas

com-iLATIVE RELAIIVF

100.000

00.000
98.516
45.413

45.412
49.339

49.339
81.242

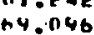

53.376

$41.5 \sin$

34.143
27.935

27.935
23.752

$2 n \cdot 1 n a$

17.139

14.400

11.201

9.3113
3.916

3.919
2.469

2.969
2.290

5.290
5.154

2.154
1.215

.010

.540
.540

.135

$.0 \% 0$

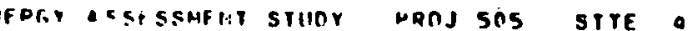

SIIE AIUIE: QGONFY SITE EXPONENT: .1900

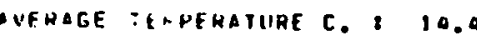

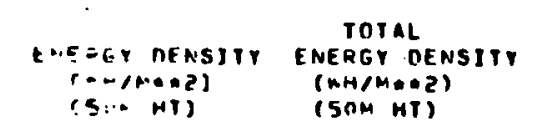

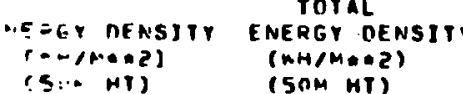

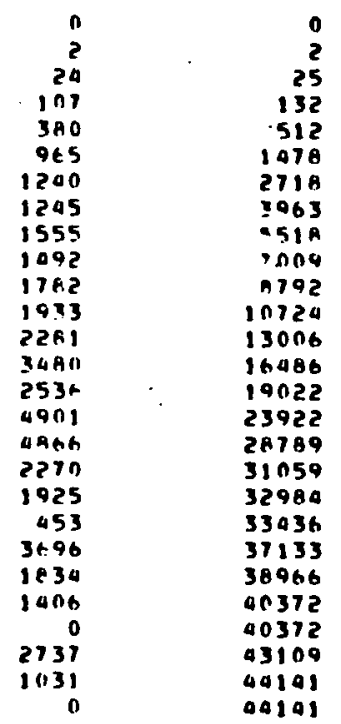




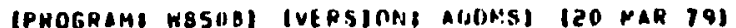

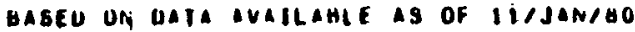

FOR IHE PERIOI NOV .1479 10 1.OV .1474
AERIOVIRONAFET INC.

cotal hlluRs DBSERVE -. 120

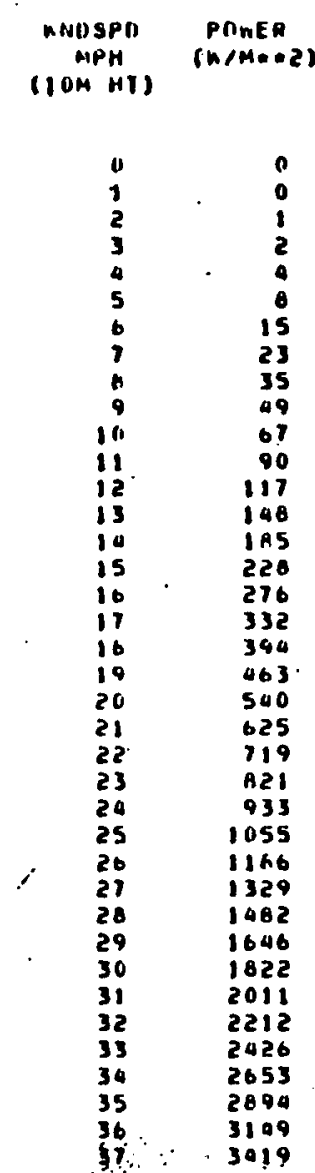

VINO FHEHGY ABSESBMENT STIIDY

PROJ SOS SITE

SJTE ALIJTUNES QGODFI

BIIE EXPONENT: .1400

TOTAL

Climingtive PEI PIIVE
PRE OUE NT, MOUPS
PERINO

HELATIVE FAEDLIFAY HOURS

nutwr.

ENERGY DENSITY
(WhINOAC)

ENEGY DENSITY

(SOA. MI)

(SOM NI)

100.000 96.250 43.056

97.710
63.472

76.250

69.722

63.611

51.11

51.667

45.53

34.028

24.167

24.044

19.167

15.417

12.003

-.AH9

h. $3 A 9$

$5.27 A$

4.028

3.472

3.190

2.917

2.361

1.006

1.528
1.309
.912

.912
.554

.556
.270

.270

.139
.139
.000

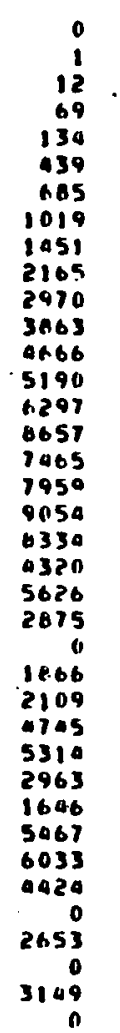

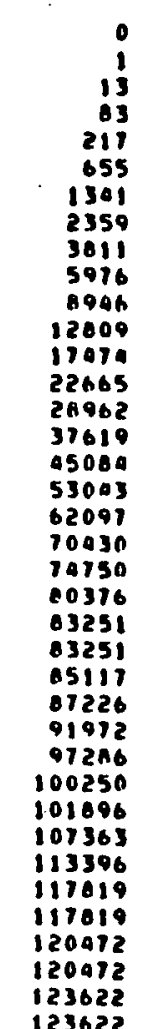


BOGHAM: MSSOAI IVEUSIOP: AIINISI IPO MAR 701

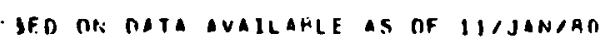

I IRE PERjoO Jill .1979 in Jill. 1979
AFGIONJROMAENT INC.

TOTAL hOLIRS UHSEWVED -. 150

\begin{tabular}{|c|c|}
\hline 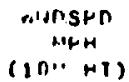 & $\begin{array}{l}\text { PUMEN } \\
\text { (WMANER ) }\end{array}$ \\
\hline$n$ & 0 \\
\hline i & 0 \\
\hline 2 & 1 \\
\hline 3 & $i$ \\
\hline$a$ & 4 \\
\hline 5 & B \\
\hline h & 10 \\
\hline 7 & 23 \\
\hline A & 34 \\
\hline 9 & 49 \\
\hline $1 n$ & 67 \\
\hline 11 & 89 \\
\hline i? & 110 \\
\hline 13 & 147 \\
\hline is & IA4 \\
\hline 15 & 226 \\
\hline in & राव \\
\hline 17 & 329 \\
\hline iA & 390 \\
\hline 16 & $459^{\circ}$ \\
\hline 20 & 535 \\
\hline 21 & 619 \\
\hline 22 & 712 \\
\hline 23 & B14 \\
\hline 24 & 925 \\
\hline 25 & \\
\hline
\end{tabular}

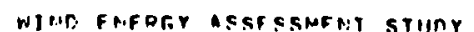

SJTE ALTITHIL: 32BOET

PROJ 505 SITE 5

avehafe tempapatule $C$. :

SIIE EXPOHENT: 1000

23.3
CIMILATIVE RELATIVE
FREDUENCY CIMILLATIV
HOIIRS

159
152
152
147
139
136
130
123
120
108
97
86
69
61
47
36
27
21
17
15
10
8
6
5
2
1
1
0

$$
\begin{aligned}
& 100.010 \\
& 94.701 \\
& 95.455 \\
& 90.260 \\
& 88.318 \\
& 94.916 \\
& 79.870 \\
& 77.922 \\
& 70.13 n \\
& 62.967 \\
& 55.849 \\
& 09.805 \\
& 39.410 \\
& 30.510 \\
& 24.675 \\
& 17.532 \\
& 13.436 \\
& 19.039 \\
& 0.740 \\
& 6.040 \\
& 3.195 \\
& 3.894 \\
& 3.247 \\
& 1.209 \\
& .099 \\
& .000
\end{aligned}
$$

\begin{tabular}{|c|c|}
\hline $\begin{array}{l}n \\
0\end{array}$ & o \\
\hline " & $\begin{array}{l}n \\
5\end{array}$ \\
\hline 5 & 10 \\
\hline $\begin{array}{l}20 \\
50\end{array}$ & $3 n$ \\
\hline 59 & 90 \\
\hline $\begin{array}{r}03 \\
075\end{array}$ & $13 \mathrm{~B}$ \\
\hline 275 & $\begin{array}{l}413 \\
790\end{array}$ \\
\hline $53 n$ & $\begin{array}{r}790 \\
1326\end{array}$ \\
\hline 1137 & 24063 \\
\hline 112 & 3175 \\
\hline 1618 & 0793 \\
\hline 1323 & A116 \\
\hline$?(1) 9$ & h135 \\
\hline 1354 & 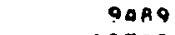 \\
\hline lngh & 10585 \\
\hline 657 & 1120? \\
\hline 1050 & 13192 \\
\hline 914 & 19110 \\
\hline 1070 & ISIAR \\
\hline 619 & 15799 \\
\hline 2137 & 11936 \\
\hline $\begin{array}{l}\text { P1 } 4 \\
075\end{array}$ & 18750 \\
\hline 92.5 & 19674 \\
\hline & $1967 a$ \\
\hline
\end{tabular}

ENEPT.Y DENSITY

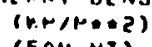
$(50 \mathrm{C})$

InIAL

Fieger DENSTTt (SOM HT) 


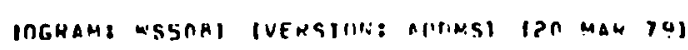

IEO nN Data avajlaible as or hijatian

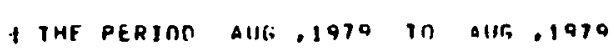

AE WOVITONAMENT IIIC.

TUTAL HIIIRS TIMSERVED -

\begin{tabular}{|c|c|c|c|}
\hline \multirow{2}{*}{ 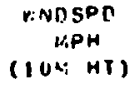 } & $\begin{array}{l}\text { PONER } \\
(N / M * P)\end{array}$ & $\begin{array}{l}\text { MOIHS } \\
\text { PEAIOD }\end{array}$ & $\begin{array}{l}\text { HELATIVE } \\
\text { FREQUENIC }\end{array}$ \\
\hline & & & \\
\hline ' & & & \\
\hline 0 & 0 & 15 & $2.05 ?$ \\
\hline 1 & $n$ & 37 & 5.062 \\
\hline 2 & 1 & 30 & 0.651 \\
\hline 3 & 2 & 34 & $0 .+51$ \\
\hline 4 & 4 & 23 & 3.146 \\
\hline 5 & 8 & 42 & 5.746 \\
\hline h & 14 & 31 & a.P41 \\
\hline 7 & 23 & 52 & 7.1114 \\
\hline A & 34 & 40 & 0.019 \\
\hline 9 & 49 & 36 & 0.925 \\
\hline 10 & 67 & 50 & A.011 \\
\hline 11 & P9 & 55 & 7.524 \\
\hline 12 & $11 \mathrm{~h}$ & as & 6.156 \\
\hline 13 & 147 & 49 & $0.7 n 3$ \\
\hline 14 & Ind & $3 n$ & $5.19 \mathrm{H}$ \\
\hline 15 & 226 & 24 & $3.2 \times 3$ \\
\hline in & 275 & 26 & 3.551 \\
\hline 17 & 324 & 20 & 2.736 \\
\hline 16 & 391 & 19 & 2.590 \\
\hline 10 & $\operatorname{sen}($ & 1 A & 2.462 \\
\hline 211 & $53 \mathrm{~h}$ & in & $1.3 \mathrm{BA}$ \\
\hline 21 & 621 & 11 & $1.5 \times 5$ \\
\hline 22 & 714 & 5 & -ta4 \\
\hline 23 & . 15 & 4 & .547 \\
\hline 24 & 026 & $n$ & . nnon \\
\hline
\end{tabular}

WHan EMFRGY ASSESSHERT STIURY

SITE ALTITIIF: 3PSOFT

PROJ 5na SITE a

averafof terofratude $C_{0}: 22 . \mathrm{A}$
CIIMULATIVE HOURS

CIIMIILATIVE RELATIVE
PEFUENCY
ENEFGY DENSITY ENERGY DENSITY

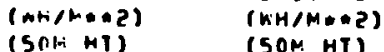

\begin{tabular}{|c|c|c|c|}
\hline 731 & lon, $100 n$ & 0 & r \\
\hline $71 \mathrm{~h}$ & $97.04 \mathrm{~A}$ & 2 & 2 \\
\hline 679 & Q?.AAB & 18 & 21 \\
\hline 605 & $A 8.235$ & $6 ?$ & $A_{C}$ \\
\hline 611 & O3.5A4 & 90 & 101 \\
\hline 58 A & BO. 43 A & $35 ?$ & 53 ? \\
\hline san & 70.592 & 409 & Q⿻一 \\
\hline 515 & 70.051 & 1195 & 217 \\
\hline 463 & $63.33 \mathrm{~A}$ & 1510 & 3687 \\
\hline 019 & 57.319 & 1759 & S4at \\
\hline 383 & 52.390 & $305 a$ & 9000 \\
\hline 324 & 40.323 & 0906 & 1030 \\
\hline $2+9$ & 36.799 & 5211 & $1951 ?$ \\
\hline 224 & 30.603 & 1215 & 2073 \\
\hline 175 & 23.900 & $\triangle Q P A$ & 33721 \\
\hline 137 & 18.791 & 5429 & 39149 \\
\hline 113 & 15.058 & 7337 & ah?A? \\
\hline A7 & 11.9118 & GSAS & 52872 \\
\hline 67 & 9.106 & Tazh & 00298 \\
\hline $4 A$ & h. Strh & A>7 4 & 60573 \\
\hline 30 & 4.104 & 5362 & 73930 \\
\hline Po & 2.736 & GAZT & A0168 \\
\hline 9 & 1.231 & $356 A$ & A 0330 \\
\hline a & .547 & 3P6? & A7592 \\
\hline 0 & $.00 n$ & $n$ & B7592 \\
\hline
\end{tabular}


ROGRAM: WSSOAI IVFASTONG AORMSI IZN MAR 70

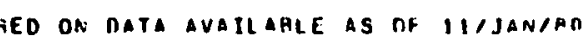

- the perion SEP. 1979 in SEP. 1979 a knvianigment inC.

TMTAL mMURS nRSERVED --

025

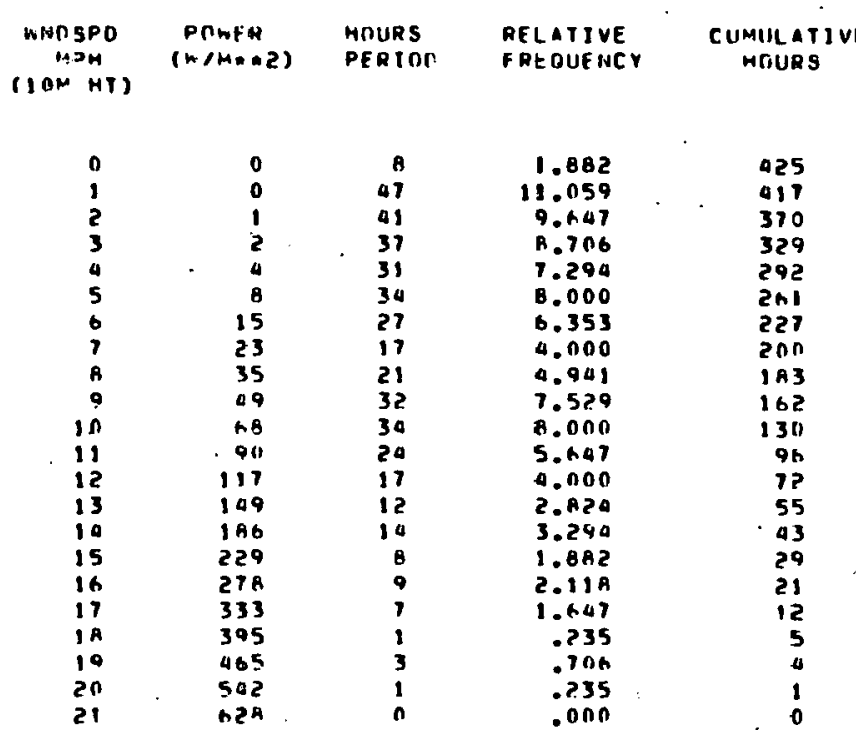

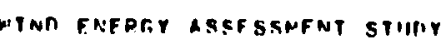

SITF al TIIITE, Jzanf

PPAJ SRS SITE 5

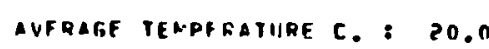

CoImul arive PELATIVE PEETIIEACY

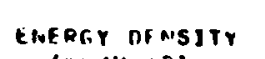
(ankm) TOTAL
TNERG DENSITY

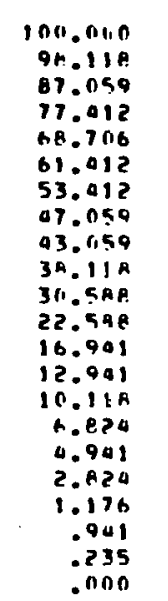

(WHIMAE?)

\begin{tabular}{|c|c|}
\hline 8 & r \\
\hline 3 & 3 \\
\hline 22 & 29 \\
\hline 130 & 35 \\
\hline PAB & 510 \\
\hline 395 & 9i1 \\
\hline 305 & 1300 \\
\hline 729 & 2035 \\
\hline 1591 & $3+16$ \\
\hline $23 n 5$ & 5921 \\
\hline PI+5 & BOAE \\
\hline 1991 & Inot \\
\hline 1787 & 11866 \\
\hline 26100 & TaAne \\
\hline 1830 & 16290 \\
\hline 2400 & IAT9A \\
\hline $23 ! 1$ & 21121 \\
\hline 395 & 21523 \\
\hline 1395 & P291 \\
\hline 54? & 23460 \\
\hline & 23460 \\
\hline
\end{tabular}




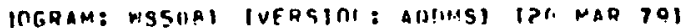

IED DN DATA AVAILAHLE Ba OF II/JABIER

: THE PERITO OCI.1974 TII OCT .1479
AFRMVIRANERT IMC.

IOTAL HIIUTS OHSFRUED -- $20 ?$

\begin{tabular}{|c|c|c|c|c|}
\hline $\begin{array}{c}\text { MNOSPO } \\
\text { YPH }\end{array}$ & 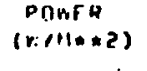 & $\begin{array}{l}\text { Hrillifs } \\
\text { PERION }\end{array}$ & $\begin{array}{l}\text { RFLARIVE } \\
\text { FREDUEINCY }\end{array}$ & $\begin{array}{l}\text { CIJMIIL ATIVF } \\
\text { MOIIRS }\end{array}$ \\
\hline
\end{tabular}

CIIMILATIVE

GELTIVE
GREOUEHEY

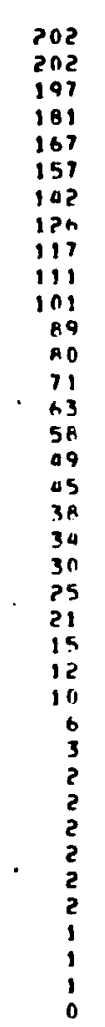

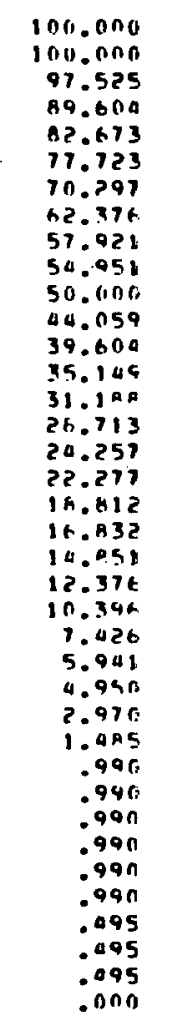

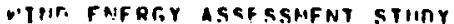

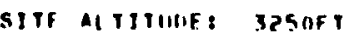

PROJ 5NS SITE 5

SITF FXFONENTS DIADO
EHERGY OENSITY ENERTY DENSITY

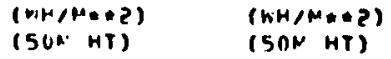

\begin{tabular}{|c|c|}
\hline 0 & $n$ \\
\hline$n$ & o \\
\hline o & 9 \\
\hline $2 t$ & 35 \\
\hline 44 & BO \\
\hline $13 n$ & $21 n$ \\
\hline 240 & 009 \\
\hline 214 & has \\
\hline 213 & A>B \\
\hline sns & 1381 \\
\hline 4.3? & 2213 \\
\hline B30 & 3043 \\
\hline $\operatorname{InTA}$ & a) 121 \\
\hline $121 \mathrm{~A}$ & 5339 \\
\hline 951 & .290 \\
\hline 2305 & e395 \\
\hline 1135 & 9530 \\
\hline 2323 & 11913 \\
\hline 1nit & 13530 \\
\hline 1401 & 15031 \\
\hline 2712 & 18203 \\
\hline 2567 & 207ו1 \\
\hline पa $2 A$ & 25198 \\
\hline 2530 & 27728 \\
\hline 1916 & 20000 \\
\hline 0331 & 33975 \\
\hline $3 \times 54$ & 37629 \\
\hline $13 \mathrm{ne}$ & 38903 \\
\hline$n$ & 38993 \\
\hline 1 & 39993 \\
\hline 0 & उА993 \\
\hline n & 38993 \\
\hline n & 38993 \\
\hline 2490 & $\triangle 1980$ \\
\hline 0 & Diana \\
\hline & $\triangle I A R \triangle$ \\
\hline 3233 & 04717 \\
\hline & 04717 \\
\hline
\end{tabular}




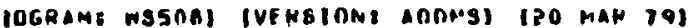

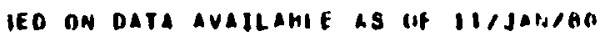

I THE PERIOD NOV .1979 in HOV , 1979
AEMTVIRONGENT INE.

WINII FNFREY ASSI BSMENT STIJAY

BITE ALIIIUINES 3250F

PRAJ SOS BITE,

average tempematthe $c$.
SIIF EXPONENT: .1400

rotal monRs OUSERVED -. IPO

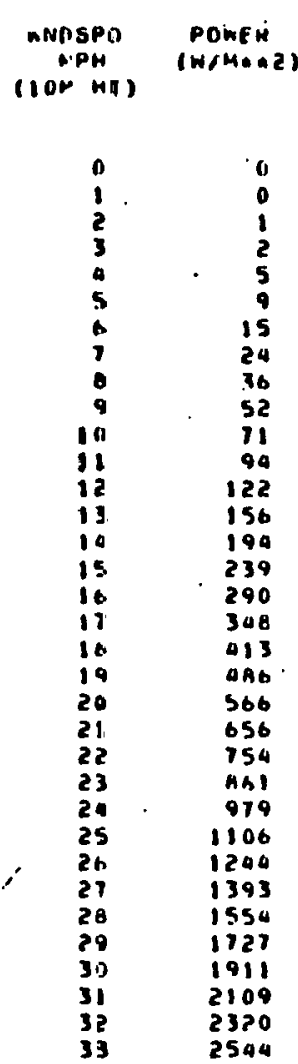

HกURS PERIND

RELATIVE reguEHCY
CUPIL ATIVE DELATIVE
FREDIIENCY CHALLTIVE
HOURS PREDUEN

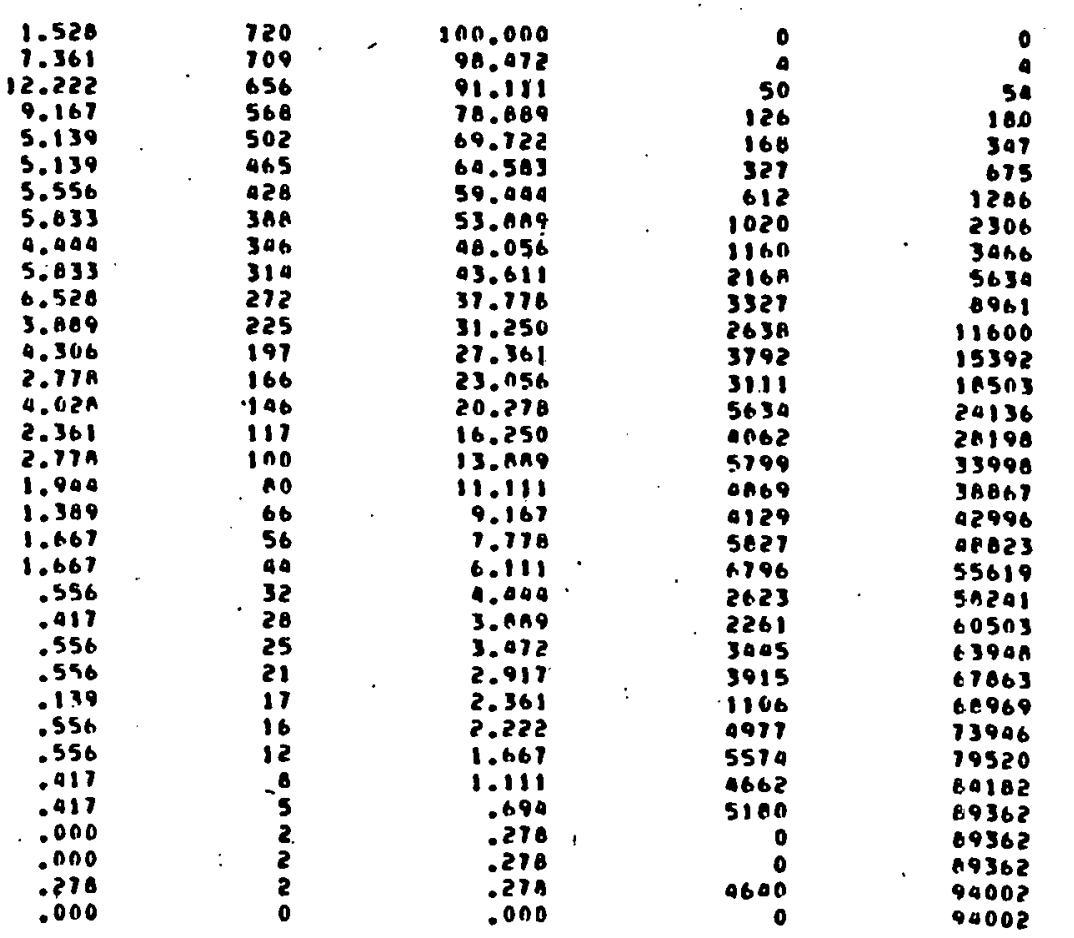

ENEREY OENSIIY ENERGY DENSIIY

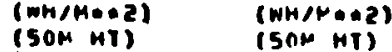




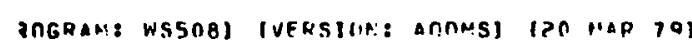
SEO ON DATA AVATLAHIE AS OF II/JANJAO

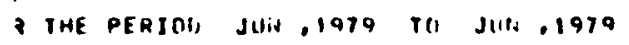

AFRUVIFGMNGHT ine.

TRTAL HOLPS OASERVEO -.

\begin{tabular}{|c|c|c|c|c|}
\hline WNOSPN & $\begin{array}{l}\text { PNhER } \\
(n / M \cdots+2)\end{array}$ & $\begin{array}{l}\text { HNIIRS } \\
\text { PERI OD }\end{array}$ & $\begin{array}{l}\text { RELATIVF } \\
\text { FREOIIENCY }\end{array}$ & $\begin{array}{c}\text { CUMIILAIIVE } \\
\text { HOLIKS }\end{array}$ \\
\hline
\end{tabular}

CIINIILATIVE PELATIVE FHE RIIEHCY

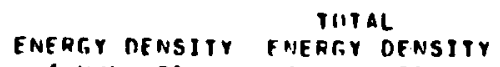

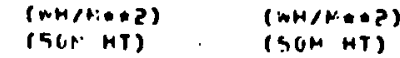

SITF Al.MITINF: 435 IIFY

DHOJ 505 SITF 6

AVERAGF TEAPEHATHRE C.: 17.R:-

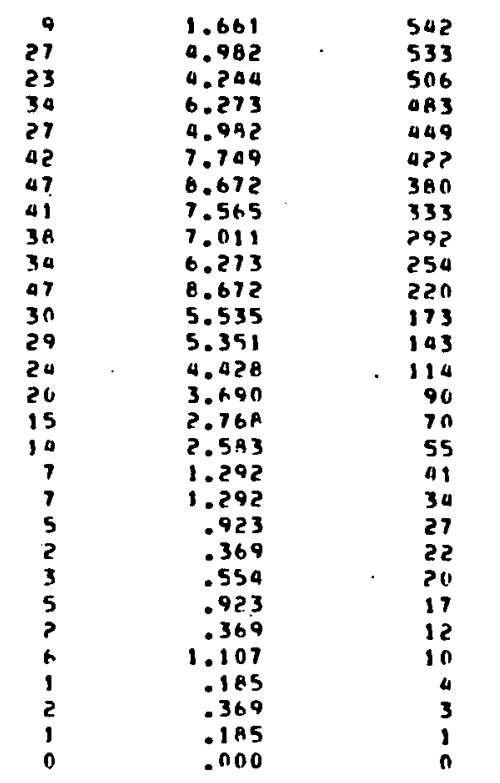

100.000
90.334
93.358
99.110
82.801
17.460
10.111
61.439
53.475
46.863
40.590
31.919
26.394
21.033
16.609
12.915
10.108
7.565
9.273
4.982
4.059
3.098
3.137
2.010
1.805
.738
.554
.185
.000

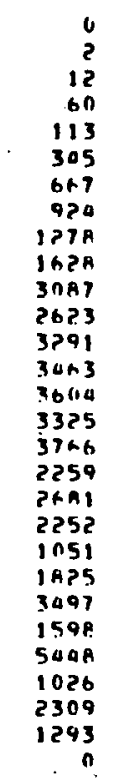




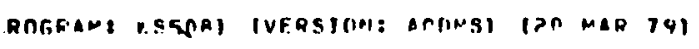

SEn nes bata avajlahle as rif hiJer,je

a the perion JUL .1479 TO JIL . 1979

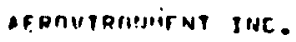

TUTAL HOUKS OPSERVED -. 744

\begin{tabular}{|c|c|c|}
\hline 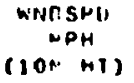 & $\begin{array}{l}\text { P(NRER } \\
(\forall: / \operatorname{lan}, P)\end{array}$ & $\begin{array}{l}\text { MNUPS } \\
\text { PEKIOD }\end{array}$ \\
\hline 0 & $n$ & 36 \\
\hline 1 & 0 & 33 \\
\hline 2 & 1 & 31 \\
\hline 3 & 2 & 50 \\
\hline 4 & 4 & 50 \\
\hline & A & 07 \\
\hline h & 14 & 51 \\
\hline 7 & 22 & aid \\
\hline A & 33 & 54 \\
\hline 9 & 47 & 45 \\
\hline $\ln$ & n. & 65 \\
\hline 11 & P. 5 & 36 \\
\hline 12 & 111 & an \\
\hline 13 & 141 & 51 \\
\hline 14 & $17 n$ & $2 A$ \\
\hline 15 & 211 & 19. \\
\hline in & $\sin 3$ & 11 \\
\hline 17 & 315 & 2 \\
\hline $1 A$ & 374 & 4 \\
\hline 14 & aun & 3 \\
\hline 26 & 513 & 3 \\
\hline 21 & 594 & h \\
\hline$P ?$ & AH 3 & 1 \\
\hline 23 & 781 & i \\
\hline 24 & A81 & 3 \\
\hline 25 & 1003 & " \\
\hline 26 & 1128 & 1 \\
\hline 27 & 1263 & $n$ \\
\hline
\end{tabular}

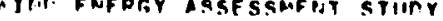

PAn.t Sng SITE

SITE ALTITINES Q35NFT

SITF. EXPONFNTI . 10 ORI

AVFAGE IENPEDAIIRF $C_{0}, 23.3$
HFLATIVF CIIMILATIVE

FRE BHENCY

CIIMILATI
HoliKS

RELATIVE

FREDIIVNCY

,

100.0010

95.131

90.726
86.559

86.559
$79.3 n 1$

72.043

65.726
52.271

50.269

43.011

36.962

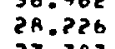

13.34
53.397

18.011

18.011
11.156
7.39 ?

$4 ., 330$

$3.3+n$

3.091
5.550

2.550
2.151

8.747

001

Ana

.

.130
.134
.000
ENERGY RENSTTY ENERGY DENSITY

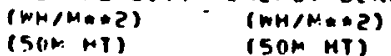

\begin{tabular}{|c|c|}
\hline 0 & ? \\
\hline 2 & ? \\
\hline $\begin{array}{l}16 \\
94\end{array}$ & 11? \\
\hline 222 & 333 \\
\hline 377 & iil \\
\hline 707 & 1018 \\
\hline 1409 & 2827 \\
\hline 1775 & 4601 \\
\hline 21 l.h & ning \\
\hline 0172 & $10 A 79$ \\
\hline 3075 & 13950 \\
\hline $043 t$ & $1 \times 391$ \\
\hline $\begin{array}{l}7197 \\
0931\end{array}$ & $\begin{array}{l}255 A^{2} \\
30519\end{array}$ \\
\hline 4116 & 30629 \\
\hline 2A9? & 37521 \\
\hline 631 & 3PIS? \\
\hline 1497 & 39609 \\
\hline 1321 & ang \\
\hline 1540 & 02510 \\
\hline 35 th & abnit \\
\hline AR3 & antho \\
\hline $156 ?$ & AA32R \\
\hline Pan? & 50984 \\
\hline 20 & $\begin{array}{l}50984 \\
52112\end{array}$ \\
\hline & $\begin{array}{l}52112 \\
52112\end{array}$ \\
\hline
\end{tabular}




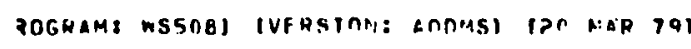
SED ON GATA AVATLAHLE AS CE II/JAF:/HC

P THE PERJOU 0116.1979 in allg .1970
AEHTVIRTN"ENT JHE.

TOTAL HIIIHS OHSFHVE --

704

\begin{tabular}{|c|c|c|c|}
\hline $\begin{array}{l}\text { MiJNSPQ } \\
\text { MPH }\end{array}$ & $\begin{array}{l}P \cap N F H \\
(W / M * \infty P)\end{array}$ & $\begin{array}{l}\text { HOUKS } \\
\text { PERIC'O }\end{array}$ & $\begin{array}{l}\text { RFL PTIVE } \\
\text { FRE DIIENC }\end{array}$ \\
\hline 11 & (1) & a) & 5.511 \\
\hline 1 & 0 & $5 H$ & 7.796 \\
\hline 2 & 1 & 49 & $B .586$ \\
\hline 3 & 2 & 56 & 7.527 \\
\hline a & 0 & 61 & 6.199 \\
\hline 5 & 6 & 43 & 5.780 \\
\hline 6 & 14 & bi & 8.065 \\
\hline 7 & 22 & ab & 6.1A3 \\
\hline A & 33 & 51 & 6.055 \\
\hline 9 & 47 & hit & 8.671 \\
\hline 10 & be & 57 & 7.661 \\
\hline 11 & 16 & 52 & 6.989 \\
\hline 12 & 111 & 39 & 5.242 \\
\hline 13 & 141 & in & 2.019 \\
\hline is & 176 & 19 & 2.554 \\
\hline 15 & 217 & 7 & .991 \\
\hline 16 & $2+3$ & in & 1.340 \\
\hline 17 & $31 \mathrm{~h}$ & 10 & 1.344 \\
\hline 18 & 375 & 1 & .134 \\
\hline 19 & 401 & $n$ & . uno \\
\hline
\end{tabular}

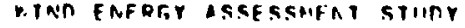

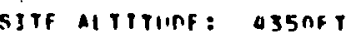

PROJ SRS SITF 6

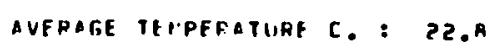

CUMHIIL ATINE RELATIUE RELATJUE
FREDIENCY

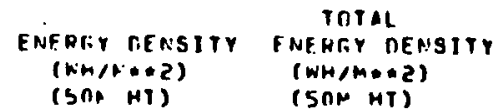

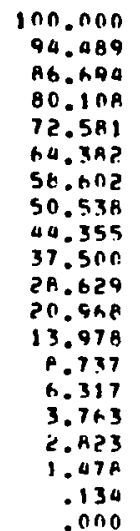

\author{
(SAR
}

0
29
126
377
723
1557
2511
4251
7306
11012
15464
19798
22342
25695
27215
29449
33009
33315
33385




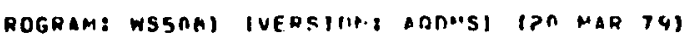

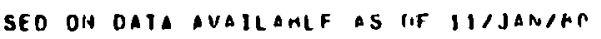

R THE PERIOD SEP. 1970 IO StP.1479
AFHUVIRBNER IHC.

TOTAL mGiHRS DHSERUFO --

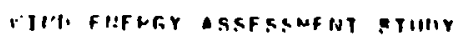

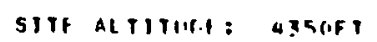

PRD.i SRE SITF 6

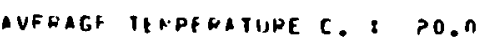

\begin{tabular}{|c|c|c|c|c|c|c|c|}
\hline $\begin{array}{l}\text { NRSSPR } \\
\text { MPM } \\
(10 N \text { Nit) }\end{array}$ & $\begin{array}{l}\text { Pnt.FR } \\
(m / M, A ?)\end{array}$ & $\begin{array}{l}\text { HOIRS } \\
\text { Prk10r: }\end{array}$ & $\begin{array}{l}\text { RELATIVE } \\
\text { FUETIUENAS }\end{array}$ & $\begin{array}{l}\text { CHMILLATIVF } \\
\text { HMIINS }\end{array}$ & 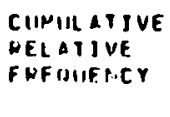 & 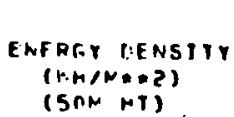 & $\begin{array}{l}\text { TOTAL } \\
\text { FNERGY OENSITY } \\
\text { (WH/M.O?) } \\
\text { (5OM.MT) }\end{array}$ \\
\hline
\end{tabular}

\begin{tabular}{|c|c|c|c|}
\hline$n$ & 0 & $7 \mathrm{~A}$ & 13.613 \\
\hline 1 & 0 & 45 & 7.053 \\
\hline 2 & 1 & 52 & 9.075 \\
\hline 3 & 2 & 49 & 8.551 \\
\hline$\Delta$ & - & 65 & 11.304 \\
\hline 5 & 6 & $\triangle A$ & 8.377 \\
\hline h & 14 & 46 & R.OPA \\
\hline 7 & 32 & 46 & A.02h \\
\hline H & 33 & 30 & h.Anb \\
\hline 9 & 47 & $3 n$ & $6.2 P 3$ \\
\hline 10 & 65 & $2 A$ & $4 . A 87$ \\
\hline 11 & A) & 11. & 1.920 \\
\hline 12 & 112 & A & 1.396 \\
\hline 13 & 143 & $\ln$ & 1.745 \\
\hline 14 & 179 & $?$ & .349 \\
\hline is & 220 & 1 & .175 \\
\hline 16 & 267 & 3 & .524 \\
\hline 17 & 320 & $n$ & . Onn \\
\hline is & 340 & 3 & .5?0 \\
\hline 19 & Dus & $i$ & .175 \\
\hline 20 & 521 & 1 & .175 \\
\hline 21 & $\operatorname{sn} 3$ & 1 & .175 \\
\hline 22 & 693 & 0 & .000 \\
\hline
\end{tabular}

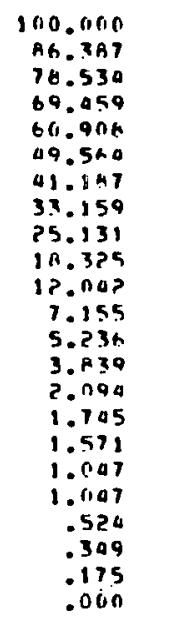

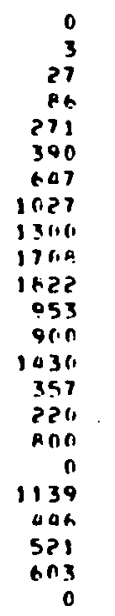

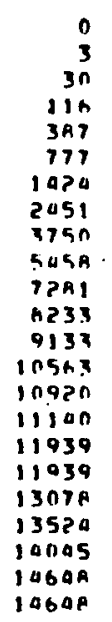




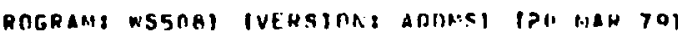

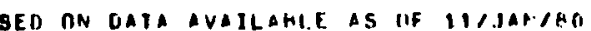

R the perJUIN nCI .1979 10 OCI .1974

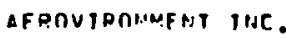

TOTAL HOLES NPSERUFD -- TI

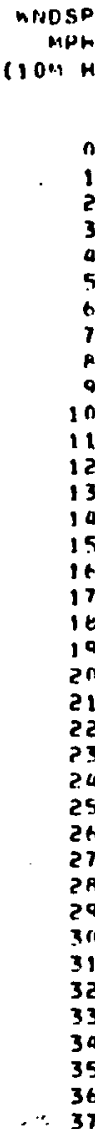

HOWE R (W:N:D?
HELATIVE FPEDUENCY

CUMIILATIVF HOIIRS

CINIILATIVE RELATIVE FKE GIIFACY

\begin{tabular}{|c|c|c|c|c|}
\hline 3.094 & 711 & $10 n .0 \mathrm{nn}$ & 0 & 0 \\
\hline 6.751 & GRQ & $96.9 n h$ & 3 & 3 \\
\hline 7.032 & 601 & 901.155 & 27 & 30 \\
\hline 0.610 & 591 & A3.12? & 85 & 110 \\
\hline 6.610 & 540 & 76.512 & 200 & .315 \\
\hline 6.610 & 097 & $69.9 n ?$ & 301 & $7 n g$ \\
\hline 7.314 & 450 & 03.291 & ToA & 1054 \\
\hline 1.032 & 396 & $55.07 \mathrm{~A}$ & 1142 & 2596 \\
\hline 6.470 & 300 & $Q A .905$ & 1569 & $\begin{array}{l}0306 \\
0165\end{array}$ \\
\hline 5.345 & 3n? & 42.475 & inas & bnin \\
\hline 6.008 & 2na. & 37.133 & 2664 & AB? \\
\hline 4.641 & 221 & $31.0 \times 3$ & 2925 & 11799 \\
\hline $5.2 n a$ & IAB & 26.462 & 0258 & 16057 \\
\hline 4.782 & 151 & $21.23 \mathrm{~A}$ & $\begin{array}{l}4075 \\
4975\end{array}$ & 21032 \\
\hline 2.472 & iii. & $.16 .45 \mathrm{~h}$ & 3072 & 20500 \\
\hline 2.954 & $\quad 9 B$ & $13.7 P 3$ & 4720 & 29225 \\
\hline 2.110 & $\therefore \pi$ & 10.930 & ang? & 33317 \\
\hline $.9+9$ & he & 0,721 & 2300 & 35607 \\
\hline .703 & 55. & $7.73 n$ & 1042 & 37509 \\
\hline.$A \Delta a$ & so & 1.032 & 2709 & anर20 \\
\hline 1.125 & 44 & h. IRH & $42 n ?$ & a 4553 \\
\hline 1.125 & 36. & $5.0 n 3$ & 0930 & A94B \\
\hline 1.125 & 26 & $3.93 \mathrm{~A}$ & 5673 & $5516 n$ \\
\hline .241 & 20 & 2.A13 & $1+21$ & S67R1 \\
\hline .101 & 18 & 2.532 & 921 & $5770 ?$ \\
\hline $.5 n 3$ & 17 & 2.391 & 0163 & G1AGQ \\
\hline $.2(1$ & is & $1.82 A$ & 2341 & 64206 \\
\hline .281 & 11 & 1.547 & 2622 & 66827 \\
\hline .141 & 9 & 1.266 & 1462 & GP289 \\
\hline $.0 n 0$ & 6 & 1.125 & n & BA2BQ \\
\hline .281 & 8 & 1.125 & 3596 & TIAB \\
\hline .101 & 6 & .800 & JOA4 & 13370 \\
\hline .000 & 5 & .103 & o & 13870 \\
\hline .141 & 5 & .703 & 2393 & 76263 \\
\hline .141 & $a$ & .563 & 2610 & $7 \times 881$ \\
\hline $.2 A_{1}$ & 3 & .422 & 5711 & A0592 \\
\hline .101 & 1 & .141 & 3107 & 87699 \\
\hline .000 & 0 & $.00 n$ & & 67699 \\
\hline
\end{tabular}

EHERTS A SBFSSMFAT STIITY

SITE ALIIUIIFA QSSOFT

PROJ SOS SITE H

AVEHAGF THAPGHATHLF $C_{0}, 19.4$ 
POGRAME WS5REI IVERRIONE AORMSI I20 MAP 791 gen on data avallahle is of H/Jan/on

I THE PEAIDd nOV .1479 In HOV .1979

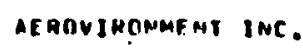

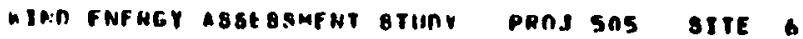

SIIF ALTITIDE, Q35OFT BITE EXPONEMTS 1900

avfrage tempepathe $c, 0.9$

TOTAL HUIKS ORSEHVD -. T20

\begin{tabular}{|c|c|c|c|}
\hline $\begin{array}{c}\text { MOSSPO } \\
\text { MPH } \\
(10 \mathrm{HT})\end{array}$ & $\begin{array}{l}P O W F A \\
(M / M A R 2)\end{array}$ & $\begin{array}{l}\text { MOHAS } \\
\text { PERJOA }\end{array}$ & $\begin{array}{l}\text { RELATIVE } \\
\text { FREOUENC }\end{array}$ \\
\hline $\begin{array}{l}0 \\
1 \\
2 \\
3 \\
9 \\
5 \\
6 \\
7 \\
6 \\
9 \\
10 \\
11 \\
12 \\
13 \\
19 \\
15 \\
16 \\
17 \\
18 \\
19 \\
20 \\
21 \\
22 \\
23 \\
20 \\
25 \\
26 \\
21 \\
28 \\
29 \\
30 \\
31 \\
32\end{array}$ & $\begin{array}{r}10 \\
0 \\
1 \\
2 \\
4 \\
9 \\
15 \\
23 \\
35 \\
56 \\
60 \\
91 \\
118 \\
150 \\
181 \\
230 \\
279 \\
335 \\
391 \\
467 \\
505 \\
631 \\
125 \\
929 \\
901 \\
1064 \\
1197 \\
1340 \\
1095 \\
1661 \\
1639 \\
2029 \\
2231\end{array}$ & $\begin{array}{l}5 \\
94 \\
33 \\
30 \\
23 \\
16 \\
22 \\
13 \\
20 \\
28 \\
30 \\
91 \\
45 \\
31 \\
35 \\
52 \\
36 \\
24 \\
35 \\
23 \\
32 \\
21 \\
15 \\
13 \\
13 \\
8 \\
11 \\
6 \\
4 \\
2 \\
1 \\
2 \\
1\end{array}$ & 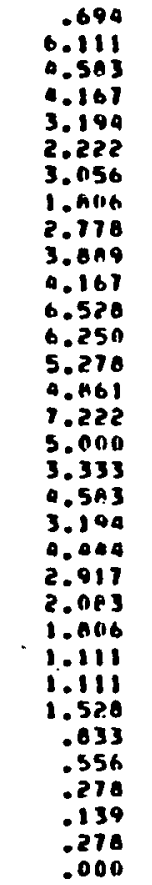 \\
\hline
\end{tabular}
CUMULiptive
MOURS
Cumiletive PELATIVE
TPEOUFNEY

120
715
611
631
608
585
569
507
534
519
086
056
4199
364
328
291
239
213
179
146
123
91
10
55
42
34
26
15
0
5
3
2
0

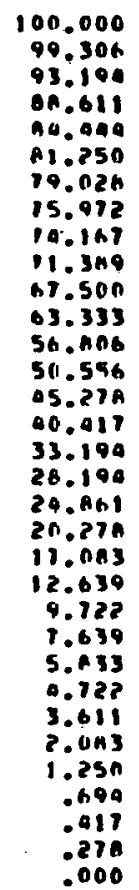

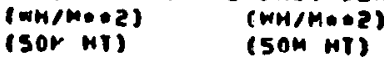

\begin{tabular}{|c|c|}
\hline 0 & \\
\hline 10 & 6 \\
\hline $\begin{array}{r}55 \\
110\end{array}$ & i16 \\
\hline i36 & 313 \\
\hline 320 & 636 \\
\hline $3 n 0$ & 940 \\
\hline 697 & 1637 \\
\hline $139 \%$ & 3027 \\
\hline $2 n 03$ & $507 n$ \\
\hline 4260 & 9330 \\
\hline 5205 & 10625 \\
\hline .5665 & 20310 \\
\hline 6500 & 26849 \\
\hline 11951 & $30 n 00$ \\
\hline 10041 & ABAMI \\
\hline An>o & Shern \\
\hline I31ES & 69976 \\
\hline 111742 & n'וn' \\
\hline 17032 & 90150 \\
\hline 13223 & 111393 \\
\hline 10A76 & 122269 \\
\hline 16871 & I3 3040 \\
\hline $\begin{array}{l}1531 \\
651 ?\end{array}$ & 100571 \\
\hline $\begin{array}{r}6512 \\
13165\end{array}$ & $\begin{array}{l}\text { lagnas } \\
\text { lop24A }\end{array}$ \\
\hline Bna? & 110290 \\
\hline 5979 & 176269 \\
\hline 3322 & 179590 \\
\hline 1039 & 181429 \\
\hline An5? & 3195406 \\
\hline & 105486 \\
\hline
\end{tabular}




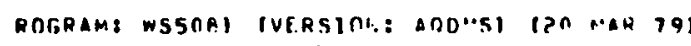
SEO OH DATA aVAJLAMLF AS OF HIJAMJaO

R THE PERIOI JIL .1979 IO JIL .1979

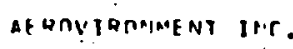

\begin{tabular}{|c|c|}
\hline $\begin{array}{c}\text { GNDSPD } \\
\text { MPM }\end{array}$ & $\begin{array}{c}\text { Pnut R } \\
(n / m \in a 2)\end{array}$ \\
\hline & \\
\hline 0 & 0 \\
\hline i & $n$ \\
\hline 2 & 0 \\
\hline 3 & 2 \\
\hline$a$ & $a$ \\
\hline 5 & 8 \\
\hline 6 & 13 \\
\hline 7 & ?1 \\
\hline A & 32 \\
\hline 9 & $\begin{array}{l}35 \\
45\end{array}$ \\
\hline 10 & 6? \\
\hline 11 & $\begin{array}{l}n_{3} \\
A_{3}\end{array}$ \\
\hline 12 & IOR \\
\hline 13 & 131 \\
\hline 14 & $i 7 i$ \\
\hline 15 & 210 \\
\hline it & 255 \\
\hline 37 & 3 rin \\
\hline$i s$ & $3 n 3$ \\
\hline 19 & 427 \\
\hline in & 498 \\
\hline 21 & 576 \\
\hline 22 & nes 3 \\
\hline 23 & 757 \\
\hline 24 & Poo \\
\hline 25 & 972 \\
\hline 30 & 1094 \\
\hline 27 & $1 \geq 25$ \\
\hline
\end{tabular}

TOTAL HMIIRS RHSERVEO -- ?Q9

RFLATIVE

FREDIIFNCY

CIIMULi it IVE HOURS.

CUMIILATIVE
RELATIUF

RELATIVE
FREDIIENCY
TOTAL
ENFHEY DENSITY FNEFGY DENSITY

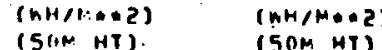

SITE ALTITIINE: 516IFT

PROJ 505 SIIE,

avepage trmperatilat C.: 23.3

\begin{tabular}{|c|c|c|}
\hline nn.non & 0 & \\
\hline $\begin{array}{l}96.662 \\
97.459\end{array}$ & ? & in \\
\hline 95.987 & $2 n$ & 3 \\
\hline 91.973 & 36 & 59 \\
\hline A. .963 & $\operatorname{lan}$ & 199 \\
\hline A2.943 & $10 \mathrm{~A}$ & 347 \\
\hline 19.264 & 192 & 539 \\
\hline $7 \mathrm{h.P9a}$ & 510 & 1048 \\
\hline $71 . .903$ & 907 & 1955 \\
\hline 64.214 & AAD & 2ban \\
\hline AD. 535 & 1242 & उAA? \\
\hline 55.518 & 2903 & B)AS \\
\hline 46.482 & 2050 & AB3A \\
\hline 01.472 & 2561 & 11347 \\
\hline 36.455 & 5670 & 17067 \\
\hline 27.425 & 6371 & $2303 \mathrm{~A}$ \\
\hline 19.nta & 6725 & 30163 \\
\hline $11.70 t$ & $36>0$ & 33797 \\
\hline A. 3n1 & PQA7 & 36770 \\
\hline h. 1120 & 1093 & 38273 \\
\hline 5.017 & 3057 & a) 130 . \\
\hline $3.0 \mathrm{in}$ & $19 A A$ & A371A \\
\hline $2.0 n 7$ & 1514 & 4523? \\
\hline $.1 .33 \mathrm{H}$ & 1720 & $4+952$ \\
\hline.+69 & 972 & 47920 \\
\hline .334 & 1090 & 00018 \\
\hline $.0 n 0$ & 0 & 09018 \\
\hline
\end{tabular}




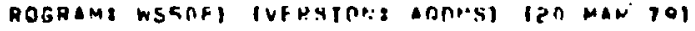

SEO IN PRATA AVAILAFLE A5 IF T1/JAHJAO

R the perion allo .1979 in alls, .1979
ATRTVJROMNENT BIIC.

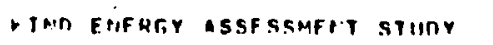

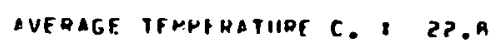

IDTAL MUIIHS OASERVED -- TUA

\begin{tabular}{|c|c|}
\hline \multirow{2}{*}{$\begin{array}{c}\text { ANISPO } \\
\text { PAPH } \\
(1 O M \text { HT })\end{array}$} & 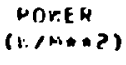 \\
\hline & \\
\hline$n$ & 0 \\
\hline 1. & 0 \\
\hline 2 & 0 \\
\hline 3 & 2 \\
\hline 4 & 4 \\
\hline 5 & A \\
\hline 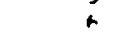 & 13 \\
\hline 7 & 21 \\
\hline p. & 32 \\
\hline 9 & 45 \\
\hline 10 & 62 \\
\hline i1 & 43 \\
\hline 12 & $\operatorname{InB}$ \\
\hline 13 & 131 \\
\hline 14 & יודי \\
\hline 15 & 210 \\
\hline in & 255 \\
\hline 17 & 306 \\
\hline is & 364 \\
\hline 19 & \\
\hline $2 n$ & 499 \\
\hline 21 & 577 \\
\hline 22 & 660 \\
\hline 23 & 754 \\
\hline 24 & ROL \\
\hline 25 & 074 \\
\hline 26 & 1096 \\
\hline
\end{tabular}

HnuPS PFRION

RFLativa FREDIIENCY

\section{CUMMILATIVE} HOUHS CIIHUATIVE
RELATIUF RELATIUF

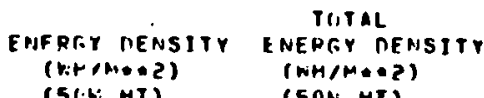

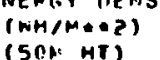

$106.010 n$ 99.464
98.656 93.508 04.946 15.94

$6 R .81$

63.44

57.258

$5 ? .151$

07.177

Q1. 935

37.03

32.06

?7.01

2).237

13.91

10.AAT

7.12

4.7110

$2 . A 23$
$1.47 A$

1.478
.672

.8xa

.134
.000

\begin{tabular}{|c|c|}
\hline n & n \\
\hline 1 & 1 \\
\hline 19 & $2 n$ \\
\hline 108 & 127 \\
\hline 267 & 395 \\
\hline 4) 3 & An \\
\hline & 1347 \\
\hline $9 R 4$ & 2330 \\
\hline 1213 & 3540 \\
\hline IAA2 & 522A \\
\hline 2032 & 1657 \\
\hline 2005 & 10562 \\
\hline sthata & 14226 \\
\hline 5754 & 10980 \\
\hline $735 \mathrm{P}$ & 27337 \\
\hline $5 A Q 3$ & 33230 \\
\hline htal & उ9A71 \\
\hline 71146 & 46917 \\
\hline ก)A? & 57100 \\
\hline 7699 & 10100 \\
\hline A9AD & 71783 \\
\hline 5775 & $77 \leq 57$ \\
\hline 39Aם & AIs01 \\
\hline 2?? & ATPIT \\
\hline Ar? & 84679 \\
\hline 974 & A5650 \\
\hline & A565a \\
\hline
\end{tabular}




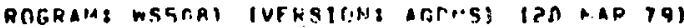

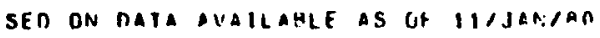

R THE PERINE SFt .1979 in SEP .1974
AFROVIORRIMENT INC.

total mouras ofigerven -. 120

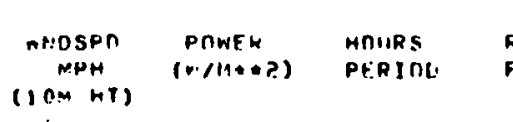

\begin{tabular}{|c|c|}
\hline$r$ & $n$ \\
\hline 1 & $n$ \\
\hline$?$ & $\begin{array}{l}1 \\
2\end{array}$ \\
\hline a & $\begin{array}{l}2 \\
4\end{array}$ \\
\hline 5 & A \\
\hline 6 & 14 \\
\hline 7 & 22 \\
\hline$\epsilon$ & 32 \\
\hline 9 & 46 \\
\hline 10 & +3 \\
\hline 11 & 84 \\
\hline 12 & lng \\
\hline 13 & 139 \\
\hline 14 & 173 \\
\hline 15 & 213 \\
\hline 16 & 259 \\
\hline 17 & 310 \\
\hline $1 \mathrm{H}$ & $3 \sin$ \\
\hline 19 & 433 \\
\hline 20 & 505 \\
\hline 21 & SAS \\
\hline 22 & +72 \\
\hline 23 & $7 \therefore B$ \\
\hline
\end{tabular}

720
698
673
645
615
577
532
472
413
356
299
234
185
151
106
67
39
26
20
12
7
4
1
6

pelative

FEOIIENCY

Cumilative HOURS

CiinILATIVE
ReLATIVE HELATIVE
FREDUFNRY

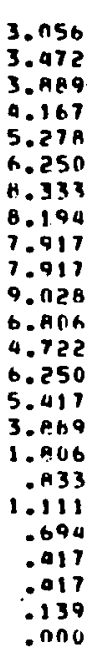

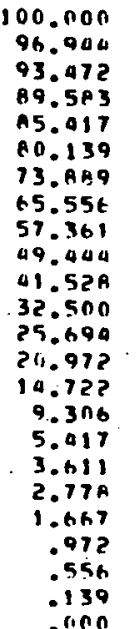
ENERTY DENSITY FERTAL TEN ENERTY DENSITY FNEREY DENSITY

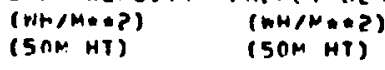

SIIF AL IIIUTE: SIAIFI

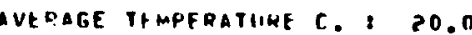




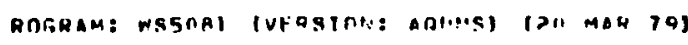

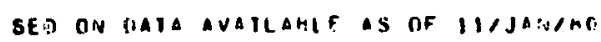

R THE PERION IIC .1079 IO OC, .1070

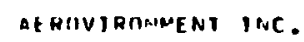

TOTAL MIIHES OPSERVED -- 744
C CHUULATIVE RELATIVE RELATIVE WNDSPR Pninfe

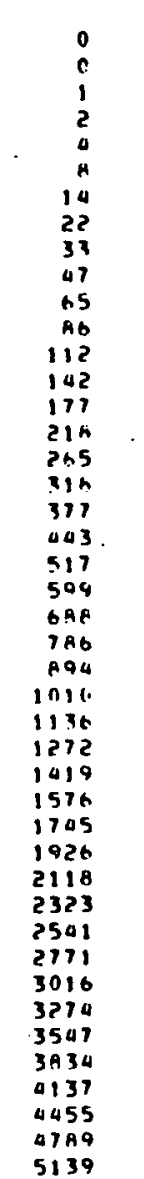

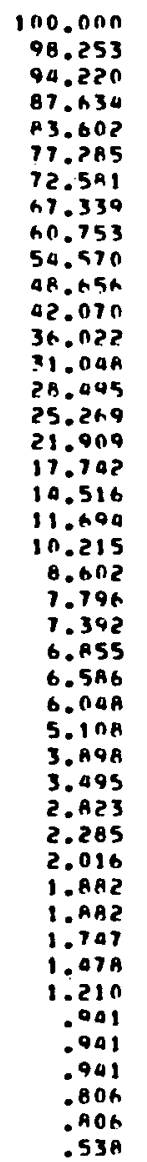

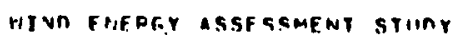

STTF ALIJTIRE: SIRSE

DROJ 505 SITE 1

average tfmperature C. 8 19.0

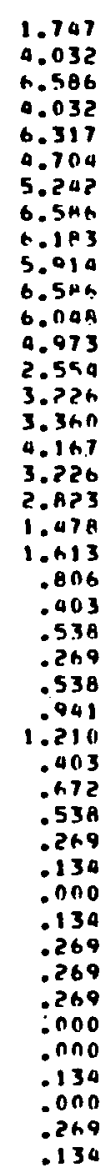

\begin{tabular}{|c|c|c|c|}
\hline 13 & 1.747 & & 709 \\
\hline 30 & 4.032 & & 131 \\
\hline 7 & 6.586 & & 101 \\
\hline 30 & 0.032 & & 658 \\
\hline 47 & 6.317 & & A22 \\
\hline $\begin{array}{l}35 \\
39 \\
39\end{array}$ & $\begin{array}{l}0.7044 \\
5.248\end{array}$ & & 575 \\
\hline $\begin{array}{l}39 \\
09\end{array}$ & $\begin{array}{l}5.227 \\
6.54 a\end{array}$ & & 540 \\
\hline 96 & $\begin{array}{l}0.046 \\
0.1 P 3\end{array}$ & & $\begin{array}{l}501 \\
45 ?\end{array}$ \\
\hline 40 & 5.010 & & and \\
\hline 49 & $6.5 \mathrm{ma}$ & & $3+2$ \\
\hline 37 & $\begin{array}{l}6.009 \\
9.973\end{array}$ & & $\begin{array}{l}313 \\
268\end{array}$ \\
\hline 19 & 2.559 & & 231 \\
\hline$?$ & 3.226 & & .212 \\
\hline 25 & $3.34 n$ & & $19 \mathrm{~B}$ \\
\hline $\begin{array}{l}31 \\
24\end{array}$ & $\begin{array}{l}4.167 \\
3.220\end{array}$ & & 163 \\
\hline 21 & $2 . A P 3$ & & $\begin{array}{l}138 \\
1119\end{array}$ \\
\hline 11 & 1.478 & & A7 \\
\hline 12 & 1.613 & & 76 \\
\hline h & .806 & & no \\
\hline 3 & $\begin{array}{r}.403 \\
.538\end{array}$ & & $\begin{array}{l}5 A \\
55\end{array}$ \\
\hline 2 & .269 & & 51 \\
\hline 4 & .538 & & 09 \\
\hline 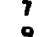 & .941 & & 45 \\
\hline 4 & 1.210 & & 38 \\
\hline 5 & $\begin{array}{l}4015 \\
: 472\end{array}$ & & 26 \\
\hline 4 & $.53 A$ & - & 2) \\
\hline 2 & .569 & & 17 \\
\hline 童 & $\begin{array}{r}-134 \\
000\end{array}$ & & 15 \\
\hline 1 & .134 & & 10 \\
\hline ? & .269 & & 13 \\
\hline$?$ & .269 & & 11 \\
\hline ? & $\begin{array}{l}260 \\
: 000\end{array}$ & & $?$ \\
\hline$n$ & . nno & & 7 \\
\hline ! & $\begin{array}{r}134 \\
000\end{array}$ & & $?$ \\
\hline & $\begin{array}{r}0000 \\
-269\end{array}$ & - & : \\
\hline 1 & .130 & & $a$ \\
\hline
\end{tabular}

ENEPGY RENBITY ENERTY TOENGITY

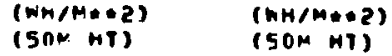

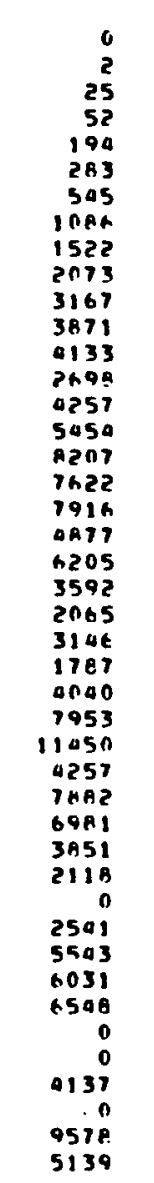

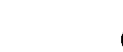

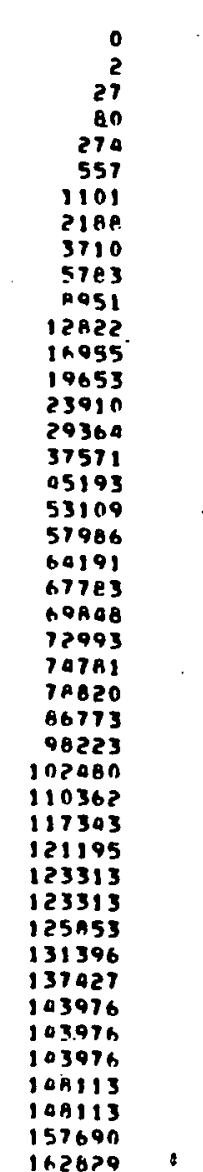




\begin{tabular}{|c|c|c|c|c|c|c|c|}
\hline $\begin{array}{l}94 \\
75\end{array}$ & $\begin{array}{l}5 s 0 n \\
5 \text { Han }\end{array}$ & n & . (1)161) & 3 & $.01 / 3$ & $n$ & 16,3820 \\
\hline an & करे? & $i$ & $\begin{array}{r}.260 \\
.134\end{array}$ & 3 & .403 & $117 A 0$ & 174610 \\
\hline 47 & n>11 & 0 & onuo & $n$ & $\begin{array}{l}134 \\
.0 n 00\end{array}$ & $\begin{array}{r}6>9 ? \\
n\end{array}$ & $\begin{array}{l}1809 n 1 \\
\text { 18n4n! }\end{array}$ \\
\hline
\end{tabular}




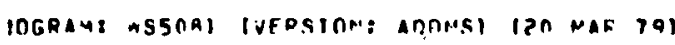

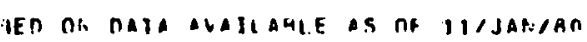

I THE PERIDO JIL .1979 10 Jill. 1479
afonviRonmant ine.

TOTAL HIUHS OHSEHVE -. 156 pelaitive cumillative

FREDIENCY

HOIIRS

$\underset{(n>M+\infty)}{P(n+m)}$

PFPIOO

(10: $H T)$

0
1
2
3
4
5
$-\quad 6$
7
8
9
10
11
12
13
10

0
0
1
2
4
8
14
22
33
47
44
86
111
142
171

19
11
15
23
20
34
18
6
6
8
0

$11.53 A$
7.051

9.615

14.704

16.667

21.795
11.536

?. 564

$5.5+4$

.000

1.282

-000
.0245

¿ू

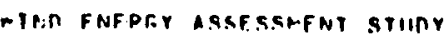

SITF ALTITHLE: DZSOFT

AVERATE TFMPHRATIRF $C_{0}: 23.3$
CIINULATIVE RELATIVE HE AIIF NC

\section{ENEREY DENSITY ERERTY TERTITY}

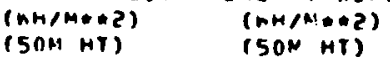

100.000
89.062
81.010
11.795
57.051
40.395
18.590
1.051
4.087
1.923
1.523
1.923
.021
.001
.0110

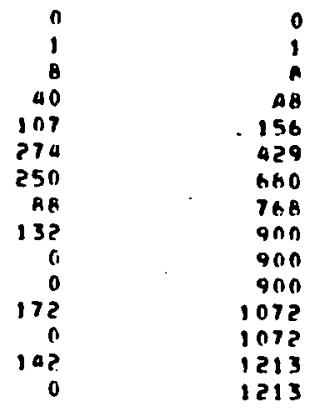


106RAME MS5OBI [VERSION: LONMSI $(20$ MAR 79]

IED ON DATA IVAJLABLE AS OF II/JAN/OO

I THE PERIOD aUG .1979 TO aUg .1979
AEROVIRONMENT INC.

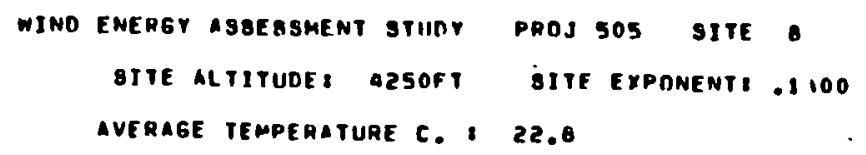

TOTAL MOURS OBgERVED -- 696

\begin{tabular}{|c|c|c|c|c|}
\hline $\begin{array}{l}\text { WNDSPD } \\
\text { MPH } \\
\text { (I OH NT) }\end{array}$ & $\begin{array}{l}\text { POWER } \\
(W / M+\infty 2)\end{array}$ & $\begin{array}{l}\text { MOURS } \\
\text { PERIOC }\end{array}$ & $\begin{array}{l}\text { RELATIVE } \\
\text { FREOUENCY }\end{array}$ & $\begin{array}{c}\text { CUMULATIV } \\
\text { MOURS }\end{array}$ \\
\hline $\begin{array}{l}0 \\
1 \\
2 \\
3 \\
0 \\
5 \\
6 \\
7 \\
6 \\
9 \\
10 \\
11 \\
12 \\
13 \\
14 \\
15 \\
16 \\
11\end{array}$ & $\begin{array}{r}0 \\
0 \\
0 \\
1 \\
2 \\
2 \\
0 \\
14 \\
22 \\
33 \\
47 \\
65 \\
86 \\
112 \\
112 \\
177 \\
218 \\
264 \\
317\end{array}$ & $\begin{array}{l}91 \\
55 \\
67 \\
118 \\
111 \\
104 \\
92 \\
46 \\
19 \\
12 \\
7 \\
2 \\
1 \\
0 \\
0 \\
0 \\
1 \\
0\end{array}$ & $\begin{array}{r}5.891 \\
7.902 \\
12.500 \\
16.959 \\
15.909 \\
10.943 \\
13.218 \\
6.609 \\
2.730 \\
1.720 \\
1.006 \\
.287 \\
1109 \\
.000 \\
.000 \\
.000 \\
9100 \\
.000\end{array}$ & $\begin{array}{r}606 \\
655 \\
600 \\
513 \\
305 \\
284 \\
180 \\
88 \\
42 \\
23 \\
11 \\
0 \\
2 \\
1 \\
1 \\
1 \\
1 \\
0\end{array}$ \\
\hline
\end{tabular}

\section{cumulative} RELATIVE FREOUENC

$$
\begin{aligned}
& 100.000 \\
& 99.109 \\
& 86.207 \\
& 73.707 \\
& 56.153 \\
& 40.805 \\
& 25.862 \\
& 12.609 \\
& 6.034 \\
& 3.305 \\
& 1.580 \\
& .575 \\
& .287 \\
& .194 \\
& .100 \\
& .109 \\
& .140 \\
& .1000
\end{aligned}
$$

EMERGY DENSITY ENETAL $\begin{array}{ll}\text { (WH/MADZ } & \text { (WH/MMAZ) } \\ \text { (5OM HT) } & \text { (5OM NT) }\end{array}$

\begin{tabular}{|c|c|}
\hline 0 & 0 \\
\hline 95 & a \\
\hline 206 & 254 \\
\hline 459 & 713 \\
\hline 630 & 1552 \\
\hline 1283 & 2835 \\
\hline 1019 & 3854 \\
\hline 628 & eanz \\
\hline 565 & 5047 \\
\hline 452 & 5099 \\
\hline 172 & 5671 \\
\hline 112 & 5782 \\
\hline 0 & 5782 \\
\hline 0 & $\begin{array}{l}3786 \\
5782\end{array}$ \\
\hline 264 & 6047 \\
\hline 0 & 6047 \\
\hline
\end{tabular}




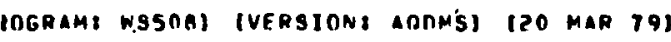

IEO ON DATa avallable as of II/Janjoo

1 THE PERIOD SEP. 1979 TO SEP .1979
IEROVIRONMENT INC.
WIND ENERGY ASSESSMENT STIURY

SITE ALTITHDE Q QSSOFT

PROJ 505 SITE

avepage temperature $c$. 20.0

TOTAL HOURS OBSERUEO $\ldots 559$

$\begin{array}{cc}\text { WNOSPD } \\ \text { MPH } \\ (1 O M H T) & \begin{array}{c}\text { POWER } \\ \text { (W/MAMZ) }\end{array} \\ & \\ 0 & \\ 1 & 0 \\ 1 & 0 \\ 2 & 1 \\ 3 & 2 \\ 9 & 4 \\ 5 & 0 \\ 6 & 19 \\ 7 & 22 \\ 9 & 33 \\ 9 & 98 \\ 10 & 65 \\ 11 & 87 \\ 12 & 113 \\ 13 & 194 \\ 10 & 179 \\ 15 & 220 \\ 16 & 260 \\ 17 & 321 \\ 17 & 381\end{array}$

HOURS
PERIDO

RELATIVE

FREOUENCY

Cumulative

CUMULATIVE

RELATIVE
FREDUENCY

ENERG DENSITY

(WH/MAR)

rorAL

HOURS

(SOM NT)

ENSITY

(WH/MACE)

$\begin{array}{rr}32 & 5.725 \\ 08 & 8.587 \\ 102 & 18.207 \\ 100 & 17.889 \\ 96 & 17.174 \\ 67 & 11.986 \\ 55 & 9.839 \\ 23 & 4.194 \\ 10 & 1.789 \\ 9 & .716 \\ 3 & .537 \\ 6 & 1.073 \\ 2 & .350 \\ 4 & .716 \\ 1 & .179 \\ 3 & .537 \\ 2 & .358 \\ 1 & .179 \\ 0 & .000\end{array}$

559
527
479
371
277
181
114
59
36
26
22
19
13
11
7
6
3
1
0

100.000
94.275
85.689
67.442
99.553
32.379
20.399
10.555
6.090
4.651
3.936
3.399
2.326
1.964
1.252
1.073
.537
.179
.000

0
3
53
176
401
597
176
515
334
190
196
522
226
514
179
661
535
321
0

0
3
56
-233
630
1181
1957
2073
2807
2994
319.9
3715
3991
0515
4690
5356
5891
6212
6212 
POGFAMI WS5OBI IVERSTONI ADORSI IZO MAR 79) BEO ON DRTA AVALABLE AS OF HIJANIOO

- THE PERIOD OCT .1979 to OCT .1979
AFROVIRONMENT INC.

TOTAL HOURS OBSERVED -.

470

\begin{tabular}{|c|c|}
\hline $\begin{array}{l}\text { WNC SPD } \\
\text { MPP } \\
\text { (ION NT })\end{array}$ & $\begin{array}{l}\text { POWER } \\
\text { [W/MACA }\end{array}$ \\
\hline 0 & \\
\hline$\cdot \begin{array}{l}1 \\
2\end{array}$ & \\
\hline 3 & \\
\hline $\begin{array}{l}4 \\
5\end{array}$ & \\
\hline 6 & 19 \\
\hline 7 & 23 \\
\hline A & 49 \\
\hline$\therefore$ & 49 \\
\hline 10 & 67 \\
\hline $\begin{array}{l}11 \\
12\end{array}$ & 116 \\
\hline $\begin{array}{l}12 \\
13\end{array}$ & $\begin{array}{l}116 \\
107\end{array}$ \\
\hline 14 & 1 A 3 \\
\hline 15 & 226 \\
\hline 16 & 274 \\
\hline 17 & 328 \\
\hline 16 & 390 \\
\hline 19 & 958 \\
\hline 26 & 535 \\
\hline
\end{tabular}

NOURS
PERIOO

RELATIVE

FRE OUENCY

CUMULATIVE
HOURS

3
25
25
53
55
65
66
51
33
29
21
18
6
2
5
3
3
2
3
2
0
CunuLATIVE RELATIVE
FRE DUENCY

100.000
99.362
90.043
60.723
17.007
65.745
51.915
37.072
27.021
20.000
13.030
9.362
5.532
4.255
3.030
2.766
2.128
1.089
1.060
.426
.000

ENERGY DENSTIY ENERGY DENSITY (NHHMEAL) (WHAMEAL)
(SOMHT)
PROJ 505 SITE.

DITE EXPONENT: .1100

AVERAGE TEMPERATURE $C$. 19.0

$\begin{array}{rr}0 & \\ 2 & 0 \\ 13 & 2 \\ 96 & 15 \\ 235 & 111 \\ 543 & 306 \\ 953 & 809 \\ 1169 & 1842 \\ 1129 & 3011 \\ 1013 & 9141 \\ 1000 & 5550 \\ 1601 & 6958 \\ 693 & 6559 \\ 294 & 9252 \\ 917 & 9546 \\ 677 & 11961 \\ 921 & 11100 \\ 657 & 11961 \\ 1110 & 12618 \\ 917 & 13788 \\ 0 & 10705 \\ & 10705 \\ & \end{array}$


DOGRAMZ WSSOBI IVERSIONE AROMSI ISO MAR 701

SED DN DaTa avaILable as OF II/JAN/aO

R THE PERIOD NOV, 1979 TO NOV .1979
AERTVIRTNMENT TNE.
WIND ENFRG ABSE 8SMENT STUDY PROJ 505 SITE

GITE ALTJTUNES AZSOFY

BITE EXPONENT: .1000

average temperature $C$. 10.9

TOTAL MOURS OBSERUED -. 120

\begin{tabular}{|c|c|c|c|}
\hline $\begin{array}{c}\text { WNDSPD } \\
\text { HPH } \\
(10 M \mathrm{HT})\end{array}$ & $\begin{array}{l}\text { POWER } \\
(W / M: A 2)\end{array}$ & $\begin{array}{c}\text { MOURS } \\
\text { PERIOD } \\
.\end{array}$ & $\begin{array}{l}\text { RELATIVE } \\
\text { FREOUENCY }\end{array}$ \\
\hline $\begin{array}{l}0 \\
1 \\
2 \\
3 \\
0 \\
5 \\
6 \\
7 \\
8 \\
9 \\
10 \\
11 \\
12 \\
13 \\
10 \\
15 \\
16 \\
17 \\
18 \\
19 \\
20 \\
21 \\
22 \\
23 \\
24 \\
25 \\
26 \\
27 \\
28 \\
29 \\
30 \\
31 \\
32 \\
33 \\
34 \\
35 \\
36 \\
36\end{array}$ & $\begin{array}{r}0 \\
0 \\
1 \\
2 \\
4 \\
9 \\
15 \\
15 \\
23 \\
35 \\
50 \\
68 \\
91 \\
118 \\
150 \\
188 \\
231 \\
280 \\
336 \\
399 \\
469 \\
547 \\
633 \\
728 \\
831 \\
945 \\
1068 \\
1201 \\
1345 \\
1500 \\
1667 \\
1845 \\
2036 \\
2239 \\
2456 \\
2686 \\
2930 \\
3188\end{array}$ & $\begin{array}{l}9 \\
29 \\
34 \\
40 \\
51 \\
36 \\
97 \\
92 \\
99 \\
37 \\
43 \\
35 \\
26 \\
36 \\
18 \\
35 \\
29 \\
22 \\
11 \\
12 \\
15 \\
19 \\
10 \\
10 \\
? \\
7 \\
2 \\
0 \\
2 \\
0 \\
1 \\
1 \\
1 \\
0 \\
1 \\
2 \\
0\end{array}$ & $\begin{array}{l}1.250 \\
4.028 \\
9.122 \\
5.556 \\
7.083 \\
5.000 \\
6.528 \\
5.833 \\
6.111 \\
5.139 \\
5.972 \\
4.861 \\
3.611 \\
4.722 \\
2.500 \\
9.861 \\
4.028 \\
3.056 \\
1.528 \\
1.667 \\
2.083 \\
2.639 \\
1.904 \\
1.389 \\
.912 \\
.912 \\
.218 \\
.556 \\
.218 \\
.000 \\
.139 \\
.139 \\
.139 \\
.000 \\
.139 \\
.278 \\
.000\end{array}$ \\
\hline
\end{tabular}

720
111
682
608
608
557
521
470
432
308
351
318
213
247
213
195
160
131
109
98
86
11
52
30
24
21
14
12
8
6
6
5
6
3
3
2
0

CumULATJUE

RELATIVE

FRE QUENCY

100.000

98.750
99.722

94.722
90.000

04.448

71.361

15.361

250

20

53.849

06.750
42.778

37.917

39.306

59.593

57.063

22.222

16.194
15.139

15.139
13.611

13.61 .1

11.904
9.061

1.222

5.276

3.889

2.917

1.949

1.667

.033

.033

.690

.556

.417

.278
.000
ENERGY DENSITY ENERGY DENSITY (WH/MEA2) (WH/MNOL)

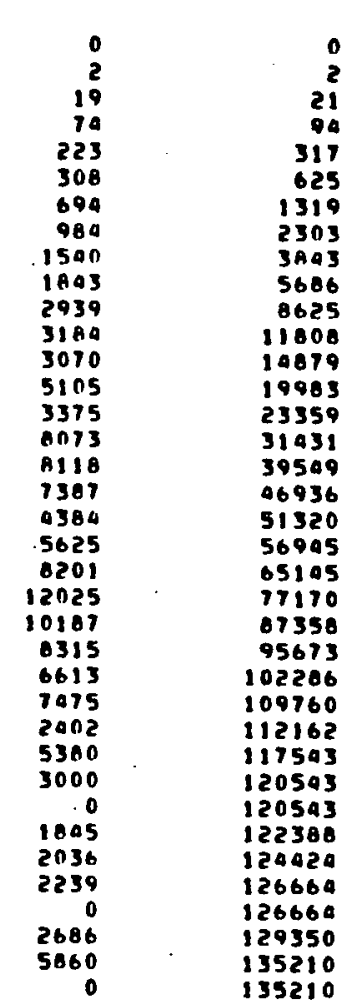




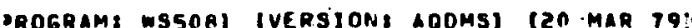

ISED ON DATA CVAILABLE AS OF MIJAN/BO JR THE PERIOD MAY 1979 TO MAY .1979
AEROVIAONMENT INC.
WIND ENERGY ASSE BSMENT BTHDY.

SITE ALTITUNE: SODOFT panj 505 site

aUfRAGE TEMPFRATURE $C$.

TOTAL MOURS OBSERVEO -. 109

\begin{tabular}{|c|c|c|c|c|c|c|c|}
\hline $\begin{array}{l}\text { WNDSPD } \\
\text { MPM } \\
(1 O M N I)\end{array}$ & $\begin{array}{l}\text { POWER } \\
\text { (W/ME: } 2)\end{array}$ & $\begin{array}{l}\text { HOURS } \\
\text { PERIOD }\end{array}$ & $\begin{array}{l}\text { RELATIVE } \\
\text { FREOUENCY }\end{array}$ & $\begin{array}{l}\text { CUMULATIVE } \\
\text { HOURS }\end{array}$ & $\begin{array}{l}\text { CUMULATIVE } \\
\text { RELATIVE } \\
\text { FRE UIIENCY }\end{array}$ & $\begin{array}{l}\text { ENERGY DENSITY } \\
\text { (WH/MELI) } \\
\text { (50M HT) }\end{array}$ & $\begin{array}{l}\text { TOTAL } \\
\text { FNERGY DENSI } \\
\text { (WH/MOEZ) } \\
\text { (SOM MT) }\end{array}$ \\
\hline $\begin{array}{r}0 \\
1 \\
2 \\
3 \\
0 \\
5 \\
6 \\
6 \\
1 \\
8 \\
9 \\
10 \\
11 \\
12 \\
13 \\
10 \\
15 \\
16 \\
17 \\
16 \\
19 \\
20 \\
21 \\
22 \\
23 \\
20 \\
25 \\
26 \\
27 \\
28 \\
29 \\
30 \\
31 \\
32 \\
33 \\
30 \\
35\end{array}$ & $\begin{array}{r}0 \\
0 \\
1 \\
2 \\
0 \\
8 \\
10 \\
22 \\
33 \\
47 \\
44 \\
86 \\
111 \\
1122 \\
117 \\
211 \\
264 \\
317 \\
316 \\
442 \\
515 \\
597 \\
686 \\
180 \\
891 \\
1007 \\
1132 \\
1268 \\
1419 \\
1571 \\
1740 \\
1919 \\
2111 \\
2315 \\
2532 \\
2762\end{array}$ & $\begin{array}{r}0 \\
2 \\
18 \\
31 \\
36 \\
35 \\
38 \\
38 \\
51 \\
36 \\
47 \\
35 \\
29 \\
34 \\
35 \\
42 \\
31 \\
80 \\
00 \\
25 \\
22 \\
6 \\
6 \\
5 \\
1 \\
2 \\
1 \\
1 \\
5 \\
1 \\
1 \\
4 \\
2 \\
2 \\
1 \\
0\end{array}$ & $\begin{array}{l}.000 \\
.282 \\
2.539 \\
0.372 \\
5.078 \\
4.937 \\
5.360 \\
5.360 \\
7.193 \\
5.078 \\
0.629 \\
0.937 \\
0.090 \\
0.795 \\
4.931 \\
5.924 \\
4.372 \\
5.642 \\
5.642 \\
3.526 \\
3.103 \\
.806 \\
.846 \\
.705 \\
.981 \\
.282 \\
.141 \\
.141 \\
.705 \\
.191 \\
.141 \\
.564 \\
.282 \\
.282 \\
.141 \\
.000\end{array}$ & $\begin{array}{l}709 \\
709 \\
707 \\
689 \\
658 \\
622 \\
587 \\
549 \\
511 \\
460 \\
424 \\
371 \\
392 \\
313 \\
279 \\
244 \\
202 \\
171 \\
131 \\
91 \\
66 \\
94 \\
38 \\
32 \\
21 \\
20 \\
18 \\
17 \\
16 \\
11 \\
10 \\
9 \\
5 \\
3 \\
1 \\
0\end{array}$ & $\begin{array}{r}100.000 \\
100.000 \\
99.718 \\
97.179 \\
92.007 \\
87.729 \\
62.793 \\
77.033 \\
72.073 \\
64.880 \\
59.003 \\
53.173 \\
48.237 \\
04.147 \\
39.351 \\
34.415 \\
28.491 \\
24.118 \\
18.477 \\
12.835 \\
9.309 \\
6.206 \\
5.360 \\
9.513 \\
3.808 \\
2.021 \\
2.539 \\
2.398 \\
2.257 \\
1.551 \\
1.410 \\
1.269 \\
.705 \\
.023 \\
.141 \\
.000\end{array}$ & $\begin{array}{r}0 \\
0 \\
9 \\
50 \\
148 \\
282 \\
529 \\
840 \\
1682 \\
1691 \\
3028 \\
3001 \\
3229 \\
0813 \\
6188 \\
9132 \\
6181 \\
12661 \\
15029 \\
1104 \\
11339 \\
3580 \\
0116 \\
3919 \\
6234 \\
2013 \\
1132 \\
1268 \\
7071 \\
1571 \\
1740 \\
7671 \\
4222 \\
4631 \\
2532 \\
0\end{array}$ & 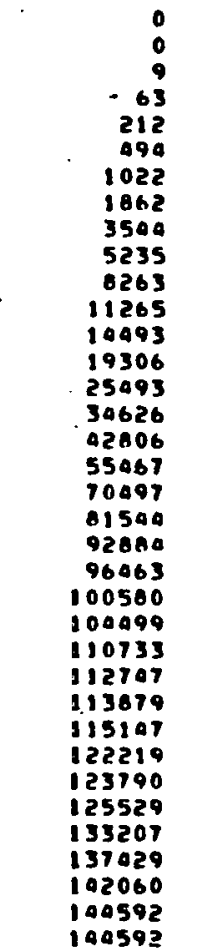 \\
\hline
\end{tabular}


[PROGRAMZ WS5OE) (VERSION: AQDMS) (2N MAR 79) BABED ON DATA AVAILABLE AS OF I1/JAN/BO

por THE PERIOD JUN 1979 TO JUN $\$ 1979$
AEROVIRONMENT INC.

TOTAL HOURS OBSERYED -- 120

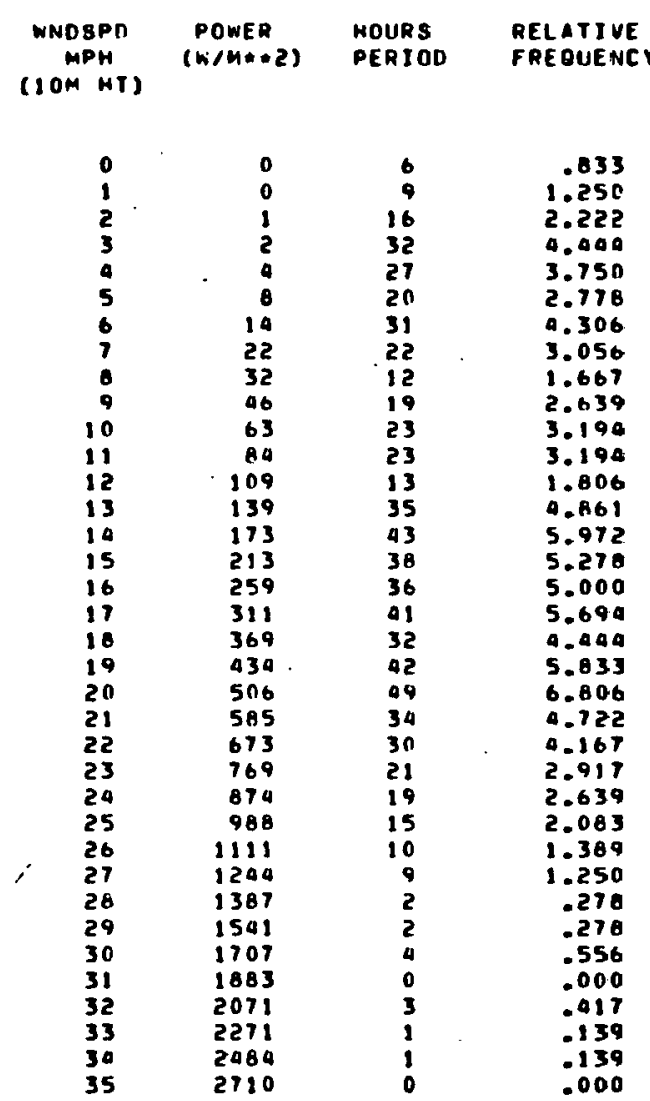

WINA ENFRGY ASSESSMENT STIINY

SJTE ALTITUNE: SA00FT

PPOJ SRS SITE 9

average temperatime C.: 17.0
CUMULATJUE RELATIVE
FREOUENCY

Cumulative

HnIIRS

720
714
705
689
657
630
610
579
557
545
526
503
480
467
432
389
351
315
270
242
210
151
117
87
66
17
32
22
13
11
9
5
5
2
1
0

TOTAL

ENERGY DENSITY ENERGY DENSTIY (WHAMANZ) (WH/MEOZ)

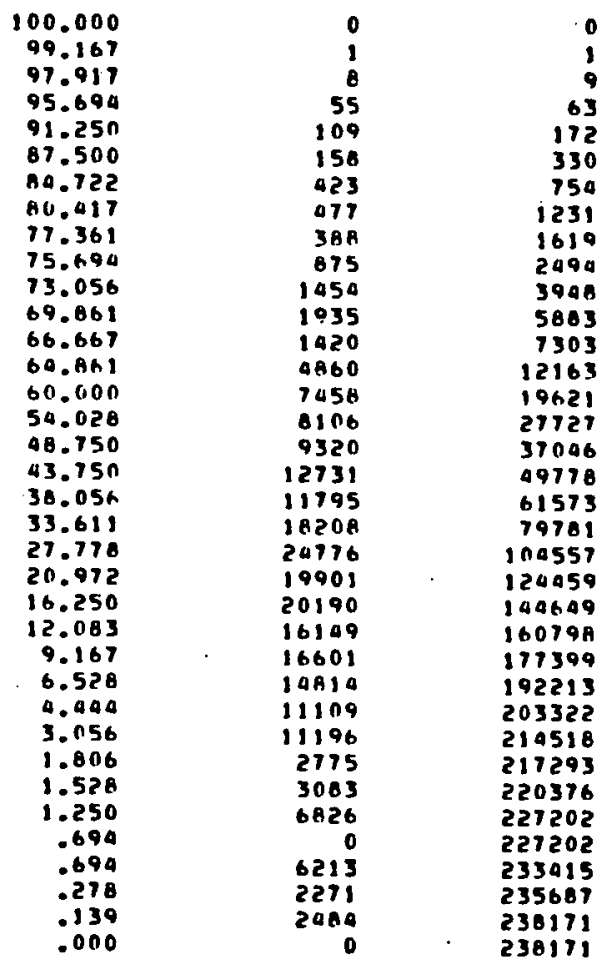


(PRIGRAMI WS5OA) (VERSIONI ADOMSI ISN MAR 19) BASED ON DATA iVAILABIE AS OF IIJJAN/AO

FOR THE PERION JUL .1979 IO JIIL .1979
AERTVIRONMENT INC.

\section{TOTAL HOURS OBSERVED -- 700}

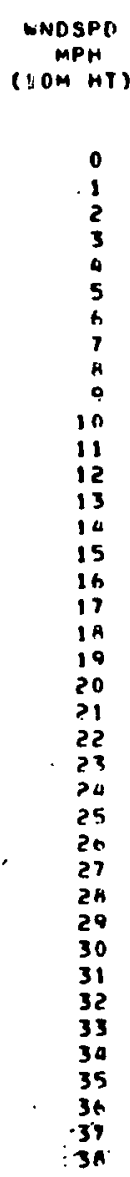

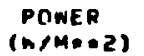

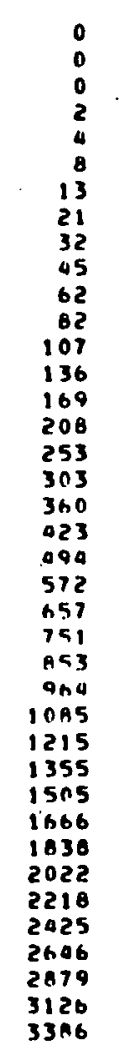

MOURS
PERIOD

RELATIVE

cumillative HOURS

ș
WINO ENERG ASSESSMFNT STUDY PROJ 5 NS SITE $\triangle$

SITE ALTITUDE: SAOOFT BITE EXPONENTI .1ONO

AVERAGe temperature $C$. 23.3

CUMILATIVE RELATIVE
FREDUENCY

ENERGY OFNSITY (MOMAME)

TOTAL
ENEAGY DENSITY

(WH/MNER)

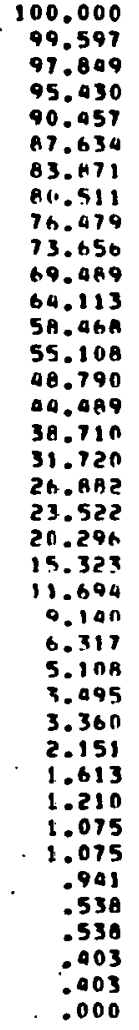

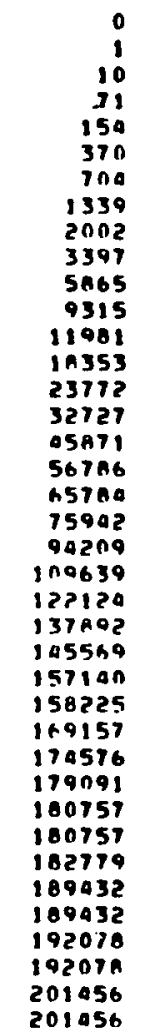


(PROGRAM: WS5OBI IVERSION: ADOMS) (20 MAR 791

BASED ON DATA AVATLABLE AS OF MJJAN/BO

FOR THE PERTOO ALG .1979 TO AUG .1979
AEROVIRTNMFET INC.

\section{TOTAL NDURS OESERVED -- 378}

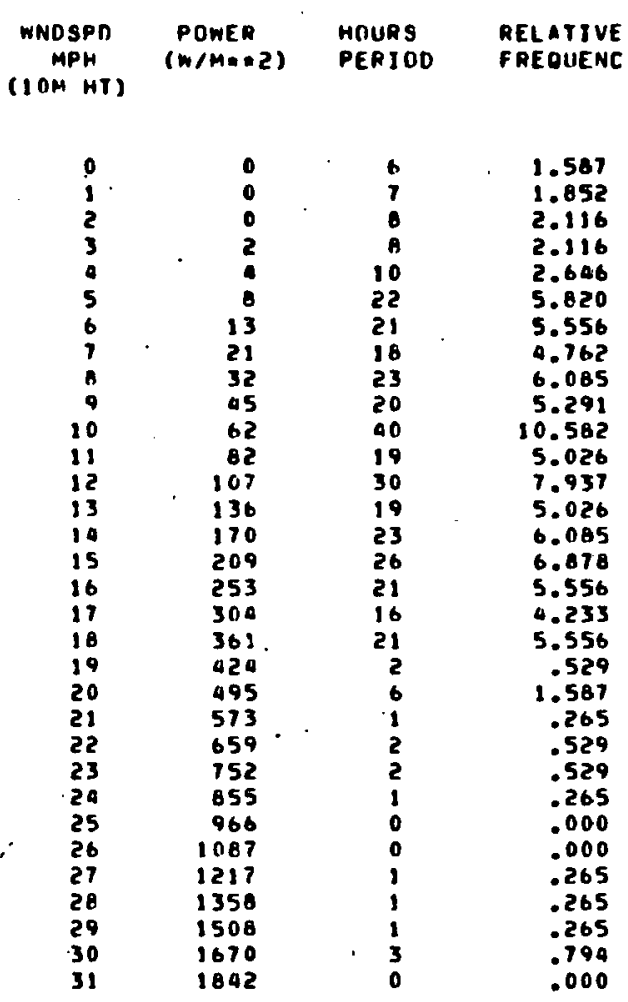

WJWI ENERG ASSF SSMENT BTIINY

SITE ALIITURE: S40OFT

PROS 505 SITE?

avfaAgF temperature $C_{0}$ : 22.0
CUMULATIVE RELATIVE Cumulative HOURS

378
372
365
357
309
339
317
296
278
255
235
195
176
196
127
104
10
57
41
20
18
12
11
9
7
6
6
6
5
4
3
0

100.000
98.013
96.561
94.040
42.328
99.683
63.862
78.307
73.505
67.060
62.169
51.587
46.561
38.620
33.598
27.513
20.635
15.079
10.097
5.291
4.762
3.175
2.910
2.381
1.852
1.567
1.587
1.581
1.323
1.058
.790
.000

ENERGY DENSITY (WH/MAOZ)

TOTAL. ENERGY DENSIIY (WH/MANZ)

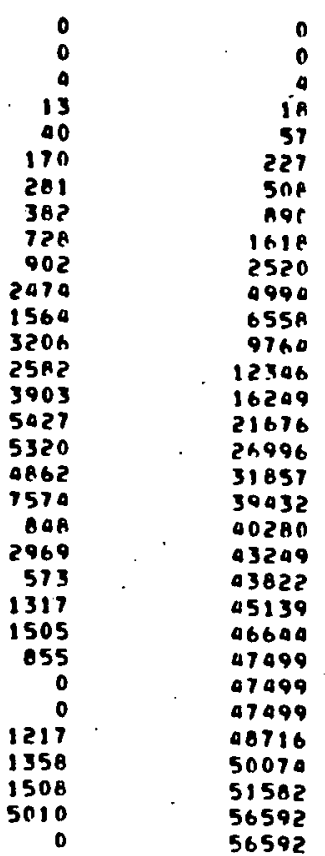


(PRCIGRAMB MSSOB) IVERSION: AODMSI (20 MAR TOI

Baseo on data avaILABLE AS OF MIJAN/BO

FOR IHE PERIOD SEP. 1979 IN SEP.1970
AFROVIRTNMENT INC.

MINO ENERGY ASSESSMENT BTHOY

SITE ALIITUNE SQOOFT

PROJ 505 SITE

Average IEMPEantuge co

SITE EXPONENTI. 1400

20.0

TOTAL HOURS OBSERVED -- 563

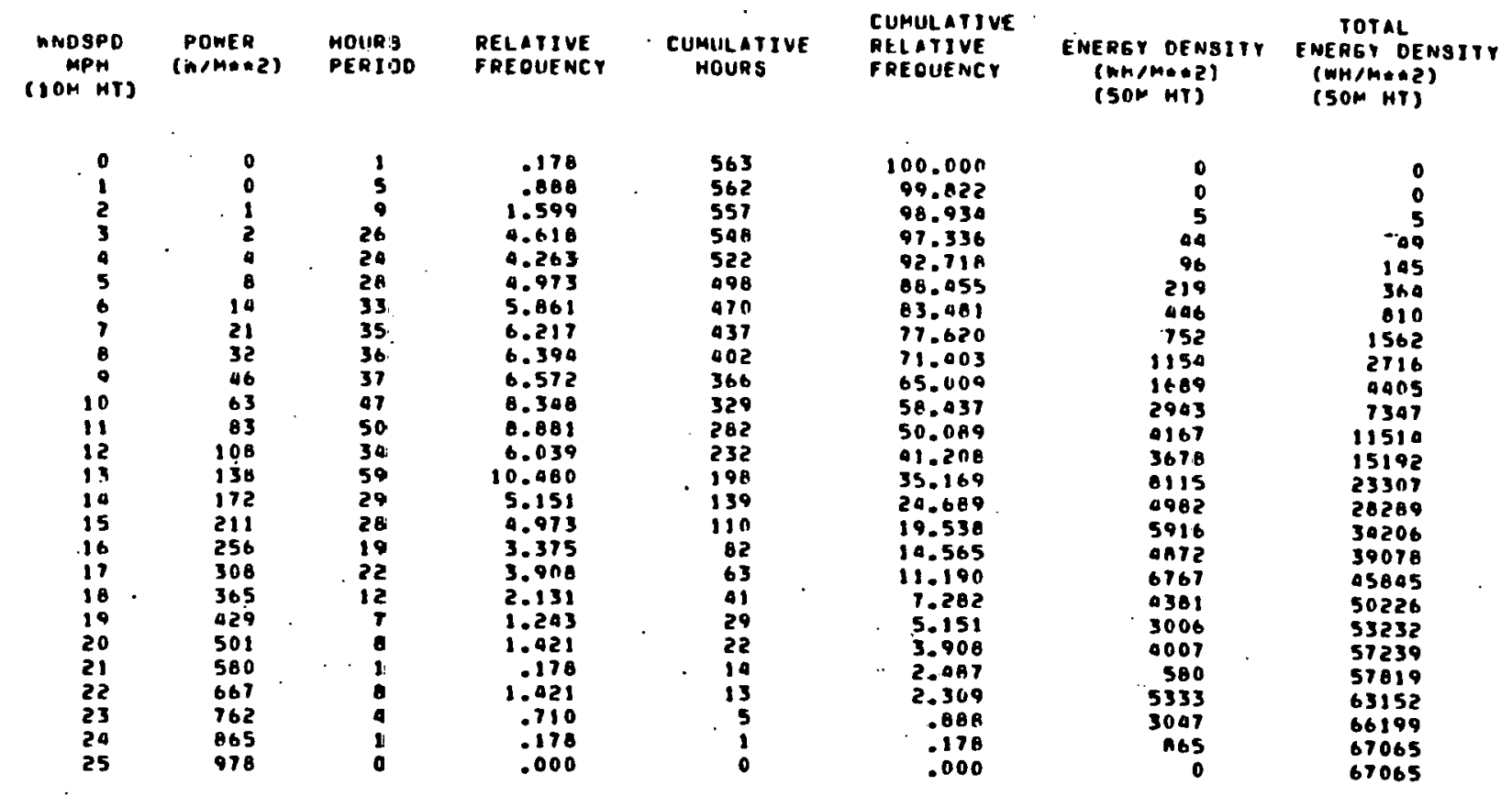


(PROGRAM: WS5OB] [VERSION, AODMS] [20 MAF 19]

Based DN DATa avaILable as OF II/JAN/Bo

FOR THE PERIOD OCT.1979 In OCT .1979
AEROVIRONMENT INC.
WINO ENERGY. ASSESSMENT STUDY

SJTE ALTITUDE: SAOOFT

PROJ 505 SITE?

BITE EXPONENTI. .1400

AVERAGE TEMPERATURE C.: 19.4

TOTAL HOURS OBSERVED -. 686

WNOSPO

POWER

MNURS PERTOD MOURS

CUMILLATIVE

RELATIVE
FRE OUENCY

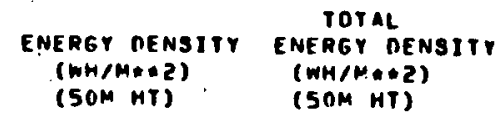
(1OM HT)
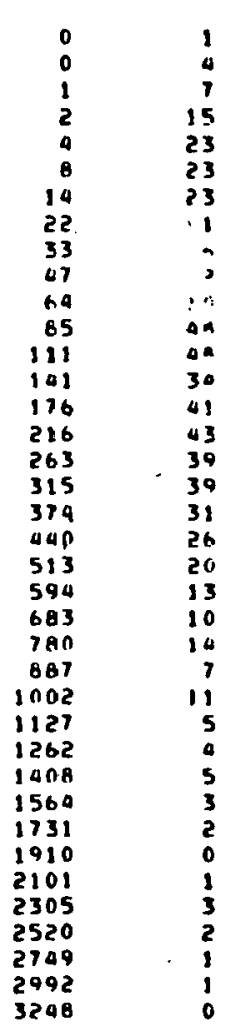

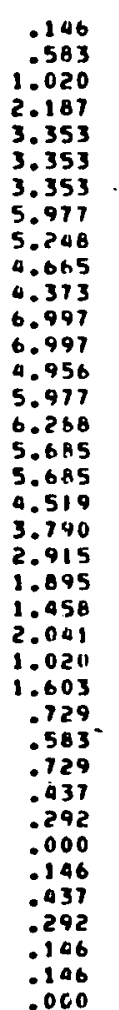

616
685
681
670
659
630
613
590
549
513
$4 A 1$
451
403
355
321
280
237
198
159
128
102
82
69
59
45
38
27
22
18
13
10
8
8
7
4
2
1
0

\begin{tabular}{|c|}
\hline 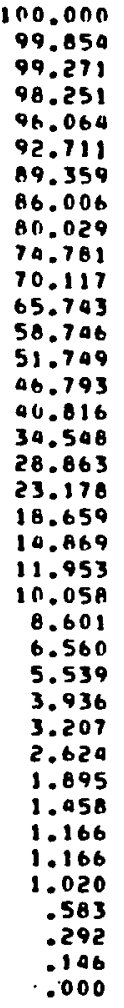 \\
\hline
\end{tabular}

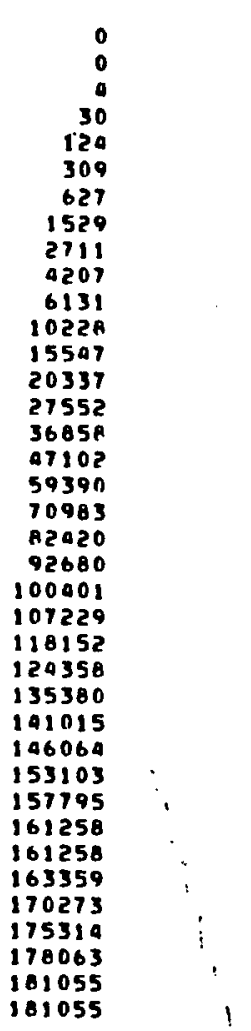


PPROGRAMI WSSOBS [VERSIONZ AORMS! I 20 MAR 791

HASEO ON OATA AVAILABLE AS OF HIJAN/BO

SOR THE PERIOD NOV .1979 10 NOV .1979
AFROVIRONMENT INC.

TOTAL MTURS OBSERVED -- 720
HOURS RELATIVE CUMULATIVE PERIOD FREOUENCY

$$
\text { TNDSPU }
$$

POWER

0
4
10
9
8
18
13
20
23
214
27
30
210
30
21
38
25
218
27
31
26
41
59
56
30
37
29
25
18
11
9
7
1
1
10

.000
.556
1.389
1.250
1.111
2.500
1.806
2.718
3.194
3.333
3.750
4.722
2.718
4.167
2.917
5.218
3.072
3.889
3.150
9.306
3.611
5.694
5.417
5.000
4.167
5.139
9.028
3.472
2.500
1.528
1.250
.972
.139
.139
.000

720
720
716
706
697
689
671
658
638
615
591
564
530
510
980
959
921
396
368
341
310
284
243
204
168
138
101
72
47
29
10
10
9
2
11
0

Cumulative RELATIVE
FREOUENCY REOIIENCY

100.000
100.000
99.409
98.056
96.806
95.690
93.190
91.389
88.611
85.011
82.083
18.333
73.611
10.833
66.667
63.750
58.972
55.000
51.111
41.361
43.056
39.044
33.150
28.333
23.333
19.167
10.028
10.000
6.528
4.028
2.500
1.250
.278
.139
.000

STTE ALTITHOEI SOONFT SITE EXPONENTI. 1000

505 SIIE

aVERAGE TEMPEQRTUPE $C$. 8.9 


\section{DISTRIBUTION}

No. of

Copies

\section{OFFSITE}

A. A. Churm

DOE Chicago Patent Group

9800 S. Cass Avenue

Argonne, IL 60439

5 D. F. Ancona/C. I. Aspliden

Department of Energy

600 E. Street, N.W.

Washington, DC 20545

5 G. P. Tennyson

Department of Energy

Albuquerque Operations Office

4501 Indian School Road N.E.

Suite 151

Albuquerque, NM 87110

F. R. Summers, P.E.

U.S. Department of Energy

Alaska Power Administration

P.0. Box 50

Juneau, AK 99802

27 DOE Technical Information Center

Peter Lissaman

Aerovironment, Inc.

$145 \mathrm{Vista}$ Avenue

Pasadena, CA 91107

W. A. Vachon

Arthur D. Little, Inc.

20 Acorn Park

Cambridge, MA 02140

Peter Smeallie

AWEA Windletter

1609 Connecticut Averiue N.W.

Washington, DC 20008

American Wind Energy Association

1621 Connecticut Avenue, N.W.

Fifth Floor

Washington, DC 20009
No. of

Copies
Richard Katzenberg

American Wind Energy Association

Natural Power, Inc.

New Boston, $\mathrm{NH}^{\cdot} 03070$

Nicholas Butler

Bonneville Power Administration

P.0. Box 3261-EIC

Portland, OR 97208

M. Ginosar/J. Lerner

California Solar Energy Commission

Energy Resources, Conservation and Development Commission

1111 Howe Avenue, Mail Stop 15

Sacramento, CA 95825

R. N. Meroney

Department of Civil Engineering

Colorado State University

Fort Collins, C0 80523

E. H. Gilmore

Department of Agriculture

Agriculture Research Service

Bushland, TX 79012

L. A. Li ljedahl

Departiment of Agriculture

Agriculture Wind Energy Program

Building 001 , Room 126 BARC-West

Beltsville, MD 20705

Jay Tappan

Department of Energy

State of Oregon

Labor and Industries Building

Rüoil 111

Salem, OR 98310

4 Frank Goodman, Jr.

Electric Power Research Institute

F.0. Box 10412

Palo Alto, CA 94025 
J. J. Riley

Senior Research Scientist

Flow Industries, Inc.

21414-68th Avenue S.

Kent, WA 98031

E. E. Johanson

JBF Scientific Corporation

2 Jewel Drive

Wilmington, MA 01887

Gerald Park

Department of Electrical Engineering

Michigan State University

East Lansing, MI 48824

Ms. Abbey Page

Maine Office of Energy Resources

55 Capital

Augusta, ME 04330

J. Konigsberg

Montana Energy Office

Capital Station

Helena, MT 59601

Phillip French

NASA Scientific and Technical

Information Facility

P.0. Box 8757

Baltimore/Washington International Airport

Baltimore, MD 21240

M. J. Changery

National Oceanic and Atmospheric Administration

National Climatic Center

Federal Building

Asheville, NC 28801

Will iam Hooke

Wave Propagation Laboratory

National Oceanic and Atmospheric Administration

Boulder, CO 80302
E. W. Hewson/J. E. Wade Oregon State University Corvallis, OR 97331

2 R. L. Simon

Pacific Gas and Electric

215 Market Street

San Francisco, CA 94106

E. L. Luther

PRC Eng. Analysis Co.

01d Springhouse Road

McLean, VA 22102

Terry J. Healy/C. Hansen

Rockwell International

Rocky Flats Plant

P. 0 . Box 464

Golden, C0 80401

E. Kadlec

Sandia Laboratories

Division 5443

P.0. Box 5800

Albuquerque, NM 87115

R. M. Traci

Science Applications, Inc.

1200 Prospect Street

P.0. Box 2351

La Jolla, CA 92038

I. Vas

Solar Energy Research Institute

1536 Cole Blvd.

Golden, C0 80401

C. M. Bhumralkar

SRI International

333 Ravenswood Avenue

Menlo Park, CA 94205

W. Owens

Tennessee Valley Authority

426 United Bank Building

Chattanooga, TN 37401 
Thomas A. Schroeder University of Hawai i at Monoa 2525 Correa Road Honolulu, HI 96822

R. A. Pielke

University of Virginia

Department of Environmental Sciences

Clark Hall

Charlottesville, VA. 22903

Ms. Susan Hosch

Washington State Energy Office $400 \mathrm{E}$. Union Avenue, lst Floor Olympia, WA 98504

L. L. Nelson

U.S. Water \& Power Resource Service Denver Federal Center, Bldg. 20

Denver, CO 80225

G. D. Thomann

Wichita State University

P.0. Box 44

Wichita, KS 67208

Farrell Smith Seiler

Wind Energy Report

Box 14 - $104 X$. Village Avenue

Rockville Centre, NY 11571

R. W. Marrs

University of Wyoming

Department of Geology

Laramie, WY 82071
ONSITE.

1 DOE Richland Operations Office P.0. Box 550 Richland, WA 99352

H. E. Ransom

44 Pacific Northwest Laboratory Battelle Boulevard

Richland, WA 99352

W. R. Barchet

J. C. Barnard

J. W. Buck

J. R. Connell

J. C. Doran

K. Drumheller

C. E. Elderkin

D. L. Elliott

R. L. George

D. L. Hadley

T. R. Hiester

V. K. Hopkins

A. H. Miller

E. L. Owzarski

W. T. Pennell

D. C. Powell

J. V. Ramsdell

D. S. Renne

H. L. Wegley

L. L. Wendell

R. K. Woodruff

$R$. Zengerle

Technical Information - Library (5) Publishing Coordination (2) 